Universidad de Lima

Facultad de Ingeniería y Arquitectura

Carrera de Arquitectura

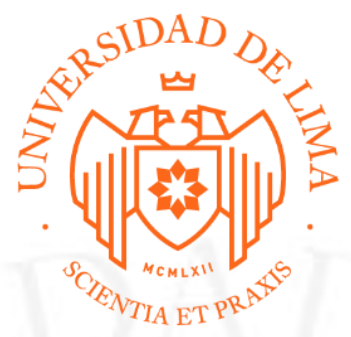

\title{
CENTRO TÉCNICO PRODUCTIVO LOMAS DE LÚCUMO
}

Trabajo de suficiencia profesional. Proyecto de Fin de Carrera para optar el Título Profesional de Arquitecto

\section{Sharen Katherine Delgado Iglesias}

Código 20110392

Asesor

Boris Zenobio Barriga Falcón

$$
\text { Lima - Perú }
$$

Agosto del 2019 


\section{PRODUCTIVE TECHNICAL CENTER LOMAS DE LUCUMO}




\section{TABLA DE CONTENIDO}

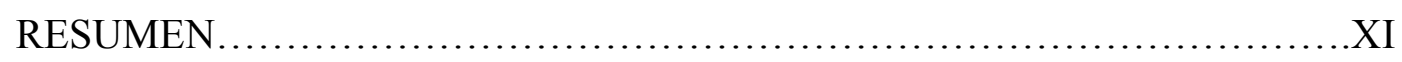

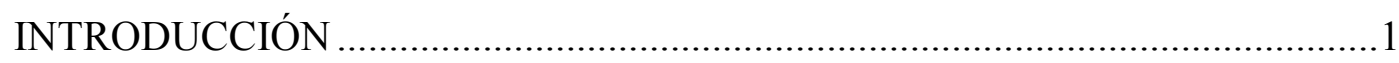

CAPÍTULO I: GENERALIDADES ...........................................

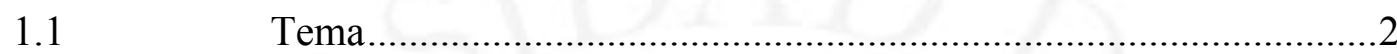

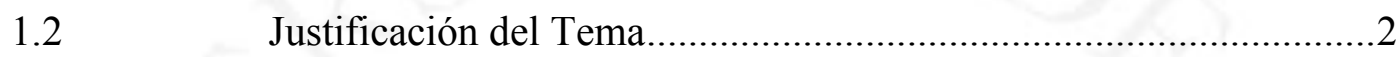

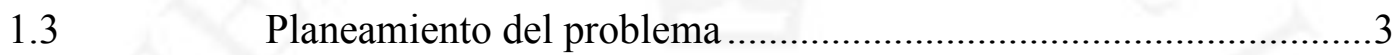

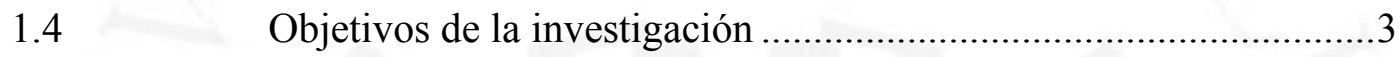

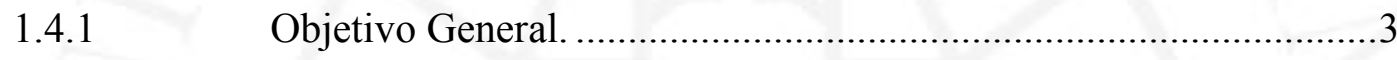

Supuesto básico de la investigación ..........................................

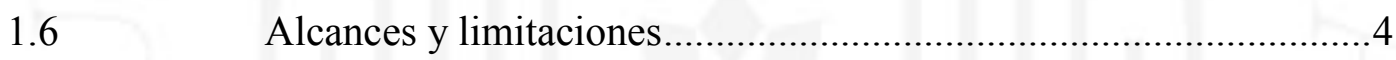

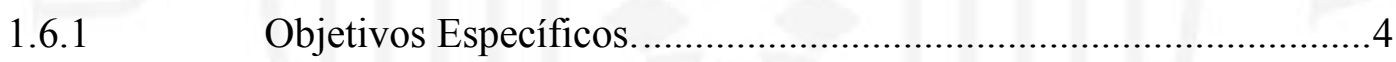

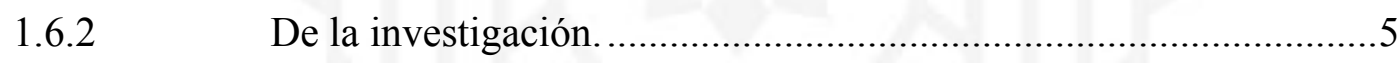

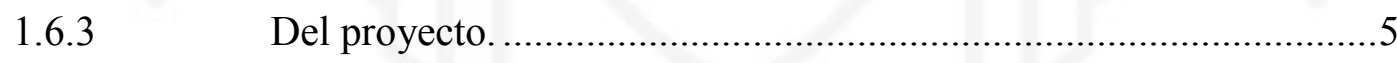

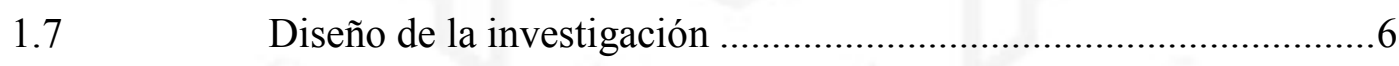

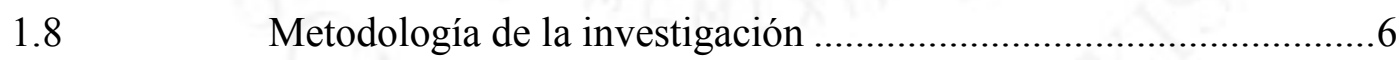

1.8.1 Forma de consulta de la información ........................................

Forma de recopilación de la información......................................6

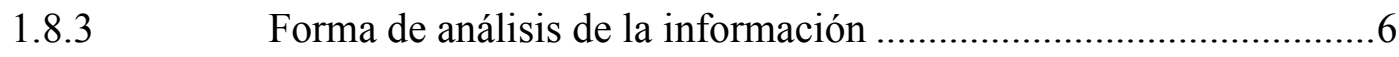

1.8.4 Forma de presentación de la información ...................................6

CAPÍTULO II: MARCO REFERENCIAL ...................................

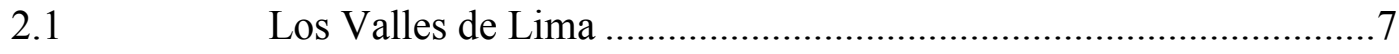

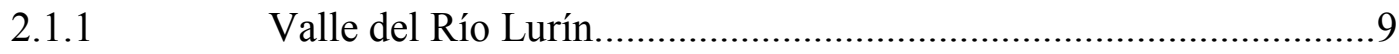




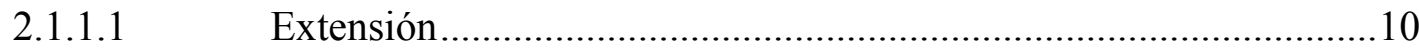

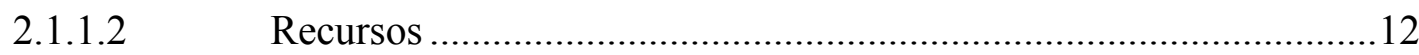

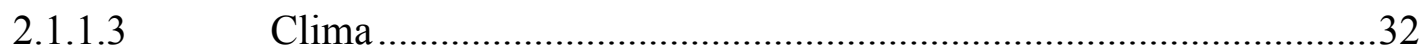

2.1.1.4 Proceso de Población del Valle.........................................................34

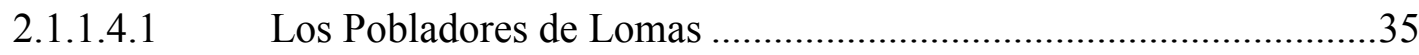

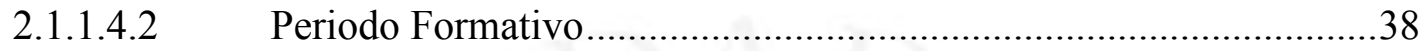

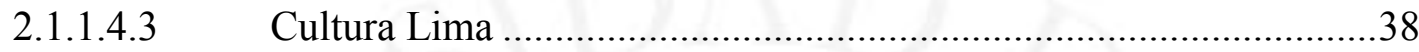

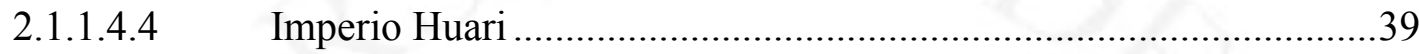

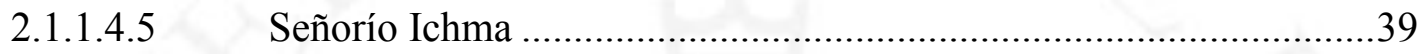

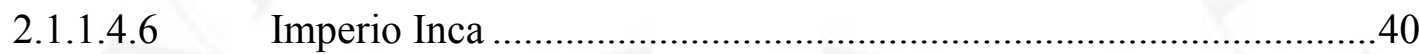

2.1.1.4.7 La Conquista Española y el desarrollo del valle en adelante ...........41

2.1.1.4.8 El Distrito de Pachacamac y el Centro Poblado Rural Quebrada Verde. 43

2.1.1.5 Análisis Socioeconómico del Valle ................................................44

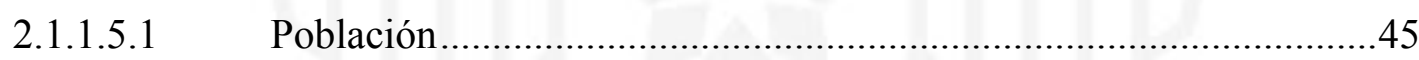

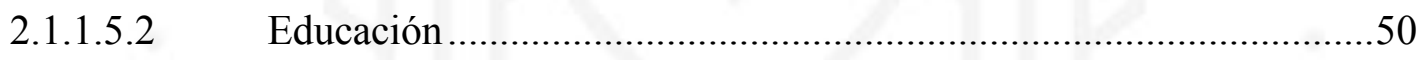

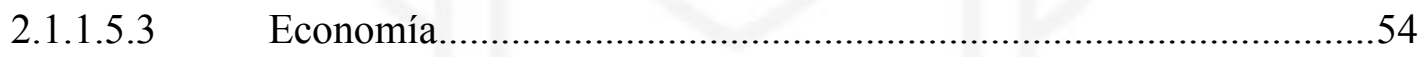

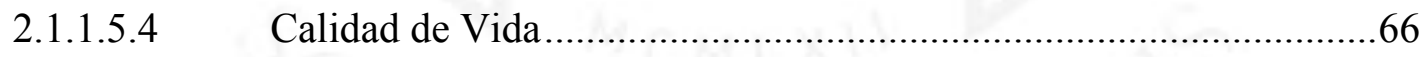

2.2 Antecedentes Históricos de los Centros Técnico Productivos .........69

2.2.1 El origen de la educación técnico productiva ................................69

2.2.2 Europa, el origen de las escuelas de artes y oficios .........................70

2.2.2.1 Origen de la Escuela de artes y oficios en España ...........................72

2.2.2.1.1 La Sociedad Económica Amigos del País.........................................72

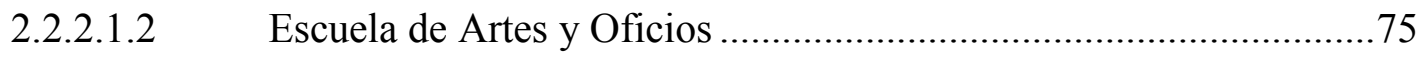

2.2.3 La transmisión de saberes de España a las Colonias Americanas ...78 
2.2.4 Las Escuelas de Artes y Oficios y su evolución tras la independencia 79

2.2.5 La educación técnico productiva en la actualidad...........................86

2.2.5.1 Centros de Educación Técnico Productiva ......................................89

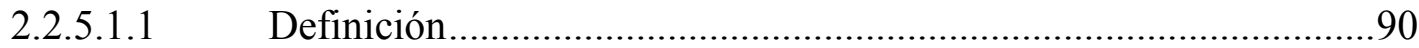

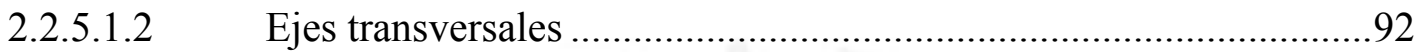

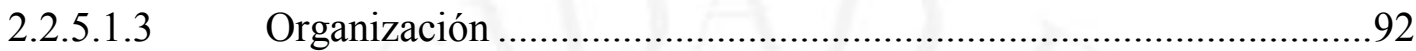

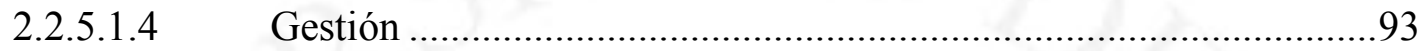

2.2.5.1.5 Presupuesto y financiamiento .......................................................94

2.2.5.1.6 Certificación, titulación y registro...................................................94

2.2.5.1.7 Técnicas para el desarrollo de un Ciclo Modular.............................95

2.2.5.1.8 Estrategias para determinar la oferta formativa en los CETPROs...96

2.2.5.1.9 Importancia de la práctica pre- profesional para la educación técnico productiva 98

2.2.5.1.10 Análisis cuantitativo de la Educación Técnico Productiva ...............99

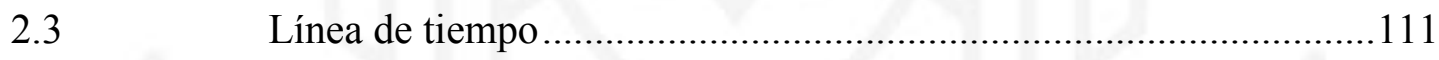

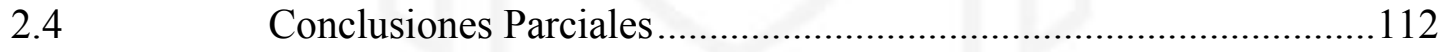

CAPÍTULO III: MARCO TEÓRICO .............................................115

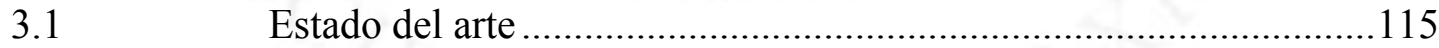

Conjunto de teorías que sustentan el proyecto ...............................116

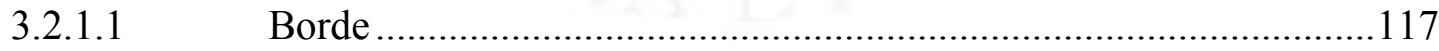

3.2.1.2 Definiciones sobre tipologías de borde .......................................118

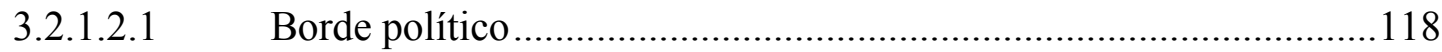

3.2.1.2.2 Borde económico-social ..............................................................122

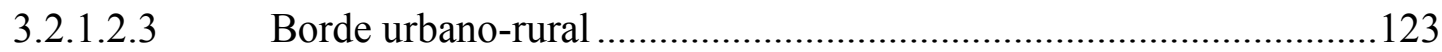




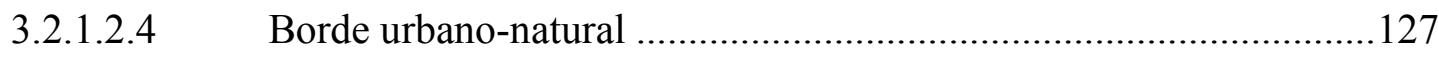

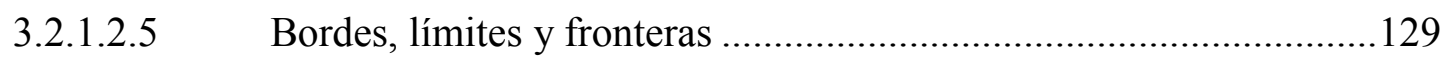

3.2.1.2.6 Bordes y Barreras ....................................................................... 130

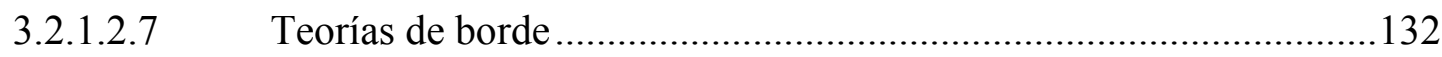

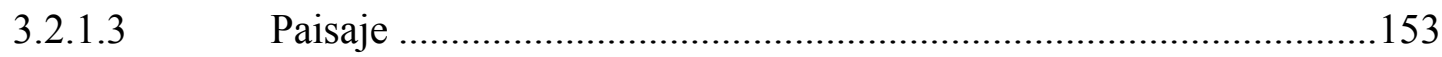

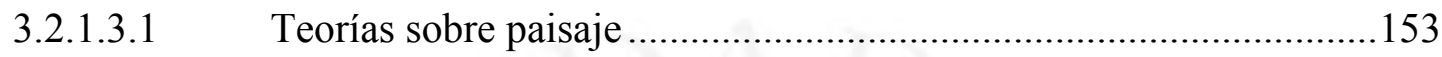

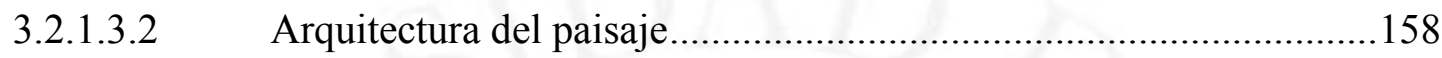

3.2.1.3.3 Paisaje urbano y paisaje natural .................................................... 159

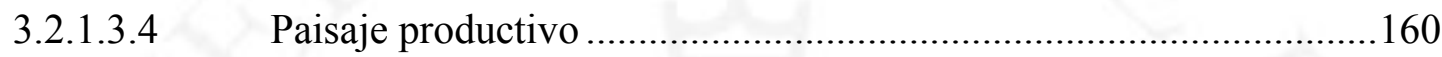

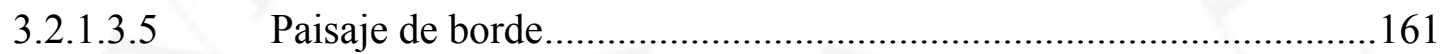

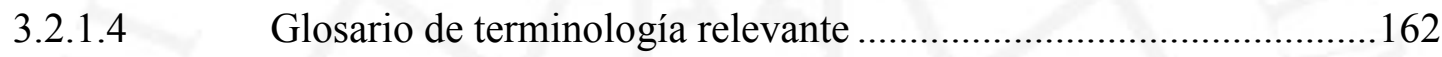

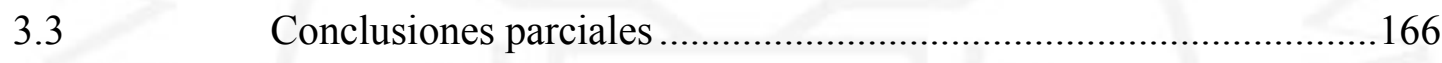

CAPITULO IV: MARCO NORMATIVO....................................169

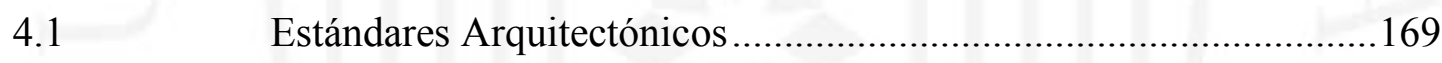

4.1.1 Reglamento Nacional de Edificaciones .....................................169

4.1.2 Normativa Ministerio de Educación .............................................173

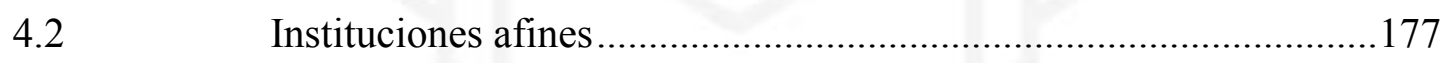

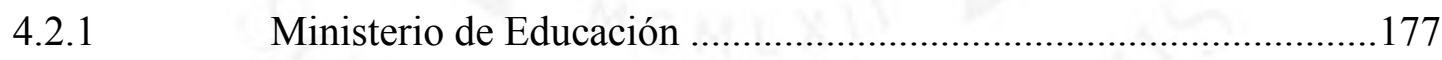

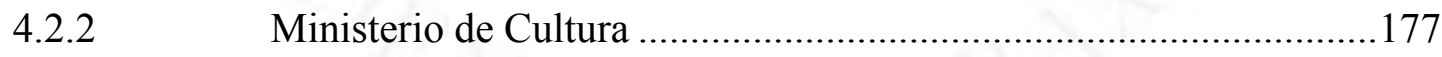

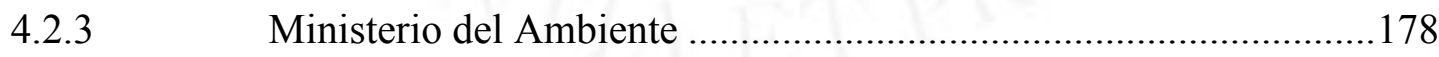

Ministerio de Agricultura ......................................................... 178

4.2.5 Municipalidad de Pachacamac ...................................................179

4.2.6 Asociación Circuito Ecoturístico Lomas de Lúcumo .......................179

4.2.7 Asociación Vive Pachacamac …..................................................179

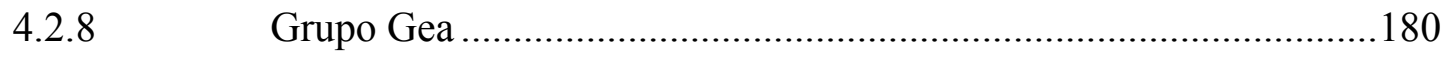


CAPITULO V: MARCO OPERATIVO........................................183

5.1 Estudio de casos análogos

5.1.1 Centro de formación para la sostenibilidad 183

5.1.1.1

Historia 183

5.1.1.2 Ubicación y relación con el entorno.................................................. 184

5.1.1.3 Programa y relaciones programáticas. …....................................... 185

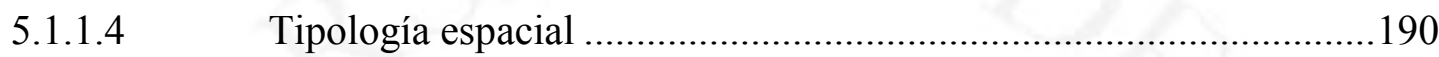

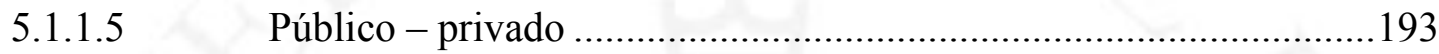

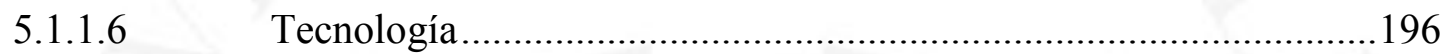

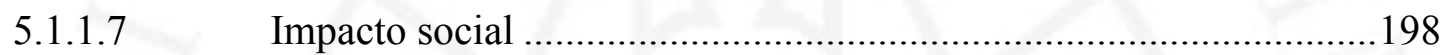

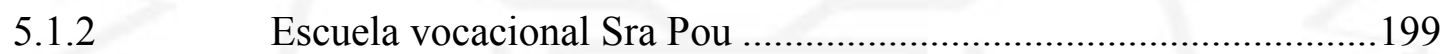

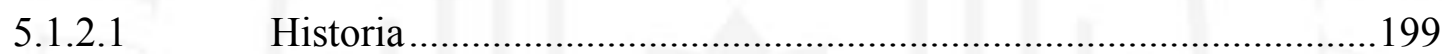

5.1.2.2 Ubicación y relación con el entorno...........................................200

5.1.2.3 Programa y relaciones programáticas. ...........................................201

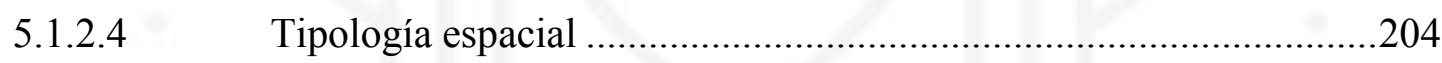

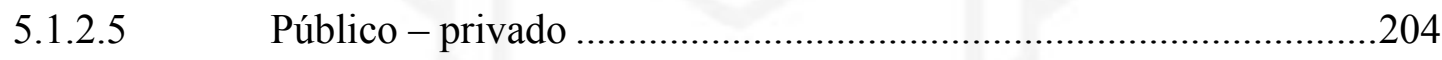

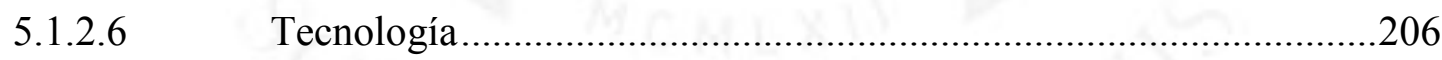

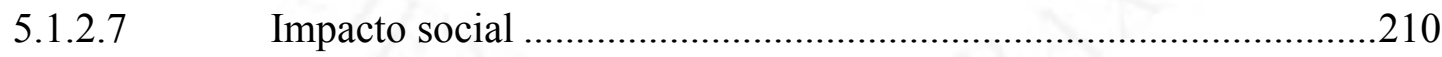

5.1.3 Centro de Entrenamiento Indígena Käpäcäjui .............................211

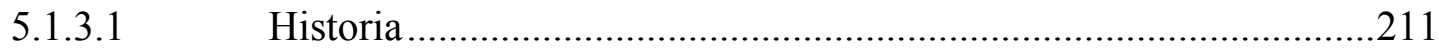

5.1.3.2 Ubicación y relación con el entorno...........................................212

5.1.3.3 Programa y relaciones programáticas ...........................................212

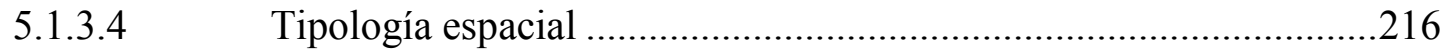

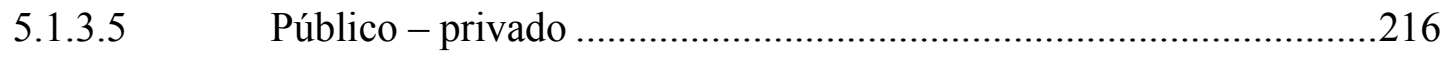




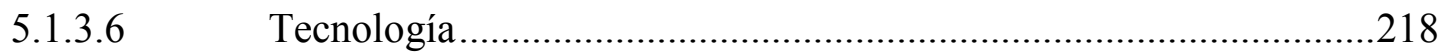

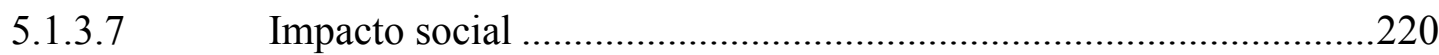

5.1.4 CETPRO Politécnico Salesiano …...............................................22

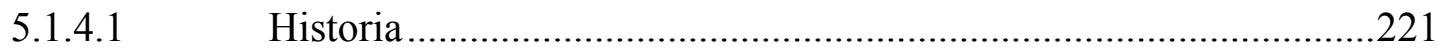

5.1.4.2 Ubicación y relación con el entorno............................................222

5.1.4.3 Programa y relaciones programáticas ..........................................223

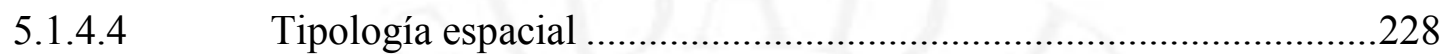

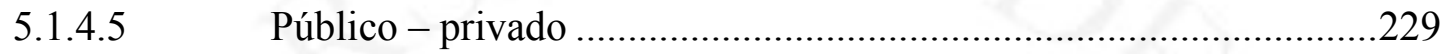

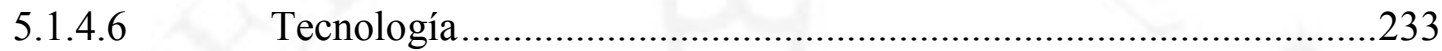

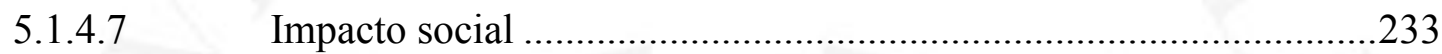

5.2 Cuadro comparativo y gráficos de casos análogos .........................233

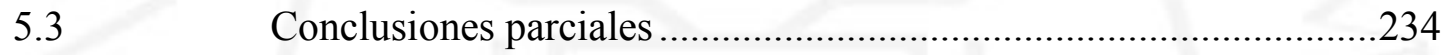

CAPÍTULO VI: MARCO CONTEXTUAL ...................................235

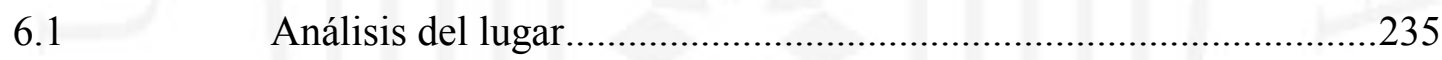

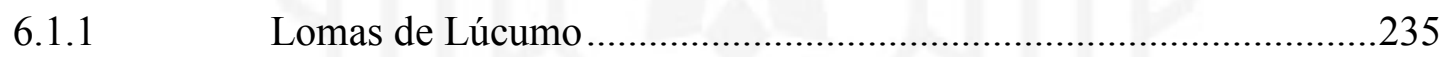

6.1.1.1 Características de las construcciones de la zona ............................238

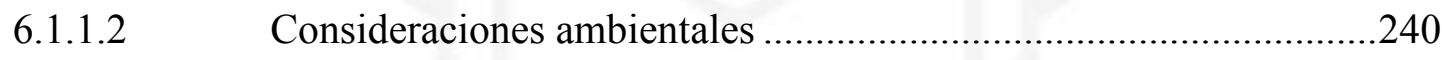

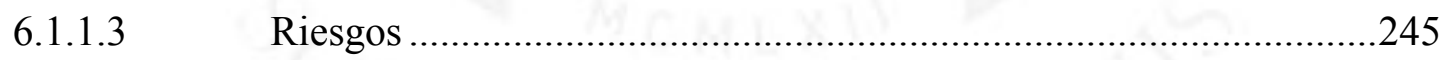

6.1.1.4 Limitaciones normativas de acuerdo al proyecto..........................249

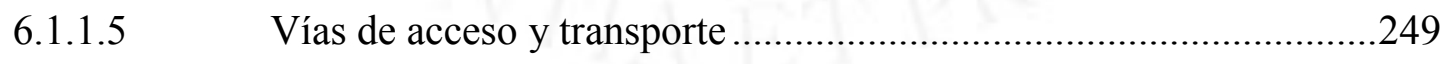

6.1.1.6 Infraestructura y servicios disponibles ....................................251

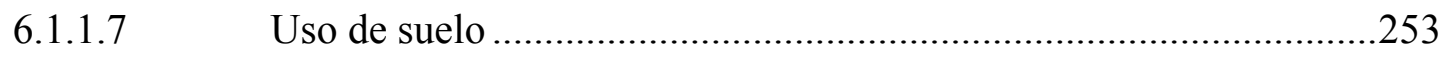

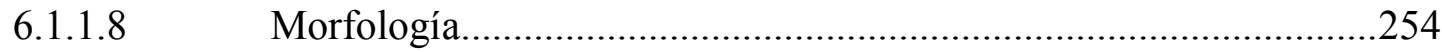

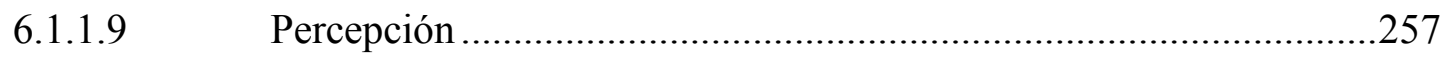

Redes de equipamiento y radio de influencia ..............................261 
$6.3 \quad$ Variables del lugar .....................................................................262

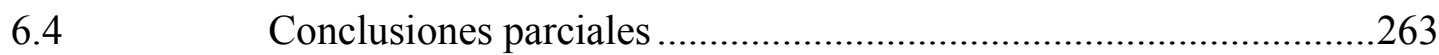

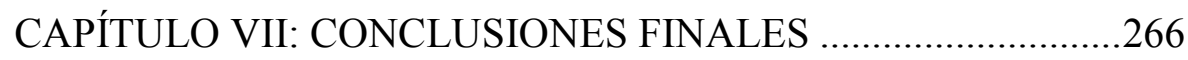

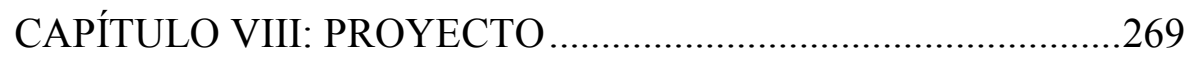

8.1 Estrategias proyectuales ................................................................269

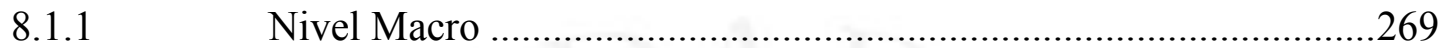

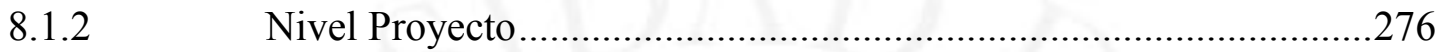

8.2 Programa arquitectónico ………………………………………......28

8.3 Cuadro de áreas y costo de obra.....................................................28

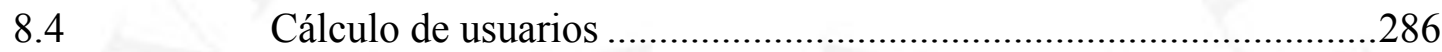

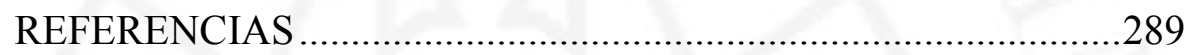




\section{ÍNDICE DE CUADROS}

Cuadro 2.1 Distritos pertenecientes a las cuencas del Río Lurín y su altitud .................. 10

Cuadro 2.2 Características Físicas de La Cuenca del Río Lurín .................................... 13

Cuadro 2.3 Inventario de Lagunas en la Cuenca del Río Lurín..................................... 15

Cuadro 2.4 Precipitación Media Mensual y Anual (mm) en la Cuenca del Río Lurín... 16

Cuadro 2.5 Análisis de pesticidas presentes en la Cuenca del Río Lurín ........................ 17

Cuadro 2.6 Valores de Calidad de Agua del Río Lurín .................................................... 18

Cuadro 2.7 Uso consuntivo del agua superficial por vertiente, 2015 ..........................20

Cuadro 2.8 Balance Hídrico de la Cuenca del Río Lurín ................................................21

Cuadro 2.9 Licencias otorgadas en (MMC) para uso agrario (2010) y no agrario (2013)

Cuadro 2.10 Ocupación del suelo en las Cuencas de Chillón, Rímac y Lurín 31

Cuadro 2.11 Temperatura media anual registrada en las estaciones meteorológicas de la Cuenca del Río Lurín. 32

Cuadro 2.12 Precipitación media anual registrada en las estaciones meteorológicas en la cuenca de Lurín. .33

Cuadro 2.13 Humedad relativa promedio anual registrada en las estaciones meteorológicas en la cuenca de Lurín. .33

Cuadro 2.14 Tipos de Climas Identificados en la Cuenca del Río Lurín .34

Cuadro 2.15 Inventario de Sitios Arqueológicos presentes en el Valle de Lurín 42

Cuadro 2.16 Evolución Histórica de la Población del Valle Lurín por Provincia, Subcuenca y Distritos 44

Cuadro 2.17 : Densidad Poblacional de los distritos del Valle de Lurín. 45 
Cuadro 2.18 Población por Grandes Grupos de Edad según provincias, subcuencas y distritos del Valle Lurín .46

Cuadro 2.19 Población por Sexo Según provincias, subcuencas y distritos del Valle de Lurín, Año 2012. .47

Cuadro 2.20 Población Urbana y Rural Según provincias, subcuencas y distritos del Valle de Lurín, Año 2012 48

Cuadro 2.21 Relación de Comunidades Campesinas en el Valle de Lurín .49

Cuadro 2.22 Población Analfabeta presente en el Valle del Lurín..... .50

Cuadro 2.23 Asistencia Escolar en el la Cuenca Baja del Valle de Lurín. .51

Cuadro 2.24 : Relación de Alumnos por Nivel de Atención en el Valle de Lurín .52

Cuadro 2.25 Matricula por tipo de Gestión y Área Geográfica, según Etapa, Modalidad y Nivel Educativo. .53

Cuadro 2.26 Población Económicamente activa del Valle de Lurín 2012 .54

Cuadro 2.27 Población Económicamente Activa Según Condición de Actividad y Sexo .55

Cuadro 2.28 Población Económicamente Activa Según Principales Sectores de Actividad Económica. .56

Cuadro 2.29 Población Económicamente Activa por grupos de edad y rama de actividad Económica, al año 2012 .57

Cuadro 2.30 Producción Agrícola en el Valle de Lurín, Año 2010-2011 .58

Cuadro 2.31 Producción Agrícola Distrito de Cieneguilla .59

Cuadro 2.32 : Producción Agrícola Distrito de Lurín 60

Cuadro 2.33 Producción Agrícola Distrito de Pachacamac. 61

Cuadro 2.34 Producción Agraria del Perú en el año 2016.. .63

Cuadro 2.35 : Producción Pecuaria en el Valle de Lurín. .64

Cuadro 2.36 Gran y Mediana Minería No Metálica en el Valle de Lurín .65 
Cuadro 2.37 Condición de Pobreza Valle de Lurín, Año 2009 .66

Cuadro 2.38 Servicios Básicos de Agua, Desagüe y Luz 2007 según distritos en el Valle Lurín. .68

Cuadro 2.39 Plan de estudios de la Escuela de Artes y Oficios de Alcoy..... .76

Cuadro 2.40 Relación de los alumnos matriculados en la Escuela de Artes y Oficios de Alcoy .76

Cuadro 2.41 Información sobre los principales oficios de la Escuela de Artes y Oficios de Alcoy de 1888- 1901

Cuadro 2.42 Evolución de la matrícula por regiones según modalidades educativas en Perú .85

Cuadro 2.43 Estrategias Formativas de Ofertas en los CETPROs .96

Cuadro 2.44 Centros educativos, según nivel y modalidad, Perú 2004 - 2013 100

Cuadro 2.45 Centros educativos públicos según nivel y modalidad, Perú2004 - 2013101

Cuadro 2.46 : Lista de CETPROS UGEL N 1 103

Cuadro 2.47 Lista de CETPROS UGEL N ${ }^{\circ} 2$ 104

Cuadro 2.48 Lista de CETPROS UGEL N ${ }^{\circ} 3$ 104

Cuadro 2.49 Lista de CETPROS UGEL N ${ }^{\circ} 4$ 105

Cuadro 2.50 Lista de CETPROS UGEL N ${ }^{\circ} 5$ 105

Cuadro 2.51 Lista de CETPROS UGEL $\mathrm{N}^{\circ} 6$ 106

Cuadro 2.52 Lista de CETPROS UGEL $\mathrm{N}^{\circ} 7$ 106

Cuadro 2.53 Número de instituciones educativas del sistema educativo, por etapa, modalidad y nivel educativo, Provincia de Lima según distrito, 2013 107

Cuadro 2.54 Número de instituciones educativas públicas, por etapa, modalidad y nivel educativo, Provincia de Lima según distrito, 2013. 108

Cuadro 2.55 Matrícula en el sistema educativo por etapa, modalidad y nivel educativo, Provincia de Lima según distrito, 2013 109 
Cuadro 2.56 : Matrícula en el sistema educativo en instituciones educativas públicas, por etapa, modalidad y nivel educativo, Provincia de Lima según distrito, 2013110

Cuadro 3.1 Taxonomía corológica propuesta por BERTRAND (1968) ........................ 157

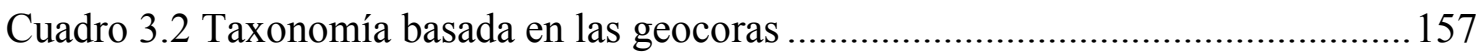

Cuadro 3.3 Taxonomía aplicable al paisaje antropizado ........................................... 158

Cuadro 5.1 Cuadro de áreas aproximado del Centro de Formación para la Sostenibilidad

Cuadro 5.2 Cuadro de áreas aproximado por paquete del Centro de Formación para la Sostenibilidad.

Cuadro 5.3 Cuadro de áreas aproximado de la Escuela vocacional Sra Pou 201

Cuadro 5.4 Cuadro de áreas aproximado por paquete de la Escuela vocacional Sra Pou

Cuadro 5.5 Cuadro de áreas aproximado del Centro de Entrenamiento Indígena

Kapacajui

Cuadro 5.6 Cuadro de áreas aproximado por paquete del Centro de Entrenamiento

Indígena Kapacajui

Cuadro 5.7 Cuadro de áreas aproximado del CETPRO Politécnico Salesiano

Cuadro 5.8 Cuadro de áreas aproximado por programa del CETPRO Politécnico

Salesiano

Cuadro 8.1 Características de la cuenca del río Lurín

Cuadro 8.2 PEA dedicada a la agricultura en Valle Bajo del Río Lurín 286

Cuadro 8.3 Matrícula en el Sistema Educativo Técnico Productivo en el distrito de

Pachacamac

Cuadro 8.4 Matrícula en el Sistema Educativo Técnico Productivo en el distrito de

Lurín. 287

Cuadro 8.5 Matrícula en el Sistema Educativo Técnico Productivo en el distrito de

Cieneguilla..... .288 


\section{ÍNDICE DE FIGURAS}

Figura 2.1 Mapa geográfico del Perú, el departamento de lima y la ubicación de sus valles.

Figura 2.2 Extensión de los valles que forman parte del departamento de Lima..... 8

Figura 2.3 Cuenca del Río Lurín .9

Figura 2.4 Mapa de los distritos pertenecientes a la cuenca del Río Lurín .11

Figura 2.5 Cuenca del Río Lurín y afluentes.... .12

Figura 2.6 Estaciones Hidrométricas en la Cuenca del Río Lurín .13

Figura 2.7 Diagrama Fluvial de la cuenca del Río Lurín. 14

Figura 2.8 Caudales Medios del Río Lurín .16

Figura 2.9 Ubicación gráfica de la Estación Antapucro .18

Figura 2.10 Oferta hídrica en el Perú. .19

Figura 2.11 Mapa Geomorfológico de la Cuenca baja del Río Lurín .23

Figura 2.12 Mapa Geológico de la Cuenca baja del Río Lurín .24

Figura 2.13 Mapa Litológico de la Cuenca baja del Río Lurín .25

Figura 2.14 Crecimiento histórico poblacional de Lima Metropolitana.........................26

Figura 2.15 Evolución de la población de Lima Metropolitana ...................................22

Figura 2.16 Cambio de Ocupación del suelo en Lima Metropolitana 1986-2016..........28

Figura 2.17 Cambio de Ocupación de suelo en Lima Metropolitana 1986-2016 en kilómetros cuadrados .

Figura 2.18 Mapa sobre la ocupación del suelo en las Cuencas de Chillón, Rímac y Lurín. .30 
Figura 2.19 Mapa de Ubicación de la Quebrada Malanche.

Figura 2.20 Asentamientos Prehispánicos en Malanche

Figura 2.21 Distritos de Lima con mayor índice de pobreza No Extrema 2012 67

Figura 2.22 Información sobre los principales oficios de la Escuela de Artes y Oficios de Alcoy de 1888- 1901 .85

Figura 2.23 Educación en el Perú .88

Figura 2.24 : Población que no estudia ni trabaja Provincia de Lima 89

Figura 2.25: Ejemplos sobre la relación existente entre una actividad productiva y los módulos ocupacionales.

Figura 2.26 Mapa de los distritos que abarca cada UGEL en Lima metropolitana...... 102

Figura 3.1 Ejemplificación conceptual de un borde

Figura 3.2 Las laderas de Lomas de Lúcumo en su estado natural y tras la intervención del hombre 118

Figura 3.3 Representación conceptual de un borde político 119

Figura 3.4 Representación del borde político existente en las Lomas de Lúcumo

Figura 3.5 Representación gráfica de un borde económico- social

Figura 3.6 Representación conceptual de un borde urbano rural

Figura 3.7 Representación actual del entorno del Ecosistema Lomas de Lúcumo

Figura 3.8 Ejemplificación de bordes urbano naturales

Figura 3.9 Representación del borde urbano natural presente en las Laderas de las Lomas de Lúcumo 128

Figura 3.10 Representación conceptual del Ecosistema Lomas de Lúcumo como borde entre los distritos de Pachacamac y Villa María del Triunfo.

Figura 3.11 Representación conceptual de borde y barrera 131

Figura 3.12 Representación de un borde fragmentado y un borde fuerte, según la teoría de Kevin Lynch. 133 
Figura 3.13 Representación de una senda como borde

Figura 3.14 Representación de un borde visualmente fuerte.

Figura 3.15 Representación gráfica de la continuidad de un borde en la ciudad.

Figura 3.16 Representación gráfica de cómo destacar a un borde mediante materiales que hagan contraste

Figura 3.17 Representación gráfica de cómo destacar a un borde mediante una concavidad que interrumpa el transcurrir de una línea

Figura 3.18 Representación gráfica de cómo destacar a un borde mediante el arbolado

Figura 3.19 Representación gráfica de cómo destacar a un borde mediante una transición.

Figura 3.20 Representación gráfica de cómo destacar a un borde mediante la individualización de un extremo con respecto al otro

Figura 3.21 Representación gráfica de cómo destacar a un borde, haciéndolo visible a grandes distancias

Figura 3.22 Representación gráfica de cómo destacar a un borde mediante al potenciar visualmente sus extremos

Figura 3.23 Representación gráfica de cómo destacar a un borde haciéndolo accesible y aumentando el uso de este espacio 138

Figura 3.24 Representación conceptual de la Teoría de Gary Leggett, sobre entender en borde tanto lo que une como lo que separa.

Figura 3.25 Representación del borde como ruptura o interrupción de una continuidad percibida. 140

Figura 3.26 Representación conceptual de los puntos de contacto y la naturaleza intrínseca de los mismos en un borde

Figura 3.27: Representación conceptual del borde como encuentro 142

Figura 3.28 Representación conceptual del borde como barrera 142 
Figura 3.29 Representación conceptual del borde como ilusión 143

Figura 3.30 Calidad visual del paisaje 155

Figura 5.1 Ubicación del Centro de Formación para la Sostenibilidad 183

Figura 5.2 Ubicación y relación con el entorno del Centro de Formación para la Sostenibilidad 184

Figura 5.3 Plano primer nivel con paquete programático del Centro de Formación para la Sostenibilidad. 187

Figura 5.4 Plano segundo nivel con paquete programático del Centro de Formación para la Sostenibilidad.. 188

Figura 5.5 Esquema de relación de ambientes del Centro de Formación para la Sostenibilidad...... 189

Figura 5.6 Tipología Espacial del Centro de Formación para la Sostenibilidad 190

Figura 5.7 Tipología Espacial del Centro de Formación para la Sostenibilidad 191

Figura 5.8 Gráfico de ingresos al Centro de Formación para la Sostenibilidad 192

Figura 5.9 Análisis de accesibilidad a los ambientes del Centro de Formación para la Sostenibilidad 193

Figura 5.10 Análisis de flujos del Centro de Formación para la Sostenibilidad 194

Figura 5.11 Análisis del área libre y área construida del Centro de Formación para la Sostenibilidad.....

Figura 5.12 Concepto energético aplicado en la construcción del Centro de Formación para la Sostenibilidad. 196

Figura 5.13 Fotografía del proceso constructivo del Centro de Formación para la Sostenibilidad. 197

Figura 5.14 Exterior del Centro de Formación para la Sostenibilidad 197

Figura 5.15 Ubicación de la Escuela Vocacional Sra Pou. 199

Figura 5.16 Gráfico de Ubicación de la Escuela vocacional Sra Pou. 200 
Figura 5.17 Gráfico de Ubicación y relación con el entorno de la Escuela vocacional Sra Pou 200

Figura 5.18 Plano primer nivel con paquete programático de la Escuela Vocacional Sra Pou 202

Figura 5.19 Plano segundo nivel con paquete programático de la Escuela Vocacional Sra Pou. 203

Figura 5.20 Esquema de relación de ambientes de la Escuela Vocacional Sra Pou.....203

Figura 5.21 Tipología Espacial de la Escuela Vocacional Sra Pou .204

Figura 5.22 Análisis de accesibilidad a los ambientes de la Escuela Vocacional Sra Pou .204

Figura 5.23 Análisis de flujos de la Escuela Vocacional Sra Pou .205

Figura 5.24 Análisis del área libre y área construida de la Escuela Vocacional Sra Pou 206

Figura 5.25 Sistema constructivo de la Escuela Vocacional Sra Pou 207

Figura 5.26 Acondicionamiento ambiental de la Escuela Vocacional Sra Pou 208

Figura 5.27 Corte arquitectónico de la Escuela Vocacional Sra Pou 208

Figura 5.28 Sistema Constructivo y materialidad 209

Figura 5.29 Fotografía de un aula taller en la Escuela Vocacional Sra Pou 210

Figura 5.30 Ubicación del Centro de Entrenamiento Indígena Kapacajui 211

Figura 5.31 Ubicación del Centro de Entrenamiento Indígena Kapacajui 212

Figura 5.32 Plano primer nivel con paquete programático del Centro de Entrenamiento Indígena Kapacajui 214

Figura 5.33 Plano segundo nivel con paquete programático del Centro de

Entrenamiento Indígena Kapacajui..... .215

Figura 5.34 Tipología espacial del Centro de Entrenamiento Indígena Kapacajui ......216 Figura 5.35 Análisis de accesibilidad a los ambientes del Centro de Entrenamiento Indígena Kapacajui 216 
Figura 5.36 Análisis de flujos en el del Centro de Entrenamiento Indígena Kapacajui

Figura 5.37 Análisis del área libre y área construida del Centro de Entrenamiento Indígena Kapacajui 218

Figura 5.38 Detalle constructivo del Centro de Entrenamiento Indígena Kapacajui ...219

Figura 5.39 Sistema constructivo del Centro de Entrenamiento Indígena Kapacajui ..220

Figura 5.40 Ubicación del CETPRO Politécnico Salesiano 221

Figura 5.41 Ubicación del CETPRO Politécnico Salesiano 222

Figura 5.42 Ubicación y relación con el entorno del CETPRO Politécnico Salesiano 222

Figura 5.43 Plano primer nivel con paquete programático CETPRO Politécnico Salesiano .226

Figura 5.44 Plano segundo nivel con paquete programático CETPRO Politécnico Salesiano 227

Figura 6.1 Vista del C.P.R. Quebrada Verde en Temporada de Verano 236

Figura 6.2 Vista del C.P.R. Quebrada Verde en Temporada de Lomas

Figura 6.3 Gráfico de Ingreso Anual de visitantes al Circuito Ecoturístico Lomas de Lúcumo 2010-2016 237

Figura 6.4 Análisis de la densidad urbana del C.P.R. Quebrada Verde 238

Figura 6.5 Gráficos sobre densidad urbana y área construida en el C.P.R. Quebrada Verde 239

Figura 6.6 Recorrido solar y estudio de sombras verano e invierno 240

Figura 6.7 Análisis de dirección y velocidad del viento en el C.P.R. Quebrada Verde241

Figura 6.8 Mapeo de Lomas Costeras en Lima Metropolitana .242

Figura 6.9 Explicación gráfica del Fenómeno de Lomas .243

Figura 6.10 Plan de Reforestación Ecosistema Lomas de Lúccumo .244

Figura 6.11 Tipos de Suelo en el Valle Lurín. .245 
Figura 6.12 Análisis de Vulnerabilidad Sísmica en el Valle Lurín .246

Figura 6.13 Gráfica del corte donde se realizó el análisis de suelos 247

Figura 6.14 Corte que muestra el Análisis de Suelo en Lomas de Lúcumo .248

Figura 6.15 Mapa de riesgos .248

Figura 6.16 Ruta desde Cercado de Lima hacia Lomas de Lúcumo .250

Figura 6.17 Plano que muestra las vías y flujos vehiculares y peatonales en Quebrada Verde .251

Figura 6.18 Mapa que muestra el acceso a la Red de Agua en Poblaciones en laderas252 Figura 6.19 Gráfico que muestra los porcentajes de suelo presentes en Quebrada Verde .253

Figura 6.20 Mapa del área total del Ecosistema Lomas de Lúcumo .255

Figura 6.21 Plano del área de estudio con cotas de nivel a escala macro .256

Figura 6.22 Plano detallado de las condiciones morfológicas del terreno. .256

Figura 6.23 Vistas fotográficas del terreno. 257

Figura 6.24 Vista fotográfica de Quebrada Verde desde el terreno. .259

Figura 6.25 Vista fotográfica del terreno desde las Lomas de Lúcumo .259

Figura 6.26 Vista fotográfica del terreno desde las Lomas de Lúcumo .260

Figura 6.27 Vista fotográfica del terreno desde las Lomas de Lúcumo .260

Figura 6.28 Redes de equipamiento en el distrito de Pachacamac .261

Figura 6.29 Fotografías de las Redes de equipamiento en el distrito de Pachacamac..262

Figura 8.1 Asoleamiento y vientos .269

Figura 8.2 Vulnerabilidad del suelo 270

Figura 8.3 Topografía del terreno 270

Figura 8.4 Propuesta a nivel macro .271

Figura 8.5 Ubicación del Puente Manchay .273 
Figura 8.6 Estrategia proyectual macro

Figura 8.7 Análisis de factibles puntos de ingreso al proyecto .274

Figura 8.8 Propuesta para equipamiento deportivo .275

Figura 8.9 Análisis de Ecosistema Lomas de Lúcumo a gran escala 276

Figura 8.10 Análisis de una quebrada en el Ecosistema Lomas de Lúcumo .277

Figura 8.11 Análisis de una toma en elevación del Ecosistema Lomas de Lúcumo ....278

Figura 8.12 Conceptualización de las reacciones ecosistémicas generadas por el hidrotropismo y tigmotropismo en el entorno natural del Ecosistema Lomas de Lúcumo.

Figura 8.13 Representación conceptual de la estrategia proyectual plateada para el proyecto .280

Figura 8.14 Representación conceptual de la estrategia proyectual plateada para el proyecto ..... .281

Figura 8.15 Representación esquemática de estrategia proyectual. .281

Figura 8.16 Representación esquemática de estrategia proyectual. 282

Figura 8.17 Fotografía de una quebrada de las Lomas de Lúcumo 282

Figura 8.18 Representación esquemática de estrategia proyectual. 283

Figura 8.19 Fotografía de las rocas en el Ecosistema Lomas de Lúcumo. 283

Figura 8.20 Análisis de las laderas en el entorno del Ecosistema Lomas de Lúcumo .284 Figura 8.21 Análisis del fenómeno estacional de Lomas .284

Figura 8.22 Representación esquemática de la estrategia proyectual propuesta .284 


\section{RESUMEN}

El Perú en el año 2018, registró la tasa de desempleo más alta de la última década según datos obtenidos del Instituto Nacional de Estadísticas, llegando éste en el departamento de Lima a un $8.1 \%$. Causa, aunque si bien no la única, de que se haya llegado a este índice de desocupación es el bajo nivel educativo alcanzado, el cual impide la obtención de un empleo digno y justamente remunerado.

Gran parte de ésta población vive en centros poblados rurales con limitado acceso a necesidades básicas, como es el caso de los habitantes de Quebrada Verde en el distrito de Pachacamac; si a esta condición le sumamos la falta de oportunidades laborales relacionadas a la característica antes descrita, su realidad es verdaderamente preocupante; aquí las herramientas para alcanzar el desarrollo social son insuficientes, no encontramos una guía de apoyo estatal, ni equipamiento público que incentive y promueva las actividades de producción local, aun estando el recurso al alcance de la comunidad.

La presente tesis busca demostrar como el diseño de un Centro Técnico Productivo, ubicado en el distrito de Pachacamac puede potenciar el desarrollo local dándole un valor agregado al producto agrícola de la zona, como estrategia para lograr la conservación del ultimo valle verde de Lima y el aprovechamiento sostenible de sus Lomas Costeras al generar un borde productivo de protección para este ecosistema.

Palabras Clave: desarrollo social, producción local, conservación, protección, aprovechamiento sostenible del ecosistema de lomas. 


\begin{abstract}
Peru in the year 2018, recorded the highest unemployment rate in a decade according to data obtained from the National Institute of statistics, reaching this in the Department of Lima as $8.1 \%$. Its cause, but even if not the only one, which has reached at this rate of unemployment is the low educational level achieved, which prevents the obtaining of a decent and fairly remunerated employment.

Most of this population lives in rural communities with limited access to basic needs, as it is the case of the Quebrada Verde inhabitants at Pachacamac district; if you add the lack of job opportunities related to the feature previously described to this condition. Their reality is truly worrying; Here the tools to achieve social development are insufficient, we cannot find a guide as public support, or public facilities that encourage and promote the activities of local production, even if the resource available to the community.

This thesis seeks to demonstrate on how the design of a productive Technical Center located in the District of Pachacamac can enhance local development giving a benefit to the agricultural product of the area, as a strategy to achieve the conservation of the last Green Valley of Lima. In addition, the sustainable use of its coastal hills to generate a productive edge-protection for this ecosystem.
\end{abstract}

Keywords: social development, local production, conservation, protection, sustainable use of the lomas ecosystem. 


\section{INTRODUCCIÓN}

Los considerables índices de desempleo a los que llegó nuestro país durante los últimos años, fueron producto, entre tanto, del bajo nivel educativo alcanzado por la población; siendo la pobreza una de sus principales causas, convirtiendo a esta realidad en un ciclo inacabable de patrones repetitivos.

Por su parte, el Estado cuenta con programas e instituciones superiores que promueven la educación y el desarrollo local, como es el caso de los Centros Técnico Productivos, donde cada módulo ocupacional dictado debe estar coherentemente relacionado a las actividades productivas desarrolladas en su entorno. Pero, es justamente aquí donde radica el problema, sobre todo en el distrito de Pachacamac, donde hasta la actualidad, ninguno de estos centros ha creado una oferta formativa vinculada al sector productivo más destacado del distrito, la agricultura.

En Pachacamac, el mayor porcentaje de la agricultura emplea conocimientos empíricos, obtenidos por la experiencia en base a la transmisión del oficio desde algún referente cercano. Este aprendizaje carece de técnica, es en su mayoría artesanal y generalmente no posee conocimientos sobre la aplicación de nuevas tecnologías, que puedan acelerar procesos productivos y promover de esta forma el desarrollo de la profesión. Los agricultores, al no obtener rentabilidad, optan por vender sus tierras para habilitaciones urbanas, peligrando así la preservación del último valle verde de Lima, el Valle del Río Lurín.

La presente tesis busca demostrar como el diseño de un Centro Técnico Productivo, ubicado en el distrito de Pachacamac puede potenciar el desarrollo local dándole un valor agregado al producto agrícola de la zona, como estrategia para lograr la conservación del ultimo valle verde de Lima y de sus Lomas Costeras al generar un borde productivo de protección para este ecosistema. 


\section{CAPÍTULO I: GENERALIDADES}

\subsection{Tema}

El presente trabajo de investigación busca impulsar el desarrollo socio-económico de los pobladores del distrito de Pachacamac, uno de los distritos con mayor índice de pobreza extrema y con menor posibilidad de acceso a necesidades básicas en Lima Metropolitana (INEI, 2014), donde la falta de oportunidades laborales y la limitada oferta educativa a su alcance agravan más aún su condición.

La actividad productiva más importante del distrito es la agricultura, pero es ésta uno de los sectores menos atendido por parte del estado, ocasionando que el agricultor abandone el oficio y opte por vender sus tierras; generando como consecuencia el desarrollo de proyectos inmobiliarios sobre áreas agrícolas. Esta expansión urbana se viene dando también en las laderas de los Ecosistemas de Lomas, áreas que, junto a los campos agrícolas deberían ser protegidas, pues Pachacamac pertenece al último valle verde de Lima siendo fundamental conservarlo.

Se propone el diseño arquitectónico de un CENTRO TÉCNICO PRODUCTIVO situado en el Centro Poblado Rural "Quebrada Verde", destinado a proporcionar conocimiento teórico-práctico aplicado al manejo de recursos agroindustriales y al cultivo en laderas de productos hortofrutícolas, contribuyendo de esta manera a la preservación del Valle del rio Lurín y al aprovechamiento sostenible de las lomas de Lima.

\subsection{Justificación del Tema}

- Pachacamac es un distrito que cuenta con 129,653 habitantes, los cuales además de su condición de pobreza se encuentran desempleados en un $36 \%$ (INEI, 2015), estadística que aumenta en el centro poblado rural Quebrada Verde, porque es poca la población que cuenta con un trabajo fijo, estos tienen que recorrer distancias muy largas para llegar a su centro de labores. 
- A pesar que existen dos centros de formación técnica en la localidad: El Instituto Juan Pablo II y El Centro Técnico Productivo José Luis Idígoras, los índices de desempleo no disminuyen siendo un factor importante la dirección incongruente de los oficios impartidos, pues en ninguno instruyen sobre el aprovechamiento y gestión de los recursos propios del lugar como el turismo y la agricultura. Otro factor a considerar es que éstos centros no tienen forma de promover el desarrollo económico ni de generar empleo directamente, por no contar con la infraestructura ni el equipamiento a nivel productivo.

\subsection{Planeamiento del problema}

¿Puede este Centro de Educación Técnico Productiva ser un dinamizador económico del centro poblado rural Quebrada Verde y generador importante de fuentes de empleo? ¿Cómo un CETPRO puede ayudar en la preservación del Valle del Río Lurín y del Ecosistema de Lomas?

¿En qué tipo de programas de instrucción deberían centrarse los talleres de producción del Centro?

\subsection{Objetivos de la investigación}

\subsubsection{Objetivo General.}

El diseño arquitectónico del Centro Técnico Productivo Lomas de Lucumo, presentado a la comunidad, y una vez ejecutada su construcción, busca conseguir que la población de Quebrada Verde, los centros poblados rurales cercanos y el distrito de Pachacamac puedan mejorar su calidad de vida en base al aprendizaje de un oficio vinculado a los recursos del entorno a la capacitación técnica que se brindará a la población agrícola de la zona y al desarrollo local que impulsa la oferta laboral promovida por las actividades productivas a desarrollarse en este equipamiento. 


\subsection{Supuesto básico de la investigación}

Si fuera comprobado que un Centro de Educación Técnico Productivo es un importante elemento de desarrollo local y generador de fuentes de empleo, entonces la presencia de este equipamiento en un sector vulnerable en la provincia de Lima mejoraría la calidad de vida de su población.

\subsection{Alcances y limitaciones}

\subsubsection{Objetivos Específicos.}

- Estudiar la consolidación en el tiempo del Valle de rio Lurín y los antecedentes históricos de los Centros de Educación Técnico Productiva, su evolución en el tiempo y situación actual.

- Comprender los conceptos fundamentales de la educación superior técnica de nivel básico en un CETPRO, su definición, características organizacionales y de gestión, así como metodologías empleadas de proyección social; todo comparado a la relación directa que tiene la arquitectura de este equipamiento con el aprendizaje y el desarrollo local. Es importante estudiar los conceptos arquitectónicos para desarrollar un proyecto en un paisaje de borde dada la ubicación del mismo.

- Analizar proyectos educacionales públicos afines realizados en el Perú y el mundo poniendo énfasis en el cumplimiento de objetivos específicos y técnicas empleadas además de índices de desarrollo social obtenidos.

- Determinar mediante el análisis de la comunidad y del distrito cuales serían los recursos con los que se cuenta actualmente: sea productos regionales, técnicas tradicionales, pequeños clusters ya establecidos o entornos con condiciones viables de producción con la finalidad de guiar el aprendizaje a estas actividades de producción local asegurando así el éxito del proyecto. 


\subsubsection{De la investigación.}

Dentro de la investigación se estudiará la realidad urbana, económica y social del Valle de rio Lurín poniendo énfasis en el distrito de Pachacamac, su situación actual de desempleo y los recursos naturales y culturales, con el fin de establecer el contexto y estrategias en las que se desarrollará el proyecto.

Una de las limitaciones del proyecto fue la información poco relevante obtenida del análisis en cuanto a diseño arquitectónico de los CETPROS de Lima Metropolitana, pues en su mayoría son edificaciones improvisadas. Tampoco pudo realizarse encuestas ni ningún tipo de estudio cuantitativo referente a las condiciones socioeconómicas del entorno inmediato al proyecto, pues la comunidad del Centro Poblado Rural Quebrada Verde es vulnerable a constantes invasiones, motivo por el cual se muestran temerosos a brindar información; dada esta limitación para la presente investigación se contó con los datos obtenidos de los distintos estudios estadísticos realizados por prestigiosas instituciones como el Instituto Nacional de Estadística e Informática (INEI), Ministerio de Educación (MINEDU), Ministerio de Trabajo y Promoción del Empleo (MTPE), entre otros.

\subsubsection{Del proyecto.}

El diseño del proyecto contempla incorporar a la capacitación técnica la producción empresarial, condiciones que derivan en un programa complejo con relaciones espaciales basadas en índices de eficiencia en el aprendizaje y la producción.

Una de las limitaciones del proyecto es la condición del centro poblado rural pues es aún un área no urbanizada ni consolidada, por lo que no existe un archivo de catastro que contenga todo el centro poblado en su extensión por lo que es necesario hacer un levantamiento topográfico del terreno y parte del entorno. 


\subsection{Diseño de la investigación}

Para la presente tesis se utilizará el método de investigación descriptiva el cual nos permitirá observar y detallar los elementos, características y teorías que componen el diseño y desarrollo de un Centro Técnico Productivo.

\subsection{Metodología de la investigación}

\subsubsection{Forma de consulta de la información}

La información contenida en este trabajo de investigación será consultada en libros, artículos científicos, revistas arquitectónicas y en documentos registrados por entidades e instituciones afines.

\subsubsection{Forma de recopilación de la información}

La información será recopilada a través de recursos informáticos como páginas web, revistas científicas digitales o repositorios de tesis; también se consultarán libros especializados en arquitectura social y desarrollo económico, tablas, encuestas y censos de instituciones como el INEI, y Ministerios afines al proyecto.

\subsubsection{Forma de análisis de la información}

Lo primero que se analizará serán los antecedentes históricos de Centros Técnicos Productivos, cuáles eran las necesidades de la población que se benefició, si los talleres tenían el fin de revalorar su cultura regional, o más bien impartieron conocimientos nuevos referidos a la demanda económica de productos en la región donde se situaban; cual fue el alcance y sobre todo si cumplieron el propósito inicial.

Una vez estudiados los casos, se procede a interpretar los datos referidos a la realidad económico-social del centro poblado y en coherencia con las necesidades encontradas establecer el enfoque de los talleres productivos.

\subsubsection{Forma de presentación de la información}

La investigación se presentará de forma escrita apoyada en diagramas y cuadros que respalden la información obtenida. También se presentarán planos a nivel de proyecto que indiquen las características de diseño arquitectónico del mismo. 


\section{CAPÍTULO II: MARCO REFERENCIAL}

\subsection{Los Valles de Lima}

Lima, la capital del Perú es una ciudad costera asentada sobre tres valles, éstos fueron formados por las cuencas de los ríos: Rímac, Chillón y Lurín y poseen una altitud entre los $3 \mathrm{msnm}$ y $5600 \mathrm{msnm}$. Su temperatura y precipitación promedio anual en la costa es de $21^{\circ} \mathrm{C}$ y $13 \mathrm{~cm}^{3}$ respectivamente y en la sierra alta, de $9^{\circ} \mathrm{C} \mathrm{y} 40 \mathrm{~cm}^{3}$.

Esta ciudad fue fundada en el siglo XVI y actualmente su población representa aproximadamente el $30 \%$ de la población total del país.

Figura 2.1 Mapa geográfico del Perú, el departamento de lima y la ubicación de sus valles.

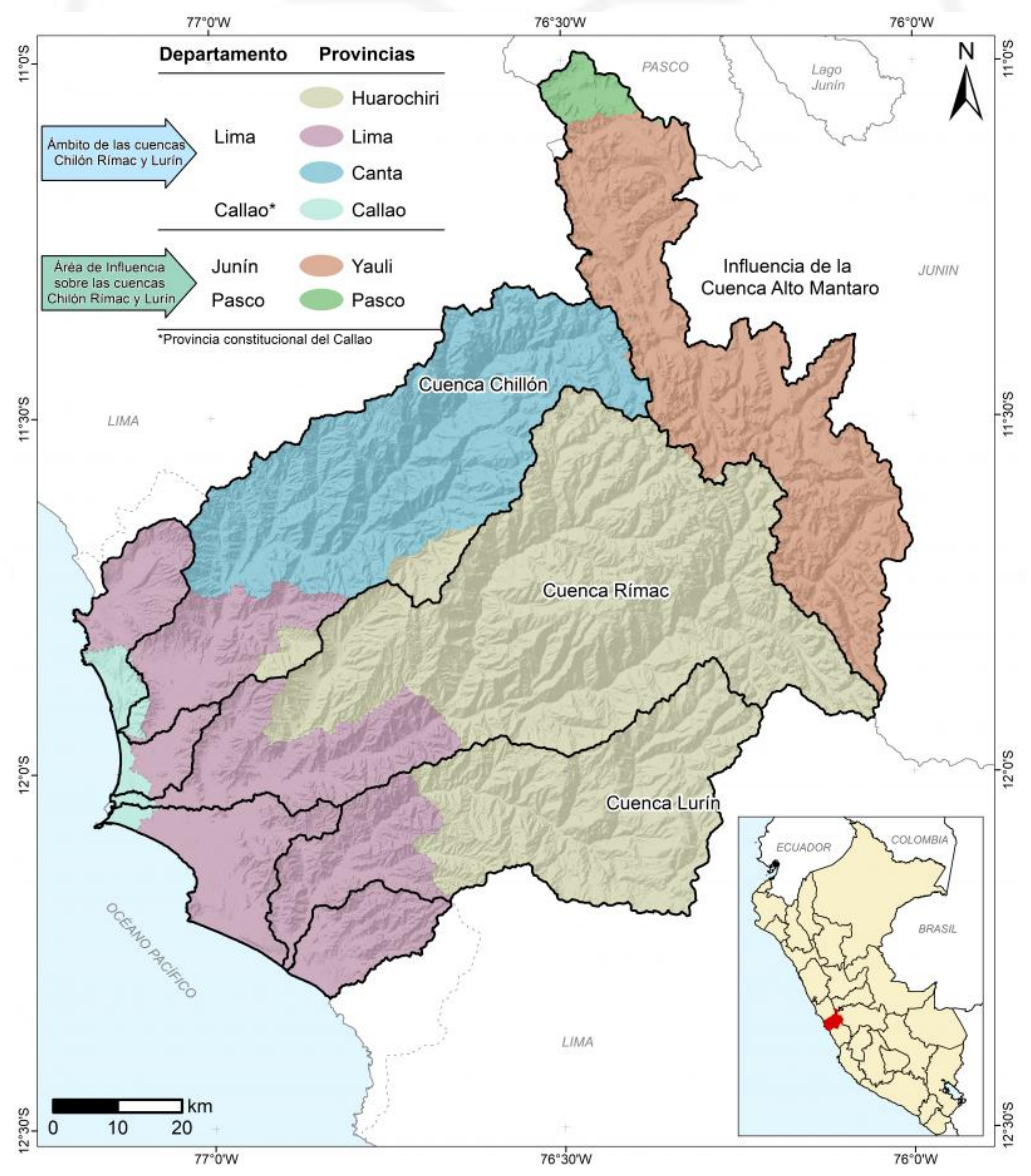

Fuente: (Autoridad Nacional del Agua, 2018) 
Los recursos hídricos del departamento de Lima provienen de las cuencas del Río Rímac, Chillón y Lurín; nacen en la cordillera de los andes y desembocan en el Océano Pacífico, conformando los valles de su mismo nombre.

El siguiente gráfico expone los valles mencionados, su respectiva extensión y la zona urbana que poseen; siendo el Valle del Rímac el más poblado, seguido de Chillón y Lurín. Éstos valles recibieron a sus primeros habitantes hace más de 12000 años siendo pobladores nómades.

Figura 2.2 Extensión de los valles que forman parte del departamento de Lima

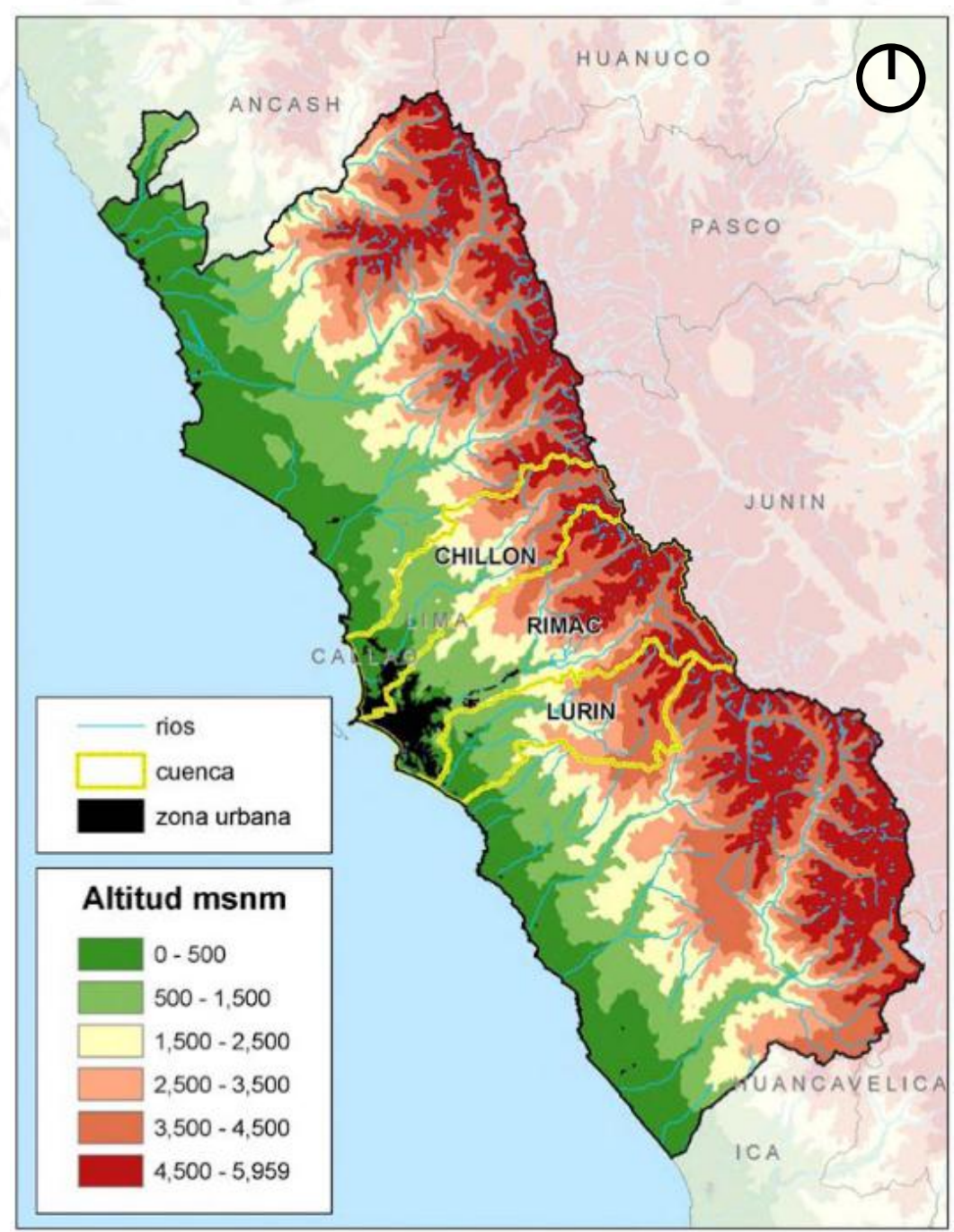

Fuente: (Raymundo, Coen, \& Prain, La dinámica de la agricultura en Lima 1972-2002, 2007) 


\subsubsection{Valle del Río Lurín.}

El Valle del Río Lurín comprende el área llana formada a partir del transcurrir del río; éste es denominado colector y está abastecido por afluentes que pertenecen a un sistema de drenaje natural. Toda esta extensión de territorio es llamada cuenca; para el caso de la Cuenca del Río Lurín se sabe que éstos afluentes se generan en las alturas a partir de aguas de lluvia y por la desglaciación del Nevado Surococha, los mismos drenan hacia este único colector desembocando en el Océano Pacífico.

Una cuenca es una delimitación de área geográfica que nos permitirá realizar un análisis más acertado acerca de las poblaciones entorno al recurso hídrico, pues su evolución y desarrollo están estrechamente ligados al aprovechamiento del mismo.

Figura 2.3 Cuenca del Río Lurín

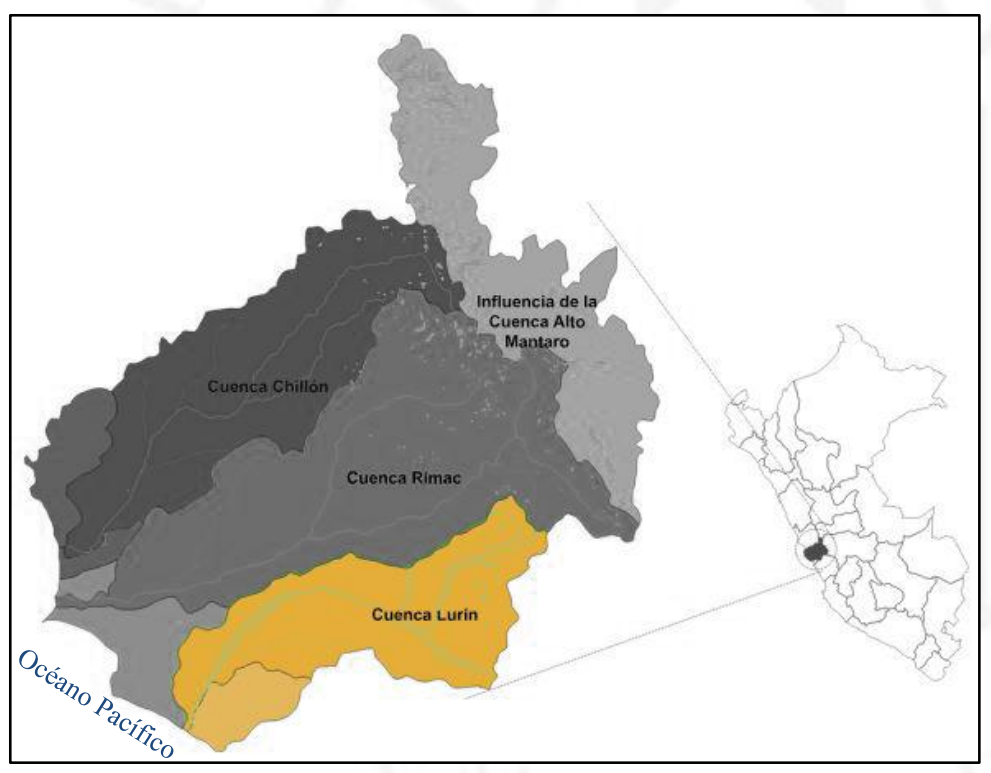

\begin{tabular}{|l|l|}
\hline \multicolumn{2}{|c|}{ Cuenca Lurín } \\
\hline Superficie & $1658 \mathrm{~km}^{2}$ \\
\hline Nacimiento & $\begin{array}{l}\text { Deshielo } \\
\text { del } \\
\text { Nevado } \\
\text { Surococha }\end{array}$ \\
\hline $\begin{array}{l}\text { Caudal medio del río } \\
\text { principal }\end{array}$ & $5,2 \mathrm{~m}^{\mathrm{s}}$ \\
\hline $\begin{array}{l}\text { Almacenamiento en } \\
\text { sistemas regulados }\end{array}$ & $5 \mathrm{hm}^{3}$ \\
\hline $\begin{array}{l}\text { Oferta de agua } \\
\text { subterránea sostenible } \\
\text { (Acuifero Chillón - } \\
\text { Rímac) }\end{array}$ & $1,1 \mathrm{~m}^{\mathrm{s}} / \mathrm{s}$ \\
\hline Población & $\begin{array}{l}774402 \\
\text { habitantes }\end{array}$ \\
\hline $\begin{array}{l}\text { Principal tipo de uso } \\
\text { de agua }\end{array}$ & Agrario \\
\hline
\end{tabular}

Fuente: (Autoridad Nacional del Agua, 2018) 


\subsubsection{Extensión}

Al Sur Este de la ciudad de Lima en el distrito de San Damián ubicado a 3000 m.s.n.m. tiene origen la cuenca del río Lurín cuya formación parte de la unión de Chalilla y Taquia, dos quebradas del distrito. El río recorre $107 \mathrm{~km}$ y posee una superficie aproximada de $1660 \mathrm{kms}^{2}$. Conforman el valle doce distritos, nueve repartidos entre la cuenca alta y media ubicados en la provincia de Huarochirí; y tres en la cuenca baja pertenecientes a la provincia de Lima.

Es importante resaltar que para la presente investigación no se ha incluido al distrito de Villa María del Triunfo, pues la población directamente relacionada con el río es pequeña y para algunos referentes de evaluación puede llevarnos a obtener resultados poco acertados.

Cuadro 2.1 Distritos pertenecientes a las cuencas del Río Lurín y su altitud

\begin{tabular}{|l|c|}
\hline \multicolumn{2}{|c|}{$\begin{array}{c}\text { PROVINCIA DE HUAROCHIRÍ } \\
\text { Cuenca Alta }\end{array}$} \\
\hline DISTRITO & ALTITUD \\
\hline Santiago de Tuna & $2871 \mathrm{msnm}$ \\
\hline San Andrés de Tupicocha & $3292 \mathrm{msnm}$ \\
\hline San Damián & $3260 \mathrm{msnm}$. \\
\hline Huarochirí & $2895 \mathrm{msnm}$ \\
\hline
\end{tabular}

\begin{tabular}{|l|c|}
\hline \multicolumn{2}{|c|}{$\begin{array}{c}\text { PROVINCIA DE HUAROCHIRÍ } \\
\text { Cuenca Media }\end{array}$} \\
\hline DISTRITO & ALTITUD \\
\hline Lahuaytambo & $3354 \mathrm{msnm}$ \\
\hline Langa & $2865 \mathrm{msnm}$ \\
\hline Cuenca & $2744 \mathrm{msnm}$ \\
\hline Antioquía & $1568 \mathrm{msnm}$. \\
\hline Sto. Domingo de Olleros & $2807 \mathrm{msnm}$ \\
\hline
\end{tabular}




\begin{tabular}{|l|c|}
\hline \multicolumn{2}{|c|}{$\begin{array}{c}\text { PROVINCIA DE LIMA } \\
\text { Cuenca Baja }\end{array}$} \\
\hline DISTRITO & ALTITUD \\
\hline Cieneguilla & $712 \mathrm{msnm}$ \\
\hline Pachacamac & $205 \mathrm{msnm}$. \\
\hline Lurín & $6 \mathrm{msnm}$. \\
\hline
\end{tabular}

Fuente: ( Instituto Metropolitano de Planificación, 2013)

Elaboración Propia

Figura 2.4 Mapa de los distritos pertenecientes a la cuenca del Río Lurín

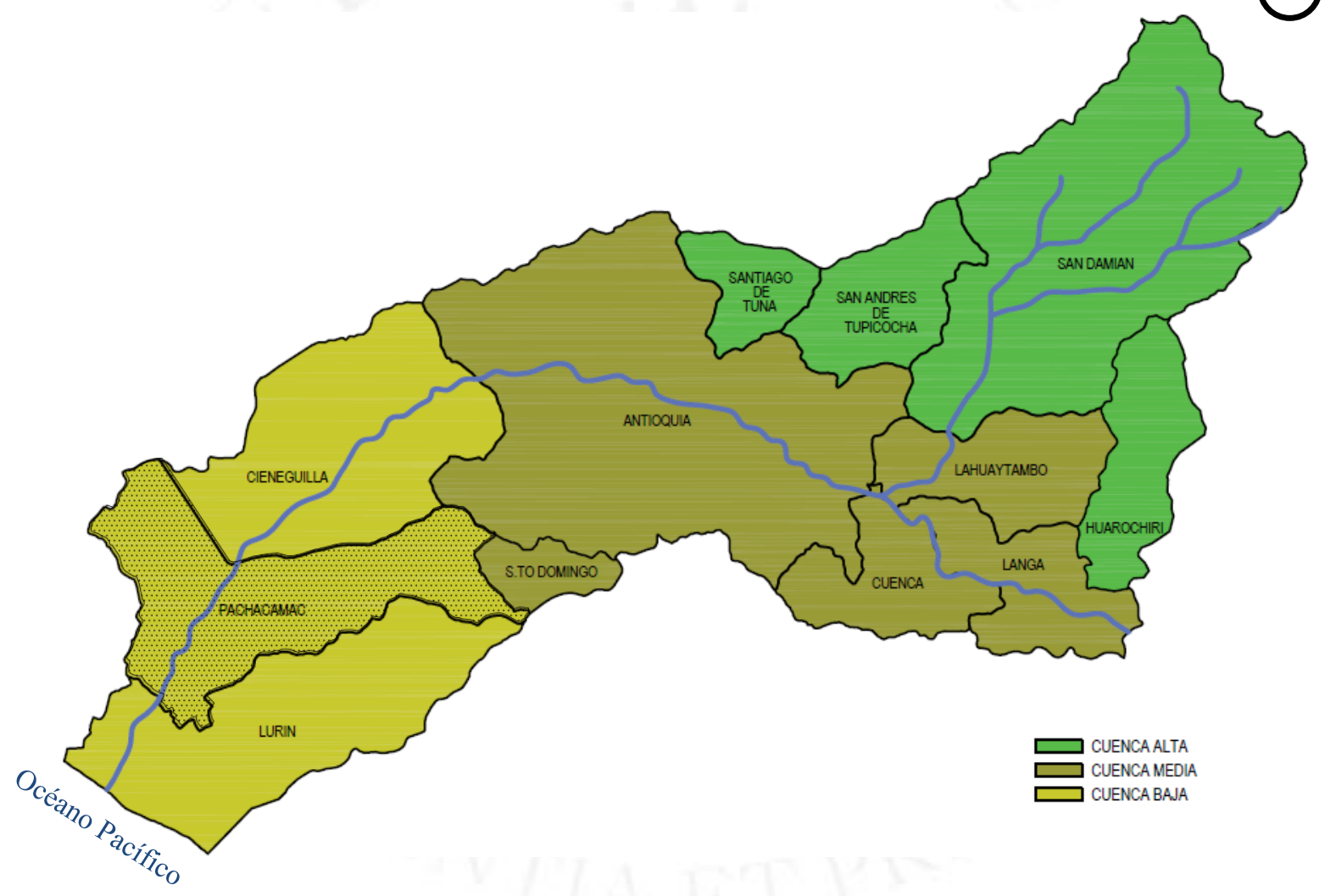

Fuente: ( Instituto Metropolitano de Planificación, 2013)

Elaboración Propia 


\subsubsection{Recursos}

Para la presente investigación de Tesis, es relevante realizar el estudio de los recursos naturales del valle, con mayor incidencia en el agua y el suelo, pues están directamente relacionados con la producción agrícola, y en caso específico del recurso hídrico con el potencial aprovechamiento sostenible de los Ecosistemas de Lomas, para definir el alcance a nivel macro del Proyecto y su replicabilidad.

El recurso hídrico requerido por el valle lo proporciona la cuenca del Río Lurín, incluyendo a sus intercuencas y microcuencas.

Figura 2.5 Cuenca del Río Lurín y afluentes

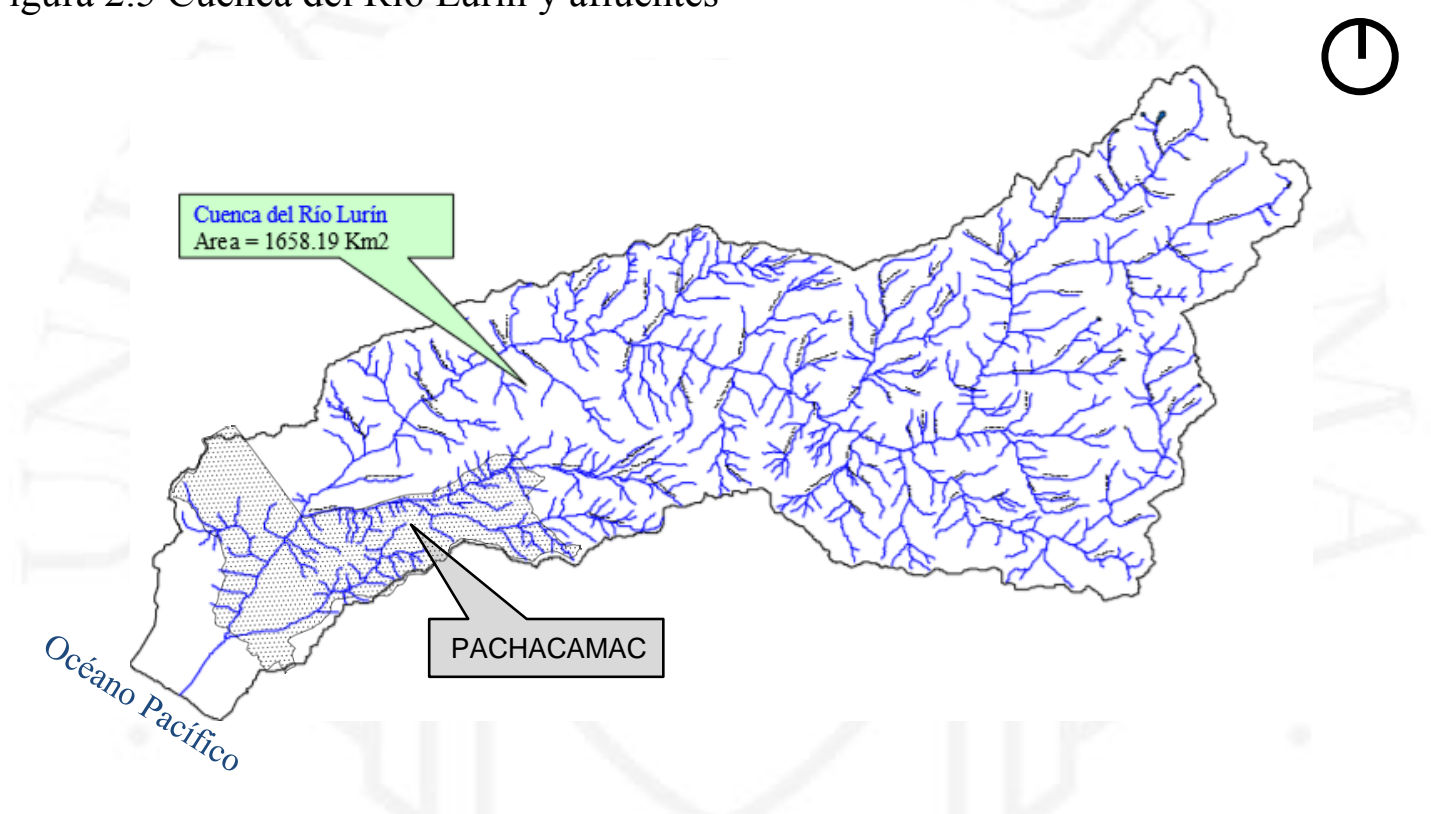

Fuente: (Chillón-Rímac-Lurín, 2004)

Según los datos obtenidos del estudio realizado por el, ( Instituto Metropolitano de Planificación, 2013), la cuenca del rio Lurín se extiende $1658.19 \mathrm{~km}^{2}$ y es parte del Sistema Hidrográfico del Pacifico, cuyas aguas se originan en los nevados y lagunas de la Cordillera Occidental de los Andes. Inicia su recorrido en el distrito de San Damián hasta el Océano Pacífico, con una pendiente estimada de $6.8 \%$, en toda su cuenca alta; de $3.2 \%$ en su cuenca media hasta la localidad de Manchay y finalmente $1.8 \%$ de pendiente en su cuenca baja hasta su desembocadura. Es importante además mencionar que el $49.1 \%$ de su extensión, pertenece a la cuenca inbrífera, o también llamada cuenca húmeda, cuya ubicación se encuentra sobre los 2500 msnm. 
A continuación se especifican las características físicas de la cuenca del Río Lurín:

Cuadro 2.2 Características Físicas de La Cuenca del Río Lurín

\begin{tabular}{|l|c|c|}
\hline \multicolumn{1}{|c|}{ Característica } & Unidades & Valor \\
\hline Área de cuenca & $\mathrm{Km}^{2}$ & 1624.0 \\
\hline Perímetro & $\mathrm{Km}$ & 256.0 \\
\hline Coeficiente de Compacidad & - & 1.75 \\
\hline Factor de forma & - & 0.09 \\
\hline Número de Orden de los cauces & - & 4 \\
\hline Densidad de Drenaje & $\mathrm{Km} / \mathrm{Km}^{2}$ & 0.18 \\
\hline Rectángulo equivalente & $\mathrm{Km}$ & $\begin{array}{c}\mathrm{L} 1: 113.3 \\
\mathrm{~L} 2: 14.7\end{array}$ \\
\hline
\end{tabular}

Fuente: ( Instituto Metropolitano de Planificación, 2013)

Para el análisis hidrológico se tomó en cuenta los datos de las Estaciones Hidrométricas Antapucro y San Damián, ambas instaladas en el año 1968, con una operatividad continua hasta la fecha. La primera estación tiene como función determinar la cantidad de agua requerida para cultivo en el valle y la segunda establecer el volumen que aporta a la cuenca la zona alta del valle.

Figura 2.6 Estaciones Hidrométricas en la Cuenca del Río Lurín

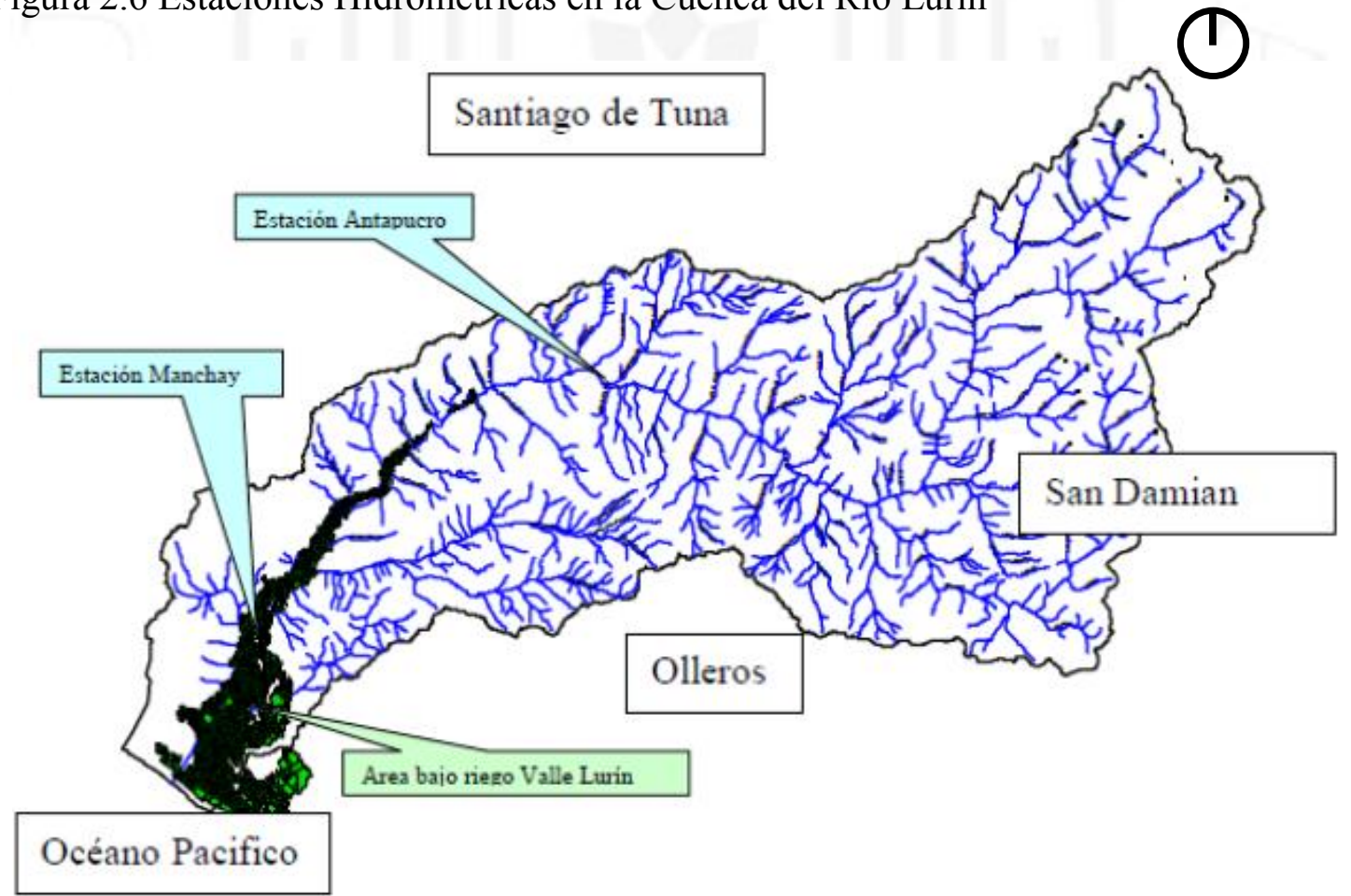

Fuente: ( Instituto Metropolitano de Planificación, 2013) 
En el inventario nacional de ríos realizado por la Ex Oficina Nacional de Recursos Naturales (ONERN) se detalla la información de los afluentes de la cuenca del Río Lurín, siendo cinco quebradas las que aportan mayor caudal.

Figura 2.7 Diagrama Fluvial de la cuenca del Río Lurín

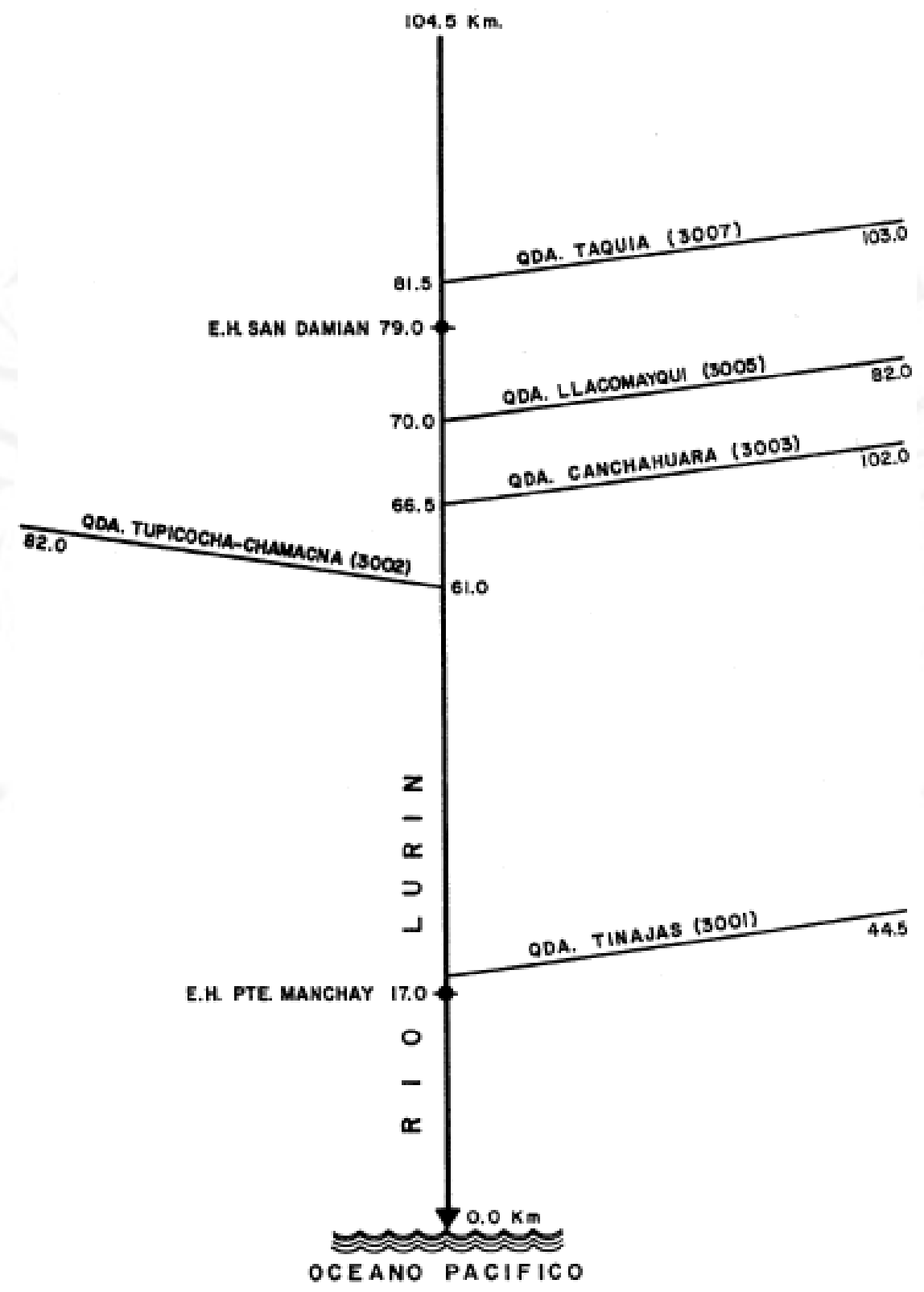

Fuente: ( Instituto Metropolitano de Planificación, 2013) 
En la cuenca del Rio Lurín se han registrado un total de catorce lagunas, ocho formadas a partir de la subcuenca Quebrada Chalilla; dos a partir de la subcuenca Río Numicancha y cuatro a partir de la subcuenca Río Canchahuara.

Para el abastecimiento hídrico al proyecto de aprovechamiento sostenible de Lomas, es necesario evaluar el recurso más factible, siendo éste Rio Lurín, dado que todas las lagunas, como podemos observar en el siguiente cuadro, se encuentran ubicadas en la cuenca alta y el proyecto se ubica en el distrito de Pachacamac, perteneciente a la cuenca baja del valle.

Cuadro 2.3 Inventario de Lagunas en la Cuenca del Río Lurín

\begin{tabular}{|c|c|c|c|}
\hline $\mathbf{N}^{\circ}$ & Laguna & $\begin{array}{c}\text { Altitud } \\
(\mathbf{m s m})\end{array}$ & Sub Cuenca \\
\hline 1 & Tuctotoca & 4450 & Qda. Chalilla \\
\hline 2 & Huasca & 4610 & Qda. Chalilla \\
\hline 3 & Atococha & 4675 & Qda. Chalilla \\
\hline 4 & Azulcocha & 4780 & Qda. Chalilla \\
\hline 5 & Suerococha & 4510 & Qda. Taquia \\
\hline 6 & Chanape & 4780 & Qda. Taquia \\
\hline 7 & Negra & 4450 & Qda. Taquia \\
\hline 8 & Compunco & 4580 & Qda. Taquia \\
\hline 9 & Yanascocha & 4414 & Río Numicancha \\
\hline 10 & Tres Lagunas & 4500 & Río Numicancha \\
\hline 11 & Culco & 4480 & Río Canchahuara \\
\hline 12 & Puchis & 4470 & Río Canchahuara \\
\hline 13 & Naña & 4600 & Río Canchahuara \\
\hline 14 & Paullacocha & 4520 & Rio Canchahuara \\
\hline
\end{tabular}

Fuente: ( Instituto Metropolitano de Planificación, 2013)

En el año 2010 se realizó el análisis de la precipitación media en la cuenca del Río Lurín tomando los datos de las siguientes estaciones meteorológicas: Santiago de Tuna, Chalilla y Cieneguilla, observándose en conjunto un factor constante de precipitación siendo los meses de diciembre a marzo donde se registran los mayores volúmenes y de mayo a septiembre donde se registran los mínimos, llegando incluso a $0.0 \mathrm{~mm}$. 
Cuadro 2.4 Precipitación Media Mensual y Anual (mm) en la Cuenca del Río Lurín

\begin{tabular}{|l|c|c|c|c|c|c|c|c|c|c|c|c|c|c|}
\hline \multicolumn{1}{|c|}{ Estación } & $\begin{array}{c}\text { Altitud } \\
(\mathrm{msnm})\end{array}$ & Ene & Feb & Mar & Abr & May & Jun & Jul & Ago & Set & Oct & Nov & Dic & $\begin{array}{c}\text { Total } \\
\text { anual }\end{array}$ \\
\hline $\begin{array}{l}\text { Santiago de } \\
\text { Tuna }\end{array}$ & 2921 & 59.3 & 103.1 & 105.7 & 16.6 & 1.4 & 0.0 & 0.1 & 0.1 & 0.9 & 3.4 & 8.1 & 31.9 & 330.4 \\
\hline Chalilla & 4050 & 66.7 & 85.3 & 102.8 & 23.0 & 0.9 & 0.0 & 0.0 & 0.5 & 0.8 & 8.9 & 12.5 & 46.7 & 348.1 \\
\hline Cieneguilla & 280 & 2.1 & 0.0 & 2.1 & 0.3 & 0.0 & 0.1 & 1.0 & 0.2 & 0.0 & 0.1 & 0.3 & 0.2 & 6.4 \\
\hline
\end{tabular}

Fuente: ( Instituto Metropolitano de Planificación, 2013)

En el siguiente gráfico se muestra las variaciones del caudal mensual en la cuenca del Río Lurín, fijando los meses de enero a abril como los de mayor caudal registrado, datos que coinciden con la temporada de alta precipitación del valle. Los meses de mayo - junio y noviembre - diciembre son periodos de transición de máximo a mínimo y de mínimo a máximo caudal respectivamente.

Figura 2.8 Caudales Medios del Río Lurín

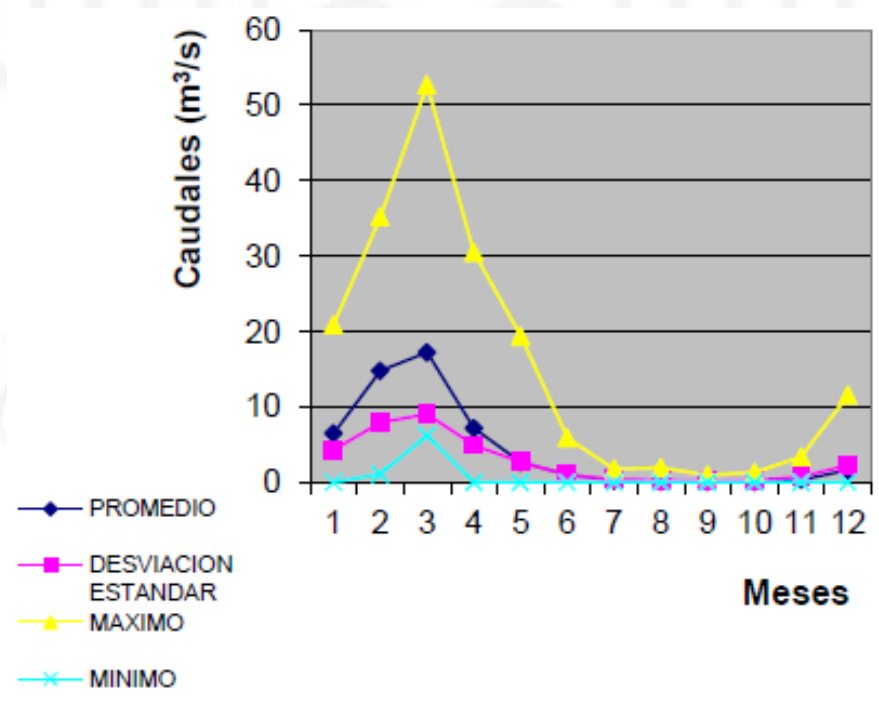

Fuente: ( Instituto Metropolitano de Planificación, 2013) 
En la información mostrada en el gráfico anterior; los meses de julio a octubre el caudal es mínimo llegando incluso a ser nulo; ésta época coincide con la temporada de Lomas, fenómeno estacional que desarrolla condiciones climatológicas que podrían permitir convertir la niebla en agua, sirviendo para el regadío de los cultivos involucrados en el proyecto. Para este fin se incorporaría al diseño arquitectónico en las áreas específicas un sistema de muro atrapa nieblas; conectándose a la red de regadío ya establecida que consiste en método por goteo.

El análisis del agua de la cuenca registró porcentajes de pesticidas DDT y Lindano ambos excediendo los límites máximos permisibles, siendo el más preocupante la concentración obtenida de DDT sobrepasando $0.117 \mathrm{ppm}$. El resultado que se observa en el siguiente cuadro permite concluir que es necesario incorporar en el programa educativo del Centro Técnico Productivo, la capacitación para el uso de fertilizantes orgánicos, con el fin de mejorar la calidad de agua del Rio Lurín.

Cuadro 2.5 Análisis de pesticidas presentes en la Cuenca del Río Lurín

\begin{tabular}{|l|c|c|}
\hline \multicolumn{1}{|c|}{ Pesticida } & $\begin{array}{c}\text { Limite } \\
\text { Máximo } \\
\text { Permisible }\end{array}$ & $\begin{array}{c}\text { Concentración } \\
\text { Obtenida }\end{array}$ \\
\hline DDT & 0.02 & 0.119 \\
\hline LINDANO & 0.004 & 0.007 \\
\hline HEPTACLORO & 0.01 & \\
\hline METAXICLORO & 0.1 & \\
\hline MALATION & 0.008 & \\
\hline
\end{tabular}

Fuente: ( Instituto Metropolitano de Planificación, 2013)

Servicio Nacional de Meteorología e Hidrología realiza temporalmente un estudio de la calidad de agua de las principales cuencas del distrito de Lima, con respecto a la cuenca del Río Lurín la toma se realiza en la estación de Antapucro localizada en la parte media de la cuenca, el siguiente mapa muestra su ubicación exacta. 
Figura 2.9 Ubicación gráfica de la Estación Antapucro

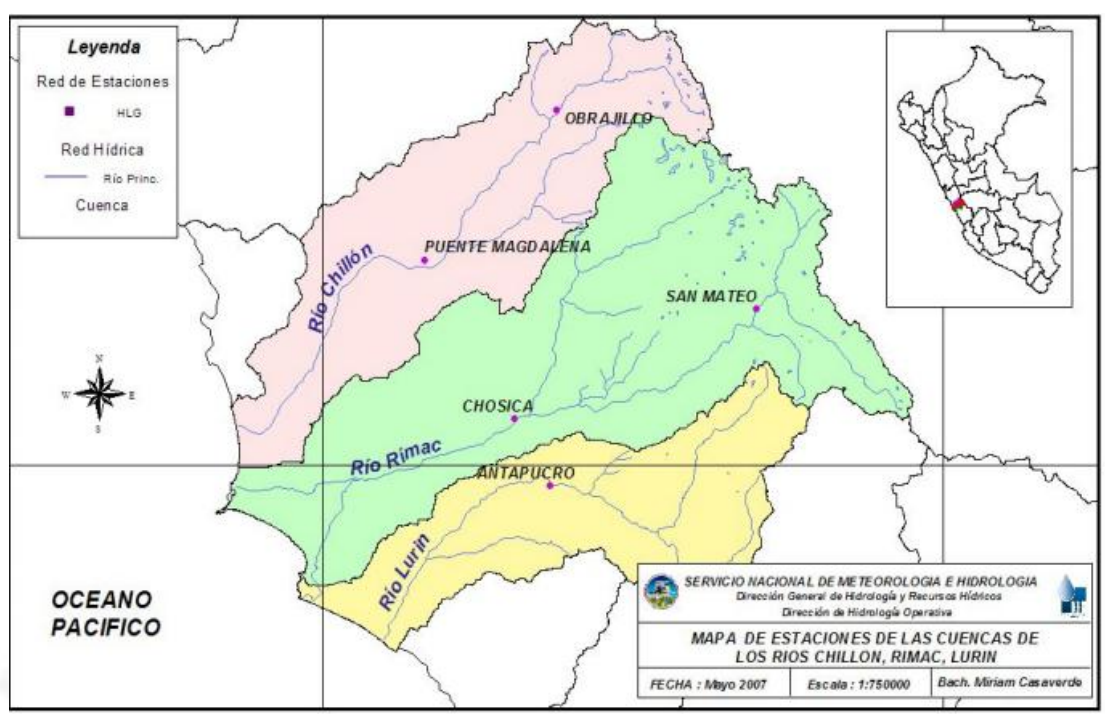

Fuente: SENAMHI

Los valores referentes a calidad de agua del Río Lurín para mayo del 2007 registran una temperatura de agua de $19,1^{\circ} \mathrm{C}$, sin presencia de nutrientes, valores bajos de calcio, magnesio, cobre y fósforo; valores medios de $\mathrm{PH}$, mineralización y sulfato, registra también valores altos de Cloruro de Sodio.

Cuadro 2.6 Valores de Calidad de Agua del Río Lurín

\begin{tabular}{|c|c|c|c|}
\hline PARÁMETROS & $\begin{array}{c}\text { VALOR } \\
\text { ANTAPUCRO }\end{array}$ & OBSERVACIONES & $\begin{array}{c}\text { DIGESA } \\
\text { ECA (GRUPO III) }\end{array}$ \\
\hline $\mathrm{T}^{\circ}$ Agua ${ }^{\circ} \mathrm{C}$ & 19,10 & & \\
\hline $\mathrm{pH}$ & 6,53 & Neutro Normal & 6,5 a 8,4 \\
\hline $\mathrm{CE}$ (uS/cm) & 320,00 & Mineralización Media & 750 \\
\hline $\mathrm{OD} \mathrm{mg/L}$ & 3,90 & Normal - Bajo & 4,00 (tipo IV) ${ }^{* *}$ \\
\hline $\mathrm{Cl} \mathrm{mg} / \mathrm{L}$ & 120,00 & Normal - Medio & 100 \\
\hline $\mathrm{NaCl}$ & 160,50 & Normal - Alto & $140^{* *}$ \\
\hline $\begin{array}{c}\text { Dureza Total como } \\
\mathrm{CaCO}_{3}\end{array}$ & 115,00 & Poco duras & $150-300$ Duras ${ }^{* *}$ \\
\hline $\mathrm{Ca} \mathrm{mg/L}$ & 33,60 & Bajo & 200 \\
\hline $\mathrm{Mg} \mathrm{mg} / \mathrm{L}$ & 7,57 & Bajo & 150 \\
\hline Alcalinidad $\mathrm{mg} / \mathrm{L}$ & 107,00 & & $200-500$ ** \\
\hline Cobre $\mathrm{mg} / \mathrm{L}$ & 0,05 & Bajo & 0,2 \\
\hline Fierro Total mg/L & 0,03 & Bajo & 1 \\
\hline Cromo $\mathrm{Cr}^{+6} \mathrm{mg} / \mathrm{L}$ & 0,14 & & 0,1 \\
\hline Yodo $\mathrm{I}_{2} \mathrm{mg} / \mathrm{L}$ & 1,27 & & \\
\hline Nitrato $\mathrm{NO}^{3} \mathrm{mg} / \mathrm{L}$ & 0,80 & $\begin{array}{l}\text { No hay presencia de } \\
\text { nutrientes }\end{array}$ & $<5$ \\
\hline Nitrto $\mathrm{NO}^{2} \mathrm{mg} / \mathrm{L}$ & 0,004 & Muy Bajo & $<1$ \\
\hline Fosforo Reactivo $\mathrm{PO}_{4}^{-3}$ & 0,10 & Bajo & 5 \\
\hline Sulfato $\mathrm{SO}_{4}^{-2} \mathrm{mg} / \mathrm{L}$ & 52,00 & Medio & 300 \\
\hline
\end{tabular}

Fuente: (Senamhi, 2007) 
La oferta hídrica anual per cápita para la Región Hidrográfica del Pacífico en el año 2009 ubica a la cuenca del Río Lurín en un estado de estrés hídrico atribuyendo un volumen anual dentro del rango de $1000-1699 \mathrm{~m}^{3}$ por persona, aún más preocupante es el estado de las cuencas del Chillón y del Rímac consideradas en escasez hídrica siendo su volumen anual por persona menor a $1000 \mathrm{~m} 3$.

Figura 2.10 Oferta hídrica en el Perú

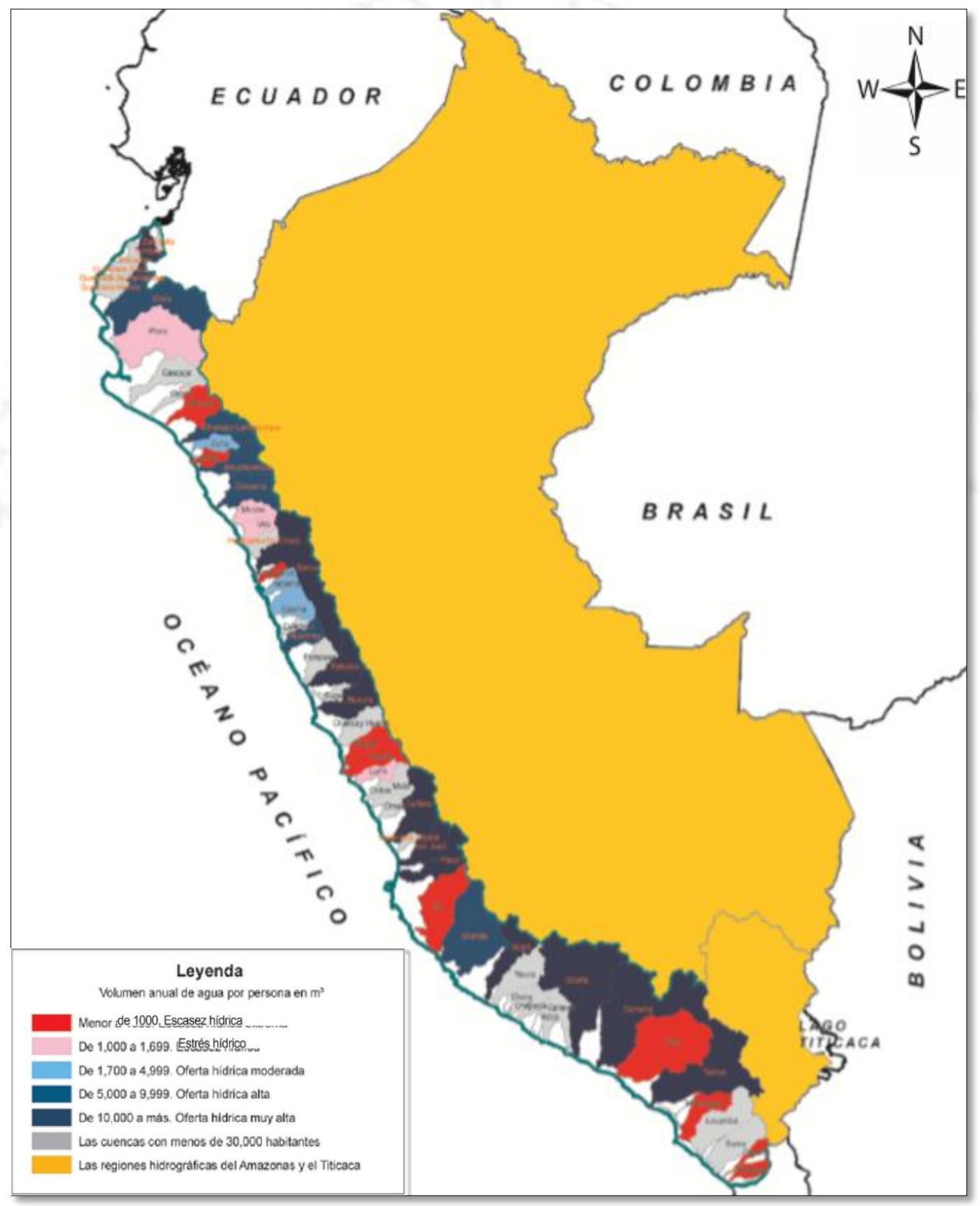

Fuente: (SINIA - Ministerio del ambiente, 2009) 
El último estudio respecto al uso consuntivo del agua del departamento de Lima fue realizado por el INEI y data del año 2015, para la cuenca del Chillón-Rímac-Lurín registra un total de 894,369 $292 \mathrm{~m}^{3}$ siendo el Río Rímac el proveedor de casi el 70\% de éste volumen; la dotación requerida para la agricultura fue de 295,150 $000 \mathrm{~m} 3$, para la industria $192840 \mathrm{~m}^{3}$ y para uso poblacional 599,026 452 $\mathrm{m}^{3}$.

Cuadro 2.7 Uso consuntivo del agua superficial por vertiente, 2015

\begin{tabular}{|c|c|c|c|c|c|}
\hline \multirow{2}{*}{$\begin{array}{c}\text { Administración local } \\
\text { del agua }\end{array}$} & \multicolumn{5}{|c|}{ Uso consuntivo $\left(\mathrm{m}^{3}\right)$} \\
\hline & Total P/ & Agrario & Industrial & Poblacional & Minero \\
\hline 2015 & $13,547,639,863$ & $12,457,427,746$ & $67,106,936$ & $958,582,337$ & $64,522,844$ \\
\hline Pacífico & $13,547,639,863$ & $12,457,427,746$ & $67,106,936$ & $958,582,337$ & $64,522,844$ \\
\hline Tacna & $117,479,639$ & $102,710,000$ & - & $14,769,639$ & - \\
\hline Locumba-Sama & $238,607,121$ & $217,511,578$ & - & $5,921,288$ & $15,174,255$ \\
\hline Moquequa & $90,099,857$ & $75,380,000$ & 27,500 & $13,436,634$ & $1,255,723$ \\
\hline Tambo-Alto-Tambo & $293,707,195$ & $285,770,000$ & $1,044,987$ & $5,871,276$ & $1,020,932$ \\
\hline Chili & $520,287,594$ & $409,000,000$ & $2,426,470$ & $72,258,666$ & $36,602,458$ \\
\hline Colca-Siguas-Chivay & $620,613,153$ & $616,650,000$ & $1,662,435$ & $2,264,490$ & 36,228 \\
\hline Camaná-Majes & $698,543,774$ & $694,510,000$ & 867,927 & $2,889,460$ & 276,387 \\
\hline Ocoña-Pausa & $306,482,485$ & $303,740,000$ & 124,102 & $2,076,368$ & 542,015 \\
\hline Chaparra Acari & $129,892,646$ & $117,389,540$ & 38,437 & $12,298,164$ & 166,505 \\
\hline Grande & $28,589,889$ & $27,550,000$ & 113,187 & 919,052 & 7,650 \\
\hline Ica & $129,910,227$ & $129,850,000$ & 163 & 59,344 & 720 \\
\hline Río Seco & - & - & - & - & - \\
\hline Pisco & $267,709,083$ & $267,690,000$ & 13,513 & 300 & 5,270 \\
\hline San Juan & $95,130,236$ & $95,120,000$ & - & 9,776 & 460 \\
\hline Mala-Omas-Cañete & $375,742,045$ & $361,580,000$ & $4,462,431$ & $5,773,382$ & $3,926,232$ \\
\hline Chillón-Rímac-Lurín & $894,369,292$ & $295,150,000$ & 192,840 & $599,026,452$ & \\
\hline Chancay-Huaral & $328,816,554$ & $322,665,200$ & 12,145 & $5,664,014$ & 475,195 \\
\hline Huaura & $813,746,057$ & $802,731,536$ & $7,568,640$ & $1,954,970$ & $1,490,911$ \\
\hline Barranca & $559,584,912$ & $539,010,000$ & $10,680,890$ & $9,622,194$ & 271,828 \\
\hline Casma Huarmey & $114,171,784$ & $111,791,051$ & - & $2,242,479$ & 138,254 \\
\hline Huaraz & $480,241,533$ & $463,875,757$ & $1,818,349$ & $13,556,293$ & 991,134 \\
\hline Santa-Lacramarca- Nepeña & $552,088,330$ & $537,248,122$ & 301,371 & $14,394,134$ & 144,703 \\
\hline Santiago de Chuco & $26,859,073$ & $24,560,000$ & - & $1,376,716$ & 922,357 \\
\hline Moche-Virú-Chao & $714,377,044$ & $714,120,000$ & 11,168 & 245,376 & 500 \\
\hline Chicama & $598,726,574$ & $593,030,000$ & $5,132,734$ & 533,038 & 30,802 \\
\hline Jequetepeque & $827,696,315$ & $820,910,000$ & 88,135 & $5,890,523$ & 807,657 \\
\hline Zaña & $175,618,132$ & $175,580,000$ & 8,132 & 30,000 & \\
\hline Chancay-Lambayeque & $1,114,664,585$ & $1,007,720,000$ & $18,928,250$ & $87,817,948$ & 198,387 \\
\hline Motupe-Olmos-La Leche & $60,783,650$ & $60,640,000$ & - & 143,650 & \\
\hline Medio y Bajo Piura & $716,786,263$ & $699,800,000$ & - & $16,986,263$ & - \\
\hline Alto Piura - Huancabamba & $98,456,183$ & $95,194,962$ & - & $3,261,221$ & - \\
\hline San Lorenzo & $385,211,666$ & $379,240,000$ & - & $5,935,385$ & 36,281 \\
\hline Chira & $940,933,117$ & $892,490,000$ & $11,288,316$ & $37,154,801$ & - \\
\hline Tumbes & $231,713,855$ & $217,220,000$ & 294,814 & $14,199,041$ & \\
\hline
\end{tabular}

Fuente: ANA 
La Autoridad Nacional del Agua en el año 2012 analizó el balance hídrico de la Cuenca del rio Lurín concluyendo que la misma abastece la total demanda hídrica del valle habiendo incluso un superávit de $2.28 \%$.

Cuadro 2.8 Balance Hídrico de la Cuenca del Río Lurín

\begin{tabular}{|c|c|c|c|c|c|c|c|c|c|c|c|c|c|}
\hline \multirow{2}{*}{ Ofreta Hídrica } & Sep & Oct & Nov & \begin{tabular}{|l|} 
Dic \\
\end{tabular} & Ene & \begin{tabular}{|l|l} 
Feb \\
\end{tabular} & Mar & Abr & May & \begin{tabular}{|l|} 
Jun \\
\end{tabular} & \begin{tabular}{|l|l} 
Jul & \\
\end{tabular} & Ago & Total \\
\hline & 0 & 0 & 0 & \begin{tabular}{|l|}
0.89 \\
\end{tabular} & 8.22 & \begin{tabular}{|l|}
23.01 \\
\end{tabular} & 25.81 & 12.62 & 4.21 & 1.01 & \begin{tabular}{|l|}
0.06 \\
\end{tabular} & 0 & 75.83 \\
\hline \multirow[t]{2}{*}{ Demanda Hídrica } & 4.68 & 7.48 & 7.26 & 8.42 & 9.09 & 11.48 & 10.26 & 5.48 & 3.03 & 1.89 & 1.67 & 2.81 & 73.55 \\
\hline & & & & & & & & & & & & & \\
\hline & & & & & & & & & & & & & \\
\hline \multirow{2}{*}{ Demanda atendida } & 0 & 0 & 0 & \begin{tabular}{|l|}
0.89 \\
\end{tabular} & 8.22 & 11.48 & 10.26 & 5.48 & 3.03 & 1.01 & 0.06 & 0 & 73.55 \\
\hline & 096 & $0 \%$ & $0 \%$ & $10.60 \%$ & 90.4096 & $100 \%$ & $100 \%$ & $100 \%$ & $100 \%$ & $53.40 \%$ & $3.60 \%$ & $0 \%$ & 1009 \\
\hline \multirow{2}{*}{ Superávit } & & & & & & 11.53 & 15.55 & 7.14 & 1.18 & & & & \\
\hline & & & & & & $50.10 \%$ & $60.20 \%$ & $56.60 \%$ & $28.00 \%$ & & & & 2.28 \\
\hline \multirow{2}{*}{ Déficit } & -4.68 & -7.48 & -7.26 & \begin{tabular}{|l|}
-7.53 \\
\end{tabular} & -0.87 & & & & & -0.88 & -1.61 & -2.81 & \\
\hline & 10096 & $100 \%$ & $100 \%$ & $89.40 \%$ & 9.6096 & & & & & $46.60 \%$ & $96.40 \%$ & $100 \%$ & \\
\hline
\end{tabular}

Fuente: (Villanueva Vargas, 2016)

Según datos del Gobierno Regional de Lima el uso total del agua de la cuenca Lurín para el año 2010 fue de $57414749.21 \mathrm{~m}^{3}$ siendo el mayor volumen el destinado para uso agrícola con $42941795.24 \mathrm{~m}^{3}$, seguido de $13704382.31 \mathrm{~m}^{3}$ para uso poblacional y $722577.16 \mathrm{~m}^{3}$ para uso industrial.

Cuadro 2.9 Licencias otorgadas en (MMC) para uso agrario (2010) y no agrario (2013)

\begin{tabular}{|l|r|}
\hline Uso & LURIN \\
\hline & \\
Poblacional & $13,704.382 .31$ \\
\hline & \\
\hline Industrial & $722,577.16$ \\
\hline Minero & 22.075 .20 \\
\hline Energético & 0 \\
\hline Acuícola & 0 \\
\hline Recreativo & $23,919.30$ \\
\hline Agrícola & $42,941,795.24$ \\
\hline TOTAL & $\mathbf{5 7 , 4 1 4 , 7 4 9 . 2 1}$ \\
\hline
\end{tabular}

\begin{tabular}{|l|r|}
\hline & \multicolumn{1}{|l|}{ Lurín } \\
\hline $\begin{array}{l}\text { Oferta } \\
\text { (superficial y } \\
\text { subterránea) }\end{array}$ & 88.683 \\
\hline $\begin{array}{l}\text { Demanda (según } \\
\text { licencias) }\end{array}$ & 57.414 \\
\hline
\end{tabular}

Fuente: (Villanueva Vargas, 2016) 
Sobre el recurso natural Suelo, se determinó que sería relevante analizar los datos sobre tipo de suelo solo de la parte baja de la cuenca que incluye al distrito de Pachacamac, zona de alcance del proyecto; puesto que manejar los registros de todo el valle resultaría muy extenso. Sin embargo para determinar la extensión de suelo agrícola, es preciso mostrar la información de los tres valles de Lima, para establecer la comparativa que nos ayudará a destacar la importancia del Valle del Lurín.

Para el análisis tipológico del suelo presente en la Cuenca del Río Lurín, ha sido necesario hacer un desglose de las características más relevantes que lo componen: La geomorfología, la geología y la litología.

Concluyendo entonces que en la Cuenca del Río Lurín se encuentran presentes seis Unidades Geomorfológicas: Colinas, conos deyectivos, cordillera occidental, depósitos eólicos, valles, quebradas y playas; abarcando el distrito de Pachacamac todas las unidades, siendo la extensión de cordillera occidental la de mayor área, siendo aquí el entorno donde se desarrolla en su mayoría el fenómeno de Lomas Costeras.

Con respecto al aspecto geográfico Las Lomas de Lúcumo y su entorno inmediato forman parte de tres Unidades Estratigráficas: El cretáceo superior en los territorios de Lomas y el cuaternario reciente y cuaternario medio en sus límites.

Para completar el análisis de la tipología de suelo en el entorno del proyecto, es importante conocer las Unidades Litológicas que lo componen, perteneciendo en este caso el área de Lomas a la unidad litológica ácida, dada esta denominación por presentar rocas ígneas; el borde inmediato a ésta área pertenece a la unidad llamada depósito eólico, compuesta en su mayoría por arena y limo, finalmente se encuentra la unidad depósito aluvial cuya composición posee arcilla y arena.

La información antes descrita se extrajo de los siguientes mapas, donde se muestra la geomorfología, geología y litología de los suelos pertenecientes a la cuenca baja del Río Lurín y parte de la cuenca media. 
Figura 2.11 Mapa Geomorfológico de la Cuenca baja del Río Lurín

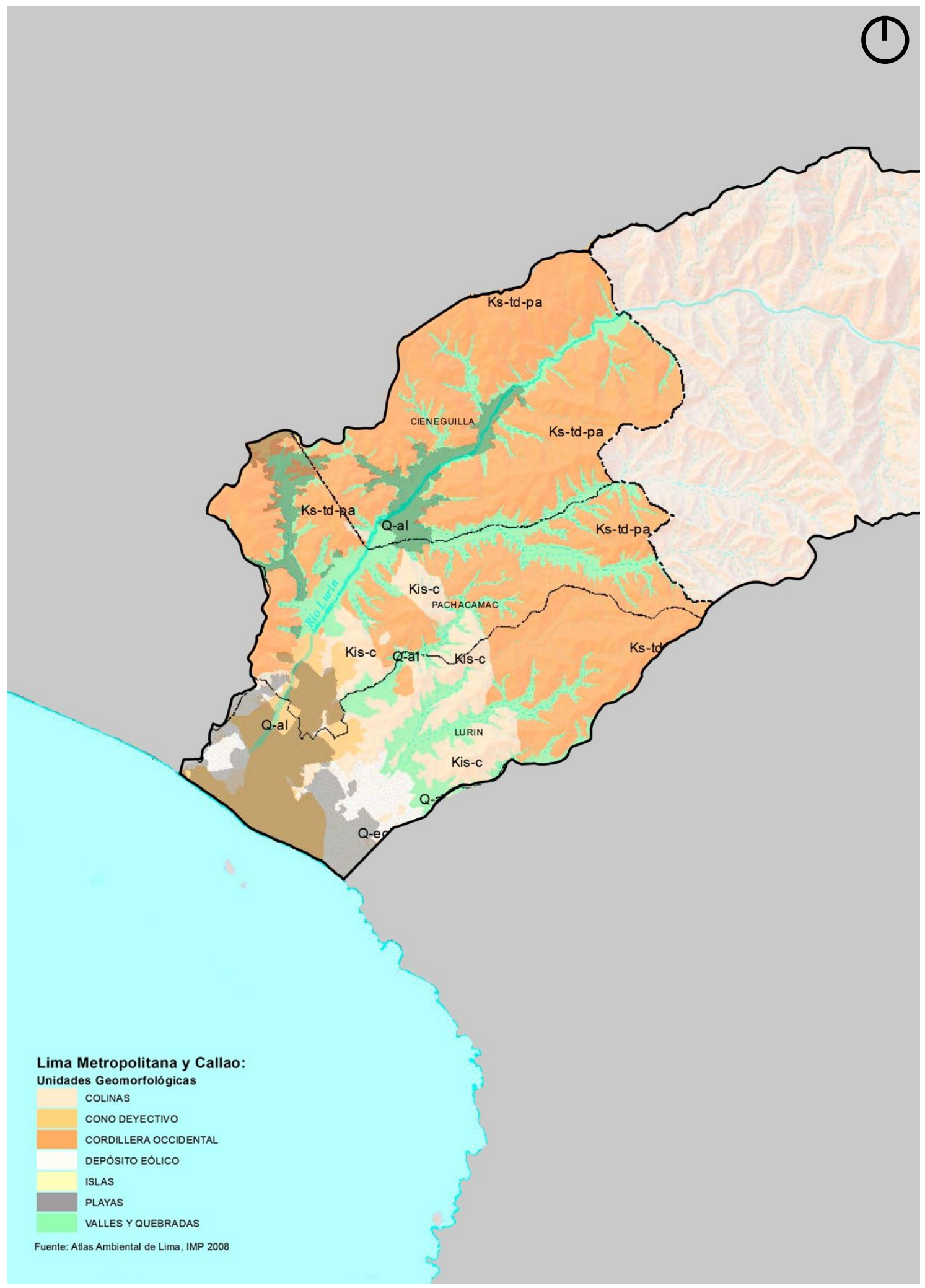

Fuente: (Instituto Metropolitano de Planificación , 2018) 
Figura 2.12 Mapa Geológico de la Cuenca baja del Río Lurín

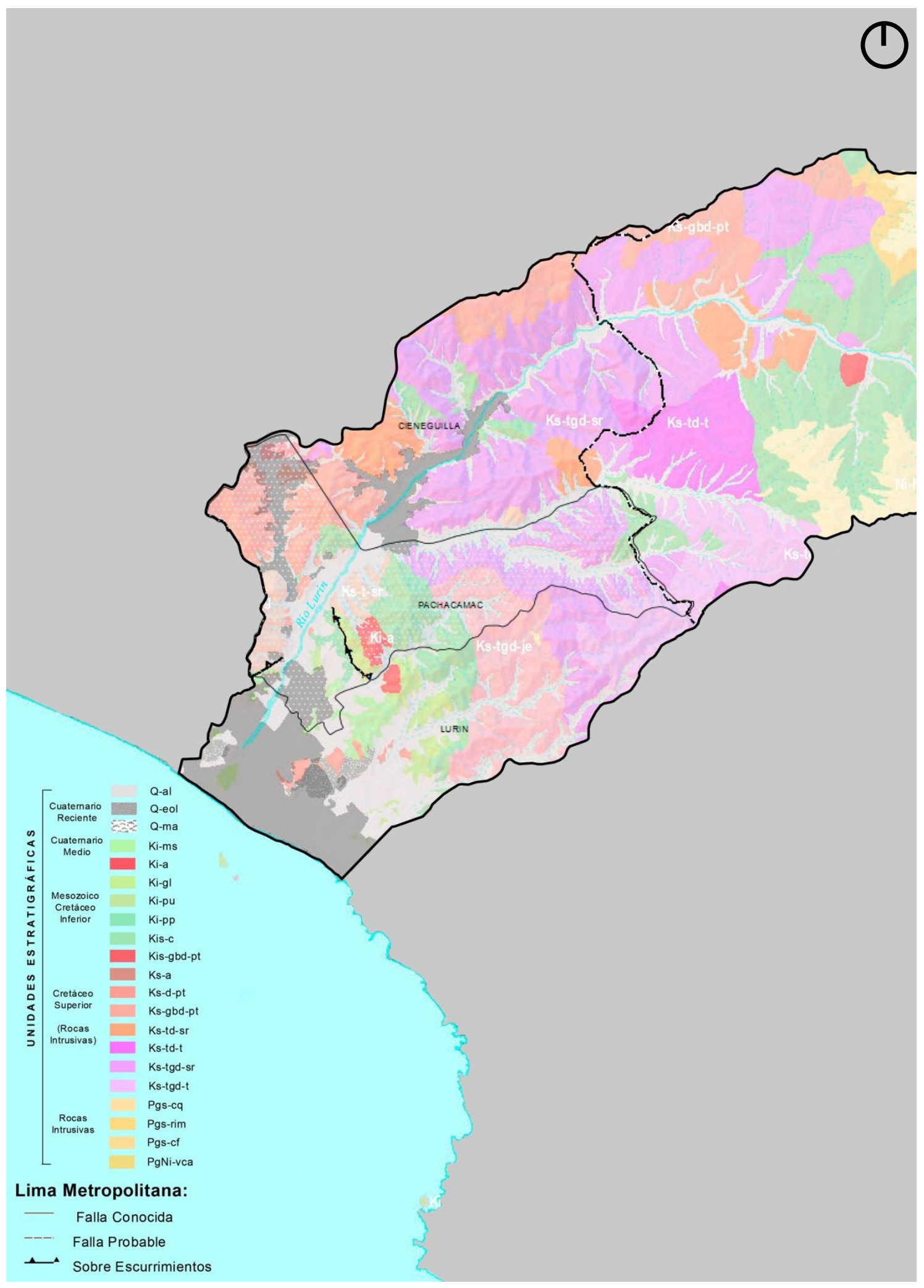

Fuente: (Instituto Metropolitano de Planificación , 2018) 
Figura 2.13 Mapa Litológico de la Cuenca baja del Río Lurín

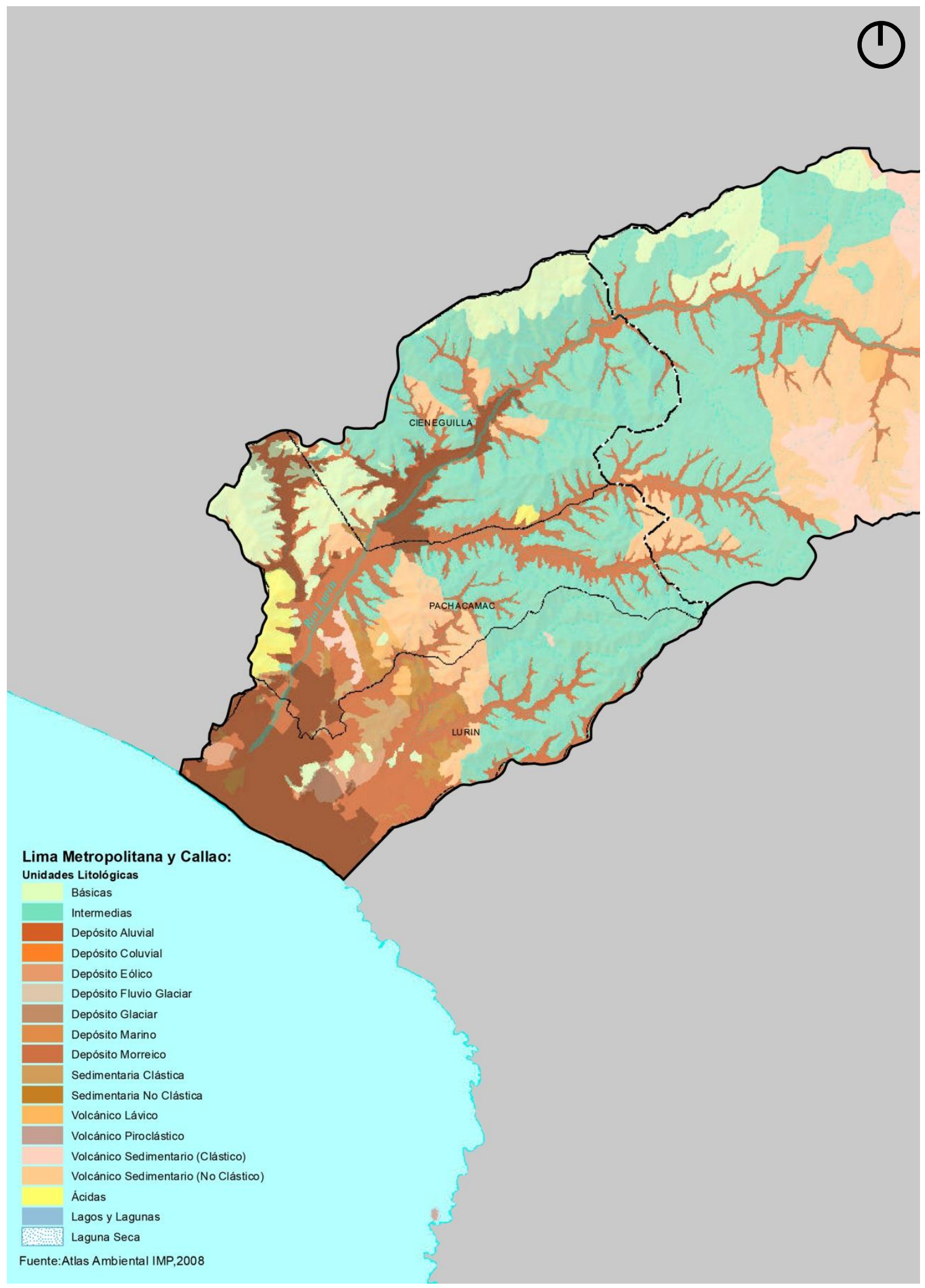

Fuente: (Instituto Metropolitano de Planificación , 2018) 
Para comprender el valor del Valle del rio Lurín dentro de la estructura ecológica de Lima Metropolitana, es importante analizar los datos sobre ocupación del suelo, siendo necesario exponer el crecimiento poblacional de Lima y Callao desde los años $1940 \mathrm{al}$ 2016.

Figura 2.14 Crecimiento histórico poblacional de Lima Metropolitana

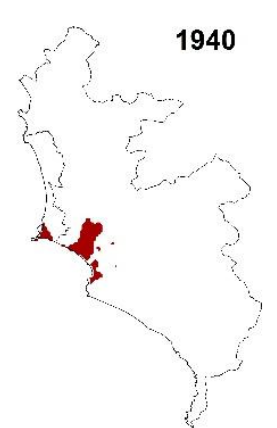

1986

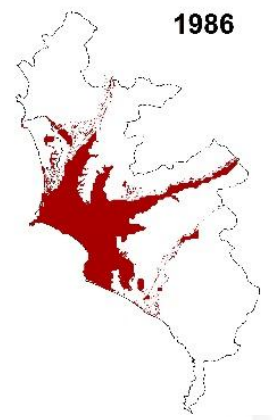

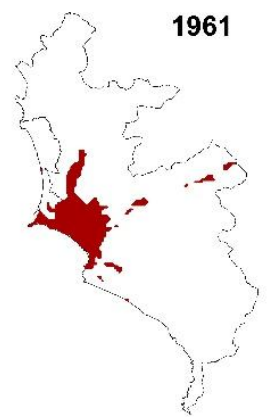

1993

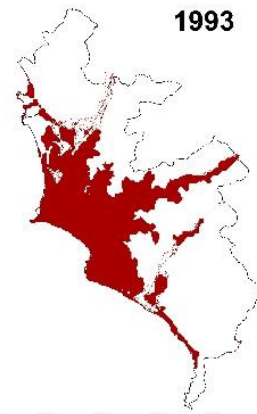

1972

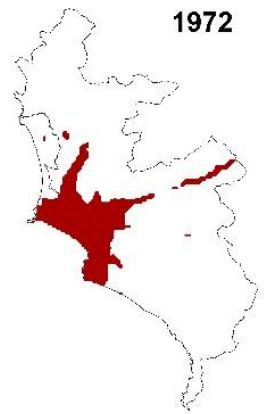

2004

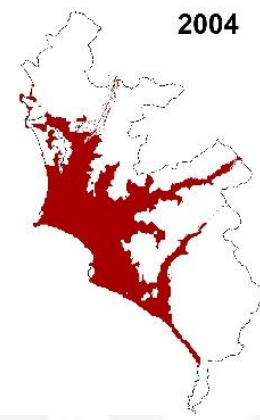

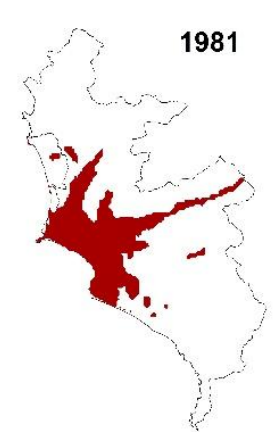

2016

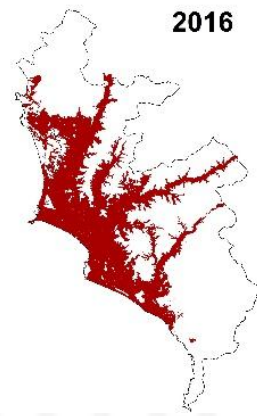

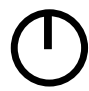

Fuente: (Autoridad Nacional del Agua, 2018)

Se observa que entre los años 1961 a1972 se produjo en Lima Metropolitana un próspero desarrollo de la industria y el comercio, lo que generó un fenómeno migratorio sin precedentes; el centralismo y la búsqueda de una mejora en educación y salud fueron también motivo para que éstas poblaciones decidieran desplazarse hasta la capital; hoy las tasas migratorias han disminuido, pero aún sigue siendo complejo atender las demandas de la población por lo extenso y difuso del territorio.

En Lima Metropolitana en el año 2015 habían alrededor de 10 millones de habitantes, representando el $32 \%$ del total de la población del país, por lo que se concluye que aproximadamente la tercera parte del Perú se encuentra asentada en las cuencas del Chillón, Rímac y Lurín. 
Se aprecia en el gráfico siguiente una proyección poblacional para el año 2035 donde se prevé llegaríamos a sobrepasar los 13 millones de habitantes; esta cifra es preocupante si Lima no establece el límite de su territorio, pues se seguirá creciendo horizontalmente, urbanizando los valles; lo que repercutirá directamente en la salud de la población al elevarse los niveles de polución del aire, pues las pocas áreas verdes urbanas no serían capaces de purificarlo.

Figura 2.15 Evolución de la población de Lima Metropolitana

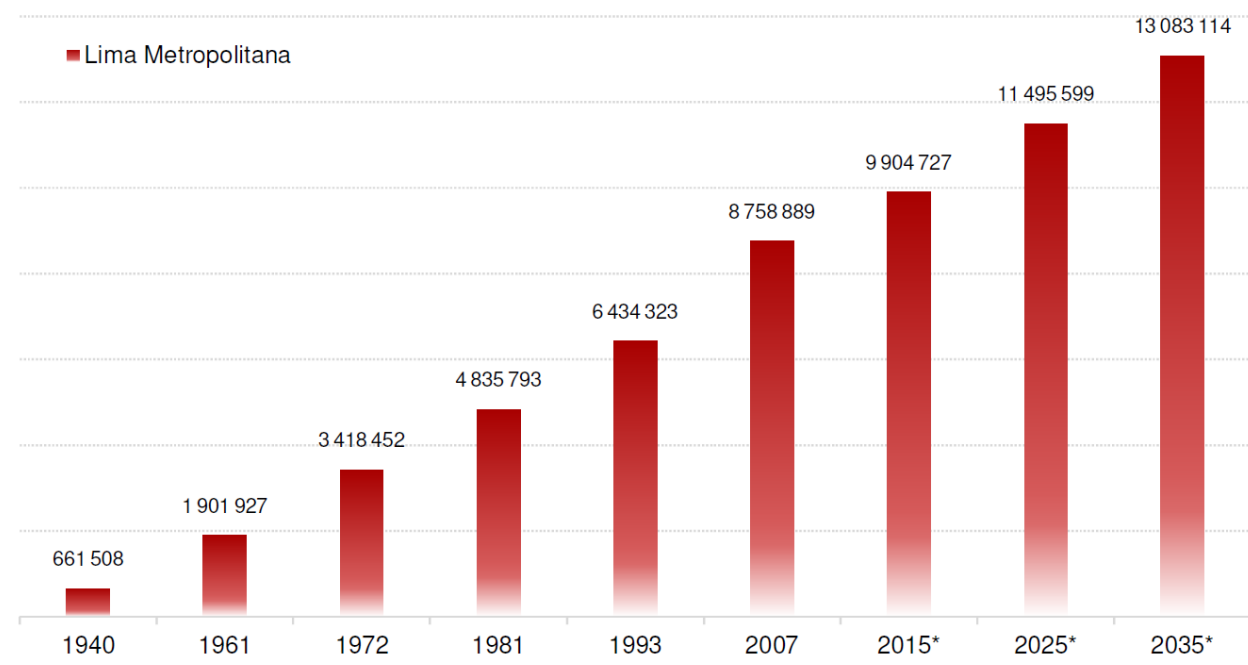

Fuente (Autoridad Nacional del Agua, 2018)

Es coherente que el crecimiento demográfico conlleve a la expansión territorial de una ciudad, pero no a grandes magnitudes como ha ocurrido con Lima Metropolitana, donde la escasa planificación ha ocasionado que el área urbana se haya incrementado en un $87 \%$ en los últimos 30 años, afectando áreas agrícolas. Hacia el año 1986 el área agrícola y áreas verdes representaban casi el 40\% de la ciudad, al 2016 éstas áreas solo alcanzan el 18\% de la extensión total del territorio limeño. 
Figura 2.16 Cambio de Ocupación del suelo en Lima Metropolitana 1986-2016

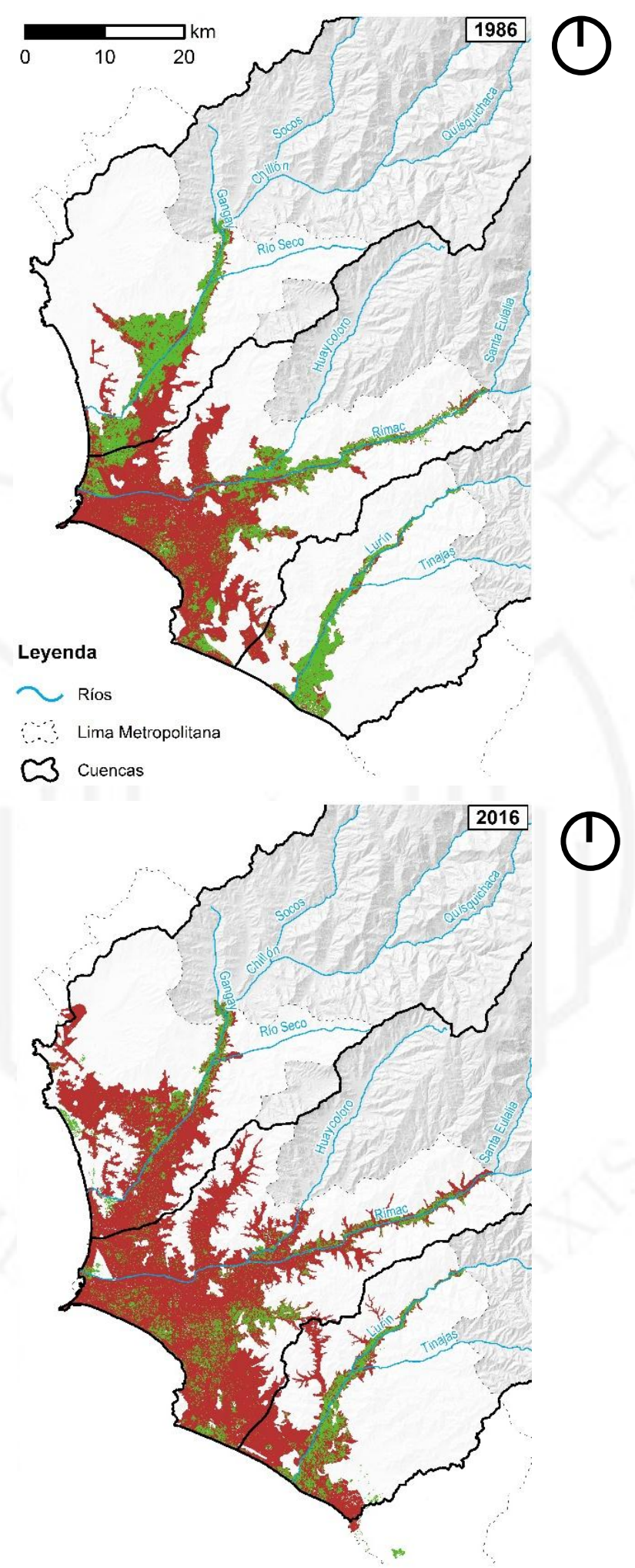

Fuente: (Autoridad Nacional del Agua, 2018) 
Figura 2.17 Cambio de Ocupación de suelo en Lima Metropolitana 1986-2016 en kilómetros cuadrados

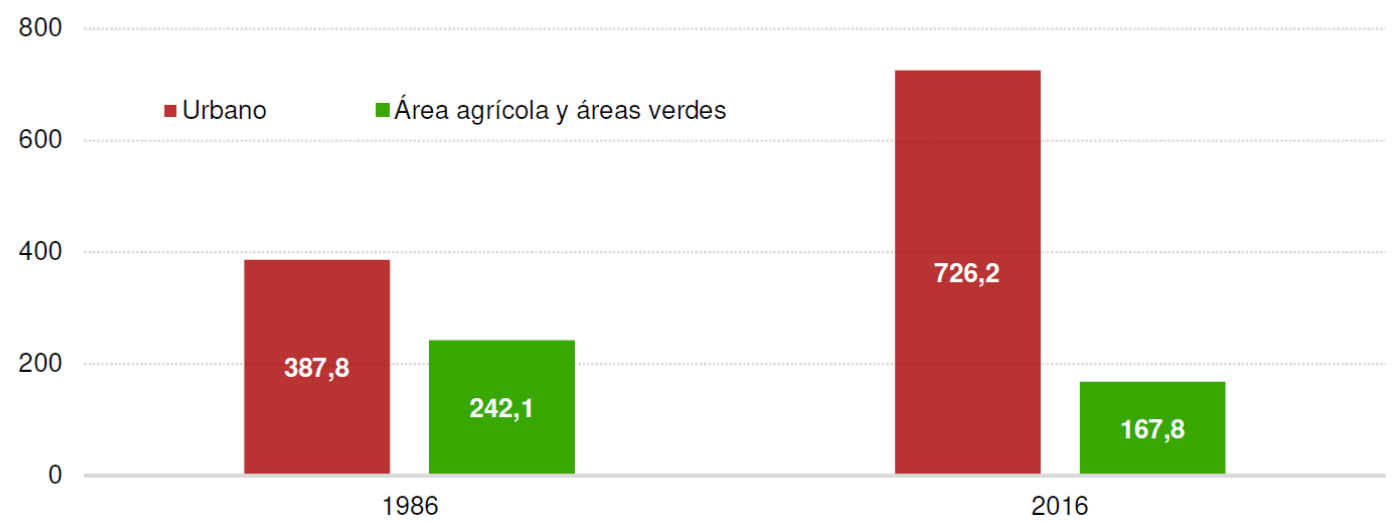

Fuente: (Autoridad Nacional del Agua, 2018)

Este cambio de ocupación de suelo de urbano por agrícola se ha dado sobre todo en zonas desérticas del litoral costero y en los valles bajos del Rímac y Chillón, siendo entonces el Valle bajo de Lurín el menos urbanizado y el de mayor potencial agrícola; a éstas características se suma que en éste territorio ocurre anualmente el $90 \%$ del Fenómeno Estacional de Lomas de Lima Metropolitana, enverdeciendo sus montañas durante aproximadamente seis meses al año, convirtiéndose de ésta forma el Valle del Lurín en el último valle verde de la provincia.

El siguiente mapa muestra la ocupación de suelo en toda la extensión de las cuencas de Chillón, Rímac y Lurín; el área urbana representada con color naranja es Lima Metropolitana, también muestra los ecosistemas de lomas y los territorios donde se desarrolla agricultura costera, andina y áreas verdes urbanas. Acompaña al mapa un cuadro donde se detallan las áreas en kilómetros cuadrados, lo cual nos ayudará a acercarnos un poco más a la información ya presentada, pero se debe tener en cuenta que los datos están referidos a la totalidad de la cuenca que incluye además de Lima a otras provincias. 
Figura 2.18 Mapa sobre la ocupación del suelo en las Cuencas de Chillón, Rímac y Lurín

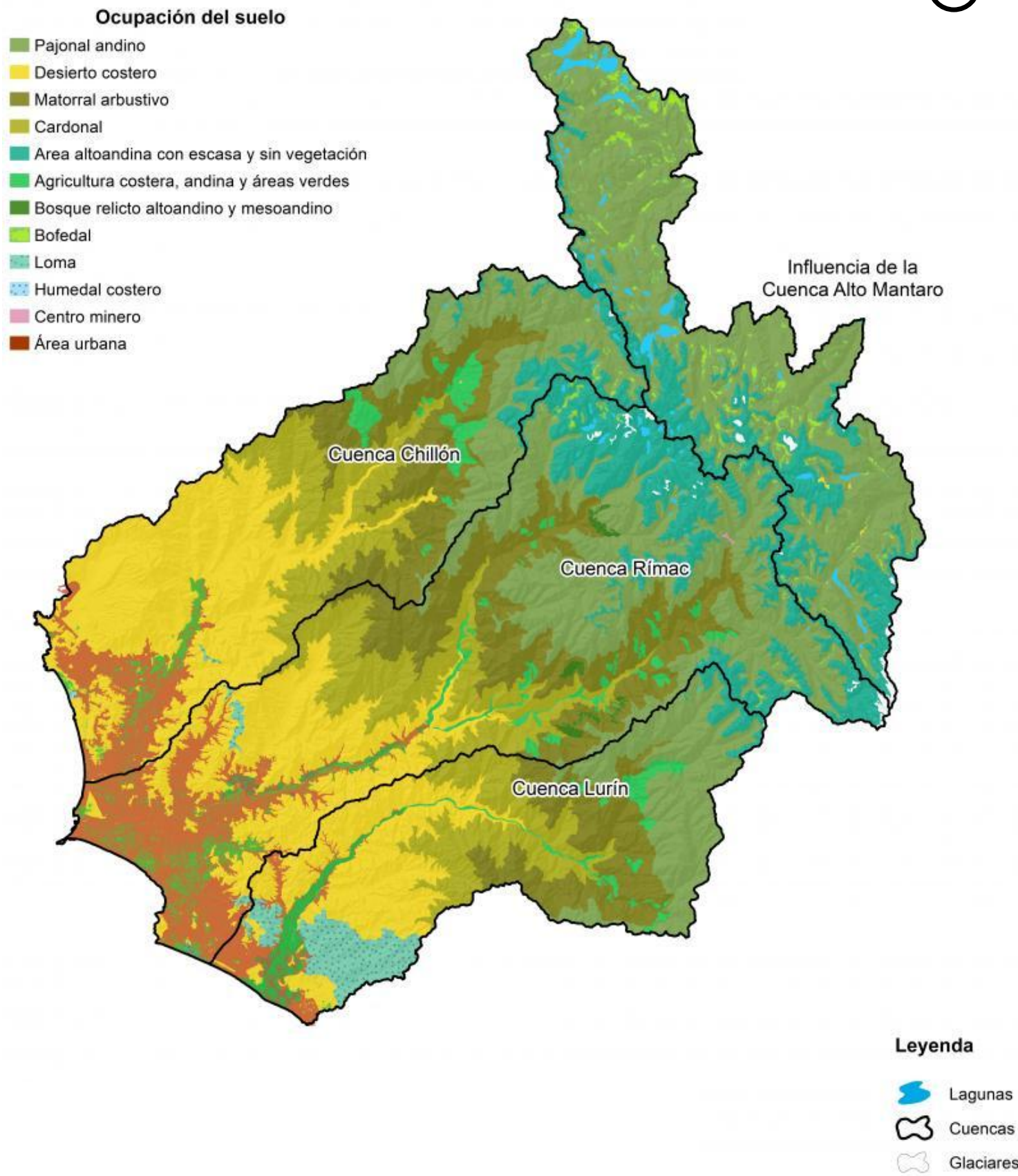

Fuente: (Autoridad Nacional del Agua, 2018) 
Cuadro 2.10 Ocupación del suelo en las Cuencas de Chillón, Rímac y Lurín

\begin{tabular}{|c|c|c|c|c|c|c|}
\hline Ocupación del suelo & $\begin{array}{l}\text { Chillón } \\
\left(\mathrm{km}^{2}\right)\end{array}$ & $\begin{array}{l}\text { Rimac } \\
\left(\mathrm{km}^{2}\right)\end{array}$ & $\operatorname{Lurín}_{\left(\mathrm{km}^{2}\right)}$ & $\begin{array}{c}\text { Alto Mantaro } \\
\left(\mathrm{km}^{2}\right)\end{array}$ & $\begin{array}{l}\text { Total } \\
\left(\mathrm{km}^{2}\right)\end{array}$ & $(\%)$ \\
\hline Pajonal Andino & 405,1 & 861,7 & 394,0 & 1141,5 & 802,3 & 28,6 \\
\hline Desierto costero & 883,5 & 597,4 & 443,7 & & $\begin{array}{r}1 \\
370,8\end{array}$ & 14,0 \\
\hline Matorral arbustivo & 429,5 & 617,0 & 324,3 & & $\begin{array}{r}1 \\
370,8\end{array}$ & 14,0 \\
\hline Cardonal & 373,9 & 409,5 & 287,2 & & $\begin{array}{r}1 \\
070,6\end{array}$ & 10,9 \\
\hline $\begin{array}{l}\text { Área alto andina con escasa y } \\
\text { sin vegetación }\end{array}$ & 116,4 & 513,4 & 39,5 & 393,1 & $\begin{array}{r}1 \\
062,4\end{array}$ & 10,9 \\
\hline Área urbana & 198,1 & 424,7 & 100,5 & 2,0 & 725,3 & 7,4 \\
\hline $\begin{array}{l}\text { Agricultura costera, andina y } \\
\text { áreas verdes urbanas }\end{array}$ & 120,2 & 157,3 & 102,5 & & 380,0 & 3,9 \\
\hline Loma & 2,0 & 13,7 & 155,7 & & 171,3 & 1,8 \\
\hline Bofedal & 6,0 & 12,3 & 0,3 & 119,2 & 137,3 & 1,4 \\
\hline $\begin{array}{l}\text { Cuerpo de agua: Lagunas, lagos } \\
\text { y conchas }\end{array}$ & 3,6 & 13,8 & 0,6 & 65,4 & 83,4 & 0,9 \\
\hline Glaciar & 0,7 & 13,2 & 0,3 & 14,8 & 29,1 & 0,3 \\
\hline $\begin{array}{l}\text { Bosque relicto alto andino y } \\
\text { meso andino }\end{array}$ & & 22,5 & & & 22,5 & 0,2 \\
\hline Humedal costero & 1,3 & 4,0 & 0,0 & & 5,2 & 0,1 \\
\hline Centro minero & & 0,9 & & & 0,9 & 0,0 \\
\hline Subtotal & $\begin{array}{r}2 \\
540,1\end{array}$ & $\begin{array}{r}3 \\
661,3\end{array}$ & $\begin{array}{r}1 \\
848,6\end{array}$ & 1736,0 & $\begin{array}{r}9 \\
786,1\end{array}$ & 100,0 \\
\hline
\end{tabular}

Fuente: (Autoridad Nacional del Agua, 2018) 


\subsubsection{Clima}

Para el análisis meteorológico del Valle del Río Lurín, se tomaron los datos de las estaciones meteorológicas presentes en el mismo; dado que el interés de la investigación se centra en los valores registrados en la cuenca baja, se toma como referencia la estación de Campo de Marte por ser la más cercana al proyecto.

Estableciéndose como valor promedio anual una temperatura de $19.0^{\circ} \mathrm{C}$, en la parte baja de la cuenca.

Cuadro 2.11 Temperatura media anual registrada en las estaciones meteorológicas de la Cuenca del Río Lurín.

\begin{tabular}{|c|c|c|c|}
\hline \multirow{2}{*}{ CUENCAS } & $\begin{array}{c}\text { ESTACIONES } \\
\text { METEREOLÓGICAS }\end{array}$ & $\begin{array}{c}\text { TEMPERATURA } \\
\text { MEDIA ANUAL }\left({ }^{\circ} \mathrm{C}\right)\end{array}$ & $\begin{array}{c}\text { ALTITUD } \\
\text { (m.s.n.m) }\end{array}$ \\
\hline \multirow{2}{*}{ Alta } & Huarochirí & 11,7 & $3000-4500$ \\
\cline { 2 - 4 } Media & San Lázaro de Escomarca & 8,9 & $2000-2900$ \\
\hline Baja & Matucana & 15,4 & 110 \\
\hline
\end{tabular}

Fuente: ( Instituto Metropolitano de Planificación, 2013)

Elaboración propia.

Con referencia a la precipitación promedio anual en la cuenca baja del valle se registra un mínimo de $8.3 \mathrm{~mm}$. 
Cuadro 2.12 Precipitación media anual registrada en las estaciones meteorológicas en la cuenca de Lurín.

\begin{tabular}{|c|c|c|c|}
\hline \multirow{2}{*}{ CUENCAS } & $\begin{array}{c}\text { ESTACIONES } \\
\text { METEREOLÓGICAS }\end{array}$ & $\begin{array}{c}\text { PRECIPITACION } \\
\text { MEDIA ANUAL (Mm) }\end{array}$ & $\begin{array}{c}\text { ALTITUD } \\
\text { (m.s.n.m) }\end{array}$ \\
\hline \multirow{2}{*}{ Alta } & Huarochirí & 581.8 & \multirow{2}{*}{$3000-4500$} \\
\cline { 2 - 4 } Media & San Lázaro de Escomarca & 562.3 & $2000-2900$ \\
\hline Baja & Matucana & 338.5 & 110 \\
\hline
\end{tabular}

Fuente: ( Instituto Metropolitano de Planificación, 2013)

Elaboración propia

Respecto a la humedad relativa promedio anual, se tiene, un valor de $81.2 \%$ para la cuenca baja del valle.

Cuadro 2.13 Humedad relativa promedio anual registrada en las estaciones meteorológicas en la cuenca de Lurín.

\begin{tabular}{|c|c|c|c|}
\hline \multirow{2}{*}{ CUENCAS } & $\begin{array}{c}\text { ESTACIONES } \\
\text { METEREOLÓGICAS }\end{array}$ & $\begin{array}{c}\text { HUMEDAD RELATIVA } \\
\text { PROMEDIO ANUAL (\%) }\end{array}$ & $\begin{array}{c}\text { ALTITUD } \\
\text { (m.s.n.m) }\end{array}$ \\
\hline \multirow{2}{*}{ Alta } & Huarochirí & 81.2 & \multirow{2}{*}{$3000-4500$} \\
\cline { 2 - 3 } Media & San Lázaro de Escomarca & 82.7 & $2000-2900$ \\
\hline Baja & Matucana & 87.3 & 110 \\
\hline
\end{tabular}

Fuente: ( Instituto Metropolitano de Planificación, 2013)

Elaboración propia

La recopilación de información meteorológica referente a temperatura, precipitación media anual y humedad relativa permitieron identificar dentro del valle del Río Lurín a tres tipos de climas, los cuales se detallan a continuación: 
Cuadro 2.14 Tipos de Climas Identificados en la Cuenca del Río Lurín

\begin{tabular}{|c|c|c|c|c|c|c|}
\hline \multicolumn{2}{|c|}{ Descripción } & $\begin{array}{c}\text { Temperatura } \\
\left({ }^{\circ} \mathrm{C}\right)\end{array}$ & $\begin{array}{l}\text { Precipitación } \\
\text { Media Anual } \\
\text { (mm) }\end{array}$ & Estación seca & $\begin{array}{c}\text { Humedad } \\
\text { Relativa } \\
(\%)\end{array}$ & $\begin{array}{l}\text { Área } \\
\text { ( ha) }\end{array}$ \\
\hline$E_{(d)} B^{\prime}{ }_{1} H_{3}$ & $\begin{array}{l}\text { Desértica } \\
\text { Semicalido }\end{array}$ & 19 a 21,1 & 60 & $\begin{array}{l}\text { Mayor a } \\
3 \text { meses }\end{array}$ & 87,3 & 163411 \\
\hline $\begin{array}{l}\mathrm{C}_{(\mathrm{O}, \mathrm{l})} \\
\mathrm{C}^{\prime} \mathrm{H}_{2}\end{array}$ & $\begin{array}{l}\text { Semiseco, } \\
\text { Templada }\end{array}$ & 15,4 & 229,3 a 338,5 & $\begin{array}{l}\text { Mayor a } \\
4 \text { meses }\end{array}$ & 87,7 & 41399 \\
\hline $\begin{array}{l}\mathrm{C}_{(\text {(o.i.p) }} \\
\mathrm{A}^{\prime} \mathrm{H}_{3}\end{array}$ & Semiseco, frio & 8 a 11,8 & 367,2 a 947,1 & $\begin{array}{l}\text { Mayor a } \\
4 \text { meses }\end{array}$ & 82,7 & 120580 \\
\hline Lomas & $\begin{array}{l}\text { Desértica } \\
\text { Semicalido }\end{array}$ & 10 a 18 & Menor 80 & $\begin{array}{l}\text { Mayor a } \\
3 \text { meses }\end{array}$ & 87,3 & \\
\hline
\end{tabular}

Fuente: ( Instituto Metropolitano de Planificación, 2013)

Dado que el proyecto de Tesis se ubica al borde de un Ecosistema de Lomas y tomando como referencia el cuadro anterior se concluye que el clima presente en esta área es Desértico Semicalido, cuya temperatura promedio fluctúa entre $\operatorname{los} 10^{\circ} \mathrm{C} \mathrm{a} 18^{\circ} \mathrm{C}$, su precipitación media anual es menor a $80 \mathrm{~mm}$; posee una estación seca mayor a 3 meses y una humedad relativa de $87.3 \%$.

\subsubsection{Proceso de Población del Valle}

Hace 10000 años grupos humanos que practicaban la caza, la pesca y la recolección habitaron el litoral y las vertientes occidentales de los Andes, mediante el aprovechamiento de los recursos de los valles, lomas y el mar de la costa central. (Shady Solis \& Quispe Loayza, 1999)

Para la presente investigación se ha considerado importante analizar el desarrollo histórico del Valle de Lurín, haciendo énfasis en los registros sobre el Distrito de Pachacamac, dado que aquí se ubica el proyecto de tesis y resulta esencial saber sobre su proceso de asentamiento, sus actividades productivas, sus construcciones arquitectónicas y su realidad económica social a lo largo del tiempo. 


\subsection{Los Pobladores de Lomas}

Mujica B., Rostworowski de Diez Canseco, \& Santillana (1983) definieron al Ecosistema de Lomas como. "El fruto de un fenómeno natural discontinuo de la costa peruana. Su límite sur es el paralelo 30 y el norte corresponde más o menos a la ciudad de Trujillo (Ferreyra 1953) o el Cerro Illescas en Piura (Brack 1977:209)” (pág. 6). condición ambiental tiene carácter estacional y ocurre mayormente en los meses de mayo a octubre que es cuando las aguas del mar enfrían el aire seco de los vientos alisios condensando la humedad de la atmósfera y haciéndola caer en forma de garúa sobre la superficie de las montañas cercanas al litoral enverdeciéndolas por completo dando lugar a un ecosistema único de flora y fauna endémicas.

En un principio la población que habitó los valles de Chillón, Rímac y Lurín fueron cazadores- recolectores quienes progresivamente se establecieron en el litoral y en las lomas de los valles, como es el caso de las lomas de Amancaes, próximas al cerro San Cristóbal. Las lomas fueron de gran importancia pues allí se recolectaron algunos frutos y raíces, además de servir como zona de pastoreo en el futuro. Se estima que la sedentarización ocurrió entre 6000 y 2500 años a.C (Raymundo, Bussink, \& Prain, La Dinámica de La Agricultura en Lima, 2007)

Los distintos autores y estudios arqueológicos realizados coinciden en que los primeros pobladores tuvieron estrecha relación con las lomas costeras, no solo para aprovechar sus recursos sino también para asentarse, en un inicio temporalmente debido a la condición estacional del fenómeno de lomas pero más adelante con la introducción de la agricultura pudieron habitarlas por temporadas más largas, prueba de ello son restos arqueológicos que contemplaban viviendas mucho más elaboradas además de canales de irrigación que formaban parte de un sorprendente sistema de agricultura de lomas.

En el seminario de investigación sobre las Poblaciones de Lomas a cargo de Mujica B., Rostworowski de Diez Canseco, \& Santillana (1983) se presenta evidencias sobre 13 asentamientos de ocupación prehistórica en la Quebrada Malanche, situada al sureste de la Cuenca del Río Lurín. Los asentamientos se encuentran distribuidos en la 
margen norte de la quebrada en un área aproximada de $8 \mathrm{~km}$ de largo y de $800 \mathrm{~km}$, a $1000 \mathrm{~km}$, de ancho, que corresponde a la amplitud de la misma.

Los sitios Malanche 1 y Malanche 10 son sin duda vestigios de una ocupación permanente, lo demuestra la dimensión de sus construcciones, la organización compleja del espacio y distribución y diseños arquitectónicos variados; elementos que responden a una importante cantidad de energía invertida, la cual no hubieran perdido para habitarla solo por cortas temporadas, es entonces que se rechaza la hipótesis que sean pastores trashumantes conocidos como "Chivateros" o recolectores nómades los que habitaron dichos asentamientos. Las estructuras techadas conectadas a espacios abiertos, la cerámica utilitaria encontrada y la existencia de fogones de cocina dan evidencia del carácter doméstico de los recintos, por otro lado la disposición de los sitios por sectores o barrios, las variaciones arquitectónicas entre si y sobre todo plataformas localizadas estratégicamente son indicios de una permanencia de fin más allá del solo doméstico.

Los estudios arqueológicos de Mujica B., Rostworowski de Diez Canseco, \& Santillana (1983) también encontraron vestigios de construcciones relacionadas a actividades productivas especializadas ligadas a la agricultura específicamente ubicándose en el sitio Malanche 5: surcos de cultivo, canales, pozos y plataformas con cuadros; en Malanche 18: sistemas de captación y distribución de aguas y Malanche 14 espacios con uso aún por analizar pero, se tiene registro de construcciones de este tipo en el litoral de Arequipa y servían para secar el cochallullo, el autor las describe como. "Estructuras de planta rectangular complementadas con otras de corte circular, aglutinadas y sin vías de comunicación entre ellas. No tienen puertas, los muros son muy finos y paredes bajas" (pág. 13).

Al analizar esta investigación podemos concluir que los antiguos pobladores de lomas además de aprovechar los recursos estacionales hicieron intervenciones en la tierra de carácter agrícola, manejaron el recurso hídrico de neblina de lomas y captación de aguas subterráneas en los meses de verano cuando la napa freática alcanzaba sus niveles más altos para regar sus cultivos y finalmente sometían a secado los excedentes para almacenarlo por más tiempo. Siendo entonces todo lo expuesto evidencia clara de 
que las lomas costeras pudieron sostener a una población permanente en tiempos prehispánicos.

Figura 2.19 Mapa de Ubicación de la Quebrada Malanche

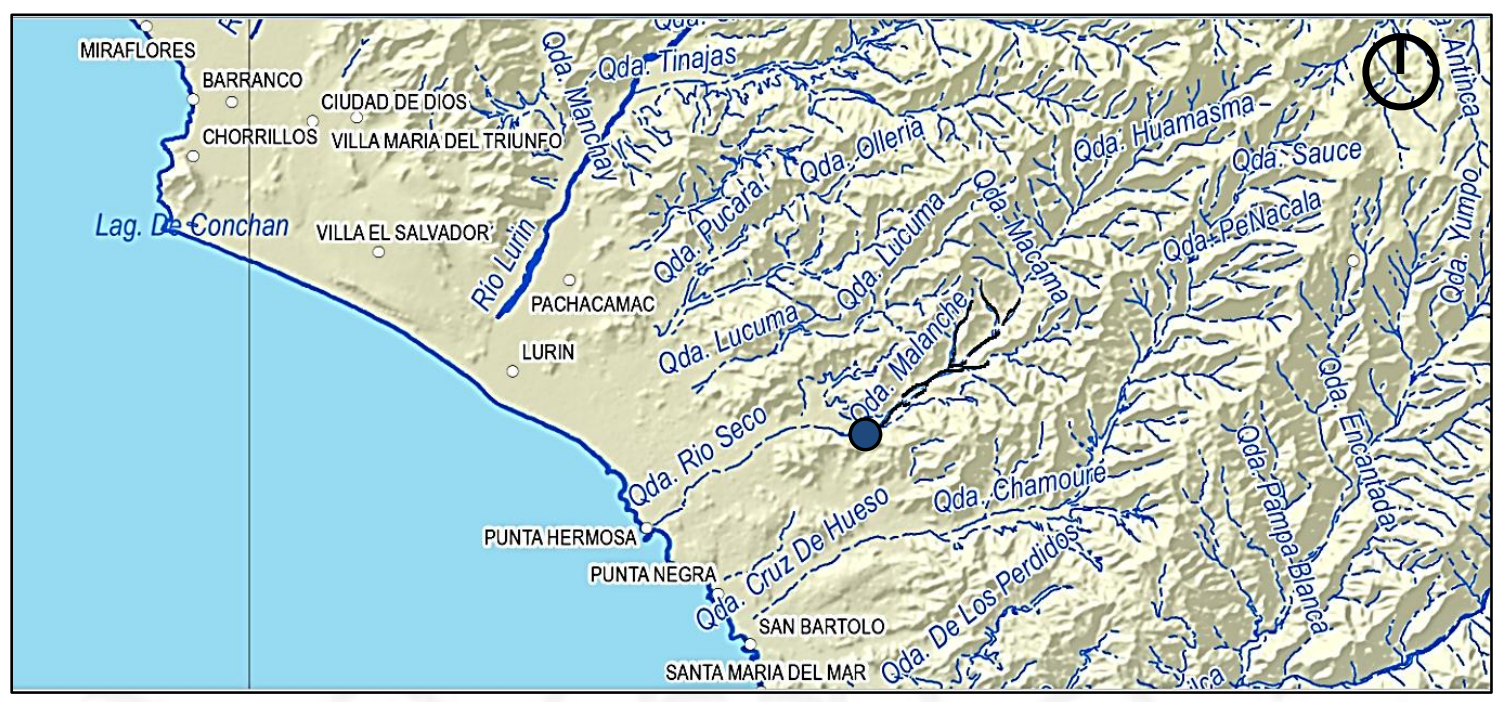

Fuente: SENASA

Figura 2.20 Asentamientos Prehispánicos en Malanche

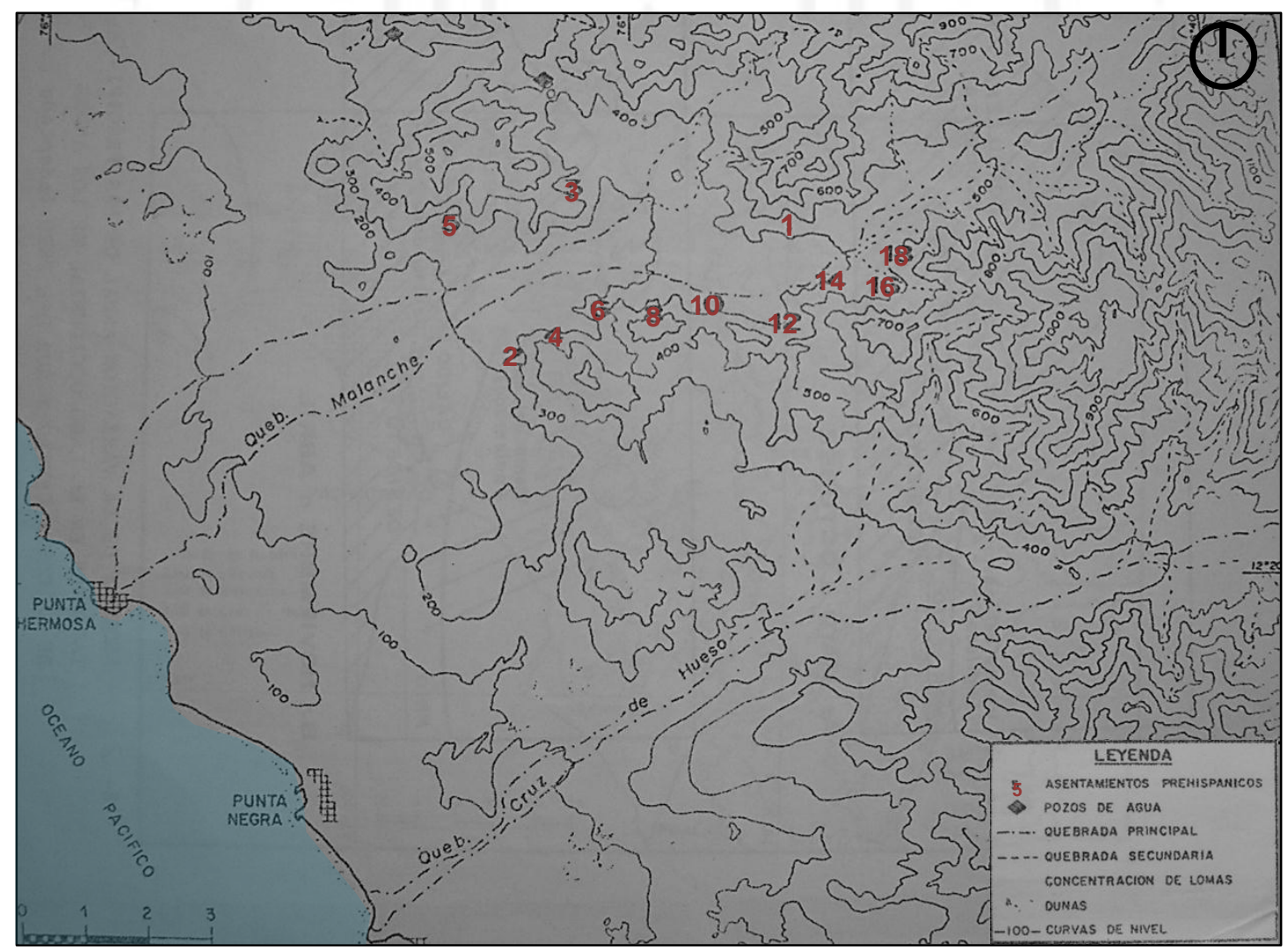

Fuente: (Mujica B., Rostworowski de Diez Canseco, \& Santillana, 1983) 


\subsection{Periodo Formativo}

Según la investigación realizada por el Instituto Metropolitano de Planificación (2013), este periodo histórico, cuya cronología data entre los años 1000 y 200 a.C representa una etapa de estabilidad económica, social y cultural, estrechamente ligada al proceso de civilización de los Andes, sus habitantes lograron domesticar y adaptar a microclimas especies botánicas y desarrollar sistemas de irrigación de corto recorrido, innovaciones tecnológicas que le permitieron obtener intensas producciones sosteniendo su economía fundamentalmente en la agricultura. De ésta época se hallan en el Valle del Lurín, Templos en forma de "U", encontrándose las siguientes representaciones de este tipo de arquitectura religiosa: Anchucaya, Piedra Lisa, Manchay Bajo, Parka, Mina Perdida, Buena Vista, Huaca Candela y Cardal, la que alcanzó el mayor desarrollo constructivo.

\subsection{Cultura Lima}

El Instituto Metropolitano de Planificación (2013) afirma que: "Luego de la decadencia de la religión, del culto a los dioses prístinos y de los grandes templos sacerdotales, prosigue un breve proceso de inestabilidad y de dispersión politica y cultural”. (pág. 64). Un nuevo poder político dirigido por una sola persona o casta social aparece, ligado a la gestión administrativa y construcción de grandes sistemas de canales de regadío abarcando desde Ancón hasta los valles del Chillón, Rímac y Lurín, siendo los canales de Lurín y Pachacamac los pertenecientes al Valle de Lurín. Además de la articulación económica regida por el sistema hidráulico, también existía una organización política territorial, dirigida desde el centro urbano de Maranga, integrándose a ella centros administrativos menores como el Santuario de Pachacamac, donde se ubica el "Templo Viejo" de Pachacamac, conocido como Urpyhuachac edificado mediante el un sistema constructivo denominado "librero", donde se asientan en sentido vertical adobitos paralelepípedos, de allí el nombre de la técnica también presente en el resto arqueológico denominado "Conjunto de Adobitos", situado en el mismo valle junto al museo de sitio. (pág. 64) 


\subsection{Imperio Huari}

Los datos referentes al imperio Huari proporcionados por El Instituto Metropolitano de Planificación (2013) describen que en la costa central la presencia de la Cultura Huari no fue de dominio territorial, éstas sociedades sostuvieron su independencia política y cultura, los indicios dan cuenta más bien de una influencia cultural generada a partir de las conexiones interregionales entre la costa y la sierra, con fines de intercambio comercial para lo que crearon redes de caminos y sistemas contables denominados QapacÑan y Quipus respectivamente, son vestigios de esta influencia el nuevo patrón de enterramiento que emplearon sustituyendo a los entierros extendidos propios de la Cultura Lima por los suntuosos "fardos funerarios con falsa cabeza" como se muestra en el Santuario de Pachacamac y en el Cementerio Uhle. (pág. 65)

\subsection{Señorío Ichma}

Según el Instituto Metropolitano de Planificación (2013) la pérdida de la hegemonía comercial del Imperio Huari termina por desintegrarlo, perdiendo influencia en territorios costeños donde la organización actual del poder se empezaba a dirigir más formalmente por Curacazgos y Señoríos, estableciéndose en la costa central el denominado Señorío Ichma, del cual fuera el Oráculo de Pachacamac, su capital política y religiosa, constituyéndose como un importante punto de encuentro de peregrinos y comerciantes de la época, el señorío estaba integrado por los valles de Rímac y Lurín, éste último incluía a los Curacazgos de Lurín, Quilcay, Manchay, Huaycán y Chontay y los subordinados al Curaca de Pachacamac: Calango, Chilca y Caringa; al parecer el curso de los principales canales de regadío establecía sus límites. Este periodo da lugar a la construcción de grandes poblados, templos, palacios y edificios administrativos siendo la llamada Pirámide con Rampa el más representativo el cual "Se caracteriza por poseer una plataforma cuadrangular baja con un patio rectangular cercado en su frente Norte, ambas se articulan mediante una rampa central. La plataforma posee en la cúspide una suerte de atrio o audiencia abierto en forma de U." (pág. 66) Pampa Flores y Panquilma son también edificaciones de este tipo ubicadas en el mismo valle. 


\subsection{Imperio Inca}

Como lo cita El Instituto Metropolitano de Planificación (2013) en el año 1470 d.C dio lugar a un nuevo proceso de integración económico-política en los andes peruanos a cargo del Estado Imperial Incaico mediante conquistas y alianzas pacíficas o sometimientos e imposiciones políticas y culturales sobre los pueblos que oponían resistencia; este imperio reorganizó el orden político territorial creando los Cuatros Suyos que se dividían en Huamanis o Provincias. En la costa central se estableció la Provincia Inca de Pachacamac, conquistada tras una pacífica alianza con el Señorío Ishma, donde acordaron éstos, sigan manteniendo sus antiguos privilegios $\mathrm{y}$ administrando la producción regional pero bajo la estructura política del Tahuantinsuyo; la nueva provincia costeña abarcaba los valles bajos del Chillón, Rímac y Lurín y se subdividía en los siguientes Hunus: Carabayllo, Maranga y Surco-Pachacamac donde se erigía la ciudadela de Armantambo, el Santuario de Pachacamac y el centro menor de Huaycán de Cieneguilla. (pág. 67)

Según el cronista Santacruz Pachacuti, el Inca Pachacutec entonces habría llegado a Pachacamac, pero no lo había conquistado. La tarea de anexar el territorio Ychsma al imperio sería del Inca Túpac Yupanqui. Éste, años más tarde aproximadamente 1470 d.c, llega al valle de Pachacamac, hoy Lurín. Según Rostworowski el Inca Túpac Yupanqui entró a Pachacamac en calidad de peregrino, aunque éste había estado en campaña militar conquistando los valles costeños. "Luego de vastos sacrificios de camélidos y de quemar gran cantidad de ropa, el oráculo hablo. Dijo ser el dios que animaba todas las cosas y auguró éxitos al Inca en sus futuras campañas guerreras. Fue entonces cuando el Inca decidió cambiar el nombre del señorío de Ychsma por el del mismo dios, y de ahí en adelante se le conoció como la macro etnia de Pachacamac" ( Instituto Metropolitano de Planificación, 2013) 


\subsection{La Conquista Española y el desarrollo del valle en adelante}

El Instituto Metropolitano de Planificación (2013) señala que hacia el año 1533 el valle del Lurín, estaba convertido en una zona de tránsito hacia el Santuario de Pachacamac; integrando la ruta de peregrinación religiosa hacia el templo, tradición que acabo tras la llegada de los españoles, quienes arrebatando idolatrías impusieron el culto católico en el valle. Pachacamac, "En 1573 fue declarado como Santísimo Salvador de Pachacamac y como todo pueblo colonial fue trazado en forma de damero, en el centro la iglesia, el ayuntamiento, la cárcel y la casa de los vecinos” (pág. 172).

Tras la conquista empezaría un nuevo periodo en la historia del valle, siendo importante destacar los vestigios que éstas culturas dejaron en la zona, inventario que estuvo a cargo del Instituto Metropolitano de Planificación. Los restos arqueológicos son en su mayoría del Horizonte Tardío y Periodo Intermedio Tardío, destacando en este último el sitio arqueológico Quebrada Verde, asentamiento perteneciente al espacio de tiempo entre el Señorío Ishma ya sometido por el Imperio Incaico, hasta la llegada de los españoles; cabe resaltar que también se ha encontrado arte rupestre en este sitio. 
Cuadro 2.15 Inventario de Sitios Arqueológicos presentes en el Valle de Lurín

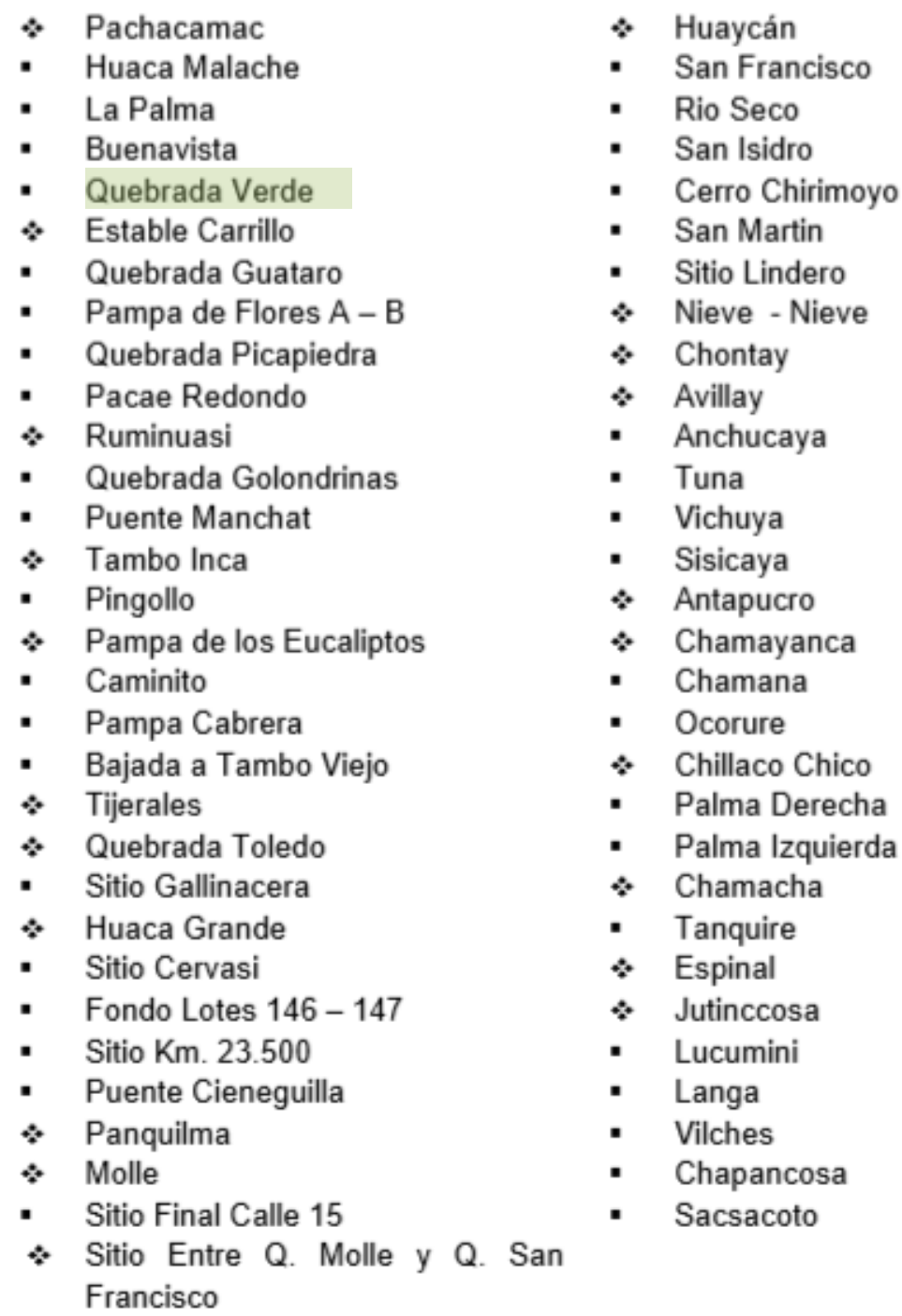

- Periodo Intermedio Tardío: asentamiento rural pre- Tawantinsuyo, perteneciente al floreciente señorío Ichimay (1200-1470 años d. C.)

* Horizonte Tardío: centro administrativo inca, en funcionamiento desde el sometimiento del señorío Ichimay hasta la llegada de los españoles al valle, en la primera mitad del siglo XVI.

Nieve-Nieve, era el centro administrativo inca de mayor importancia en el valle de Lurín.

Fuente: ( Instituto Metropolitano de Planificación, 2013) 


\subsection{El Distrito de Pachacamac y el Centro Poblado Rural Quebrada Verde.}

La cronología expuesta por el Instituto Metropolitano de Planificación (2013), refiere que en 1856 es creado el Municipio de Pachacamac. En 1857 se lo declara Distrito Republicano y en 1983 la Municipalidad Metropolitana de Lima lo declara Distrito Ecológico. Desde los años 60 aproximadamente fueron iniciándose los procesos de urbanización del distrito, siendo alto el porcentaje de población que lo hizo de manera informal, en su mayoría migrantes pobres que invadieron las laderas de los cerros, concentrándose especialmente en la Quebrada Manchay; también hubieron asentamientos de carácter formal realizados mediante habilitaciones urbanas, aunque la mayoría de las veces solo se hacía la compra de un predio directamente con el propietario, provocando un crecimiento de la ciudad con poco planificación urbana. (pág. 172)

En el año 1990, producto de las migraciones originadas por el terrorismo, poblaciones rurales se desplazaron en busca de mejores condiciones de vida, acentuándose en distintos distritos limeños como Pachacamac.

Parte de esta población, se estableció en las laderas de las lomas de Lúcumo, esta comunidad años más tarde conformaría El Centro Poblado Rural Quebrada Verde; sus habitantes siempre se preocuparon por la preservación del ecosistema de Lomas, es así que en año 1996, socios voluntarios apoyados por la ONG Eco ciudad, establecen la formación de una comisión del Circuito Eco turístico Lomas de Lúcumo, registrándose como asociación formalmente en el año 2009. El circuito se inaugura por primera vez en agosto del 2003, y es desde entonces que la comunidad trabaja conjuntamente en esta iniciativa cada temporada de Lomas.

La evolución histórica del distrito de Pachacamac, desde el año 1972, hasta el año 2012, muestra una taza de crecimiento final de $8.15 \%$, datos poblacionales importantes para este proyecto de tesis pues nos acercan a la realidad del distrito. Detallándose en el siguiente cuadro, junto a los demás distritos del valle. 
Cuadro 2.16 Evolución Histórica de la Población del Valle Lurín por Provincia, Subcuenca y Distritos

\begin{tabular}{|c|c|c|c|c|c|c|c|c|c|c|c|c|}
\hline \multirow{2}{*}{ PROVINCIA } & & \multirow{2}{*}{ CUENCA } & \multirow{2}{*}{ DISTRITO } & \multicolumn{9}{|c|}{ AÑOS } \\
\hline & & & & 1972 & 1981 & T.C. & 1993 & T.C. & 2007 & T.C. & 2012 & T.C. \\
\hline \multirow{12}{*}{ Huarochiri } & \multirow{17}{*}{ Lurín } & \multirow{5}{*}{ Alta } & Santiago de Tuna & 646 & 516 & -2.47 & 556 & 0.62 & 675 & 1.39 & 717 & 1.21 \\
\hline & & & San Andrés de Tupicocha & 1,708 & 1,490 & -1.51 & 1,722 & 1.21 & 1,443 & -1.25 & 1,354 & -1.27 \\
\hline & & & San Damián & 1,961 & 2,016 & 0.31 & 2,221 & 0.81 & 1,510 & -2.72 & 1,321 & -2.64 \\
\hline & & & Huarochirí & 2,446 & 2,177 & -1.29 & 2,282 & 0.39 & 1,613 & -2.45 & 1,428 & -2.41 \\
\hline & & & Sub Total Subcuenca & 6,761 & 6,199 & -4.95 & 6,781 & 3.04 & 5,241 & -5.03 & 4,820 & -1.66 \\
\hline & & \multirow{7}{*}{ Media } & Lahuaytambo & 1,411 & 1,458 & 0.36 & 1,222 & -1.46 & 849 & -2.57 & 748 & -2.50 \\
\hline & & & Langa & 1,518 & 1,452 & -0.49 & 1,538 & 0.48 & 1,071 & -2.55 & 945 & -2.47 \\
\hline & & & Sn José de Chorrillos o Cuenca & 547 & 507 & -0.84 & 472 & -0.59 & 398 & -1.21 & 406 & 0.40 \\
\hline & & & Sub Total Subcuenca & 3,476 & 3,417 & -0.97 & 3,232 & -1.57 & 2,318 & -6.33 & 2,099 & -1.97 \\
\hline & & & Antioguía & 1,179 & 1,502 & 2.73 & 1,639 & 0.73 & 1,395 & -1.14 & 1,316 & -1.16 \\
\hline & & & Sto. Domingo de los Olleros & 987 & 970 & -0.19 & 1,138 & 1.34 & 2,947 & 7.03 & 3,983 & 6.21 \\
\hline & & & Sub Total Subcuenca & 2,166 & 2,472 & 2.53 & 2,777 & 2.07 & 4,342 & 5.89 & 5,299 & 4.06 \\
\hline \multirow{11}{*}{ Lima } & & & Cieneguilla & 2,527 & 4,546 & 6.74 & 10,035 & 6.82 & 27,104 & 7.36 & 38,328 & 7.18 \\
\hline & & & Pachacamac & 4,534 & 6,780 & 4.57 & 22,151 & 10.37 & 69,411 & 8.50 & 102,691 & 8.15 \\
\hline & & Baja & Lurín & 12,789 & 17,331 & 3.43 & 38,240 & 6.82 & 63,832 & 3.73 & 76,874 & 3.79 \\
\hline & & & Villa Ma. del Triunfo (José Galvez) & 27,472 & 47,655 & 6.31 & 44,648 & -0.54 & 58,270 & 1.92 & 64,742 & 2.13 \\
\hline & & & Sub Total Subcuenca & 47,322 & 76,312 & 5.45 & 115,074 & 3.48 & 218,617 & 4.69 & 282,635 & 5.27 \\
\hline & \multirow{6}{*}{$\begin{array}{l}\text { Pampas de } \\
\text { San Bartolo }\end{array}$} & \multirow{8}{*}{ Marítima Costera } & Punta Negra & 744 & 553 & -3.24 & 2,648 & 13.94 & 5,359 & 5.16 & 6,878 & 5.12 \\
\hline & & & Punta Hermosa & 908 & 1,010 & 1.19 & 3,661 & 11.33 & 5,844 & 3.40 & 6,935 & 3.48 \\
\hline & & & San Bartolo & 1,458 & 2,913 & 7.99 & 3,686 & 1.98 & 6,503 & 4.14 & 7,008 & 1.51 \\
\hline & & & Santa María del Mar & 44 & 96 & 9.06 & 202 & 6.40 & 163 & -1.52 & 1,220 & 49.57 \\
\hline & & & Pucusana & 2,835 & 4,124 & 4.25 & 4,724 & 1.14 & 10,784 & 6.07 & 14,403 & 5.96 \\
\hline & & & Sub Total Subcuenca & 5,989 & 8,696 & 4.23 & 14,921 & 4.60 & 28,653 & 4.77 & 36,444 & 4.93 \\
\hline \multirow{2}{*}{ Cañete } & \multirow{2}{*}{ Chilca } & & Chilca & 5,374 & 7,634 & 3.98 & 13,880 & 5.11 & 14,765 & 0.44 & 15,517 & 1.00 \\
\hline & & & Sub Total Subcuenca & 5,374 & 7,634 & 3.98 & 13,880 & 5.11 & 14,765 & 0.44 & 15,517 & 1.00 \\
\hline \multirow{3}{*}{\multicolumn{3}{|c|}{ Total x Provincia }} & Huarochiri & 12,403 & 12,088 & -0.29 & 12,790 & 0.47 & 11,901 & -0.51 & 12,218 & 0.53 \\
\hline & & & Lima & 53,311 & 85,008 & 5.32 & 129,995 & 3.60 & 247,270 & 4.70 & 319,079 & 5.23 \\
\hline & & & Cañete & 5,374 & 7,634 & 3.98 & 13,880 & 5.11 & 14,765 & 0.44 & 15,517 & 1.00 \\
\hline \multirow{3}{*}{\multicolumn{3}{|c|}{ Total $x$ Cuenca }} & Lurín & 59,725 & 88,400 & 4.45 & 127,864 & 3.12 & 230,518 & 4.30 & 294,853 & 5.05 \\
\hline & & & Pampas de San Bartolo & 5,989 & 8,696 & 4.23 & 14,921 & 4.60 & 28,653 & 4.77 & 36,444 & 4.93 \\
\hline & & & Chilca & 5,374 & 7,634 & 3.98 & 13,880 & 5.11 & 14,765 & 0.44 & 15,517 & 1.00 \\
\hline \multicolumn{4}{|c|}{ Total } & 71,088 & 104,730 & 4.40 & 156,665 & 3.41 & 273,936 & 4.07 & 346,814 & 4.83 \\
\hline
\end{tabular}

Fuente: ( Instituto Metropolitano de Planificación, 2013)

\subsubsection{Análisis Socioeconómico del Valle}

Es relevante para la presente investigación de Tesis, analizar la realidad socio económica del Valle del Rio Lurín, destacando al distrito de Pachacamac, pues el estudio de la población en rango de edad, nivel educativo, actividades productivas, nivel de desempleo y calidad de vida delimitaran los alcances del proyecto.

Los datos consignados en el desarrollo del presente título, toman como referencia el último estudio demográfico realizado por el INEI con fecha 2012, para El Instituto Metropolitano de Planificación. 


\subsection{Población}

La densidad poblacional del valle, referida al número de habitantes por $\mathrm{km}^{2}$, se muestra en el siguiente cuadro, el cual además expone la población y superficie territorial de cada distrito perteneciente a la cuenca del rio Lurín.

Cieneguilla es el distrito con menor densidad de la cuenca baja con 159.5 hab/ $\mathrm{km}^{2}$, seguido de Lurín con $424.4 \mathrm{hab} / \mathrm{km}^{2}$ y finalmente Pachacamac con la mayor densidad alcanzando los $640.9 \mathrm{hab} / \mathrm{km}^{2}$.

Cuadro 2.17 : Densidad Poblacional de los distritos del Valle de Lurín

\begin{tabular}{|c|c|c|c|c|c|c|c|}
\hline \multirow{2}{*}{ PROVINCIA } & \multirow{2}{*}{\multicolumn{3}{|c|}{ CUENCA }} & \multirow{2}{*}{ DISTRITO } & \multirow{2}{*}{ HABITANTES } & \multirow{2}{*}{$\frac{\text { SUPERFICIE }}{\left(\mathrm{km}^{2}\right)}$} & \multirow{2}{*}{$\begin{array}{c}\text { DENSIDAD } \\
\text { POBLACIONAL }\end{array}$} \\
\hline & & & & & & & \\
\hline \multirow{12}{*}{ Huarochiri } & \multirow{17}{*}{ Lurín } & \multirow{5}{*}{ Alta } & \multirow{5}{*}{ Alta } & Santiago de Tuna & 717 & 54.3 & 13.2 \\
\hline & & & & San Andrés de Tupicocha & 1,354 & 83.4 & 16.2 \\
\hline & & & & San Damián & 1,321 & 343.2 & 3.8 \\
\hline & & & & Huarochirí & 1,428 & 249.1 & 5.7 \\
\hline & & & & Sub Total Subcuenca & 4,820 & 729.9 & 6.6 \\
\hline & & \multirow{7}{*}{ Media } & \multirow{4}{*}{ Alta } & Lahuaytambo & 748 & 81.88 & 9.1 \\
\hline & & & & Langa & 945 & 81.0 & 11.7 \\
\hline & & & & Sn José de Chorrillos o Cuenca & 406 & 60.0 & 6.8 \\
\hline & & & & Sub Total Subcuenca & 2,099 & 222.89 & 9.4 \\
\hline & & & \multirow{3}{*}{ Media } & Antioquía & 1,316 & 388.0 & 3.4 \\
\hline & & & & Sto. Domingo de los Olleros & 3,983 & 552.3 & 7.2 \\
\hline & & & & Sub Total Subcuenca & 5,299 & 940.3 & 5.6 \\
\hline \multirow{11}{*}{ Lima } & & & & Cieneguilla & 38,328 & 240.3 & 159.5 \\
\hline & & & & Pachacamac & 102,691 & 160.2 & 640.9 \\
\hline & & Baja & & Lurín & 76,874 & 181.1 & 424.4 \\
\hline & & & & Villa Ma. del Triunfo (José Galvez) & 64,742 & 6.37 & $10,163.6$ \\
\hline & & & & Sub Total Subcuenca & 282,635 & 588.1 & 480.6 \\
\hline & \multirow{6}{*}{$\begin{array}{l}\text { Pampas de } \\
\text { San Bartolo }\end{array}$} & \multirow{8}{*}{\multicolumn{2}{|c|}{$\begin{array}{l}\text { Marítima } \\
\text { Costera }\end{array}$}} & Punta Negra & 6,878 & 130.5 & 52.7 \\
\hline & & & & Punta Hermosa & 6,935 & 119.5 & 58.0 \\
\hline & & & & \begin{tabular}{|l|} 
San Bartolo \\
\end{tabular} & 7,008 & 45.0 & 155.7 \\
\hline & & & & Santa María del Mar & 1,220 & 9.8 & 124.4 \\
\hline & & & & Pucusana & 14,403 & 37.39 & 385.2 \\
\hline & & & & Sub Total Subcuenca & 36,444 & 342.2 & 106.5 \\
\hline \multirow{2}{*}{ Cañete } & \multirow{2}{*}{ Chilca } & & & Chilca & 15,517 & 475.47 & 32.6 \\
\hline & & & & Sub Total Subcuenca & 15,517 & 475.47 & 32.6 \\
\hline \multirow{3}{*}{\multicolumn{4}{|c|}{ Total x Provincia }} & Huarochiri & 12,218 & $1,893.10$ & 6.5 \\
\hline & & & & Lima & 319,079 & 930.26 & 343.0 \\
\hline & & & & Cañete & 15,517 & 475.47 & 32.6 \\
\hline \multirow{3}{*}{\multicolumn{4}{|c|}{ Total x Cuenca }} & Lurín & 294,853 & $2,481.15$ & 118.8 \\
\hline & & & & Pampas de San Bartolo & 36,444 & 342.2 & 106.5 \\
\hline & & & & Chilca & 15,517 & 475.47 & 32.6 \\
\hline \multicolumn{5}{|c|}{ Total } & 346,814 & $3,298.83$ & 105.1 \\
\hline
\end{tabular}

Fuente: ( Instituto Metropolitano de Planificación, 2013)

El siguiente cuadro presenta los datos poblacionales subdivididos por rangos según grupos de edad, la población total del Valle del Lurín en el 2012 ascendía a un total de 230111 habitantes. El distrito de Pachacamac, era el más poblado, con un total de 102,691 habitantes, donde el $62.4 \%$ son personas en edad de trabajar, de 15 a 65 
años de edad, el $35.3 \%$ son niños de $0-14$ años y el $2.3 \%$ lo conforman adultos mayores.

Cuadro 2.18 Población por Grandes Grupos de Edad según provincias, subcuencas y distritos del Valle Lurín

\begin{tabular}{|c|c|c|c|c|c|c|c|c|c|c|c|}
\hline \multirow{2}{*}{ PROVINCIA } & \multirow{2}{*}{\multicolumn{3}{|c|}{ CUENCA }} & \multirow{2}{*}{ DISTRITO } & \multicolumn{7}{|c|}{ POBLACIÓN POR GRUPOS DE EDAD } \\
\hline & & & & & $0-14$ & $\%$ & $15-64$ & $\%$ & 65AMAS & $\%$ & TOTAL \\
\hline \multirow{12}{*}{ Huarochiri } & \multirow{17}{*}{ Lurín } & \multirow{5}{*}{ Alta } & \multirow{5}{*}{ Alta } & Santiago de Tuna & 164 & 229 & 429 & 59.8 & 124 & 17.3 & 717 \\
\hline & & & & San Andrés de Tupicocha & 499 & 36.9 & 704 & 520 & 151 & 112 & 1,354 \\
\hline & & & & San Damián & 447 & 33.8 & 681 & 516 & 193 & 14.6 & 1,321 \\
\hline & & & & Huarochirí & 414 & 29.0 & 819 & 57.4 & 195 & 13.7 & 1,428 \\
\hline & & & & Sub Total Subcuenca & 1,524 & 31.6 & 2,633 & 54.6 & 663 & 13.8 & 4,820 \\
\hline & & \multirow{7}{*}{ Media } & \multirow{4}{*}{ Alta } & Lahuaytambo & 179 & 23.9 & 436 & 58.3 & 133 & 17.8 & 748 \\
\hline & & & & Langa & 271 & 28.7 & 507 & 53.7 & 167 & 17.7 & 945 \\
\hline & & & & Sn José de Chorrillos o Cuenca & 129 & 31.8 & 227 & 55.9 & 50 & 123 & 406 \\
\hline & & & & Sub Total Subcuenca & 579 & 27.6 & 1,170 & 55.7 & 350 & 16.7 & 2,099 \\
\hline & & & \multirow{3}{*}{ Media } & Antioguia & 345 & 26.2 & 826 & 628 & 145 & 110 & 1,316 \\
\hline & & & & Sto. Domingo de los Olleros & 1,300 & 326 & 2,516 & 63.2 & 167 & 4.2 & 3,983 \\
\hline & & & & Sub Total Subcuenca & 1,645 & 31.0 & 3,342 & 63.1 & 312 & 5.9 & 5,299 \\
\hline \multirow{11}{*}{ Lima } & & & & Cieneguilla & 11,371 & 29.7 & 25,271 & 65.9 & 1,686 & 4.4 & 38,328 \\
\hline & & & & Pachacamac & 36,282 & 35.3 & 64,028 & 624 & 2,381 & 23 & 102,691 \\
\hline & & Baja & & Lurin & 24,036 & 31.3 & 49,805 & 64.8 & 3,033 & 3.9 & 76,874 \\
\hline & & & & Villa Ma. del Triunfo (José Galvez) & 16,121 & 24.9 & 43,830 & 67.7 & 4,791 & 7.4 & 64,742 \\
\hline & & & & Sub Total Subcuenca & 87,810 & 31.1 & 182,934 & 64.7 & 11,891 & 4.2 & 282,635 \\
\hline & \multirow{6}{*}{$\begin{array}{l}\text { Pampas de } \\
\text { San Bartolo }\end{array}$} & \multirow{8}{*}{\multicolumn{2}{|c|}{ Maritima Costera }} & Punta Negra & 1,989 & 28.9 & 4,565 & 66.4 & 324 & 4.7 & 6,878 \\
\hline & & & & Punta Hermosa & 1,863 & 26.9 & 4,750 & 68.5 & 322 & 4.6 & 6,935 \\
\hline & & & & San Bartolo & 1,854 & 26.5 & 4,783 & 68.3 & 371 & 5.3 & 7,008 \\
\hline & & & & Santa María del Mar & 446 & 36.6 & 761 & 624 & 13 & 11 & 1,220 \\
\hline & & & & Pucusana & 4,959 & 34.4 & 8,909 & 619 & 535 & 3.7 & 14,403 \\
\hline & & & & Sub Total Subcuenca & 11,111 & 30.5 & 23,768 & 65.2 & 1,565 & 4.3 & 36,444 \\
\hline \multirow{2}{*}{ Cañete } & \multirow{2}{*}{ Chilca } & & & Chilca & 4,866 & 31.4 & 9,742 & 628 & 909 & 5.9 & 15,517 \\
\hline & & & & Sub Total Subcuenca & 4,866 & 31.4 & 9,742 & 628 & 909 & 5.9 & 15,517 \\
\hline \multirow{3}{*}{\multicolumn{4}{|c|}{ Total x Provincia }} & Huarochiri & 3,748 & 30.7 & 7,145 & 58.5 & 1,325 & 10.8 & 12,218 \\
\hline & & & & Lima & 103,787 & 310 & 216,444 & 64.7 & 14,365 & 4.3 & 334,596 \\
\hline & & & & Cañete & 4,866 & 314 & 9,742 & 628 & 909 & 5.9 & 15,517 \\
\hline \multirow{3}{*}{\multicolumn{4}{|c|}{ Total x Cuenca }} & Lurin & 91,558 & 31.1 & 190,079 & 64.5 & 13,216 & 4.5 & 294,853 \\
\hline & & & & Pampas de San Bartolo & 11,111 & 30.5 & 23,768 & 65.2 & 1,565 & 4.3 & 36,444 \\
\hline & & & & Chilca & 4,866 & 31.4 & 9,742 & 628 & 909 & 5.9 & 15,517 \\
\hline \multicolumn{5}{|c|}{ Total } & 107,535 & 31.0 & 223,589 & 64.5 & 15,690 & 4.5 & 346,814 \\
\hline
\end{tabular}

Fuente: ( Instituto Metropolitano de Planificación, 2013)

Otro tipo de enfoque que nos permite evaluar la población es al dividirla en grupos según sexo, la información al respecto para el valle está referida en el siguiente cuadro, en el cual se observa que del total de habitantes del Valle del Río Lurín, 51.6\% son hombres con un número de 118,767 y $48.4 \%$ de la población del valle son mujeres sumando un total de 111344.

Con respecto al distrito de Pachacamac, se observa que representa el $29.6 \%$ del total de habitantes del valle, siendo el distrito más poblado y del total de sus habitantes $50.7 \%$ son hombres, y $49.3 \%$ son mujeres. 
Cuadro 2.19 Población por Sexo Según provincias, subcuencas y distritos del Valle de Lurín, Año 2012

\begin{tabular}{|c|c|c|c|c|c|c|c|c|c|c|}
\hline \multirow{2}{*}{ PROVINCIA } & \multirow{2}{*}{\multicolumn{3}{|c|}{ CUENCA }} & \multirow{2}{*}{ DISTRITO } & \multicolumn{6}{|c|}{ POBLACIÓN POR SEXO } \\
\hline & & & & & HOMBRE & $\%$ & MUJER & $\%$ & TOTAL & $\%$ \\
\hline \multirow{12}{*}{ Huarochiri } & \multirow[t]{12}{*}{ Lurín } & \multirow[t]{5}{*}{ Alta } & \multirow[t]{5}{*}{ Alta } & Santiago de Tuna & 379 & 52.9 & 338 & 47.1 & 717 & 0.2 \\
\hline & & & & San Andrés de Tupicocha & 674 & 49.8 & 680 & 50.2 & 1,354 & 0.4 \\
\hline & & & & San Damián & 665 & 50.3 & 656 & 49.7 & 1,321 & 0.4 \\
\hline & & & & Huarochirí & 720 & 50.4 & 708 & 49.6 & 1,428 & 0.4 \\
\hline & & & & Sub Total Subcuenca & 2438 & 50.6 & 2382 & 49.4 & 4820 & 1.4 \\
\hline & & \multirow[t]{7}{*}{ Media } & \multirow[t]{4}{*}{ Alta } & Lahuaytambo & 391 & 52.3 & 357 & 47.7 & 748 & 0.2 \\
\hline & & & & Langa & 478 & 50.6 & 467 & 49.4 & 945 & 0.3 \\
\hline & & & & Sn José de Chorrillos o Cuenca & 241 & 59.4 & 165 & 40.6 & 406 & 0.1 \\
\hline & & & & Sub Total Subcuenca & 1110 & 52.9 & 989 & 47.1 & 2099 & 0.6 \\
\hline & & & \multirow[t]{3}{*}{ Media } & Antioquia & 697 & 53.0 & 619 & 47.0 & 1,316 & 0.4 \\
\hline & & & & Sto. Domingo de los Olleros & 2,129 & 53.5 & 1,854 & 46.5 & 3,983 & 1.1 \\
\hline & & & & Sub Total Subcuenca & 2,826 & 53.3 & 2,473 & 46.7 & 5,299 & 1.5 \\
\hline \multirow[t]{11}{*}{ lima } & & \multirow{5}{*}{\multicolumn{2}{|c|}{ Baja }} & Cieneguilla & 23,016 & 60.1 & 15,312 & 39.9 & 38,328 & 11.1 \\
\hline & & & & Pachacamac & 50,667 & 49.3 & 52,024 & 50.7 & 102,691 & 29.6 \\
\hline & & & & Lurin & 38,710 & 50.4 & 38,164 & 49.6 & 76,874 & 22.2 \\
\hline & & & & Villa Ma. del Triunfo (José Galvez) & 31,724 & 49.0 & 33,018 & 51.0 & 64,742 & 18.7 \\
\hline & & & & Sub Total Subcuenca & 144,117 & 51.0 & 138,518 & 49.0 & 282,635 & 81.5 \\
\hline & Pampas de & \multirow{8}{*}{\multicolumn{2}{|c|}{ Maritima Costera }} & Punta Negra & 3,531 & 51.3 & 3,347 & 48.7 & 6,878 & 2.0 \\
\hline & San Bartolo & & & Punta Hermosa & 3,577 & 51.6 & 3,358 & 48.4 & 6,935 & 2.0 \\
\hline & & & & San Bartolo & 3,458 & 49.3 & 3,550 & 50.7 & 7,008 & 2.0 \\
\hline & & & & Santa Maria del Mar & 645 & 52.9 & 575 & 47.1 & 1,220 & 0.4 \\
\hline & & & & \begin{tabular}{|l|} 
Pucusana \\
\end{tabular} & 7,130 & 49.5 & 7,273 & 50.5 & 14,403 & 4.2 \\
\hline & & & & Sub Total Subcuenca & 18,341 & 50.3 & 18,103 & 49.7 & 36,444 & 10.5 \\
\hline \multirow[t]{2}{*}{ Cañete } & \multirow[t]{2}{*}{ Chilca } & & & Chilca & 7,664 & 49.4 & 7,853 & 50.6 & 15,517 & 4.5 \\
\hline & & & & Sub Total Subcuenca & 7,664 & 49.4 & 7,853 & 50.6 & 15,517 & 4.5 \\
\hline & \multirow{3}{*}{\multicolumn{3}{|c|}{ Total x Provincia }} & Huarochiri & 6,374 & 52.2 & 5,844 & 47.8 & 12,218 & 3.5 \\
\hline & & & & Lima & 162,458 & 50.9 & 156,621 & 49.1 & 319,079 & 92.0 \\
\hline & & & & Cañete & 7,664 & 49.4 & 7,853 & 50.6 & 15,517 & 4.5 \\
\hline & \multirow{3}{*}{\multicolumn{3}{|c|}{ Total x Cuenca }} & Lurin & 150,491 & 51.0 & 144,362 & 49.0 & 294,853 & 85.0 \\
\hline & & & & Pampas de San Bartolo & 18,341 & 50.3 & 18,103 & 49.7 & 36,444 & 10.5 \\
\hline & & & & Chilca & 7,664 & 49.4 & 7,853 & 50.6 & 15,517 & 4.5 \\
\hline \multicolumn{5}{|c|}{ Total } & 176,496 & 50.9 & 170,318 & 49.1 & 346,814 & 100.0 \\
\hline
\end{tabular}

Fuente: ( Instituto Metropolitano de Planificación, 2013)

En el siguiente cuadro se hace referencia a la población urbana y rural de todo valle, donde se tiene que 218167 habitantes pertenecen al ámbito urbano, representando el 94.8\% del total del valle. Pachacamac tiene el $98.1 \%$ de población urbana con 100,719 habitantes, y solo el 1.9\% conforman la población rural con un total de 1972 pobladores. 
Cuadro 2.20 Población Urbana y Rural Según provincias, subcuencas y distritos del Valle de Lurín, Año 2012

\begin{tabular}{|c|c|c|c|c|c|c|c|c|c|}
\hline \multirow{2}{*}{ PROVINCIA } & \multirow{2}{*}{\multicolumn{3}{|c|}{ CUENCA }} & \multirow{2}{*}{ DISTRITO } & \multicolumn{5}{|c|}{ TIPO DE ÁREA } \\
\hline & & & & & URBANA & $\%$ & RURAL & $\%$ & TOTAL \\
\hline \multirow{12}{*}{ Huarochiri } & \multirow{17}{*}{ Lurin } & \multirow{5}{*}{ Alta } & \multirow{5}{*}{ Alta } & Santiago de Tuna & 565 & 78.8 & 152 & 21.2 & 717 \\
\hline & & & & San Andrés de Tupicocha & 713 & 52.7 & 641 & 47.3 & 1,354 \\
\hline & & & & San Damián & 1,055 & 79.9 & 266 & 20.1 & 1,321 \\
\hline & & & & Huarochiri & 1,217 & 85.2 & 211 & 14.8 & 1,428 \\
\hline & & & & Sub Total Subcuenca & 3,550 & 73.7 & 1270 & 26.3 & 4820 \\
\hline & & \multirow{7}{*}{ Media } & \multirow{4}{*}{ Alta } & Lahuaytambo & 390 & 52.1 & 358 & 47.9 & 748 \\
\hline & & & & Langa & 544 & 57.6 & 401 & 42.4 & 945 \\
\hline & & & & Sn José de Chorrillos o Cuenca & 86 & 21.2 & 320 & 78.8 & 406 \\
\hline & & & & Sub Total Subcuenca & 1,020 & 48.6 & 1,079 & 51.4 & 2,099 \\
\hline & & & \multirow{3}{*}{ Media } & Antioquia & 379 & 28.8 & 937 & 71.2 & 1,316 \\
\hline & & & & Sto. Domingo de los Olleros & 124 & 3.1 & $3,859.00$ & 96.9 & 3,983 \\
\hline & & & & Sub Total Subcuenca & 503 & 9.5 & 4,796 & 90.5 & 5,299 \\
\hline \multirow{11}{*}{ Lima } & & & & Cieneguilla & 37,952 & 99.0 & 376 & 1.0 & 38,328 \\
\hline & & & & Pachacamac & 100,719 & 98.1 & $1,972.00$ & 1.9 & 102,691 \\
\hline & & Baja & & Lurin & 74,423 & 96.8 & $2,451.00$ & 3.2 & 76,874 \\
\hline & & & & Villa Ma. del Triunfo (José Galvez) & 64,742 & 100.0 & 0 & - & 64,742 \\
\hline & & & & Sub Total Subcuenca & 277,836 & 98.3 & 4,799 & 1.7 & 282,635 \\
\hline & \multirow{6}{*}{$\begin{array}{l}\text { Pampas de } \\
\text { San Bartolo }\end{array}$} & \multirow{8}{*}{\multicolumn{2}{|c|}{ Maritima Costera }} & Punta Negra & 6,878 & 100.0 & 0 & - & 6,878 \\
\hline & & & & Punta Hermosa & 6,451 & 93.0 & 484 & 7.0 & 6,935 \\
\hline & & & & San Bartolo & 6,886 & 98.3 & 122 & 1.7 & 7,008 \\
\hline & & & & Santa Maria del Mar & 1,010 & 82.8 & 210.00 & 17.2 & 1,220 \\
\hline & & & & Pucusana & 14,282 & 99.2 & 121 & 0.8 & 14,403 \\
\hline & & & & Sub Total Subcuenca & 35,507 & 97.40 & 937 & 2.6 & 36,444 \\
\hline \multirow{2}{*}{ Cañete } & \multirow{2}{*}{ Chilca } & & & Chilca & 14,903 & 96.0 & 614 & 4.0 & 15,517 \\
\hline & & & & Sub Total Subcuenca & 14,903 & 96.0 & 614 & 4.0 & 15,517 \\
\hline \multirow{3}{*}{\multicolumn{4}{|c|}{ Total x Provincia }} & Huarochiri & 5,073 & 41.5 & 7,145 & 58.5 & 12,218 \\
\hline & & & & Lima & 313,343 & 98.2 & 5,736 & 1.8 & 319,079 \\
\hline & & & & Cañete & 14,903 & 96.0 & 614 & 4.0 & 15,517 \\
\hline \multirow{3}{*}{\multicolumn{4}{|c|}{ Total x Cuenca }} & Lurin & 282,909 & 95.9 & 11,944 & 4.1 & 294,853 \\
\hline & & & & Pampas de San Bartolo & 35,507 & 97.4 & 937 & 2.6 & 36,444 \\
\hline & & & & Chilca & 14,903 & 96.0 & 614 & 4.0 & 15,517 \\
\hline \multicolumn{5}{|c|}{ Total } & 333,319 & 96.1 & 13,495 & 3.9 & 346,814 \\
\hline
\end{tabular}

Fuente: (Instituto Metropolitano de Planificación, 2013)

Las Comunidades Campesinas pertenecientes al Valle del Lurín reflejadas en el siguiente cuadro, suman en su totalidad 21, distribuidas en la parte alta, media y baja del mismo. Se ha resaltado a la comunidad campesina de Cucuya y Santa Rosa de Manchay por encontrarse en la cuenca baja del Valle en el distrito de Pachacamac, Antioquia y Cieneguilla. 
Cuadro 2.21 Relación de Comunidades Campesinas en el Valle de Lurín

\begin{tabular}{|c|l|l|c|c|}
\hline $\mathbf{N}^{\circ}$ & Comunidad Campesina & \multicolumn{1}{|c|}{ Distrito } & Territorio & $\begin{array}{c}\text { Ubicación En La } \\
\text { Cuenca }\end{array}$ \\
\hline 1 & Llanabilla & Cieneguilla & (parte) & Parte Baja \\
\hline 2 & Cucuya & Pachacamac y Antioquia & (parte) & Parte Baja \\
\hline 3 & Sisicaya & Antioquia & & Parte Media \\
\hline 4 & Cochahuayco & Antioquia & & Parte Baja \\
\hline 5 & Santiago De Tuna & Santiago de Tuna & & Parte Alta \\
\hline 6 & Acurana & Chorrillos & & Parte Baja \\
\hline 7 & Santa Ana & Lahuaytambo & Parte Baja \\
\hline 8 & Sunicancha & San Damián & (parte) & Parte Baja \\
\hline 9 & Suni o Escomarca & Huarochirí, Langa & & Parte Baja \\
\hline 10 & Llambilla & Lahuaytambo & & Parte Baja \\
\hline 11 & Concha & San Damián & (parte) & Parte Baja \\
\hline 12 & Lupo & San Damián, Huarochirí & & Parte Baja \\
\hline 13 & Checa & San Damián & (parte) & Parte Baja \\
\hline 14 & Viso & San Damián, San Mateo & & Parte Baja \\
\hline 15 & Pariapongo & Lahuaytambo & & Parte Baja \\
\hline 16 & San Andrés de Tupicocha & Tupicocha & & Parte Baja \\
\hline 17 & Langa & Langa & (parte) & Parte Media \\
\hline 18 & Espiritu Santo & Antioquia, Lahuaytambo & Parte Alta \\
\hline 19 & Avichuca & Antioquia, Chorrillos & (parte) & Parte Baja \\
\hline 20 & Santa Rosa de Manchay & Cieneguilla, Pachacamac & (parte) & Parte Alta \\
\hline 21 & Canlle & Lahuaytambo & & \\
\hline
\end{tabular}

Fuente: ( Instituto Metropolitano de Planificación, 2013)

La información presentada sobre población sitúa al distrito de Pachacamac como el de mayor población del Valle de Lurín y también el de mayor densidad poblacional, sin embargo ésta se estima baja en comparación de los otros distritos de Lima Metropolitana.

Pachacamac es uno de los territorios menos urbanizados de la provincia y esto se debe sobre todo a su lejanía con respecto al centro de la ciudad y a la presencia de considerables elevaciones naturales de terreno, que por estar muy cerca a la costa son partícipes del fenómeno de lomas. Los asentamientos informales en Lima tienden a invadir las laderas de éstas montañas, pero en este distrito las poblaciones aún no han llegado a hacerlo, es por ello la importancia de prevenir estas futuras expansiones urbanas, estableciendo bordes de protección para éstos ecosistemas. 


\subsection{Educación}

En el sector educación el indicador que resume a nivel macro la instrucción alcanzada por la población es el porcentaje de analfabetismo de la misma, información presentada en el siguiente cuadro; donde el índice de analfabetismo en el valle llega a $8 \%$, siendo el valle medio la que menor porcentaje de población analfabeta posee con $2.2 \%$, seguido de la cuenca alta con $2.7 \%$ y finalmente la cuenca baja con $8.4 \%$.

El distrito de Pachacamac posee un 2.28\% de analfabetismo representado por 1565 habitantes, este distrito es uno de los que posee la tasa más alta de personas que no tienen acceso a educación básica del valle.

Cuadro 2.22 Población Analfabeta presente en el Valle del Lurín

\begin{tabular}{|c|c|c|c|c|c|}
\hline Provincia & Cuenca & Distritos & $\begin{array}{l}\text { Pob. } \\
\text { Total }\end{array}$ & $\begin{array}{c}\text { Pob. } \\
\text { Analfabeta }\end{array}$ & $\%$ \\
\hline \multirow{12}{*}{$\begin{array}{l}\text { 든 } \\
\text { 등 } \\
\text { 인 } \\
\text { 몰 }\end{array}$} & \multirow{5}{*}{ Alta } & ${ }^{\star}$ Huarochirí & & & \\
\hline & & Santiago De Tuna & 666 & 19 & 2.9 \\
\hline & & $\begin{array}{l}\text { San Andrés De } \\
\text { Tupicocha }\end{array}$ & 1423 & 51 & 3.6 \\
\hline & & San Damián & 1489 & 27 & 1.8 \\
\hline & & Total Alta & 3578 & 97 & 2.7 \\
\hline & \multirow{3}{*}{$\begin{array}{l}\text { Media } \\
\text { Alta }\end{array}$} & Lahuaytambo & 837 & 20 & 2.4 \\
\hline & & Langa & 1056 & 32 & 3 \\
\hline & & Cuenca & 392 & 5 & 1.3 \\
\hline & \multirow{4}{*}{ Media } & Antioquia & 1376 & 45 & 3.3 \\
\hline & & Mariatana & 288 & & \\
\hline & & $\begin{array}{l}\text { Santo Domingo De } \\
\text { Los Olleros }\end{array}$ & 2906 & 49 & 1.7 \\
\hline & & Total Media & 6855 & 151 & 2.2 \\
\hline \multirow{13}{*}{ 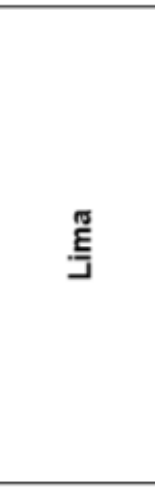 } & \multirow{4}{*}{ Baja } & Lurín & 62940 & 790 & 1,26 \\
\hline & & Pachacamac & 68441 & 1565 & 2.28 \\
\hline & & Cieneguilla & 26725 & 790 & 2,9 \\
\hline & & Total Baja & 159730 & 13394 & 8.4 \\
\hline & \multicolumn{2}{|c|}{ Total Cuenca Del Rio Lurín } & 170163 & 13642 & 8 \\
\hline & \multirow{6}{*}{$\begin{array}{c}\text { Zona } \\
\text { Maritima } \\
\text { Costera }\end{array}$} & Punta Hermosa & 5762 & 76 & 1.32 \\
\hline & & Punta Negra & 5284 & 67 & 1.26 \\
\hline & & San Bartolo & 5812 & 124 & 2.13 \\
\hline & & $\begin{array}{l}\text { Santa María Del } \\
\text { Mar }\end{array}$ & 761 & 17 & 2.23 \\
\hline & & Pucusana & 10633 & 143 & 1.34 \\
\hline & & Chilca & 14559 & 281 & 1.93 \\
\hline & \multicolumn{2}{|c|}{ Total Zona Maritima Costera } & 42811 & 565 & 1.32 \\
\hline & \multicolumn{2}{|c|}{ Total } & 212974 & 14207 & 6.67 \\
\hline
\end{tabular}

Fuente: ( Instituto Metropolitano de Planificación, 2013) 
El porcentaje de asistencia escolar de la población de la cuenca baja del valle, de 3 a 16 años, según la información del cuadro siguiente, es de 88.09 \%. Siendo 5289 los niños que no tienen acceso a educación.

Pachacamac cuenta con una asistencia escolar de 17664 niños, de los cuales 2466 niños en edad escolar no asisten a un centro educativo, representando el $12.25 \%$ del total de niños del distrito.

Cuadro 2.23 Asistencia Escolar en el la Cuenca Baja del Valle de Lurín

\begin{tabular}{|c|c|c|c|c|c|c|}
\hline Distritos & Pob. & $\begin{array}{l}\text { Pob. Total } \\
\text { (3 A } 16 \text { Años) }\end{array}$ & $\begin{array}{c}\text { Pob. Asiste } \\
\text { C.E. }\end{array}$ & $\%$ & $\begin{array}{c}\text { Pob. No } \\
\text { Asiste C.E. }\end{array}$ & $\%$ \\
\hline Lurin & 62940 & 17488 & 15534 & 88.83 & 1954 & 11.17 \\
\hline Pachacamac & 68441 & 20130 & 17664 & 87.75 & 2466 & 12.25 \\
\hline Cieneguilla & 26725 & 6784 & 5915 & 87.19 & 869 & 12.81 \\
\hline Total Baja & 158106 & 44402 & 39113 & 88.09 & 5289 & 11.91 \\
\hline
\end{tabular}

Fuente: ( Instituto Metropolitano de Planificación, 2013)

La información presentada en la siguiente tabla registra el número de alumnos por nivel educativo en la totalidad del valle, de esta información podemos deducir que al 2012 en la provincia de Huarochirí los distritos de Santiago de Tuna y Santo Domingo de Olleros no tienen implementado el programa PRONOEI, ni se instruye en educación secundaria en el distrito de Cuenca y finalmente la única institución que brinda educación superior es un Centro Técnico Productivo presente en la cuenca alta en el distrito de San Damián.

Con respecto a la Provincia de Lima, la educación que se imparte es hasta el nivel superior en los distritos de Cieneguilla, Lurín y Pachacamac. 
Cuadro 2.24 : Relación de Alumnos por Nivel de Atención en el Valle de Lurín

\begin{tabular}{|c|c|c|c|c|c|c|c|c|c|c|c|}
\hline \multirow{3}{*}{ Prov. } & \multirow{3}{*}{ Cuenca } & \multirow{3}{*}{ Distrito } & \multirow{3}{*}{$\begin{array}{c}\text { Población } \\
2012\end{array}$} & \multicolumn{7}{|c|}{ Nivel } & \multirow{3}{*}{ Total } \\
\hline & & & & \multicolumn{2}{|c|}{ Inicial Jardin } & \multirow{2}{*}{ Prim. } & \multirow{2}{*}{ Secun. } & \multirow{2}{*}{ Cetpro } & \multirow{2}{*}{$\begin{array}{l}\text { Educ. } \\
\text { Sup. } \\
\text { Tec. }\end{array}$} & \multirow{2}{*}{$\begin{array}{l}\text { Educ. } \\
\text { Espec. }\end{array}$} & \\
\hline & & & & Escolarizada & PRONOEI & & & & & & \\
\hline \multirow{13}{*}{ 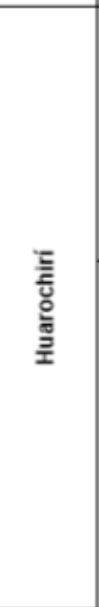 } & \multirow{5}{*}{$\frac{\Xi}{\longleftarrow}$} & "Huarochirí & & & & & & & & & \\
\hline & & $\begin{array}{l}\text { Santiago } \\
\text { De Tuna }\end{array}$ & 717 & 22 & & 46 & 28 & & & & 96 \\
\hline & & $\begin{array}{l}\text { San Andrés } \\
\text { De Tupicocha }\end{array}$ & 1354 & 28 & 40 & 232 & 89 & & & & 389 \\
\hline & & San Damián & 1321 & 67 & & 232 & 126 & 15 & & & 440 \\
\hline & & Total & 3392 & 117 & 40 & 510 & 243 & 15 & & & 925 \\
\hline & \multirow{8}{*}{$\begin{array}{l}\frac{\pi}{\bar{g}} \\
\frac{\mathrm{m}}{\Sigma}\end{array}$} & Lahuaytambo & 748 & 27 & & 68 & 55 & & & & 150 \\
\hline & & Langa & 945 & 33 & 12 & 143 & 130 & & & & 318 \\
\hline & & \begin{tabular}{|l|} 
Cuenca \\
\end{tabular} & 406 & & 17 & 44 & & & & & 61 \\
\hline & & Antioquía & 1316 & 43 & 31 & 162 & 80 & & & & 316 \\
\hline & & Mariatana & 288 & & & & & & & & \\
\hline & & $\begin{array}{l}\text { Santo Domingo } \\
\text { De Los Olleros }\end{array}$ & 3983 & 72 & & 250 & 83 & & & & 405 \\
\hline & & Total & 7686 & 175 & 60 & 667 & 348 & & & & 1250 \\
\hline & & Total Huarochirí & 11078 & 292 & 100 & 1177 & 591 & 15 & & & 2175 \\
\hline \multirow{10}{*}{ 茝 } & \multirow{4}{*}{$\frac{\pi}{g}$} & Lurín & 76874 & 3332 & 665 & 9018 & 5349 & 828 & 639 & 122 & 20888 \\
\hline & & Pachacamac & 102691 & 4774 & 452 & 10782 & 7717 & 452 & 204 & & 24024 \\
\hline & & Cieneguilla & 38328 & 774 & 48 & 2161 & 1732 & 0 & 40 & & 4755 \\
\hline & & Total & 217893 & 8880 & 1165 & 21961 & 14798 & 1280 & 883 & 122 & 49089 \\
\hline & \multicolumn{2}{|c|}{ Total Cuenca } & 228971 & 9172 & 1265 & 23138 & 15389 & 1295 & 883 & 122 & 51264 \\
\hline & \multirow{6}{*}{ 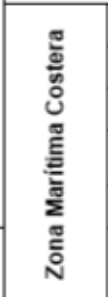 } & Punta Hermosa & 6935 & 232 & 15 & 295 & 170 & & & & 712 \\
\hline & & Punta Negra & 6878 & 222 & 69 & 574 & 422 & & & & 1287 \\
\hline & & San Bartolo & 7008 & 260 & 63 & 608 & 698 & & & 40 & 1669 \\
\hline & & $\begin{array}{l}\text { Santa María Del } \\
\text { Mar }\end{array}$ & 1220 & 7 & & 61 & 59 & & & & 127 \\
\hline & & Pucusana & 14403 & 561 & 169 & 1333 & 815 & & & 31 & 2909 \\
\hline \multirow[t]{2}{*}{ Cañete } & & Chilca & 15517 & 671 & 163 & 2125 & 1541 & & & 29 & 4529 \\
\hline & \multicolumn{2}{|c|}{$\begin{array}{l}\text { Total De Zona Marítima } \\
\text { Costera }\end{array}$} & 51961 & 1953 & 479 & 4996 & 3705 & & & 100 & 11202 \\
\hline \multicolumn{3}{|l|}{ Total } & 280644 & 11125 & 1744 & 28134 & 19094 & 1295 & 883 & 191 & 62466 \\
\hline
\end{tabular}

Fuente: ( Instituto Metropolitano de Planificación, 2013)

Estadísticamente para el sector educación, en el distrito de Pachacamac se pudieron obtener datos actualizados del año 2017 con respecto a la población escolar matriculada, como se muestra existe un total de 31936 matriculados. En la modalidad de Básica regular hay 29372 escolares, aquí se puede apreciar que la zona urbana cuenta con 15298 alumnos y el área rural con 77 matriculados.

La Educación Básica Alternativa tiene un total de 1319 alumnos matriculados de los cuales en la zona urbana, 150 alumnos pertenecen al sector público y 1169 al sector privado. En la modalidad de Básica Especial solo hay matriculados 13 alumnos en el área urbana privada. 
Sobre la educación Técnico Productiva es importante destacar que cuenta con un total de 558 inscritos, todos pertenecientes a gestiones privadas.

Cuadro 2.25 Matricula por tipo de Gestión y Área Geográfica, según Etapa, Modalidad y Nivel Educativo.

\begin{tabular}{|c|c|c|c|c|c|c|c|c|c|c|c|}
\hline \multicolumn{12}{|c|}{ PACHACAMAC 2017} \\
\hline \multicolumn{12}{|c|}{$\begin{array}{l}\text { PACHACAMAC: MATRICULA EN EL SISTEMA EDUCATIVO POR TIPO DE GESTIÓN Y ÁREA GEOGRÁFICA, } \\
\text { SEGÚN ETAPA, MODALIDAD Y NIVEL EDUCATIVO, } 2017\end{array}$} \\
\hline \multirow{2}{*}{$\begin{array}{l}\text { Etapa, modalidad y nivel } \\
\text { educativo }\end{array}$} & \multirow{2}{*}{ Total } & \multicolumn{2}{|c|}{ Gestión } & \multicolumn{2}{|c|}{ Área } & \multicolumn{2}{|c|}{ Sexo } & \multicolumn{2}{|c|}{ Pública } & \multicolumn{2}{|c|}{ Privada } \\
\hline & & Pública & Privada & Urbana & Rural & Masculino & Femenino & Urbana & Rural & Urbana & Rural \\
\hline Total & $\underline{31938}$ & 15525 & $\underline{16413}$ & $\underline{30788}$ & $\underline{1150}$ & 16064 & 15874 & $\underline{15448}$ & $\underline{77}$ & $\underline{15340}$ & 1073 \\
\hline Básica Regular & $\underline{29372}$ & $\underline{15375}$ & $\underline{13997}$ & $\underline{28222}$ & $\underline{1150}$ & 14824 & $\underline{14548}$ & $\underline{15298}$ & $\underline{77}$ & $\underline{12924}$ & 1073 \\
\hline Inicial & 7672 & 3648 & 4024 & 7361 & 311 & 3931 & 3741 & 3627 & 21 & 3734 & 290 \\
\hline Primaria & 13284 & 6594 & 6690 & 12715 & 569 & 6668 & 6616 & 6538 & 56 & 6177 & 513 \\
\hline Secundaria & 8416 & 5133 & 3283 & 8146 & 270 & 4225 & 4191 & 5133 & - & 3013 & 270 \\
\hline Básica Alternativa & $\underline{1319}$ & $\underline{150}$ & 1169 & $\underline{1319}$ & $=$ & $\underline{707}$ & $\underline{612}$ & $\underline{150}$ & $=$ & 1169 & $=$ \\
\hline Básica Especial & $\underline{13}$ & $=$ & 13 & $\underline{13}$ & $=$ & $\underline{8}$ & $\underline{5}$ & $=$ & $=$ & $\underline{13}$ & $=$ \\
\hline Técnico-Productiva & $\underline{558}$ & $=$ & $\underline{558}$ & $\underline{558}$ & $=$ & $\underline{245}$ & $\underline{313}$ & $=$ & $=$ & $\underline{558}$ & $=$ \\
\hline Superior No Universitaria & $\underline{676}$ & $=$ & $\underline{676}$ & $\underline{676}$ & $=$ & $\underline{280}$ & $\underline{396}$ & $=$ & $=$ & $\underline{676}$ & $=$ \\
\hline Pedagógica & 36 & - & 36 & 36 & - & 3 & 33 & - & - & 36 & - \\
\hline Tecnológica & 640 & - & 640 & 640 & - & 277 & 363 & - & - & 640 & - \\
\hline Artistica & - & - & - & -1 & - & - & - & - & - & - & - \\
\hline
\end{tabular}

Fuente: ESCALE

De la información presentada con respecto al sector educación, es relevante incidir en los índices de analfabetismo del Valle, los cuáles hacia el 2012 sobrepasaban el $8 \%$, es preocupante también como Pachacamac siendo un distrito urbano, asentado en la capital posee según los registros analizados, un $2,28 \%$ de población analfabeta y un $12,25 \%$ de su población en edad escolar que no asistía a un centro educativo.

Es sin duda la educación un área a atender, se estima que solo un $15 \%$ de la población del distrito de Pachacamac logra acceder a educación superior, siendo 558 los alumnos que siguen educación técnico productiva dentro del distrito, pero en CETPROS de gestión privada, pues no existe una institución pública que imparta ésta instrucción. El actual número de matriculados en ésta modalidad educativa es bajo considerado que no solo va dirigido a egresados de secundaria, sino también a adultos; 
esto se debe sobre todo a que la oferta formativa de éstos centros no está ligada a las actividades productivas desarrolladas en el distrito, como la agricultura y el turismo.

\subsection{Economía}

La población económicamente activa presente en el Valle del Lurín, está organizada en tres Zonas Económicas como se detalla en el cuadro siguiente.

En la provincia de Huarochirí se agrupa a Lahuaytambo, San Andrés de Tupicocha, San Damián y Huarochirí en la Zona Alto andina, cuya población económicamente activa (PEA) asciende a 4316 habitantes, constituyendo el porcentaje más importante el distrito de Huarochirí; Santiago de Tuna, Langa, Cuenca, Antioquía y Santo Domingo de Olleros conforman la Zona Interandina, representando este último a la mayor PEA del sector que suma un total de 6318 habitantes.

Finalmente en la provincia de Lima los distritos de Cieneguilla, Pachacamac y Lurín conforman la denominada Zona Económica Valle y es Pachacamac el distrito con mayor población que trabaja de la zona y del valle, con un total de 82661 habitantes económicamente activos según registros al año 2012.

Cuadro 2.26 Población Económicamente activa del Valle de Lurín 2012

\begin{tabular}{|c|c|c|c|c|}
\hline Provincia & Cuenca & $\begin{array}{l}\text { Zonas } \\
\text { Económicas }\end{array}$ & Distrito & Total \\
\hline \multirow{13}{*}{ Huarochirí } & \multirow{18}{*}{ Lurín } & \multirow{5}{*}{$\begin{array}{c}\text { ZEA } \\
\text { ZE. Altoandina }\end{array}$} & Lahuaytambo & 682 \\
\hline & & & San Andrés de Tupicocha & 1.176 \\
\hline & & & San Damián & 1.170 \\
\hline & & & Huarochirí & 1.288 \\
\hline & & & Sub Total ZEA & 4.316 \\
\hline & & \multirow{8}{*}{$\begin{array}{c}\text { ZEI } \\
\text { ZE. Interandina }\end{array}$} & Santiago de Tuna & 652 \\
\hline & & & Langa & 857 \\
\hline & & & Sn José de Chorrillos o Cuenca & 348 \\
\hline & & & Sub Total Sub-cuenca & 1.857 \\
\hline & & & Antioquía & 1.171 \\
\hline & & & Sto. Domingo de los Olleros & 3.290 \\
\hline & & & Sub Total Sub-cuenca & 4.461 \\
\hline & & & Sub Total ZEI & 6.318 \\
\hline \multirow{5}{*}{ Lima } & & \multirow{5}{*}{$\begin{array}{c}\text { ZEV } \\
\text { ZE. Valle }\end{array}$} & Cieneguilla & 32.336 \\
\hline & & & Pachacamac & 82.661 \\
\hline & & & Lurín & 65.513 \\
\hline & & & Villa M. del Triunfo (J. Gálvez) & 57.524 \\
\hline & & & Sub Total ZEV & 238.034 \\
\hline
\end{tabular}

Fuente: ( Instituto Metropolitano de Planificación, 2013) 
La población económicamente activa según sexo y condición laboral, en la información del siguiente cuadro concluye que en la Zona Altoandina el porcentaje de la PEA desocupada es $1.04 \%$, obteniendo la población femenina la mayor tasa de desempleo con $1.22 \%$ frente a la población masculina con $0.91 \%$; este escenario se repite también en las siguientes zonas económicas, Interandina y Valle.

En la Zona Valle un la PEA desocupada asciende a un total de 3.80\% representando ésta última el mayor porcentaje de población en condición de laborar que se encuentra desempleada y/o buscando trabajo de todo el Valle del Lurín.

Específicamente en el distrito de Pachacamac, el total de PEA es de 82661 personas de los cuales 79437 , se encuentra ocupados y 3224 desocupados.

Cuadro 2.27 Población Económicamente Activa Según Condición de Actividad y Sexo

\begin{tabular}{|c|c|c|c|c|c|c|c|c|c|c|}
\hline \multirow[t]{2}{*}{ Provincia } & \multirow[t]{2}{*}{ Cuenca } & \multirow{2}{*}{$\begin{array}{l}\text { Zonas } \\
\text { Económicas }\end{array}$} & \multirow[t]{2}{*}{ Distrito } & \multirow{2}{*}{$\begin{array}{l}\text { Total } \\
\text { Pea }\end{array}$} & \multicolumn{2}{|c|}{ Sexo } & \multicolumn{2}{|c|}{ PEA Ocupada } & \multicolumn{2}{|c|}{$\begin{array}{c}\text { PEA } \\
\text { Desocupada }\end{array}$} \\
\hline & & & & & M & $\mathrm{F}$ & M & $\mathrm{F}$ & $\mathrm{M}$ & $F$ \\
\hline \multirow{18}{*}{$\begin{array}{c}\text { Huarochirí } \\
\text { Lima }\end{array}$} & \multirow{18}{*}{ Lurín } & \multirow{5}{*}{ ZE. Altoandina } & Lahuaytambo & 682 & 414 & 268 & 414 & 268 & - & - \\
\hline & & & San Andrés de Tupicocha & 1.176 & 686 & 490 & 678 & 479 & 8 & 11 \\
\hline & & & San Damián & 1.170 & 667 & 503 & 667 & 498 & - & 5 \\
\hline & & & Huarochirí & 1.288 & 749 & 539 & 734 & 533 & 15 & 6 \\
\hline & & & Sub Total Sub cuenca & 4.216 & 2.516 & 1.800 & 2.493 & 1.778 & 23 & 22 \\
\hline & & \multirow{8}{*}{$\begin{array}{c}\text { ZEI } \\
\text { ZE. Interandina }\end{array}$} & Santiago de Tuna & 652 & 435 & 217 & 433 & 213 & 2 & 4 \\
\hline & & & Langa & 857 & 564 & 293 & 546 & 291 & 18 & 2 \\
\hline & & & Sn J. Chorrillos. o Cuenca & 348 & 228 & 120 & 218 & 118 & 10 & 2 \\
\hline & & & Sub Total Sub cuenca & 1.857 & 1.227 & 630 & 1.197 & 622 & 30 & 8 \\
\hline & & & Antioquía & 1.171 & 841 & 330 & 829 & 326 & 12 & 4 \\
\hline & & & Sto. Dmgo de los Olleros & 3.290 & 2.556 & 734 & 2.507 & 711 & 49 & 23 \\
\hline & & & Sub Total Sub cuenca & 4.461 & 3.397 & 1.064 & 3.336 & 1.037 & 61 & 27 \\
\hline & & & Sub Total & 6.318 & 4.624 & 1.694 & 4.533 & 1.659 & 91 & 35 \\
\hline & & \multirow{5}{*}{$\begin{array}{c}\text { ZEV } \\
\text { ZE. Valle }\end{array}$} & \begin{tabular}{|l|} 
Cieneguilla \\
\end{tabular} & 32.336 & 20.565 & 11.771 & 19.530 & 11.318 & 1.035 & 453 \\
\hline & & & Pachacamac & 82.661 & 51.332 & 31.329 & 49.348 & 30.089 & 1.984 & 1.240 \\
\hline & & & Lurin & 65.513 & 41.994 & 23.519 & 40.684 & 22.667 & 1.310 & 852 \\
\hline & & & Villa M.Triunfo (J Gálvez) & 57.524 & 28.095 & 29.429 & 24.395 & 25.594 & 3.700 & 3.835 \\
\hline & & & Sub Total Sub cuenca & 238.034 & 141.986 & 96.048 & 133.957 & 89.668 & 8.029 & 6.380 \\
\hline
\end{tabular}

Fuente: ( Instituto Metropolitano de Planificación, 2013)

La información presente en el siguiente cuadro nos permite analizar el tipo de sector en el que se desarrolla la población económicamente activa presente en el valle, así observamos que en la provincia de Huarochirí tanto en la Zona Económica Altoandina como en la Interandina se repite el mismo escenario siendo la actividad económica predominante en el sector primario, es la agricultura y la ganadería. 
Por otro lado en la provincia de Lima el sector terciario es el que mayor porcentaje expone, representando un $61.6 \%$ de la PEA total del Valle; siendo Pachacamac el distrito con mayor porcentaje en este sector con un 18.7\%. El sector secundario es el segundo en la lista cuyos aportes sitúan al distrito de Pachacamac en primer lugar con $7.5 \%$, Lurín con 5,7\% y Cieneguilla con 2,2\%; finalmente el de menor incidencia es el sector primario donde Lurín sobresale con un $2.3 \%$ de aporte a la PEA, seguido de Pachacamac con un $2 \%$ y Cieneguilla con un $0.9 \%$.

Los resultados totales muestran que el mayor porcentaje de la población económicamente activa perteneciente al Valle se desarrolla laboralmente en el sector terciario, la quinta parte en el sector secundario y aproximadamente el $10 \%$ de la población trabaja en el sector primario, valor de gran importancia pues para la provincia de Lima representa el último sector agrícola con capacidad y condiciones para seguir desarrollándose.

Cuadro 2.28 Población Económicamente Activa Según Principales Sectores de Actividad Económica

\begin{tabular}{|c|c|c|c|c|c|c|c|c|c|c|c|}
\hline \multirow{3}{*}{ Provincia } & \multirow{3}{*}{ Cuenca } & \multirow{3}{*}{$\begin{array}{c}\text { Zonas } \\
\text { Económicas }\end{array}$} & \multirow{3}{*}{ Distrito } & \multirow{2}{*}{\multicolumn{2}{|c|}{ Total }} & \multicolumn{6}{|c|}{ Sectores Económicos } \\
\hline & & & & & & \multicolumn{2}{|c|}{ Primario } & \multicolumn{2}{|c|}{ Secundario } & \multicolumn{2}{|c|}{ Terciario } \\
\hline & & & & ABS. & $\%$ & ABS. & $\%$ & ABS. & $\%$ & ABS. & $\%$ \\
\hline \multirow{13}{*}{ Huarochirí } & \multirow{18}{*}{ Lurin } & \multirow{5}{*}{$\begin{array}{c}\text { ZEA } \\
\text { ZE. Altoandina }\end{array}$} & Lahuaytambo & 682 & 0,2 & 592 & 0,2 & 13 & - & 77 & - \\
\hline & & & San Andrés de Tupicocha & 1.176 & 0,4 & 1.019 & 0,3 & 9 & - & 148 & 0,1 \\
\hline & & & San Damián & 1.170 & 0,4 & 1.002 & 0,3 & 19 & - & 149 & 0,1 \\
\hline & & & Huarochirí & 1.288 & 0,4 & 771 & 0,3 & 96 & $=$ & 421 & 0,1 \\
\hline & & & Sub Total Sub-cuenca & 4.216 & 1,5 & 3.384 & 1,1 & 137 & - & 795 & 0,3 \\
\hline & & \multirow{8}{*}{$\begin{array}{c}\text { ZEI } \\
\text { ZE. } \\
\text { Interandina }\end{array}$} & Santiago de Tuna & 652 & 0,2 & 508 & 0,2 & 9 & - & 135 & - \\
\hline & & & Langa & 857 & 0,3 & 624 & 0,2 & 56 & - & 177 & 0,1 \\
\hline & & & Sn J.d Chorrillos o Cuenca & 348 & 0,1 & 275 & 0,1 & 23 & - & 50 & - \\
\hline & & & Sub Total Sub-cuenca & 1.857 & 0,6 & 1.407 & 0,5 & 88 & - & 362 & 0,1 \\
\hline & & & Antioquia & 1.171 & 0,4 & 743 & 0,3 & 87 & - & 341 & 0,1 \\
\hline & & & Sto. Domgo. de los Olleros & 3.290 & 1,1 & 2.051 & 0,7 & 271 & 0,1 & 968 & 0,3 \\
\hline & & & Sub Total Sub-cuenca & 4.461 & 1,5 & 2.794 & 1,0 & 358 & 0,1 & 1.309 & 0,4 \\
\hline & & & Sub Total & 6.318 & 2,1 & 4.201 & 1,5 & 446 & 0,1 & 1671 & 0,5 \\
\hline \multirow{11}{*}{ Lima } & & & Cieneguilla & 32.336 & 11,0 & 2.549 & 0,9 & 6.509 & 2,2 & 23.278 & 7,9 \\
\hline & & & Pachacamac & 82.661 & 28,2 & 5.908 & 2,0 & 21.900 & 7,5 & 54.853 & 18,7 \\
\hline & & ZEV & Lurín & 65.513 & 22,4 & 6.772 & 2,3 & 16.639 & 5,7 & 42.102 & 14,4 \\
\hline & & & Villa M. del Triunfo (1. Gálvez) & 57.524 & 19,6 & 519 & 0,2 & 13.418 & 4,6 & 43.587 & 14,9 \\
\hline & & & Sub Total Sub-cuenca & 238.034 & 81,2 & 15.748 & 5,4 & 58.466 & 19,9 & 163.820 & 55,9 \\
\hline & \multirow{6}{*}{$\begin{array}{c}\text { Pampas } \\
\text { de San } \\
\text { Bartolo }\end{array}$} & \multirow{6}{*}{$\begin{array}{c}\text { ZEL } \\
\text { ZE. Litoral }\end{array}$} & Punta Negra & \begin{tabular}{|l|}
5.929 \\
\end{tabular} & 2,0 & 238 & 0,1 & 1.237 & 0,4 & 4.454 & 1,5 \\
\hline & & & Punta Hermosa & 6.050 & 2,1 & 390 & 0,1 & 1.457 & 0,5 & 4.203 & 1,4 \\
\hline & & & San Bartolo & 6.288 & 2,1 & 461 & 0,2 & 1.189 & 0,4 & 4.638 & 1,6 \\
\hline & & & Santa María del Mar & 878 & 0,3 & 62 & - & 170 & 0,1 & 646 & 0,2 \\
\hline & & & Pucusana & 11.847 & 4,0 & 2421 & 0,8 & 2258 & 0,8 & 7.168 & 2,4 \\
\hline & & & Sub Total Sub-cuenca & 30.992 & 10,6 & 3.572 & 1,2 & 6.311 & 2,2 & 21.109 & 7,2 \\
\hline \multirow{2}{*}{ Cañete } & \multirow{2}{*}{ Chilca } & \multirow{2}{*}{$\begin{array}{c}\text { ZEM } \\
\text { ZE. Maritimo }\end{array}$} & Chilca & 13.433 & 4,6 & 2.669 & 0,9 & 2.763 & 0,9 & 8.001 & 2,7 \\
\hline & & & Sub Total Sub-cuenca & 13.433 & 4,6 & 2.669 & 0,9 & 2.763 & 0,9 & 8.001 & 2,7 \\
\hline \multirow{3}{*}{\multicolumn{3}{|c|}{ Total x Provincia }} & Huarochirí & 10.634 & 3,6 & 7.585 & 2,6 & 583 & 0,2 & 2.466 & 0,8 \\
\hline & & & Lima & 269.026 & 91,8 & 19.320 & 6,6 & 64.777 & 22,1 & 184.929 & 63,1 \\
\hline & & & Cañete & 13.433 & 4,6 & 2.669 & 0,9 & 2.763 & 0,9 & 8.001 & 2,7 \\
\hline \multirow{3}{*}{\multicolumn{3}{|c|}{ Total x Cuenca }} & Lurín & 248.668 & 84,8 & 23.333 & 8,0 & 59.049 & 20,1 & 166.286 & 56,7 \\
\hline & & & Pampas de San Bartolo & 30.992 & 10,6 & 3.572 & 1,2 & 6.311 & 2,2 & 21.109 & 7,2 \\
\hline & & & Chilca & 13.433 & 4,6 & 2.669 & 0,9 & 2.763 & 0,9 & 8.001 & 2,7 \\
\hline \multicolumn{4}{|c|}{ Total } & 293.093 & 100,0 & 29.574 & 10,1 & 68.123 & 23,2 & 195.396 & 66,7 \\
\hline
\end{tabular}

Fuente: ( Instituto Metropolitano de Planificación, 2013) 
En el distrito de Pachacamac del total de pobladores económicamente activos, se ocupan en el Sector Primario 5908 de la PEA, en el Sector Secundario 21,900 y finalmente en el Sector Terciario 54853 pobladores; como notamos en el cuadro la PEA más alta del distrito se ubica en el sector terciario cuya actividad económica es el comercio donde 36226 habitantes se dedican a este rubro.

Cuadro 2.29 Población Económicamente Activa por grupos de edad y rama de actividad Económica, al año 2012

\begin{tabular}{|c|c|c|c|c|c|c|}
\hline \multirow{3}{*}{ Provincia, Sectores Y Actividad Económica } & \multirow{3}{*}{ Total } & \multicolumn{5}{|c|}{ Grandes Grupos De Edad } \\
\hline & & \multicolumn{5}{|c|}{ AÑOS } \\
\hline & & 6 A 14 & 15 A 29 & $30 \mathrm{~A} 44$ & 45 A 64 & $\begin{array}{l}65 \mathrm{~A} \\
\text { MAS }\end{array}$ \\
\hline \multicolumn{7}{|l|}{ PROVINCIA LIMA } \\
\hline Dist. Pachacamac & 82.661 & 784 & 32.481 & 33.156 & 14.612 & 1.628 \\
\hline I. SECTOR PRIMARIO & 5.908 & 81 & 1.763 & 2.011 & 1.539 & 514 \\
\hline Agri.ganaderia, caza y silvicultura & 5.665 & 81 & 1.679 & 1.891 & 1.500 & 514 \\
\hline Pesca & 24 & $\cdot$ & 6 & 12 & 6 & - \\
\hline Explotación de minas y canteras & 219 & - & 78 & 108 & 33 & - \\
\hline II. SECTOR SECUNDARIO & 21.900 & 138 & 9.300 & 8.435 & 3.732 & 295 \\
\hline Industrias manufactureras & 10.380 & 87 & 5.343 & 3.507 & 1.347 & 96 \\
\hline Suministro electrkidad, gas y agua & 242 & 6 & 81 & 87 & 61 & 7 \\
\hline Construcción & 11.278 & 45 & 3.876 & 4.841 & 2.324 & 192 \\
\hline III. SECTOR TERCIARIO & 54.853 & 565 & 21.418 & 22.710 & 9.341 & 819 \\
\hline COMERCIO & 36.226 & 436 & 13.952 & 14.878 & 6.318 & 642 \\
\hline Venta,mant.yrep.veh.autom.ymotoc. & 2.325 & 21 & 1.058 & 815 & 395 & 36 \\
\hline Comercio por mayor & 836 & 9 & 386 & 303 & 132 & 6 \\
\hline Comercio por menor & 13,448 & 257 & 4.464 & 5.701 & 2.720 & 306 \\
\hline Hoteles y restaurantes & 5.021 & 102 & 2.049 & 1.890 & 884 & 96 \\
\hline Transp.almac.y comunicaciones & 8.822 & 29 & 3.553 & 3.772 & 1.372 & 96 \\
\hline Intermediación financiera & 180 & $\cdot$ & 99 & 72 & 9 & $\cdot$ \\
\hline Activit.inmobil.,empres.y alquileres & 5.594 & 18 & 2.343 & 2.325 & 806 & 102 \\
\hline SERVICIOS & 18.627 & 129 & 7.466 & 7.832 & 3.023 & 177 \\
\hline Admin.pub.ydefensa;p.segur.soc.afil. & 1.950 & $\cdot$ & 509 & 884 & 530 & 27 \\
\hline Enseñanza & 3.011 & - & 1.043 & 1.351 & 578 & 39 \\
\hline Servicios sociales y de salud & 1.168 & - & 386 & 530 & 249 & 3 \\
\hline Otras activi. serv.comun.,soc.y personales & 3.955 & 30 & 1.510 & 1.738 & 617 & 60 \\
\hline Hogares privados y servicios domésticos & 8.525 & 99 & 4.015 & 3.323 & 1.043 & 45 \\
\hline Organiz.yorganos extraterritoriales & 18 & - & 3 & 6 & 6 & 3 \\
\hline
\end{tabular}

Fuente: ( Instituto Metropolitano de Planificación, 2013)

El Sector primario abarca a la agricultura dentro de sus actividades productivas. Los cuadros estadísticos mostrados a continuación no dan un indicador sobre la producción agrícola en los distritos de la cuenca baja del Valle, población estrechamente vinculada al proyecto de investigación a realizar. 
Donde podemos observar que hacia el año 2011 la Zona Económica de mayor producción obtenida era la Zona Valle llegando a las 69340 toneladas, teniendo los distritos de Pachacamac y Lurín aportes muy similares de 30886 t. y 33062 t. respectivamente y Cieneguilla 5392 t..

La Zona Altoandina alcanzó en ese mismo año un total de 21900 t. y la Zona Interandina 17980 t., cantidades que guardan relación en todos los casos con su superficie de cosecha pero no necesariamente con el rendimiento referido a kilogramo por hectárea donde la Zona Altoandina es la que mayor rendimiento alcanza con 89812 $\mathrm{kg} / \mathrm{ha}$., la sigue la Zona Valle con $69716 \mathrm{~kg} / \mathrm{ha}$. Y finalmente la Zona Interandina con $42718 \mathrm{~kg} / \mathrm{ha}$.

El distrito de Pachacamac tuvo una producción agrícola en el año 2010 de 32,554 toneladas, el año 2011 esta producción llego a 30886 toneladas, entonces se deduce que la producción agrícola va decreciendo cada año.

Cuadro 2.30 Producción Agrícola en el Valle de Lurín, Año 2010-2011

\begin{tabular}{|c|c|c|c|c|c|c|c|c|c|}
\hline \multirow[b]{2}{*}{ Provincia } & \multirow[b]{2}{*}{ Cuenca } & \multirow[b]{2}{*}{$\begin{array}{c}\text { Zonas } \\
\text { Económicas }\end{array}$} & \multirow[b]{2}{*}{ Distrito } & \multicolumn{3}{|c|}{2010} & \multicolumn{3}{|c|}{2011} \\
\hline & & & & $\begin{array}{l}\text { Produc. } \\
\text { (t.) }\end{array}$ & $\begin{array}{l}\text { Rendto. } \\
\text { (kg/ha) }\end{array}$ & $\begin{array}{c}\text { Supf. } \\
\text { Cosech. } \\
\text { (ha.) }\end{array}$ & $\begin{array}{l}\text { Produc. } \\
\text { (t.) }\end{array}$ & $\begin{array}{l}\text { Rendto. } \\
\text { (kg/ha) }\end{array}$ & $\begin{array}{l}\text { Supf. } \\
\text { Cosech. } \\
\text { (ha.) }\end{array}$ \\
\hline \multirow{13}{*}{ Huarochirí } & \multirow{18}{*}{ Lurín } & \multirow{5}{*}{$\begin{array}{c}\text { ZEA } \\
\text { ZE. } \\
\text { Altoandina }\end{array}$} & Lahuaytambo & 2.102 & 8.276 & 254 & 2.252 & 8.219 & 274 \\
\hline & & & San Andrés de Tupicocha & 2.074 & 20.949 & 99 & 2.517 & 20.975 & 120 \\
\hline & & & San Damián & 4.426 & 25.883 & 171 & 5.728 & 27.276 & 210 \\
\hline & & & Huarochirí & 12.375 & 31.250 & 396 & 11.403 & 33.342 & 342 \\
\hline & & & Total Sub cuenca & 20.977 & 86.358 & 920 & 21.900 & 89.812 & 946 \\
\hline & & \multirow{8}{*}{$\begin{array}{c}\text { ZEI } \\
\text { ZE. } \\
\text { Interandina }\end{array}$} & Santiago de Tuna & 807 & 8.495 & 95 & 875 & 9.831 & 89 \\
\hline & & & Langa & 4.445 & 10.337 & 430 & 4.324 & 9.917 & 436 \\
\hline & & & Sn José de Chorrillos o Cuenca & 2.147 & 9.059 & 237 & 2.118 & 8.899 & 238 \\
\hline & & & Total Sub cuenca & 7.933 & 27.891 & 762 & 7.317 & 28.647 & 763 \\
\hline & & & Antioquía & 8.479 & 9.506 & 892 & 8.247 & 8.974 & 919 \\
\hline & & & Sto. Domingo de los Olleros & 2.448 & 7.922 & 309 & 2.416 & 5.097 & 474 \\
\hline & & & Total Sub cuenca & 10.927 & 17.428 & 1.201 & 10.663 & 14.071 & 1.393 \\
\hline & & & Total Sub & 18.860 & 45.319 & 1963 & 17.980 & 42.718 & 2156 \\
\hline \multirow{11}{*}{ Lima } & & & Cieneguilla & 5.147 & 14.621 & 352 & 5.392 & 14.998 & 360 \\
\hline & & ZEV & Pachacamac & 32.544 & 25.505 & 1.276 & 30.886 & 25.589 & 1.207 \\
\hline & & ZE. Valle & Lurín & 37.689 & 29.676 & 1.270 & 33.062 & 29.129 & 1.135 \\
\hline & & & Villa Ma. del Triunfo & & & & & & \\
\hline & & & Total Sub cuenca & 75.380 & 69.802 & 2.898 & 69.340 & 69.716 & 2.702 \\
\hline & \multirow{6}{*}{$\begin{array}{l}\text { Pampas } \\
\text { de San } \\
\text { Bartolo }\end{array}$} & \multirow{6}{*}{$\begin{array}{c}\text { ZEL } \\
\text { ZE. Litoral }\end{array}$} & Punta Negra & & & & & & \\
\hline & & & Punta Hermosa & & & & & & \\
\hline & & & San Bartolo & & & & & & \\
\hline & & & Santa María del Mar & & & & & & \\
\hline & & & Pucusana & & & & & & \\
\hline & & & Total Sub cuenca & & & & & & \\
\hline \multirow{2}{*}{ Cañete } & \multirow{2}{*}{ Chilca } & \multirow{2}{*}{$\begin{array}{c}\text { ZEM } \\
\text { ZE. Marítimo } \\
\end{array}$} & Chilca & 7.318 & 14.127 & 518 & 6.440 & 12.677 & 508 \\
\hline & & & Total Sub cuenca & 7.318 & 14.127 & 518 & 6.440 & 12.677 & 508 \\
\hline \multirow{3}{*}{\multicolumn{3}{|c|}{ Total x Provincia }} & Huarochirí & 39.303 & 13.633 & 2.883 & 39.880 & 12.856 & 3.102 \\
\hline & & & Lima & 75.380 & 26.011 & 2.898 & 69.339 & 25.667 & 2.702 \\
\hline & & & Cañete & 7.318 & 14.127 & 518 & 6.440 & 12.677 & 508 \\
\hline \multirow{3}{*}{\multicolumn{3}{|c|}{ Total x Cuenca }} & Lurín & 114.683 & 19.838 & 5.781 & 109.219 & 18.819 & 5.804 \\
\hline & & & Pampas de San Bartolo & - & & - & - & & - \\
\hline & & & Chilca & 7.318 & 14.127 & 518 & 6.440 & 12.677 & 508 \\
\hline \multicolumn{4}{|c|}{ Total } & 122.535 & 215.606 & 6.299 & 115.660 & 214.923 & 6.312 \\
\hline
\end{tabular}

Fuente: ( Instituto Metropolitano de Planificación, 2013) 
Para el año 2011 el distrito de Cieneguilla tuvo una producción agrícola total de 5392 toneladas, destacándose la producción de ají, también la de maíz chala, pimiento, palto y lúcuma pero en menores proporciones con respecto al primero, son éstos dos últimos los frutos de mayor producción en el distrito con 346 t. y 262 t. al año respectivamente, pero es la lúcuma la de mayor precio en chacra, llegando a s/. 2.59 el kilo; por otro lado el cultivo con mayor superficie de cosecha es el ají seguido del palto, la berenjena, la lúcuma, el manzano y el maíz chala; las producciones con mayor rendimiento son la alfalfa, el tomate, el maíz chala y el ají, también el pimiento y la Lúcuma pero en proporciones más bajas.

Cuadro 2.31 Producción Agrícola Distrito de Cieneguilla

\begin{tabular}{|c|c|c|c|c|c|c|c|c|c|}
\hline \multirow[b]{2}{*}{ Distrito } & \multirow[b]{2}{*}{ Producto } & \multicolumn{4}{|c|}{2010} & \multicolumn{4}{|c|}{2011} \\
\hline & & $\begin{array}{c}\text { Precio } \\
\text { chacra } \\
\text { (S/.Kg.) }\end{array}$ & $\begin{array}{c}\text { Produc. } \\
\text { (t.) }\end{array}$ & $\begin{array}{c}\text { Rendmto } \\
\text { (kg/ha) }\end{array}$ & $\begin{array}{l}\text { Superf. } \\
\text { Cosech. } \\
\text { (ha.) }\end{array}$ & $\begin{array}{l}\text { Precio } \\
\text { chacra } \\
\text { (S/.Kg.) }\end{array}$ & $\begin{array}{c}\text { Produc. } \\
\text { (t.) }\end{array}$ & $\begin{array}{c}\text { Rendmto } \\
\text { (kg/ha) }\end{array}$ & $\begin{array}{c}\text { Superf. } \\
\text { Cosech. } \\
\text { (ha.) }\end{array}$ \\
\hline \multirow{16}{*}{ CIENEGUILLA } & Aji & 1,44 & 2.618 & 19.393 & 135 & 1,26 & 2.929 & 19.527 & 150 \\
\hline & Alfalfa & 0,27 & 238 & 23.800 & 10 & 0,22 & 179 & 44.750 & 4 \\
\hline & Berenjena & 0,7 & 158 & 5.636 & 28 & 0,77 & 138 & 5.192 & 27 \\
\hline & Frijol vainita & 1,4 & 15 & 5.000 & 3 & 1,28 & 50 & 5.000 & 10 \\
\hline & Lúcuma & 2,32 & 313 & 15.650 & 20 & 2,59 & 262 & 13.100 & 20 \\
\hline & Maíz amarillo duro & 0,76 & 78 & 4.869 & 16 & 0,81 & 64 & 4.938 & 13 \\
\hline & Maíz chala & 0,08 & 469 & 21.318 & 22 & 0,09 & 418 & 20.900 & 20 \\
\hline & Mango & 0,9 & 26 & 8.667 & 3 & 0,8 & 23 & 7.667 & 3 \\
\hline & Manzano & 0,78 & 192 & 9.600 & 20 & 0,79 & 195 & 9.750 & 20 \\
\hline & Membrillo & 1,03 & 79 & 15.800 & 5 & 1,03 & 80 & 10.000 & 8 \\
\hline & Palto & 1,94 & 236 & 6.743 & 35 & 1,97 & 346 & 9.886 & 35 \\
\hline & Pecano & 2,8 & 16 & 4.000 & 4 & 3,8 & 17 & 4.250 & 4 \\
\hline & Pimiento & 0,9 & 275 & 13.750 & 20 & 1,05 & 268 & 15.765 & 17 \\
\hline & Plátano & 0,59 & 91 & 7.583 & 12 & 0,6 & 120 & 10.000 & 12 \\
\hline & Tomate & 1,13 & 294 & 21.000 & 14 & 0,79 & 254 & 21.167 & 12 \\
\hline & Tuna & 1,46 & 49 & 9.800 & 5 & 1,26 & 49 & 9.800 & 5 \\
\hline \multicolumn{2}{|c|}{ Total Distrito } & & 5.147 & 14.621 & 352 & & 5.392 & 14.998 & 360 \\
\hline
\end{tabular}

Fuente: ( Instituto Metropolitano de Planificación, 2013) 
Para el mismo año el siguiente cuadro muestra la producción total del distrito de Lurín llegando a 33062 toneladas, sobresaliendo notablemente el maíz chala con 21 887 t., continúan aunque con cantidades productivas más baja la cebolla con 4247 t. y el camote con 3197 t., también se destaca la lúcuma como el fruto de mayor producción en el distrito con 1336 t. y posee al igual que en Cieneguilla el mayor precio en chacra de S/. 2.52 el kilo; la superficie de cosecha es en este caso relativa a la producción, por otro lado el rendimiento si difiere un poco de los resultados antes mencionados, sigue destacando el maíz chala pero sorprende la alfalfa y el zapallo con $43862 \mathrm{~kg} / \mathrm{ha}$., $43750 \mathrm{~kg} / \mathrm{ha}$. y $32000 \mathrm{~kg} / \mathrm{ha}$.

Cuadro 2.32 : Producción Agrícola Distrito de Lurín

\begin{tabular}{|c|c|c|c|c|c|c|c|c|c|}
\hline \multirow[b]{2}{*}{ Distrito } & \multirow[b]{2}{*}{ Producto } & \multicolumn{4}{|c|}{2010} & \multicolumn{4}{|c|}{2011} \\
\hline & & $\begin{array}{l}\text { Precio } \\
\text { chacra } \\
\text { (S/.Kg.) }\end{array}$ & $\begin{array}{l}\text { Produc. } \\
\text { (t.) }\end{array}$ & $\begin{array}{l}\text { Rendmto } \\
\text { (kg/ha) }\end{array}$ & $\begin{array}{l}\text { Superf. } \\
\text { Cosech. } \\
\text { (ha.) }\end{array}$ & $\begin{array}{c}\text { Precio } \\
\text { chacra } \\
\text { (S/.Kg.) }\end{array}$ & $\begin{array}{l}\text { Produc. } \\
\text { (t.) }\end{array}$ & $\begin{array}{c}\text { Rendmto } \\
\text { (kg/ha) }\end{array}$ & $\begin{array}{c}\text { Superf. } \\
\text { Cosech. } \\
\text { (ha.) }\end{array}$ \\
\hline \multirow{21}{*}{ LURIN } & Ajo & 3,5 & 6 & 6.200 & 1 & 0,5 & 6 & 6.000 & 1 \\
\hline & Alfalfa & 0,27 & 275 & 30.589 & 9 & 0,23 & 175 & 43.750 & 4 \\
\hline & Caigua & 0,87 & 97 & 5.105 & 19 & 0,74 & 87 & 5.438 & 16 \\
\hline & Camote & 0,76 & 3.401 & 22.826 & 149 & 0,72 & 3.197 & 23.167 & 138 \\
\hline & Cebolla & 0,28 & 4.702 & 23.049 & 204 & 0,51 & 4.247 & 23.208 & 183 \\
\hline & Coliflor & 0,73 & 1.838 & 18.948 & 97 & 0,8 & 1.099 & 18.948 & 58 \\
\hline & Frijol vainita & 0 & - & - & - & 1,4 & 5 & 5.000 & 1 \\
\hline & Higuera & 1,88 & 148 & 4.933 & 30 & 0,89 & 145 & 4.833 & 30 \\
\hline & Lucuma & 2,47 & 1.337 & 14.856 & 90 & 2,52 & 1.336 & 11.719 & 114 \\
\hline & Maiz amarillo duro & 0,76 & 191 & 5.026 & 38 & 0,8 & 141 & 5.226 & 27 \\
\hline & Maiz chala & 0,09 & 24.798 & 44.361 & 559 & 0,08 & 21.887 & 43.862 & 499 \\
\hline & Maiz choclo & 1,26 & 166 & 9.765 & 17 & 1,14 & 100 & 10.000 & 10 \\
\hline & Manzano & 0,68 & 48 & 9.680 & 5 & 0,8 & 59 & 11.800 & 5 \\
\hline & Membrillo & 1,12 & 50 & 10.000 & 5 & 1,12 & 49 & 9.800 & 5 \\
\hline & Palto & 1,82 & 87 & 12.429 & 7 & 1,82 & 92 & 10.222 & 9 \\
\hline & Pepinillo & 0 & - & - & - & 0,9 & 10 & 9.500 & 1 \\
\hline & Platano & 0,57 & 39 & 7.800 & 5 & 0,56 & 70 & 14.000 & 5 \\
\hline & Tomate & 1,07 & 210 & 23.333 & 9 & 0,85 & 94 & 23.500 & 4 \\
\hline & Tuna & 1,37 & 196 & 9.800 & 20 & 1,42 & 192 & 9.600 & 20 \\
\hline & Vid & 1,55 & 37 & 9.250 & 4 & 1,45 & 39 & 9.750 & 4 \\
\hline & Zapallo & 0,4 & 62 & 31.000 & 2 & 0,4 & 32 & 32.000 & 1 \\
\hline \multicolumn{2}{|c|}{ Total Distrito } & & 37.689 & 29.676 & 1.270 & & 33.062 & 29.129 & 1.135 \\
\hline
\end{tabular}

Fuente: ( Instituto Metropolitano de Planificación, 2013) 
El último distrito limeño perteneciente al Valle del Río Lurín es Pachacamac, cuyos datos de producción agrícola se muestran en el siguiente cuadro, donde observamos que para el año 2011 obtuvo una producción total de 30886 toneladas, destacando al igual que en Lurín el maíz chala con 21364 t., se alcanzaron grandes producciones también aunque en menor escala de ají, camote y lúcuma con 2457 t., 1 433 t. y 773 t. respectivamente.

Cuadro 2.33 Producción Agrícola Distrito de Pachacamac

\begin{tabular}{|c|c|c|c|c|c|c|c|c|c|}
\hline \multirow[b]{2}{*}{ Distrito } & \multirow[b]{2}{*}{ Producto } & \multicolumn{4}{|c|}{2010} & \multicolumn{4}{|c|}{2011} \\
\hline & & $\begin{array}{c}\text { Precio } \\
\text { chacra } \\
\text { (S/.Kg.) }\end{array}$ & $\begin{array}{c}\text { Produc. } \\
\text { (t.) }\end{array}$ & $\begin{array}{c}\text { Rendmto } \\
\text { (kg/ha) }\end{array}$ & $\begin{array}{c}\text { Superf. } \\
\text { Cosech. } \\
\text { (ha.) }\end{array}$ & $\begin{array}{c}\text { Precio } \\
\text { chacra } \\
\text { (S/.Kg.) }\end{array}$ & $\begin{array}{l}\text { Produc. } \\
\text { (t.) }\end{array}$ & $\begin{array}{c}\text { Rendmto } \\
\text { (kg/ha) }\end{array}$ & $\begin{array}{c}\text { Superf. } \\
\text { Cosech. } \\
\text { (ha.) }\end{array}$ \\
\hline \multirow{11}{*}{ PACHACAMAC } & Aji & 1,07 & 1.799 & 19.554 & 92 & 1,28 & 2.457 & 19.195 & 128 \\
\hline & Alfalfa & 0,27 & 444 & 26.118 & 17 & 0,24 & 433 & 43.300 & 10 \\
\hline & Arveja grano verde & 1,24 & 29 & 4.867 & 6 & 1,35 & 21 & 5.250 & 4 \\
\hline & Berenjena & 0,78 & 108 & 5.405 & 20 & 0,77 & 107 & 5.114 & 21 \\
\hline & Brócoli & 0,71 & 502 & 8.807 & 57 & 0,78 & 496 & 8.702 & 57 \\
\hline & Caigua & 0,7 & 15 & 5.100 & 3 & 0,8 & 20 & 10.000 & 2 \\
\hline & Camote & 0,81 & 1.698 & 21.769 & 78 & 0,73 & 1.433 & 21.712 & 66 \\
\hline & Cebolla & 0,23 & 226 & 22.600 & 10 & 0 & - & - & - \\
\hline & Coliflor & 0,72 & 313 & 16.474 & 19 & 0,77 & 251 & 16.733 & 15 \\
\hline & Esparrago & 3,92 & 92 & 5.412 & 17 & 3,5 & 58 & 5.800 & 10 \\
\hline & Fresa-frutilla (semi p) & 1,27 & 644 & 17.405 & 37 & 1,14 & 462 & 23.100 & 20 \\
\hline & Frijol vainita & 1,4 & 15 & 5.000 & 3 & 0 & - & - & - \\
\hline & Higuera & 1,7 & 27 & 4.500 & 6 & 0,94 & 28 & 4.667 & 6 \\
\hline & Lechuga & 0,76 & 66 & 5.077 & 13 & 0,71 & 70 & 4.986 & 14 \\
\hline & Lúcuma & 2,37 & 739 & 12.317 & 60 & 2,62 & 773 & 10.307 & 75 \\
\hline & Maíz amarillo duro & 0,76 & 179 & 4.972 & 36 & 0,8 & 132 & 5.088 & 26 \\
\hline & Maíz chala & 0,09 & 23.069 & 41.792 & 552 & 0,08 & 21.364 & 41.243 & 518 \\
\hline & Mandarina & 0,9 & 5 & 5.000 & 1 & 1 & 5 & 5.000 & 1 \\
\hline & Mango & 1 & 21 & 7.000 & 3 & 0,9 & 20 & 6.667 & 3 \\
\hline & Manzano & 0,73 & 639 & 10.146 & 63 & 0,86 & 611 & 9.698 & 63 \\
\hline & Melocotonero & 1,4 & 42 & 8.400 & 5 & 1,48 & 60 & 12.000 & 5 \\
\hline & Membrillo & 1,04 & 48 & 9.600 & 5 & 1,04 & 49 & 9.800 & 5 \\
\hline & Palto & 1,67 & 304 & 7.238 & 42 & 1,72 & 411 & 9.786 & 42 \\
\hline & Papa & 0,3 & 66 & 16.500 & 4 & 0,35 & 36 & 18.000 & 2 \\
\hline & Pecano & 3 & 8 & 4.000 & 2 & 2,8 & 9 & 4.500 & 2 \\
\hline & Peral & 1,4 & 19 & 4.850 & 4 & 1,45 & 20 & 5.000 & 4 \\
\hline & Pimiento & 0,93 & 613 & 15.325 & 40 & 1,08 & 608 & 17.371 & 35 \\
\hline & Plátano & 0,61 & 109 & 8.377 & 13 & 0,6 & 131 & 11.909 & 11 \\
\hline & Tomate & 0,94 & 437 & 23.000 & 19 & 0,94 & 274 & 22.833 & 12 \\
\hline & Tuna & 1,2 & 114 & 3.800 & 30 & 1,36 & 287 & 9.567 & 30 \\
\hline & Vid & 1,67 & 133 & 7.824 & 17 & 1,49 & 160 & 9.412 & 17 \\
\hline & Yuca & 0,5 & 20 & 10.000 & 2 & 0 & - & - & - \\
\hline & Zapallo & 0 & - & - & - & 0,3 & 99 & 33.000 & 3 \\
\hline \multicolumn{2}{|c|}{ Total Distrito } & & 32.544 & 25.505 & 1.276 & & 30.886 & 25.589 & 1.207 \\
\hline
\end{tabular}

Fuente: ( Instituto Metropolitano de Planificación, 2013) 
La Lúcuma se vuelve a posicionar como el fruto de mayor producción y el de más alto costo del distrito de Pachacamac y de la cuenca baja del Valle, como se detalló en los cuadros anteriores; siendo este fruto un potencial producto agrícola y a modo de rememorar la historia del lugar donde se viene realizando la presente investigación, se eligió el árbol de lúcumo para reforestar las laderas de Las lomas de Lúcumo, a fin de consolidar un borde de protección para este ecosistema y desarrollar un proyecto de aprovechamiento sostenible de las lomas teniendo a la lúcuma como materia prima principal para la elaboración de harina de lúcuma, para lo cual se contará con una planta de procesamiento.

Para afianzar la investigación es necesario exponer información de la lúcuma como materia prima a utilizar. El Ministerio de Agricultura y Riego (2018) señala que el lúcumo es originario del Perú andino, de la especie arbórea, familia de las sapotáceas y del genero Lúcuma. Según los cronistas el uso de este fruto data de épocas antes de los incas, por las evidencias de imágenes encontradas en los huacos Nazca y Mochica y fue parte de la dieta ancestral de los pobladores asentados en la costa y sierra del Perú; se sabe también que la madera de este árbol se empleó para la construcción del Santuario de Pachacamac.

El clima favorable para el cultivo de lúcuma es entre $8^{\circ} \mathrm{C}$ y $27^{\circ} \mathrm{C}$, y con una humedad media entre $80 \%$ y 90\%; este frutal se desarrolla hasta los 3000 m.s.n.m. en suelos arenosos de leve drenaje y no requiere irrigación constante, además soporta bien periodos breves de sequía. El lúcumo es un árbol que alcanza una altura de $15 \mathrm{~m}$ a 20 $\mathrm{m}$, de follaje denso y verdoso, cuyo diámetro de copa puede llegar hasta los $10 \mathrm{~m}$ y en condiciones propicias cada árbol produce de 200 a 300 frutos a partir del cuarto año.

Según El Sistema Integrado de Estadística Agraria (SIEA), el departamento de Lima es el mayor productor de Lúcuma, representando el $44 \%$ de la producción del país, seguido de Ica y la Libertad.

Es importante señalar que en Lima Metropolitana la producción de este fruto representa el $14 \%$ del total del país, además en esta provincia se concentra más del $30 \%$ de la producción del departamento de Lima. 
En el siguiente cuadro se detallan los datos de la producción agraria del país, en donde se muestra la diversidad de productos agrícolas por departamento entre ellos la lúcuma.

Cuadro 2.34 Producción Agraria del Perú en el año 2016

\begin{tabular}{|c|c|c|c|c|c|c|c|c|c|c|c|c|c|}
\hline Región & Guinda & Capulf & $\begin{array}{l}\text { Melo- } \\
\text { cotón }\end{array}$ & Ciruela & Nispero| & $\begin{array}{l}\text { Poma- } \\
\text { rosa }\end{array}$ & Lúcuma & Fresa & $\begin{array}{l}\text { Arản- } \\
\text { dano }\end{array}$ & Marañón & $\begin{array}{l}\text { Pacae y } \\
\text { guaba }\end{array}$ & Sauco & Tuna \\
\hline Nacional & 178 & 209 & 5552 & 193 & 373 & 223 & 1589 & 1280 & 1945 & 558 & 6009 & 48 & 13720 \\
\hline Amazonas & 0 & 0 & 25 & 0 & 0 & 0 & 0 & 0 & 0 & 0 & 1112 & 0 & 0 \\
\hline Áncash & 0 & 4 & 445 & 0 & 0 & 0 & 15 & 0 & 108 & 0 & 17 & 0 & 260 \\
\hline Apurimac & 0 & 52 & 211 & 41 & 28 & 0 & 14 & 18 & 0 & 0 & 41 & 35 & 1635 \\
\hline Arequipa & 0 & 0 & 98 & 4 & 1 & 0 & 96 & 35 & 1 & 0 & 28 & 0 & 1855 \\
\hline Ayacucho & 101 & 0 & 397 & 25 & 32 & 0 & 63 & 0 & 0 & 1 & 116 & 0 & 2450 \\
\hline Cajamarca & 0 & 0 & 0 & 0 & 67 & 0 & 0 & 0 & 0 & 0 & 801 & 0 & 174 \\
\hline Cusco & 0 & 46 & 233 & 13 & 0 & 0 & 0 & 0 & 0 & 0 & 7 & 0 & 1571 \\
\hline Huancavelica & 6 & 44 & 55 & 0 & 20 & 0 & 6 & 0 & 0 & 0 & 22 & 0 & 1812 \\
\hline Huánuco & 0 & 0 & 245 & 0 & 4 & 25 & 13 & 11 & 0 & 0 & 135 & 0 & 78 \\
\hline Ica & 0 & 0 & 101 & 0 & 0 & 0 & 157 & 0 & 55 & 0 & 87 & 0 & 1421 \\
\hline Junin & 71 & 0 & 20 & 8 & 6 & 0 & 16 & 0 & 0 & 9 & 190 & 13 & 25 \\
\hline La Libertad & 0 & 28 & 19 & 0 & 10 & 0 & 119 & 19 & 1640 & 0 & 81 & 0 & 256 \\
\hline Lambayeque & 0 & 0 & 0 & 0 & 0 & 0 & 13 & 0 & 0 & 0 & 90 & 0 & 0 \\
\hline Lima & 0 & 0 & 3531 & 48 & 185 & 0 & 701 & 1162 & 141 & 0 & 10 & 0 & 1627 \\
\hline Lima Metropolitana & 0 & 0 & 3 & 0 & 0 & 0 & 228 & 29 & 0 & 0 & 0 & 0 & 58 \\
\hline Loreto & 0 & 0 & 0 & 0 & 0 & 178 & 21 & 0 & 0 & 237 & 948 & 0 & 0 \\
\hline Madre de Dios & 0 & 0 & 0 & 0 & 0 & 0 & 0 & 0 & 0 & 8 & 0 & 0 & 0 \\
\hline Moquegua & 0 & 0 & 31 & 26 & 4 & 0 & 14 & 0 & 0 & 0 & 12 & 0 & 405 \\
\hline Pasco & 0 & 0 & 0 & 0 & 0 & 0 & 24 & 6 & 0 & 0 & 0 & 0 & 5 \\
\hline Piura & 0 & 35 & 0 & 0 & 16 & 0 & 89 & 0 & 0 & 0 & 254 & 0 & 0 \\
\hline Puno & 0 & 0 & 48 & 0 & 0 & 0 & 0 & 0 & 0 & 0 & 0 & 0 & 0 \\
\hline San Martin & 0 & 0 & 0 & 0 & 0 & 20 & 0 & 0 & 0 & 0 & 1227 & 0 & 0 \\
\hline Tacna & 0 & 0 & 91 & 28 & 0 & 0 & 0 & 0 & 0 & 0 & 0 & 0 & 88 \\
\hline Tumbes & 0 & 0 & 0 & 0 & 0 & 0 & 0 & 0 & 0 & 0 & 0 & 0 & 0 \\
\hline Ucayali & 0 & 0 & 0 & 0 & 0 & 0 & 0 & 0 & 0 & 303 & 832 & 0 & 0 \\
\hline
\end{tabular}

Fuente: (Sifuentes, Albujar, Contreras, \& Leon, 2017)

Los datos referidos a la producción pecuaria, también contemplada en el sector primario nos muestran que dentro de la provincia de Huarochirí la Zona Altoandina es la que genera mayor producción vacuna y ovina, también producen carne de alpaca y llama, la Zona Interandina es la que posee mayor producción de caprinos.

Con respecto a la provincia de Lima, los distritos pertenecientes al Valle poseen un sólida producción de carnes convencionales, sobresaliendo la de ave con 34883 toneladas mensuales, también presentan una alta producción de leche vacuna y huevos.

Pachacamac es un distrito con una producción total de 10599 de carne de ave, seguida de carne de porcino con 2232 unidades como se observa en el cuadro siguiente. 
Cuadro 2.35 : Producción Pecuaria en el Valle de Lurín

\begin{tabular}{|c|c|c|c|c|c|c|c|c|c|c|c|c|}
\hline \multirow{2}{*}{ Provincia } & \multirow{2}{*}{ Cuenca } & \multirow{2}{*}{$\begin{array}{c}\text { Zonas } \\
\text { Económicas }\end{array}$} & \multirow{2}{*}{ Distrito } & \multicolumn{7}{|c|}{ Carne } & \multirow{2}{*}{$\begin{array}{l}\text { Leche } \\
\text { Vacun }\end{array}$} & \multirow{2}{*}{ Huevo } \\
\hline & & & & Ave & Vacuno & Ovino & Porcino & Caprino & Alpac. & Ulama & & \\
\hline \multirow{13}{*}{ Huarochiri } & \multirow{18}{*}{ Lurin } & \multirow{5}{*}{$\begin{array}{c}\text { ZEA } \\
\text { ZE. Altoandina }\end{array}$} & Lahuaytambo & & 804 & 1326 & & 240 & & & & \\
\hline & & & Sn Adrés Tupicocha & & 614 & 1639 & & 1802 & & & & \\
\hline & & & San Damián & & 1711 & 2573 & & & & & & \\
\hline & & & Huarochiri & & 1761 & 3232 & & 450 & 933 & 236 & & \\
\hline & & & Sub Tot. Subcuenca & - & 4.890 & 8.770 & $=$ & 2.942 & 933 & 236 & $=$ & - \\
\hline & & \multirow{8}{*}{$\begin{array}{c}\text { ZEI } \\
\text { ZE. Interandina }\end{array}$} & Santiago de Tuna & & 85 & 328 & & 387 & & & & \\
\hline & & & Langa & & 821 & 1092 & & 857 & & & & \\
\hline & & & Sn J. Chorr. Cuenca & & 249 & 130 & & 1411 & & & & \\
\hline & & & Sub TotSubcuenca & 0 & 1155 & 1150 & 0 & 2655 & 0 & $\mathbf{0}$ & 0 & 0 \\
\hline & & & Antioquia & & 142 & 156 & & 583 & & & & \\
\hline & & & Sto. Dmgo. d Olleros & & 468 & 815 & & 4222 & & & & \\
\hline & & & Sub TotSubcuenca & 0 & 610 & 971 & 0 & 4805 & 0 & 0 & 0 & 0 \\
\hline & & & Sub Total & 0 & 1765 & 2121 & 0 & 7460 & 0 & $\mathbf{0}$ & 0 & 0 \\
\hline \multirow{11}{*}{ Lima } & & & Cieneguilla & 11.024 & 67 & 3 & 562 & 2 & & & 221 & 2.709 \\
\hline & & ZEV & Pachacamac & 10.599 & 1.178 & 2 & 2.232 & 3 & & & 7.597 & 7.621 \\
\hline & & ZE. Valle & Lurin & 13.260 & 6.350 & 7 & 3.009 & 4 & & & 31.069 & 2.817 \\
\hline & & & Villa Ma. del Triunfo & & & 6 & 188 & 3 & & & & \\
\hline & & & Sub TotSubcuenca & 34.883 & 7.595 & 18 & 5.991 & 12 & - & - & 38.887 & 13.147 \\
\hline & \multirow{6}{*}{$\begin{array}{l}\text { Pampas } \\
\text { San } \\
\text { Bartolo }\end{array}$} & \multirow{6}{*}{$\begin{array}{c}\text { ZEL } \\
\text { ZE. Litoral }\end{array}$} & Punta Negra & 8.9366 & & & & & & & & \\
\hline & & & Punta Hermosa & & & & & & & & & \\
\hline & & & San Bartolo & 15.815 & & & & & & & & $7.073,9$ \\
\hline & & & Santa Maria del Mar & 7.3421 & & & & & & & & \\
\hline & & & Pucusana & & & & & & & & & \\
\hline & & & Sub TotSubcuenca & 32.092 & $=$ & - & - & - & - & - & - & $7.073,9$ \\
\hline \multirow{2}{*}{ Cañete } & \multirow{2}{*}{ Chilca } & \multirow{2}{*}{$\begin{array}{c}\text { ZEM } \\
\text { ZE. Maritimo }\end{array}$} & Chilca & & & & & & & & & \\
\hline & & & Sub TotSubcuenca & 0 & 0 & 0 & 0 & 0 & 0 & 0 & 0 & 0 \\
\hline \multirow{3}{*}{\multicolumn{3}{|c|}{ Total x Provincia }} & Huarochirí & 0 & 6.655 & 11.291 & 0 & 9.952 & 933 & 236 & 0 & 0 \\
\hline & & & Lima & 66.975 & 7.595 & 18 & 5.991 & 12 & 0 & 0 & 38.887 & 20.221 \\
\hline & & & Cañete & 0 & 0 & 0 & 0 & 0 & 0 & 0 & 0 & 0 \\
\hline \multirow{3}{*}{\multicolumn{3}{|c|}{ Total x Cuenca }} & Lurin & 34.883 & 14.250 & 11.309 & 5.991 & 9.964 & 933 & 236 & 38.887 & 13.147 \\
\hline & & & Pampas San Bartolo & 32.092 & 0 & 0 & 0 & 0 & 0 & 0 & 0 & 7.074 \\
\hline & & & Chilca & 0 & 0 & 0 & 0 & 0 & 0 & 0 & 0 & 0 \\
\hline \multicolumn{4}{|c|}{ Total } & 66.975 & 14.250 & 10.909 & 5.991 & 10.414 & 933 & 236 & 38.887 & 20.221 \\
\hline
\end{tabular}

Fuente: ( Instituto Metropolitano de Planificación, 2013)

Los datos referidos a la producción minera se muestran a continuación, teniendo en cuenta que en el valle no se ha hallado presencia de minería metálica, el cuadro muestra más bien actividades de extracción de materiales de construcción.

Con respecto a la provincia de Huarochirí, en su Zona Económica Interandina, la empresa Cerámica San Lorenzo realiza la extracción de 57589 toneladas mensuales de arcilla en el distrito de Cuenca.

En Lima representada por la Zona Económica Valle se realiza la extracción mensual de piedra y arena con un total de 376782 y 295299 toneladas respectivamente; por parte de la industria Firth Industries Perú.

En el Distrito de Pachacamac también se realiza la actividad extractora, en este caso de caliza y dolomita en la unidad Pucará por parte de la Empresa Cementos Lima, quien también tiene en el Centro Poblado José Gálvez una cantera donde extrae Puzalona entre otros materiales. Cabe resaltar que éste yacimiento se encuentra muy 
cerca al Ecosistema Frágil "Lomas de Lúcumo" y amenaza contantemente su preservación.

Cuadro 2.36 Gran y Mediana Minería No Metálica en el Valle de Lurín

\begin{tabular}{|c|c|c|c|c|c|c|c|}
\hline Provincia & Cuenca & $\begin{array}{c}\text { Zonas } \\
\text { Económicas }\end{array}$ & Distrito & Titular & Unidad & Producto & T.M. \\
\hline \multirow[t]{2}{*}{ Huarochirí } & \multirow{8}{*}{ Lurín } & \multirow[t]{2}{*}{$\begin{array}{c}\text { ZEI } \\
\text { ZE. Interandina }\end{array}$} & Sn J.de Chorrillos o Cuenca & $\begin{array}{l}\text { Cerámica } \\
\text { San Lorenzo } \\
\text { S.A.C. }\end{array}$ & $\begin{array}{l}\text { San } \\
\text { Lorenzo } \\
750\end{array}$ & Arcillas & \multirow{2}{*}{$\begin{array}{l}57.589 \\
\mathbf{5 7 . 5 8 9}\end{array}$} \\
\hline & & & \multicolumn{4}{|l|}{ Sub Total Cuenca } & \\
\hline \multirow{6}{*}{ Lima } & & \multirow{6}{*}{$\begin{array}{c}\text { ZEV } \\
\text { ZE. Valle } \\
\text {. }\end{array}$} & Pachacamac & $\begin{array}{l}\text { Cementos } \\
\text { Lima S.A.A }\end{array}$ & Pucará & Caliza/Dolomita & 1.954 .336 \\
\hline & & & \multirow{2}{*}{ Lurín } & \multirow{2}{*}{$\begin{array}{l}\text { Firth } \\
\text { Industries } \\
\text { Peru S.A. }\end{array}$} & \multirow{2}{*}{$\begin{array}{l}\text { Flor de } \\
\text { Nieve } \\
\mathrm{N}^{\circ} 2\end{array}$} & $\begin{array}{l}\text { Piedra } \\
\text { (construcción) }\end{array}$ & 376.782 \\
\hline & & & & & & $\begin{array}{l}\text { Arena Gruesa } \\
\text { /fina) }\end{array}$ & 295.299 \\
\hline & & & \multirow{2}{*}{$\begin{array}{l}\text { Villa Ma. del Triunfo } \\
\text { (José Gálvez) }\end{array}$} & \multirow{2}{*}{$\begin{array}{l}\text { Cementos } \\
\text { Lima S.A.A }\end{array}$} & \multirow{2}{*}{ Atocongo } & Caliza/Dolomita & 3.297 .206 \\
\hline & & & & & & Puzolana & 66.257 \\
\hline & & & \multicolumn{4}{|l|}{ Sub Total Cuenca } & 5.989 .880 \\
\hline \multicolumn{7}{|c|}{ Total } & 6.047 .469 \\
\hline
\end{tabular}

Fuente: ( Instituto Metropolitano de Planificación, 2013)

Para fines de la presente investigación es relevante resaltar los datos referidos al distrito de Pachacamac, en relación a su desarrollo económico es éste el distrito con mayor población de personas en edad de trabajar, pero el $4 \%$ de ellas se encuentra desempleada. El mayor porcentaje de la PEA, pertenece al sector terciario, siendo el 7\% de su población la que trabaja en el sector primario, es decir en actividades ganaderas y en su mayoría agrícolas; éste dato resulta difícil de creer, pues al referenciarnos a un plano satelital del distrito, lo que más resalta son sus grandes extensiones de terreno agrícola, siendo lógico pensar que sus habitantes tienen a la agricultura como actividad económica, y en efecto así sucede, pero no es su principal actividad económica, la mayoría de ellos llevan a la par otros trabajos, que les permitan mayores ingresos, esto se refleja en los Censos Poblacionales, por ello la incongruencia de los datos.

Es importante destacar también la producción agrícola del distrito para dirigir la oferta formativa del Centro Técnico Productivo, tras éste análisis se determinó que además de la planta de procesamiento de harina de lúcuma, existiría también una planta piloto agroindustrial como generadora de herramientas de desarrollo local, donde se enseñará a preparar harinas, deshidratados, jugos, néctares, mermeladas, encurtidos y chips, para que el agricultor del valle le dé un valor agregado a su producto y de esta forma pueda expandir su actividad. 


\subsection{Calidad de Vida}

La calidad de vida de un ciudadano o de una población está estrechamente ligada no solo al bienestar físico y mental sino también a las condiciones necesarias para un desarrollo integral de todos los factores en los que influye la vida de un ser humano.

Para establecer la calidad de vida de los pobladores del Valle Lurín es necesario analizar los distintos factores que evalúan el nivel de la misma, uno de ellos es la condición de pobreza, datos que se muestran en el siguiente cuadro correspondiente al año 2009, donde observamos que el distrito con mayor incidencia de pobreza es Langa ubicado en la cuenca media alta, reflejando esta condición más de la mitad de su población con un 50,9\%; los distritos de San Damián, Pachacamac, Lurín y San Andrés de Tupicocha poseen también altos índices de pobreza con 48.5\%, 32.9\%. 30.2\% y $30.0 \%$ respectivamente. Por otro lado los porcentajes de pobreza extrema son también alarmantes siendo Langa y San Damián los distritos con mayor población del valle que vive en pobreza extrema registrándose un $19.9 \%$ y $17.7 \%$ respectivamente.

Cuadro 2.37 Condición de Pobreza Valle de Lurín, Año 2009

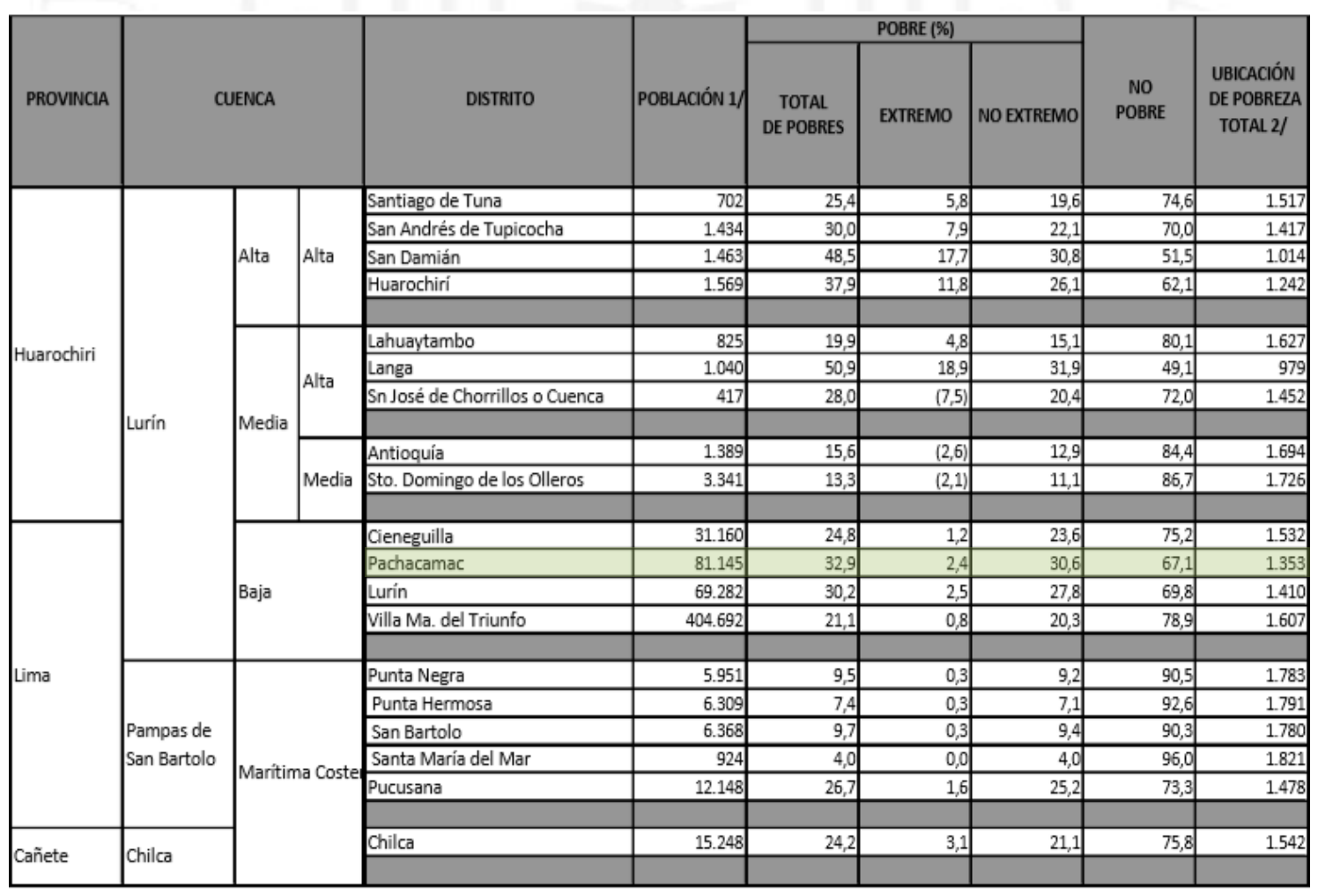

Fuente: ( Instituto Metropolitano de Planificación, 2013) 
Se tomó en cuenta los datos del cuadro anterior para tener una visión sobre la condición de pobreza del Valle de Lurín, pero estos datos representan un registro antiguo por lo que fue necesario actualizar esta información al año 2012 siendo éstos los últimos datos publicados.

Para este año, Pachacamac era el distrito con mayor índice de pobreza de Lima Metropolitana ascendiendo a 25\%; condición que comparte aunque en menor escala con los otros distritos también de la Cuenca baja del Valle: Lurín y Cieneguilla, cuya pobreza representa $18.8 \%$ y $16.7 \%$ respectivamente como se muestra en el la figura siguiente.

Figura 2.21 Distritos de Lima con mayor índice de pobreza No Extrema 2012

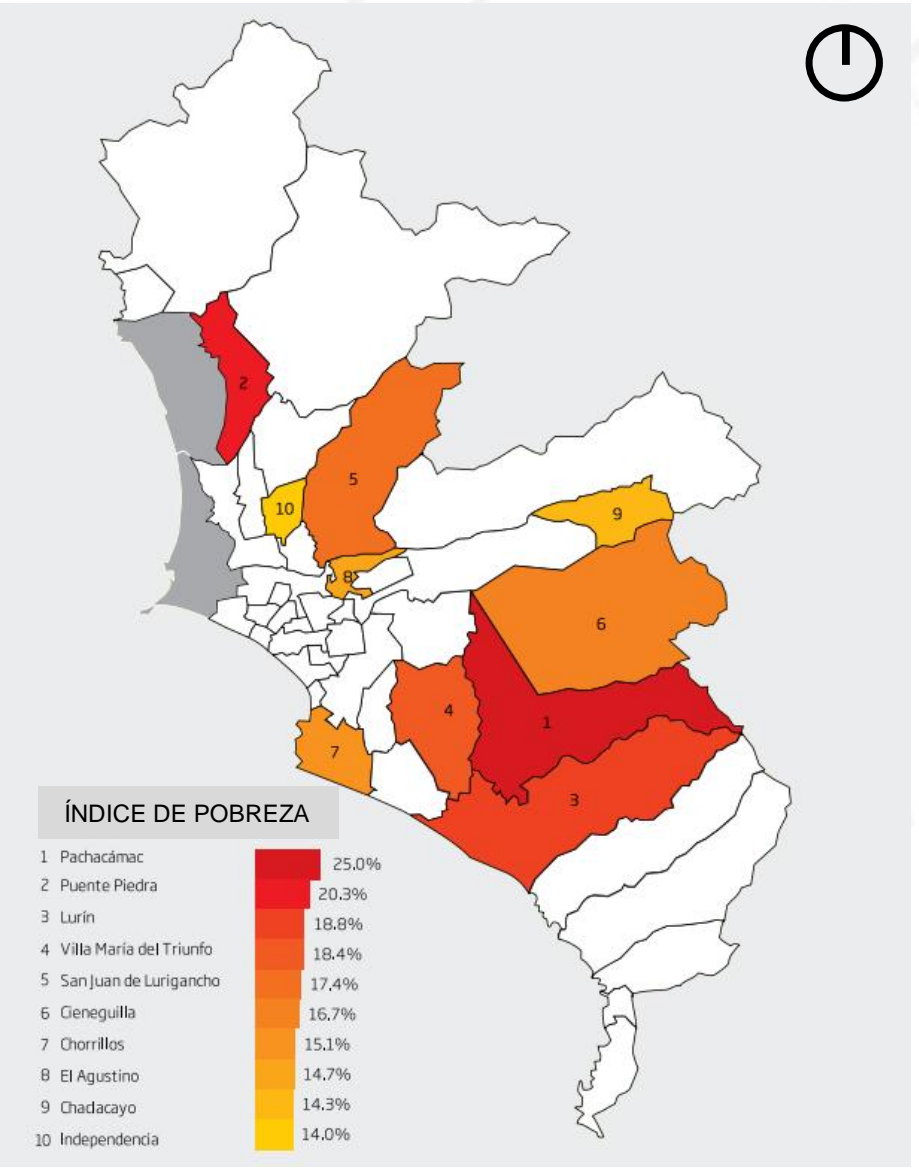

Fuente: Lima como vamos 2013 
Otro nivel que mide la calidad de vida de una población es el acceso a necesidades básicas, en el cuadro siguiente se muestran datos respecto a alcantarillado, agua y alumbrado eléctrico para el Valle del Lurín, podemos observar que Lurín es el distrito con mayor población sin acceso a saneamiento.

Por otro lado dentro del valle los distritos de la provincia de Lima cuyos porcentajes importantes de población aún no han podido acceder al servicio de agua potable se encuentran en en el siguiente orden: Cieneguilla, Lurín y Pachacamac y son éstos mismos distritos los que poseen mayor porcentaje de población sin alumbrado eléctrico.

Cuadro 2.38 Servicios Básicos de Agua, Desagüe y Luz 2007 según distritos en el Valle Lurín

\begin{tabular}{|c|c|c|c|c|c|c|c|c|c|c|c|c|c|c|c|c|c|}
\hline \multirow{4}{*}{$\begin{array}{l}\text { Provincia/ } \\
\text { Distritos }\end{array}$} & \multicolumn{7}{|c|}{ Desagüe } & \multicolumn{7}{|c|}{ Agua } & \multicolumn{3}{|c|}{ Alumbrado Eléctrico } \\
\hline & \multirow{3}{*}{ 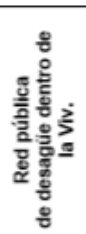 } & \multirow{3}{*}{ 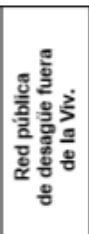 } & \multirow{3}{*}{ 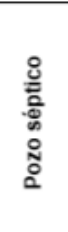 } & \multirow{3}{*}{ 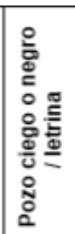 } & \multirow{3}{*}{ 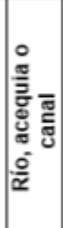 } & \multirow{3}{*}{ 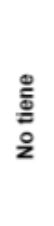 } & \multirow{3}{*}{ ㅎ̆ㅇ } & \multirow{2}{*}{\multicolumn{2}{|c|}{$\begin{array}{c}\begin{array}{c}\text { Red } \\
\text { pública } \\
\text { Dentro de } \\
\text { la Viv. }\end{array} \\
\text { (Agua } \\
\text { potable) } \\
\end{array}$}} & \multirow{2}{*}{\multicolumn{2}{|c|}{$\begin{array}{c}\text { Red } \\
\text { Pública } \\
\text { Fuera de } \\
\text { la } \\
\text { vivienda }\end{array}$}} & \multirow{2}{*}{\multicolumn{2}{|c|}{$\begin{array}{c}\text { Pilón de } \\
\text { uso } \\
\text { público }\end{array}$}} & \multirow{3}{*}{ Total } & \multirow{3}{*}{ SI } & \multirow{3}{*}{ NO } & \multirow{3}{*}{ Total } \\
\hline & & & & & & & & & & & & & & & & & \\
\hline & & & & & & & & SI & NO & SI & NO & SI & NO & & & & \\
\hline \multicolumn{18}{|c|}{ Ámbito de estudio } \\
\hline \multicolumn{18}{|l|}{ Prov. De Lima } \\
\hline Lurín & 6.18 & 706 & 2.927 & 3.567 & 424 & 758 & 14.562 & 6.463 & 184 & 515 & 56 & 554 & 245 & \begin{tabular}{|l|}
8.017 \\
\end{tabular} & 12.46 & \begin{tabular}{|l|}
2.098 \\
\end{tabular} & 14.562 \\
\hline $\begin{array}{l}\text { Punta } \\
\text { Hermosa }\end{array}$ & 65 & 24 & 188 & 1.474 & 3 & 13 & 1.767 & 62 & 2 & 5 & - & 2 & - & 71 & 1.334 & 433 & 1.767 \\
\hline Punta Negra & 16 & 6 & 784 & 581 & 1 & 27 & 1.415 & 10 & 5 & 6 & - & 14 & 15 & 50 & 1.233 & 182 & 1.415 \\
\hline San Bartolo & 548 & 127 & 283 & 424 & 1 & 23 & 1.406 & 30 & 10 & - & 1 & 3 & 6 & 50 & 1.094 & 312 & 1.406 \\
\hline $\begin{array}{l}\text { Santa María } \\
\text { del Mar }\end{array}$ & 182 & 10 & 6 & 16 & 1 & & 215 & 61 & 45 & 3 & 7 & - & 2 & 118 & 196 & 19 & 215 \\
\hline Pachacamac & 1.12 & 196 & 4.998 & 9.627 & 34 & 1.43 & 17.403 & 1.489 & 92 & 257 & 48 & 177 & 489 & 2.552 & 12.12 & 5.284 & 17.403 \\
\hline Cieneguilla & 710 & 192 & 1.395 & 2.02 & 25 & 227 & 4.569 & 709 & 723 & 98 & 429 & 14 & 80 & 2.053 & 3.76 & 809 & 4.569 \\
\hline \multicolumn{18}{|c|}{ Prov. De Huarochirí } \\
\hline Antioquía & 43 & 9 & 28 & 109 & 9 & 241 & 439 & 193 & 6 & 49 & 7 & 38 & 2 & 295 & 179 & 260 & 439 \\
\hline $\begin{array}{l}\text { Santiago de } \\
\text { Tuna }\end{array}$ & & & & 5 & & 234 & 250 & 12 & 9 & & & 182 & 34 & 237 & 107 & 143 & 250 \\
\hline $\begin{array}{l}\text { San Andrés de } \\
\text { Tupicocha }\end{array}$ & 41 & 17 & 2 & 60 & 1 & 306 & 427 & 66 & 13 & 16 & 17 & 74 & 83 & 269 & 335 & 92 & 427 \\
\hline San Damián & 36 & 50 & 2 & 9 & & 356 & 453 & 31 & 3 & 271 & 9 & 4 & 1 & 319 & 357 & 96 & 453 \\
\hline Huarochirí & 210 & 31 & 5 & 8 & 3 & 297 & 554 & 26 & & 2 & & 8 & & 36 & 426 & 128 & 554 \\
\hline Langa & 53 & & & 11 & 1 & 253 & 318 & 226 & 28 & 2 & 1 & - & - & 257 & 242 & 76 & 318 \\
\hline Cuenca & 6 & & & 4 & 3 & 132 & 145 & 47 & 2 & 2 & - & 2 & 3 & 56 & 89 & 56 & 145 \\
\hline $\begin{array}{l}\text { Santo } \\
\text { Domingo de } \\
\text { los Olleros }\end{array}$ & 118 & & 81 & 292 & 29 & 321 & 841 & 133 & 2 & 4 & 10 & 1 & 10 & 160 & 271 & 570 & 841 \\
\hline
\end{tabular}

Fuente: ( Instituto Metropolitano de Planificación, 2013)

La información mostrada sobre los índices de calidad de vida del valle sitúan al distrito de Pachacamac como el más pobre de Lima Metropolitana, además hacia el 2007 un porcentaje importante de su población no tenía alumbrado eléctrico ni contaba con 
acceso a agua y desagüe; esta condición expone una realidad preocupante que solo encuentra como aliados a la educación y a la explotación sostenible de sus recursos para generar desarrollo local; siendo además imprescindible el apoyo público y privado para impulsar el acceso total a saneamiento y de ésta forma teniendo las necesidades básicas satisfechas, mejorar la calidad de vida del distrito.

\subsection{Antecedentes Históricos de los Centros Técnico Productivos}

\subsubsection{El origen de la educación técnico productiva}

La Educación Técnico-Productiva es una forma de educación orientada a la adquisición y desarrollo de competencias laborales y empresariales en una perspectiva de desarrollo sostenible, competitivo y humano, así como a la promoción de la cultura innovadora que responda a la demanda del sector productivo y a los avances de la tecnología, del desarrollo local, regional y nacional, así como a las necesidades educativas de los estudiantes en sus respectivos entornos. (Ministerio de Educación, 2015)

Actualmente en el Perú, los Centros que imparten la Educación Técnico Productiva son denominados CETPROS (Centro Técnico Productivo), son la evolución de lo que hasta el año 2008 se conoció bajo el nombre de CEO (Centro Educativo Ocupacional), y representan el nuevo modelo educacional de lo que históricamente se conoció en el mundo como Escuela de Artes y Oficios, esta última tuvo sus inicios en los gremios profesionales.

Rodrigues (2013) considera al oficio de artesano, una entidad gremial que se inicia con la civilización, donde su formación técnico practico no permitía la interacción con la sociedad con el fin de proteger el secreto de la profesión.

La historia atribuye a Numa Pompilio (716-674 a. C.), segundo rey de Roma la organización e instauración de los primeros gremios, asociación de trabajadores con un mismo oficio, en un inicio fueron nueve los fundados pero llegan a treinta durante el imperio de Constantino I. 
Es entonces el siglo VII a. C. un punto histórico clave para la investigación, pues se instituyen formalmente los oficios como tal, con normas y reglamentos internos aunque se sabe siempre limitados y excluyentes. Un artesano solo tenía la posibilidad de pertenecer a un solo gremio y había oficios como el de panadero que pasaban de generación en generación haciendo más restringida la transmisión de conocimientos, siendo estos los motivos del pausado desarrollo de estas asociaciones.

Sousa y Pereira (1988) concluyen que tradicionalmente, la enseñanza va ligada a los gremios, los artesanos se formaban mediante el trabajo el cual tenía como eje principal el aprendizaje directo de un oficio, el joven debería ser primero "aprendiz", para llegar a ser "oficial" y posteriormente "maestro" es este último, quien hacía un contrato privado con los jóvenes que estaban interesados en aprender un oficio. La imitación y práctica sostenían a este sistema docente, la transmisión de conocimientos se caracterizaban por ser rígida, razón por lo que el alumno frecuente caía en la rutina y estancamiento. (pág. 1)

Los gremios bajo estas premisas llegan a su fin hacia los siglos VII y VIII; y no es hasta los siglos XI y XII donde reaparecen pero con una concepción distinta enrumbada al crecimiento comercial y a traspasar fronteras; siguieron siendo instituciones donde se impartía conocimientos sobre las artes y oficios aunque siempre desde una posición individualista y restringida, condiciones que terminaron por obstaculizar el desarrollo económico que buscaban lograr.

\subsubsection{Europa, el origen de las escuelas de artes y oficios}

En los años 1750 a 1850 se desarrolla en Europa la primera revolución industrial, la cual significo el reemplazo del trabajo manual por el mecanizado, pues con éste último se conseguía niveles de producción inalcanzables para los artesanos de la época.

El paso del taller a la fábrica fue desalentador, muchos oficios no lograron competir con la industrialización y fueron desapareciendo, sin embargo varios de ellos lograron insertar a la máquina y terminaron adaptando el oficio a las necesidades de esta nueva era, aunque Sousa y Pereira (1988) consideran lo contrario afirmando que: "La introducción del maquinismo empeoró más la situación al relegar el trabajo 
manual, perdiéndose así el oficio" (pág. 3); considero que los autores se refieren a la pérdida del arte al desarrollar un determinado oficio, pues la maquina está diseñada para producir en serie, eliminando por completo la creatividad, herramienta principal desde los inicios de los oficios, ejercidos por los artesanos.

A lo largo de la historia, la instrucción de la clase obrera ha sido factor importante en el desarrollo de sociedades, es entonces en el siglo XVIII tras la industrialización y decadencia de los gremios cuando aprender el oficio se hace necesario, y hablo de aprender porque la realidad social en la que se vivía no permitía al obrero acceder a la educación primaria, la carencia económica aceleraba y en el peor de los casos omitía procesos, razones por las cuales se tenía en la industria obreros no calificados en el oficio y con bajo rendimiento productivo lo que concluía en salarios poco remunerados y en el pausado desarrollo industrial, limitando su progreso y perfeccionamiento. Es entonces donde aparece como solución educativa la capacitación técnico productiva, bajo el nombre de Escuela de artes y Oficios, siendo Francia el país pionero.

Sousa y Pereira (1988) consideran que es Francia el país, donde primeramente se creó el Conservatorio de Artes y Oficios y las primera Escuelas de Artes y Oficios tal cual, un antecedente de esto es la famosa Escuela Obrera de La Montagne (Oise), fundada en el año 1780, por el duque de La Rochefoucault. Napoleón transforma la antigua escuela La Montagne en la primera Escuela Imperial de Artes y Oficios lo cual es considerado como un espaldarazo oficial en el país, esta escuela estaba destinada a la formación de oficiales involucradas en la industria, específicamente para las manufacturas francesas. Luego se crearía la segunda escuela de Angers, según los autores es con la revolución de 1830 cuando ambas escuelas dejan el carácter militar para convertirse en escuelas de índole civil.

España tomo como referencia para la creación de escuelas los ejemplos de Francia y Prusia, y las experiencias útiles de Inglaterra, país donde se forma la primera escuela pública en el año 1837. Siendo Italia el país que en el año 1860 difunde con mayor énfasis la formación de estas escuelas. (pág. 2)

Pedrera (1998), explica que la educación de estas instituciones eran de tipo técnico, y se crearon con un fin específico, que era el de facilitar un nivel cultural 
fundamental que llegue a las clases sociales medias y bajas, el soporte técnico que impartían estas escuelas estaban dirigidas a generar empleo a corto plazo; la educación que impartían estaban dirigidas a las necesidades inmediatas en el país, se podría decir que estaban orientadas a favorecer las exigencias de una pequeña burguesía industrial de un mismo lugar, siendo escaso el aporte en los altos niveles del estado.

\subsubsection{Origen de la Escuela de artes y oficios en España}

\subsection{La Sociedad Económica Amigos del País}

En España hacia el siglo XVIII eran tres los principales organismos que promovían la instrucción de la clase obrera: los pocos gremios que quedaban, algunas escuelas de las juntas de comercio y la Sociedad Económica de Amigos del País, institución que jugó un rol importante en el desarrollo económico de las ciudades y fue la principal promotora de las institucionalidad de las Escuelas de Artes y Oficios.

Caballero Cortez (1986) el autor describe que la Sociedad Económica de Amigos del País, empieza alrededor de 1775. Agrupaban a la minoría selecta del país, y a hombres con voluntad de servir. La actividad de esta Sociedad se sitúa de manera particular en el dominio de la agricultura, la industria y el comercio, pero su principal objetivo era la educación, construcción de escuelas patrióticas y bibliotecas. Los ilustrados pretendían como idea fundamental, mejorar las condiciones materiales y sociales de España, y tenían como modelo la Sociedad Económica de Amigos del País para poder conseguirlo. La primera de estas fue la Sociedad Vascongada de Amigos del País, creada en 1765 , en este año hasta 1808 se crean un gran número de estas Sociedades, en casi todo el pais. (pág. 339)

En definitiva, fueron la nobleza y el clero los estamentos sociales que participaron más activamente en las Sociedades de Amigos del País, junto con una serie de personas procedentes de la administración, funcionarios, militares, profesiones liberales, una nutrida representación de hacendados, labradores, comerciantes y en menor medida algunos artesanos, de gran importancia por su 
labor de asesores en los trabajos de la sociedad. (Arias De Saavedra Alías, 2001, pág. 18)

La forma de organización de éstas sociedades fue casi la misma en todo el país, solo se encontraba diferencia en aquellas que correspondían a importantes ciudades pues como era lógico resaltaban por la elevada cantidad de socios y una sobresaliente actividad en comparación con las de pequeños pueblos; pero algo común fue según el autor Caballero Cortéz (1986) que "todas ellas se adecuaron al modelo de instituto diseñado por Campomanes en su Discurso sobre el fomento de la industria popular" (pág. 339).

Fue la Sociedad Madrinense Amigos del País, la institución que alcanzó su máximo desarrollo y se convirtió en la sede principal, encargada de supervisar y aprobar la formación de las nuevas sociedades.

La Sociedad económica de Amigos del País nace bajo dos objetivos: el de enseñanza y el económico.

Arias de Saavedra Alias (2001) señala a la enseñanza como el propósito principal de esta organización, cuya mentalidad relacionaba directamente a la educación con la mejora de la calidad de vida de la población. Bajo este pensamiento las sociedades económicas iniciarían un movimiento de renovación social bajo el lema “despensa y escuela” (pág. 23).

Para estos organismos el autor destaca también la importancia del impulso económico. El poder Central analizaba los datos referidos a población y actividades productivas de cada provincia para evaluar cuáles eran los potenciales sectores a fomentar. (pág. 27)

La Sociedad llevaba como premisa fomentar el crecimiento de las ciudades mediante la educación en pro del desarrollo económico, por esta razón los cursos impartidos en las mismas estaban estrechamente ligados a las actividades de producción da un ejemplo de esto en la ciudad de Málaga el autor Caballero Cortez (1986) “ El objetivo de fundar en esta ciudad la Sociedad Económica de Amigos del País de Málaga fue servir al Estado, fomentando la agricultura en todas sus ramas, promoviendo cuanto le sea posible al comercio, la navegación y adelantando las artes e industria popular" (pág. 341) 
Los objetivos planteados por la Sociedad Económica amigos del País instituyeron en el siglo XVIII, un método de organización que a la actualidad ejecutan los Centros Técnicos Productivos del Perú, estableciendo a la educación como generador de desarrollo social y basando su oferta educativa en las actividades productivas establecidas en el entorno de la institución para potenciar la economía de la zona.

La Sociedad económica Amigos del País fue hacia el siglo XVIII, la principal impulsadora y pionera de la formación técnica en España, la institución se preocupaba por la instrucción de la clase obrera y la prevalecía de las artes y oficios.

Fue de gran apoyo en el desarrollo social de las clases menos favorecidas, pero alcanzar sus objetivos no fue camino fácil, si bien existían fondos privados el apoyo no era suficiente y las organizaciones no se daban abasto frente a la gran demanda. El costo de enseñanza se cubría con rendimientos efectivos de producción en los talleres escuela pero estos ingresos no bastaban, se necesitaba apoyo gubernamental pues estas eran de gestión privada, también eran necesarios decretos que rijan el libre funcionamiento de estas entidades en pro de la educación y el desarrollo.

Si bien la institución de estas sociedades como organización en Andalucía data del siglo XVIII, en su mayoría es hasta un siglo después donde empiezan a educar, como fue el caso de Sevilla.

Pedrera (1998) sostiene que es en Sevilla en el año1875, cuando se imparte por primera vez, la educación aplicada a las Artes y Oficios bajo la gestión de la Real Sociedad Económica de Amigos del País. Llegaron a inscribirse más de trecientos adultos en su mayoría obreros, y dada esta demanda se empiezan las gestiones para la instalación formal de una escuela de Artes y Oficios apresurándose por real decreto del Gobierno Central en el año1886. 


\subsection{Escuela de Artes y Oficios}

Como hemos visto en lo anteriormente citado, La Sociedad Madrinense de Amigos del País fue la primera en instituirse y por consiguiente haber alcanzado su máximo desarrollo, era de esperarse que Madrid sea donde se instaure la primera Escuela de Artes y Oficios de España bajo el reconocimiento y apoyo del Gobierno y desde ese entonces empieza a replicarse en todas las comunidades autónomas del reino.

Sousa y Pereira (1988). España siguió el modelo francés, en el año 1824 se crea el Real Conservatorio de Artes en Madrid, que sirvió como inicio de la enseñanza oficial de las artes y oficios, estaba compuesta por un museo y un taller de construcciones. El programa de estudios del Conservatorio paso por diferentes reformas, siendo la más importante la del año 1850, tomando como referencia el modelo de Prusia, lo convirtió en Real Instituto Industrial, siendo este el que da lugar en 1871 a la primera Escuela Oficial de Artes y Oficios en España. (pág. 2).

Según (Blanes Nadal \& Millán Verdú, 2002-2003) era de gran importancia que las escuelas de artes y oficios se ubiquen en zonas industrializadas, pues esto aseguraba la inserción laboral futura del estudiante. "Por ello, las primeras Escuelas de Artes y Oficios se emplazaron en Cataluña, País Vasco, Asturias, Madrid y, particularmente en comarcas industriales de las que Alcoy es un claro exponente” (pág. 86).

De la enseñanza y el profesorado dentro de este tipo de instrucción se ha referido el arquitecto Bastida (1919) que de manera general es necesario la experiencia y la practica sin dejar de lado la teoría que es la base para el dominio de este aprendizaje.

Es entonces y desde la instauración de las escuelas de artes y oficios que la teoría estrechamente ligada a la práctica, es fundamental en el desarrollo productivo del estudiante técnico. Como ejemplo de los cursos impartidos en 1887 por la Escuela de Artes y Oficios de Alcoy de España, se tiene el siguiente cuadro, donde se puede apreciar que los cursos de ciencias estaban relacionados con la aplicación a las artes. 
Cuadro 2.39 Plan de estudios de la Escuela de Artes y Oficios de Alcoy

\begin{tabular}{|l|l|l|}
\hline $\begin{array}{l}\text { Curso } \\
\text { académico }\end{array}$ & Carácter & Asignatura \\
\hline $1^{\circ}$ & Troncal & $\begin{array}{l}\text { Aritmética, Geometría y Principios del } \\
\text { Arte de la Construcción }\end{array}$ \\
\hline $2^{\circ}$ & Troncal Industrial con \\
\hline $3^{\circ}$ & $\begin{array}{l}\text { Dibujo Geométrico } \\
\text { instrumentos y mano alzada }\end{array}$ \\
\cline { 2 - 3 } & $\begin{array}{l}\text { Especialidad Mecánicos } \\
\text { Artes Decorativas }\end{array}$ & Física, Química yecánica \\
\hline $4^{\circ}$ & $\begin{array}{l}\text { Especialidad } \\
\text { Artes Decorativas }\end{array}$ & Modelado y Vaciado de Adorno y Figura \\
\hline
\end{tabular}

Fuente: Blanes Nadal \& Millán Verdú, 2002-2003

Como vemos en el cuadro siguiente, los cursos teóricos impartidos eran afines a todos los oficios de la sección siendo solo las clases prácticas de conocimiento impartido específico, constituyendo de esta manera nueva forma de metodología educativa.

Es importante resaltar que estaba previsto dentro del programa la realización de visitas a fábricas locales, acercando de esta manera al estudiante a la realidad de su futura vida profesional, aprendiendo de primera mano conocimientos que jamás podrán ser impartidos en las aulas, ni en los talleres, que si bien asemejan el trabajo en la industria no enseña los verdaderos conflictos a los que el profesional se enfrentará años más tarde.

Cuadro 2.40 Relación de los alumnos matriculados en la Escuela de Artes y Oficios de Alcoy

\begin{tabular}{|l|l|l|l|}
\hline \multirow{2}{*}{ Asignaturas } & \multicolumn{3}{|l|}{ Inscripciones por Asignatura } \\
\cline { 2 - 4 } & $\begin{array}{l}\text { Estudiant } \\
\text { es }\end{array}$ & $\begin{array}{l}\text { Artesan } \\
\text { os }\end{array}$ & Total $^{\mathbf{2 9}}$ \\
\hline $\begin{array}{l}\text { Aritmética, Geometría y Principios del } \\
\text { Arte de la Construcción }\end{array}$ & $300(36)$ & $6(6)$ & $306(42)$ \\
\hline $\begin{array}{l}\text { Dibujo Geométrico Industrial con } \\
\text { instrumentos y a mano alzada }\end{array}$ & $3(3)$ & $110(16)$ & $113(19)$ \\
\hline Física, Química y Mecánica & $1(1)$ & $29(5)$ & $30(6)$ \\
\hline Dibujo de Adorno y Figura & $1(1)$ & $223(29)$ & $224(30)$ \\
\hline Modelado y Vaciado & $1(1)$ & $17(6)$ & $18(7)$ \\
\hline Total & 306 & 385 & $691(104)$ \\
\hline
\end{tabular}

Fuente: Blanes Nadal \& Millán Verdú, 2002-2003 
Cuadro 2.41 Información sobre los principales oficios de la Escuela de Artes y Oficios de Alcoy de 1888- 1901.

\begin{tabular}{|c|c|c|c|c|c|c|c|c|c|c|c|c|}
\hline Artesanos & $88 / 89$ & $89 / 90$ & $90 / 91$ & $91 / 92$ & $92 / 93$ & $93 / 94$ & $94 / 95$ & $96 / 97$ & $97 / 98$ & $98 / 99$ & $99 / 00$ & $00 / 01$ \\
\hline Albantiles & 4 & 6 & 9 & 3 & 4 & 8 & 14 & 14 & 24 & 22 & 23 & 21 \\
\hline Baberos & 7 & 5 & 1 & 0 & 0 & 0 & 0 & 0 & 0 & 0 & 0 & 0 \\
\hline Bameros & 0 & 0 & 4 & 14 & 10 & 11 & 14 & 10 & 16 & 14 & 15 & 14 \\
\hline Cagistas & 1 & 3 & 10 & 14 & 14 & 18 & 11 & 9 & 4 & 4 & 4 & 0 \\
\hline Canteros & 8 & 8 & 0 & 0 & 0 & 0 & 0 & 0 & 0 & 0 & 0 & 0 \\
\hline Caminteros & 42 & 21 & 33 & 37 & 29 & 33 & 41 & 42 & 0 & 27 & 24 & 0 \\
\hline Carajeros & 38 & 32 & 9 & 13 & 19 & 20 & 22 & 24 & 21 & 24 & 27 & 16 \\
\hline Camiscos & 0 & 0 & 0 & 4 & 3 & 4 & 2 & 3 & 0 & 0 & 0 & 0 \\
\hline Comerciantes & 0 & 0 & 1 & 13 & 10 & 17 & 18 & 11 & 12 & 10 & 11 & 12 \\
\hline Dependientes & 13 & 22 & 10 & 5 & 6 & 9 & 15 & 22 & 26 & 28 & 26 & 20 \\
\hline Ebanistas & 14 & 8 & 3 & 10 & 10 & 17 & 22 & 22 & 23 & 21 & 20 & 13 \\
\hline Escribientes & 4 & 12 & 10 & 16 & 14 & 16 & 19 & 19 & 18 & 16 & 14 & 10 \\
\hline Escultores & 0 & 2 & 3 & 19 & 17 & 22 & 16 & 16 & 15 & 12 & 14 & 11 \\
\hline Fundidores & 16 & 10 & 7 & 53 & 31 & 34 & 29 & 26 & 0 & 23 & 24 & 0 \\
\hline Quamicioneros & 0 & 0 & 3 & 2 & 2 & 4 & 3 & 4 & 3 & 3 & 3 & 1 \\
\hline Herneros & 15 & 14 & 4 & 16 & 18 & 25 & 28 & 18 & 17 & 18 & 17 & 9 \\
\hline Hiladores & 13 & 15 & 0 & 0 & 0 & 0 & 0 & 0 & 0 & 0 & 0 & 0 \\
\hline Hojdateros & 6 & 2 & 2 & 3 & 4 & 7 & 9 & 8 & 5 & 5 & 4 & 4 \\
\hline lempresores & 0 & 0 & 0 & 4 & 12 & 12 & 8 & 4 & 14 & 28 & 27 & 14 \\
\hline Litógnafos & 1 & 2 & 1 & 13 & 10 & 14 & 16 & 17 & 13 & 11 & 10 & 6 \\
\hline Maquinistas & 7 & 10 & 0 & 0 & 0 & 0 & 0 & 0 & 0 & 0 & 0 & 0 \\
\hline Marmolistas & 2 & 3 & 2 & 0 & 0 & 0 & 0 & 0 & 0 & 0 & 0 & 0 \\
\hline Operanid'Jomal ero & 22 & 18 & 10 & 14 & 16 & 21 & 15 & 20 & 14 & 13 & 19 & 29 \\
\hline Papdoros & 34 & 28 & 19 & 21 & 13 & 20 & 14 & 12 & 14 & 18 & 17 & 8 \\
\hline Panaderos & 0 & 0 & 4 & 7 & 5 & 7 & 8 & 3 & 3 & 2 & 14 & 3 \\
\hline Pintores & 10 & 4 & 10 & 22 & 20 & 21 & 11 & 2 & 8 & 8 & 4 & 5 \\
\hline Sastes & 0 & 0 & 3 & 7 & 5 & 7 & 3 & 4 & 11 & 20 & 14 & 6 \\
\hline Tapiceros & 6 & 6 & 0 & 0 & 0 & 0 & 0 & 0 & 0 & 0 & 0 & 0 \\
\hline Tejedores & 55 & 47 & 53 & 9 & $2 f$ & 40 & 53 & 40 & 50 & 80 & 61 & 33 \\
\hline Tenedores de libros & 1 & 1 & 0 & 0 & 0 & 0 & 0 & 0 & 0 & 0 & 0 & 0 \\
\hline Tintoreros & 0 & 10 & 3 & 0 & 0 & 0 & 0 & 0 & 0 & 0 & 0 & 0 \\
\hline Tomeros & 11 & 0 & 0 & 0 & 0 & 0 & 0 & 0 & 0 & 0 & 0 & 0 \\
\hline Zapateros & 10 & 12 & 5 & 4 & 3 & 4 & 5 & 5 & 6 & 6 & 8 & 7 \\
\hline SubTotal & 340 & 301 & 219 & 323 & 296 & 391 & 396 & 355 & 317 & 413 & 400 & 242 \\
\hline Otros & 11 & 7 & 2 & 41 & 42 & 58 & 43 & 40 & 77 & 36 & 20 & 23 \\
\hline Total Artesanos & 351 & 308 & 241 & 364 & 338 & 49 & 439 & 395 & 394 & 449 & 20 & 265 \\
\hline
\end{tabular}

Fuente: (Blanes \& Garrigós, 2001)

Las Escuelas de artes y oficios cambiaron entonces la concepción que se tenía socialmente sobre la instrucción del obrero, en éstas se instruía en saberes tanto teóricos como prácticos constituyendo así la sólida formación técnica del estudiante. 


\subsubsection{La transmisión de saberes de España a las Colonias Americanas}

La conquista de América data del año 1492 con la llegada de Cristóbal al continente, desde entonces Europa específicamente España inicia el proceso de colonización y con éste la transmisión de su cultura. Como lo dio a conocer Dittbor Cordua (2007) sosteniendo que España compartió con sus colonias lengua, religión costumbres, leyes y en materia de educación planes de estudio y enseñanza, es así que por intermedio del Rey se establecen acuerdos con los gremios de artesanos de diferentes oficios para que se sea viable la inserción de estas modalidades en las Colonias de América. la instrucción de oficios en Chile eran transmitidos en su mayoría por órdenes religiosas donde sobresalieron en esta enseñanza tradicional los Dominicos, Jesuitas y Salesianos. (pág. 3)

Según la Historia de la Educación Técnica UNAM (2013) sostiene que en México sobresale la Escuela de Artes y Oficios de San Jose de los Naturales, creado por misioneros como Gray Pedro de Gante, donde aparte de la religión se enseñaba escritura, lectura, latín y artes y oficios como: pintura, escultura, artesanías etc., en los talleres laboraban canteros, herreros, carpinteros, albañiles, sastres y zapateros.

Helg (1984) escribe que en Colombia los encomenderos según la ley, estaban en la obligación de crear y financiar escuelas de encomienda para los indígenas las cuales debían de administrarlas y educarlos en el idioma español, religión y trabajos artesanales. (pág. 18)

La real instauración de artes y oficios escrita por Miró Quesada Sosa (19071998) explica que es con la colonización de España donde se inicia el artesanado en el Perú; tras las reducciones indígenas del Virrey Toledo en lugares estratégicos del territorio peruano, con esta medida se logra unir nuevos trabajos a los indios. Es entonces que un grupo de artesanos españoles de la época dan un significativo aporte en la organización y desarrollo de la forma de vida económica y artística del país en donde el trabajo estaba dirigido a resaltar lo útil y bello que se elaboraba. (pág. 8) 
Los artesanos medioevales y las organizaciones religiosas fueron las encargadas de evangelizar e ilustrar a la población indígena tras la dominación de la Colonias en América; pero el fin que se persiguió por obvias razones jamás fue el desarrollo social de la clase indígena, el interés en la instrucción de la misma estaba más bien ligado a obtener mano de obra calificada, se ejercía el oficio en pro de los requerimientos de la Corona Española.

Es hacia 1810 donde las colonias empiezan a independizarse, abriendo paso a la instauración de nuevas instituciones pedagógicas de carácter público iniciándose así una nueva etapa en la educación técnica.

\subsubsection{Las Escuelas de Artes y Oficios y su evolución tras la independencia}

En el siglo XIX, en Latinoamerica, según Alvares Olivares, (2014) se instituyo la idea de "educar", como un ejercicio eficaz para consolidar el sentimiento nacional, motivo por el cual hubo una preocupación en crear escuelas para resaltar el auge a la educación, que se convirtió en un reglamento importante y sirvió como requisito primordial para el ejercicio de la ciudadanía. (pág. 100)

La proclamación de la independencia del Perú se da el 28 de Julio de 1821, por el general José de San Martin, según el autor Robles Ortiz (2004) es el libertador quien asume el gobierno del país el 03 de Agosto de 1821, suscribiendo un decreto, en el cual queda al mando político y militar de un Perú libre; adquiriendo el título de protector hasta que se decidiera la forma de gobierno y se instaure un congreso como representación nacional. Con el fin de poder administrar el estado. San Martin preparó y juramento ante una ley que denomino Estatuto Provisorio y juntamente con sus ministros dicto varios decretos en los que se incluían temas relacionados a la cultura y educación, un ejemplo de ello es la creación de la Biblioteca Nacional y la Libertad de Imprenta. (pág. 59)

Los talleres como espacios de formación que nacieron producto de las generaciones gremiales, no contaban con reglas que los sustente, San Martin tuvo la voluntad de normar este nuevo sistema educativo, creando en las capitales de cada departamento centros de enseñanza de artes y oficios, penosamente no se llevó a la práctica. 
Otro intento de poner en práctica esta idea se dio el 23 de octubre de 1849 , donde se reitera el mandato de San Martin de establecer escuelas de artes y oficios, nuevamente esta ley es dejada de lado y no logra validarse. Sin embargo, años después, 3 de julio de 1858, el Perú se encontraba en un „estado de paz ece, es ahí cuando se manda que se lleve a debido efecto la ley de 1849, pues con la naciente industria el Perú demandaba técnicos en diversas áreas. Posteriormente, en 1867, el Congreso decidió optar por otra alternativa para implantar la educación ocupacional: propuso que en cada colegio nacional de las capitales provinciales y en cada distrito funcionase una escuela dominical gratuita para artesanos. Como las normas anteriores esta tampoco llego a desarrollarse (pág. 771)

En su libro Sobre el Perú: homenaje a José Agustín de la Puente Candamo, señala que el 3 de octubre de 1860, el entonces Presidente del Perú, Ramón Castilla, creó bajo decreto supremo la Escuela de Artes y Oficios de Lima, esto significó un paso importante en la historia de la formación profesional del siglo XIX. Sin embargo; este momento tiene sus inicios con San Martin, que impulsó a los gobiernos de Castilla, Pezet, Balta, M. Pardo, Piérola y finamente culmina con José Pardo. Para Castilla primero se tenía que preparar las condiciones, materiales y personas, y luego dar inicio a la reclamada escuela. Fue gracia a esto que el 3 de octubre de 1860 se da el paso decisivo en el proceso de la Escuela de Artes y Oficios de Lima, hoy "Instituto Superior Tecnológico Público José Pardo”, se procedió a dictar clases de matemática, física, química y mecánica industrial, además se buscó construir un cuerpo de profesores a fín de que el Perú no dependiera de los extranjeros para abastecerse de profesores en un futuro; ya que en ese entonces el personal a cargo de la enseñanza en dicha institución, en su mayoría, eran extranjeros. Posteriormente, el 8 de marzo de 1864, Pezet da curso a un decreto ordenando la apertura de la EAO (Escuela de Artes y Oficios) con 50 alumnos de Lima y provincias costeñas, pues ahora esta institución debía albergar a 125 alumnos, el decreto se aprueba y el 9 de diciembre del mismo año la EAO queda bajo la dependencia del Ministerio de Gobierno. No obstante, por diversos problemas surgidos a partir del cambio de dependencia, el 12 de septiembre de 1871 el presidente Balta cambia el reglamento y la EAO pasa a depender del Ministerio de Instrucción. Con esta cambio se reafirma la finalidad de forma „ärtesanos honrados e instruidos ${ }^{\text {eece }}$ Los estudios prácticos y teóricos duran cinco años para los mecánicos, modeleros y 
fundidores y cuatro años para simples herreros, carpinteros, carroceros, calderos, etc. (pág. 781)

"El Instituto Superior Tecnológico Publico José Pardo" (2013), considerado como Alma Mater de la enseñanza Tecnológica del Perú, se creó en 1848, como escuela de Artes y Oficios por el presidente Ramón Castilla y empezó a funcionar en el año 1864, fue clausurada en 1879 debido a que todos sus talleres fueron saqueados durante la guerra con Chile.

El presidente José Pardo y Barreda lo reinstala en el año 1905 como Escuela Nacional de Artes y Oficios, y en 1945 se le dio la denominación de politécnico principal del Perú , y a partir de 1951 Politécnico Nacional "José Pardo", en 1970 cambió su nombre a, Instituto Tecnológico Nacional "José Pardo", en 1976, a Escuela de Educación Profesional. Cambia finalmente su nombre en 1983, a Instituto Superior Tecnológico Público "José Pardo", ofreciendo actualmente siete carreras profesionales. (“Instituto Superior Tecnológico Público José Pardo", 2013)

Por otro lado, en 1867, el Congreso decidió optar por otra alternativa para implantar la educación ocupacional, según Candamo (2002) se "propuso que en cada colegio nacional de las capitales provinciales y en cada distrito funcionase una escuela dominical gratuita para artesanos". Como las normas anteriores esta tampoco llegó a desarrollarse, fue recién en la época de José Balta y Manuel Prado cuando se comenzó a poner en práctica las ideas de San Martin, pues estos trataron de ligar la educación con el desarrollo ferrocarrilero. Como resultado, se crea en Ayacucho una escuela taller para capacitar en competencias propias de platería, herrería, escultura y carpintería, esto estaba dirigido a las pobladores tanto de Ayacucho como los de Cusco, Huancavelica y Junín. En 1888 y 1889 se crean las Escuelas Taller o secciones técnicas en escuelas primarias, por decreto del presidente de la república se construyen estas instituciones en los departamentos de: Lima, Callao, Arequipa, Huánuco, Cajamarca y Moyobamba.

El principal objetivo de las Escuelas Taller era 'formar artesanos entendidos y laboriosos, al mismo tiempo que el perfeccionamiento de la instrucción obligatoria'. Por tal motivo la formación se organizaba en dos secciones: una para las clases teóricas y otra para los talleres, basados en un plan de gobierno. La enseñanza duraba solo tres años y los talleres debían guardar una estrecha relación con las principales industrias 
del país; como por ejemplo, existían talleres de zapatería, sastrería, carpintería, alfarería y escultura. El dinero obtenido de las ventas de los objetos fabricados, servían para cubrir los sueldos de los jefes de taller, y los sobrantes para atender necesidades de los alumnos.

Contrariamente a los intentos fallidos por crear centros de educación ocupacional, se logra observar buenos resultados logrados por las sociedades de artesanos, por el gran éxito de estas instituciones es que en 1907 ya existían escuelas nocturnas para obreros en Arequipa, Cusco, Trujillo, Chiclayo y Piura. (pág. 772)

Sulmont, Valcarcel, y Twanama (1991) explican que hacia 1972 aproximadamente data la evolución trascendental de las escuelas taller tras la Reforma de Educación referida a la Calificación Profesional Extraordinaria, este modelo educativo no escolarizado tenía la función de la "capacitación de trabajadores para oficios específicos a través de centros particulares y estatales, denominados Centros No Estatales de Calificación Profesional Extraordinaria (CENECAPES) y los Centros Nacionales de Calificación Profesional Extraordinaria (CENACAPES)" .

Se creó la Certificación Profesional Extraordinaria para oficios específicos, no escolazrizada e impartida en centros privados y públicos (CENECAPES y CENACAPES), y en las "Unidades de Instrucción (UIs), ubicadas en las empresas de los sectores de producción y servicios. (Ley General de Educación $N^{\circ} 193272,1972$ )

Diez años después los CENECAPES Y CENACAPES dejan de existir, muchos de ellos pasan a convertirse en Centros Educativos Ocupacionales (CEO), mientras que a otros se les otorga carácter profesional de mayor nivel, instituyéndose como Instituto Superior Técnico (IST).

Se creó la Educación Ocupacional como modalidad formativa dirigida a las personas que no hubieran terminado la educación secundaria. Se imparte a través de los Centros de Educación Ocupacional (CEO), Servicios Nacionales de Capacitación Sectorial y programas de capacitación de empresas, incluidas las ex Uis. (Ley General de Educación D.S N 193272, 1982) 
El objetivo de la educación ocupacional era capacitar a adolescentes y adultos desempleados o subempleados, en ocupaciones vinculadas a las diversas ramas de la actividad productiva. Asimismo, aspiraba a facilitar la conversión profesional (a una actividad o carrera profesional) entre actividades ocupacionales afines, de acuerdo con la demanda y el desarrollo del país. Finalmente, intentó promover la eficiencia (productividad) de los trabajadores en el servicio y elevar su nivel cultural y técnico. Los CEOs organizan cursos o módulos en ocupaciones determinadas en función del diagnóstico de necesidades de su zona de influencia. La duración de los cursos es flexible, en función de las posibilidades de cada centro o programa y de los requerimientos de los usuarios. Los cursos técnicos o de actualización, perfeccionamiento y especialización, pueden tener una duración de entre 30 y 120 horas y los modulares de entre 480 y 650 horas. El contenido curricular destina 80 por ciento a la formación técnica y 20 por ciento a la parte teórica. El MINED también autoriza y regula el funcionamiento de CEOs privados, o Centros de Gestión Ocupacional no Estatal (CEOGNE). (Saavedra \& Chacaltana, 2001)

Esta modalidad educativa permitía un mayor grado de convergencia entre los sectores de Educación y Trabajo y Promoción Social, regida bajo la Ley General de Educación y como mencionó el (Ministerio de Trabajo y Promocion del empleo, 1996) : "tiene carácter formativo y busca desarrollar en el educando aptitudes, habilidades y destrezas que lo preparen para el trabajo, integrando la acción educativa con la preparación y perfeccionamiento de la actividad laboral”. (pág. 69)

Este tipo de educación buscaba que los alumnos sean capacitados en diversas ramas de la actividad productiva con el fin de cubrir la demanda del país y elevar su nivel técnico; se encargó de brindar diversos servicios, por medio del (Ministerio de Trabajo y Promocion del empleo, 1996) entre ellos: „'programas de formación básica, actualización y perfeccionamiento técnico; programas integrados a las acciones de alfabetización y a otros niveles y modalidades, y servicios de apoyo al desarrollo de la asignatura de Formación Laboral y variantes técnicas de educación secundaria eeee (pág. 70) 
Cabe mencionar que la Educación Ocupacional estuvo orientada, principalmente, hacia grupos urbano- marginales, rurales y de frontera, pues buscó que estos se adapten rápidamente a las cambiantes exigencias de capacitación planteadas por el mercado de trabajo. Los Centros de Educación Ocupacional, que estuvieron a cargo del Ministerio de Educación se denominaron escolarizados y por el tipo de gestión estatales y no estatales; los primeros promovidos y organizados por el Ministerio de Educación, mientras que los otros fueron supervisados por personas naturales o jurídicas.

Para ingresar a los centros de educación ocupacional no se necesitaba un nivel previo de estudios; sin embargo, por la naturaleza de algunos cursos eran exigidos tener ciertos requisitos académicos. Una vez concluido los cursos solicitados, aprobadas todas las asignaturas y haber asistido a por lo menos el $70 \%$ de horas de clase, el alumno recibía un Certificado de Capacitación. Asimismo todo CEO estaba obligado a contar con un Servicio de Orientación Profesional, esto permitía que el alumno pueda elegir una ocupación y al egresar pueda tener un puesto de trabajo. (Ministerio de Trabajo y Promocion del empleo, 1996)

El siguiente gráfico muestra el número de CEOs de característica pública y privada a 4 años de su institución como modalidad educativa, hacia 1986 existían ya en el Perú 790 CEOs instituidos de los cuales 421 eran públicos y 369 privados, este último número llega casi a triplicarse diez años más tarde superando por más de 300 al número de centro públicos. El gráfico nos muestra también la comparación con el número de instituciones técnicas, cifras bastante inferiores con relación a los centros de educación ocupacional, atribuyendo la mayoría de la instrucción técnica superior de la población a los CEOs de la época. 
Figura 2.22 Información sobre los principales oficios de la Escuela de Artes y Oficios de Alcoy de 1888- 1901

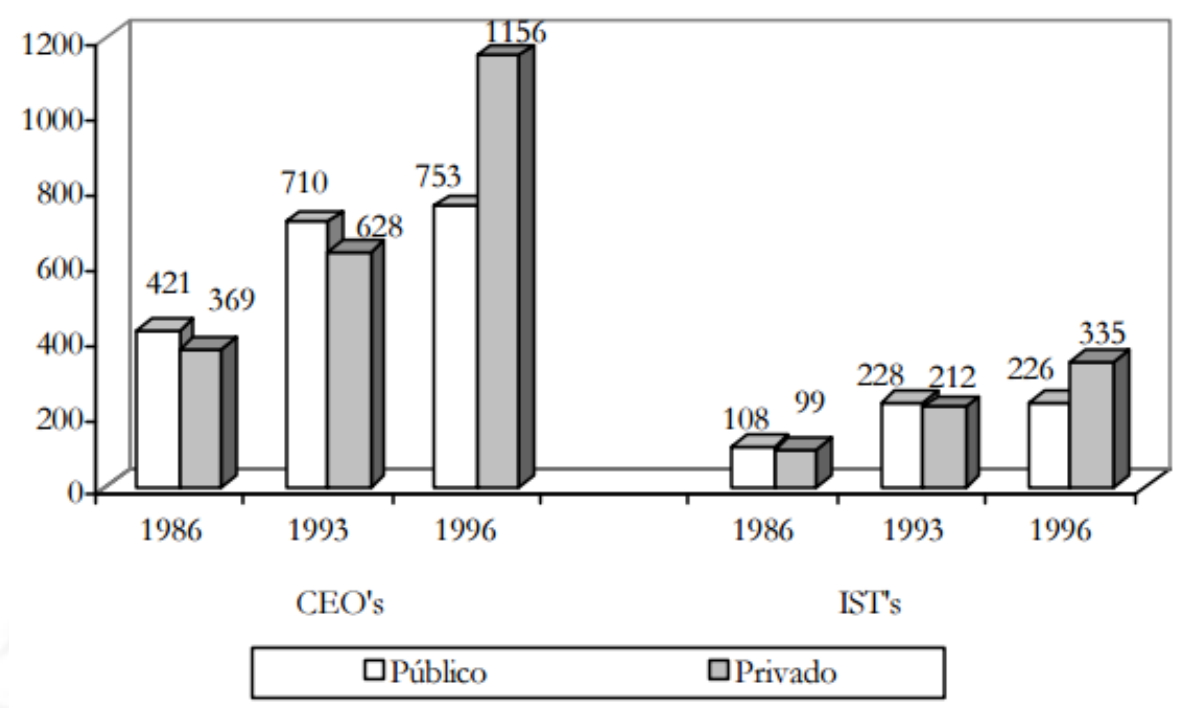

Fuente: Censo Escolar, Ministerio de Educación 1996.

En referencia a la incidencia en la matrícula en centros educativos ocupacionales, este número se eleva a 188136 alumnos a nivel nacional en el año 1993 siendo la región costa la de mayor porcentaje de matriculados, se observa casi el mismo panorama frente al año 1997 aunque aumentaron los CEOs en la costa y disminuyeron notablemente en la sierra.

Cuadro 2.42 Evolución de la matrícula por regiones según modalidades educativas en Perú

\begin{tabular}{|c|c|c|c|c|c|c|c|c|}
\hline & \multicolumn{4}{|c|}{1993} & \multicolumn{4}{|c|}{1997} \\
\hline & ISTs (1) & CEOs (2) & Total & $\%$ & ISTs(1) & CEOs (2) & Total & $\%$ \\
\hline Nivel nacional & 161.898 & 188.136 & 350.034 & 100,0 & 191.001 & 228.712 & 419.713 & 100,0 \\
\hline \multicolumn{9}{|l|}{ Región } \\
\hline Costa & 110.451 & 126.178 & 236.629 & 67,6 & 128.548 & 156.876 & 285.424 & 68,0 \\
\hline Sierra & 40.784 & 41.108 & 81.892 & 23,4 & 50.401 & 50.762 & 101.163 & 24,1 \\
\hline Selva & 8.794 & 15.398 & 24.192 & 6,9 & 12.052 & 21.074 & 33.126 & 7,9 \\
\hline
\end{tabular}

Fuente: Unidad Estadística del Ministerio de Educación 1997. 
Saavedra \& Chacaltana, (2001) escribe que el crecimiento de la oferta de los CEOs e ISTs ha estado influenciado por dos factores. En primer lugar, la demanda por cursos de capacitación se ha incrementado notablemente. A esto ha contribuido de manera decisiva el tamaño absoluto de la población de jóvenes, notablemente superior a la de décadas pasadas, y la mayor demanda por servicios de capacitación que permitían a la persona insertarse rápidamente en el mercado de trabajo. En segundo lugar, se flexibilizaron notablemente los requisitos administrativos para la constitución de entidades de capacitación.

De acuerdo con Molero (2013) en el año 2000, la Unidad de Estadísticas del MED (Ministerio de Educación) informó una serie de problemáticas en la formación técnica en el país, tales como: falta de capacitación de los docentes, infraestructura educativa deficiente, herramientas y maquinarias obsoletas, dificultad de alianzas estratégicas para las prácticas pre-profesionales, etc. Por tal motivo, es que en el 2003 se introduce una ley con el concepto de „Educación Técnico Productiva ${ }^{\text {eeee }}$, esto dio origen a los Centros de Educación Técnico Productiva- CETPRO, estas instituciones estaban a cargo de ofrecer con la debida certificación y titulación, servicios educativos para las personas con debida autorización, para el año 2005 el Ministerio de Educación, inició el proceso de conversión progresiva de los Centros de Educación Ocupacional CEO (Centros escolarizados donde se ofrecen servicios de educación ocupacional), a Centros de Educación Técnico Productivo - CETPRO, que culmina en el 2008. (pág. 18)

\subsubsection{La educación técnico productiva en la actualidad}

La educación técnico productiva en el mundo a la actualidad sigue siendo un medio eficaz en la transmisión de conocimientos prácticos para el trabajo además de ser un importante instrumento de desarrollo social sobre todo para poblaciones vulnerables y sectores marginales. 
Varios son los casos tangibles de acupuntura urbana donde un Centro de Educación Técnico Productiva ha transformado totalmente a la comunidad, otorgándole mejoras en la calidad de vida mediante la inserción laboral, tal es el caso del CEDEZO (Centro de Desarrollo Zonal) del Centro de Desarrollo Cultural de Moravia, Colombia 2008, institución dedicada a incentivar el emprendimiento en la población mediante programas productivos referidos a actividades artísticas y creativas; en el 2011 en Cambodia se terminaba de construir la Escuela Vocacional Sra Pou, misma que lleva el nombre de la comunidad donde se ejecutó el proyecto que imparte actualmente enseñanza sobre oficios de costura, cosmetología y mecánica. El Centro de Formación para la Sostenibilidad en Marruecos construido hacia el año 2013 también es un reciente ejemplo de desarrollo local, su idea radicó en aprovechar la construcción en tierra como actividad productiva local, para instruir a la población en técnicas de constructivas sostenibles, otorgándole un valor agregado a su producción; en el año siguiente en Costa Rica se construyó el Centro de Capacitación Indígena Käpäcläjui, destinado la enseñanza de actividades relacionadas al fomento del turismo en la región.

Un país que tiene como prioridad importante la educación, asegura una población que utilizará el conocimiento como herramienta de desarrollo. En el Perú existen aún poblaciones que no han tenido acceso a Educación Básica Regular, lo que les impide continuar estudios superiores y en pro de hacer inclusiva la educación se crean los Centros de Educación Técnico Productivos.

Según el INEI (2014)

'La educación es un proceso de aprendizaje y enseñanza que se desarrolla a lo largo de toda la vida y que contribuye a la formación integral de las personas, al pleno desarrollo de sus potencialidades, a la creación y al desarrollo de la familia y de la comunidad nacional, latinoamericana y mundial. . " (pág. 9) 
En el Perú, la institución encargada de normar y orientar la formación educativa es el Ministerio de Educación, su función principal es supervisar, implementar y formar la política nacional de educación. Por otro lado, la educación formal y no formal está establecida bajo la Ley General de Educación según INEI (2014) La educación formal se da de manera escolarizada y no escolarizada y a través de diferentes modalidades y niveles, por lo que su contenido es evaluable y certificable. Asimismo, la educación no formal, está consolidada bajo las reglas del autoaprendizaje, donde los agentes educativos muchas veces son la familia, el centro de trabajo, las agrupaciones políticas, etc.

Figura 2.23 Educación en el Perú

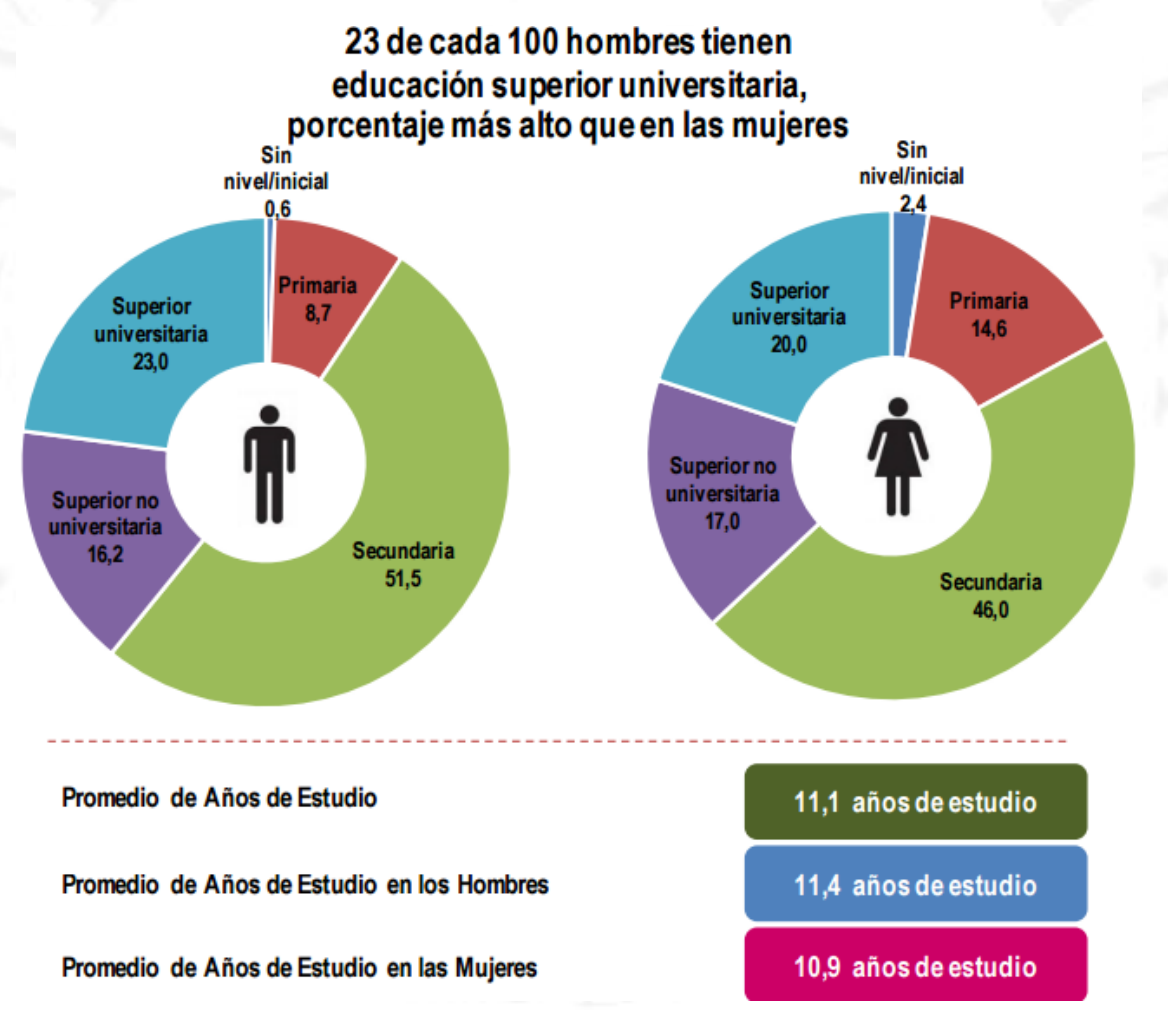

Fuente: Instituto Nacional de Estadística e Informática-Encuesta Nacional de Hogares. 2013 
Figura 2.24 : Población que no estudia ni trabaja Provincia de Lima

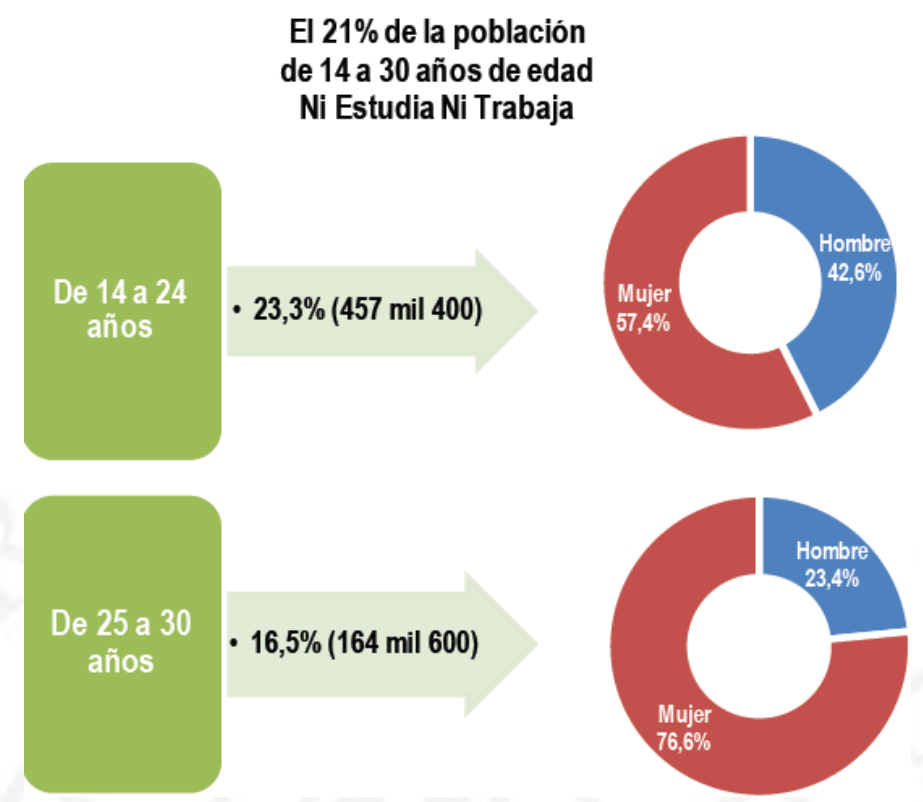

Fuente: Instituto Nacional de Estadística e Informática-Encuesta Nacional de Hogares. 2013

\subsubsection{Centros de Educación Técnico Productiva}

El Ministerio de Educación del Perú tiene bajo su poder tres conjuntos de instituciones formativas: los Colegios Secundarios con Variante Técnica (CSVT), los Institutos Superiores Tecnológicos (IST) y los Centros Técnico Productivos (CETPRO).

El Ministerio de Trabajo y Promoción del Empleo (1996) señala que el programa educativo de Secundaria con Variante Técnica o Secundaria Diversificada se constituyó en 1945, una época en la cual la política buscaba incentivar la formación técnica de los trabajadores peruanos; pero fue recién en 1982 y bajo la Ley General de Educación que se determinó que este tipo de instrucción tendría una duración de cinco años. Los dos primeros años comprendían la formación general y la orientación vocacional, y los tres siguientes la formación diversificada la que comprendía áreas como: artesanal, agropecuaria, comercial e industrial. (pág. 210). El documento también expone información sobre los Institutos Superiores Tecnológicos (IST), los cuales brindan servicios en educación superior tecnológica desde 1982; éstos sustituyeron a las Escuelas Superiores de Educación Profesional, creadas en los años setenta. Los ISTs 
ofrecen los mismos servicios que sus antecesores, pero llegaron a ampliar los requisitos académicos, pues representaron una alternativa post-secundaria preparando a sus alumnos en aspectos humanistas y científicos; definiéndose a este tipo de educación como: "El cuarto nivel del sistema educativo que comprende la educación profesional y el cultivo de las más altas manifestaciones de la técnica'’. (pág. 213)

Se ha realizado una descripción superficial con respecto a los Colegios Secundarios con Variante Técnica y a los Institutos Superior Tecnológicos pues el tema central de la investigación es la Educación Técnico Productiva; nivel educativo que se define a continuación.

\subsection{Definición}

La Dirección Regional de Educación (2016), describe a la Educación TécnicoProductiva como un sistema educativo indicada para el logro de conocimientos y desarrollo de los diferentes retos laborales y empresariales, bajo una óptica orientada al avance sostenible, y humanamente competitivo, promocionando una cultura innovadora acorde con el avance tecnológico local, regional o nacional del sector productivo.

Los Centros de Educación Técnico Productiva tienen su modalidad educativa enmarcada bajo la Ley General de Educación №28044, están ubicados dentro de la educación superior técnica referida al nivel básico. Tienen por finalidad impartir enseñanza de carácter técnico productivo, es decir capacita a los alumnos difundiendo conocimientos sobre mecanismos y procedimientos relacionados al ejercicio de un oficio ligado a una actividad que involucre la producción de bienes o servicios, contribuyendo de esta forma a mejorar en el alumno su nivel de empleabilidad y desarrollo personal insertándolo en el mercado laboral.

La educación técnico productiva está dirigida a todos los niveles socioeconómicos de la población pero presta especial atención a los más vulnerables y de menores recursos, en su mayoría ubicados en el ámbito rural y sectores marginales.

La Dirección de Educación Superior Tecnológica y Técnico Productiva (DESTP), según Canales Arévalo \& Sabelino Torres (2008) establece como objetivos: El desarrollo de destrezas laborales y capacidades para realizar un trabajo operativo impulsando la innovación y el emprendimiento en actividades productivas; así como 
formar alumnos de calidad con la capacidad de enfrentar responsabilidades donde se desempeñe profesionalmente. (pág. 9)

La educación que se imparte en estos centros se basa en tres enfoques: cultural, productivo y afectivo.

El enfoque cultural hace referencia al contexto donde se inserta la modalidad educativa pues este condiciona las pautas de desarrollo del centro que debe estar siempre vinculado a las "potencialidades y proyecciones de desarrollo de la comunidad y/o la región, así como a las características y necesidades de las personas involucradas, tomando en cuenta su diversidad cultural, étnica y lingüística” (pág. 10)

El enfoque productivo expone que es también fin de la educación técnico productiva desarrollar capacidades en los alumnos que les permitan en el futuro ejercer eficientemente una profesión relacionada a la producción de bienes o a la prestación de servicios, así mismo velar por instruir sobre gestión empresarial y emprendimiento a los estudiantes, conocimientos que les permitirán competir con éxito en el mercado laboral al momento de iniciar su propio negocio.

Sobre el enfoque afectivo se dice que el CETPRO deberá fomentar el desarrollo de actitudes y valores que asegurarán que el alumno pueda en un futuro desenvolverse con ética profesional en su centro laboral.

El Ministerio de Educación (2005) señala en la Educación Técnico-Productiva las siguientes características: pertinente, flexible, innovador, promotor de la cultura y desarrollo de actividades productivas. (pág. 2)

Los CETPRO tienen como función brindar asistencia educativa a adolescentes, jóvenes, adultos y personas con necesidades educativas de especial atención, el estudiante espera que esta institución le permita desarrollar sus intereses vocacionales, sus potencialidades laborales y su capacidad de emprendimiento; busca además perfeccionar, formalizar y darle valor técnico a aprendizajes ocupacionales de previo conocimiento; esperan mediante este sistema validar sus estudios y que se le otorgue reconocimiento a sus experiencias laborales. 


\subsection{Ejes transversales}

Esta modalidad educativa se sustenta en Ejes Transversales específicos, Canales Arévalo \& Sabelino Torres (2008) definen a estos ejes como situaciones que afectan los distintos espacios y agentes de la comunidad educativa como problemáticas actuales y sociales relevantes, son determinados por la institución educativa u organizaciones representativas de la localidad en función de los requerimientos de cada participante. Estos ejes en síntesis tienen como fin construir y afianzar conocimientos, desarrollar capacidades éticas y generar un vínculo de la institución con su contexto, involucrando al estudiante con su realidad actual brindando herramientas para mejorar su calidad de vida. (pág. 12)

El Currículo de Educación Técnico-Productiva tiene como Ejes Transversales a: la ciudadanía, encargada de promover los derechos de la persona; el medio ambiente, dirigido a su preservación; la equidad, propiciando la inclusión y la interculturalidad relacionada a la importancia de la diversidad étnica y cultural. (págs. 12-13)

Estos ejes transversales son importantes dado que son los lineamientos que deben de seguir estos centros de enseñanza.

\subsection{Organización}

Los CETPROs, en conformidad con la ley educativa bajo la cual se ampara está organizada en dos ciclos: Ciclo Básico y Ciclo Medio.

Se trata de dos tipos distintos de educación, no está limitado a un carácter secuencial pues no se necesita haber culminado el Ciclo Básico para proseguir con el Ciclo Medio, ambos ciclos son autónomos e independientes y el egresado que haya culminado cualquiera de estos se encuentra listo para ser insertado en el mercado laboral.

Canales (2007) define al Ciclo Básico como la instrucción educativa que. "Provee al estudiante de las competencias laborales y capacidades necesarias para ejecutar trabajos de menor complejidad en los sectores de la economía local, regional y nacional que le permitan incorporarse al mercado ocupacional” (pág. 10) 
El Ministerio de Educación (2005) señala que no es requisito en el Ciclo Básico los estudios básicos escolares, deben de contar con capacidades para el aprendizaje del trabajo no complicado. Es obligatorio contar con un sistema de módulos que aseguren el logro de los conocimientos impartidos y de esta manera insertar al alumno en el campo laboral.

Con referencia al Ciclo Medio, Canales (2007) explica que éste brinda al alumno capacidades que le permitirán ejercer una actividad ocupacional especializada, además "Contribuye a un mejor desempeño de la persona que trabaja, a mejorar su nivel de empleabilidad y su desarrollo personal” (pág. 10).

Para tener acceso al ciclo medio según el Ministerio de Educación (2005) pide como requisito una capacidad laboral equivalente al nivel educativo Primaria o al ciclo intermedio de la Educación Básica Alternativa dado que en este ciclo se requiere el trabajo de una labor especializada, deben ser impartidos en módulos afines, que unidos formen una especialidad Técnico Productiva que sustenten el perfil técnico del profesional.

Los CETPRO pueden elegir entre brindar enseñanza a solo un Ciclo específico o a ambos simultáneamente, pues esta modalidad organizacional también es permitida. Con respecto a la convalidación de estudios esta puede darse siempre y cuanto se presenten certificados oficiales que argumenten tal instrucción.

\subsection{Gestión}

Para el funcionamiento de los CETPROs, es necesaria la autorización otorgada por la Dirección Regional de Educación previa aprobación de la UGEL responsable de su jurisdicción.

Según el Ministerio de Educación (2005) El centro basará su gestión en lo establecido dentro de su Proyecto Educativo Institucional (PEI) elaboración que involucraría tanto a "la comunidad educativa a, representantes del gobierno local y regional, sectores productivos de su entorno, gremios laborales y organizaciones sociales" teniendo en cuenta sobre todo a las necesidades y expectativas del contexto y ámbito de influencia del proyecto educativo. (pág. 7)

Son características de la gestión de los Centros de Educación Técnico-Productiva: 
Definir las necesidades y perspectiva de la Educación Técnico-Productiva en su área de dominio, mediante el apoyo de los sectores de Trabajo y Promoción del Empleo se hace el estudio de factibilidad total de oferta y demanda, para de esta forma sustentar el Proyecto Educativo Institucional (PEI)

Perfeccionar, promover y apoyar la tecnología productiva, organizando programas de pasantías, investigación e innovación de nuevas tecnologías, así como estrategias de aprendizaje adaptados a la producción.

Respaldar y cumplir la labor técnico pedagógica de la Educación Básica Alternativa y Regular y de Gestión Institucional, participando en sistemas de cooperación con instituciones educativas locales. (págs. 8-9)

El cumplimiento del PEI en los Centros Educativos Técnico Profesionales será evaluado y supervisado por el Consejo Educativo Institucional, entidad que representa un órgano de participación, concertación y vigilancia ciudadana, contribuyendo así a una gestión eficiente enmarcada dentro de la ética y la democracia.

\subsection{Presupuesto y financiamiento}

En relación a la educación impartida en los centros de variante técnico productiva, esta es gratuita y financiada en su totalidad por el estado, en competencia quienes establecen el presupuesto destinado en relación al presentado dentro del Proyecto Educativo Anual y del Plan Anual de Trabajo elaborados y ejecutados por cada institución. La condición de este modelo educativo fomenta la producción en talleres de los cursos impartidos como metodología practica de enseñanza, el reglamento establece como recursos propios a todas las utilidades obtenidas bajo este sistema.

\subsection{Certificación, titulación y registro}

Los CETPROs están autorizados a otorgar certificados de estudios que comprueben los conocimientos del oficio impartido que le otorguen un valor legal con el fin de insertarse en el mercado laboral como trabajador activo. Los certificados de estudio 
corresponderán a cada módulo ocupacional aprobado, sea de Ciclo Básico o Medio, este documento según el Ministerio de Educación (2005) detallará “las competencias laborales, capacidades terminales logradas y cantidad de horas efectivas de aprendizaje” (pág. 10)

El Ministerio de Trabajo y Promoción del empleo es el organismo encargado de evaluar el proceso de Certificación Ocupacional, amparado en el D.S. N022-85-TR en mérito al conocimiento adquirido y a la enseñanza de formación profesional producto del desarrollo de habilidades y destreza de los participantes.

\subsection{Técnicas para el desarrollo de un Ciclo Modular}

Con respecto al Diseño Curricular Básico de la Educación Técnico-Productiva, se organiza en módulos y cada uno comprende un paquete específico de conocimientos, está orientado a una opción laboral determinada y posee carácter terminal.

Los alumnos que al terminar el Ciclo Básico o Medio, logren completar las competencias de formación establecidas y tengan sus prácticas pre-profesionales, obtendrán el certificado del módulo, respectivo a la ocupación estudiada.

El Ciclo Modular Básico tiene tres componentes: Formación específica, complementaria y Práctica pre-profesional. La Formación específica cuyo referente es el Catalogo Nacional de Títulos y Certificaciones se encarga de promover en los alumnos métodos, técnicas y éticas; y su planificación está orientada a la producción de bienes o prestación de servicios, originado por ideas, recursos o materias primas.

La formación complementaria está diseñada para que una vez culminado sus estudios, los alumnos estén aptos para el desarrollo empresarial y logren un puesto de trabajo independiente en el mercado local, regional o nacional.

La práctica pre-profesional es de índole obligatorio, siendo necesario un total del $30 \%$ de horas por modulo, este componentes es importante porque mediante estas prácticas se consolida los conocimientos teórico prácticos alcanzados. 


\subsection{Estrategias para determinar la oferta formativa en los CETPROs}

Existen cuatro pasos para determinar la oferta formativa en los Centros Técnico Productivos, los cuáles se detallan y explican en el siguiente cuadro:

Cuadro 2.43 Estrategias Formativas de Ofertas en los CETPROs

\begin{tabular}{|l|l|}
\hline $\begin{array}{l}\text { Primer paso: Estudio de la demanda laboral } \\
\text { local y regional. }\end{array}$ & $\begin{array}{l}\text { Consultar los planes de desarrollo de la localidad } \\
\text { y/o región. }\end{array}$ \\
\hline $\begin{array}{l}\text { Segundo paso: Articulación referente } \\
\text { productivo y referente educativo. }\end{array}$ & $\begin{array}{l}\text { Consultar el Catálogo Nacional de Títulos y } \\
\text { Certificaciones y el Diseño Curricular Básico de la } \\
\text { Educación Técnico-Productiva: Ciclo Básico. }\end{array}$ \\
\hline $\begin{array}{l}\text { Tercer paso: Requerimientos mínimos de las } \\
\text { instituciones educativas. }\end{array}$ & $\begin{array}{l}\text { Requisitos básicos: Infraestructura, docente } \\
\text { Capacitado, equipamiento y características del } \\
\text { estudiante. }\end{array}$ \\
\hline $\begin{array}{l}\text { Cuarto paso: Determinación de la oferta } \\
\text { formativa. }\end{array}$ & $\begin{array}{l}\text { Módulos ocupacionales, tomando como referente } \\
\text { el Catálogo Nacional de Titulos y Certificaciones. }\end{array}$ \\
\hline
\end{tabular}

Fuente: Guía de orientación para la programación modular: ciclo básico

Para el Estudio de la demanda laboral local y regional es necesario realizar un análisis del entorno con el fin de identificar las actividades productivas locales que se encuentran desempeñando en la actualidad y que signifiquen potenciales ejes de desarrollo; bajo esta premisa se tomaron los datos desarrollados sobre la economía del Valle del Lurín y en específico del distrito de Pachacamac, donde se ha podido observar que la agricultura es una importante actividad productiva en la zona y que el promover su desarrollo otorgándole un valor agregado al producto agrícola, va a repercutir no solo en la mejora de los niveles socioeconómicos de la población local, sino también en la mejora de la calidad de vida a nivel provincia, con la preservación de éstas áreas verdes.

Como segundo paso es necesaria la articulación entre referente productivo y referente educativo, por lo que ya identificadas las necesidades de capacitación ocupacional se hace una comparación entre éste y la oferta educativa inscrita en el Catálogo Nacional de Títulos y Certificaciones.

Como ejemplo, el Ministerio de Educación (2005) explica cómo puede darse ésta relación en el siguiente gráfico: 
Figura 2.25: Ejemplos sobre la relación existente entre una actividad productiva y los módulos ocupacionales.

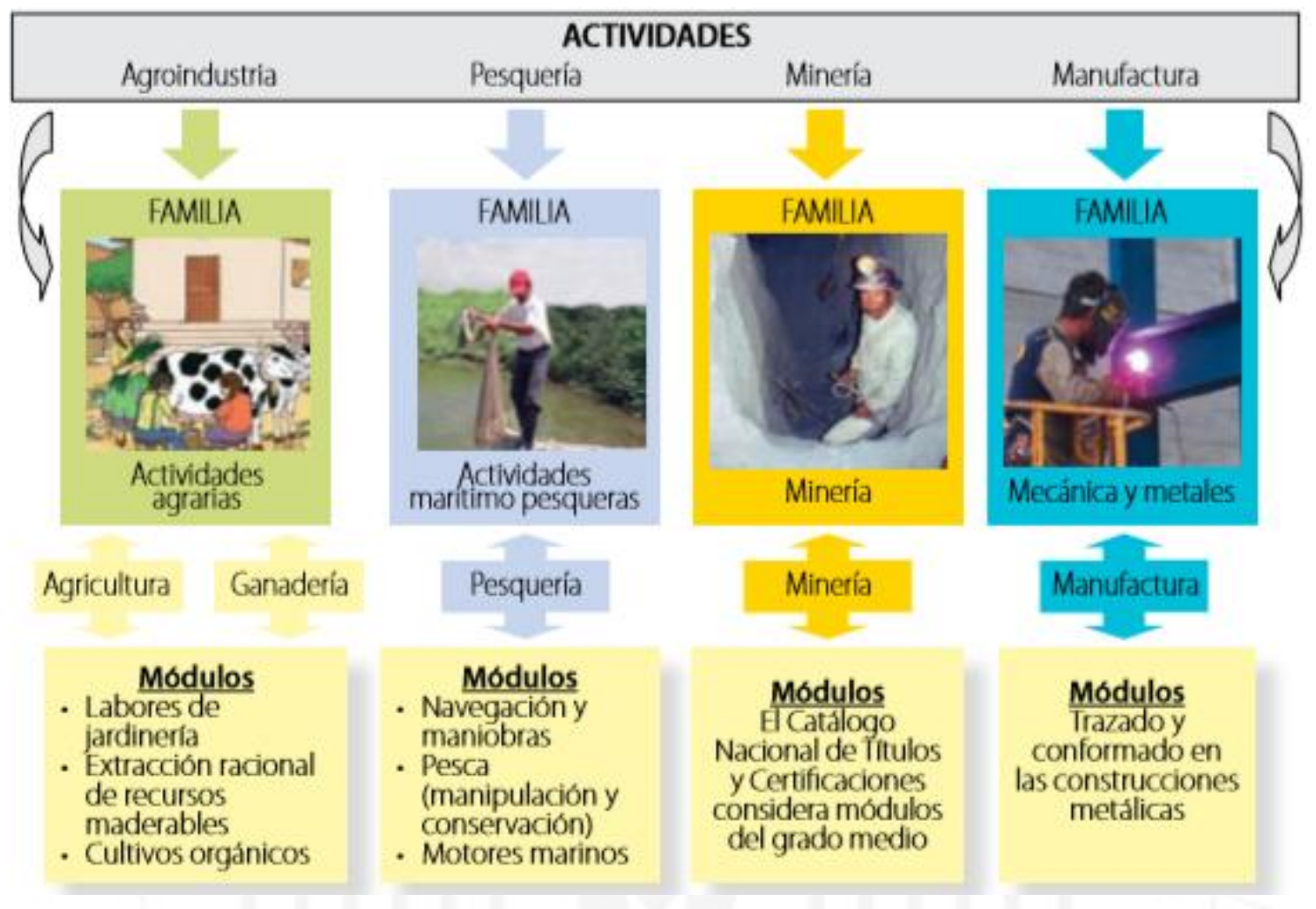

Fuente: Guía de Orientación para la Programación Modular

Como Requerimientos mínimos de un Centro Técnico Educativo, es necesario resaltar que éste deberá contar con la demanda del mercado laboral de la localidad o región para asegurar de esta manera la inserción del egresado, el mismo deberá contar también con infraestructura adecuada para el módulo a ofertar referida a estructura y espacios arquitectónicos funcionales y confortables, información que se desarrollará en el Capítulo de Marco Normativo.

Canales Arévalo \&Sabelino Torres (2008) señala al respecto: “Los talleres deben tener áreas de seguridad e higiene delimitadas y una correcta ambientación, en función a las características de las opciones ocupacionales y/o módulos a ofertarse" (pág. 23).

También deberá contar con equipamiento adecuado que responda a las condiciones del oficio, además de docentes preparados y actualizados en relación a las nuevas tecnologías productivas. 
Una vez cumplidos los pasos anteriores se procederá a determinar la oferta formativa del CETPRO que tendrá como referente al Catálogo Nacional de Títulos y Certificaciones que es un documento estructurado en familias, títulos profesionales, certificaciones modulares y niveles de formación.

Siendo entonces la agroindustria el eje de desarrollo que seguiría el Centro Técnico Productivo Lomas de Lúcumo, pertenecería según el Catálogo Nacional de Títulos y Certificaciones a la Familia de Actividades Agrarias, siendo los Módulos a impartir los siguientes:

- Procesamiento de frutas

- Agricultura de Costa ( En Laderas)

- Agricultura Orgánica

- Jardinería

- Manejo de Instalaciones Hortofrutícolas

La formación Profesional-técnica según Canales Arévalo \&Sabelino Torres (2008) se organiza en tres grados continuos dentro del catálogo: elemental o de habilitación laboral, medio y superior, estos se caracterizan por garantizar las demandas del mundo productivo y se determinan en base al trabajo tecnológico, estructurado e independencia profesional.

\subsection{Importancia de la práctica pre- profesional para la educación técnico productiva}

La producción de bienes y/o servicios empresariales que desarrollan los Centros de Educación Técnico-Productiva constituye parte del proceso de enseñanza y aprendizaje. Sirve para contribuir a la formación técnico-profesional de los estudiantes y es una fuente de financiamiento complementaria para fortalecer las capacidades institucionales. Los procedimientos pertinentes se establecerán por norma expresa del Ministerio de Educación.

Las prácticas pre-profesionales y pasantías laborales sirven para reforzar el desarrollo de las competencias laborales y capacidades en una situación real de aprendizaje en el 
mundo del trabajo. Se realizan en talleres o empresas, como parte del desarrollo del currículo formativo.

Los Centros de Educación Técnico-Productiva según el Ministerio de Educación (2005) promoverán actividades productivas en sus planes y programas de desarrollo, teniendo en cuenta su capacidad instalada y potencial humano calificado y ejes de desarrollo local y regional. Tanto las actividades productivas como las prácticas preprofesionales tienen por finalidad: completar la formación integral, fortalecer las competencias emprendedoras de gestión y autogestión y fortalecer las capacidades teniendo como prioridad el mantenimiento, la modernización y equipamiento de los CETPROs. (pág. 9)

\subsection{Análisis cuantitativo de la Educación Técnico Productiva}

En el Perú en la última proyección realizada hacia el 2013 con respecto a educación técnico productiva eran un total de 1853 el número de CETPROS en todo el país, incluyendo públicos, privados y de convenio; el gráfico siguiente muestra que desde el 2004 este número viene descendiendo aunque no a gran escala.

Se destaca además que esta modalidad educativa supera la demanda por la educación denominada no universitaria que incluye a la formación magisterial, la educación tecnológica y la artística que suman un total de 1002 instituciones. 
Cuadro 2.44 Centros educativos, según nivel y modalidad, Perú 2004 - 2013

\begin{tabular}{|c|c|c|c|c|c|c|c|c|c|c|}
\hline Nivel / Modalidad & 2004 & 2005 & 2006 & 2007 & 2008 & 2009 & 2010 & 2011 & 2012 & 2013 \\
\hline Total & 83361 & 87090 & 89665 & 91744 & 92370 & 93720 & 94954 & 96611 & 94947 & 104467 \\
\hline A. Educación básica regular & 79852 & 83501 & 85620 & 87341 & 87992 & 88438 & 89887 & 91939 & 90617 & 99611 \\
\hline Educación inicial $1 /$ & 33253 & 35701 & 37046 & 38078 & 38472 & 39717 & 40490 & 41961 & 42173 & 48444 \\
\hline Educación primaria $2 /$ & 35276 & 35944 & 36220 & 36458 & 36567 & 36566 & 36949 & 37198 & 35917 & 37753 \\
\hline Educación secundaria 2 & 11323 & 11856 & 12354 & 12805 & 12953 & 12155 & 12448 & 12780 & 12527 & 13414 \\
\hline B. Educación no universitaria & 1046 & 1062 & 1094 & 1112 & 1116 & 1133 & 1117 & 1008 & 943 & 1002 \\
\hline Formación magisterial & 349 & 349 & 347 & 346 & 341 & 329 & 317 & 213 & 188 & 218 \\
\hline Educación tecnológica & 660 & 674 & 704 & 722 & 732 & 762 & 759 & 756 & 720 & 748 \\
\hline Educación artística & 37 & 39 & 43 & 44 & 43 & 42 & 41 & 39 & 35 & 36 \\
\hline C. Educación especial $2 /$ & 446 & 449 & 450 & 458 & 456 & 459 & 462 & 461 & 441 & 469 \\
\hline . Escolarizada & 400 & 399 & 400 & 403 & 403 & 405 & 407 & 402 & 382 & 409 \\
\hline No escolarizada & 46 & 50 & 50 & 55 & 53 & 54 & 55 & 59 & 59 & 60 \\
\hline D. Educación téenico productiva & 2,017 & 2,078 & 2,211 & 2,240 & 2,161 & 2,013 & 1,849 & 1,862 & 1,644 & 1,853 \\
\hline E. Básica alternativa 3/ & 0 & 0 & 290 & 593 & 645 & 1677 & 1639 & 1341 & 1302 & 1532 \\
\hline
\end{tabular}

Fuente: Ministerio de Educación (MINEDU) - Censo Escolar - Unidad de Estadística Educativa.

A continuación se analiza el número de centros técnicos productivos del sector público del país cantidad que se eleva hacia el 2013 a 758 representado el $41 \%$ de la oferta nacional, su aumento desde el 2004 fue pausado con un pequeño descenso en el 2011 pero aun así logra sumar un número significativo hacia el 2013 con respecto al año anterior a este. 
Cuadro 2.45 Centros educativos públicos según nivel y modalidad, Perú2004 - 2013

\begin{tabular}{|c|c|c|c|c|c|c|c|c|c|c|}
\hline Nivel / modalidad & 2004 & 2005 & 2006 & 2007 & 2008 & 2009 & 2010 & 2011 & 2012 & 2013 \\
\hline Total & 64141 & 66099 & 67337 & 69097 & 69485 & 70174 & 70879 & 72205 & 71681 & 78590 \\
\hline A. Educación básica regular & 62443 & 64420 & 65352 & 66741 & 67120 & 67702 & 68486 & 69794 & 69439 & 76125 \\
\hline Educación inicial $1 /$ & 26601 & 28478 & 29288 & 30032 & 30280 & 31019 & 31470 & 32585 & 33065 & 38212 \\
\hline Educación primaria 2/ & 28614 & 28684 & 28550 & 28739 & 28783 & 28920 & 29104 & 29138 & 28356 & 29434 \\
\hline Educación secundaria 2 & 7228 & 7258 & 7514 & 7970 & 8057 & 7763 & 7912 & 8071 & 8018 & 8479 \\
\hline B. Educación no universitaria & 440 & 441 & 453 & 469 & 472 & 484 & 488 & 476 & 460 & 480 \\
\hline Formación magisterial & 123 & 119 & 118 & 122 & 123 & 120 & 120 & 108 & 110 & 115 \\
\hline Educación tecnológica & 286 & 288 & 300 & 311 & 314 & 330 & 334 & 334 & 319 & 333 \\
\hline Educación artística & 31 & 34 & 35 & 36 & 35 & 34 & 34 & 34 & 31 & 32 \\
\hline C. Educación especial $2 /$ & 372 & 359 & 359 & 377 & 375 & 380 & 381 & 385 & 371 & 397 \\
\hline . Escolarizada & 327 & 311 & 310 & 323 & 323 & 327 & 326 & 326 & 371 & 337 \\
\hline No escolarizada & 45 & 48 & 49 & 54 & 52 & 53 & 55 & 59 & 0 & 60 \\
\hline D. Educación técnico productiva & 886 & 879 & 890 & 926 & 882 & 752 & 728 & 740 & 687 & 758 \\
\hline E. Básica alternativa $3 /$ & 0 & 0 & 283 & 584 & 636 & 856 & 796 & 810 & 724 & 830 \\
\hline
\end{tabular}

$1 /$ Incluye centros educativos en programas de articulación.

2 Incluye centros educativos de menores y de adultos.

3/ Es una modalidad de la Educación Básica Regular.

Fuente: Ministerio de Educación (MINEDU) - Censo Escolar - Unidad de Estadística Educativa. 
Lista de CETPROS en la provincia de Lima según UGEL que lo administra, distrito y tipo de gestión:

Figura 2.26 Mapa de los distritos que abarca cada UGEL en Lima metropolitana

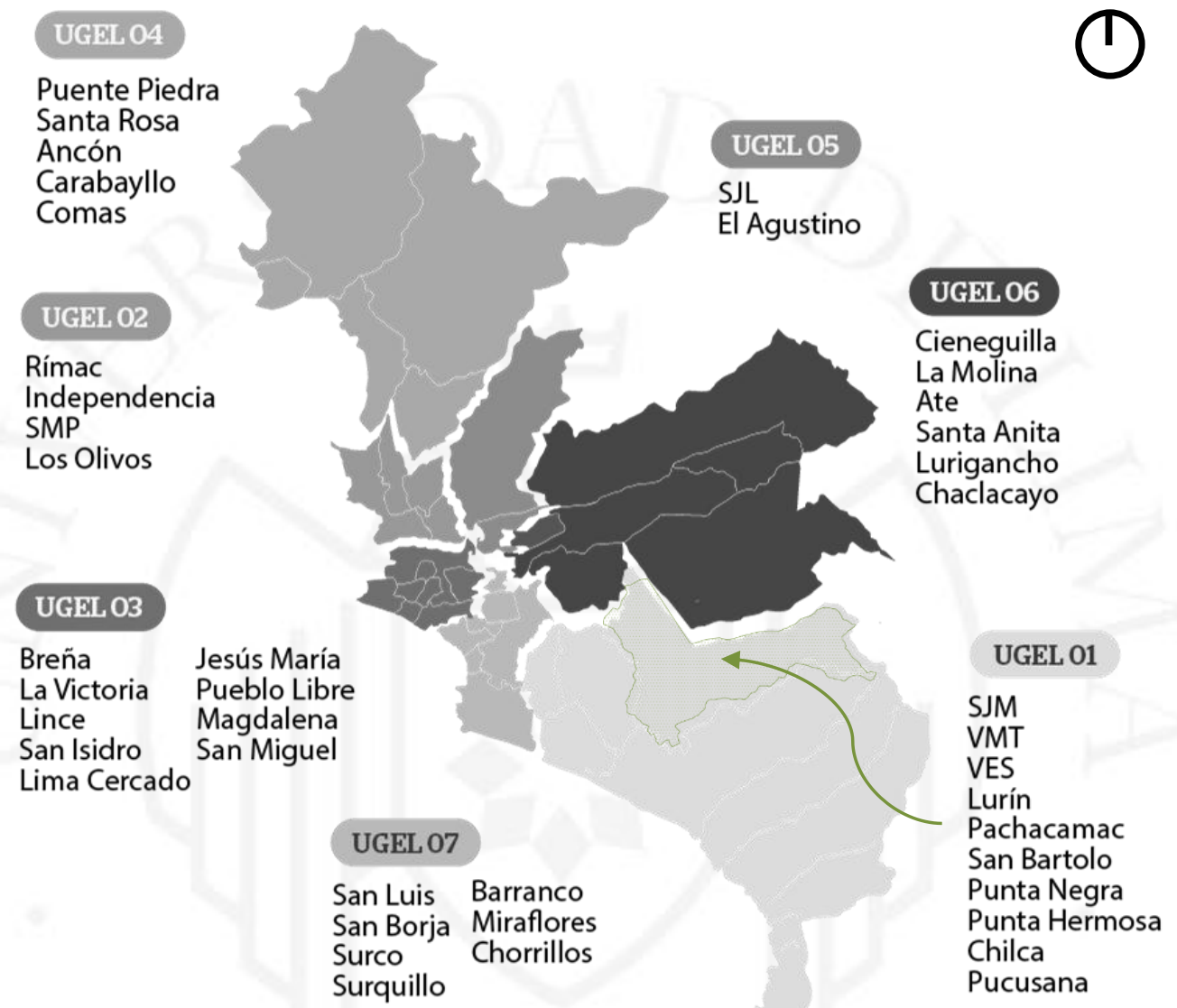

Fuente: Ministerio de Educación 


\section{Cuadro 2.46 : Lista de CETPROS UGEL $N^{\circ} 1$}

\begin{tabular}{|c|c|c|c|c|}
\hline UGEL & DISTRITO & NOMBRE DEL CETPRO & GESTIÓN & DIRECCION \\
\hline \multirow{26}{*}{ 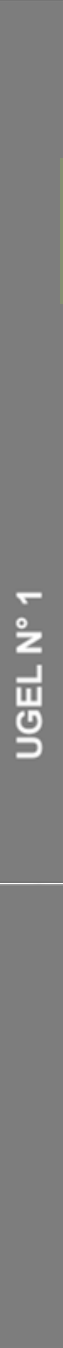 } & LURIN & JOSÉ FAUSTINO SÁNCHEZ CARRIÓN & PÚBLICA & JIRÓN CASTILLA SIN,5TA/C \\
\hline & LURIN & NAZARETH & CONVENIO & CALLE LOS MANZANOS MZ. F2 LOTE 6A. \\
\hline & LURIN & SANTISIMA TRINIDAD & CONVENIO & SAN PEDRO 133 LURIN. \\
\hline & PACHACAMAC & MUNDO LIBRE & CONVENIO & $\begin{array}{l}\text { AV.RIO LURIN ESQ CALLE } 2 \text { Y } 3 \text { FUNDO CASA BLANCA } \\
\text { PARCELA } 82\end{array}$ \\
\hline & PACHACAMAC & PADRE JOSÉ LUIS IDIGORAS GOYA & CONVENIO & $\begin{array}{l}\text { AV. MANCHAY STN PLAZA PRINCIPAL DE MANCHAY } \\
\text { COSTADO COMISARIA }\end{array}$ \\
\hline & PACHACAMAC & VIRGEN DEL PILAR & CONVENIO & JR. EL COMERCIO -PACHACAMAC \\
\hline & $\begin{array}{l}\text { SAN JUAN DE } \\
\text { MIRAFLORES }\end{array}$ & YACHAYHUASI & PÚBLICA & AV. CENTENARIO SNN VIRGEN DEL BUEN PASO \\
\hline & $\begin{array}{l}\text { SAN JUAN DE } \\
\text { MIRAFLORES }\end{array}$ & PEDRO PAULET & PÚBLICA & AV. SAN JUAN 1410 - CIUDAD DE DIOS \\
\hline & $\begin{array}{l}\text { SAN JUAN DE } \\
\text { MIRAFLORES }\end{array}$ & VIRGEN DEL ROSARIO & PÚBLICA & ASOCIACIÓN DE VIVIENDA 27 DE JULIO MZ. D LT. 21 \\
\hline & $\begin{array}{l}\text { SAN JUAN DE } \\
\text { MIRAFLORES }\end{array}$ & MARGARITA GONZALES DANKER & PÚBLICA & $\begin{array}{l}\text { AVENIDA DANIEL TIMORAN, CUADRA 1, SAN JUAN, } \\
\text { ZONAA }\end{array}$ \\
\hline & $\begin{array}{l}\text { SAN JUAN DE } \\
\text { MIRAFLORES }\end{array}$ & LA INMACULADA & CONVENIO & AV. BAMBAREN Y SOLIDARIDAD STN \\
\hline & $\begin{array}{l}\text { SAN JUAN DE } \\
\text { MIRAFLORES }\end{array}$ & SAGRADO CORAZON DE JESÚS & CONVENIO & MZ. G6 LT 28 SECTOR 5 DE MAYO \\
\hline & $\begin{array}{l}\text { VILLA EL } \\
\text { SALVADOR }\end{array}$ & 7215 NACIONES UNIDAS & PÚBLICA & SECTOR 3,GRUPO 31, MZ C 6 LT.8 \\
\hline & $\begin{array}{l}\text { VILLA EL } \\
\text { SALVADOR }\end{array}$ & PROMAE VES & PÚBLICA & AV. BOLIVIAR GRUPO 1697 SECTOR 3 \\
\hline & $\begin{array}{l}\text { VILLA EL } \\
\text { SALVADOR }\end{array}$ & LA INMACULADA CONCEPCIÓN & PÚBLICA & SECRTOR 6, GRUPO 4, MZ C1 L2B, PARQUE CENTRAL \\
\hline & $\begin{array}{l}\text { VILLA EL } \\
\text { SALVADOR }\end{array}$ & MARIAA AUXILIADORA & PÚBLICA & CARRETERA CENTRAL MZ K1 LOTE 0218 SECTOR I \\
\hline & $\begin{array}{l}\text { VILLA EL } \\
\text { SALVADOR }\end{array}$ & JAVIER PÉREZ DE CUELLAR & PÚBLICA & AV. LAS AMÉRICAS GR 14 MZ C SECTOR 3 \\
\hline & $\begin{array}{l}\text { VILLA EL } \\
\text { SALVADOR }\end{array}$ & LA MEDALLA MILAGROSA & PÚBLICA & PARQUE CENTRAL 27 SECTOR 3 \\
\hline & $\begin{array}{l}\text { VILAEEL } \\
\text { SALVADOR } \\
\end{array}$ & SANTA RAFAELA & CONVENIO & AV. REVOLUCIÓN S/N SECTOR 3, GRUPO 15 \\
\hline & $\begin{array}{l}\text { VILLA MARIA DEL } \\
\text { TRIUNFO }\end{array}$ & JOSÉ GÁLVEZ BARRENECHEA & PÚBLICA & AV. LIMA 503 JOSÉ GÁLVEZ \\
\hline & $\begin{array}{l}\text { VILLA MARIA DEL } \\
\text { TRIUNFO }\end{array}$ & VIRGEN DEL CARMEN & PÚBLICA & JIRÓN 160 MZ 24 ICA / JR. ABANCAY \\
\hline & $\begin{array}{l}\text { VILLA MARIA DEL } \\
\text { TRIUNFO }\end{array}$ & SAN FRANCISCO & PÚBLICA & $\begin{array}{l}\text { AV. SAN MARTIN MZ E LOTE } 7 \text { PRIMER SECTOR - } \\
\text { TABLADA DE LURIN }\end{array}$ \\
\hline & $\begin{array}{l}\text { VILLA MARIA DEL } \\
\text { TRIUNFO }\end{array}$ & VILLA JARDIN & PÚBLICA & AV. LAS BEGONIAS CD 2 I ZONA VILLA JARDÍN \\
\hline & $\begin{array}{l}\text { VILLA MARIA DEL } \\
\text { TRIUNFO } \\
\end{array}$ & SAN GABRIEL & PÚBLICA & AV. JOSÉ DE LA MAR 267, SAN GABRIEL ALTO \\
\hline & $\begin{array}{l}\text { VILLA MARIA DEL } \\
\text { TRIUNFO }\end{array}$ & FE Y ALEGRIA 23 & CONVENIO & AV. GARCILAZO DE LA VEGA 156 \\
\hline & $\begin{array}{l}\text { VILLA MARIA DEL } \\
\text { TRIUNFO }\end{array}$ & VILLAREGIA & CONVENIO & $\begin{array}{l}\text { JJOSE DE LA TORRE UGARTE SNN LOTE } 60 \\
\text { (FRENTE LA PARROQUIAA LA TRINIDAD) }\end{array}$ \\
\hline
\end{tabular}

Fuente: Ministerio de Educación 


\section{Cuadro 2.47 Lista de CETPROS UGEL N²}

\begin{tabular}{|c|c|c|c|}
\hline INDEPENDENCIA & SANTA MARIA MAZZARELLO & PÚBLICA & JR. PISAC N` $199 \mathrm{~B}$ \\
\hline INDEPENDENCIA & BUEN PASTOR & CONVENIO & $\begin{array}{l}\text { CALLE HECTOR REVOREDO SIN VICTOR RAUL HALLA } \\
\text { DE LA TORRE }\end{array}$ \\
\hline LOS OLIVOS & SAN MARCOS & PÚBLICA & CALLE 04 MZ F L 21 ASOC. DE VIVIENDA EL OLIVAR \\
\hline LOS OLIVOS & VILLA DEL NORTE & PÚBLICA & PASANE PEDRO HELMES - LOS OLIVOS \\
\hline RIMAC & NSTRA. SEÑORA DELOS ANGELES & CONVENIO & JR. PATROCINIO 164. \\
\hline RIMAC & SANTO DOMINGO SAVIO & CONVENIO & JR. MADERA 401 \\
\hline RIMAC & 18 AVA. DIVISIÓN BLINDADA & PÚBLICA & AV. PROLONGACIÓN ELESPURU SIN \\
\hline RIMAC & PROMAE RIMAC & PÚBLICA & AV. SAMUEL ALCAZAR N 351 A \\
\hline $\begin{array}{l}\text { SAN MARTIN DE } \\
\text { PORRES } \\
\end{array}$ & LOS LIBERTADORES & PÚBLICA & MZ. N L5 URB. S/N LOS LIBERTADORES \\
\hline $\begin{array}{l}\text { SAN MARTIN DE } \\
\text { PORRES }\end{array}$ & PERU & PÚBLICA & $\begin{array}{l}\text { JR. PEDRO GENARO DELGADO (ALT. 39 JOSE } \\
\text { GRANDA) }\end{array}$ \\
\hline $\begin{array}{l}\text { SAN MARTIN DE } \\
\text { PORRES }\end{array}$ & PROMAE CONDEVILLA & PÚBLICA & JR. MAX UHLE N² 2402 \\
\hline $\begin{array}{l}\text { SAN MARTIN DE } \\
\text { PORRES } \\
\end{array}$ & ROSA DE AMÉRICA & PÚBLICA & JR. ANTÓN SANCHEZ N 312 \\
\hline $\begin{array}{l}\text { SAN MARTIN DE } \\
\text { PORRES }\end{array}$ & SAN MARTIN DE PORRES & PÚBLICA & JR. SANTA CLORINDA N` 971,2 DA ETAPA DE PALAO \\
\hline
\end{tabular}

Fuente: Ministerio de Educación

\section{Cuadro 2.48 Lista de CETPROS UGEL N 3}

\begin{tabular}{|c|c|c|c|}
\hline BREÑA & $\begin{array}{l}\text { CENTRO FOLCLORICO DEL } \\
\text { MAGISTERIO }\end{array}$ & PÚBLICA & JR. HUANTAR 140 \\
\hline BREÑA & PROMAE BREÑA & PÚBLICA & CALLE FRANCISCO MAZZOCCHIO 179 \\
\hline BREÑA & REPÚBLICA DE CHILE & PÚBLICA & JR GENERAL VARELA 1637 \\
\hline BREÑA & MARIA AUXILIADORA & CONVENIO & AV. BRASIL 450 \\
\hline BREÑA & POLITECNICO SALECIANO & CONVENIO & AV. BRASIL 210 \\
\hline CERCADO DE LIMA & LA MEDALLA MILAGROSA & CONVENIO & JR. PUNO 1717 \\
\hline CERCADO DE LIMA & NUESTRA SEÑORA DE MONSERRAT & CONVENIO & JR. LIMA 653 \\
\hline JESUS MARIA & SANTA VICENTA MARIA & CONVENIO & AV. OLAVEGOYA 1821 \\
\hline LA VICTORIA & EL PORVENIR & PÚBLICA & AV. 28 DE JULIO 1952 \\
\hline LA VICTORIA & MANUELA FELICIA GÓMEZ & PÚBLICA & JR. MENDOZA MERINO 590 \\
\hline LA VICTORIA & NUESTRA SEÑORA DE GUADALUPE & PÚBLICA & ITALIA 1357 \\
\hline LA VICTORIA & $\begin{array}{l}\text { PROMAE ESCUELA NACIONAL DE } \\
\text { ARTES GRAFICAS }\end{array}$ & PÚBLICA & JR. GARCIA NARANJO 647 \\
\hline LIMA & 16 ALMIRANTE MIGUEL GRAU & PÚBLICA & BLOCK 46 A UNIDAD VECINAL N 03 \\
\hline LIMA & $\begin{array}{l}\text { CASA DEL NIÑO TRABAJADOR - } \\
\text { SAN MARTIN DE PORRES - PNP }\end{array}$ & PÚBLICA & JR. PUNO N`412 \\
\hline LIMA & CORCOVADO & PÚBLICA & JR. MOQUEGUA 377 PISO 2 \\
\hline LIMA & OCTAVA DIVISIÓN DE INFANTERIAA & PÚBLICA & AV. PASEO DE LA REPÚBLICA 874 \\
\hline LIMA & PILOTO FEMENINO DE LIMA & PÚBLICA & JR. MANUEL DEL PINO 169 \\
\hline $\begin{array}{l}\text { MAGDALENA DEL } \\
\text { MAR }\end{array}$ & MAGDALENA & PÚBLICA & JR. LEONCIO PRADO 686 \\
\hline $\begin{array}{l}\text { MAGDALENA DEL } \\
\text { MAR }\end{array}$ & PROMAE MAGDALENA & PÚBLICA & JR. CUZCO 620 \\
\hline $\begin{array}{l}\text { MAGDALENA DEL } \\
\text { MAR }\end{array}$ & LA MILAGROSA & CONVENIO & CALLE SAMUEL BELARDE 110 \\
\hline $\begin{array}{l}\text { MAGDALENA DEL } \\
\text { MAR }\end{array}$ & $\begin{array}{l}\text { COMP EDUC EXP AUGUSTO PEREZ } \\
\text { ARANIBAR }\end{array}$ & PÚBLICA & AV. PÉREZ ARANIBAR 650 \\
\hline PUEBLO LIBRE & FRANCISCO GARCÍA CALDERÓN & PÚBLICA & AV. SAN MARTIN 1377 \\
\hline PUEBLO LIBRE & SAN LUCAS & CONVENIO & JR. MOREIRA Y LIRIOS 197 \\
\hline SAN MIGUEL & NUESTRA SEÑORA DEL CARMEN & PÚBLICA & AV. LIBERTAD 1951 \\
\hline
\end{tabular}


Fuente: Ministerio de Educación

\section{Cuadro 2.49 Lista de CETPROS UGEL N 4}

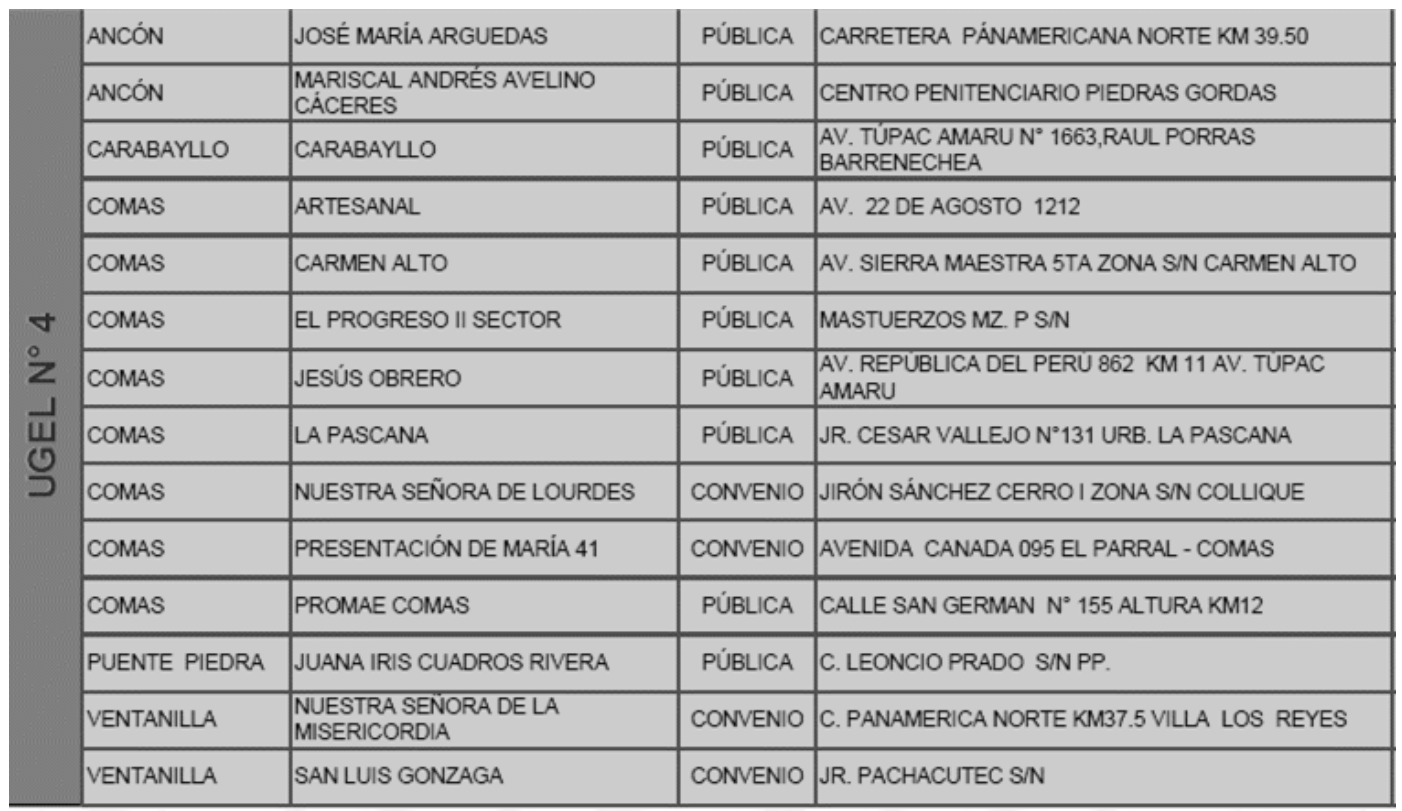

Fuente: Ministerio de Educación

\section{Cuadro 2.50 Lista de CETPROS UGEL N ${ }^{\circ} 5$}

\begin{tabular}{|c|c|c|c|}
\hline EL AGUSTINO & 1045 NUESTRA SEÑORA DE FÁTIMA & PÚBLICA & JR. AGUAS VERDES S/N \\
\hline EL AGUSTINO & BARBONES & PÚBLICA & JR. LLAMELLIN 330 \\
\hline Sال & 090 DANIEL ALCIDES CARRIÓN & PÚBLICA & AV. PRINCIPAL SIN \\
\hline SIL & BAYOVAR & PÚBLICA & AV. 1 DE MAYO SNNBAYÓVAR \\
\hline Sاl & HUANTA & PÚBLICA & MZ. PLOTE 13 HUANTA \\
\hline Sال & INDUSTRIAL SAN CARLOS & PÚBLICA & JR. GALAXIA YEL SOL SNN \\
\hline SIL & JESÚS OROPEZA CHONTA & PÚBLICA & JESÚS OROPEZA CHONTA MZ. H LOTE 4 \\
\hline SIL & JOSÉ OLAYA & PÚBLICA & $\begin{array}{l}\text { AV. SANTA ROSA SIN - PENAL SAN PEDRO - } \\
\text { LURIGANCHO }\end{array}$ \\
\hline Sal & JUAN PABLO II & PÚBLICA & $\begin{array}{l}\text { AV. SANTA ROSA SIN - PENAL SAN PEDRO- } \\
\text { LURIGANCHO }\end{array}$ \\
\hline SL & MANGOMARCA & PÚBLICA & AV. TEMPLO DE LUNA S/N \\
\hline SLL & MICAELA BASTIDAS & PÚBLICA & JR. JOSÉ ANTONIO ENCINAS S 400 \\
\hline SIL & NÉSTOR ESCUDERO OTERO & PÚBLICA & AV. PROLONGACIÓN WIESSE SIN \\
\hline SIL & SAGRADA FAMILIA & PÚBLICA & AV. MZ. L, LOTE 16 URB. SAN IGNACIO \\
\hline SIL & SEÑOR DE LOS MILAGROS & PÚBLICA & JR. AGUA MARINA 121 \\
\hline SlL & TÉCNICO SAN HILARIÓN & PÚBLICA & CALLE LAS MANDRÁGORAS 417 SAN HILARIÓN \\
\hline Sال & FE Y ALEGRIA 25 & CONVENIO & AV. MACHUPICCHU SIN CANTO GRANDE \\
\hline SLL & FE Y ALEGRIA 32 & CONVENIO & AV. EL MERCADO S/N \\
\hline
\end{tabular}

Fuente: Ministerio de Educación 
Cuadro 2.51 Lista de CETPROS UGEL Nº

\begin{tabular}{l|l|l|l|l|}
\hline & ATE & HUAYCAN & PÚBLICA & UNIDAD COMUNAL DE VIVIENDA LOTE 01 ZONA A \\
\cline { 2 - 5 } & ATE & VICTOR RAÚl HAYA DE LA TORRE & PÚBLICA & CALLE PRINCIPAL SIN \\
\cline { 2 - 5 } & UURIGANCHO & NICOLÁS DE PIÉROLA & PÚBLICA & AV. LIMA SUR 1592 \\
\cline { 2 - 5 } & SANTA ANITA & NSTRA. SEÑORA DE LA MERCED & CONVENIO & JR. JOSÉ CARLOS MARIATEGUI 355 - UNIVERSAL \\
\cline { 2 - 5 } & LA MOLINA & LA MOLINA & CONVENIO & CALLE LAS ALMENDRAS MZ. I, LOTE 1, MONTERRICO
\end{tabular}

Fuente: Ministerio de Educación

Cuadro 2.52 Lista de CETPROS UGEL N ${ }^{\circ} 7$

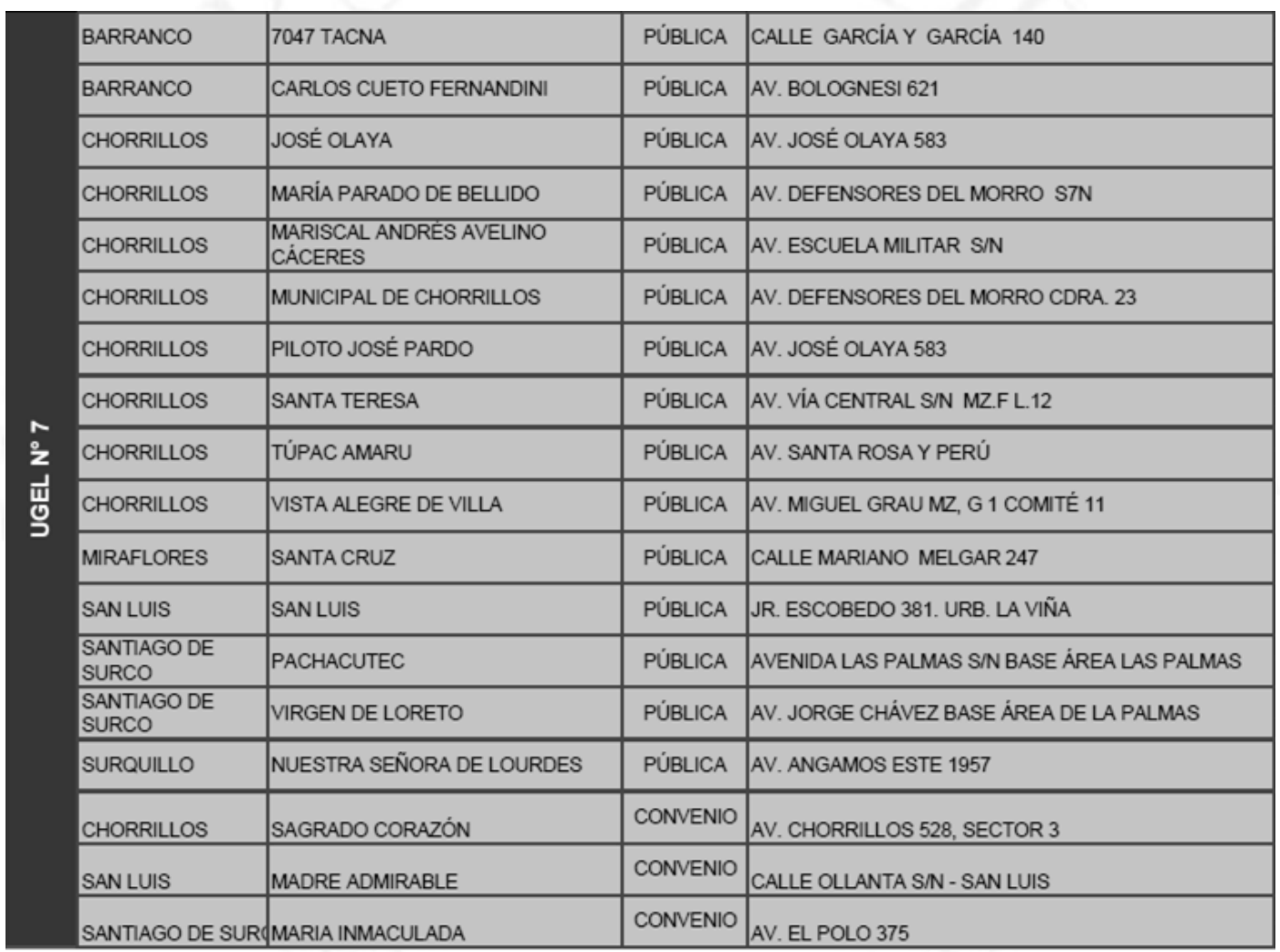

Fuente: Ministerio de Educación

En lo que respecta a la provincia de Lima, analizada en el cuadro siguiente, la educación técnico productiva suma un total de 432 instituciones representando el $23 \%$ de la oferta nacional en este modelo educativo, el distrito con mayor número de centros es el distrito de Lima con 49 instituciones, seguida de San Juan de Lurigancho y Comas. Los distritos con menor número son La Molina y Pachacamac con dos CETPROS cada uno y Cieneguilla con uno ; el distrito de Chaclacayo no presenta este 
modelo al igual que los balnearios de Pucusana, Punta Hermosa, Punta Negra, San Bartolo, Santa María del Mar y Santa Rosa.

Cuadro 2.53 Número de instituciones educativas del sistema educativo, por etapa, modalidad y nivel educativo, Provincia de Lima según distrito, 2013

\begin{tabular}{|c|c|c|c|c|c|c|}
\hline \multirow{2}{*}{ Distriro } & \multirow{2}{*}{$\begin{array}{l}\text { Básica } \\
\text { Especial }\end{array}$} & \multirow{2}{*}{$\begin{array}{l}\text { Técnico- } \\
\text { Productiva }\end{array}$} & \multicolumn{4}{|c|}{ Superior No Universitaria } \\
\hline & & & Total & Pedagógica & Tecnológica & Artistica \\
\hline Total & 100 & 432 & 206 & 33 & 168 & 5 \\
\hline Lima & 6 & 49 & 39 & 5 & 32 & 2 \\
\hline Ancón & 1 & 3 & - & - & - & - \\
\hline Ate & 2 & 19 & 5 & - & 4 & 1 \\
\hline Barranco & 2 & 2 & 1 & - & 1 & - \\
\hline Breña & 1 & 11 & 7 & 3 & 4 & - \\
\hline Carabayllo & 2 & 4 & 2 & - & 2 & - \\
\hline Chaclacayo & 1 & - & 2 & 1 & 1 & - \\
\hline Chorrillos & 4 & 16 & 2 & - & 2 & - \\
\hline Cieneguilla & - & 1 & 1 & - & 1 & - \\
\hline Comas & 4 & 29 & 3 & 2 & 1 & - \\
\hline El Agustino & 2 & 3 & - & - & - & - \\
\hline Independencia & 2 & 6 & 2 & - & 2 & - \\
\hline Jesús Maria & 1 & 17 & 12 & 2 & 10 & - \\
\hline La Molina & 3 & 2 & 5 & 2 & 3 & - \\
\hline La Victoria & 1 & 10 & 4 & 1 & 3 & - \\
\hline Lince & - & 17 & 9 & 1 & 8 & - \\
\hline Los Olivos & 3 & 25 & 8 & - & 8 & - \\
\hline Lurigancho & 2 & 12 & 2 & - & 2 & - \\
\hline Lurin & 2 & 3 & 2 & - & 2 & - \\
\hline Magdalena del Mar & 2 & 6 & 5 & 1 & 4 & - \\
\hline Miraflores & 4 & 25 & 18 & 1 & 16 & 1 \\
\hline Pachacámac & - & 2 & 3 & 1 & 2 & - \\
\hline Pucusana & 1 & - & - & - & - & - \\
\hline Pueblo Libre & 1 & 6 & 5 & - & 5 & - \\
\hline Puente Piedra & 4 & 6 & 4 & 1 & 3 & - \\
\hline Punta Hermosa & - & - & - & - & - & - \\
\hline Punta Negra & - & - & - & - & - & - \\
\hline Rímac & 1 & 4 & - & - & - & - \\
\hline San Bartolo & 1 & - & - & - & - & - \\
\hline San Borja & 5 & 9 & 4 & - & 4 & - \\
\hline San Isidro & - & 16 & 17 & - & 17 & - \\
\hline San Juan de Lurigancho & 9 & 31 & 8 & 4 & 4 & - \\
\hline San Juan de Miraflores & 4 & 17 & 6 & 1 & 5 & - \\
\hline San Luis & 2 & 5 & - & - & - & - \\
\hline San Martín de Porres & 4 & 13 & 6 & 2 & 4 & - \\
\hline San Miguel & 2 & 9 & 5 & 1 & 4 & - \\
\hline Santa Anita & - & 5 & 1 & - & 1 & - \\
\hline Santa María del Mar & - & - & - & - & - & - \\
\hline Santa Rosa & - & - & - & - & - & - \\
\hline Santiago de Surco & 11 & 15 & 7 & 1 & 6 & - \\
\hline Surquillo & 3 & 10 & 1 & - & - & 1 \\
\hline Villa El Salvador & 2 & 13 & 5 & 2 & 3 & - \\
\hline Villa Maria del Triunfo & 5 & 11 & 5 & 1 & 4 & - \\
\hline
\end{tabular}

Fuente: Ministerio de Educación - Censo Escolar. 
En referencia a la oferta de CETPROS de carácter público en la provincia de Lima se tiene que suman en total 95, poco menos de la cuarta parte de la oferta nacional, el mayor número de ellos se ubica en el distrito de San Juan de Lurigancho con 15 centros, en la lista le siguen Chorrillos con 8 y Comas con 7, mientras que Pachacamac y Cieneguilla no cuentan con ningún centro técnico productivo público hasta la fecha.

Cuadro 2.54 Número de instituciones educativas públicas, por etapa, modalidad y nivel educativo, Provincia de Lima según distrito, 2013

\begin{tabular}{|c|c|c|c|c|c|c|}
\hline \multirow{2}{*}{ Distriro } & \multirow{2}{*}{$\begin{array}{r}\text { Básica } \\
\text { Especial }\end{array}$} & \multirow{2}{*}{$\begin{array}{l}\text { Técnico- } \\
\text { Productiva }\end{array}$} & \multicolumn{4}{|c|}{ Superior No Universitaria } \\
\hline & & & Total & Pedagógica & Tecnológica & Artistica \\
\hline Total & 70 & 95 & 28 & 3 & 23 & \\
\hline Lima & 6 & 6 & 4 & 1 & 2 & 1 \\
\hline Ancón & - & 2 & - & - & - & \\
\hline Ate & 2 & 2 & 1 & - & 1 & \\
\hline Barranco & 2 & 2 & 1 & - & 1 & \\
\hline Breña & 1 & 3 & - & - & - & \\
\hline Carabayllo & 2 & 2 & - & - & - & \\
\hline Chaclacayo & 1 & - & 1 & - & 1 & \\
\hline Chorrillos & 3 & 8 & 1 & - & 1 & \\
\hline Cieneguilla & - & - & 1 & - & 1 & \\
\hline Comas & 3 & 7 & 1 & - & 1 & \\
\hline EIAgustino & 2 & 2 & - & - & - & \\
\hline Independencia & 2 & 1 & - & - & - & \\
\hline Jesús Maria & 1 & - & 1 & - & 1 & \\
\hline La Molina & 1 & 1 & - & - & - & \\
\hline La Victoria & 1 & 4 & 2 & - & 2 & \\
\hline Lince & - & - & - & - & - & \\
\hline Los Olivos & 1 & 2 & 1 & - & 1 & \\
\hline Lurigancho & 2 & 1 & 1 & - & 1 & \\
\hline Lurin & 2 & 1 & 1 & - & 1 & \\
\hline Magdalena del Mar & 2 & 3 & - & - & - & \\
\hline Miraflores & 1 & 1 & - & - & - & \\
\hline Pachacámac & - & - & - & - & - & \\
\hline Pucusana & 1 & - & - & - & - & \\
\hline Pueblo Libre & - & 1 & 1 & - & 1 & \\
\hline Puente Piedra & 4 & 1 & - & - & - & \\
\hline Punta Hermosa & - & - & - & - & - & \\
\hline Punta Negra & - & - & - & - & - & \\
\hline Rimac & 1 & 2 & - & - & - & \\
\hline San Bartolo & 1 & - & - & - & - & \\
\hline San Borja & 1 & - & - & - & - & \\
\hline San Isidro & - & - & - & - & - & \\
\hline San Juan de Lurigancho & 9 & 15 & 1 & - & 1 & \\
\hline San Juan de Miraflores & 3 & 4 & 1 & - & 1 & \\
\hline San Luis & 2 & 2 & - & - & - & \\
\hline San Martin de Porres & 4 & 5 & 1 & - & 1 & \\
\hline San Miguel & - & 1 & 1 & - & 1 & \\
\hline Santa Anita & - & 1 & - & - & - & \\
\hline Santa Maria del Mar & - & - & - & - & - & \\
\hline Santa Rosa & - & - & - & - & - & \\
\hline Santiago de Surco & 3 & 1 & 1 & 1 & - & \\
\hline Surquillo & 2 & 2 & 1 & - & - & \\
\hline Villa El Salvador & 1 & 6 & 2 & 1 & 1 & \\
\hline Villa María del Triunfo & 3 & 6 & 3 & - & 3 & \\
\hline
\end{tabular}

Fuente: Ministerio de Educación - Censo Escolar. 
El cuadro a continuación muestra la incidencia de matrícula referida a educación técnico productiva en Lima siendo hasta el año 2013, 98205 los estudiantes de esta modalidad educativa superior básica. En referencia al distrito de Pachacamac es notable la baja incidencia de matrícula, siendo solo 429 alumnos representando menos del 1\% de la demanda de la provincia.

Cuadro 2.55 Matrícula en el sistema educativo por etapa, modalidad y nivel educativo, Provincia de Lima según distrito, 2013

\begin{tabular}{|c|c|c|c|c|c|c|}
\hline \multirow{2}{*}{ Distrito } & \multirow{2}{*}{$\begin{array}{r}\text { Básica } \\
\text { Especial }\end{array}$} & \multirow{2}{*}{$\begin{array}{r}\text { Técnico- } \\
\text { Productiva } 2 /\end{array}$} & \multicolumn{4}{|c|}{ Superior No Universitaria } \\
\hline & & & Total & Pedagógica & Tecnológica & Artistica \\
\hline Total & 6920 & 98205 & 170327 & 3331 & 166430 & 566 \\
\hline Lima & 476 & 18150 & 52570 & 495 & 51693 & 382 \\
\hline Ancón & 52 & 237 & - & - & - & - \\
\hline Ate & 153 & 2554 & 1318 & - & 1286 & 32 \\
\hline Barranco & 336 & 1135 & 498 & - & 498 & - \\
\hline Breña & 58 & 5326 & 4488 & 189 & 4299 & - \\
\hline Carabayllo & 110 & 784 & 284 & - & 284 & - \\
\hline Chaclacayo & 105 & - & 450 & 59 & 391 & - \\
\hline Chorrillos & 232 & 3068 & 1632 & - & 1632 & - \\
\hline Cieneguilla & - & 48 & 53 & - & 53 & - \\
\hline Comas & 355 & 2805 & 1698 & 114 & 1584 & - \\
\hline El Agustino & 140 & 319 & - & - & - & - \\
\hline Independencia & 214 & 1441 & 3744 & - & 3744 & - \\
\hline Jesús Maria & 100 & 4206 & 6012 & 153 & 5859 & - \\
\hline La Molina & 211 & 552 & 11533 & 94 & 11439 & - \\
\hline La Victoria & 119 & 1760 & 2962 & 5 & 2957 & - \\
\hline Lince & - & 2338 & 4974 & 60 & 4914 & - \\
\hline Los Olivos & 337 & 5796 & 4307 & - & 4307 & - \\
\hline Lurigancho & 56 & 1537 & 755 & - & 755 & - \\
\hline Lurín & 99 & 965 & 383 & - & 383 & - \\
\hline Magdalena del Mar & 169 & 3050 & 1207 & 39 & 1168 & - \\
\hline Miraflores & 224 & 3135 & 10945 & 55 & 10775 & 115 \\
\hline Pachacámac & - & 429 & 320 & 25 & 295 & - \\
\hline Pucusana & 38 & - & - & - & - & \\
\hline Pueblo Libre & 106 & 915 & 7564 & - & 7564 & - \\
\hline Puente Piedra & 132 & 1092 & 481 & 65 & 416 & - \\
\hline Punta Hermosa & - & - & - & - & - & - \\
\hline Punta Negra & - & - & - & - & - & \\
\hline Rimac & 71 & 2364 & - & - & - & \\
\hline San Bartolo & 24 & - & - & - & - & \\
\hline San Borja & 217 & 1115 & 1966 & - & 1966 & \\
\hline San Isidro & - & 4347 & 31313 & - & 31313 & \\
\hline San Juan de Lurigancho & 620 & 8275 & 2355 & 351 & 2004 & - \\
\hline San Juan de Miraflores & 279 & 4429 & 2759 & 144 & 2615 & - \\
\hline San Luis & 48 & 1667 & - & - & - & - \\
\hline San Martin de Porres & 276 & 4104 & 2137 & 75 & 2062 & - \\
\hline San Miguel & 183 & 866 & 2032 & 185 & 1847 & \\
\hline Santa Anita & - & 336 & 1302 & - & 1302 & \\
\hline Santa Maria del Mar & - & - & - & - & - & \\
\hline Santa Rosa & - & - & - & - & - & \\
\hline Santiago de Surco & 709 & 1989 & 4997 & 796 & 4201 & - \\
\hline Surquillo & 207 & 1337 & 37 & - & - & 37 \\
\hline Villa EI Salvador & 178 & 2722 & 1655 & 322 & 1333 & - \\
\hline Villa María del Triunfo & 286 & 3012 & 1596 & 105 & 1491 & - \\
\hline
\end{tabular}

Fuente: Ministerio de Educación - Censo Escolar 
Si nos referimos a las estadísticas educacionales sobre el sector público 38545 son actualmente los CETPROS a cargo de Gobiernos Locales llegando con esfuerzo al 40\% de la oferta en Lima situación preocupante pues deberían ser estas instituciones quienes más promuevan la educación superior en pro del desarrollo económico y social del distrito. Santiago de Surco es el distrito con menor incidencia de matrículas en centros públicos llegando solo a 40, más arriba está Santa Anita con 87, cantidades entendibles pues en estos distritos solo existe un CETPRO de gestión pública.

Cuadro 2.56 : Matrícula en el sistema educativo en instituciones educativas públicas, por etapa, modalidad y nivel educativo, Provincia de Lima según distrito, 2013

\begin{tabular}{|c|c|c|c|c|c|c|}
\hline \multirow{2}{*}{ Distrito } & \multirow{2}{*}{$\begin{array}{r}\text { Básica } \\
\text { Especial }\end{array}$} & \multirow{2}{*}{$\begin{array}{l}\text { Técnico- } \\
\text { Productiva }\end{array}$} & \multicolumn{4}{|c|}{ Superior No Universitaria } \\
\hline & & & Total & Pedagógica & Tecnológica & Artistica \\
\hline Total & 5110 & 38545 & 19910 & 1152 & 18541 & 217 \\
\hline Lima & 476 & 3420 & 3649 & 158 & 3311 & 180 \\
\hline Anoón & - & 208 & - & - & - & - \\
\hline Ate & 153 & 610 & 667 & - & 667 & - \\
\hline Baranco & 336 & 1135 & 498 & - & 498 & - \\
\hline Breña & 58 & 1499 & - & - & - & - \\
\hline Carabayllo & 110 & 667 & - & - & - & - \\
\hline Chaclacayo & 105 & - & 391 & - & 391 & \\
\hline Chorrillos & 228 & 2699 & 1176 & - & 1176 & - \\
\hline Cieneguilla & - & - & 53 & - & 53 & \\
\hline Comas & 276 & 1391 & 1584 & - & 1584 & - \\
\hline ElAgustino & 140 & 295 & - & - & - & - \\
\hline Independencia & 214 & 277 & - & - & - & - \\
\hline Jesús Maria & 100 & - & 135 & - & 135 & - \\
\hline La Molina & 82 & 355 & - & - & - & - \\
\hline La Victoria & 119 & 1500 & 1858 & - & 1858 & - \\
\hline Lince & - & - & - & - & - & - \\
\hline Los Olivos & 55 & 1112 & 588 & - & 588 & - \\
\hline Lurigancho & 56 & 239 & 541 & - & 541 & - \\
\hline Lurin & 99 & 419 & 317 & - & 317 & - \\
\hline Magdalena del Mar & 169 & 2803 & - & - & - & - \\
\hline Miraflores & 95 & 265 & - & - & - & - \\
\hline Pachacámac & - & - & - & - & - & - \\
\hline Pucusana & 38 & - & - & - & - & - \\
\hline Pueblo Libre & - & 660 & 457 & - & 457 & - \\
\hline Puente Piedra & 132 & 594 & - & - & - & - \\
\hline Punta Hermosa & - & - & - & - & - & - \\
\hline Punta Negra & - & - & - & - & - & - \\
\hline Rimac & 71 & 1539 & - & - & - & - \\
\hline San Bartolo & 24 & - & - & - & - & - \\
\hline San Borja & 56 & - & - & - & - & - \\
\hline San Isidro & - & - & - & - & - & - \\
\hline San Juan de Lurigancho & 620 & 5828 & 1335 & - & 1335 & - \\
\hline San Juan de Miraflores & 256 & 1612 & 1096 & - & 1096 & - \\
\hline San Luis & 48 & 1301 & - & - & & - \\
\hline San Martin de Porres & 276 & 3070 & 653 & - & 653 & - \\
\hline San Miguel & - & 203 & 1546 & - & 1546 & - \\
\hline Santa Anita & - & 87 & - & - & - & - \\
\hline Santa Maria del Mar & - & & - & - & & - \\
\hline Santa Rosa & - & - & - & - & - & - \\
\hline Santiago de Surco & 254 & 40 & 796 & 796 & - & - \\
\hline Surquillo & 93 & 991 & 37 & - & - & 37 \\
\hline Villa El Salvador & 126 & 1503 & 1131 & 198 & 933 & - \\
\hline Villa Maria del Truunfo & 245 & 2223 & 1402 & - & 1402 & - \\
\hline
\end{tabular}

Fuente: Ministerio de Educación - Censo Escolar. 
2.3 Línea de tiempo 


\subsection{Conclusiones Parciales}

Lima es una ciudad asentada sobre tres Valles, formados a partir de las cuencas del Rímac, del Chillón y del Lurín; ésta última tiene origen a 3000 m.s.n.m. en el distrito de San Damián, recorre $107 \mathrm{~km}$ y posee una superficie aproximada de 1660 $\mathrm{kms}^{2}$. El Valle abarca la provincia de Huarochirí en su cuenca alta, incluyendo a los distritos de Lahuaytambo, San Andrés de Tupicocha, San Damián y Huarochirí, en su cuenca media a los distritos de Santiago de Tuna, Langa, Santo Domingo de los Olleros, Cuenca y Antioquía; finalmente en su cuenca baja a los distritos de Cieneguilla, Lurín y Pachacamac pertenecientes a la provincia de Lima.

El Valle Lurín representa el último valle verde de Lima, pues los otros valles de la provincia se encuentran urbanizados casi en su totalidad, representando éste una oportunidad de conservación mediante políticas de protección y promoción de los ecosistemas aquí presentes y de sus áreas agrícolas. Con el objetivo de impulsar la preservación de este valle se desarrollará la presente tesis titulada: Centro Técnico Productivo Lomas de Lúcumo, cuya oferta educativa estará dirigida a promover el cultivo en laderas como estrategia de protección de los ecosistemas de lomas y a brindar capacitación sobre valor agregado de productos agrícolas mediante la agroindustria y cultivos orgánicos.

Es importante situarnos históricamente en el lugar para entender el proceso de población del valle; este es iniciado por grupos nómades quienes se asentaron largas temporadas sobre los ecosistemas de lomas, habiéndose encontrado vestigios de viviendas, y canales de irrigación que formaban parte de un ingenioso sistema de agricultura de lomas, andenes agrícolas y construcciones que tienen características de plazas públicas como las encontradas en la Quebrada de Malanché, localizada en el distrito de Pachacamac. En el valle se desarrolló también el Periodo Formativo, la Cultura Lima, el Imperio Huari, El Señorio Ichma y el Imperio Inca que concluyo con la conquista española hacia el año 1533. Aproximadamente en el año 1960 se fueron iniciando los procesos de urbanización del distrito donde el mayor porcentaje de la población se asentó de forma informal, en su mayoría migrantes pobres que invadieron las laderas de los cerros concentrándose, en la Quebrada Manchay y en los centros poblados rurales del margen derecho del Río Lurín como Quebrada Verde lugar en donde se desarrolla el presente proyecto de tesis. 
Se evaluó también los índices socioeconómicos de la población del valle para acercarnos a su realidad y establecer la calidad de vida que poseen sus habitantes, siendo para el año 2012, Pachacamac, el distrito con mayor densidad poblacional del valle, con un total de $640.9 \mathrm{hab} / \mathrm{km}^{2}$ además para este año aproximadamente la tercera parte de su población era pobre, convirtiéndose en el distrito con mayor pobreza de Lima Metropolitana. Pachacamac es también uno de los distritos con menor oportunidad de acceso a las necesidades básicas, y con mayor índice de desempleo del valle donde del total de los 82661 habitantes que conforman la PEA del distrito, el 4\% está desocupado; estas cifras son preocupantes y sitúan a Pachacamac en un marco de interés para gestionar alternativas de desarrollo social.

Una herramienta de desarrollo es la explotación sostenible de los recursos, y Pachacamac tiene la agricultura como una de sus más importantes actividades productivas, donde la cuenca baja del Valle de Lurín, llegaba al 2011 con una producción de 69340 toneladas, siendo Pachacamac el distrito que más aporto a este sector, destacando el maíz chala, ají, camote y lúcuma. Siendo la lúcuma el fruto de mayor producción y mayor costo del valle y como medio para rememorar la historia del lugar de emplazamiento del proyecto, se ha considerado este árbol para la reforestación de las laderas de las Lomas de Lúcumo y consolidar así un borde de protección. Para este fin se evaluó la factibilidad del cultivo concluyendo que el suelo presente en el entorno es propicio para el desarrollo de este frutal, pues pertenece a la unidad litológica deposito eólico, compuesta en su mayoría por arena y limo; las consideraciones climáticas del valle también son favorables ya que cuentan con un valor mínimo registrado de $19^{\circ} \mathrm{C}$ y máximo de $21.1^{\circ} \mathrm{C}$; con respecto a las precipitaciones, éstas registran mayores volúmenes en los meses de diciembre a marzo y menores volúmenes de mayo a setiembre, donde llegan incluso a $0.0 \mathrm{~mm}$.

El análisis realizado sobre las características del Valle de Lurín, fija a Pachacamac como unos de los distritos con mayor oportunidad de desarrollo económico, sin embargo es también el de menores índices de calidad de vida; un 2,2\% de su población es analfabeta y solo el 15\% logra acceder a educación superior. Expuesta esta realidad y definiendo a la educación como una importante herramienta de desarrollo se determina que el proyecto arquitectónico a diseñar en la presente tesis será un equipamiento educativo superior básico, encargado de instruir a la población en 
oficios que puedan ser certificados y rápidamente ejercidos, contribuyendo de ésta forma al desarrollo local, el cual influirá directamente en la mejora de la calidad de vida del distrito.

El equipamiento educativo a diseñar se denomina Centro Técnico Productivo, y tiene su inicio en las Escuelas de artes y Oficios (EAYO), la historia hace referencia a los gremios como instauradores de esta enseñanza, pero del análisis realizado se concluye que si bien en estos existió una transmisión de conocimientos del maestro al aprendiz, ésta no puede considerarse como el inicio de la educación técnico productiva, pues su carácter restringido no favoreció en nada a la capacitación de la clase obrera; fueron más bien capitales privados los que años más tarde impulsarían este modelo de instrucción. Siendo el ejemplo más sobresaliente la Sociedad Económica Amigos del País, en España, cuya organización sustituyó en un inicio la labor formativa del estado, gestionando la apertura de Escuelas de Artes y Oficios en todo el país en pro de la ilustración y la mejora económico-social de los sectores excluidos de la población. Europa fue el continente donde éste modelo educativo alcanzó su máximo desarrollo, siendo Francia el país donde se instituye la primera escuela hacia 1780.

Éste tipo de instrucción se instaura en Latinoamérica pocos años después de la conquista española, inicialmente también con gremios artesanales y tiempo después mediante órdenes religiosas que se encargaban de brindar educación en artes y oficios a la población indígena durante la época. Tras la independencia en el año 1821, durante el gobierno del General San Martín se promulgan varias normas con el fin de instituir en Lima las EAYO pero este hecho no logra concretarse sino hasta 1860, donde Ramón Castilla crea la primera Escuela de Artes y Oficios en la capital; tiempo después en el año 1867 se publica la normativa para la instauración de la educación ocupacional la cual se impartiría en CENECAPES, los que años más tarde se convertirían en CEO (Centro de Educación Ocupacional) y éstos finalmente en CETPRO (Centro Técnico Productivo) hacia el 2008; sumando actualmente un total de 1853 centros en todo el país y 432 en Lima Metropolitana. Es importante resaltar que la presencia pública de estas instituciones es inexistente en el distrito de Pachacamac, y dadas sus condiciones sociales y potenciales recursos, se considera necesaria la creación de un Centro Técnico Productivo cuya oferta formativa estará basada en las actividades productivas del entorno y dirigida a promover el desarrollo local y la preservación del valle. 


\section{CAPÍTULO III: MARCO TEÓRICO}

\subsection{Estado del arte}

Sobre la instrucción de las artes y los oficios, la historia hace referencia a los gremios como instauradores de la misma, aunque su carácter restringido no favoreció la capacitación de la clase obrera, siendo finalmente los capitales privados quienes años más tarde establecerían el comienzo de este modelo de enseñanza, como es el caso de la Sociedad Económica Amigos del País en España que fue la principal promotora de la Escuela de Artes y Oficios de gestión privada en este país y la que agilizó trámites y presionó al sector público para que se instituyeran mayor cantidad de escuelas de este tipo en todas ciudades de las comunidades autónomas en pro de la ilustración y el desarrollo económico social de los sectores excluidos de la población.

Europa fue el continente donde las Escuelas de Artes y Oficios ( EAYO) alcanzaron su máximo desarrollo, pues precisamente es este de donde data la primera escuela en Francia hacia 1780; ésta modalidad educativa se instituye en Latinoamérica pocos años después de la conquista española (1492) así que en este continente se instauraron también los gremios artesanales que estaban aún en vigencia y quienes fueron junto a las órdenes religiosas las instituciones encargadas de la instrucción de la población indígena durante esta época.

Tras la independencia en el año 1821, durante el Gobierno del general San Martín se promulgaron varias normas con el fin de que se instauraran en Lima las Escuelas de Artes y Oficios, pero este hecho nunca llega a concretarse si no hasta 1860 en el gobierno de Ramón Castilla que logra crearse la primera Escuela de Artes y Oficios de Lima, convirtiéndose en el año 1945 en Instituto Técnico al igual que similares instituciones.

Las EAYO fueron perfeccionándose, su nueva condición por consiguiente exigía haber culminado los niveles de educación previa, requisito que limitaba el acceso a sectores de la población con instrucción básica en su mayoría habitantes de zonas marginales y con menor índice de desarrollo; es así que en el año 1867 se publica una norma para 
instaurar la educación ocupacional la cual se impartiría en CENECAPES Y CENACAPES los cuales llegan a convertirse años más tarde en CEO (Centro de Educación Ocupacional) y éstos finalmente en CETPRO ( Centro Técnico Productivo) hacia el 2008 contando actualmente con 1644 CETPROS en todo el país.

\subsection{Conjunto de teorías que sustentan el proyecto}

A continuación se desarrollarán teorías referentes a los conceptos de borde y paisaje, pues el presente proyecto de tesis se sitúa en un entorno natural de paisaje de borde, justo en el punto donde concluye el Ecosistema Lomas de Lúcumo y comienza la ciudad representada por el Centro Poblado Rural Quebrada Verde.

El análisis histórico referencial presentado en el capítulo anterior identificó como potencial estrategia de protección de Lomas la reforestación de sus laderas con el árbol de lúcumo, éste cinturón verde establecería un límite para la improvisada expansión urbana que viene afrontando Quebrada Verde. El Centro Técnico Productivo Lomas de Lúcumo sería parte de éste cinturón y el punto estratégico donde confluye la producción para ser procesada y convertida en harina de lúcuma.

La línea de frutales reforestados en las laderas de la Loma será percibido como un límite, pero la arquitectura del CETPRO tendrá otro carácter, al ser éste el único punto de acceso a las Lomas, además del ingreso formal al circuito ecoturístico, deberá constituir un espacio de transición entre dos entornos: el natural y el urbano.

Éste punto de encuentro es denominado borde y será la primera teoría a desarrollar, seguidamente se desarrollará teorías sobre paisaje y finalmente a modo de conclusión se formará un concepto sobre paisaje de borde para aplicarlo como estrategia proyectual en el diseño arquitectónico. 


\subsubsection{Borde}

Se asume que los bordes se generan por las prácticas de construcción de la ciudad y se presentan como zonas de interacción de varias actividades que en su desarrollo sobreponen procesos de muy diversa índole; por lo tanto la diversidad y la complejidad son sus características fundamentales y son cambiantes, ya que se encuentran en constante movimiento y transformación. (Ramírez Velázquez, 2010)

Figura 3.1 Ejemplificación conceptual de un borde

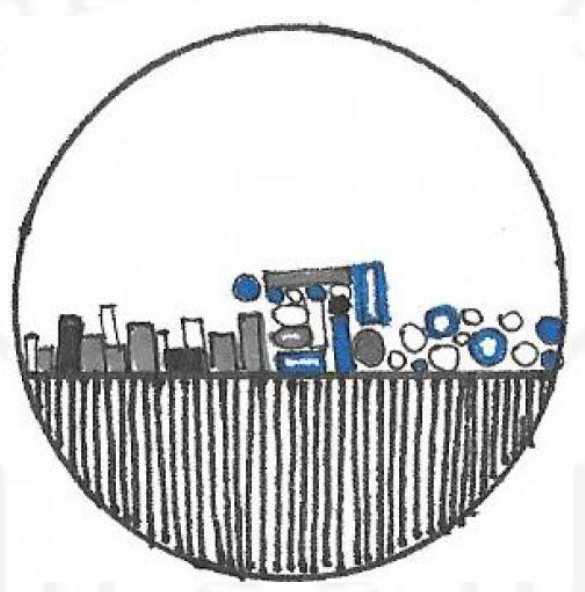

Elaboración Propia

El caso de estudio en priticular representa un bos te donde confluye un contexto urbano con uno natural, gen srado a partir del proceso de ásentamiento de la población de Quebrada Verde, la cual en un inicio pobló parte de la má rgen derecha del Río Lurín pero, con el pasar del tiemr o se fue expandiendo llegando a scupar las laderas bajas del Ecosistema Lomas de Lúcurıo.

Al no existir un límite c'aro de expansión este 'jorde actualmente representa la extensión del jardín o patio trasero de is raca uuyacentes a la Loma y aquí confluyen actividades propias de la flora y fauna del ecosistema con actividades domésticas, independientes a cada vivienda y de carácter privado; claramente este borde viene afrontando una apropiación informal del espacio natural sin ningún tipo de filtro que proteja a las especies que habitan las Lomas. 
Figura 3.2 Las laderas de Lomas de Lúcumo en su estado natural y tras la intervención del hombre

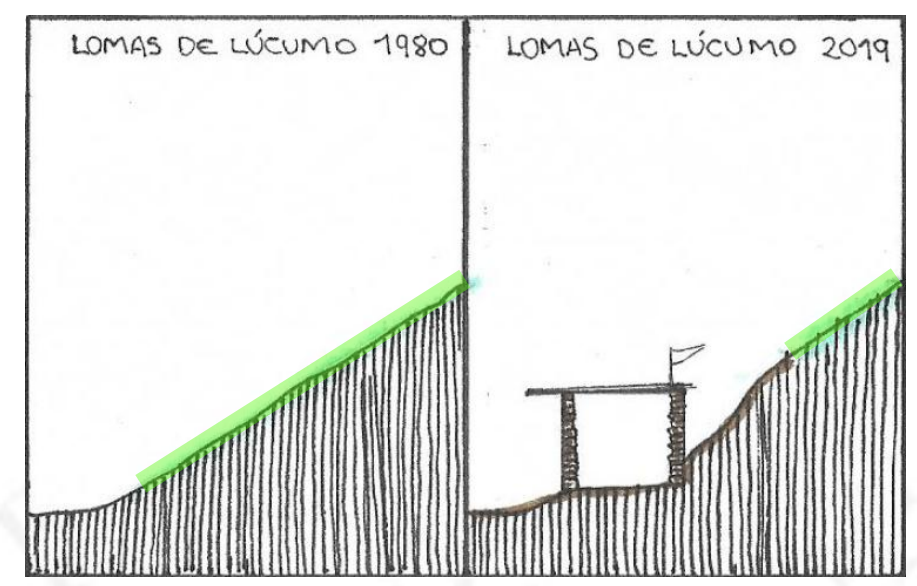

Elaboración Propia

Ramirez Velázquez define también a los bordes como espacios cambiantes y en constante movimiento, el borde de las Lomas de Lúcumo es un espacio que presenta también éstas características pues la población sigue urbanizando las lomas con invasiones informales en pendientes no habitables y cambiando drástica y continuamente el entorno natural.

3.2.1.2 Definiciones sobre tipologías de borde

\subsection{Borde político}

En la imagen urbana no se reconocen dos ciudades, sino una pluralidad de ciudades o de esbozos de ciudades en las que diversas fuerzas organizadas o dispersas logran establecer escalas de agrupación, denominadas fronteras invisibles o bordes. (Salazar Hernández \& Zuleta Ruiz, 2014) 
Figura 3.3 Representación conceptual de un borde político

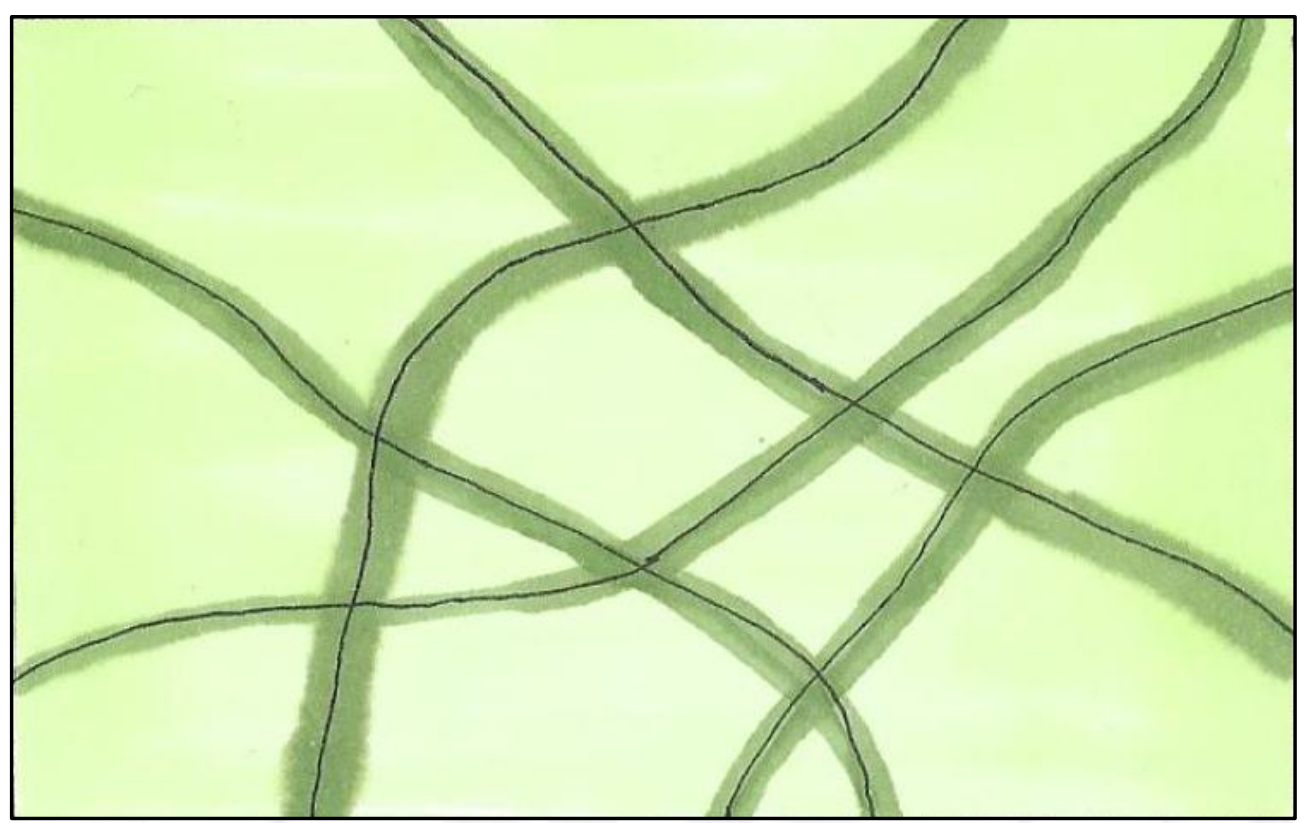

Elaboración Propia

En concordancia con Salazar y Zuleta, Blanca Ramírez define a los bordes como "zonas diferenciadas que se forman como resultado de la articulación compleja de procesos que se generan en las zonas ubicadas entre la mancha urbana de la ciudad y los limites político administrativos de los municipios considerados como conurbados" (pág. 6) y especifica que la extensión de éstos difícilmente suele estar limitada por las fronteras de adjudicación municipal, "Se asume que los procesos territoriales que caracterizan a los bordes trasgreden los límites políticos constantemente, dando formas diferenciadas a los procesos que generan" (pág. 6) es por ello que con mayor razón aún los municipios fronterizos se deben poner de acuerdo para revalorar éstos espacios híbridos donde confluyen culturas y tradiciones comunes a ambos, generando finalmente una nueva identidad.

Bajo un escenario político un territorio está supeditado al dominio distrital, provincial o departamental (refiriéndonos a pequeña escala), cada gobierno establece los límites de su soberanía mediante acuerdos consensuados, es así que casi en la mayoría de los casos son precisamente éstas franjas donde menor interés le ponen los 
gobiernos, constituyendo entonces los bordes políticos espacios urbanos donde confluyen dos estados que en su mayoría manejan leyes y ordenanzas independientes dejando en el vacío el ordenamiento territorial de sus límites, el cual debería regirse a un acuerdo que involucrando a ambas partes desarrolle aunque no sea posible en todo, pero sí en determinados espacios de contacto, conexiones de transición para que dejen de sentirse límites políticos marcados e impenetrables y de ésta forma empezar a conectar la ciudad, conectar cultura y tradición; formando una nueva identidad con la diversidad de ambos territorios.

Como lo define Torres Tovar en las siguientes líneas:

Durante la última década un enfoque multidisciplinar sobre los bordes ha propuesto entenderlos como una territorialidad independiente, como un espacio complejo en donde convergen, se encuentran y se superponen elementos de territorios con diferentes características y en donde, a partir de dicha superposición, puede surgir una nueva entidad territorial. (Torres Tovar, 2014)

Desde la perspectiva del ordenamiento territorial, (Villamizar Duarte, 2014) hace incidencia en la importancia del control del borde indicando que no existiría tal ordenamiento sin una relación del borde con sus contextos regionales involucrados y las autoridades que lo preceden, las cuales deben establecer políticas de manejo consensuadas, entendiendo a éste territorio como un área común en la que es necesario poner esfuerzos para conservarla, revalorarla y potenciarla.

El Ecosistema Lomas de Lúcumo, contexto del que forma parte la presente investigación, alberga en sus laderas centros poblados pertenecientes a los distritos de Pachacamac y Villa María del Triunfo, pero solo tres de ellos están involucrados seriamente en su conservación, siendo éstos: Quebrada Verde, Picapiedra y Guayabo, todos pertenecientes al distrito de Pachacamac.

Las Lomas de Lúcumo y sus alrededores representan entonces un borde político entre Pachacamac y Villa María del Triunfo, donde es necesaria la intervención en conjunto de ambos municipios en pro de su conservación y aprovechamiento sostenible. 
Figura 3.4 Representación del borde político existente en las Lomas de Lúcumo

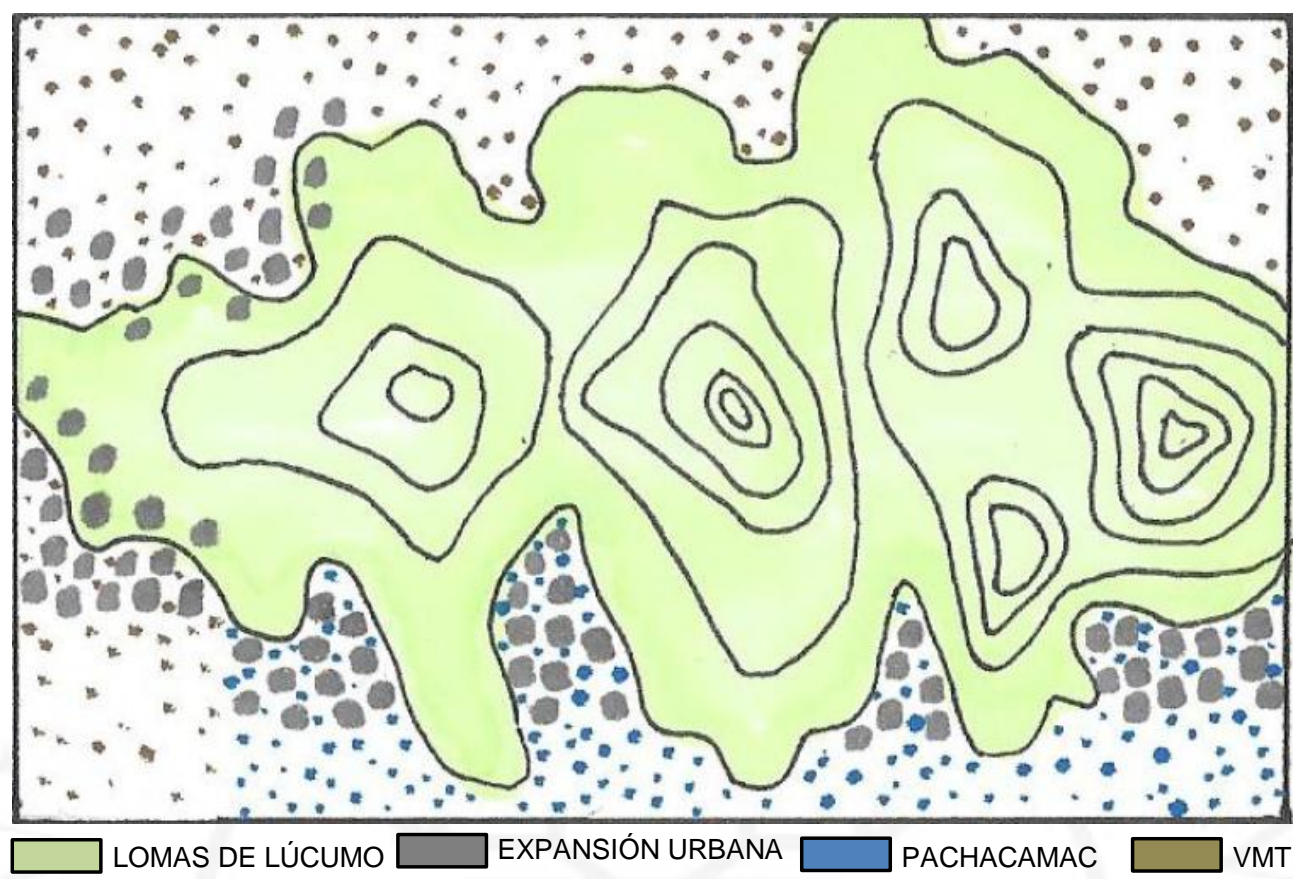

Elaboración Propia

Sin Embargo, el municipio de Villa María del Triunfo sin autorización del municipio de Pachacamac viene permitiendo que la empresa Cementos Lima explote las laderas del Ecosistema Lomas de Lúcumo en el C.P.R. José Gálvez, con el fin de obtener material de construcción. Ésta actividad viene poniendo en grave peligro la conservación del ecosistema, de su flora y fauna.

Por ésta razón es clave que ambos municipios lleguen a acuerdos mutuos en pro de la conservación de éstos ecosistemas frágiles o de otra forma solicitar al Ministerio del Ambiente declare intangible no solo el recurso, sino también el suelo, ya que así se detendrían también las constantes invasiones que atentan contra la preservación de las Lomas. 


\subsection{Borde económico-social}

Un borde económico-social se define como el espacio donde se encuentran dos realidades distintas, con diferenciado nivel socioeconómico, una franja donde convergen dos centros urbanos con una marcada desigualdad de desarrollo local determinado directamente por la falta de políticas de gestión en pro de mejorar la calidad de vida de un lado de la población.

Figura 3.5 Representación gráfica de un borde económico- social

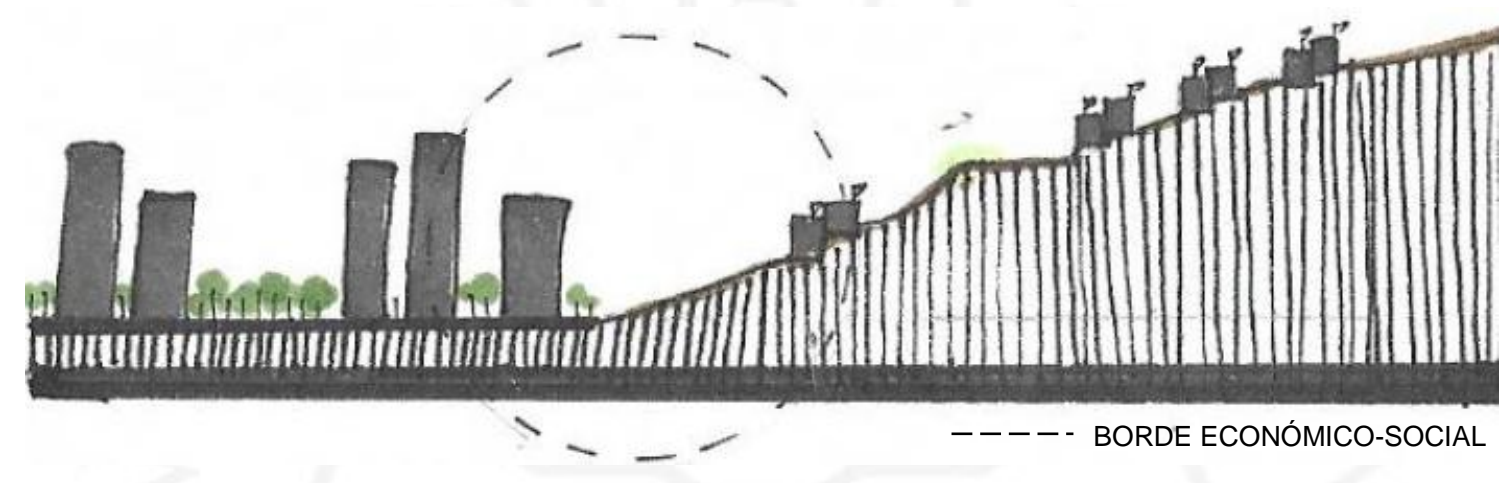

Elaboración Propia

Comúnmente se piensa en bordes en términos políticos (bordes nacionales y político-administrativos). Sin embargo, los bordes están presentes (cumpliendo múltiples funciones) a diversas escalas $\mathrm{y}$ dimensiones. De esta manera, los bordes cumplen la función de delinear no sólo el espacio, sino también procesos en el espacio. Por ejemplo, muchas de las formas más evidentes de identidad social se trazan mediante bordes que construyen territorialidades (...) Los bordes son entonces instrumentales para relaciones y procesos sociales nuestros. (Sánchez Ayala, 2015)

El contexto inmediato donde se desarrolla el proyecto no da a lugar este tipo de borde, pues como se analizó en el capítulo anterior, Pachacamac en un distrito con una marcada pobreza, lo que se refleja en su entorno y la precariedad de sus viviendas sobre todo en sus Centros Poblados Rurales, y no existe una diferenciada realidad económico social. 


\subsection{Borde urbano-rural}

( Barsky, 2005) define a este borde como "una situación de interfase entre dos tipos geográficos aparentemente bien diferenciados: el campo y la ciudad.” (pág. 2), el autor también hace énfasis en las condiciones cambiantes de este escenario urbano el cual dice se encuentra en un constante proceso de extensión, relocalización y movilidad, suscribe además que "Se trata de un territorio en consolidación, bastante inestable en cuanto a la constitución de redes sociales y de una gran heterogeneidad en los usos del suelo” (pág. 2)

Figura 3.6 Representación conceptual de un borde urbano rural

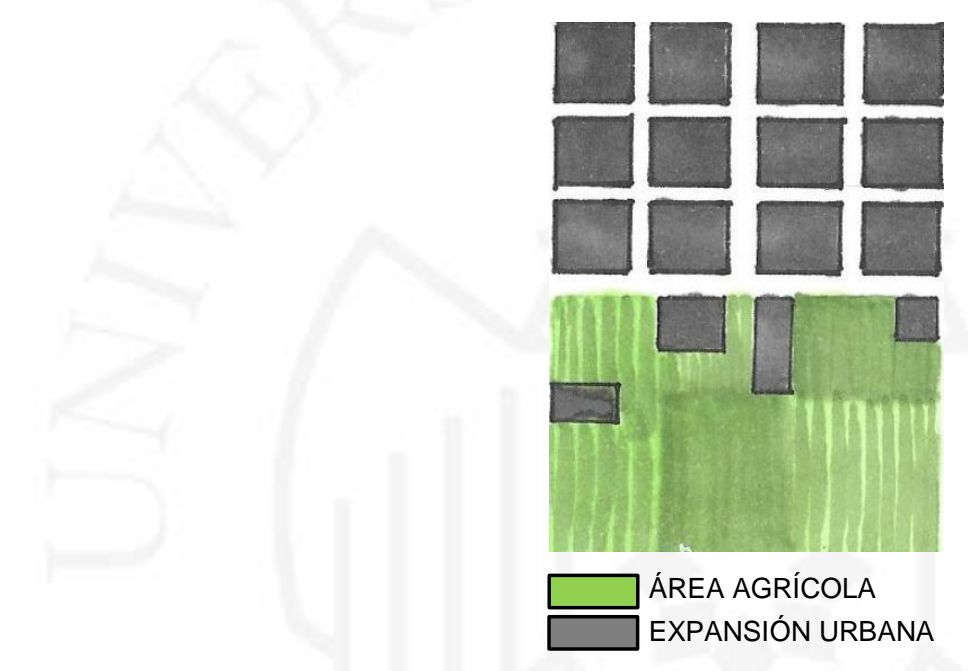

Elaboración Propia

El Valle Bajo del Río Lurín es un valle verde y productivo del cual forma parte Pachacamac, este distrito ha tenido un extraño proceso de consolidación pues la ciudad no ha ido expandiéndose a partir de su centro histórico, sino más bien ha sufrido un asentamiento disgregado, lo que ha ocasionado que el Centro Poblado Rural Quebrada Verde que es un entorno urbano en consolidación, esté situado entre dos entornos naturales: Un ecosistema estacional y campos de cultivo; la confluencia de éstos contextos como menciona Barsky ha generado un borde geográfico donde es notable la variedad en los usos de suelo, algunos destinados a la agricultura, casas huerta, vivienda comercio, vivienda taller entre otros. 
La geografía es la ciencia que a lo largo de la historia ha estudiado las relaciones que fueron desarrollándose entre el ser humano y su entorno natural, estas conexiones comúnmente ocurren en la periferia de la ciudad constituyéndose un claro espacio de intercambio entre sociedad y ecología. Geográficamente, desde antiguas civilizaciones, las poblaciones se han asentado en valles y han aprovechado el agua para el desarrollo de su agricultura, siendo una de las actividades económicas de mayor relevancia. En Pachacamac la agricultura se extiende desde la margen del Río Lurín hasta Pachacamac Pueblo y hacia los centros poblados rurales que representan áreas urbanas en proceso de consolidación.

El borde urbano-rural es un espacio con frecuencia situado en la periferia de la ciudad, ( Barsky, 2005) define a la periferia como un territorio de borde "sometido a procesos económicos relacionados con la valorización capitalista del espacio, como consecuencia de la incorporación real o potencial de nuevas tierras a la ciudad." (pág. 5)

El distrito de Pachacamac está localizado al sur de la Provincia de Lima, y desde un punto de vista macro éste es parte de la periferia de la urbe limeña, como tal posee un área urbana en desarrollo, además de áreas agrarias las cuales vienen afrontando procesos de cambio de uso de suelo de agrícola a residencial; tal como lo menciona el autor, existe en este borde una valoración capitalista del espacio, corriendo peligro la preservación del Valle de Lurín. 
Figura 3.7 Representación actual del entorno del Ecosistema Lomas de Lúcumo

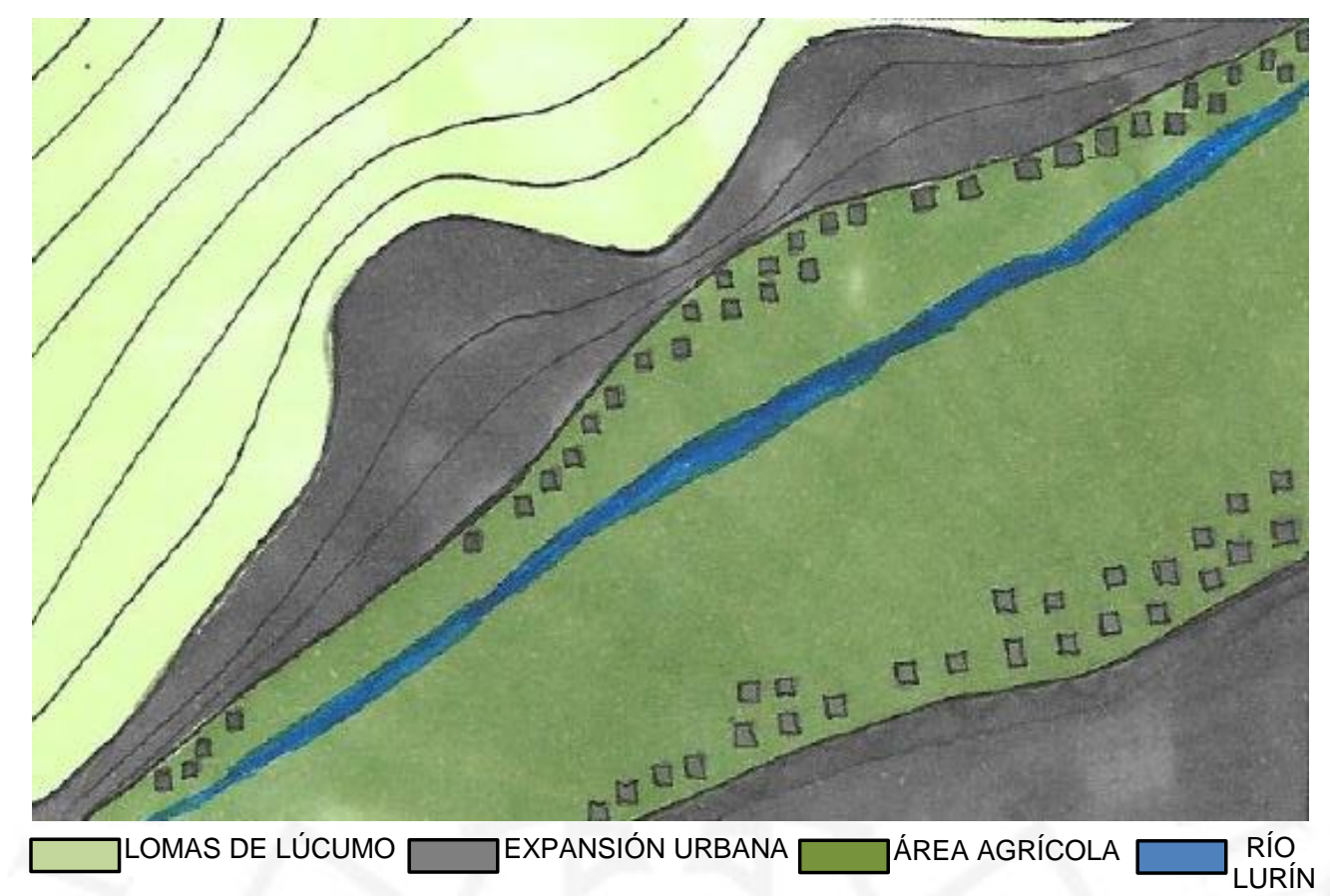

Elaboración Propia

Por otro lado (Núñez Inoguchi \& Pinto Balcazar, 2016) definen a éste borde como un territorio en constante transformación y de diversas características sociales, producto del constante crecimiento de la ciudad, donde se encuentran dos realidades, la urbana y la rural, generando distintas formas de habitar el espacio y usar el recurso suelo, ya sea para la agricultura o para residencia mediante habilitaciones urbanas de terrenos antes agrícolas.

El borde urbano rural es el espacio donde se encuentran éstos dos entornos, y como ya lo describieron los autores es un territorio en continuo cambio, pero lo realmente preocupante es ver como éste borde va desplazándose a medida que la ciudad va absorbiendo al campo, en éste caso a los terrenos agrícolas presentes en el Valle del Lurín, corriendo peligro de desaparecer.

Al asumir los bordes urbano-rurales no sólo como un espacio concreto en el que se integran tres realidades: las eco sistémicas, las del sector rural y de las de la ciudad, sino como un sistema en sí mismo con sus propios procesos y actores es posible identificar las conexiones, redes y flujos 
que intervienen en la estructuración de las periferias urbanas, al igual que su condición de espacio de confluencia de varios "desbordes" de situaciones sociales. ( Ballén Velásquez, 2014)

( Ballén Velásquez, 2014) explica que si asumimos al borde no solo como un espacio si no como un sistema nos ayudará a identificar las conexiones que intervienen en su estructura y sobre todo los "desbordes" sociales que aquejan a éste territorio; representados específicamente en el caso de Pachacamac, por la pobreza, el limitado acceso a necesidades básicas, el bajo nivel educativo, el desempleo y la falta de oportunidades. Estas condiciones que afectan en su mayoría a las poblaciones rurales, conllevan a los agricultores a abandonar el oficio y vender sus tierras a desarrolladoras inmobiliarias contribuyendo a la urbanización a gran escala del último valle verde de Lima.

Las ciudades crecen y se extienden sobre la totalidad del territorio impactando el suelo rural productivo que resulta urbanizado (...). Esta situación hace que hoy sea fundamental considerar los bordes y fronteras de las ciudades como un espacio sobre el cual discutir acerca de las actuaciones y decisiones de planeamiento, y como un espacio para la negociación de los intereses de los diferentes agentes presentes en el espacio urbano y rural, ya sean estos comunitarios, privados o públicos. (Torres Tovar, 2014)

Desde otra perspectiva ( Ballén Velásquez, 2014) también define a los bordes urbano-rurales como organizaciones socio-espaciales originadas a partir de interacciones, conflictos y negociaciones desarrolladas entre los distintos ámbitos de las periferias, es decir "la relación entre lo urbano, lo rural y lo ambiental que son construidos y movilizados por la multiplicidad de actores que allí confluyen, mediante diferentes recursos e instrumentos de poder.” (pág. 33) 


\subsection{Borde urbano-natural}

Un borde urbano natural se define como el punto de encuentro entre la ciudad y su entorno natural, hace referencia a las relaciones que se establecen entre ambos, aludiendo además a características tangibles del territorio, como topografía, uso de suelo y perfil urbano.

Figura 3.8 Ejemplificación de bordes urbano naturales

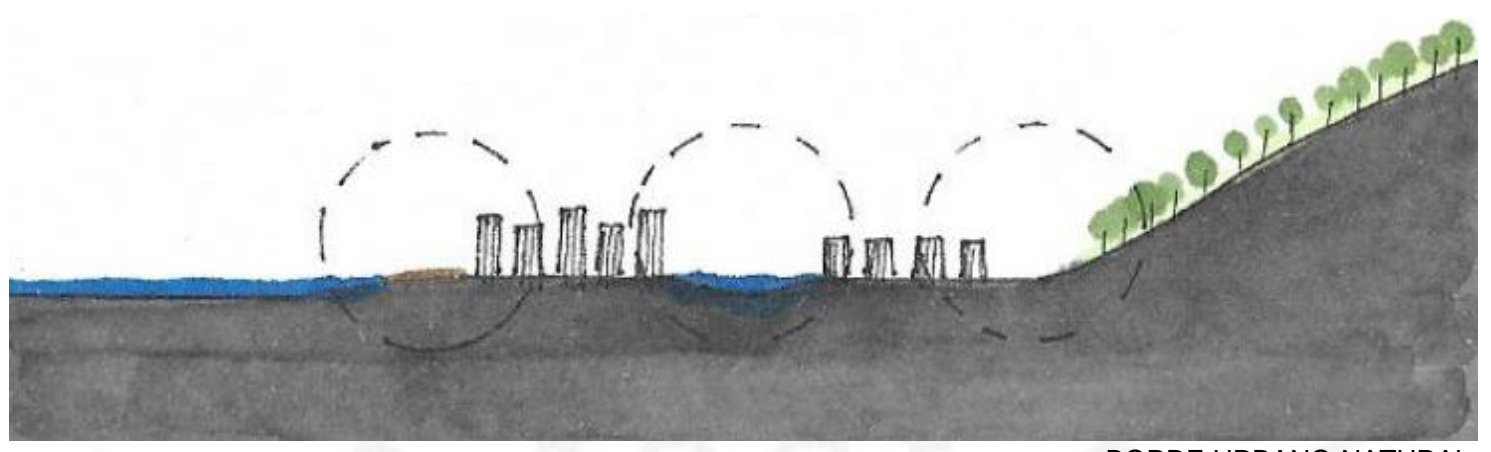

Elaboración Propia

(Aponte, 2012) expone que casi siempre es "la morfología urbana la que se implanta sobre la natural"; sin importar lo agreste del territorio, el ser humano lo modifica para volverlo "habitable" destruyendo drásticamente el paisaje.

El contexto donde se desarrolla el proyecto de tesis guarda las características de esta tipología de borde; aquí coexiste el entorno urbano conformado por el Centro Poblado Rural Quebrada Verde y el entorno natural representado por el Ecosistema Estacional Lomas de Lúcumo. Este espacio donde se superponen ambos territorios va mutando constantemente, pues la ciudad no considera límite en su expansión y mediante ocupaciones informales va invadiendo cada vez más área de Lomas, atentando contra este ecosistema que por casi 6 meses es elemento de purificación importante para el aire de la cogestionada Lima. 
Figura 3.9 Representación del borde urbano natural presente en las Laderas de las Lomas de Lúcumo

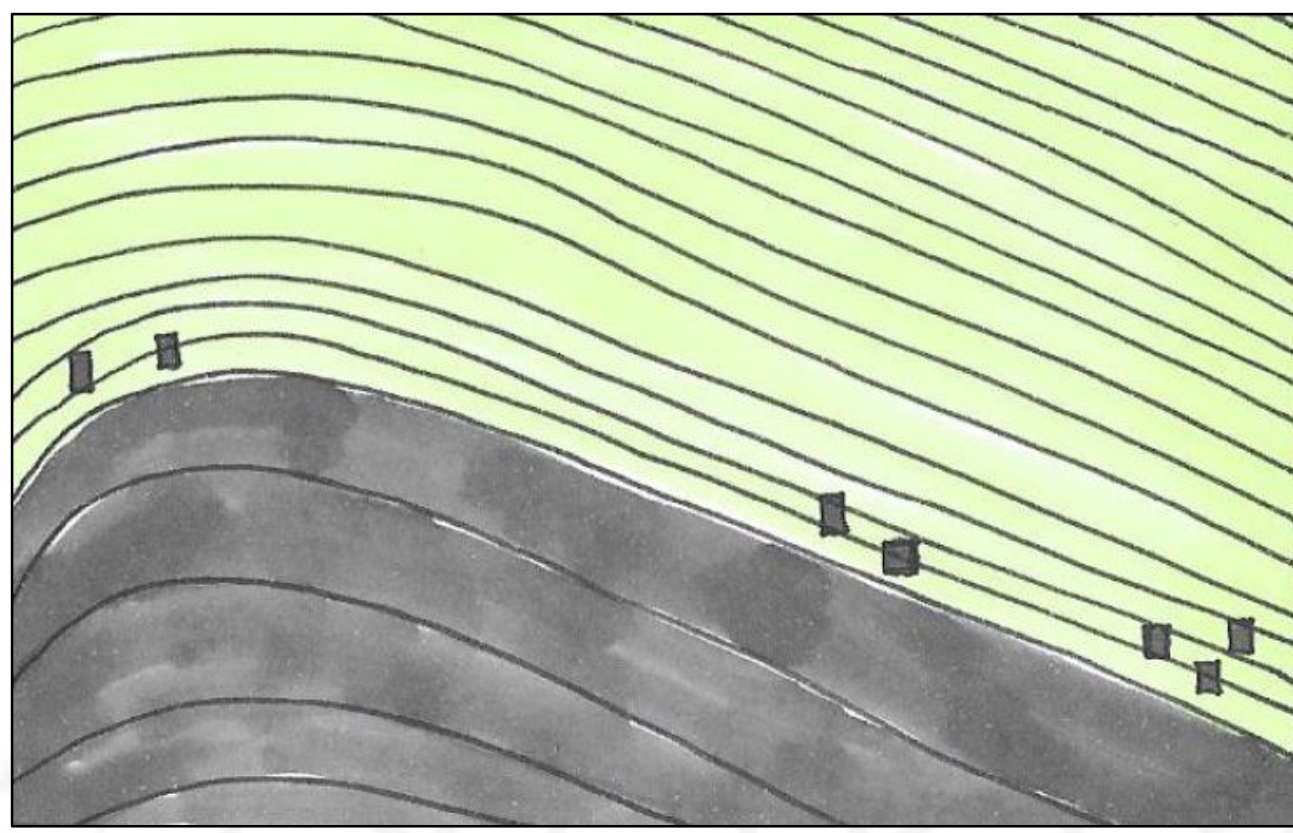

LOMAS DE LÚCUMO $\square$ EXPANSIÓN URBANA

Elaboración Propia

Cabe resaltar que estas invasiones no las promueve la comunidad de Quebrada Verde, si no organizaciones inescrupulosas dedicadas al tráfico de tierras, que emplean la fuerza y la violencia para apropiarse de terrenos de propiedad estatal, pues las Lomas Costeras han sido declarados Ecosistemas Frágiles y sus laderas, áreas de tratamiento paisajista. A pesar de ésta normativa es necesario se declare ésta área como intangible y de ésta manera no solo proteger al recurso natural, sino también al recurso suelo.

Expuesta la realidad de éste borde el proyecto de tesis realizará una propuesta macro de delimitación y protección de Lomas Costeras, buscando además el aprovechamiento sostenible de las mismas. 


\subsection{Bordes, límites y fronteras}

Para la presente investigación es importante definir el concepto de borde, límite y frontera, pues éstos están tan ligados que suelen confundirse.

(Sánchez Ayala, 2015) explica cómo estos elementos concretizan el territorio, cada uno con una función específica y a diferente escala pero todos ligados a la composición de éste; se refiere al borde como un espacio de doble función la de señalarlos y a la vez unirlos; al límite como la línea divisoria entre éstos y a la frontera como el área donde se integran o separan gradualmente, la zona de transición entre ambos, siendo éstos específicamente ciudades, países o regiones.

Figura 3.10 Representación conceptual del Ecosistema Lomas de Lúcumo como borde entre los distritos de Pachacamac y Villa María del Triunfo
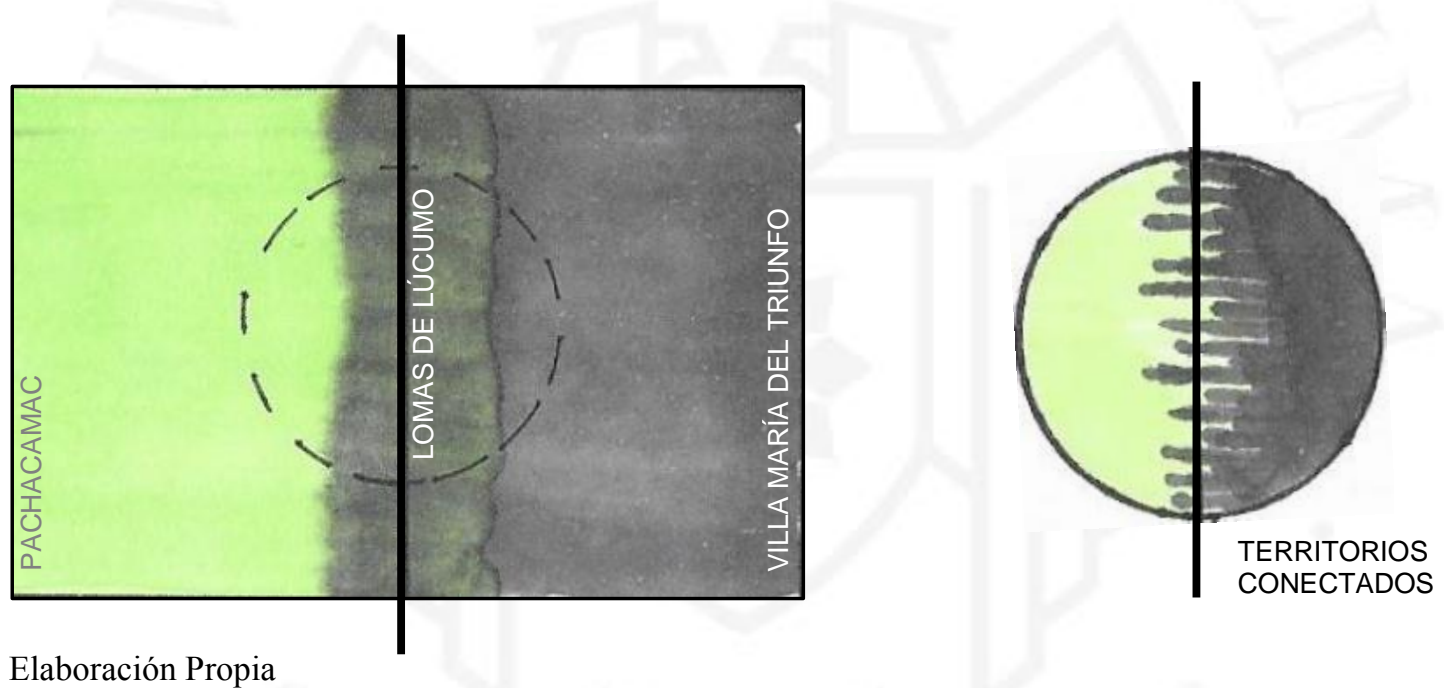

(Sennett , 2006) También estudió los conceptos y diferencias entre límite, frontera y borde, definiendo al límite como un elemento que involucra un cierre, comparándolo con un muro medieval; con respecto a las fronteras dentro de un contexto natural las define como el lugar donde los organismos elevan su interacción producto del encuentro entre distintas especies y condiciones físicas; finalmente define al borde como un espacio liminal, palabra derivada del latín limen que significa umbral y hace referencia al espacio intersticial entre medios. 
Es importante especificar que la frontera es el espacio físico donde se produce la interacción entre dos entornos y el borde implica además de esto las relaciones sociales, económicas, ambientales y/o culturales que se derivan producto de ésta conexión, generando nuevas identidades únicas a éste entorno; así lo explica Villamizar Duarte en la siguiente cita:

Recientemente, los enfoques multidisciplinares han propuesto entender los bordes como un espacio dinámico de relación entre territorios $\mathrm{y}$ actores que permite el surgimiento de nuevas territorialidades, y en donde el problema del límite implica clasificaciones construidas socialmente a partir de interacción entre dinámicas urbanas, rurales y ambientales. (Villamizar Duarte, 2014)

Tras definir estos tres conceptos, se tiene claro que el entorno donde se desarrolla el presente proyecto de tesis conforma un borde, pues representa el área urbana donde confluyen por encima de sus características territoriales, los aspectos sociales y ambientales propios del Ecosistema Lomas de Lúcumo y del C.P.R. Quebrada Verde.

Territorialmente el borde entre éstos entornos es tácito, se demarca implícitamente por la línea de casas asentadas en las laderas de las Lomas, pero la ciudad tiene la percepción de que puede seguir expandiéndose hacia el ecosistema; es aquí donde debe incidir la propuesta arquitectónica, en demarcar los límites de la ciudad sobre el entorno natural.

\subsection{Bordes y Barreras}

Resulta importante realizar una comparación entre los conceptos de borde y barrera, pues la forma en la que se maneje este territorio puede terminar por convertir en barreras entornos de borde, y en vez de potenciar las dinámicas de este espacio, puede terminar por anularlas totalmente. 
En urbanismo, el término barrera designa obstáculos o limitaciones, que pueden ser físicos, naturales y/o creados por los mismos procesos de evolución y crecimiento de la ciudad, que impiden que determinados grupos de población puedan acceder, circular o moverse por un lugar o zona en particular. (Castillo Ventura, 2016)

Para Sennett, como se citó en (Castillo Ventura, 2016) "Una barrera es un límite que marca el final de una situación, un borde es un límite donde diferentes grupos pueden interactuar". El autor da como ejemplo de barrera en la ciudad las líneas ferroviarias y las vías expresas, en la naturaleza una barrera podría ser un río como elemento en sí, el mar por su extensión o un espacio protegido, considerado intangible.

Figura 3.11 Representación conceptual de borde y barrera

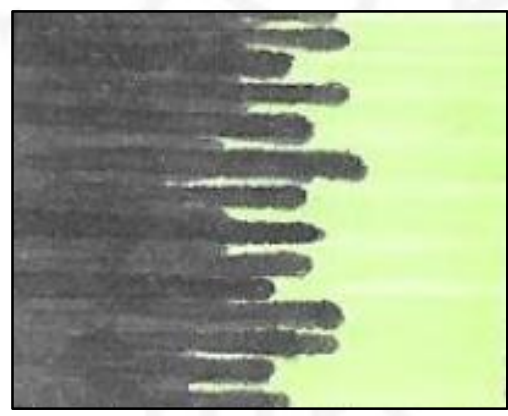

BORDE

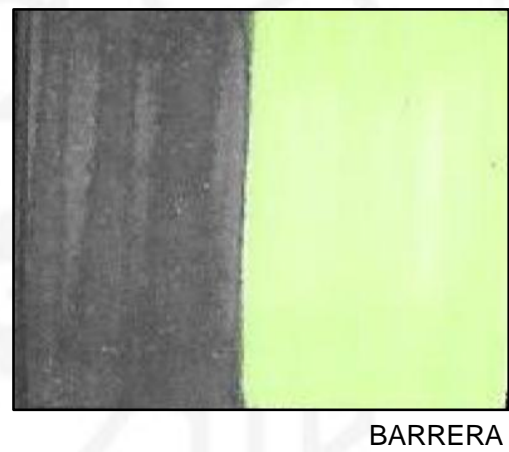

BARRERA

Elaboración Propia

Considerando entonces el contexto urbano- natural donde se desarrolla la presente tesis como un entorno que permitirá la interacción de éstos dos espacios, es esencial que el diseño arquitectónico genere las condiciones para que éstas dinámicas se ejecuten y este espacio no quede convertido en una barrera. 


\subsection{Teorías de borde}

La presente investigación analiza las teorías desarrolladas sobre borde, desde el punto de vista de dos autores que comparten perspectivas comunes frente a la definición de este concepto. El primer autor, fue quizás uno de los primeros en estudiar el borde como tal en la ciudad, a continuación se presenta la definición exacta que le otorgó al concepto de borde, Kevin Lynch.

"Los bordes son aquellos elementos lineales que son considerados sendas; son por lo común, pero no siempre necesariamente, los límites entre zonas de dos clases diferentes. Obran como referencias laterales." (Lynch, 2015)

(Lynch, 2015) interpreta al borde desde una perspectiva urbana, estudiando la ciudad, es allí donde encuentra ejemplos y referentes para definirlo; analiza concretamente Estados Unidos, por ejemplo cita a la avenida Central Artery, localizada en Boston y la define como un borde fragmentario visualmente pues aunque es un todo continuo solo se lo puede observar en determinados puntos; la arteria además posee la cualidad de intransitable frente al peatón constituyendo otra tipología de borde descrita por Lynch, quien la cataloga como un borde fuerte, "Los bordes que parecen más fuertes son aquellos que no sólo son visualmente prominentes sino que también tienen una forma continua y son impenetrables al movimiento transversal.(...) Los bordes, sean de ferrocarriles, topografía, vías directas o límites de barrios constituyen un rasgo muy típico de este medio y tienden a fragmentarlo." (pág. 79) Aunque la cualidad de impenetrable aquí mencionada es aclarada líneas más adelante donde abre la posibilidad al cambio de esta condición "Muchos bordes son verdaderas suturas y unen, en vez de ser vallas que separan” (pág. 80) 
Figura 3.12 Representación de un borde fragmentado y un borde fuerte, según la teoría de Kevin Lynch

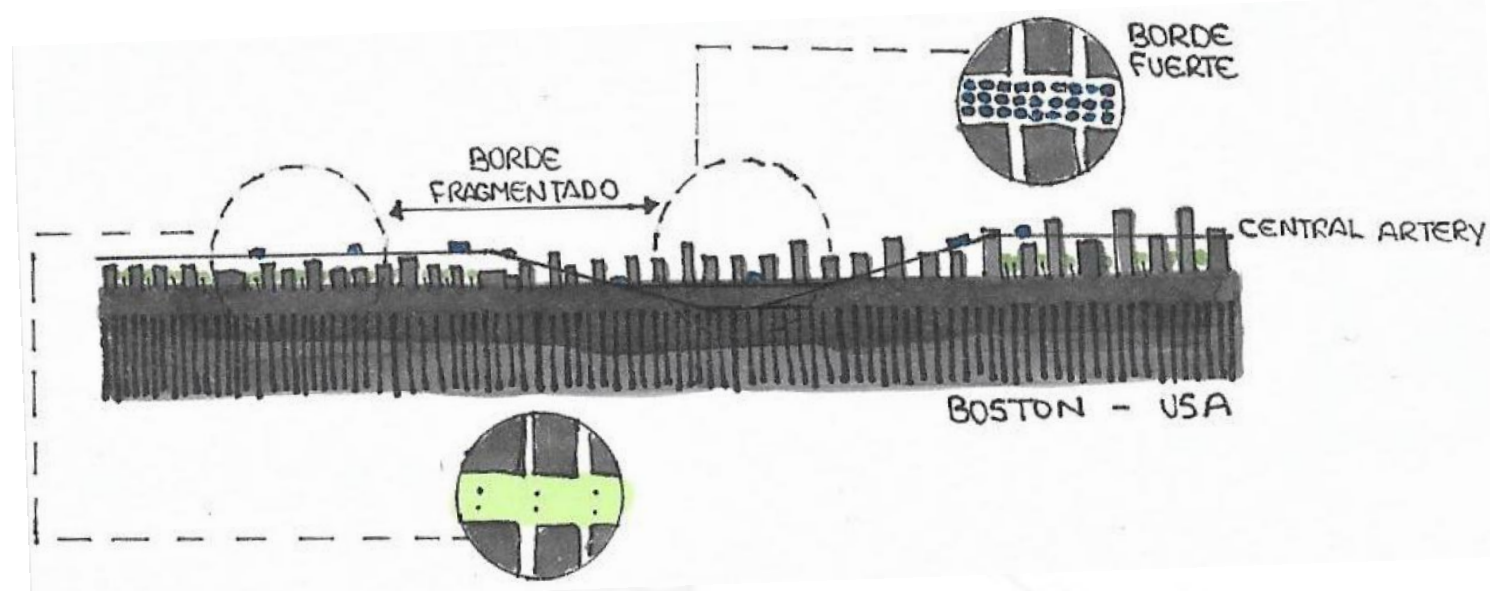

Elaboración Propia

A menudo Lynch asocia al borde como una senda con un fuerte rasgo delimitante, afirma también que muchos de éstos bordes pueden poseer cualidades directivas, al igual que las sendas:

Los trenes elevados de Jersey City y Boston constituyen ejemplos de lo que se podría llamar bordes aéreos o en lo alto. El "elevado" a lo largo de Washington Street en Boston identifica la senda, visto desde abajo, y fija la dirección hacia el centro de la ciudad. Cuando deja la calle, en Broadway, la senda pierde dirección y fuerza. Cuando varios bordes como éstos se curvan y cruzan en lo alto, como ocurre cerca de North Station, el resultado puede confundir mucho. Pese a esto, los altos bordes aéreos, que no serían vallas al nivel del suelo, podrían en el futuro constituir elementos de orientación muy eficaces en una ciudad. (Lynch, 2015) 
Figura 3.13 Representación de una senda como borde

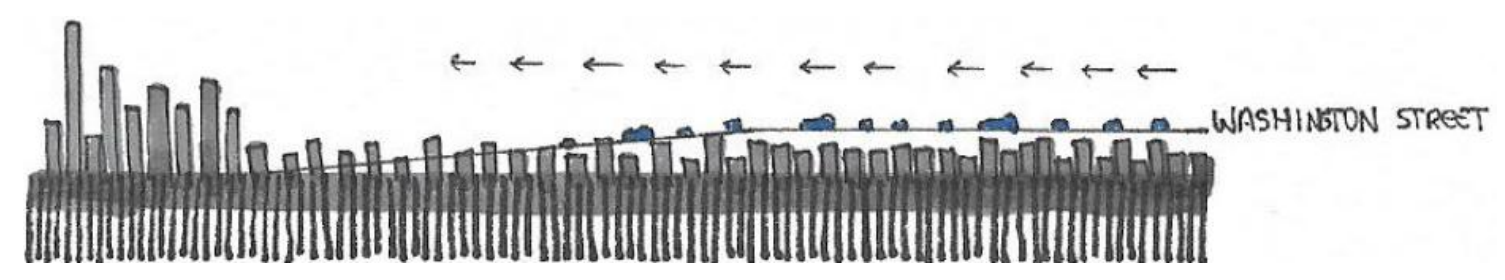

Elaboración Propia

Una senda como borde puede darle a la ciudad un sentido de direccionalidad, y ayudar a orientar a sus habitantes

Otra tipología de borde propuesta por el autor, son los bordes visibles, refiriéndose a aquellos de escala gigantesca, como el Lago Michigan en Chicago el cual visto en planta desde una dimensión aérea puede identificar sustantivamente a la ciudad.

Figura 3.14 Representación de un borde visualmente fuerte

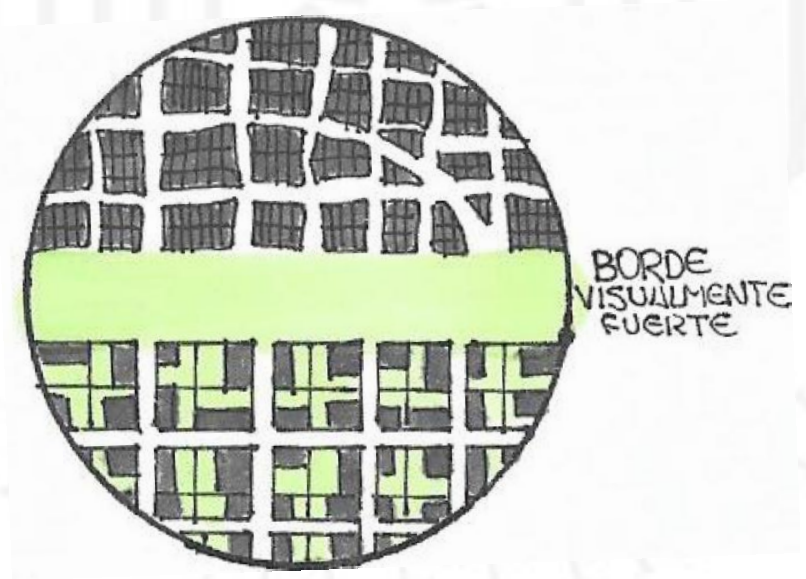

Elaboración Propia

(Lynch, 2015) se caracteriza por asemejar constantemente los bordes a sendas, de ésta comparación deduce que el borde para ser percibido como tal, debe conservar continuidad en su forma, al igual que una senda. Esta continuidad involucra características como perfil urbano, estilo arquitectónico, tipología, color, estrategias 
proyectuales frente al contexto, entre otras. Expone también, que en el impacto visual que genere un borde en su entorno, radica la fortaleza del mismo, poniendo como ejemplo más claro, la transición del agua a la tierra en un frente marino; explicando que cuando el borde de unión donde coexisten dos regiones yuxtapuestas está bien diferenciado la atención visual se concentrará fácilmente en él y permitirá identificarlo.

Figura 3.15 Representación gráfica de la continuidad de un borde en la ciudad.

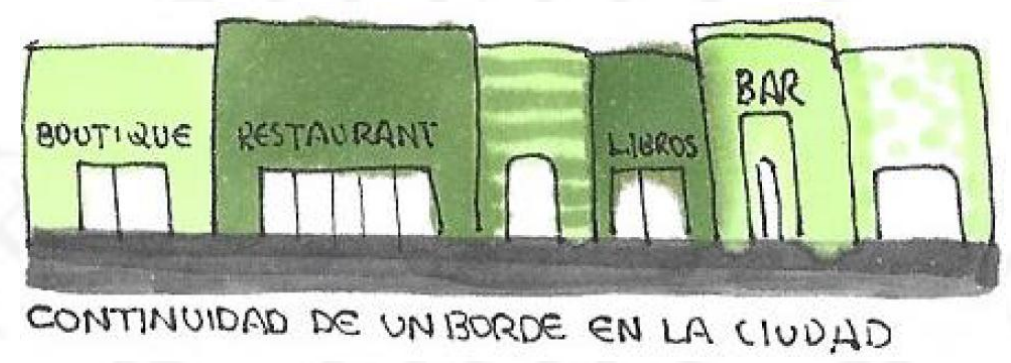

Elaboración Propia

Los estudios de Lynch hablan de como un borde es más claramente perceptible, al ser el mediador entre dos territorios opuestos, cuando el escenario no es éste se puede hacer uso de distintas herramientas que hagan notar al borde como las descritas a continuación:

Figura 3.16 Representación gráfica de cómo destacar a un borde mediante materiales que hagan contraste

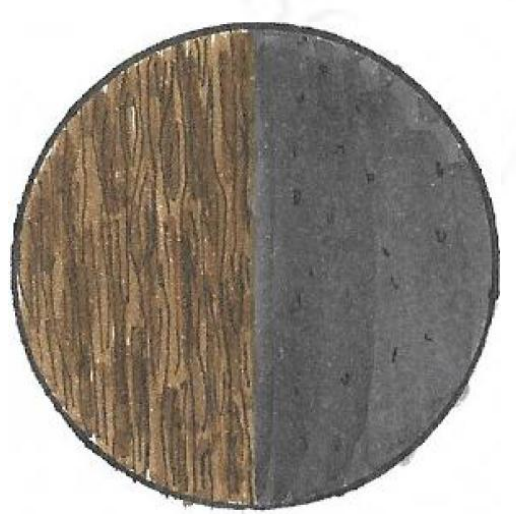

Elaboración Propia 
Figura 3.17 Representación gráfica de cómo destacar a un borde mediante una concavidad que interrumpa el transcurrir de una línea

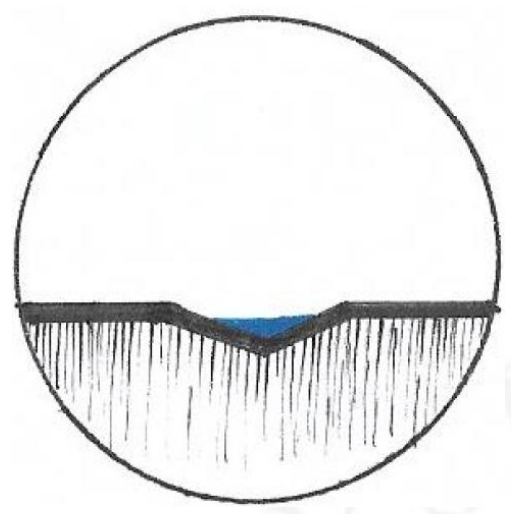

Elaboración Propia

Figura 3.18 Representación gráfica de cómo destacar a un borde mediante el arbolado

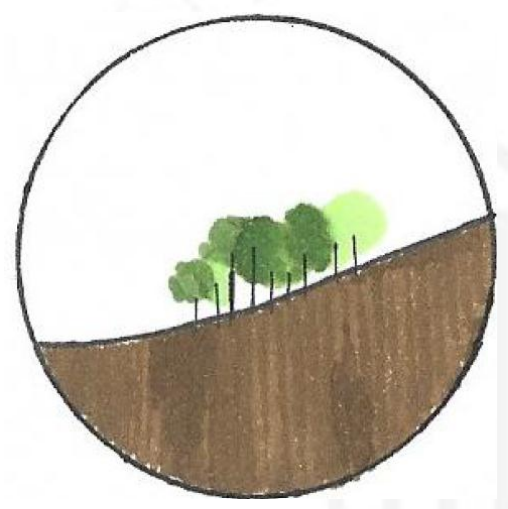

Elaboración Propia

Figura 3.19 Representación gráfica de cómo destacar a un borde mediante una transición

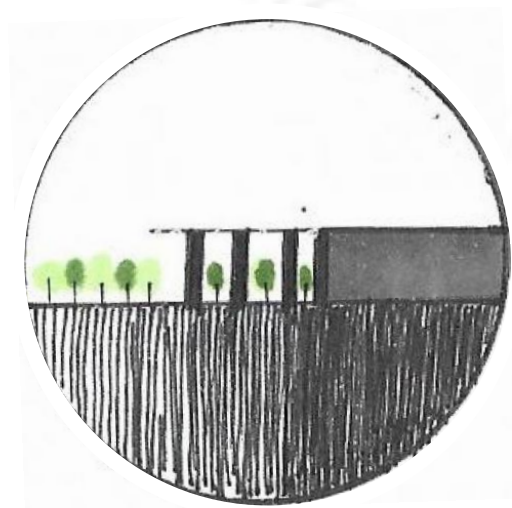

Elaboración Propia 
Figura 3.20 Representación gráfica de cómo destacar a un borde mediante la individualización de un extremo con respecto al otro

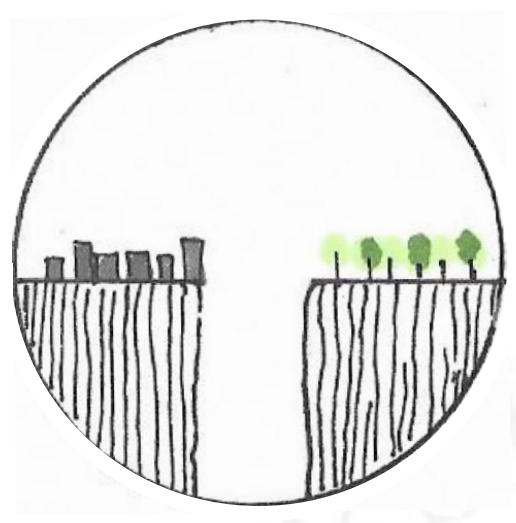

Elaboración Propia

Figura 3.21 Representación gráfica de cómo destacar a un borde, haciéndolo visible a grandes distancias

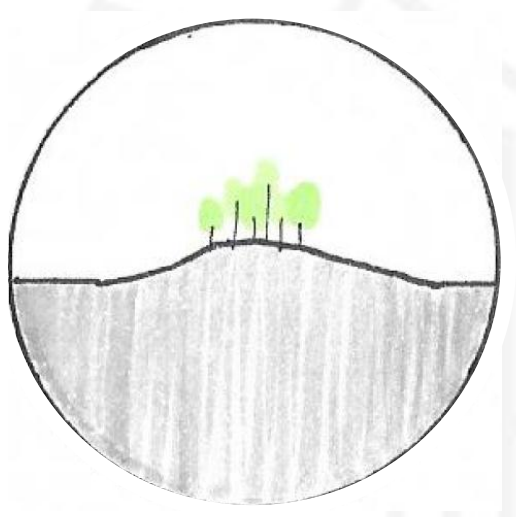

Elaboración Propia

Figura 3.22 Representación gráfica de cómo destacar a un borde mediante al potenciar visualmente sus extremos

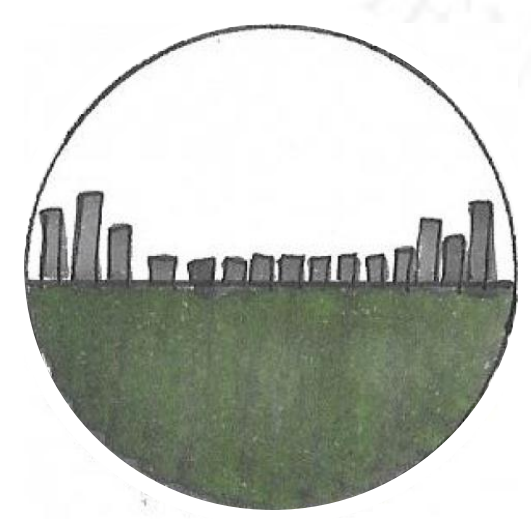

Elaboración Propia 
Figura 3.23 Representación gráfica de cómo destacar a un borde haciéndolo accesible y aumentando el uso de este espacio

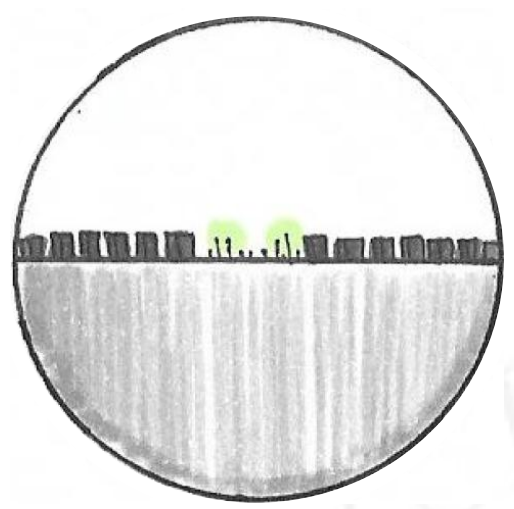

Elaboración Propia

Finalmente Lynch concluye

Un borde puede ser algo más que una barrera dominante, tan sólo si se permite que pase a través de él una penetración visual o de movimiento; si, por así decirlo, se lo estructura en cierta profundidad con las regiones laterales. Entonces se convierte en una junta y deja de ser una barrera, constituyéndose en una línea de intercambio. (Lynch, 2015) 
El siguiente autor Gary Leggett, en su libro "Polis, visiones y versiones de Lima a inicios del siglo 21", consolida la teoría de borde bajo un contexto nacional, netamente limeño, por lo cual se consideró de suma relevancia citarlo en este escrito; a continuación se presenta parte de sus investigaciones.

"Toda división o distinción implica algún grado de comunión y semejanza. La naturaleza del borde devela cuando entendemos tanto lo que une como lo que separa." (Leggett, 2006)

Figura 3.24 Representación conceptual de la Teoría de Gary Leggett, sobre entender en borde tanto lo que une como lo que separa

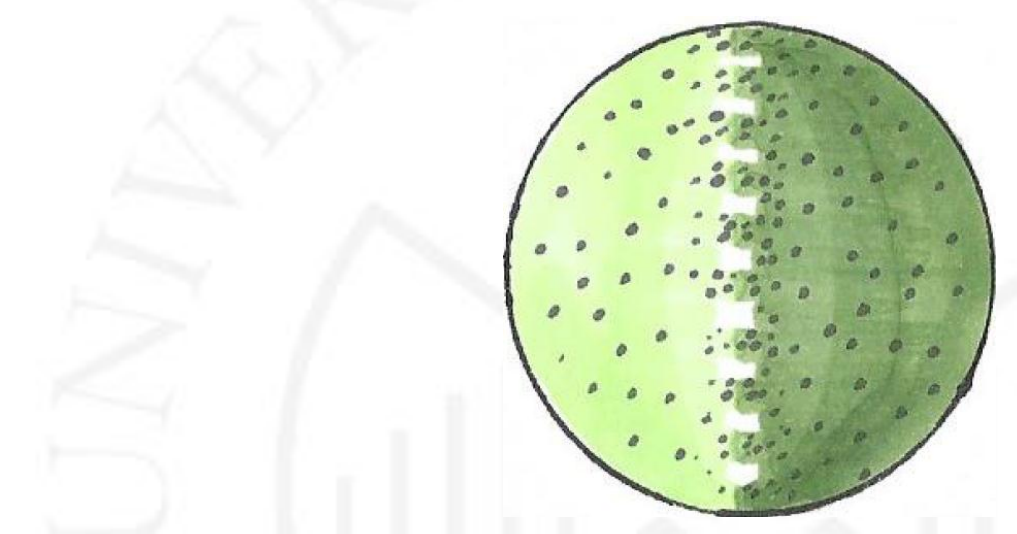

Elaboración Propia

(Leggett, 2006) al observar la ciudad empieza a situar conflictos urbanos concluyendo que el origen de los mismos no es más que el contacto entre elementos distantes dentro del entorno urbano, denominando borde a "La línea, zona o punto, sobre el que colindan estos elementos” (pág. 208), más adelante suscribe: “La palabra borde representa, en todas sus variantes, la ruptura e interrupción de continuidad percibida.” (pág. 208) 
Figura 3.25 Representación del borde como ruptura o interrupción de una continuidad percibida

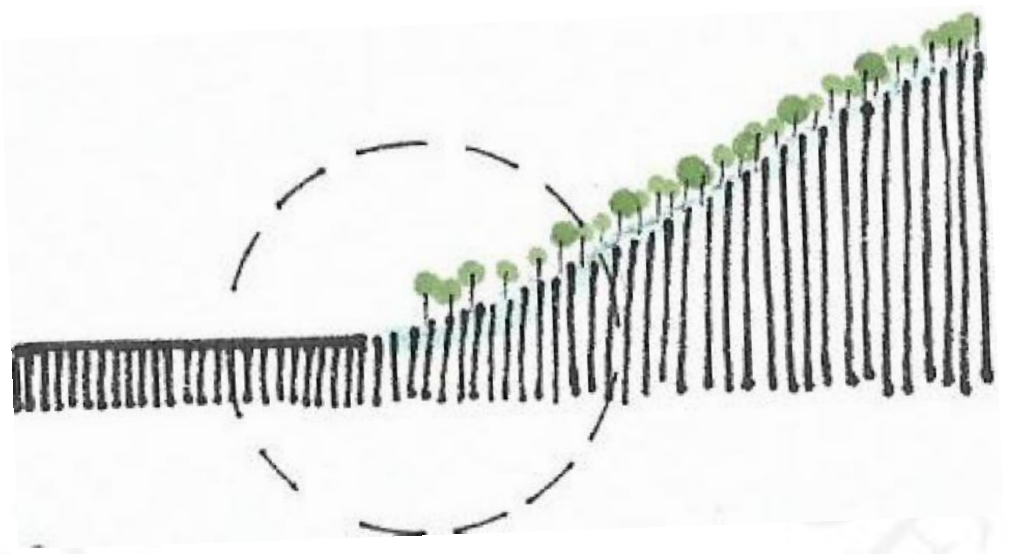

Elaboración Propia

Es importante analizar como Leggett a diferencia de los otros autores citados en la presente investigación le da al borde una connotación más allá de una línea, amplía la categoría permitiéndole ser una zona, como por ejemplo 279 hectáreas del Ecosistema Estacional de Lomas, que representa un espacio de borde entre Pachacamac y Villa María del Triunfo. El autor también expone que el borde puede ser un punto, una percepción cercana a esta interpretación la dio Lynch cuando determinó que un gran lago en medio de la ciudad representaba un borde.

Este autor al ser muy crítico de la ciudad, le atribuye a los bordes el origen de muchos de los conflictos urbanos, pero yo creo que se refiere no al borde por su naturaleza conceptual en sí, si no a como éstos espacios han sido relegados por los municipios en los bordes políticos y por las entidades competentes en los bordes económico-sociales y urbano-naturales; el mal manejo de los bordes ocasiona no solo problemas urbanos, como deficiente movilidad o inseguridad, si no también sociales como falta de acceso a necesidades básicas, a equipamiento urbano y falta de empleo.

Leggett al igual que Lynch le atribuye al borde más allá de sus características territoriales, un valor social que involucra a los actores de ambos espacios, y resalta la importancia de estudiar estas relaciones para entender los tipos de conexiones establecidos que juntos determinan el funcionamiento de la ciudad. 
La noción del borde exige, entonces, que descubramos no solo el punto de contacto entre dos campos diferentes sino también la naturaleza intrínseca de los mismos. En ese sentido, no se trata meramente de una demarcación espacial; también puede constituirse en un principio de clasificación y articulación. La idea nos aleja de una visión lineal de la urbe, considerando en cambio, la complejidad de contactos y roces que determinan su funcionamiento. (Leggett, 2006)

Figura 3.26 Representación conceptual de los puntos de contacto y la naturaleza intrínseca de los mismos en un borde

Elaboración Propia

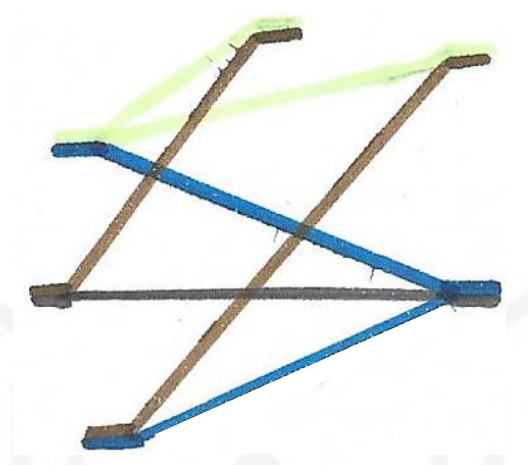

El autor evalúa conceptos cercanos a la definición de borde, como límite y frontera; fijando al primero como un punto intransgredible y al segundo como algo que comúnmente implica una relación con lo lejano, ajeno y desconocido; también cita a Saskia Sassen quien define al borde como una serie de "coyunturas e intersticios que enmarcan y deslindan las interacciones económicas en la ciudad contemporánea. (...) sugiere trascender las categorías topográficas y locales del análisis urbanístico para lograr una comprensión más penetrante y veraz de las dinámicas socio-económicas de una urbe." (Leggett, 2006)

Leggett establece las siguientes tres formas de percibir un borde:

El borde como encuentro:

"Bajo esta visión, se considera que el mundo está hecho de partes que componen, en interacción, la totalidad". 
Figura 3.27: Representación conceptual del borde como encuentro

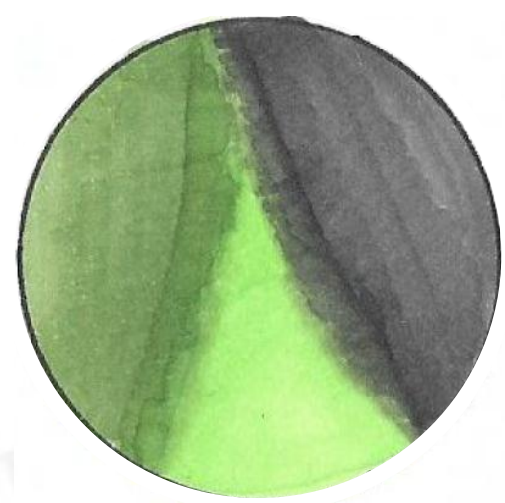

Elaboración Propia

El borde como barrera:

Esta visión considera que el mundo está hecho de separaciones intrínsecas y no solo cognitivas. La unidad es un mito que nace de la necesidad humana de darle coherencia a los fragmentos, pero que no tiene ningún sustento fuera de la mente. (Leggett, 2006)

Figura 3.28 Representación conceptual del borde como barrera

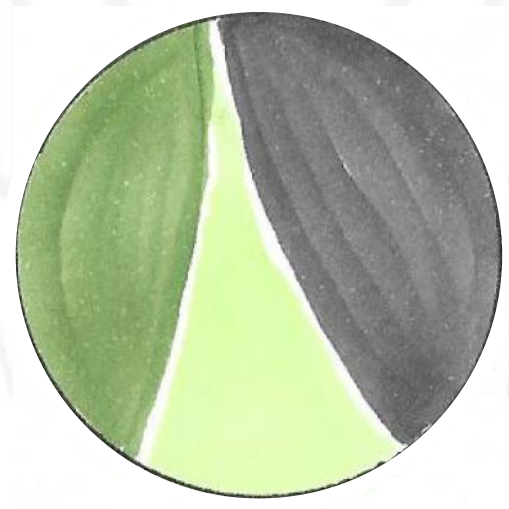

Elaboración Propia 
El borde como ilusión:

En esta visión, se considera que las partes o fragmentos son simplemente una ilusión, pues en realidad no existen las diferencias fuera de nuestra mente. En el fondo todo es todo, aunque nuestra percepción sugiera lo contrario. El conflicto se resuelve conociendo esta verdad. Ya que no puede haber roces cuando no existen las separaciones. (Leggett, 2006)

Figura 3.29 Representación conceptual del borde como ilusión

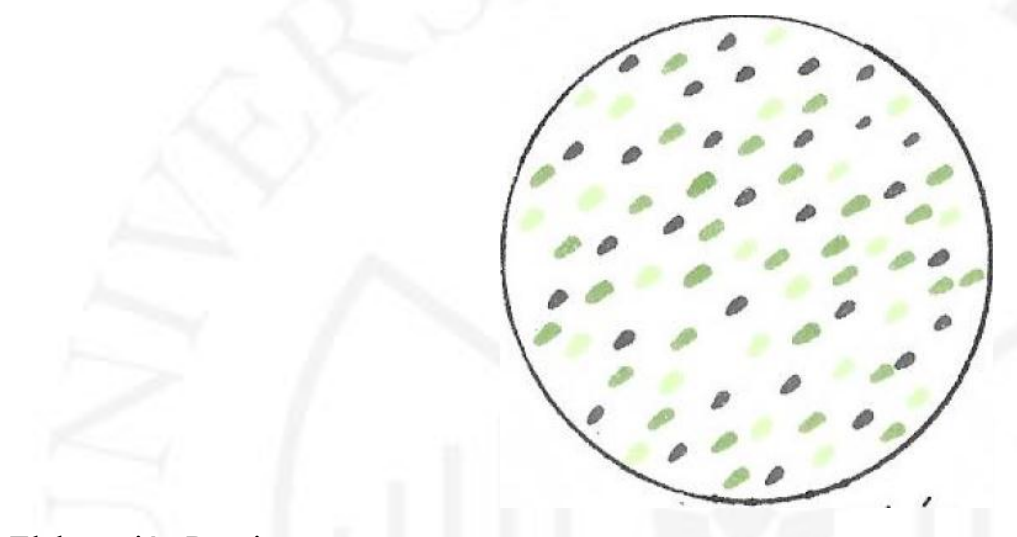

Elaboración Propia

Tras un detenido proceso de observación de la capital, el autor establece las siguientes tipologías de borde presentes en Lima Metropolitana, aunque muchas veces son presentadas más bien como barreras, el interés del autor es que lleguen a convertirse en verdaderos bordes.

Bordes personales:

"Lo límites de Lima no yacen solamente en los confines ulteriores de la urbe, sino que están inscritos en cada persona." (Leggett, 2006)

(Leggett, 2006) suscribe: "Las categorías de lo interno y externo nacen cuando se toma conciencia del primer borde que las separa: el cuerpo humano” (pág. 211), siendo entonces la forma en que se vincula ambas categorías lo que lo identifica como un ente cultural, "La conciencia cataloga la realidad según las exigencias del cuerpo y le otorga un valor basado en las comparaciones que fabrica.” (pág. 211), mediante la 
memoria interiorizamos estas comparaciones convirtiéndolas en categorías, es allí donde surge la fragmentación, definida como la observación individual de las partes sin encontrarles relación tras la división de un todo.

"La fragmentación no solo es un fenómeno físico, sino que echa raíces en un plano mental que luego encuentra en el espacio una justificación para sostenerse." (Leggett, 2006)

Este tipo de borde es llamado personal porque cada individuo apoyado en su experiencia, conocimientos, formación y cultura, divide su entorno separándolo en grupos según características comunes que solo él percibe y que no necesariamente comparte el resto de la población. También influyen en esta dinámica mental el entorno y la forma de habitar la ciudad, específicamente en los circuitos cerebrales que se asocian a la conciencia y a la empatía.

"El verdadero significado del individuo, que por desgracia se ha olvidado, contempla a aquella persona cuya conciencia no tiende a la división, sino que representa una totalidad en sí misma (pág. 212), por esta razón está únicamente en la mente del ciudadano reducir la forma en la que percibimos fragmentariamente los elementos de la ciudad, pues la concepción de su imagen depende solo del espacio construido y del hombre que lo ocupa, "Todos llevamos una versión distinta de la ciudad inscrita en nuestra mente y es allí, en principio, donde debemos alterar nuestras nociones habituales de la misma.”. (pág. 212)

Kevin Lynch ni ningún otro autor antes citado había incluido a los bordes personales como una tipología pero creo que su estudio es relevante, y en él recaen muchos de los problemas urbano-sociales a los que ahora nos enfrentamos. El habitante está continuamente cuestionando su entorno, y construye una barrera para diferenciarse de él, volviéndose así seres insensibles, que esperan que el otro haga algo por mejorarlo, creando de esta forma una sociedad ausente e indiferente.

En caso de Lima nos muestra una situación en la cual la identidad urbana, profundamente heterogenea y conflictiva en su estructura, conlleva a la destrucción de los parámetros políticos y espaciales que 
permitirán que una ciudadanía formule un proyecto mancomunado como sociedad. La fragmentación social, a juzgar por ello, es condenable porque atenta contra la posibilidad de crear incentivos de colaboración y crecimiento entre poblaciones disgregadas. Cualquier intento de limpiar o mejorar una ciudad encontrara en este hecho un límite innegable: cuanto más cerrada la noción de lo propio, más amplio y menos relevante será lo ajeno. (Leggett, 2006)

En base a las líneas suscritas por Leggett, observamos la realidad urbana y recapitulamos cada proyecto de intervención que ha concluido en el fracaso o si no es así es fuertemente criticado por los ciudadanos aunque no dejen de usarlo porque los vincula a este una necesidad como el transporte por ejemplo; es así que entendemos que si bien se pensó en una mejora de la calidad de vida del poblador, nunca se hizo un estudio al usuario directo para establecer por lo menos una media y apuntar específicamente a solucionar problemas reales, no los percibidos por diseñadores ajenos a las dinámicas urbanas de un determinado escenario; además enmarcándonos en la teoría de Leggett sobre bordes personales es importante poder comprender las visiones intrínsecas a cada individuo respecto a la ciudad y encontrar un común denominador a tan variadas percepciones así como tratar de disminuir las fricciones generadas por ésta variedad de alguna forma, tal vez la educación sea la clave.

La imagen de una ciudad toma, por lo tanto, años en cambiar ya que su transformación no solo ocurre en un plano físico, sino también en el espacio mental de sus habitantes. De allí que sea tan importante adjudicarle un acercamiento pedagógico al urbanismo; uno que no se limite, ciertamente, a campañas esporádicas de publicidad, sino que también ingrese a los currículos colegiales y opere, como mínimo, en un marco de 30 años. (Leggett, 2006) 
Bordes construidos:

"La Muralla de Lima aún no ha sido derribada, simplemente se ha trasladado al perimetro de nuestras casas.”. (Leggett, 2006)

(Leggett, 2006) establece como el primer borde construido a la vivienda, por el carácter excluyente que posee, que nos lleva a interiorizar mentalmente delimitando el afuera del adentro, percibiendo al interior como un espacio donde nos sentimos seguros y autónomos, refiriendo el autor que "Al demarcar el espacio de la intimidad, toda morada se convierte en la medida de su entorno, ya que es a partir de ella que juzgamos los demás espacios de la urbe.”. (pág. 13)

"Bordes solidifados. Se suele pensar que el barrio o distrito en que uno vive es una isla, un muro imaginario, con manifestaciones concretas, en el perímetro de su espacio." (Leggett, 2006)

Bajo este concepto encontramos que además son muy pocos los edificios privados o institucionales que intentan hacer de esta barrera entre privado y público un verdadero borde donde exista el espacio correcto donde ambos se encuentren e interactúen, muy por el contrario el programa Mi Vivienda no establece entre su normativa de licitación pública ningún aporte a la ciudad pues esto repercutiría directamente sobre el área vendible, haciendo que pocos empresarios sean los que apuesten por las mismas, esto último como lo cita . (Leggett, 2006) "atenta directamente contra la posibilidad de construir una ciudad ecológica, pues cualquier franja de pasto o verdor que pudo concederse a la ciudad, termina tristemente empaquetada de cemento y automóviles."

El autor además, es muy claro al decir cuan perjudicial puede ser para la ciudad invadir las veredas y aún más no instalarlas, eliminado por completo la interacción de individuos en la urbe pues "La ausencia de un objeto se convierte, así, en una especie de barrera morfológica, que en este caso niega cualquier interacción entre el mundo del hogar y de la calle, (...) se ve trágicamente comprometida por una simple negación urbanística.”. (Leggett, 2006) 
Como parte de lo construido, debemos también considerar el ordenamiento de elementos urbanos en gran escala. Por ejemplo, si hacemos un contraste entre las tramas de un distrito como San Borja y una urbanización “informal” como Pachacútec (en Ventanilla), podremos ver como la configuración de las calles lleva inscrita una lógica social de crecimiento muy particular. En el caso de Pachacútec, las calles han sido trazadas en línea recta como vaticinando la expansión continua de la comunidad, mientras que en San Borja las calles son curvas y ensimismadas con el propósito de mantener una autonomía espacial, y por ende, cierto grado de exclusión social. El círculo, a diferencia de la línea, no es extensible, y como trama urbana, cumple un papel de autolimitación y ensimismamiento. (Leggett, 2006)

Bordes políticos y legales:

Ente las distinciones legales peor definido y más problemáticas de este país, tenemos sin duda la eterna dicotomía de lo urbano y lo rural. En cierto sentido, Lima no es tan "urbana" como se piensa, en el este y en el sur, la urbe sigue siendo, a duras penas, una ciudad rural. (Leggett, 2006)

El autor refiere que los bordes políticos y legales son producto de la nula comunicación establecida entre municipios, cada municipalidad se valida de su carácter autónomo para establecer políticas individuales sobre gestión del territorio lo que termina por fragmentar la estética de la ciudad, pues además no existe tampoco un consenso decretado por el municipio metropolitano que regule la normativa ni establezca un plan de gestión urbana central.

El sistema municipal está estructurado de forma que no existen incentivos para la colaboración entre distritos; por el contrario, la fragmentación de intereses es mucho más rentable puesto que no requiere una extensión del organismo administrativo (ni de los recursos que este maneja). De allí que sea tan irónico que Los Olivos se denomine 
un distrito Sin Fronteras: actualmente se enfrenta a un litigio sobre los límites con Independencia, o mejor dicho, sobre los arbitrios del Mega Plaza que está situado en el mismo borde del distrito (zona del conflicto, según el lenguaje catastral). (Leggett, 2006)

No son solo las condiciones internas de los organismos estatales, sino la interacción entre los mismos los que generan los problemas mencionados. Si la planificación urbana no ha sido un proyecto exitoso en este país -y no hay que ser planificador para darse cuenta- no es tanto por una falta de recursos ni proyectos, sino por la ausencia total de una consistencia administrativa. Bastaría preguntarse de qué manera las condiciones actuales del centro histórico están ligadas al impasse burocrático que se ha forjado entre el municipio, el INC, el poder ejecutivo, y el capital privado, para juzgar la validez de este argumento. (Leggett, 2006)

Bordes socioeconómicos:

En el año 2005 se instaló y seguidamente retiró la malla metálica de Bucaramanga instalada entre los límites de Ate y La Molina, la cual representaba un latente ejemplo de barrera socioeconómica, es así en nuestra ciudad se han venido replicando ejemplos como este y no solo en el límite urbano, pues el autor también considera al hogar como un espacio urbano donde las diferencias económicas aún coexisten donde el resultado "puede ser virtuoso, como cuando se respetan las diferencias y se llega a un acuerdo de apoyo mutuo, o puede bien ser desastroso, como cuando se ahondan los prejuicios mutuos y se atenta contra la dignidad del otro”. (Leggett, 2006)

La urbe es el terreno de la peor clase de inanición: aquella que debe enfrentarse no solo a una ausencia de necesidades básicas (agua, alimento morada, etc.), sino a la imposibilidad de complacer aquellas necesidades adicionales que fomenta la vida en la ciudad (entretenimiento, comodidad, belleza, etc.). Llamamos a estas últimas necesidades porque la salud emocional, y por consiguiente, la armonía física de un ser humano termina dependiendo (o bien, suele medirse en términos) de su obtención. (Leggett, 2006) 
Bordes geográficos:

Leggett suscribe que la configuración geográfica de un terreno generalmente determina los parámetros y el ritmo de crecimiento de una ciudad, identificando tres elementos que constituyen un borde geográfico: "los bordes naturales del terreno, la constitución morfológicas de la trama urbana y el contacto entre zonas que no necesariamente colindan en el espacio pero que gracias a la tecnología actual gozan de una comunicación sin precedentes". (Leggett, 2006)

La expansión incauta de la urbe, frente a la engañosa "carta blanca" del desierto, se convirtió en una especie de pacto a priori con el diablo: la ciudad crecía, desde luego, pero lo hacía a expensas de sí misma. Los bordes del terreno y del hogar fueron antepuestos a los límites de la comunidad que los albergaría. (Leggett, 2006)

Más allá del terreno en que se explaya, la ciudad genera su propia geografía con el tiempo. Si bien Lima se expandió desenfrenadamente durante la segunda mitad del siglo XX, ocupando cada vez un área mayor y más endeble en el desierto circundante, las tendencias actuales de crecimiento indican que la expansión se ha volcado sobre sí misma, llenando las ranuras y reductos que dejó tras su primer pasaje. (Leggett, 2006)

Bordes temporales:

La manera en que construimos el tiempo sin duda está supeditada a los parámetros que nos ha impuesto la experiencia para medir nuestras acciones. En el caso de Lima, el tiempo ha sido labrado a la imagen de una interrupción constante; no concebimos el futuro como una extensión del presente, sino que le atribuimos un quiebre -producto directo del funambulismo político que nos enmarca- que lo aleja paulatinamente de nuestra condición actual. El tiempo limeño se mueve, o bien suele dar vueltas, en bloques de cinco años. (Leggett, 2006) 
El autor refiere que al tiempo en Lima se le atribuye un doble carácter al que denomina descomposición cíclica, esto formado a partir de las dos formas de percibir el tiempo.

Si entendemos la "identidad urbana" como el conjunto de imágenes o memorias que constituye el carácter de una ciudad en la mente de sus ocupantes, queda claro que su construcción, en tanto provenga de la experiencia y la termine condicionando, determinara el tipo de relación (o conciencia) que tendrán los habitantes con su entorno. (...) Toda identidad, al ser intrínsecamente ilusoria, se apoya en la memoria para constatarse. El tiempo que nace de esta memoria marca el terreno en el que dicha identidad florece y se marchita; es decir, nadie puede atribuirse una identidad -por falsa que esta sea- sin situarse, ante todo, en un flujo temporal que delimite su existencia. (Leggett, 2006)

Las ruinas de una ciudad nos proporcionan evidencia sobre la concepción que propugna una sociedad no solo en torno a su historia, sino principalmente con respecto a su futuro, de modo que resultaría erróneo suponer que una ruina representa exclusivamente al pasado y no tiene mayor valor fuera de su contenido históricomaterial. (Leggett, 2006)

El autor explica que aunque muchos piensen que reconstruyendo ciertas ruinas se podría instaurar en los ciudadanos una conciencia histórica de aprecio y protección, el solo hecho de la reconstrucción no bastaría para lograr dicho fin, pues éste se percibe como un hecho de restauración arquitectónica mas no urbana pues no existe un plan de integración, haciendo que "Los restos de nuestra historia se preservan así como hitos inconexos y no como circuitos dinámicos que el poblador común podría integrar con sus quehaceres cotidianos.”. (Leggett, 2006)

Pocos realmente se sienten herederos de esta ciudad, o porque 1) no habitan los espacios de la urbe que sus antepasados ocuparon o porque 2) no han nacido en Lima. Para los primero, la historia no pasa de ser un acto de agria 
rememoración, y para los segundos siempre resulta algo ajeno, deberá representar un beneficio a futuro y no un simple recuerdo prostético. (Leggett, 2006)

La única posibilidad que tenemos los peruanos de forjar entonces una conciencia histórica no yace, paradójicamente, en nuestra historia, sino en la visión que construyamos del futuro.(...) Como si se tratara de una fragancia de revista, nos quedamos siempre con el gusto plastificado, no completo, de lo que pudo ser ("en su momento") Lima; lo que pudo ser el tren urbano y ahora sólo es un paseo de excursión entre Villa El Salvador y el puente de Atocongo; lo que pudo ser la Costa Verde, y ahora sólo es un eclectico corredor vial sin un programa urbano coherente; lo que podría ser el Centro, y hoy sólo es un cascaron abandonado. (Leggett, 2006)

Bordes funcionales

Leggett se refiere por bordes funcionales a aquellos espacios que por alguna razón no se encuentran cumpliendo su verdadera función o que representan una barrera para el desarrollo de la misma y cita como ejemplo a los centros comerciales mal llamados "plazas" donde más allá de promover el consumismo hasta en el mismo hecho de vender recreación no expanden su función, también describe como a partir de que el acalde Orrego enrejara la mayoría de los parques en el centro de Lima para detener la invasión en éste por parte de los ambulantes se empezó a pensar al espacio público "en oposición al concepto de comercio" resultando la relación entre ambos "una contradicción incultivable.". (Leggett, 2006)

"La creación de espacios filtrados y artificiales, donde la exclusión de gente se convierte en el principio ordenador de la ciudad, parece dictar el futuro, cuando no el final, del desarrollo urbano en Lima." (Leggett, 2006)

Bordes culturales

Las ciudades son, sin duda, un hervidero de diferencias y conflictos. Hay quienes se apoyan en el concepto de diversidad para aceptar y celebrar 
esta condición, pero queda claro que la diversidad como tal no ofrece ningún beneficio en sí misma; deber ir de la mano con una lógica de cooperación, inclusive dentro de lo que algunos llamarían el "conflicto", para incentivar el crecimiento incluyente de una urbe. (Leggett, 2006)

El autor explica con el ejemplo de Bogotá la forma en que las fricciones sociales se han podido aliviar en gran medida con la creación de corredores peatonales dentro de los barrios, diseñados específicamente para conectar la ciudad en éstos espacios de fricción, además se gestionó una base de programas educativos que potenciaron la vida comunitaria de la ciudad.

El autor expone que cuando en un entorno formado por elementos diferentes, éstos en vez de encontrar elementos comunes y unirse para establecer relaciones se encapsulan evitando cualquier contacto, eliminan por completo la biodiversidad preexistente.

La diversidad se destruye a sí misma cuando acentúa solamente las diferencias; aísla, y al aislar no permite que entren en contacto las diferencias que celebra. El contacto cuando se da, termina siendo áspero y lleno de perjuicios. Paradójicamente, se diría entonces que la fricción es el resultado de una falta (no un exceso) de contacto. (...) El hombre por naturaleza, se acopla a lo que más se le asemeja. La ignorancia hace que su concepción de lo semejante sea bastante limitada y que, en muchos casos este supeditada exclusivamente a un plano material (el aspecto físico o los recursos económicos de una persona). (Leggett, 2006) 


\subsubsection{Paisaje}

\subsection{Teorías sobre paisaje}

El término paisaje se deriva, en las lenguas románicas, de la palabra latina pagus, que significa país. Las lenguas germánicas presentan un claro paralelismo a través de la expresión originaria land, de la que derivan landschaft (alemán), landscape (inglés), landschap (holandés), etc. (Cancer, 1994)

Luis Cáncer en su artículo Aproximación crítica a las teorías más representativas de la de ciencia del paisaje, cita a dos autores que definen el concepto de paisaje de la siguiente manera; Sancho Royo suscribe "el concepto de paisaje engloba una fracción importante de los valores plásticos y emocionales del medio natural"; Morgan en 1978 da una visión más subjetiva del paisaje "el paisaje no existe como tal más que a través del fenómeno psicológico de la percepción”, acercándonos a esta teoría Laurie 1975 nos explica las condiciones y mecanismos psicológicos empleados por el ser humano mediante los cuales puede percibir bella una cosa, el primero es relacionado a las sensaciones y percepciones intrínsecas al observador, la segunda está relacionada a la educación y cultura aprendidas o desarrolladas socialmente por el observador, continúa las referidas a las conexiones personales que pudiera existir entre el observador y el paisaje como familiaridad o predisposición a algún tipo. (Cancer, 1994)

"En este contexto es donde conviene entender el origen de la palabra "paisaje", vocablo que viene del francés pays, que también significa "lugar" en la geografía. Paysan significa campesino, alguien que es parte del paisaje." (Arredondo González, 2015)

El paisaje es, por tanto, algo subjetivo, es «lo que se ve», no «lo que existe». Pero el que sea subjetivo no quiere decir que sea una fantasía o una invención sino que se trata de una interpretación que se realiza sobre una realidad, el territorio, que viene determinada por la morfología de sus elementos físicos, que son objetivos, pero en la que intervienen 
factores estéticos, que le unen a categorías como la belleza, lo sublime, lo maravilloso y lo pintoresco, y a factores emocionales, que tienen que ver con la formación cultural y con los estados de ánimo de quienes contemplan. (Maderuelo, 2010)

Georges Bertrand, un geógrafo francés, citado en (Cancer, 1994) ha construido con sus investigaciones toda una teoría sobre el paisaje "el paisaje no es la simple suma de elementos geográficos separados sino que es -para cierta superficie espacial- el resultado de las combinaciones dinámicas, a veces inestables, de elementos físicos, biológicos y antropológicos que, engarzados dialécticamente, hacen del paisaje un cuerpo único e indisociable en perpetua evolución” (p. 24), su estudio específico se centra en el paisaje integrado el cual se sustenta en la integración misma, el dinamismo y la globalidad, él visualiza a cada elemento del paisaje como una particular estructura espacial desarrollada a partir de unidades independientes agrupándola en tres conjuntos, el potencial abiótico, el biótico y la utilización antrópica, "cada unidad se define por una dinámica propia, determinada por las interacciones de todos los elementos del complejo bajo un sistema de evolución que engloba el sistema morfogenético, la dinámica biológica y el sistema socioeconómico"

(Másmela Díaz, 2010) en su investigación sobre El Paisaje como Elemento de Ordenación Territorial cita a Escribano 1987, quien desde un enfoque visual asocia al paisaje con recuerdos y sensaciones de algo que pudimos percibir como agradable o bello y que difícilmente lo podemos expresar en palabras "puede decirse en una primera aproximación que se trata de una voz abstracta e intuitiva"; cita también la definición de Ballester 2002 quien define al paisaje como "todo aquello que percibe una persona en un punto determinado, es decir, el entorno de percepción plurisensorial que rodea a una persona en un momento dado."

Másmala Díaz a partir de la teoría propuesta por escribano, realizó el siguiente mapa donde muestra a las tipologías de la calidad visual del paisaje, según análisis intrínsecos, de entorno inmediato $\mathrm{y}$ de fondo escénico; muestra también sus componentes y elementos. 
Figura 3.30 Calidad visual del paisaje

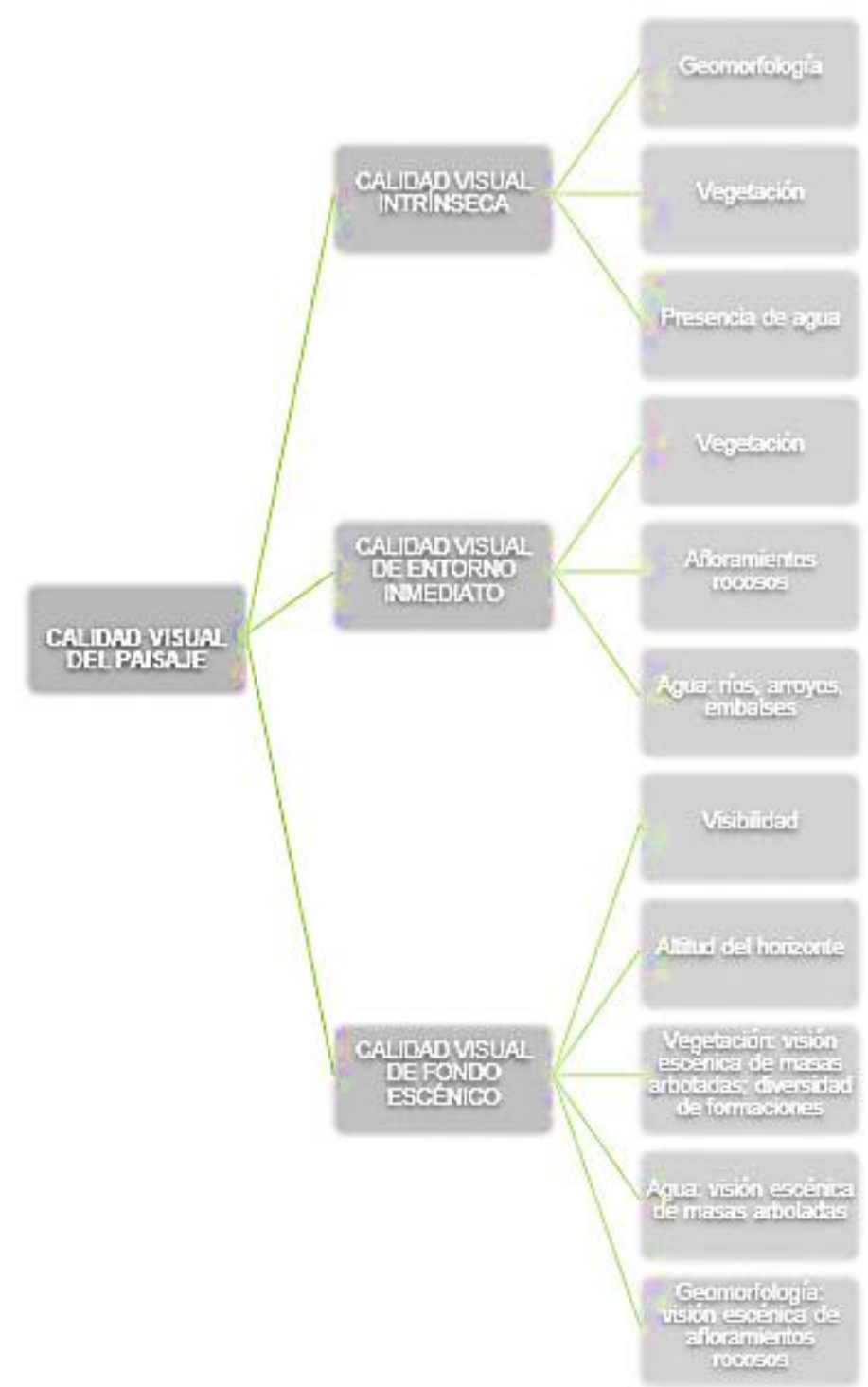

Fuente: (Cancer, 1994)

El paisaje revela su forma, su función y su contenido simbólico a través de una escala y una localización. La escala establece el tamaño del marco y el nivel de detalle con que se aborda el paisaje. Dado que el observador, sea virtual o real, es potencialmente móvil, la escala obedece a unas dinámicas de percepción que se establecen con la mediación, por ejemplo, del automóvil y los estilos de vida, que fijan el tamaño de los desplazamientos laborales o recreativos. (Riesco Chueca, Gómez Zotano, \& Álvarez Sala, 2008) 
Dentro del análisis del paisaje, la escala es un elemento de gran importancia, está directamente relacionada al punto de contemplación desde donde se sitúa el observador, he allí la importancia de valorar cada elemento a distinta escala.

Ha de tenerse en cuenta que la complejidad de los paisajes da lugar a la manifestación u ocultación (a medida que se recorren las escalas de contemplación) de propiedades emergentes, entendidas éstas como rasgos del sistema que sólo son pertinentes en una determinada escala. A otras escalas, estos rasgos dejan de ser perceptibles o relevantes. Ello es común en sistemas complejos cuya organización supone varias escalas en lo espacial y en lo temporal, lo que engendra un comportamiento global inédito, que no se deduce directamente de las partes componentes. (Riesco Chueca, Gómez Zotano, \& Álvarez Sala, 2008)

(Riesco Chueca, Gómez Zotano, \& Álvarez Sala, 2008) Citan a Hermann y Baudry 2002, quienes hablan del paisaje y su escala suscribiendo:

Los paisajes son por naturaleza heterogéneos en su composición y dependientes de la escala. Ello se debe al hecho de originarse por interacción entre factores físicos, biológicos y humanos, cuyos radios de influencia y dinámicas propias son variados, lo cual da lugar a mosaicos. Con una misma resolución temática, un paisaje puede ser homogéneo en la escala local, pero heterogéneo en otra escala incluida o inclusiva de la anterior. (Riesco Chueca, Gómez Zotano, \& Álvarez Sala, 2008)

Los mismos autores citan a Forman, 1995 y Zonne Veld 1995 quienes definieron los siguientes conceptos sobre la valoración de escalas del paisaje:

(Riesco Chueca, Gómez Zotano, \& Álvarez Sala, 2008) desarrollan los siguientes cuadros que muestran las teorías de tres autores sobre Modos de zonificación paisajística 
Cuadro 3.1 Taxonomía corológica propuesta por BERTRAND (1968)

\begin{tabular}{|c|c|c|}
\hline $\begin{array}{l}\text { Unidades } \\
\text { de paisaje }\end{array}$ & $\begin{array}{l}\text { Escala Espacial } \\
\text { (Superficie) }\end{array}$ & Elementos del medio que definen las categorías \\
\hline Zona & millones de $\mathrm{km}^{2}$ & $\begin{array}{l}\text { Grandes franjas climáticas y biomas del pla- } \\
\text { neta que manifiestan la influencia del reparto } \\
\text { de tierras. Ciertas megaestructuras de primer } \\
\text { orden como el Himalaya. }\end{array}$ \\
\hline Dominio & miles de $\mathrm{km}^{2}$ & $\begin{array}{l}\text { Climas regionales y grandes masas vegetales, } \\
\text { relativos a grandes accidentes orográficos de } \\
\text { dominio macroestructural. }\end{array}$ \\
\hline Región Natural & $\begin{array}{c}\text { decenas de cientos } \\
\text { de } \mathrm{km}^{2}\end{array}$ & $\begin{array}{l}\text { Morfoestructuras individualizadas tectóni- } \\
\text { camente y definidas accesoriamente por un } \\
\text { clima regional y unas condiciones hidrológicas, } \\
\text { geomorfológicas y biogeográficas originales. }\end{array}$ \\
\hline Geosistema & $\begin{array}{c}\text { unidades a cientos } \\
\text { de } \mathrm{km}^{2}\end{array}$ & $\begin{array}{l}\text { Complejo definido por un matiz regional que } \\
\text { incluye una combinación más o menos de } \\
\text { potencial ecológico, explotación biológica y } \\
\text { acciones humanas. }\end{array}$ \\
\hline Geofacies & cientos de $\mathrm{m}^{2}$ & $\begin{array}{l}\text { Formas de relieve de detalle subordinadas al } \\
\text { influjo de topoclimas y distinguibles por un } \\
\text { cierto tipo de explotación natural o humana. }\end{array}$ \\
\hline Geotopo & decenas de $\mathrm{m}^{2}$ & $\begin{array}{l}\text { Microtopografía y elementos biogeográficos } \\
\text { (complejo biotopo-biocenosis), subordinados } \\
\text { al influjo de un microclima. }\end{array}$ \\
\hline
\end{tabular}

Fuente: (Cancer, 1994)

Cuadro 3.2 Taxonomía basada en las geocoras

\begin{tabular}{cl}
\hline Dimensión Espacial & \multicolumn{1}{c}{ Características delimitadoras } \\
\hline Geotopo & $\begin{array}{l}\text { Composiciones geomorfológicas, materiales y energéticas, } \\
\text { procesos laterales y verticales. }\end{array}$ \\
\hline Nano-geocora & $\begin{array}{l}\text { Mosaicos de geotopos, amalgamados por semejanza ecológica, } \\
\text { o procesos dinámicos en curso, o procesos dinámicos de raíz } \\
\text { histórica. }\end{array}$ \\
\hline Micro-geocora & $\begin{array}{l}\text { Asociaciones genéticas, cuya base es petromorfologica (es- } \\
\text { tructuras, sustratos, relieve, drenaje); diferencias y semejanzas } \\
\text { en la estructura. }\end{array}$ \\
\hline Meso-geocora & $\begin{array}{l}\text { Semejanzas genéticas (estructura orográfica y disposición; } \\
\text { asociaciones meso- y macroclimáticas). }\end{array}$ \\
\hline Macro-geocora & Características geológicas y de base climático-regional. \\
\hline
\end{tabular}

Fuente: (Cancer, 1994) 
Cuadro 3.3 Taxonomía aplicable al paisaje antropizado

\begin{tabular}{|c|c|c|}
\hline $\begin{array}{c}\text { Dimension } \\
\text { Espacial }\end{array}$ & Características Espaciales & Criterios \\
\hline $\begin{array}{l}\text { Elemento } \\
\text { de paisaje }\end{array}$ & $\begin{array}{l}\text { Ámbito homogéneo en cuanto al } \\
\text { uso del suelo, generalmente bien } \\
\text { delimitado. Complejos heterogéneos, } \\
\text { de escala pequeña definidos por su } \\
\text { uso (cercas, lagunas, caminos) }\end{array}$ & $\begin{array}{l}\text { Uso del suelo. Ocupación del } \\
\text { suelo. }\end{array}$ \\
\hline $\begin{array}{c}\text { Paisaje } \\
\text { (primer orden) }\end{array}$ & $\begin{array}{l}\text { Mosaicos de uso del suelo heterogéneo, } \\
\text { generalmente dominados por uno de } \\
\text { estos usos del suelo. Puede incluir } \\
\text { núcleos rurales }\end{array}$ & $\begin{array}{l}\text { Mosaicos de uso de suelo; bordes } \\
\text { claramente definidos, basados en las } \\
\text { microcoras; áreas funcionales dentro } \\
\text { de una ciudad; núcleos de hasta } 5.000 \\
\text { habitantes. }\end{array}$ \\
\hline $\begin{array}{c}\text { Paisaje } \\
\text { (segundo orden) }\end{array}$ & $\begin{array}{l}\text { Mosaicos de uso de suelo heterogéneo, } \\
\text { sin restricción de dominante. Inclusión } \\
\text { de ciudades pequeñas }\end{array}$ & $\begin{array}{l}\text { Mosaicos de uso de suelo; bordes } \\
\text { menos precisos, basados en las meso- } \\
\text { coras de orden inferior; combinación } \\
\text { de áreas funcionales dentro de una } \\
\text { ciudad; núcleos de entre } 5.000 \text { y } \\
20.000 \text { habitantes. }\end{array}$ \\
\hline $\begin{array}{c}\text { Paisaje } \\
\text { (tercer orden) }\end{array}$ & $\begin{array}{l}\text { Mosaicos de uso de suelo heterogéneo, } \\
\text { sin restricción de dominante. Inclusión } \\
\text { de ciudades medias }\end{array}$ & $\begin{array}{l}\text { Mosaicos de uso de suelo; bordes } \\
\text { menos precisos, basados en las meso- } \\
\text { coras de orden superior; combinación } \\
\text { de áreas funcionales dentro de una } \\
\text { ciudad; núcleos de entre } 20.000 \text { y } \\
200.000 \text { habitantes. }\end{array}$ \\
\hline $\begin{array}{c}\text { Región } \\
\text { paisajística }\end{array}$ & $\begin{array}{l}\text { Mosaicos de uso de suelo muy he- } \\
\text { terogéneos }\end{array}$ & $\begin{array}{l}\text { Mosaicos de uso de suelo; bordes } \\
\text { menos precisos, basados en las ma- } \\
\text { crocoras; inclusión (potencial) de } \\
\text { conurbaciones extensas y áreas mu- } \\
\text { nicipales. }\end{array}$ \\
\hline
\end{tabular}

Fuente: (Cancer, 1994)

\subsection{Arquitectura del paisaje}

La arquitectura del paisaje como especialidad se origina a fines del siglo XIX donde tras la Segunda Guerra Mundial se reunieron varios profesionales de los países devastados para establecer criterios, métodos y principios a seguir a fin de reconstruir las ciudades y su entorno natural, conjugando la arquitectura y la ingeniería con la naturaleza, buscando simultáneamente la belleza con el fin de conformar un todo integral. "La arquitectura de paisaje es justamente la disciplina que maneja de modo 
coordinado en sus proyectos, tanto aspectos técnicos como estéticos para incorporar y comunicar a la arquitectura con la naturaleza, integrándolas de manera atractiva, para lo cual se vale del lenguaje común de diseño.” (Arredondo González, 2015)

El uso adecuado de la vegetación nativa junto con la adaptada, común en el sitio donde se desarrolle el proyecto, facilita obtener, en gran medida, el carácter e identidad deseados, al lado del diseño y la incorporación de materiales locales que caracterizan ese paisaje. (Arredondo González, 2015)

\subsection{Paisaje urbano y paisaje natural}

Desde el punto de vista cultural, el paisaje no es la naturaleza ni siquiera el medio físico que nos rodea o sobre el que nos situamos, sino que se trata de una elaboración intelectual que realizamos a través de ciertos fenómenos de la cultura. De la misma manera que el paisaje no es la naturaleza ni el territorio, el «paisaje urbano» no es la ciudad, ni alguno de sus enclaves significativos, sino la imagen que de ella se destila, bien sea esta individual o colectiva. (Maderuelo, 2010)

Arredondo Gonzáles suscribe que el paisaje urbano se rige por el uso del espacio en todas tus dimensiones, el cual en muchas ocasiones fragmenta la ciudad debido a sus edificaciones colosales y vías de tránsito sobre escaladas, lo que conlleva a construir paisajes urbanos deshumanizados. (Arredondo González, 2015)

El paisaje natural ha sido percibido como el espacio donde no ha intervenido el hombre en su concepción, sin embargo en la actualidad son muy pocos los lugares hacia donde no ha llegado el ser humano, es por ello distintos autores engloban al paisaje como una suma elementos en los que incluye a lo natural y lo antrópico.

Dentro del componente espacial y perceptual, la diversidad se multiplica, pues no depende solamente de la espacialidad construida entre el relieve, la vegetación y la morfología urbana, lo natural y lo antrópico, sino que depende de quién la observa y la percibe, desde dónde la observa y la percibe. (Aponte, 2012) 


\subsection{Paisaje productivo}

El paisaje adquiere la dimensión de recurso en la medida en que es percibido por la población, gracias a su concepción como bien o como elemento destinado a satisfacer una necesidad. El paisaje es un bien perceptible y utilizable por parte de la sociedad, pero además es un recurso, en la medida en que es utilizable. (Zubelzu Mínguez \& Allende Álvarez, 2015)

El paisaje puede convertirse en un ente generador de desarrollo local mediante su capacidad de proporcionar recursos para generar actividades económicas que ayuden a la población, sea suelo agrícola, actividades turísticas o recreativas y actividades extractivas sostenibles y sustentables que prevalezcan las cualidades del entorno.

El desarrollo urbano es el proceso programado de adecuación y ordenamiento del medio urbano en sus aspectos físicos, económicos y sociales, en función de factores dinámicos como el crecimiento y el cambio. El desarrollo urbano debe concebirse como parte integral del desarrollo regional o territorial, pues difícilmente se da en forma independiente; además, este afecta y repercute en el medio natural regional. (Arredondo González, 2015)

Johann Heinrich von Thünen citado por Andrés Barsky en ( Barsky, 2005) realizó un estudio sobre el mejor modelo de distribución espacial de sistemas productivos según calidad de suelo y acceso, empleando éstas lógicas económicas delimitó círculos concéntricos en torno a un centro de consumo urbano, los cuales se organizaban desde la periferia hacia el centro en cinco cordones, ubicando en el primero a la horticultura y producción lechera, en el segundo cordón a la producción forestal, seguido del cultivo de cereales en el tercer cordón, el cuarto cordón con cultivos menos intensivos y el último con cultivos de rotación trianual; estableció además un último cordón para cría de ganado y producción de manteca, constituyendo de ésta forma "una secuencia de intensidades decrecientes en el uso del suelo partiendo desde el borde de la ciudad" 
Según la definición Etimológica significa coger, apoderarse y adquirir para la Conductista es un cambio relativamente permanente de la conducta producida por la práctica reforzada y para la Constructivista es un proceso de construcción de estructuras mentales que se traducen en representaciones personales significativas y con sentido de un objeto o situación de la realidad. (Canales Arévalo \& Sabelino Torres, 2008)

\subsection{Paisaje de borde}

El proyecto arquitectónico parte del presente trabajo de investigación se sitúa en un entorno de borde urbano-natural en el distrito de Pachacamac, tomando como base los conceptos presentados, entendemos que el diseño debe potenciar las cualidades intrínsecas al paisaje de borde, es decir deberá significar un espacio de transición entre lo urbano y lo natural, una grapa, una costura, una articulación entre ambos medios uno regido por el hombre y otro netamente natural que además conserva un ecosistema frágil otorgándole al borde un carácter protector, a continuación se presentan conceptos que servirán como herramientas sólidas a fin de lograr con éxito la integración planteada.

Hablar de borde lleva implícito un sesgo hacia la dimensión física y paisajística del espacio, supone la existencia de dos realidades espaciales diferenciadas y de un límite material entre ellas, lo cual, es difícil de establecer teniendo en cuenta que la particularidad de los territorios periféricos es la constante mutación de las formas territoriales y de los procesos. ( Ballén Velásquez, 2014)

Este espacio se viene definiendo además como un ecotono:

Cabe resaltar que según la visión paisajista: “en este caso el borde no es un límite sino un ecotono, es decir, el espacio común a dos ecosistemas", aclara Gloria Aponte García. Es donde convergen las fortalezas y las debilidades de dos universos distintos. Por ejemplo: la playa es el ecotono entre el mar y la tierra. (Aristizábal Uribe, 2013) 
Entendido como zona de transición o ecotono entre el campo y la ciudad, el periurbano constituye un espacio donde se despliegan complejos fenómenos ecológicos y sociales. El tema ha sido objeto de estudio de distintas disciplinas, lo cual muestra una diversidad de abordajes y preocupaciones. A grandes rasgos se puede decir que el funcionamiento de las áreas periurbanas ha sido trabajado desde tres perspectivas diferentes: la mirada ecológica, la mirada urbanística y la mirada socio-económica. Si bien debe considerarse que no son necesariamente excluyentes entre sí, cada una enfatiza en determinados aspectos que, integrados, explican la dinámica de los espacios periurbanos. (Di Pace, Crojethovich Martín , \& Barsky, 2007)

María Di Pace, quien viene estudiando esta definición más ampliamente lo define de la siguiente forma citada en (Di Pace, Crojethovich Martín , \& Barsky, 2007)

\subsubsection{Glosario de terminología relevante}

- Articulación: La articulación está indisolublemente ligada a las nociones de artículo y articulado. Se presenta -desde su entronización por la filosofía escolástica en el pensamiento del medioevo occidental. Como un mecanismo intelectual de acción y comprensión de la realidad. A partir de la visión tomista -en que totalidades se constituyen de partes unidas coherentemente en un total; en que para ser tal, ,el todo es a la parte como la parte es al todoe- transforma a la subdivisión, en un arte, haciendo prevalecer el dominio constante de la naturaleza del vínculo en la noción del total. Las partes -los artículos-, aunque autónomas, adquieren un nuevo sentido en el todo, en la summa, que no es ya una simple adición aleatoria sino sinérgica. (Letelier, 1996)

- Conectividad: continuidad espacial de un tipo

- Configuración: disposición específica de elementos espaciales. Se usa a veces el término estructura.

- Convergencia: La convergencia es un fenómeno de gran semejanza en seres sin relación alguna por descendencia, por lo que, si careciéramos de la información necesaria, llegaríamos a la errónea suposición de que están relacionados muy de cerca. (...) Es como si hubiera en la Naturaleza algún mecanismo intrínseco por el que cualquier animal o planta, al hacer frente a un problema que se deba resolver a fin de 
sobrevivir, pueda desarrollar una estructura, usando esta palabra en el sentido amplio anteriormente indicado, que resuelva el problema de la forma más económica y eficiente. (Custance, 1975)

- Composición: número de clases y abundancia de éstas (porcentaje del área total ocupada por cada una de ellas).

- Corredor: Franja estrecha, con diferencias marcadas con respecto a las áreas adyacentes que la flanquean.

- Ecotono: El ecotono o zona de borde es un área de contacto entre ecosistemas (...) una interacción activa entre dos o más ecosistemas (o mosaicos de ecosistemas) (...) las ciudades impactan los sistemas circundantes, transformando su suelo y sus recursos hídricos superficiales y subterráneos: por la exportación de residuos sólidos y líquidos domiciliarios e industriales-, la presencia de cavas, basurales a cielo abierto, etc. (...). Pero a su vez es impactado por el sistema rural: recibe la influencia de los agroquímicos y los residuos sólidos, los contenedores de los productos agroquímicos que están constituyéndose en un elemento contaminador de importancia, etc. Es decir, el periurbano también es un sistema en mosaico que contiene relictos "naturales" o ecosistemas residuales ("parches"), (...) donde coexisten los sistemas productivos o agroecosistemas que explotan el suelo fósil, los ecosistemas consumidores o aglomeraciones urbanas, y los cada vez más reducidos ecosistemas balanceados (naturales) remanentes”. (Di Pace, Crojethovich Martín , \& Barsky, 2007)

- Espacio Híbrido: Definimos hibridación arquitectónica como el proceso en el que, a través del acto de unificar diferentes naturalezas arquitectónicas, realiza la consecución de una nueva realidad -una realidad con carácter propio y con nuevas cualidades arquitectónicas que no existen en los elementos iniciales concebidos por separado. Como consecuencia, se reconoce como híbrida toda arquitectura que es simultáneamente objeto, paisaje e infraestructura., una intervención arquitectónica que reúne simultáneamente tres condiciones:

Ser una intervención física que, como resultado de un proyecto, proponga un espacio arquitectónico generado a partir de la propia intervención humana. 
_Ser una intervención arquitectónica que sea simultáneamente paisaje, más allá de lo que sería el propio objeto colocado en el paisaje: a través de diferentes posibles mecanismos (fusión, transformación, reconfiguración...), la intervención arquitectónica se integra de forma indisociable en el paisaje

_Ser una intervención arquitectónica que sea simultáneamente infraestructura, más allá de lo que sería la vinculación directa con la infraestructura: convirtiéndose en un tramo de infraestructura, el objeto arquitectónico se convierte en parte de la infraestructura e incorpora sus leyes y mecanismos de funcionamiento. (SantosFernandes Pinto de Freitas, 2011)

- Espacio Intersticial: (Águila Flores, 2014) en su investigación sobre intersticios urbanos, cita a cuatro autores con las siguientes definiciones sobre este concepto: Bazant (2001) los define como "Baldíos intermedios, espacios que van quedando por la expansión urbana incontrolada en la periferia"; Méndez $(2009 ; 2011)$ hace referencia al "Espacio intermedio entre mesetas"; por otro lado Peimbert (2008) suscribe que los espacios intersticiales son la "Relación forzosa con lo construido: paisaje intersticial"; finalmente Cedeño (2007) lo establece como "Un espacio discontinuo de la ciudad".

- Fragmentación: rotura de un área, tipo o hábitat en trozos más pequeños e inconexos.

- Heterogeneidad: diferencia entre los elementos constitutivos de un paisaje.

- Permeabilidad: Permeable es aquello que se deja influir o afectar, por lo tanto el concepto incluye también un cambio de estado moderado a partir de influencias determinadas, ya sean meteorológicas, orgánicas o sociales. (...) La permeabilidad es una cualidad geométrica, material y urbana, que permite relaciones estrechas y cruzadas con el medio ambiente y el clima, pero además de ser una propiedad tectónica es también una importante característica para el funcionamiento de los ecosistemas y sus comunidades ligadas a la arquitectura. (Mesa \& Mesa, 2013)

- Protección: La protección de los paisajes depende de su manejo. (...) Esto no implica una preservación estricta sino una conservación dinámica, que exige asimismo un manejo robustecido por estrategias de largo plazo que pueden revertir y evitar la 
erosión producida por los usos agrícolas intensos o por el crecimiento que conduce a la pérdida de las cualidades naturales o culturales.(...) Como el paisaje refleja de alguna forma la influencia recíproca entre el hombre y la naturaleza, la conservación de un escenario natural y su belleza exige necesariamente la preservación de la fauna, la flora y las características geográficas. (...) El propósito de designar un área como Paisaje Protegido es fortalecer los aspectos positivos de la relación entre el hombre y la naturaleza minimizando los impactos negativos que puedan destruir esa armonía. De esta manera, el concepto aspira a promover que la gente visite y experimente el área de modo de favorecer el bienestar económico local sin perjudicar sus valores sociales y culturales. (Castelli \& Spallasso, 2007)

- Tesela (patch): superficie con rasgos distintivos que permiten la diferenciación con las vecinas. A veces las teselas recubren de forma completa y excluyente el espacio considerado. A veces, sin embargo, se establecen como parches de excepción sobre una matriz o fondo continuo.

- Transición: Se entiende por transición al intervalo de cambio entre un territorio, medio o espacio y otro, siendo éste concepto el que rige la mayoría de intervenciones urbanas basadas en estrategias de integración para la ciudad.

Es posible definir el "Umbral Urbano" como: elemento que demarca un punto de transición entre dos espacios urbanos y que, al igual que el umbral arquitectónico, representa un doble papel hacia adentro y hacia fuera, hacia un lado y hacia el otro, un punto de enlace entre dos espacios, estableciendo un dialogo entre ambos espacios de manera simultánea. Es una estructura, que representa e identifica un espacio de transformación permeable, tanto física como perceptualmente, entre fronteras urbanas, ya sean fronteras entre espacios construidos, entre espacios verdes urbanos naturales o intervenidos o entre espacios construidos y espacios verdes urbanos. (García Aguaida, 2011)

- Transitividad: articulación entre tipos diferentes y contiguos de paisajes, y entre órdenes superiores e inferiores de la secuencia escalar. Se trata de caracterizar la transición entre paisajes tipológicamente distintos y contiguos, y entre órdenes escalares. (Riesco Chueca, Gómez Zotano, \& Álvarez Sala, 2008) 


\subsection{Conclusiones parciales}

El diseño arquitectónico del presente trabajo de investigación implica gestionar un límite protector del Ecosistema de Lomas Costeras, el proyecto conformará parte de éste cinturón de protección situado bajo éste paisaje, por lo que se creyó necesario estudiar teorías sobre borde y paisaje para crear herramientas que permitan desarrollar coherentemente el proyecto.

Se incluyó en la investigación del presente marco cinco definiciones sobre tipologías de borde; el borde geográfico se define como el punto de intercambio entre el hombre y la naturaleza incluyendo a las relaciones que se producen en éste; el borde político que constituye un espacio donde confluyen dos estados que en su mayoría manejan leyes y ordenanzas independientes dejando en el vacío el ordenamiento territorial de sus límites; el borde económico-social que se define como el espacio donde se encuentran dos realidades distintas, con diferenciado nivel socioeconómico ocasionado por la falta de políticas de gestión en pro de mejorar la calidad de vida de un lado de la población; el borde urbano-rural, formado comúnmente por el avance de la ciudad sobre el área rural, está presente por lo general en la periferia de las ciudades; finalmente se define a la tipología de borde urbano-natural que se determina como el punto de encuentro entre la ciudad y su entorno natural, aludiendo a características tangibles propias de ambos territorios, como topografía y perfil urbano.

Con respecto a la confusa definición entre fronteras, límites y bordes se define a la frontera como un espacio que integra o separa gradualmente dos territorios físicos y al límite como trazo divisorio entre ambos, siendo el borde por consiguiente el área urbana donde confluyen éstos territorios por encima de sus características jurisdiccionales y los aspectos socioculturales propios de ambos lugares, generando nuevas identidades únicas a este entorno.

Con respecto al estudio teórico realizado sobre los bordes, se basó la investigación en las teorías impartidas por Kevin Lynch y Gary Leggett; ambos analizan ejemplos propios de sus ciudades para apoyar sus tesis, Lynch estudia Estados Unidos, mientras que Leggett interpreta los bordes limeños con una visión cargada de sensibilidad urbana y social. A menudo Lynch asocia al borde con una senda de fuerte rasgo delimitante pues señala que la mayoría de bordes son a su vez sendas. 
Afirma también que muchos de éstos bordes pueden poseer cualidades directivas, al igual que las sendas; sus ejemplificaciones de borde casi siempre terminan siendo sendas, por ejemplo un borde fraccional visualmente es una avenida elevada que solo logra distinguirse desde determinados puntos de la ciudad, un borde fuerte es aquella avenida impenetrable sea porque los límites de su velocidad no permiten pases peatonales o por el nivel de altura de la misma; el autor también asocia la definición de borde con la de barrera pero solo para dejar claro como la intervención en esta puede terminar siendo un borde que integre eliminado el carácter restringido de la misma.

Leggett por otro lado muestra la realidad de Lima tomando como elemento de análisis al borde estableciendo definiciones para cada tipología empezando por los bordes personales los cuales desde una visión subjetiva intrínseca a cada individuo establecen límites y diferenciaciones con respecto al otro, esto producto de la educación y aspectos socioculturales desarrollados por cada habitante, ante la fragmentación social que puede generar este tipo de borde Leggett señala que es importante de alguna forma abrir las nociones de lo propio para poder comprender, interactuar y ser parte de lo ajeno, solo así tendrán éxito las políticas urbanas en pro de mejorar la ciudad.

La siguiente definición la realiza sobre los bordes construidos, estableciendo al primero de este tipo a los límites de la vivienda, es así que los multifamiliares, las torres de oficinas y hasta los edificios institucionales contemplan diseños que ejercen barreras frente a la ciudad, el cambio entre privado y público es brusco, sin ninguna transición, el autor refiere que el mismo Ministerio de Vivienda no contempla, entre su normativa para viviendas sociales, la solución para este conflicto pues considera que los empresarios no estarían dispuestos a "donar" espacios para la ciudad, primando entonces el valor por metro cuadrado sobre la calidad de vida urbana; dentro de su estudio Leggett también realiza definiciones sobre bordes políticos y legales sobre los que refiere son producto de la nula comunicación establecida entre municipios, cada municipalidad se valida de su carácter autónomo para establecer políticas individuales sobre gestión del territorio lo que termina por fragmentar la estética de la ciudad, pues además no existe tampoco un consenso decretado por el municipio metropolitano que regule la normativa ni establezca un plan de gestión urbana central.

Respecto a los bordes socioeconómicos, el autor expone como ejemplo a la malla metálica de Bucaramanga instalada entre los límites de Ate y La Molina, la cual 
representaba un latente ejemplo de barrera socioeconómica, es así en nuestra ciudad se han venido replicando ejemplos como este y no solo en el límite urbano, pues el autor también considera al hogar como un espacio urbano donde las diferencias económicas aún coexisten; Leggett define también a los geográficos, los temporales, los culturales y los funcionales, en estos casos como en lo ya expuestos el autor expone más bien la problemática del borde, nos lo muestra como un límite, como una barrera pero sustenta también las soluciones que cambiarían esta condición.

Respecto a las teorías sobre paisaje, los distintos autores citados concuerdan en que el paisaje es una visión subjetiva propia a cada individuo, sustentada en su educación, cultura o conocimiento previo respecto a un lugar sea urbano o natural, este juicio es intrínseco al perceptor y es solo él quien determina el nivel de belleza del mismo, aunque claro está existes patrones comunes a cada sociedad.

El proyecto arquitectónico parte del presente trabajo de investigación se sitúa en un entorno de borde urbano-natural en el distrito de Pachacamac, tomando como base los conceptos presentados, entendemos que el diseño debe potenciar las cualidades intrínsecas al paisaje de borde, es decir deberá significar un espacio de transición entre lo urbano y lo natural, una grapa, una costura, una articulación entre ambos medios uno regido por el hombre y otro netamente natural que además conserva un ecosistema frágil otorgándole al borde un carácter protector. 


\section{CAPITULO IV: MARCO NORMATIVO}

\subsection{Estándares Arquitectónicos}

\subsubsection{Reglamento Nacional de Edificaciones}

En el Título III .1 sobre Arquitectura en edificaciones, del Capítulo II de la Norma A.040 referido a condiciones de habitabilidad y funcionalidad establece lo siguiente:

Artículo 4.-Los criterios a seguir en la ejecución de edificaciones de uso educativo son:

a). Idoneidad de los espacios al uso previsto.

b). Las medidas del cuerpo humano en sus diferentes edades.

c). Cantidad, dimensiones y distribución del mobiliario necesario para cumplir con la función establecida.

d). Flexibilidad para la organización de las actividades educativas, tanto individuales como grupales.

Artículo 5.-Las edificaciones de uso educativo, se ubicarán en los lugares señalados en el Plan Urbano, y/o considerando lo siguiente:

a). Acceso mediante vías que permitan el ingreso de vehículos para la atención de emergencias.

b). Posibilidad de uso por la comunidad.

c). Capacidad para obtener una dotación suficiente de servicios de energía y agua.

d). Necesidad de expansión futura

e). Bajo nivel de riesgo en términos de morfología del suelo, o posibilidad de ocurrencia de desastres naturales.

f). Impacto negativo del entorno en términos acústicos, respiratorios o de salubridad. (Ministerio de Vivienda Construcción y Saneamiento, 2006) 
Artículo 6.-El diseño arquitectónico de los centros educativos tiene como objetivo crear ambientes propicios para el proceso de aprendizaje, cumpliendo con los siguientes requisitos:

a). Para la orientación y el asoleamiento, se tomará en cuenta el clima predominante, el viento predominante y el recorrido del sol en las diferentes estaciones de manera de lograr que se maximice el confort.

b). El dimensionamiento de los espacios educativos estará basado en las medidas y proporciones del cuerpo humano en sus diferentes edades y en el mobiliario a emplearse.

c). La altura mínima será de $2.50 \mathrm{~m}$.

d). La ventilación en los recintos educativos debe ser permanente, alta y cruzada.

e). El volumen de aire requerido dentro del aula será de $4.5 \mathrm{mt} 3$ de aire por alumno.

f). La iluminación natural de los recintos educativos debe estar distribuida de manera uniforme.

g). El área de vanos para la iluminación deberá tener como mínimo el 20\% de la superficie del recinto.

h). La distancia entre la ventana única y la pared opuesta a ella será como máximo 2.5 veces la altura del recinto. (Ministerio de Vivienda Construcción y Saneamiento, 2006)

\section{Artículo 12.5.- Retiros}

Norma A.010: según zonificación y parámetros

Certificado de parámetros del Distrito de Pachacamac: Si es que el frente de la edificación da a la calle se considerarán $3 \mathrm{ml}$ y si da a una avenida $5 \mathrm{ml}$.

\section{Artículo 12.6.- Número de Niveles o pisos de la edificación}

Norma A.010: de acuerdo al servicio educativo

Certificado de parámetros del Distrito de Pachacamac: según entorno 


\section{Artículo 12.7.- Altura interior de los ambientes}

Norma A.010: se considerar una altura de $2.30 \mathrm{~m}$ de piso terminado a cielo raso, las vigas y dinteles deben estar mínimo a $2.10 \mathrm{~m}$ sobre el piso terminado.

Norma A.040: Se considerará una altura mínima de 2.50m.

\section{Artículo 12.9.- Áreas libres}

Certificado de parámetros del Distrito de Pachacamac: según entorno

\section{Artículo 12.10.- Áreas verdes}

Se considerarán áreas verdes de confort y de predominante uso pedagógico

\section{Artículo 12.11.- Flujos de circulación}

Flujo 1: estudiantes que ingresan y egresan del local educativo y su traslado entre ambientes.

Flujo 2: personal docente, auxiliar y otros; cuyas actividades están relacionadas al servicio educativo, de bienestar, tutorial u otros.

Flujo 3: personal administrativo, cuyas actividades están dedicadas a la gestión pedagógica.

Flujo 4: personal de servicio en general, limpieza, mantenimiento, seguridad, con el consiguiente de insumos, herramientas, residuos sólidos u otros.

Flujo 5: personal involucrado en la prestación de servicios tercerizados (quiosco, cafetería, comedor, tópico)

Flujo 6: padres de familia

Flujo 7: visitas en general recinto. (Ministerio de Vivienda Construcción y Saneamiento, 2006) 


\section{Artículo 12.12.- Circulaciones}

12.12.1. Corredores, pasillos y pasadizos

a. A.10: Los espacios de circulación tendrán $1.20 \mathrm{~m}$ de ancho

b. La dimensión deberá respetar la circulación de evacuación y deberá encontrarse libre de obstáculos. (Ministerio de Vivienda Construcción y Saneamiento, 2006)

\subsubsection{Rampas}

a. A.10: Se desarrollarán las rampas peatonales con una pendiente máxima de $12 \%$ y un ancho mínimo de $0.90 \mathrm{~m}$.

A.130: las rapas para discapacitados tendrán una pendiente no mayor a $6 \%$.

b. Ningún elemento debe obstaculizar la circulación en estos espacios.

c. El ancho de la rampa deberá ser mínimo 1.50ml, de modo que permita el paso simultáneo de una persona con silla de ruedas y otra sin ella. (Ministerio de Vivienda Construcción y Saneamiento, 2006)

\subsubsection{Escaleras}

A.10: se deberá considerar el uso de escaleras incorporadas como único elemento de circulación vertical siempre y cuando la edificación no exceda los 4 niveles. El ancho de la escalera será de $1.20 \mathrm{~m}$ si el aforo no sobrepasa los 250 estudiantes. Los pasos máximos entre descansos serán 17. (Ministerio de Vivienda Construcción y Saneamiento, 2006)

\section{Artículo 15.- Dotación de servicios sanitarios}

Norma A.040: De 141 a 200 alumnos se considerarán 3 unidades por cada tipo de aparato sanitario, tanto para hombre como para mujeres, añadiéndose un aparato por cada 80 alumnos adicionales. (Ministerio de Vivienda Construcción y Saneamiento, 2006) 


\subsubsection{Normativa Ministerio de Educación}

\section{Artículo 11.-Planeamiento Arquitectónico}

A partir de los lineamientos pedagógicos establecidos, por la dirección pedagógica correspondiente, a tener en cuenta en el planeamiento y diseño arquitectónico de una Institución Educativa considerará que la formulación de un Plan Maestro sostenible en el tiempo es primordial.

a. Considerar un acceso principal que relacione a la Institución Educativa con el entorno, le dé presencia y carácter institucional, a manera de hito urbano, enfatizado por medio de elementos arquitectónicos como plazas, logotipo del local, escultura, etc.

b. La organización espacial considerará los siguientes aspectos:

-Estará adecuadamente zonificada, priorizando relaciones funcionales bajo criterios de confort y habitabilidad.

- Los estacionamientos (de ser tomados en cuenta dentro del terreno) deben ser diseñados para crecimientos futuros, además de considerar áreas para ubicar nuevas plazas, que no queden alejados de las áreas pedagógicas.

-La conexión de las aulas con los talleres y laboratorios debe ser por medio de espacios intermedios o de transición.

- La zona deportiva (de existir según la propuesta pedagógica) tiene la ventaja de favorecer a la práctica del deporte, el acceso a esta zona no debe ser por la zona pedagógica.

- Las áreas verdes se emplearán para delimitar o separar edificios creando espacios o ambientes de socialización.

- Las circulaciones deben evitar cruces que perjudiquen el adecuado funcionamiento de los ambientes pedagógicos. . (Ministerio de Vivienda Construcción y Saneamiento, 2006) 


\subsection{Plan Maestro}

El desarrollo de un Plan Maestro es una propuesta estratégica de organización que corresponde a una visión consensuada de un grupo de actores involucrados (en nuestro caso los docentes, los sectores productivos, la comunidad, la Municipalidad, entre otros) que miran el desarrollo de dicha propuesta o proyecto a largo plazo. El Plan abarca varias líneas de acción, entre las que destacan tres:

a. Una propuesta espacial

b. Una propuesta normativa

c. Una propuesta de gestión

El Plan Maestro de Desarrollo enmarca el desarrollo del proyecto de infraestructura y debe garantizar las acciones siguientes:

- Posibilidad de construcción por etapas dentro de una propuesta integral, que garantice su sostenibilidad en el tiempo.

- Posibilidades de expansión futura de acuerdo con el PEI (Programa Educativo Institucional), destinando una parte del terreno para tal fin (considera el espacio para construir edificios para ambientes pedagógicos de nueva creación, sin afectar el proyecto original).

-Coordinación con proyectos técnicos urbanísticos generales y específicos de la zona o región.

- Desarrollo de un proyecto paisajístico integral.

- Coordinación con el amueblamiento, la dotación y el equipamiento pertinentes.

- Coordinación con el proyecto institucional de señalización y seguridad. (Ministerio de Vivienda Construcción y Saneamiento, 2006) 


\subsection{Clasificación de los ambientes de un local educativo y sus características}

Para el planeamiento del diseño arquitectónico de la Institución Educativa se han definido distintos niveles de planificación como los espacios pedagógicos, las zonas y los ambientes, agrupándolos en atención a sus características similares dentro de los procesos pedagógicos y sus similitudes tanto funcionales y simbólicas como técnicas, físicas y/o espaciales. Dentro de la clasificación de espacios se identifican los siguientes:

a. Espacio pedagógicos básicos (con énfasis pedagógico)

b. Espacios pedagógicos complementarios (con énfasis de servicio)

Se considera la siguiente clasificación pedagógica (según Cuadro $\mathrm{N}^{\circ}$ 1, Anexo 1)

1. Para los ambientes definitivos de cada tipo de Institución Superior, se requerirá información del Área pedagógica que debe encontrarse claramente señalada en el documento de soporte Técnico-Pedagógico emitido por cada Institución Educativa, herramienta importante para realizar la propuesta arquitectónica.

2. Los ambientes pedagógicos complementarios se consideran como áreas de apoyo a la actividad pedagógica.

3. Tanto el Taller Multifuncional como el Laboratorio Integrado son los ambientes flexibles preparados para desarrollar más de una actividad pedagógica. Se utilizan cuando la estrechez del terreno lo impone o la demanda es muy variable.

4. El término Sala se asigna por convención a los ambientes dedicados a las Artes Escénicas como Música, Ballet, Canto, entre otros.

5. La Capilla o cualquier infraestructura de índole religiosa (Sinagoga, Asamblea, etc.) dependerá de lo indicado en la propuesta pedagógica de cada Institución Educativa. 
6. La Residencia debe ser pensada tanto para estudiantes cuanto para docentes cuando la ubicación de la institución educativa o la procedencia de los usuarios lo haga necesario.

7. El comedor y/o cafetería debe albergar en un solo turno hasta un tercio del número de estudiantes matriculados (o lo que indique el documento de soporte Técnico-Pedagógico). Si la propuesta pedagógica lo señala, debido a la baja utilización, se pueden convertir en ambientes $\mathrm{F}$ debidamente acondicionados $\mathrm{y}$ la cocina puede utilizarse para el desarrollo de proyectos pedagógicos. La cocina representa alrededor de un tercio del área del comedor.

8. El estacionamiento para los autos del personal administrativo debe disponer aproximadamente de un puesto por cada $250 \mathrm{~m} 2$. construidos, siempre que no altere lo dispuesto por los parámetros municipales. El estacionamiento para estudiantes debe prever espacios para motocicletas y bicicletas, así como parqueo para personas con limitaciones físicas como lo señala la Norma A. 120. (Ver norma de ciclo vías de RNE).

9. Se recomienda instalar aparatos sanitarios de bajo consumo. Se deben calcular según dotación RNE como mínimo. No deben estar a más de $50 \mathrm{~m}$. del puesto de trabajo más lejano.

10. Los vestidores serán opcionales como apoyo a los ambientes C, D y F sobre todo.

11. Los talleres y/o salas artísticas, gimnasio, losa y/o campo deportivo, dependiendo de la propuesta pedagógica, requerirán ambientes de apoyo o complementarios específicos (vestidores, depósitos, casa de fuerza, etc.)

12. Para ambientes tipo $G$ considerar las normas y criterios internacionales, como las normas Global CAP entre otras, y las recomendaciones del INIA, así como otras disposiciones de los sectores involucrados. (MINEDU, 2015) 


\subsection{Instituciones afines}

\subsubsection{Ministerio de Educación}

El Ministerio de Educación es el órgano rector de las políticas educativas nacionales y ejerce su rectoría a través de una coordinación y articulación intergubernamental con los Gobiernos Regionales y Locales, propiciando mecanismos de diálogo y participación.

Los objetivos de la Institución son generar oportunidades y resultados educativos de igual calidad para todos; garantizar que estudiantes e instituciones educativas logren sus aprendizajes pertinentes y de calidad; lograr una educación superior de calidad como factor favorable para el desarrollo y la competitividad nacional, así como promover una sociedad que educa a sus ciudadanos y los compromete con su comunidad. (Ministerio de Educación, 2017)

\subsubsection{Ministerio de Cultura}

El Ministerio de Cultura es un organismo del Poder Ejecutivo responsable de todos los aspectos culturales del país y ejerce competencia exclusiva $\mathrm{y}$ excluyente, respecto a otros niveles de gestión en todo el territorio nacional. Fue creado el 21 de julio de 2010 mediante Ley $N^{\circ} 29565$, suscrita por el Presidente de la República, Alan García Pérez.

Las funciones principales del Ministerio son formular, ejecutar y establecer estrategias de promoción cultural de manera inclusiva y accesible, realizar acciones de conservación y protección del patrimonio cultural, fomentar toda forma de expresiones artísticas, convocar y reconocer el mérito de quienes aporten al desarrollo cultural del país, planificar y gestionar con todos los niveles de gobierno actividades que permitan el desarrollo de los pueblos amazónicos, andinos y afroperuanos, todo ello propiciando el fortalecimiento de la identidad cultural y abriendo espacios de participación de todas las culturas. (Ministerio de Cultura, 2017) 


\subsubsection{Ministerio del Ambiente}

El Ministerio del Ambiente es un organismo del Poder Ejecutivo que tiene por misión:

Asegurar el uso sostenible, la conservación de los recursos naturales y la calidad ambiental en beneficio de las personas y el entorno, de manera normativa, efectiva, descentralizada y articulada con organizaciones públicas y privadas y sociedad civil, en el marco del crecimiento verde y la gobernanza ambiental. (Ministerio del Ambiente, 2017)

\subsubsection{Ministerio de Agricultura}

El Ministerio de Agricultura es un organismo del Poder Ejecutivo que tiene por misión:

"Diseñar y ejecutar políticas para el desarrollo de negocios agrarios y de la agricultura familiar, a través de la provisión de bienes y servicios públicos de calidad". (Ministerio de Agricultura, 2017)

Este Ministerio viene ejerciendo su competencia en las siguientes materias:

a. Tierras de uso agrícola y de pastoreo, tierras forestales y tierras erizas con aptitud forestal.

b. Recursos forestales y su aprovechamiento.

c. Flora y fauna.

d. Recursos hídricos.

e. Infraestructura agraria.

f. Riego y utilización de agua para uso agrario

g. Cultivos y crianzas.

h. Sanidad, investigación, extensión, transferencia de tecnología y otros servicios vinculados a la actividad agraria. 


\subsubsection{Municipalidad de Pachacamac}

La Municipalidad de Pachacamac tiene por misión:

Planificar, ejecutar e impulsar a través de los organismos competentes el conjunto de acciones destinadas a proporcionar al ciudadano condiciones vitales en aspectos de vivienda, salubridad, abastecimiento, educación, recreación, transporte y comunicaciones. Asimismo, promueve el desarrollo económico local con incidencia en la micro y pequeña empresa, el desarrollo turístico y el desarrollo integral para viabilizar el crecimiento económico, la justicia social y sostenibilidad ambiental, en concordancia con el Plan de Desarrollo Local Concertado. (Municipalidad de Pachacamac, 2017)

\subsubsection{Asociación Circuito Ecoturístico Lomas de Lúcumo}

Apoyados por la ONG Ecociudad, el Centro Poblado Rural Quebrada Verde, con el apoyo de los socios voluntarios realiza hacia el año 1996 su plan de desarrollo, esta comisión en ese entonces la conformaban solo cuatro familias las que con numerosas faenas registraron por primera vez los atractivos del Ecosistema Lomas de Lúcumo, dando iniciado el trazado del circuito ecoturístico, aperturándose las camitas en el año 2000, pero no es hasta el año 2002 que los proyectos logran ser tangibles, después que la comisión ganara un concurso presentado a Fondevalle y destinara el dinero a la ejecución de las obras de equipamiento para el circuito (Lomas de Lúcumo, 2017)

\subsubsection{Asociación Vive Pachacamac}

El proyecto Vive Pachacámac es una iniciativa del Grupo GEA en el marco del Programa VALLE VERDE que tiene como aliados estratégicos al Fondo Ítalo Peruano, la Asociación Atocongo y la Municipalidad Distrital de Pachacámac.

El Proyecto contribuye a mitigar la pobreza en el distrito de Pachacámac, insertando a las comunidades de los Centros Poblados Rurales Quebrada Verde, Cardal y Santa Rosa de Malpaso en actividades de Turismo Rural 
Comunitario (TRC), fortaleciendo sus capacidades de emprendimiento bajo un enfoque social y ambientalmente sustentable. (Grupo GEA, 2017)

\subsubsection{Grupo Gea}

Esta organización se fundó en el año 1992, teniendo como fin impulsar el cambio social, nace en un inicio como OACA, siglas que representaban su denominación como Oficina de Asesoría y Consultoría Ambiental, la cual estaba especializada en temas de maneo de agua, saneamiento y educación ambiental y sanitaria. Hacia el año 2004 cambia su denominación a Grupo GEA, como apoyo a empresas, comunidades, ciudades, turismo y escuelas sustentables. 


\subsection{Conclusiones parciales}

El Reglamento Nacional de Edificaciones en la Norma A.040 en su Artículo 5 establece que los locales educacionales deberán tener en cuenta para su ubicación la presencia de vías de acceso cuya dimensión permita el ingreso de vehículos de emergencia, que al equipamiento educativo pueda tener acceso la población, que el lugar donde se ubique le brinde la capacidad para abastecerse de dotaciones de servicios básicos, que el terreno permita incorporar áreas de futura expansión y que sus condiciones morfológicas no generen riesgos frente a un eventual desastre natural.

El Reglamento Nacional de Edificaciones en la Norma A.040 en su 6 referido a los requisitos del diseño arquitectónico en locales institucionales especifica que para la orientación y asoleamiento debe tomarse en cuenta las condiciones climáticas predominantes en las distintas estaciones a fin de lograr el mayor confort posible en los espacios, el dimensionamiento de éstos y el mobiliario se fundamentará en las medidas antropométricas según edades, la altura mínima de los ambientes será de $2.50 \mathrm{~m}$, se considerará en el diseño ventilación cruzada elevada e iluminación natural en todos los recintos, representando los vanos como mínimo el 20\% de la superficie del mismo.

La Normativa establecida por el Ministerio de Educación dispone que la organización espacial esté adecuadamente zonificada priorizando la funcionabilidad, confort y habitabilidad de los espacios, que los estacionamientos y plazas deben estar diseñados sobre un área que permita su expansión futura, que es necesario un espacio intersticial que conecte aulas, talleres y laboratorios; que no se debe acceder al área deportiva directamente por la zona pedagógica, el área verde tendrá la función de delimitar edificios y se debe tener especial cuidado en el diseño funcional de las circulaciones; finalmente establece dos tipos de espacios dentro de éstos locales institucionales, los espacios pedagógicos básicos que lo conforman las aulas y los espacios pedagógicos complementarios que con aquellos que apoyan las labores de enseñanza como talleres, laboratorios, bibliotecas, etc.

Dentro de las instituciones afines gubernamentales se encuentra el Ministerio de Educación, el cual establece la normativa de diseño y funcionamiento de locales educacionales; el Ministerio de Cultura puesto que en el Ecosistema Lomas de Lúcumo se han encontrado manifestaciones de arte rupestre, que sería factible analizar, registrar y proteger como parte de nuestro patrimonio cultural; el Ministerio del Ambiente, 
entidad que será de gran ayuda en las gestiones a ejercer para la preservación de las Lomas como ecosistema frágil; el Ministerio de Agricultura, puesto que se evaluó la necesidad de incorporar al programa del proyecto un área de apoyo al mejoramiento productivo de la agricultura local a fin de conservar las condiciones fértiles del Valle; finalmente la última institución de gobierno público afín al proyecto es la Municipalidad de Pachacamac la cual deberá apoyar con el decreto de parámetros urbanísticos que limiten la expansión de la población hacia las lomas y sobre todo acelerar los trabajos de habitabilidad que permitirán dotar de los servicios básicos al Centro Poblado Rural Quebrada Verde.

Las instituciones afines de carácter privado son el Grupo Gea, mediante la asociación Vive Pachacamac, la cual fue la principal gestora de la construcción del circuito ecoturístico y de su equipamiento, la misma tiene un compromiso pendiente sobre la segunda parte del plan de protección de Lomas que incluía un mecanismo de protección del borde de las mismas que podía involucrar la construcción de andenes productivos revalorando la memoria del lugar y la reforestación con especies nativas como el lúcumo cuyo fin de revalorización sería el mismo; esto último ya lo viene realizando desde el año 2011 el grupo ecologista Comando Ecológico sumando un total de 180 especies reforestadas entre lúcumo, huarango y tara; pero ninguna de éstas plantaciones se han realizado con fines de borde de protección, su objetivo actualmente es más bien recuperar el Ecosistema de Lomas. 


\section{CAPITULO V: MARCO OPERATIVO}

\subsection{Estudio de casos análogos}

\subsubsection{Centro de formación para la sostenibilidad}

\subsubsection{Historia}

Cliente: Fundación ALIANZA, Alami Lazraq

Ubicación: Chwitter / Marrakech, Marruecos

Figura 5.1 Ubicación del Centro de Formación para la Sostenibilidad

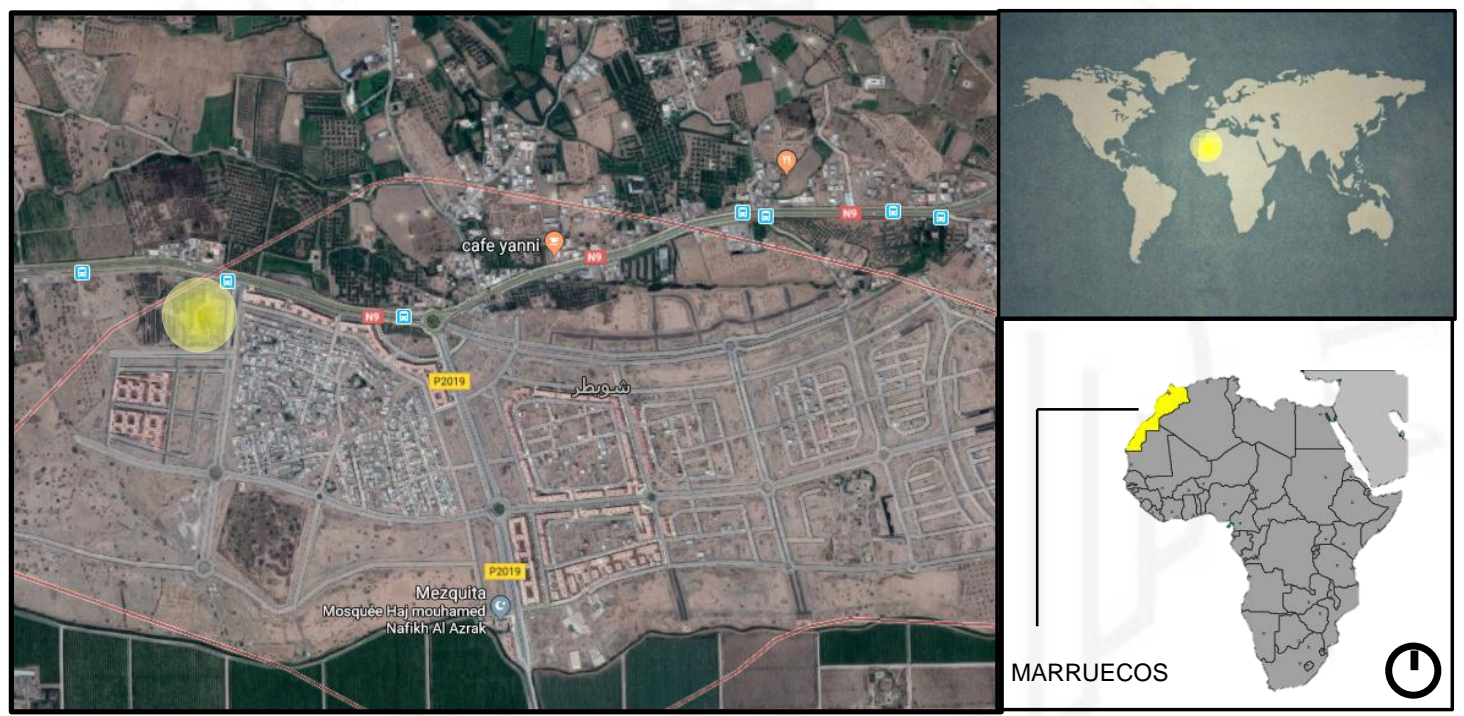

Elaboración propia

Año: 2012-2013

Diseño: Anna Heringer, Martin Rauch, Elmar Naegele, Ernst Waibel y Salima Naji.

Consultores: Thomas Steinmann, Suiza (la arquitectura del paisaje), Merz Kley + Partner, Austria (ingeniería estructural), Christoph Muss, Austria (física de la construcción, el concepto de energía), Jean Dethier, Francia (consejero cultural), Teamgmi, Austria (líquidos y Térmica), Hecht Elektroplanung, Austria (concepto eléctrico).

Área del proyecto: $6300 \mathrm{~m} 2$.

Costo estimado: $\$ 8000000$ 
El artículo Training Center Marrakesh (2013), habla sobre el planeamiento para la ejecución del Centro de Formación para la Sostenibilidad, idea concebida por la fundación ALIANZA, dirigida por el arquitecto Alami Lazraq, quien viene trabajando desde hace 30 años con la construcción en tierra, siendo el Centro un "programa piloto promotor de la asociación entre el desarrollo sostenible y la industria". Lazraq ve en el proyecto una oportunidad para tener mano de obra calificada dentro de su empresa, de la misma manera que va mejorando la calidad de vida de la población del sector empleándolos directamente una vez terminado el curso, cerrando así el ciclo de desarrollo local.

\subsubsection{Ubicación y relación con el entorno}

El proyecto se emplaza en Chwitter, ciudad a las afueras de Marrakech en Marruecos, dentro de un área agrícola. Limita al norte con la avenida Número 9, vía principal que conecta a las demás ciudades, y por donde solo transita transporte pesado y vehículos privados, frente a esta condición la arquitectura responde con un grueso muro de tierra y un colchón verde como elementos protectores, solidos muros limitan el espacio público impidiendo que este se abra a la ciudad.

Figura 5.2 Ubicación y relación con el entorno del Centro de Formación para la Sostenibilidad

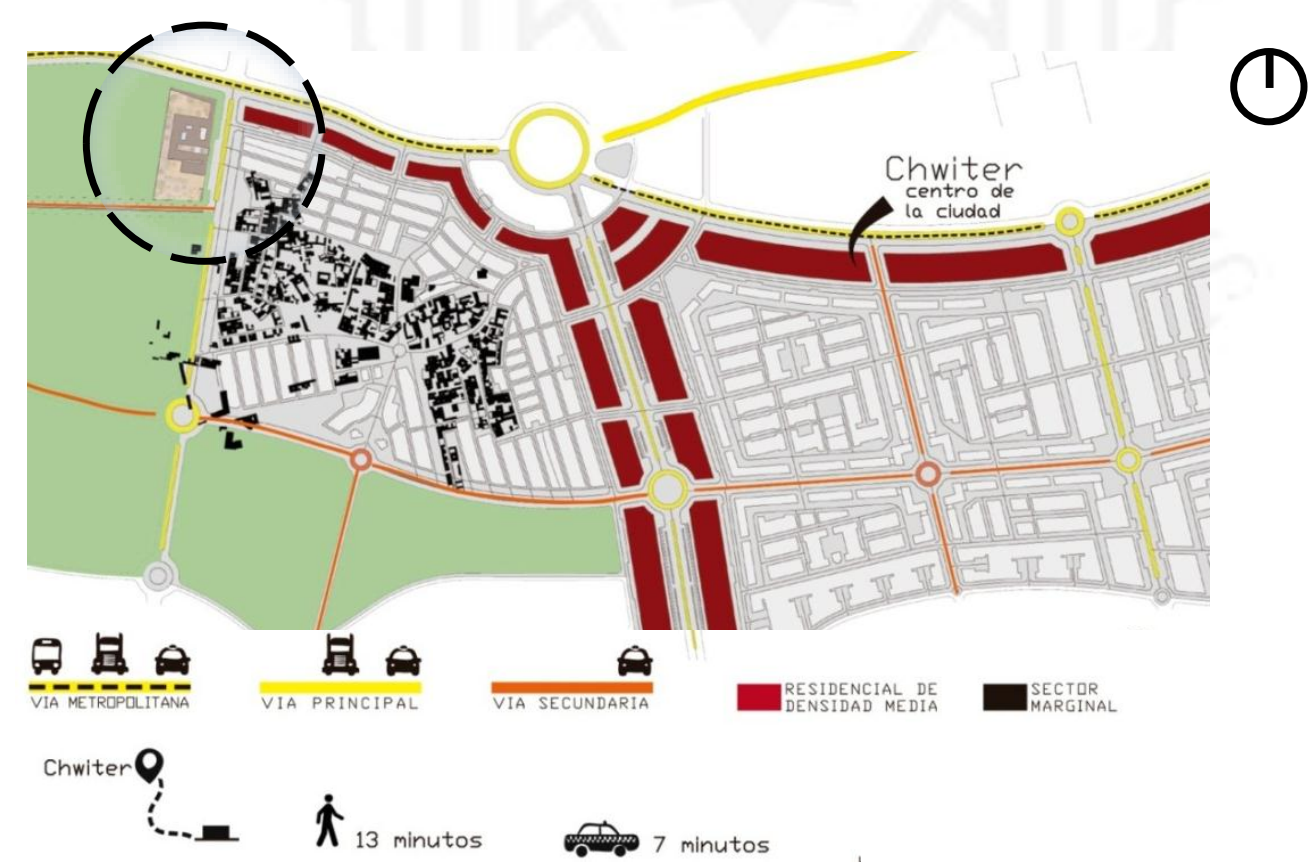

Elaboración propia 


\subsubsection{Programa y relaciones programáticas.}

El proyecto agrupado en paquetes programáticos sumaría 5 tipos referidos a:

Aprendizaje: de este paquete forman parte las aulas que suman un total de 12, los 4 talleres, los espacios de asesoría dispuestos en su mayoría en la segunda planta, la sala de profesores y por último la sala de entrenamiento práctico de dimensión mucho mayor que los talleres, implementada en un volumen adyacente al edificio.

Equipamiento educativo: forman parte la sala de exposiciones, el auditorio con una capacidad para 250 personas aproximadamente y la biblioteca que se encuentra precisamente sobre el anterior y se desarrolla en un solo nivel, siendo este volumen el central y el que más resalta dentro del complejo en altura y diseño.

Administración: comprende las oficinas administrativas, se ubican en el primer nivel cerca al hall de ingreso

Servicios: dentro de los servicios están los referidos a la cafetería, a los baños y camerinos.

Recreación: Existe un amplio jardín y un vivero de hortalizas a cargo del alumnado.

Cuadro 5.1 Cuadro de áreas aproximado del Centro de Formación para la Sostenibilidad

\begin{tabular}{|c|c|c|c|}
\hline \multicolumn{4}{|c|}{ CUADRO DE ÁREAS APROXIMADO } \\
\hline PAQUETES & AMBIENTE & $\begin{array}{l}\text { ÁREA APROXIMADA } \\
\text { (M2) }\end{array}$ & APORTE (\%) \\
\hline \multirow{5}{*}{ APRENDIZAJE } & AULAS & 654 & $5 \%$ \\
\hline & TALLERES & 500 & $4 \%$ \\
\hline & SALA DE ENTRENAMIENTO & 520 & $4 \%$ \\
\hline & ASESORÍA & 312 & $3 \%$ \\
\hline & SALA DE PROFESORES & 134 & $1 \%$ \\
\hline \multirow{3}{*}{ EQUIPAMIENTO EDUCATIVO } & SALA DE EXPOSICIÓNES & 740 & $6 \%$ \\
\hline & AUDITORIO & 330 & $3 \%$ \\
\hline & BIBLIOTECA & 420 & $3 \%$ \\
\hline ADMINISTRACIÓN & OFICINAS & 250 & $2 \%$ \\
\hline \multirow{3}{*}{ SERVICIOS } & CAFETERÍA & 278 & $2 \%$ \\
\hline & SERVICIOS & 395 & $3 \%$ \\
\hline & CIRCULACIÓN & 1767 & $14 \%$ \\
\hline \multirow[t]{2}{*}{ RECREACIÓN } & ÁREA LIBRE & 5968 & $49 \%$ \\
\hline & TOTAL & 12268 & $100 \%$ \\
\hline
\end{tabular}

Elaboración Propia 
Cuadro 5.2 Cuadro de áreas aproximado por paquete del Centro de Formación para la Sostenibilidad

\begin{tabular}{|c|c|c|}
\hline \multicolumn{3}{|c|}{ CUADRO DE ÁREAS APROXIMADO POR PAQUETE } \\
\hline \hline \multicolumn{3}{|c|}{ APRENDIZAJE } \\
\hline \hline AMBIENTE & $\begin{array}{c}\text { ÁREA APROXIMADA } \\
(\mathrm{M} 2)\end{array}$ & APORTE (\%) \\
\hline \hline AULAS & 654 & $31 \%$ \\
\hline TALLERES & 500 & $24 \%$ \\
\hline SALA DE ENTRENAMIENTO & 520 & $25 \%$ \\
\hline ASESORÍA & 312 & $15 \%$ \\
\hline \hline SALA DE PROFESORES & 134 & $6 \%$ \\
\hline TOTAL & 2120 & $100 \%$ \\
\hline
\end{tabular}

\begin{tabular}{|c|c||c|}
\hline \multicolumn{3}{|c|}{ CUADRO DE ÁREAS APROXIMADO POR PAQUETE } \\
\hline \hline \multicolumn{2}{|c|}{ EQUIPAMIENTO EDUCATIVO } \\
\hline \hline \multirow{2}{*}{ AMBIENTE } & $\begin{array}{c}\text { ÁREA APROXIMADA } \\
(\text { M2) }\end{array}$ & APORTE (\%) \\
\hline \hline SALA DE EXPOSICIÓNES & 740 & $50 \%$ \\
\hline AUDITORIO & 330 & $22 \%$ \\
\hline BIBLIOTECA & 420 & $28 \%$ \\
\hline \hline TOTAL & 1490 & $100 \%$ \\
\hline
\end{tabular}

\begin{tabular}{|c|c||c|}
\hline \multicolumn{3}{|c|}{ CUADRO DE ÁREAS APROXIMADO POR PAQUETE } \\
\hline \hline \multicolumn{3}{|c|}{ ADMINISTRATIVO } \\
\hline \hline AMBIENTE & $\begin{array}{c}\text { ÁREA APROXIMADA } \\
(\mathrm{M} 2)\end{array}$ & APORTE (\%) \\
\hline \hline OFICINAS & 250 & $100 \%$ \\
\hline \hline TOTAL & 250 & $100 \%$ \\
\hline
\end{tabular}

\begin{tabular}{|c|c|c|}
\hline \multicolumn{3}{|c|}{ CUADRO DE ÁREAS APROXIMADO POR PAQUETE } \\
\hline \hline \multicolumn{3}{|c|}{ SERVICIOS } \\
\hline \hline AMBIENTE & ÁREA APROXIMADA & APORTE (\%) \\
& $(\mathrm{M} 2)$ & $41 \%$ \\
\hline \hline CAFETERÍA & 278 & $59 \%$ \\
\hline SERVICIOS & 395 & $100 \%$ \\
\hline \hline TOTAL & 673 & \\
\hline
\end{tabular}




\begin{tabular}{|c|c|c|}
\hline \multicolumn{3}{|c|}{ CUADRO DE ÁREAS APROXIMADO POR PAQUETE } \\
\hline \hline \multicolumn{3}{|c|}{ RECREATIVO } \\
\hline \hline AMBIENTE & ÁREA APROXIMADA & APORTE (\%) \\
& $(\mathrm{M} 2)$ & $100 \%$ \\
\hline \hline ÁREA LIBRE & 5968 & $100 \%$ \\
\hline \hline TOTAL & 5968 & \\
\hline
\end{tabular}

Elaboración Propia

Figura 5.3 Plano primer nivel con paquete programático del Centro de Formación para la Sostenibilidad

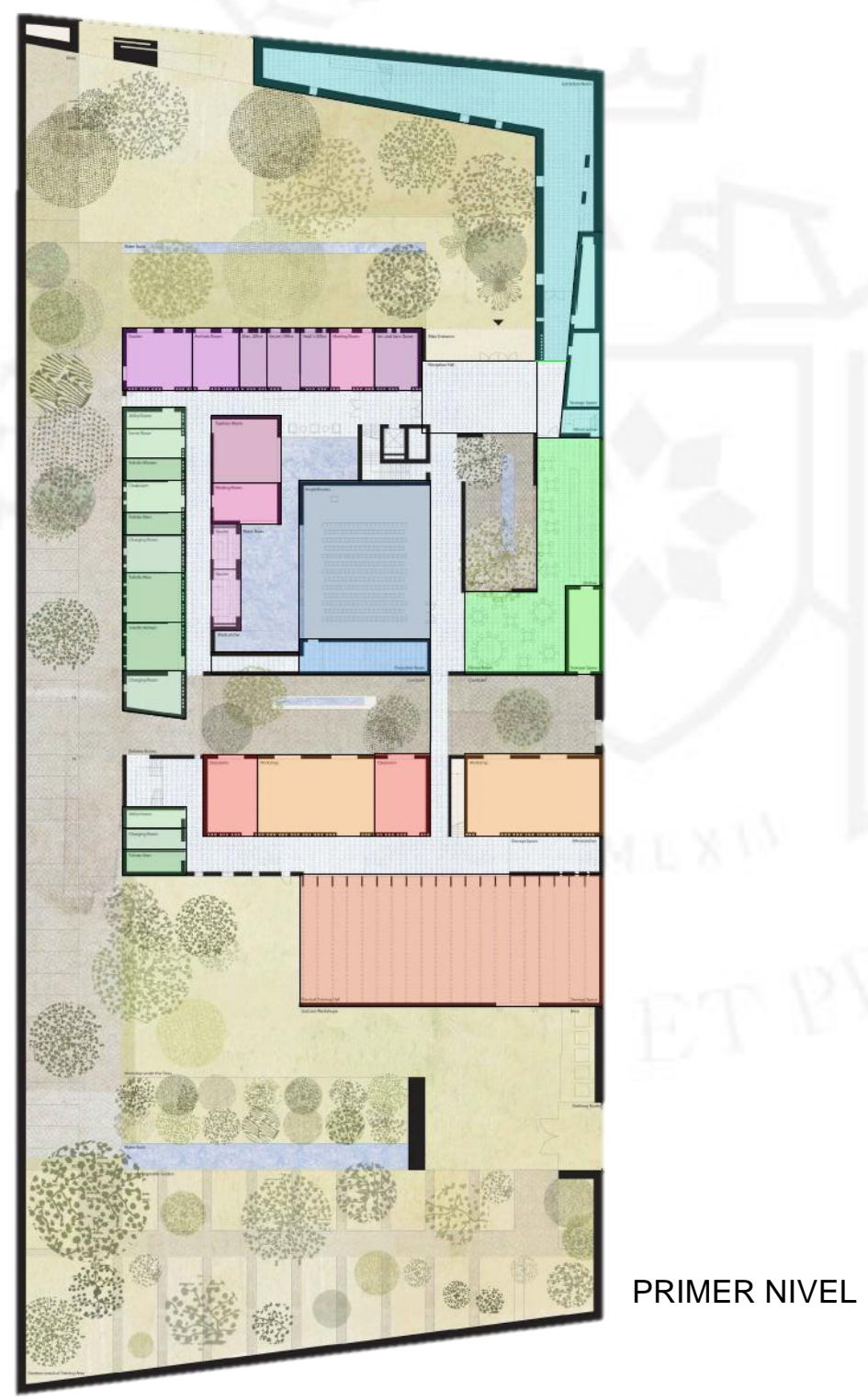




\begin{tabular}{|c|c|c|c|}
\hline APRENDIZAJE & EQUIPAMIENTO EDUCATIVO & ADMINISTRATIVO & SERVICIO \\
\hline AULA & BIBLIOTECA & & CAFETERÍA \\
& AUDITORIO & OFICINA & COCINA \\
TALLER & SALA DE ENTRENAMIENTO & VESTIDORES \\
& SALA DE ESTUDIO & ARCHIVO & BAÑOS \\
SALA DE ENTRENAMIENTO & SALA DE EXPOSICIÓN & & MANTENIMIENTO \\
\hline
\end{tabular}

Fuente: Training Center Marrakesh (2013),

Elaboración Propia

Figura 5.4 Plano segundo nivel con paquete programático del Centro de Formación para la Sostenibilidad

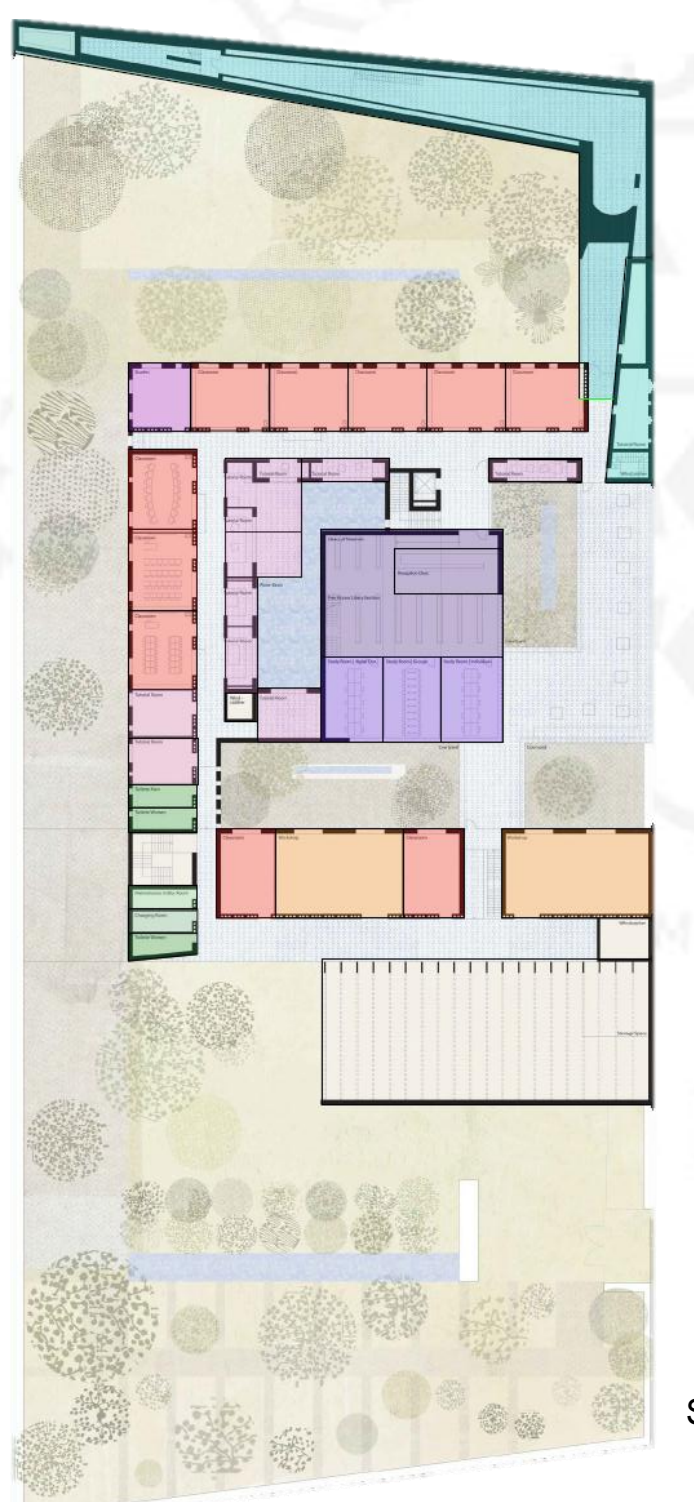




\begin{tabular}{|c|c|c|c|}
\hline APRENDIZAJE & EQUIPAMIENTO EDUCATIVO & ADMINISTRATIVO & SERVICIO \\
\hline AULA & BIBLIOTECA & & CAFETERÍA \\
& AUDITORIO & OFICINA & COCINA \\
TALLER & SALA DE ENTRENAMIENTO & & VESTIDORES \\
& SALA DE ESTUDIO & ARCHIVO & BAÑOS \\
SALA DE ENTRENAMIENTO & SALA DE EXPOSICIÓN & & MANTENIMIENTO \\
\hline
\end{tabular}

Fuente: Training Center Marrakesh (2013),

Elaboración Propia

Figura 5.5 Esquema de relación de ambientes del Centro de Formación para la Sostenibilidad

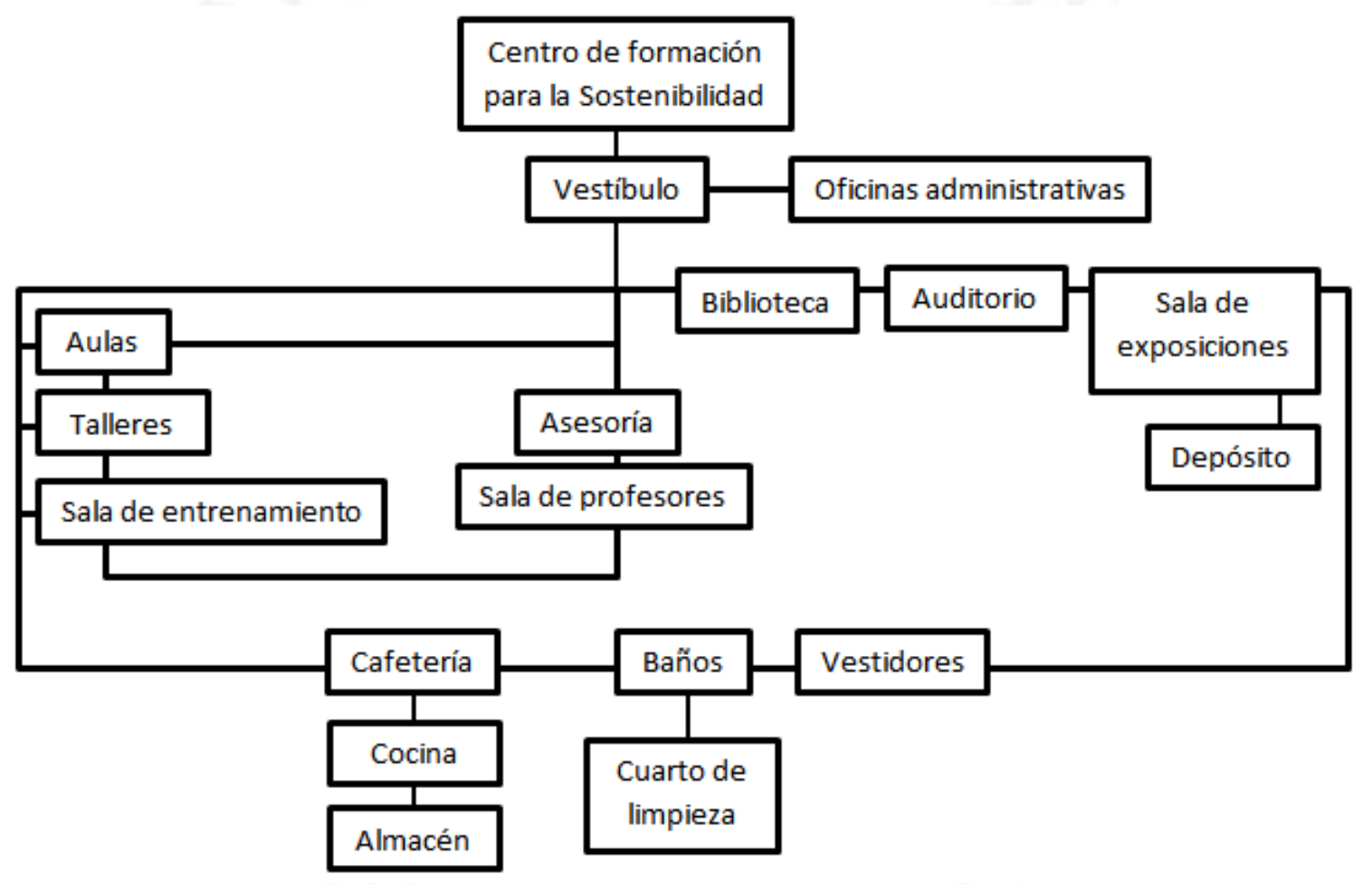

Elaboración Propia 


\subsubsection{Tipología espacial}

Figura 5.6 Tipología Espacial del Centro de Formación para la Sostenibilidad
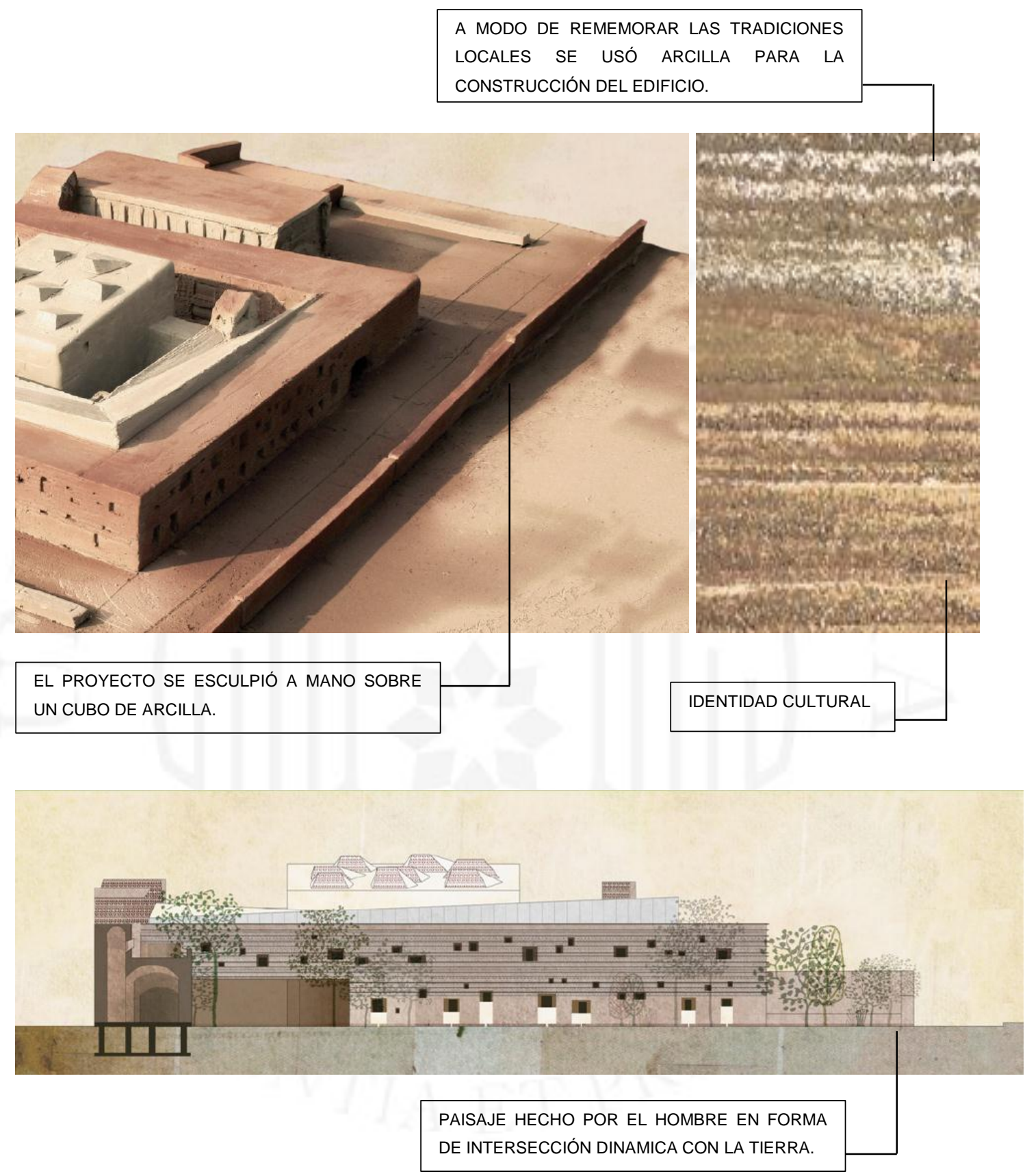

Fuente: Training Center Marrakesh (2013),

Elaboración Propia 
Figura 5.7 Tipología Espacial del Centro de Formación para la Sostenibilidad

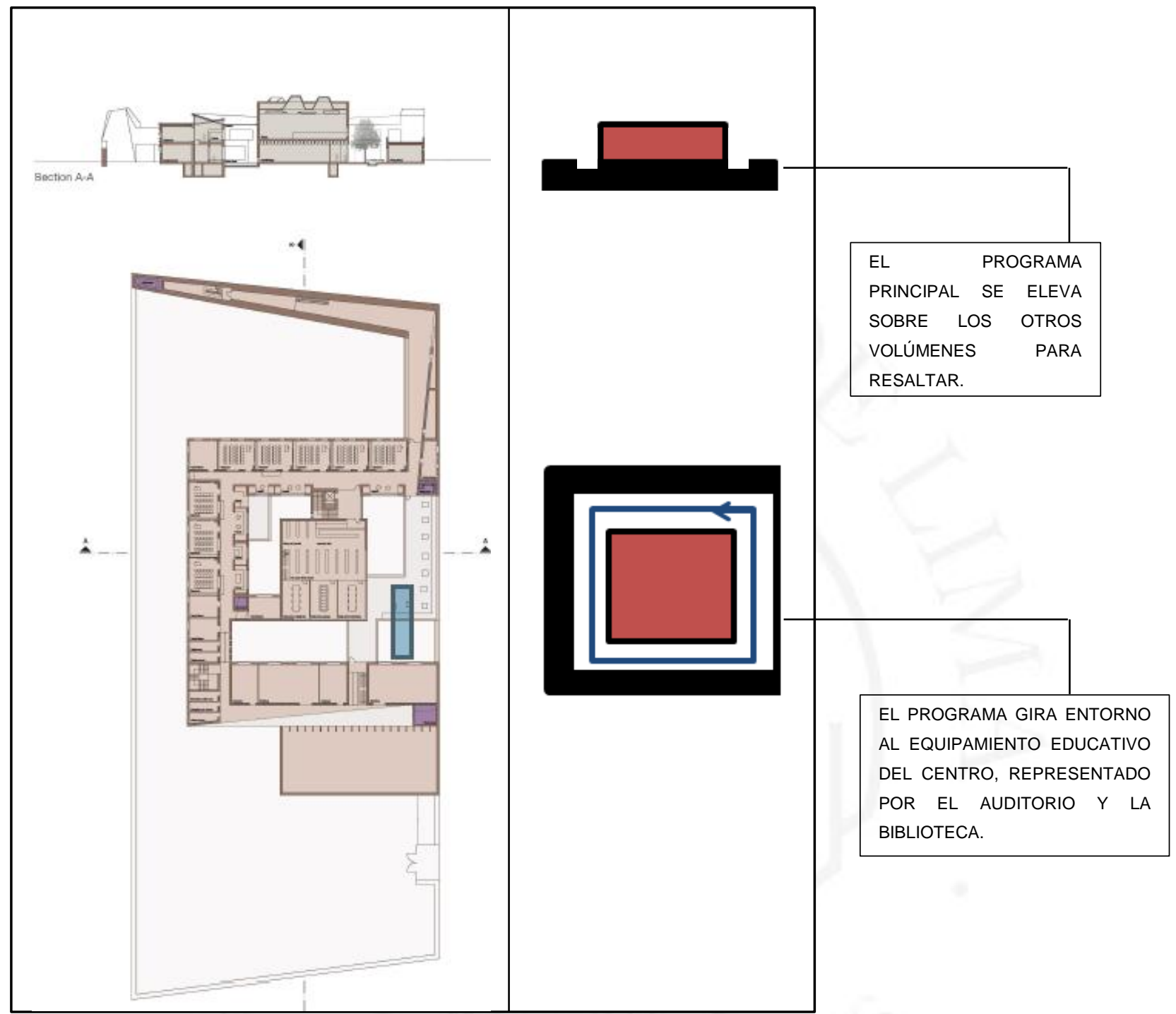

Fuente: Training Center Marrakesh (2013),

Elaboración Propia 
Figura 5.8 Gráfico de ingresos al Centro de Formación para la Sostenibilidad
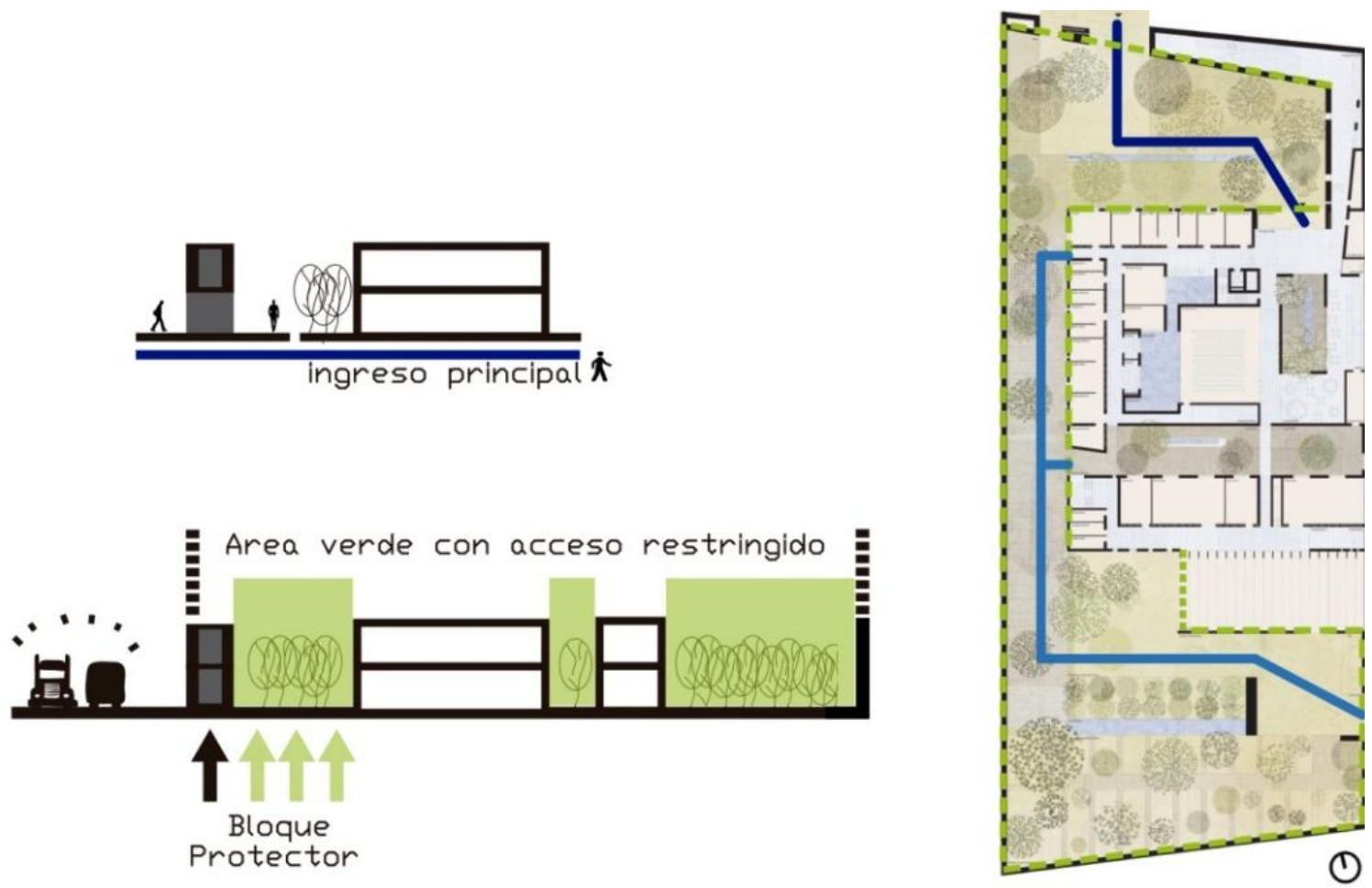

INGRESO PRINCIPAL INGRESO SECUNDARIO

Fuente: Training Center Marrakesh (2013),

Elaboración Propia

"Un edificio en U puede utilizarse como contenedor y organizar en el interior de su campo una agrupación de formas y espacios" (D. K. Ching, 2015, pág. 163)

La tipología empleada en el proyecto del Centro de formación para la sostenibilidad se compone a partir de un volumen en $U$ contenedor de aulas, talleres y oficinas que envuelve a otro central que alberga equipamiento educativo colectivo, jerarquizándolo de esta manera, además el volumen central resalta su importancia al elevarse en altura por encima de la demás arquitectura del complejo educativo. 


\subsubsection{Público - privado}

Figura 5.9 Análisis de accesibilidad a los ambientes del Centro de Formación para la Sostenibilidad
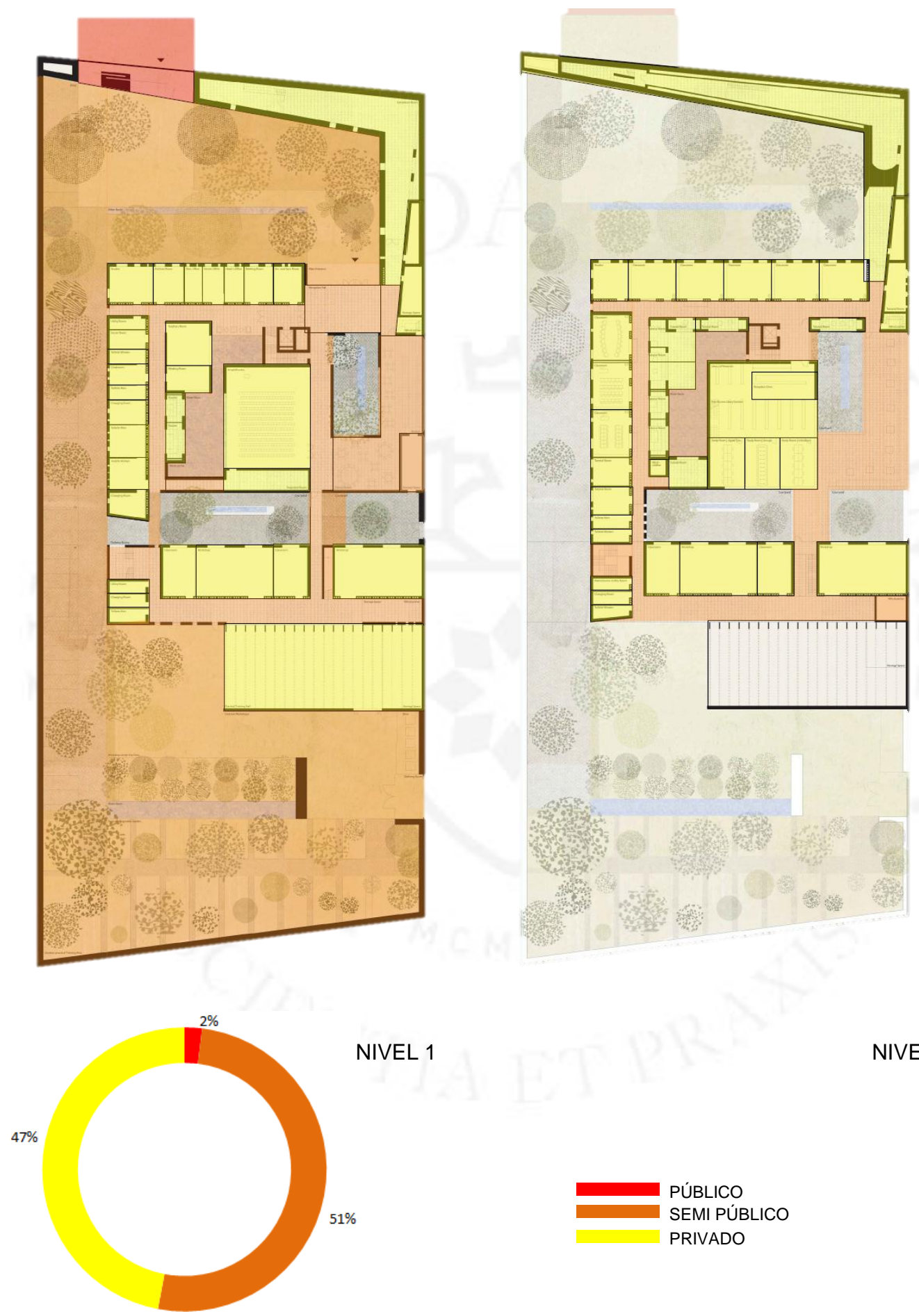

NIVEL 2

Fuente: Training Center Marrakesh (2013),

Elaboración Propia 
Figura 5.10 Análisis de flujos del Centro de Formación para la Sostenibilidad
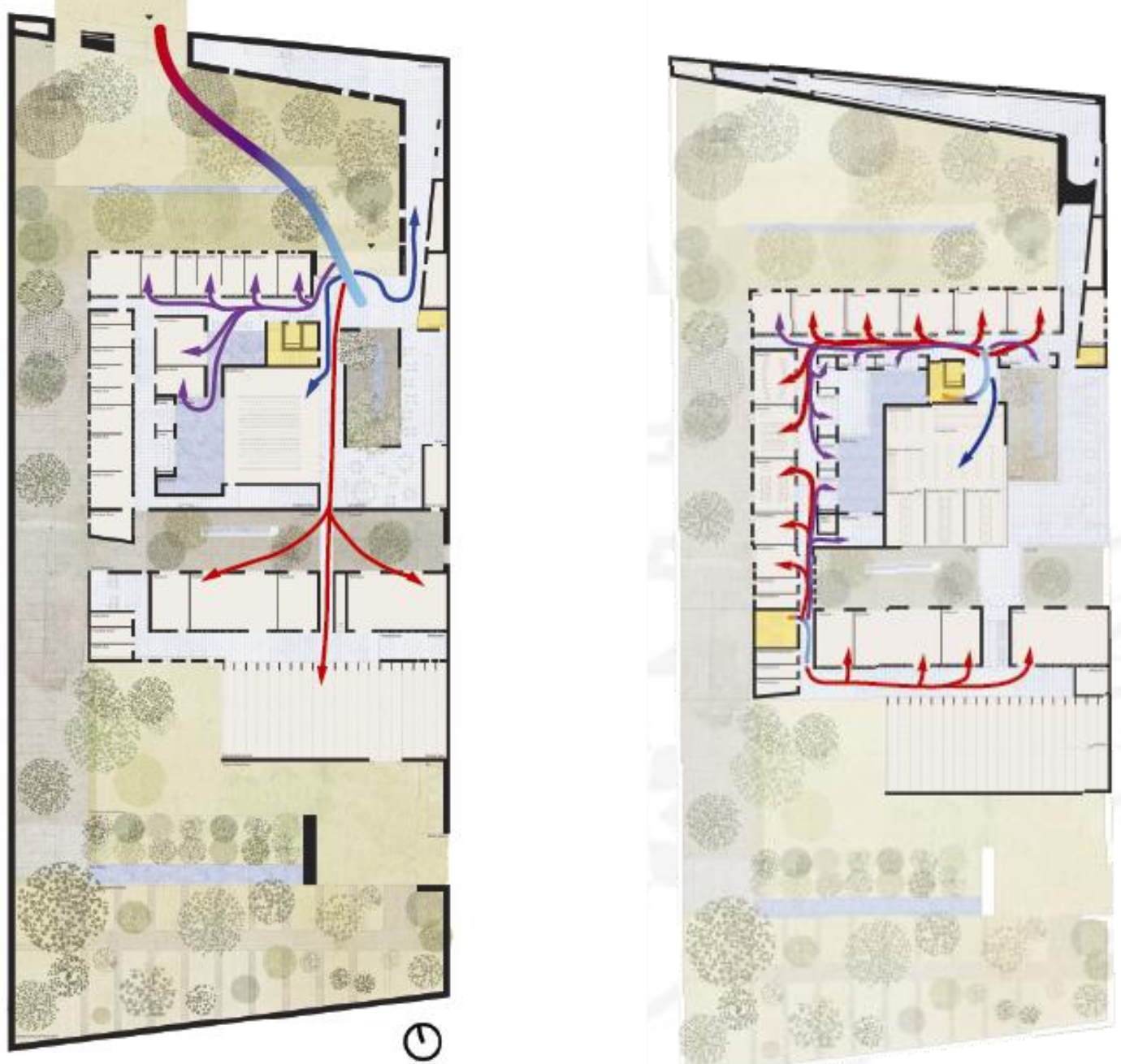

FLUJO EDUCATIVO

FLUJO EQUIPAMIENTO EDUCATIVO

FLUJO ADMINISTRATIVO

Fuente: Training Center Marrakesh (2013),

Elaboración Propia 
Figura 5.11 Análisis del área libre y área construida del Centro de Formación para la Sostenibilidad

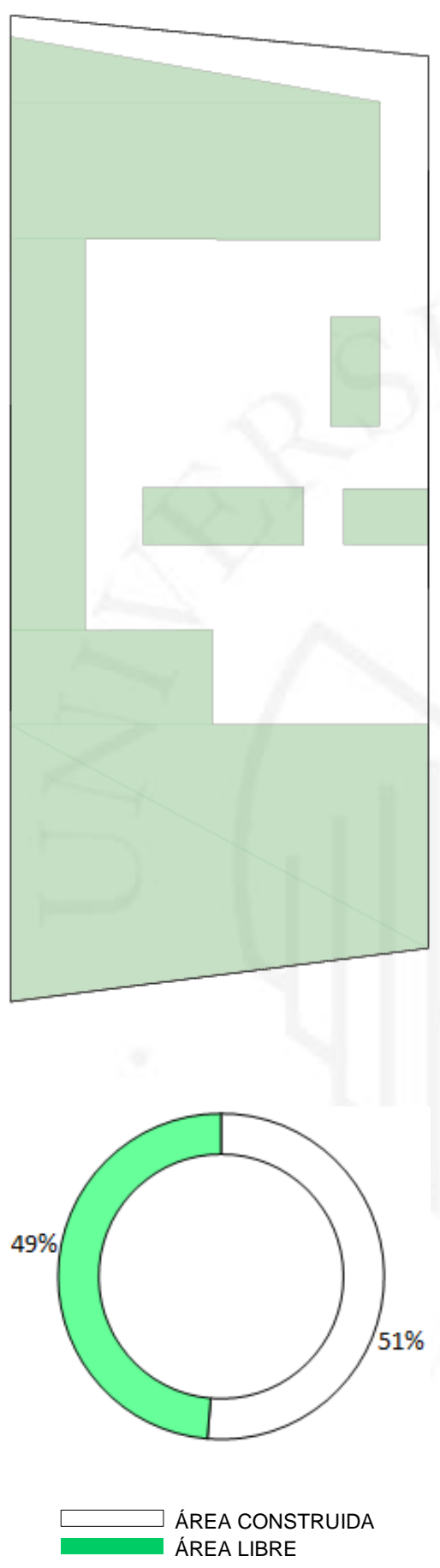

Fuente: Training Center Marrakesh (2013)

Elaboración Propia 


\subsubsection{Tecnología}

Todo el material proviene de la excavación del sitio, pues la tierra es un material de construcción que perdura en el tiempo, y las reparaciones en referencia a los acabados se harían solo con barro y agua. Se instalaron paneles solares en la parte superior de la sala taller producen el 100\% de la energía necesaria para el edificio, además el agua de lluvia recogida de todas las áreas del techo y patios se recicla para el sistema de refrigeración, jardines y centros de producción. Cuenta con protección solar eficiente con persianas fijas que evita altas ganancias de calor solar en las zonas interiores, además de techos ventilados con alto nivel de aislamiento que reducen la pérdida de calor en invierno, bajo estos conceptos de sostenibilidad, "Las simulaciones demuestran que el consumo de energía para el edificio en uso se reduce a 19,9 $\mathrm{kwh} / \mathrm{m} 2$ / año, mediante el uso de claraboyas y estrategias pasivas". ("Heringer", 2008)

Figura 5.12 Concepto energético aplicado en la construcción del Centro de Formación para la Sostenibilidad

\section{Energy Concept}

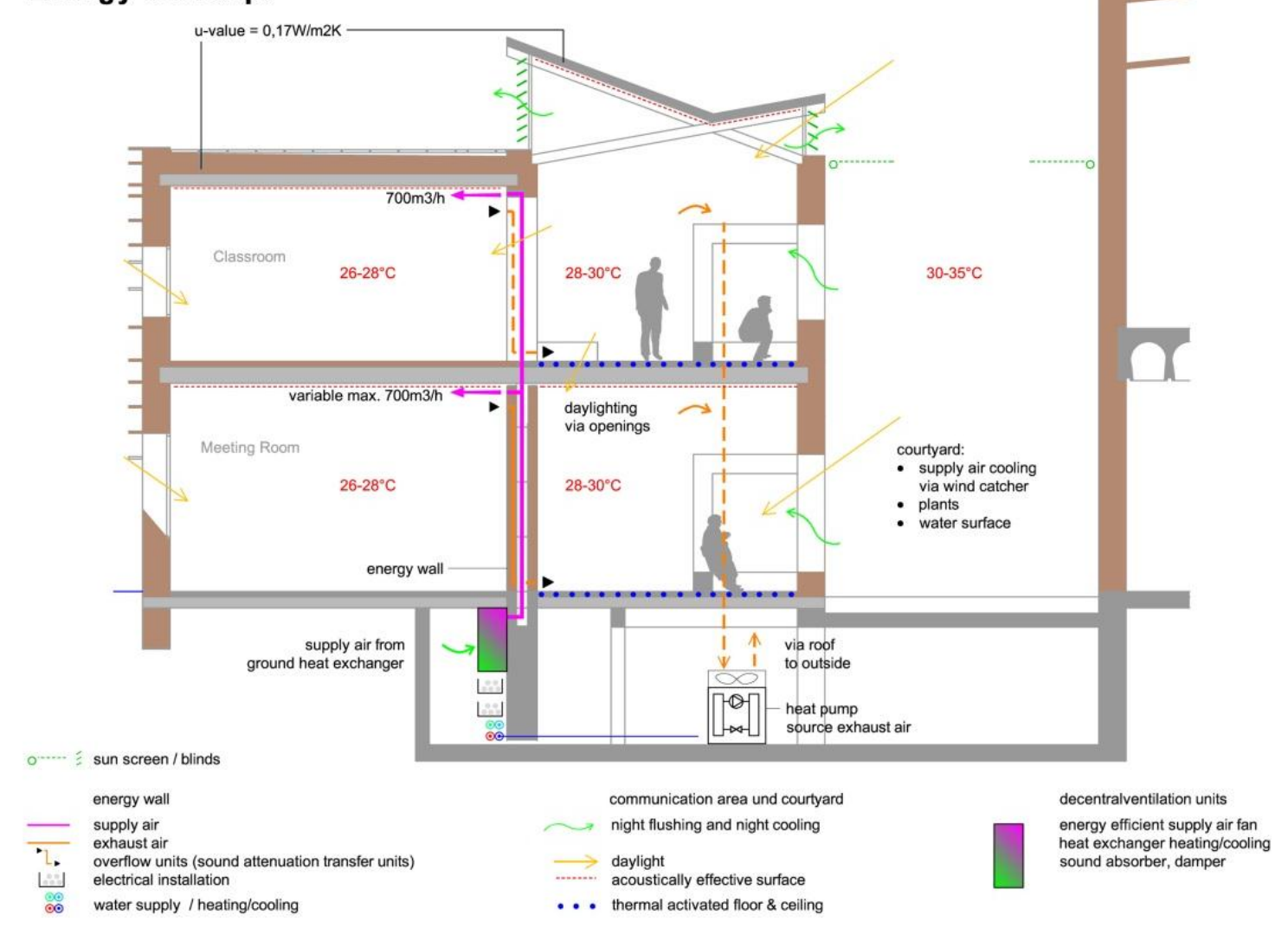

Fuente: Training Center Marrakesh (2013) 
Figura 5.13 Fotografía del proceso constructivo del Centro de Formación para la Sostenibilidad

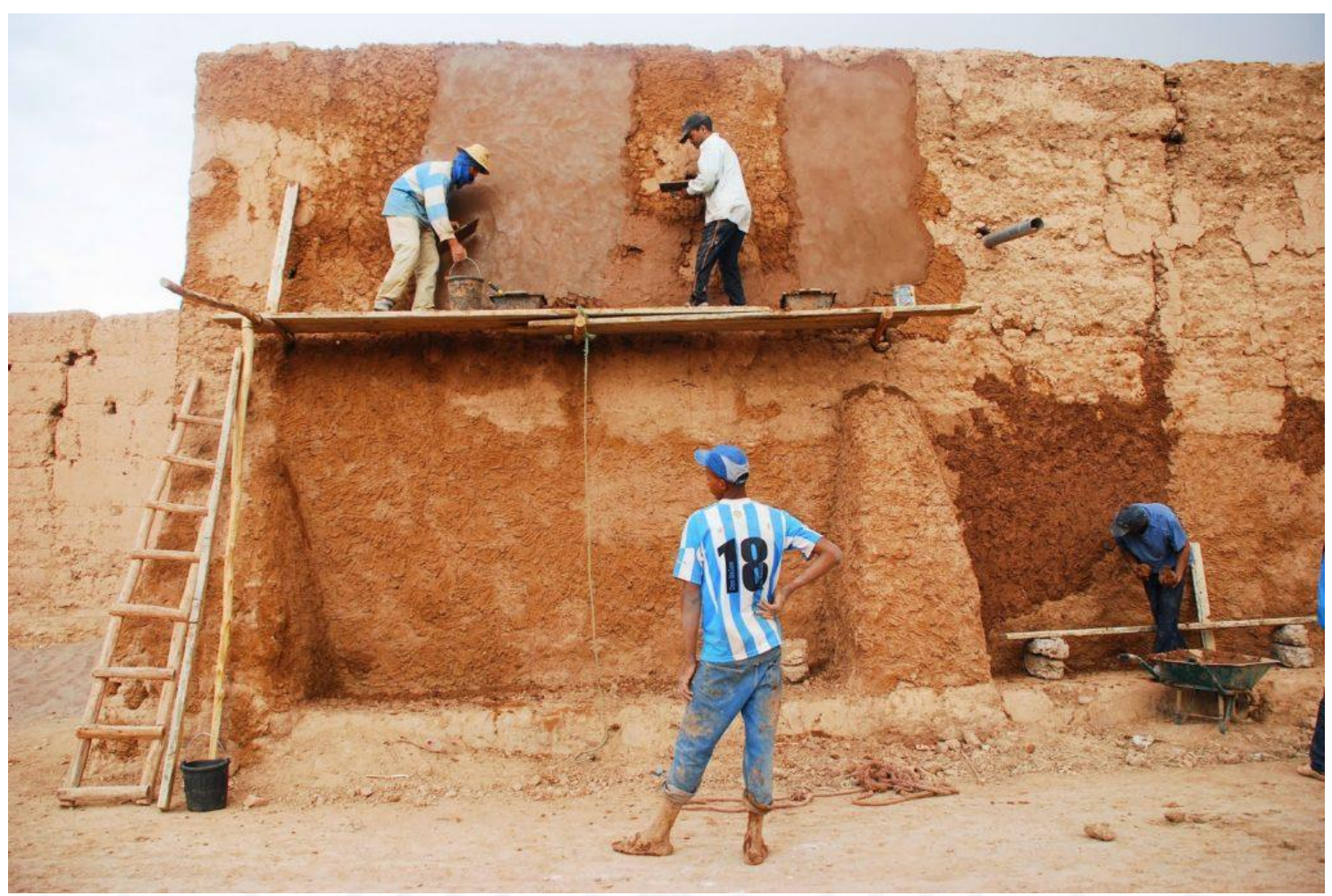

Fuente: Training Center Marrakesh (2013)

Figura 5.14 Exterior del Centro de Formación para la Sostenibilidad

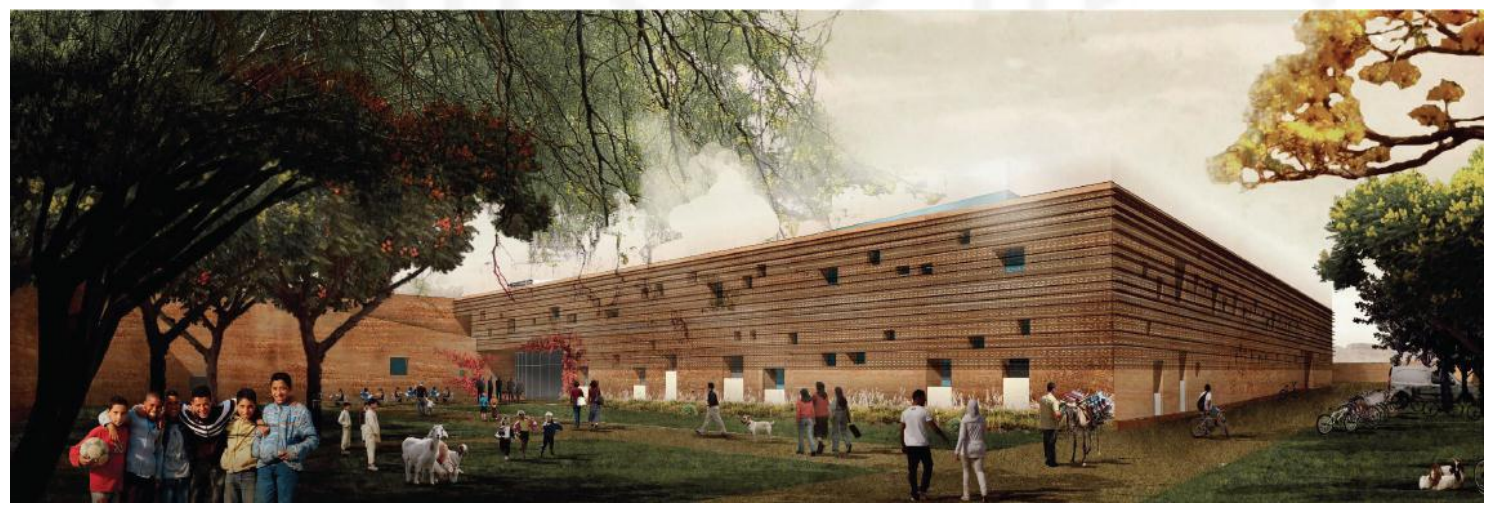

Fuente: Training Center Marrakesh (2013) 


\subsubsection{Impacto social}

El propósito del edificio es ser un centro de enseñanza para la construcción sostenible, el 30\% de los jóvenes en Marruecos en edades de 15 a 25 años son analfabetos. La formación profesional es esencial para evitar el desempleo. El sector de la construcción en Marruecos está prosperando, pero no existen modelos aplicados a la construcción sostenible que sean adecuados en tecnología, así como sensibles a la identidad cultural y con recursos del lugar. El Centro de Formación para la sostenibilidad en Chwitter ofrece a los jóvenes de los suburbios de Marrakech una posibilidad de aprender una futura profesión. ("Heringer", 2008)

El proyecto busca promover el desarrollo económico y social de Chwitter, una ciudad satélite de Marruecos, capacitando a la población sobre métodos constructivos en tierra, actividad local ya establecida pero trabajada de forma empírica, ignorando además conceptos sostenibles como métodos de bajo impacto en la extracción de recursos y huella ecológica.

Analizando el contexto local, se encontró que uno de los principales materiales de construcción tradicional para cualquier clase de propósito y dimensión, era la tierra (...) el proyecto adopta el saber hacer tradicional, complementado con modernas tecnologías apropiadas con el fin de satisfacer las necesidades en materia de seguridad y el confort de la sociedad actual. ("Heringer", 2008)

El nuevo centro ofrecerá puestos de trabajo y formación profesional a la comunidad de Chwiter, la aplicación de las técnicas aprendidas en el dará como resultado el mejoramiento de la calidad constructiva sostenible en Marrakech, además la construcción del centro mejorará la economía local, a través de proporcionar un trabajo justamente remunerado, por último la tecnología de la construcción de la tierra será accesible a personas de todo nivel económico. 


\subsubsection{Escuela vocacional Sra Pou}

\subsubsection{Historia}

Cliente: Comunidad Sra Pou

Ubicación: Sra Pou, Camboya

Figura 5.15 Ubicación de la Escuela Vocacional Sra Pou

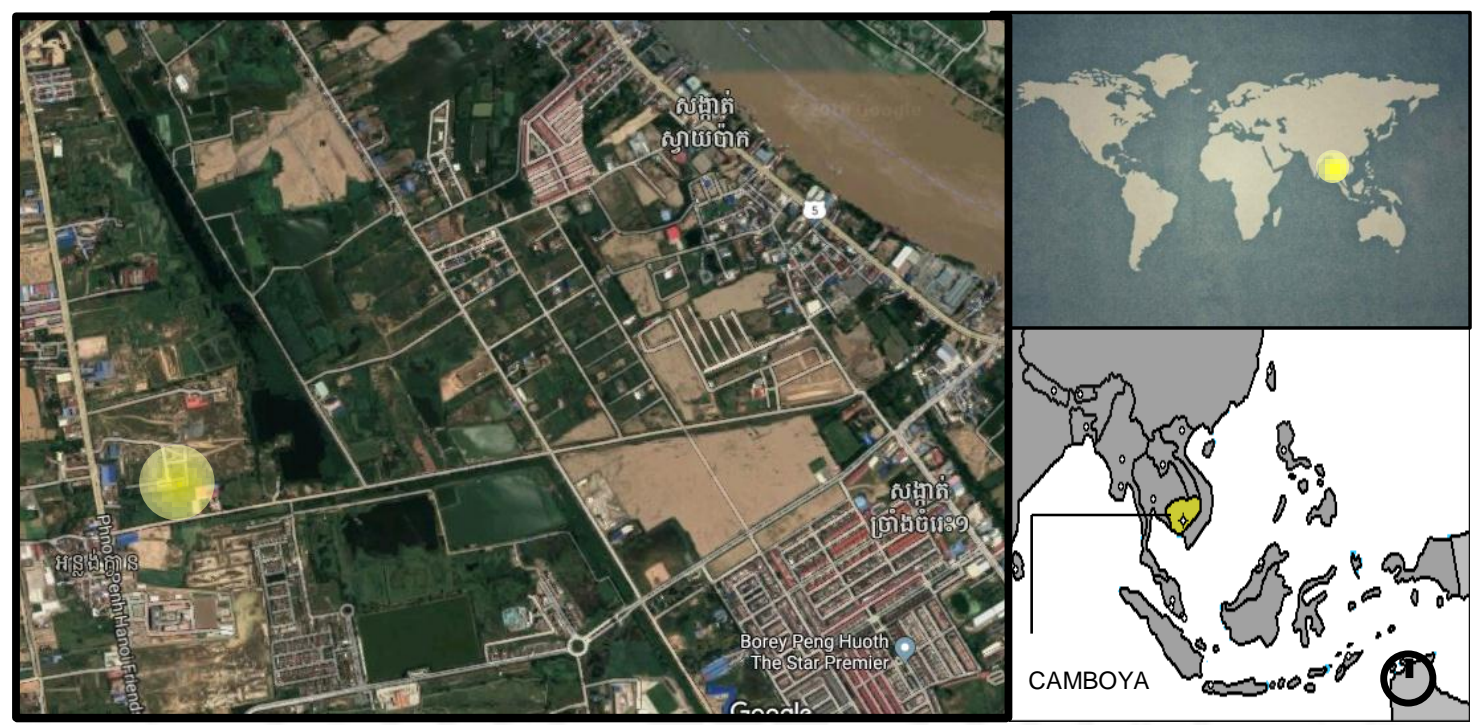

Elaboración propia

Año: 2011

Diseño: Rudanko + Kankkunen

Área del proyecto: $238 \mathrm{~m} 2$.

\section{Costo estimado: -}

El proyecto se inició cuando tomamos parte en un estudio de diseño de la Universidad de Aalto dirigido por fundadores Ukumbi en la primavera de 2010. Durante el estudio, los estudiantes viajamos a Camboya para encontrar una tarea de diseño con una ONG local. Nos encontramos con la comunidad Sra Pou a través de la ONG Azul, y se nos pidió para ayudar con el diseño de una pequeña escuela de formación profesional. Los trabajos de estudio fueron al principio imaginarios, decidieron comenzar a trabajar en la construcción de la escuela profesional Sra Pou junto con la comunidad y la ONG, ya que había una necesidad urgente de ella y el diseño inspiraría a la comunidad y a los donantes. (Basulto \& Assael, 2008) 


\subsubsection{Ubicación y relación con el entorno}

Figura 5.16 Gráfico de Ubicación de la Escuela vocacional Sra Pou

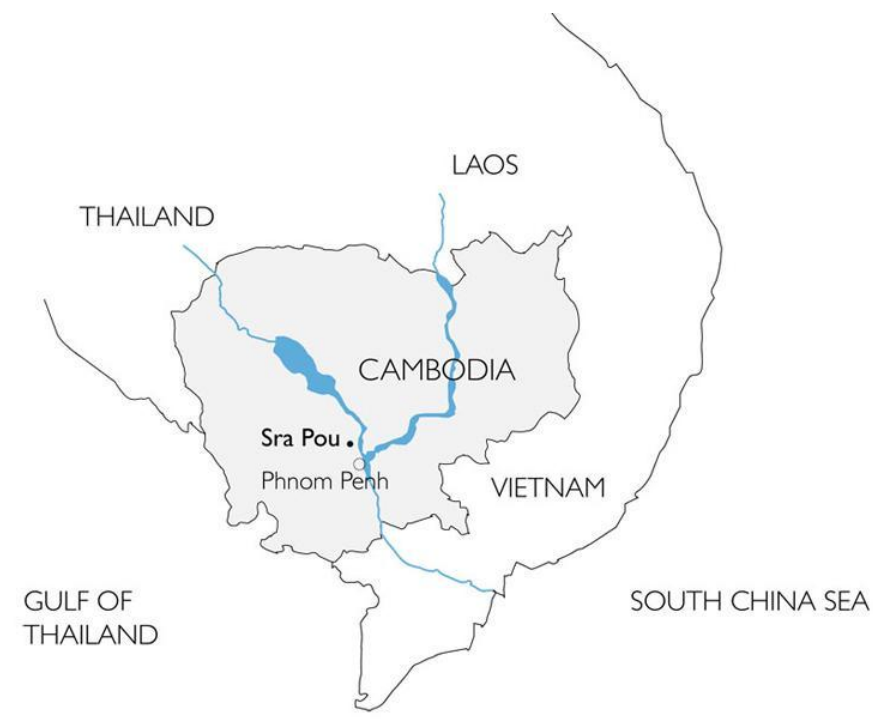

Fuente: Plataforma de arquitectura

Figura 5.17 Gráfico de Ubicación y relación con el entorno de la Escuela vocacional Sra Pou
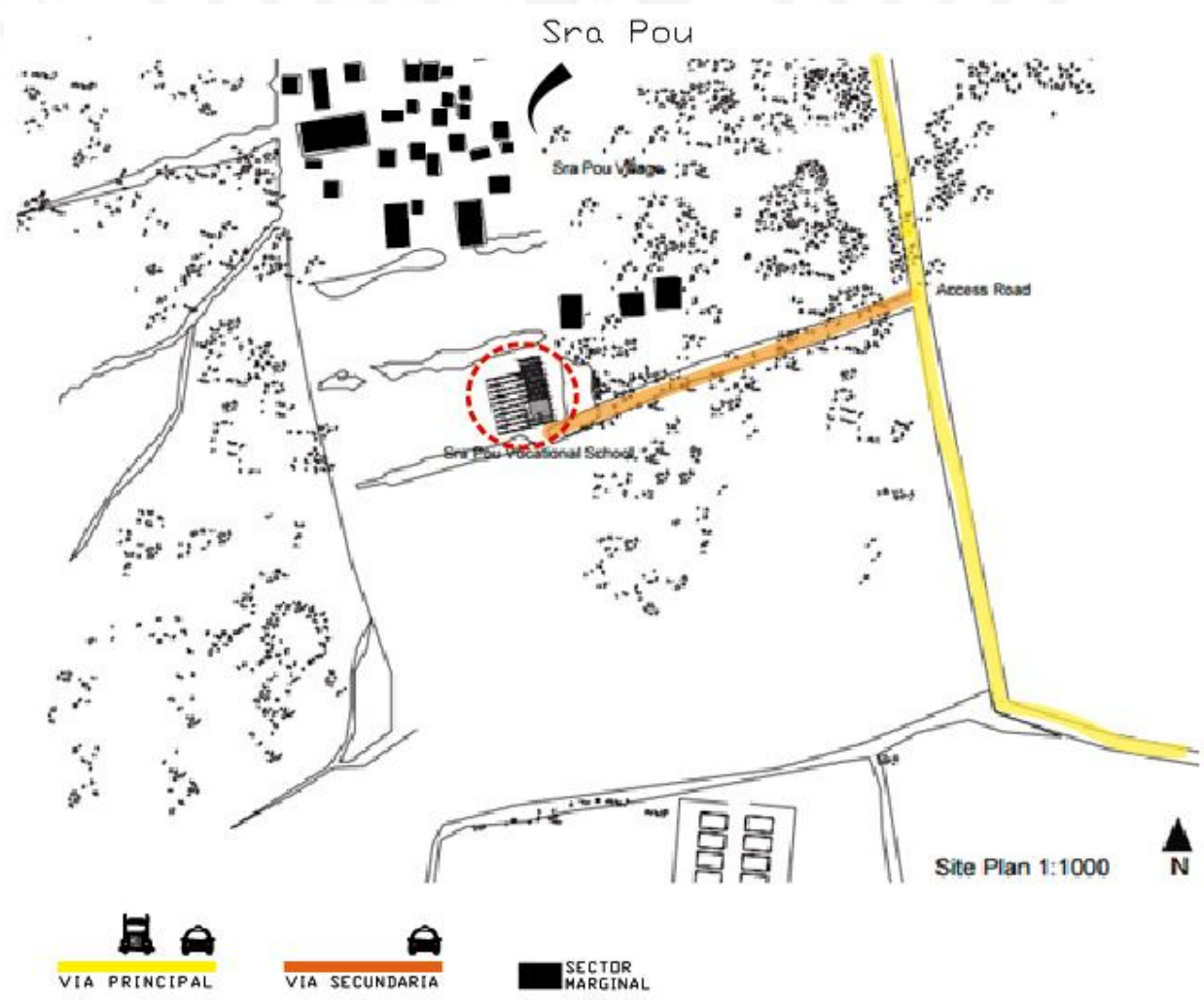

Fuente: Plataforma de arquitectura 


\subsubsection{Programa y relaciones programáticas.}

El proyecto agrupado en paquetes programáticos sumaría 4 tipos referidos a:

Aprendizaje: de este paquete forman parte una gran aula y dos talleres, ambos funcionan como espacios multifuncionales.

Administración: comprende una sola oficina administrativa, ubicada en el segundo nivel

Servicios: baños de hombres y de mujeres, ubicados solo en el primer nivel.

Comunidad: dentro del proyecto existe un espacio destinado a actividades comunales, dentro del primer nivel

Cuadro 5.3 Cuadro de áreas aproximado de la Escuela vocacional Sra Pou

\begin{tabular}{|c|c|c||c|}
\hline \multicolumn{4}{|c|}{ CUADRO DE AREAS APROXIMADO } \\
\hline \hline \multirow{2}{*}{ PAQUETES } & AMBIENTE & $\begin{array}{c}\text { AREA } \\
\text { APROXIMADA (M2) }\end{array}$ & APQRTE (\%) \\
\hline \hline \multirow{2}{*}{ APRENDIZAJE } & AULA & 50 & $21 \%$ \\
\cline { 2 - 4 } COMUNAL & TALLERES & 55 & $23 \%$ \\
\cline { 2 - 4 } ADMINISTRACIÓN & SALON COMUNITARIO & 59 & $25 \%$ \\
\cline { 2 - 4 } SERVICIOS & OFICINA & 17 & $7 \%$ \\
\cline { 2 - 4 } & SERVICIOS & 11.5 & $5 \%$ \\
\cline { 2 - 4 } RECREACIÓN & CIRCULACIÓN & 34 & $5 \%$ \\
\cline { 2 - 4 } & AREA LIBRE & 12 & $100 \%$ \\
\hline
\end{tabular}

Elaboración propia

Cuadro 5.4 Cuadro de áreas aproximado por paquete de la Escuela vocacional Sra Pou

\begin{tabular}{|c|c|c|}
\hline \multicolumn{3}{|c|}{ CUADRO DE AREAS APROXIMADO POR PAQUETE } \\
\hline \multicolumn{3}{|c|}{$\begin{array}{l}\text { APRENDIZAJE } \\
\end{array}$} \\
\hline AMBIENTE & AREA APROXIFADA (H2) & APORTE (\%) \\
\hline AULAS & $\mathbf{5 0}$ & $48 \%$ \\
\hline TALLERES & 55 & $52 \%$ \\
\hline TOTAL & 105 & $100 \%$ \\
\hline
\end{tabular}

\begin{tabular}{|c|c|c|}
\hline \hline \multicolumn{3}{|c|}{ CUADRO DE AREAS APROXIMADO POR PAQUETE } \\
\hline \hline \multicolumn{2}{|c|}{ COHUNAL } & APORTE (\%) \\
\hline \hline AMBIENTE & AREA APROXIMADA (H2) & $100 \%$ \\
\hline \hline SALON & 59 & $\mathbf{1 0 0 \%}$ \\
\hline \hline TOTAL & 59 &
\end{tabular}




\begin{tabular}{|c|c|c||}
\hline \multicolumn{2}{|c|}{ CUADRO DE AREAS APROXIFADO POR PAQUETE } \\
\hline \hline \multicolumn{2}{|c|}{ ADFIINISTRACIOK } \\
\hline \hline AMBIENTE & AREA APROXIFADA (H2) & APDRTE (\%) \\
\hline OFICINAS & 17 & $100 \%$ \\
\hline \hline TOTAL & 17 & $100 \%$ \\
\hline
\end{tabular}

\begin{tabular}{||c|c|c|}
\hline \hline \multicolumn{3}{|c|}{ CUADRO DE ÁREAS APROXIMADO POR PAQUETE } \\
\hline \multicolumn{2}{|c|}{ SERVICIOS } \\
\hline AMBIENTE & ÁREA APROXIMADA (M2) & APORTE (\%) \\
\hline SERVICIOS & 11.5 & $100 \%$ \\
\hline TOTAL & 11.5 & $100 \%$ \\
\hline \hline
\end{tabular}

\begin{tabular}{||c|c|c|}
\hline \multicolumn{3}{|c|}{ CUADRD DE AREAS APROXIMADO PDR PAQUETE } \\
\hline \hline \multicolumn{2}{|c|}{ RECREACION } \\
\hline AMBIENTE & AREA APROXIMADA (M2) & APORTE (\%) \\
\hline AREA LIBRE & 12 & $100 \%$ \\
\hline TOTAL & 12 & $100 \%$ \\
\hline
\end{tabular}

Elaboración propia

Figura 5.18 Plano primer nivel con paquete programático de la Escuela Vocacional Sra Pou

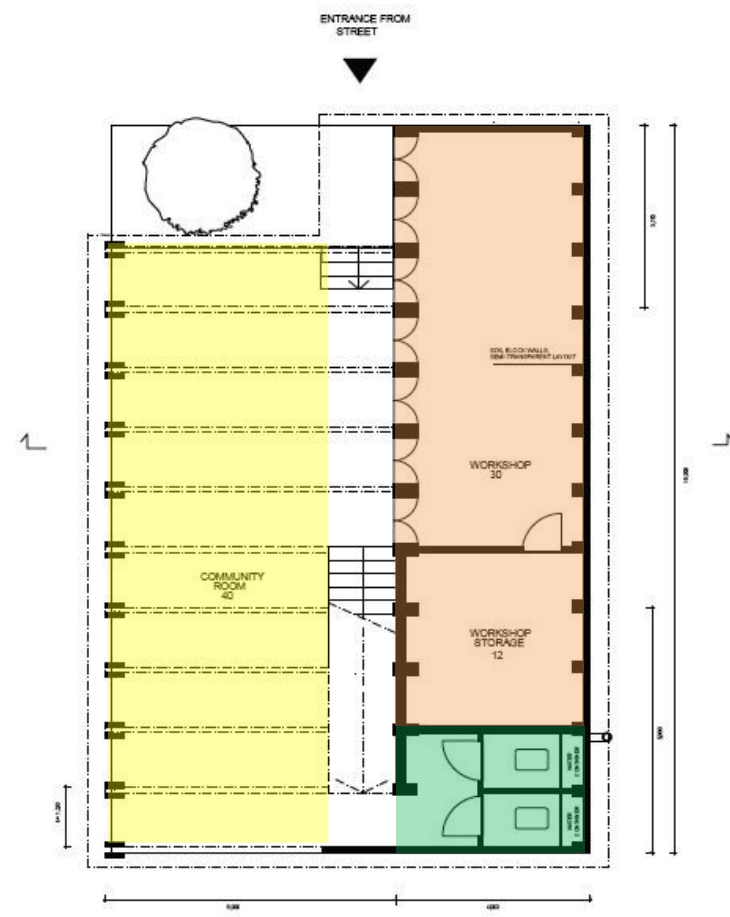

PRIMER NIVEL

Fuente: Plataforma de arquitectura

Elaboración propia 
Figura 5.19 Plano segundo nivel con paquete programático de la Escuela Vocacional Sra Pou

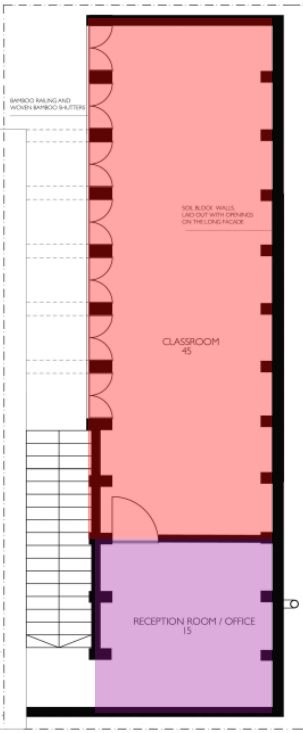

SEGUNDO NIVEL

Fuente: Plataforma de arquitectura

Elaboración propia

\begin{tabular}{|c|c|c|c|}
\hline APRENDIZAJE & EQUIPAMIENTO EDUCATIVO & ADMINISTRATIVO & SERVICIO \\
\hline $\begin{array}{c}\text { AULA } \\
\text { TALLER }\end{array}$ & - & OFICINA & BAÑOS \\
\hline
\end{tabular}

Elaboración propia

Figura 5.20 Esquema de relación de ambientes de la Escuela Vocacional Sra Pou

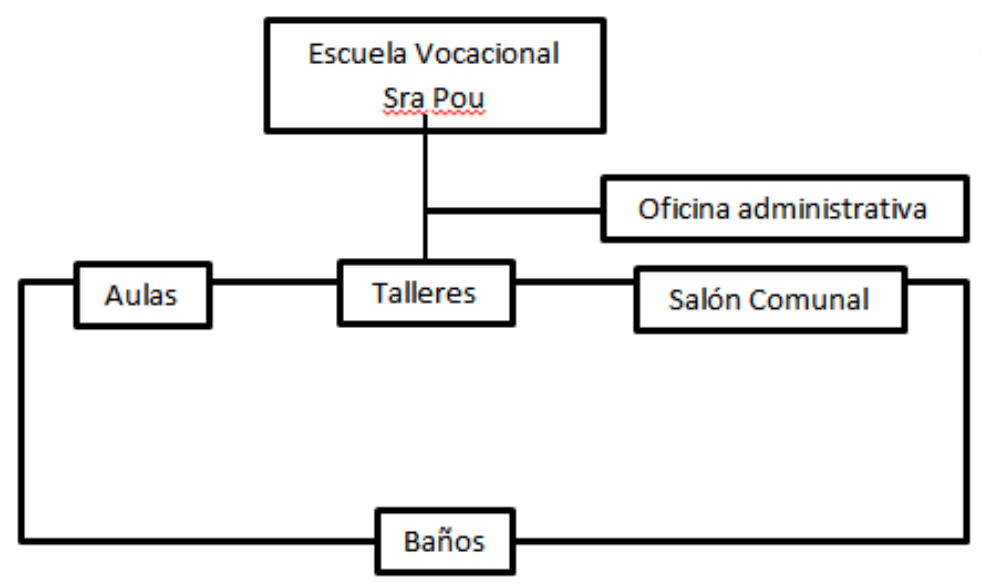

Elaboración propia 


\subsubsection{Tipología espacial}

Figura 5.21 Tipología Espacial de la Escuela Vocacional Sra Pou

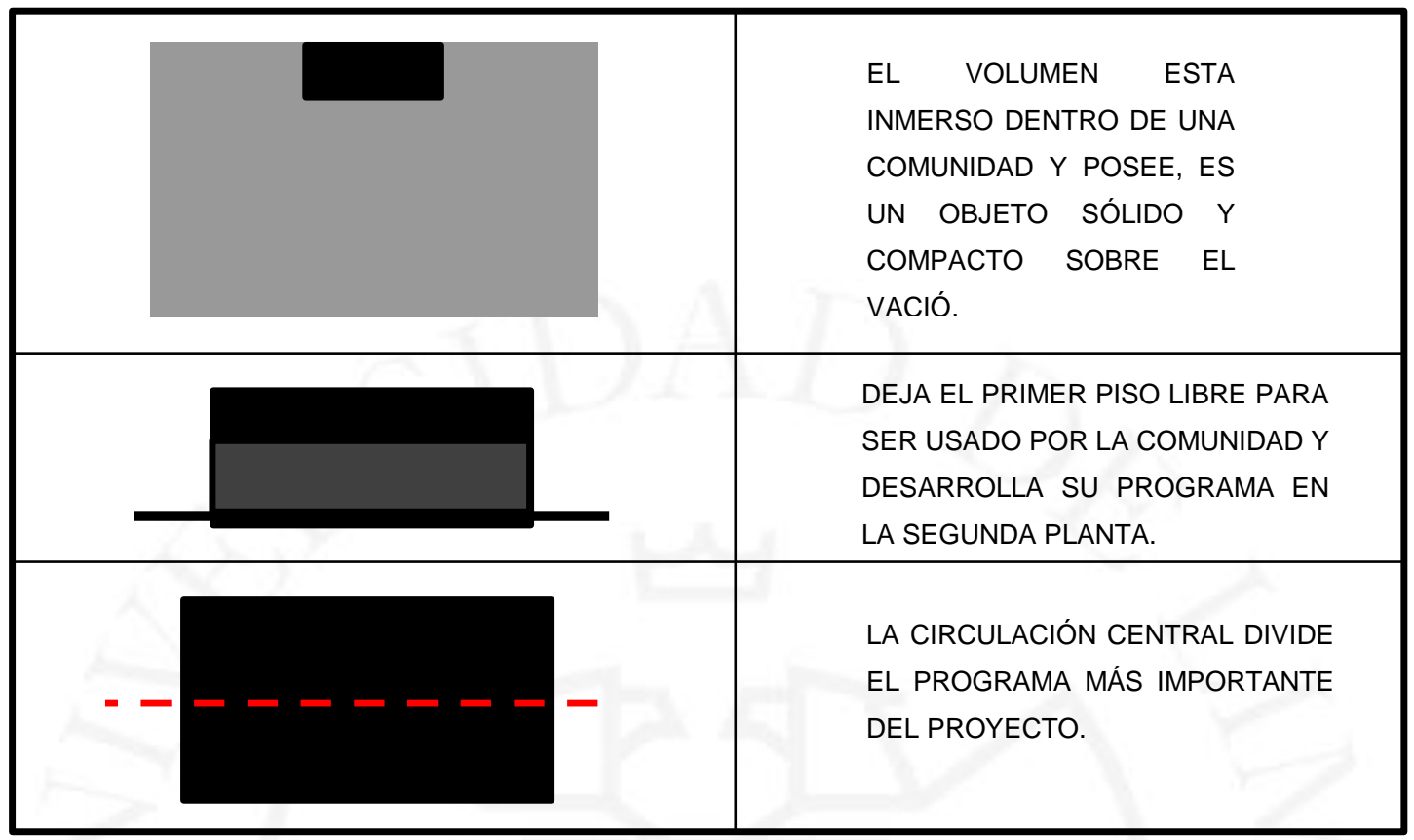

Elaboración propia

5.1.2.5 Público - privado

Figura 5.22 Análisis de accesibilidad a los ambientes de la Escuela Vocacional Sra Pou
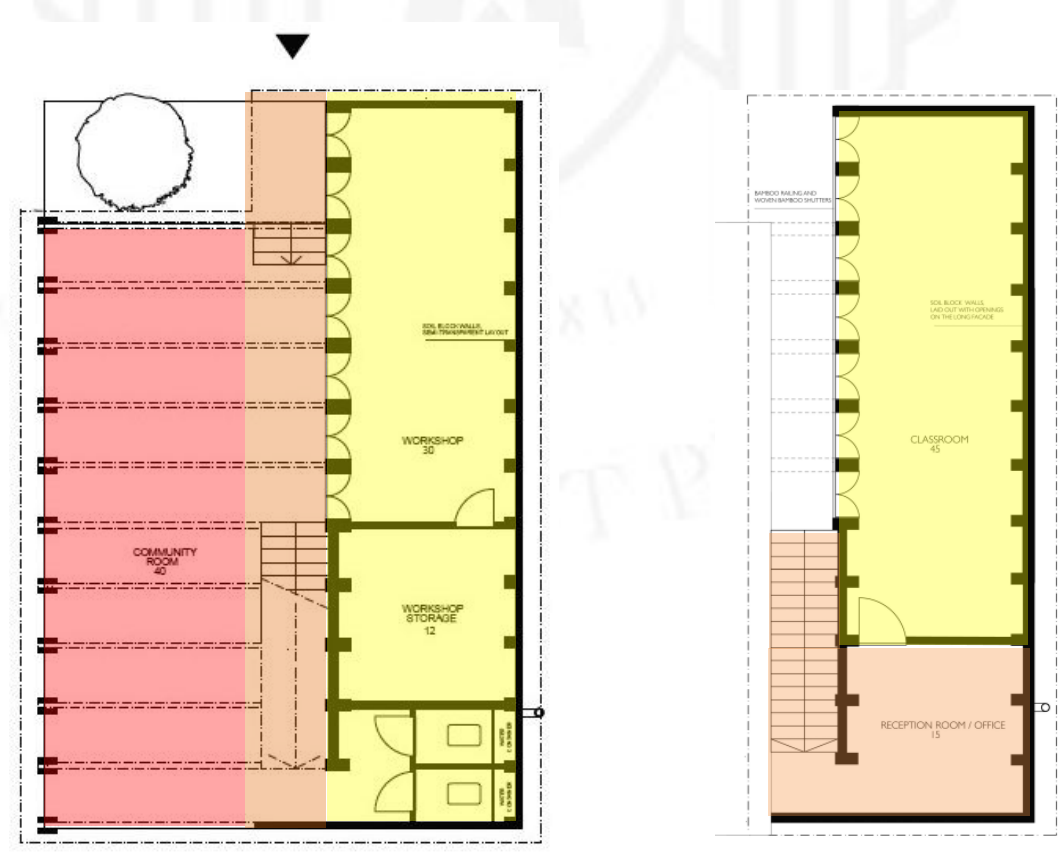

Fuente: Plataforma de arquitectura

Elaboración propia 

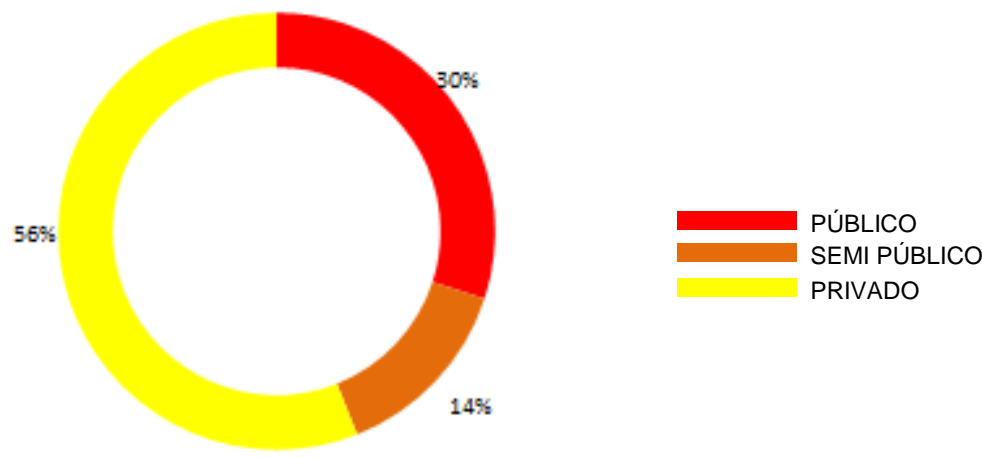

Elaboración propia

Figura 5.23 Análisis de flujos de la Escuela Vocacional Sra Pou
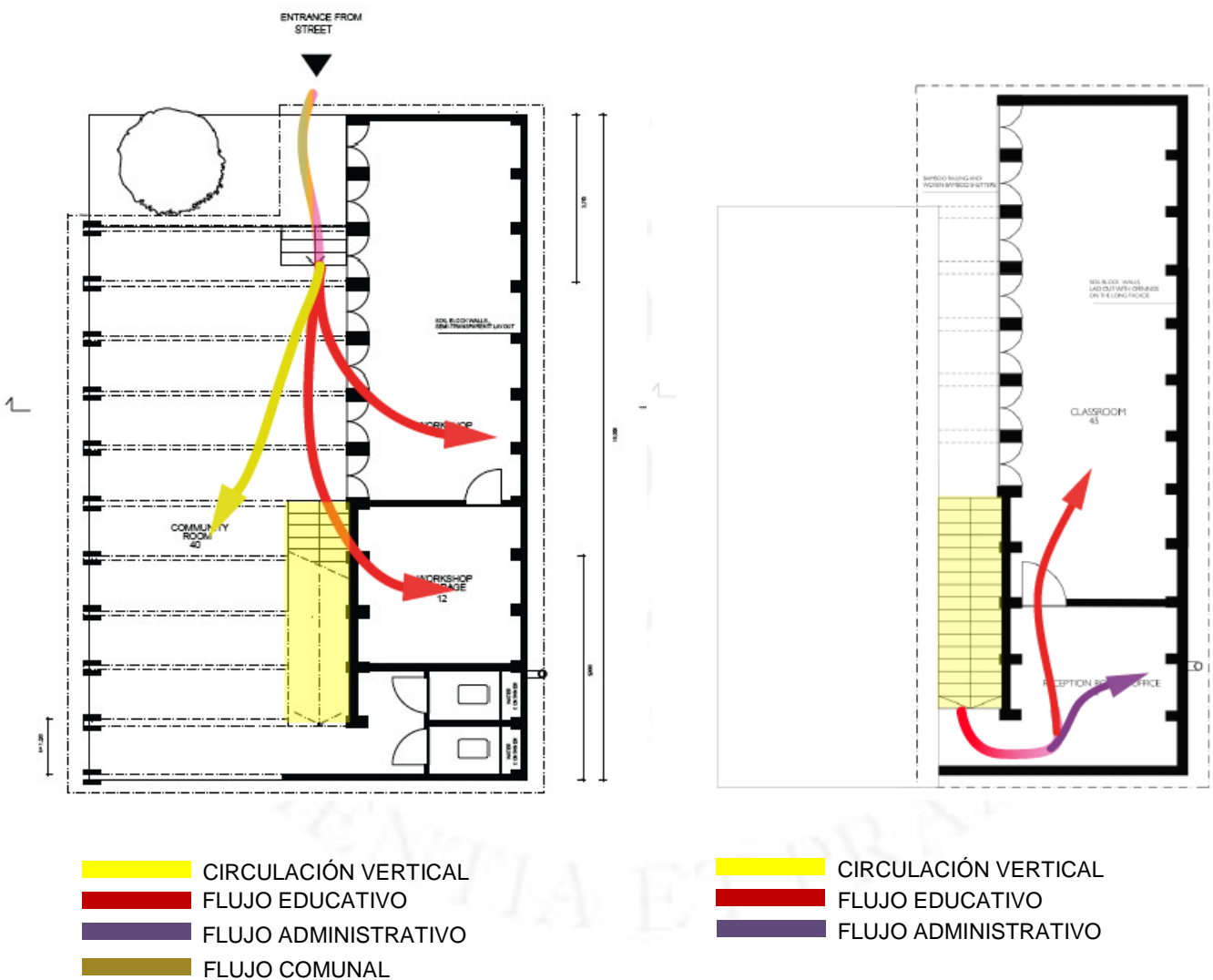

Fuente: Plataforma de arquitectura

Elaboración propia 
Figura 5.24 Análisis del área libre y área construida de la Escuela Vocacional Sra Pou

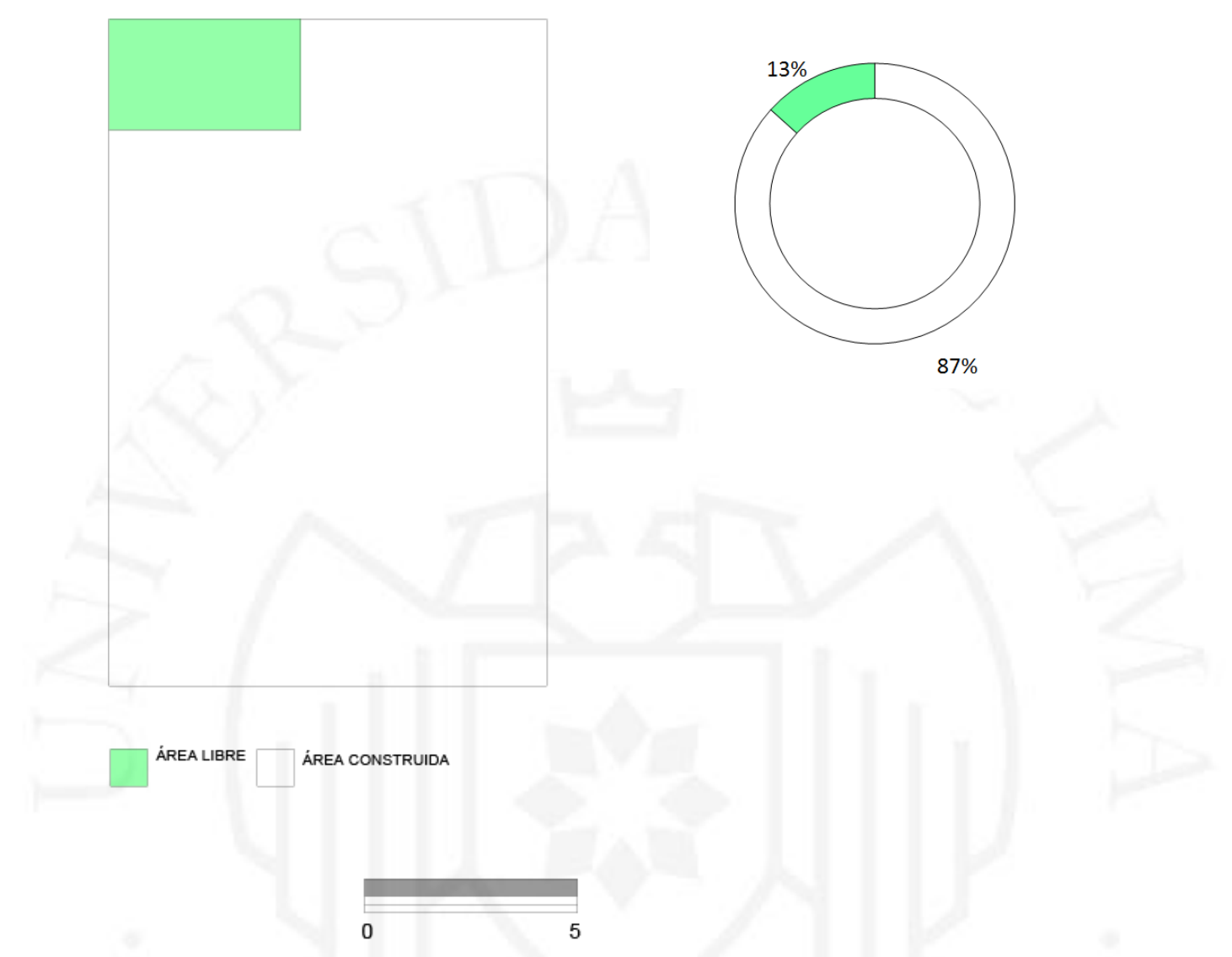

Elaboración propia

\subsubsection{Tecnología}

El edificio de la escuela está hecho de materiales locales con mano de obra local. El objetivo era alentar a la comunidad a sacar el máximo provecho de los materiales que están fácilmente disponibles, de modo que pudieran aplicar las mismas técnicas de construcción en sus futuros proyectos. (Ukumbi ONG, 2007) 
Figura 5.25 Sistema constructivo de la Escuela Vocacional Sra Pou

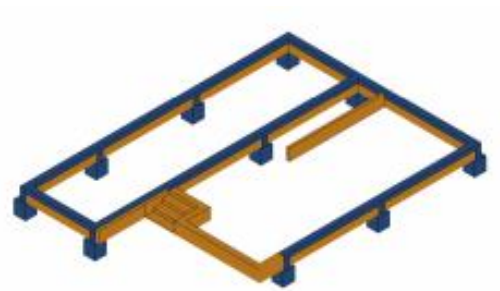

1. Buildi concrete bases. Connect them using mud bricks.

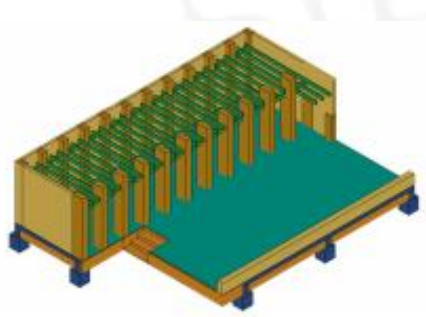

3. Insert the floor beams using timber frame system.

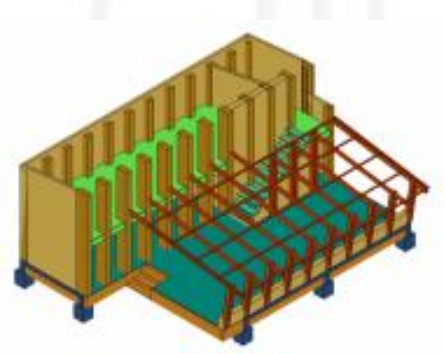

5. Continue building brick columns and walls on the upper floor.

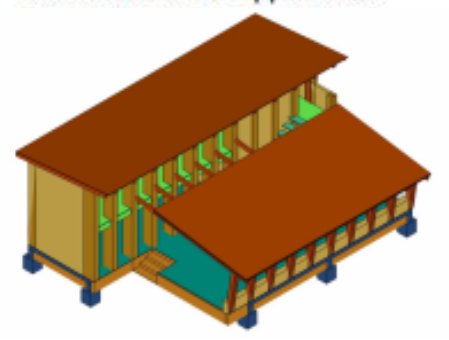

7. Add bamboo mats for insulation and corrogated sheets on the roof.

Fuente: (Ukumbi ONG, 2007)

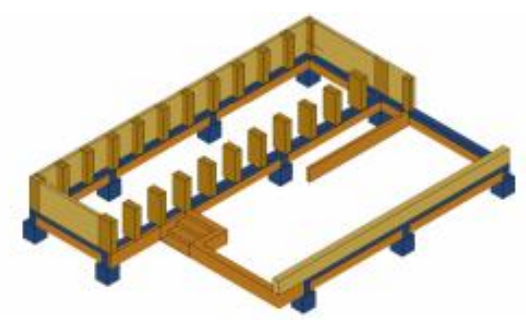

2. Laying brick walls and columns.

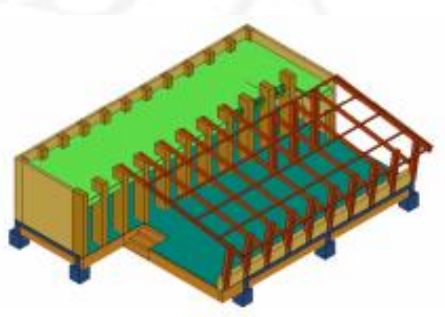

4. Add wooden columns and grid beams over the open space.

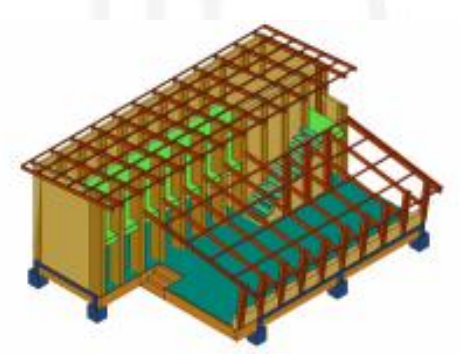

6. Add wooden beams on the upper roof.

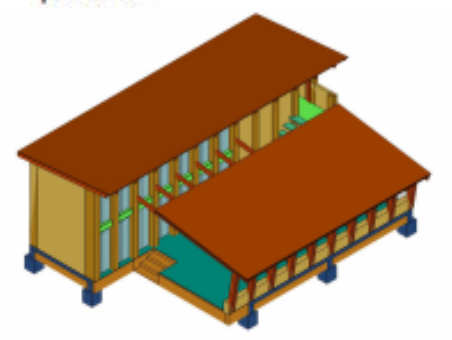

8. Put ton the wooden tiles for the ground and install the handmade doors. 
Figura 5.26 Acondicionamiento ambiental de la Escuela Vocacional Sra Pou

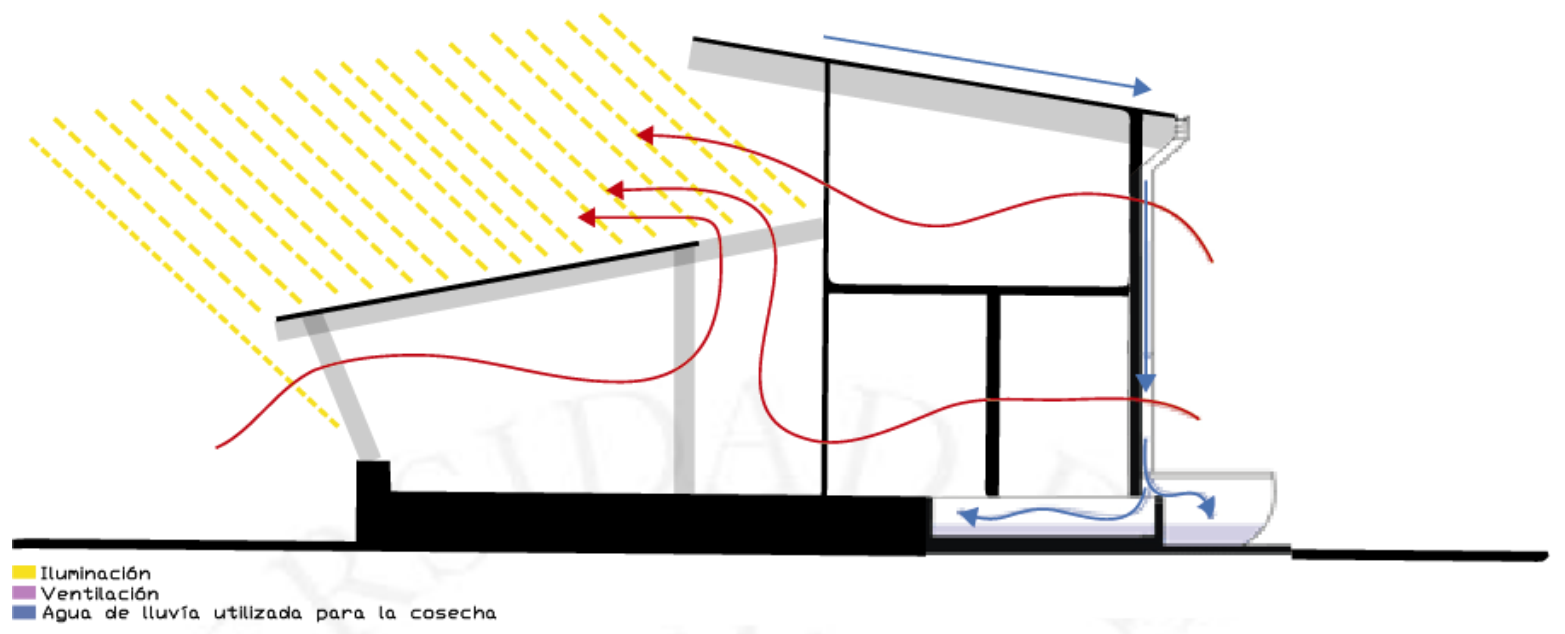

Fuente: (Ukumbi ONG, 2007)

Figura 5.27 Corte arquitectónico de la Escuela Vocacional Sra Pou

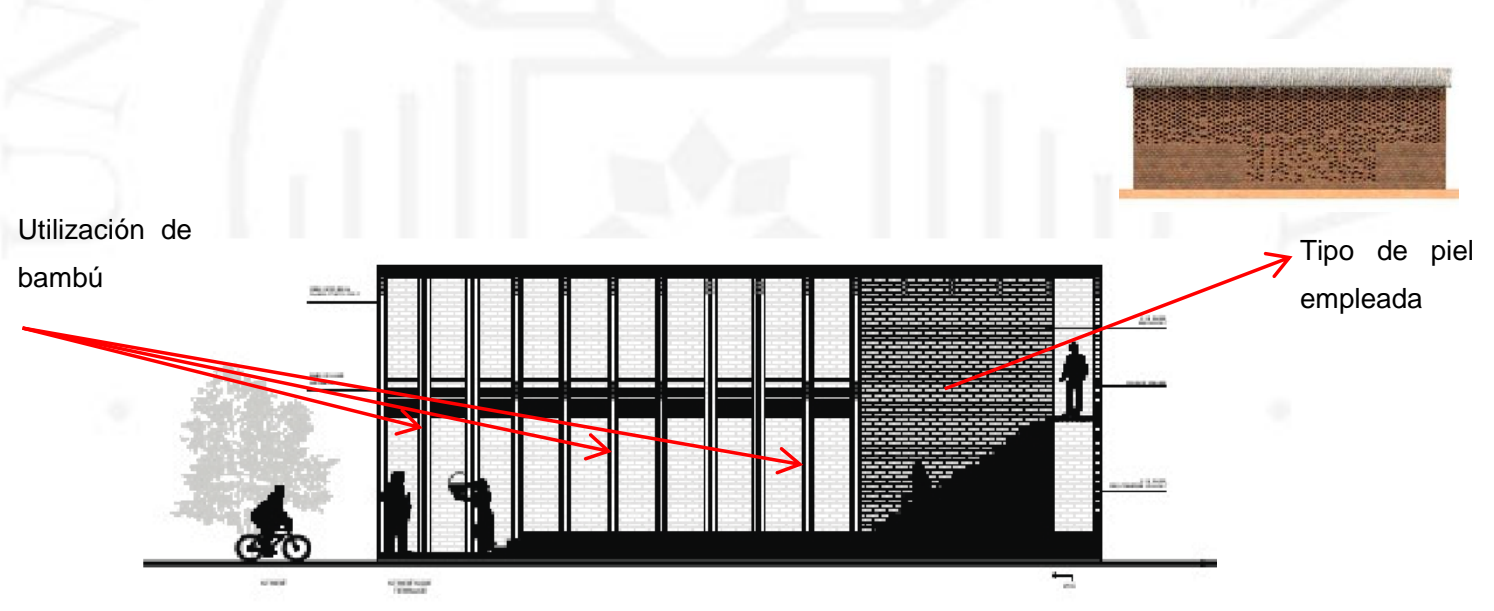

Fuente: (Ukumbi ONG, 2007) 
Figura 5.28 Sistema Constructivo y materialidad

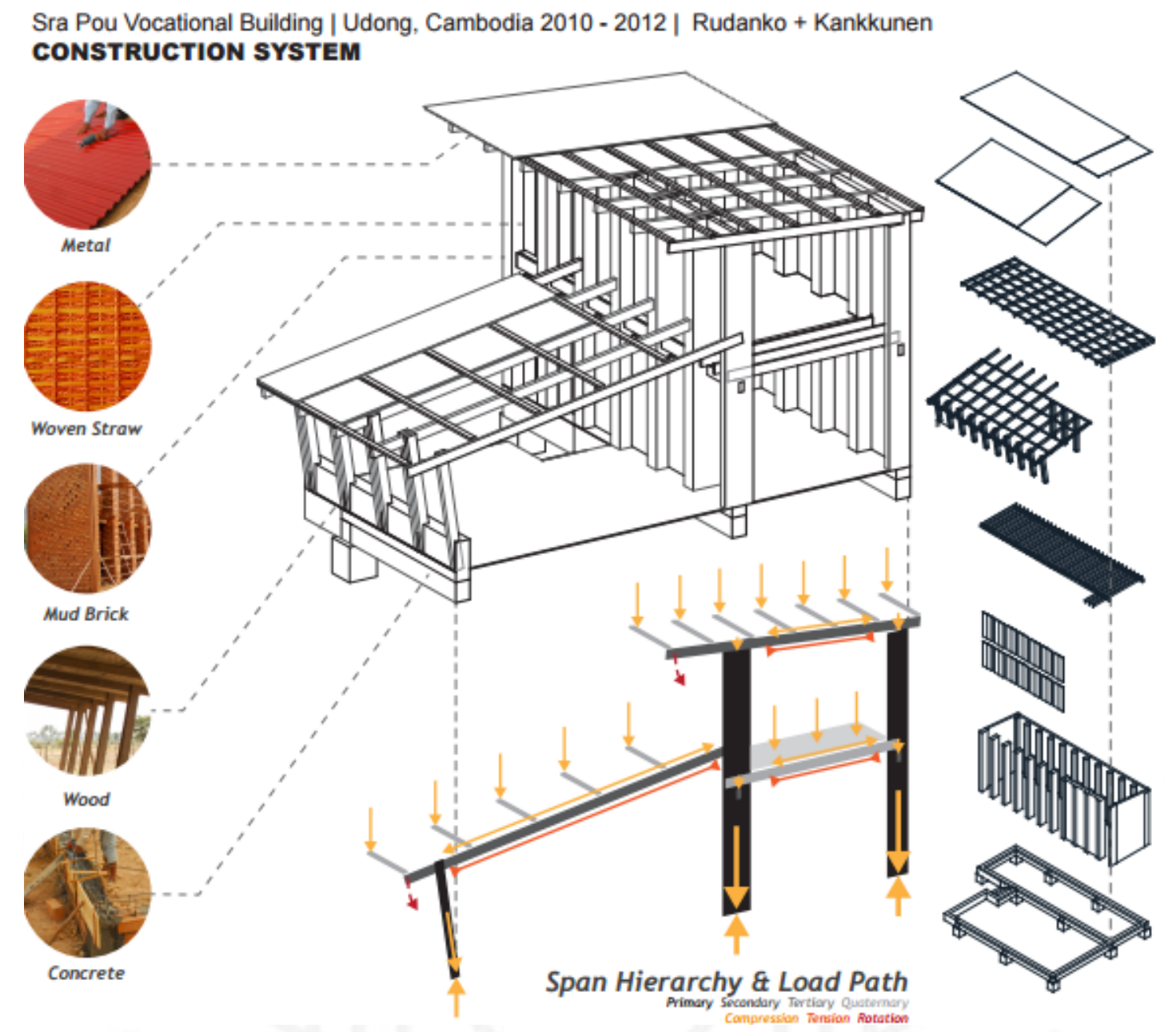

Fuente (Ukumbi ONG, 2007)

El proyecto consiste en la construcción de paredes con ladrillos de barro, hechos con una mezcla de tierra, arcilla, paja, cemento y agua y luego se deja secar al sol. Trabajadores locales sin la ayuda de medios mecánicos levantaron los dos pisos del proyecto. Las paredes tenían pequeños agujeros que permiten que la luz y el viento penetren durante el día y la transformación del edificio en un gran farol durante la noche. (Ukumbi ONG, 2007) 


\subsubsection{Impacto social}

El propósito del centro de formación profesional es estimular y enseñar a las familias pobres a ganarse la vida. La comunidad Sra Pou es una de las comunidades no privilegiadas en Camboya, que ha sido desalojada de sus hogares en la ciudad y llevada al campo. Carecen de infraestructura básica, medio construido decente e ingresos seguros. La nueva escuela ofrece formación profesional y ayuda a la gente a iniciar negocios sostenibles juntos. También es un lugar de reunión pública y la toma de decisiones democrática para toda la comunidad, la ONG camboyana Azul organiza la enseñanza.

Las puertas fueron hechas a mano por parte de la comunidad. El objetivo principal del proceso de auto-construcción es involucrar a la población local, fomentando el uso de técnicas y materiales conocidos por los artesanos locales, de manera que los trabajadores aprenden a adoptar soluciones tecnológicas a través del uso de materiales disponibles, sin tener recurrir a técnicas económicamente menos ventajosas. (Ukumbi ONG, 2007)

Actualmente la escuela imparte tres tipos de oficios, el salón comunal mientras no es usado por la comunidad sirve de taller de mecánica de bicicletas, los talleres del primer piso de imparten clases de cosmetología y en el segundo nivel es un taller de costura, la escuela es supervisada por la ONG local Azul y el proyecto beneficia actualmente a más de 75 pobladores de la comunidad de Sra Pou.

Figura 5.29 Fotografía de un aula taller en la Escuela Vocacional Sra Pou

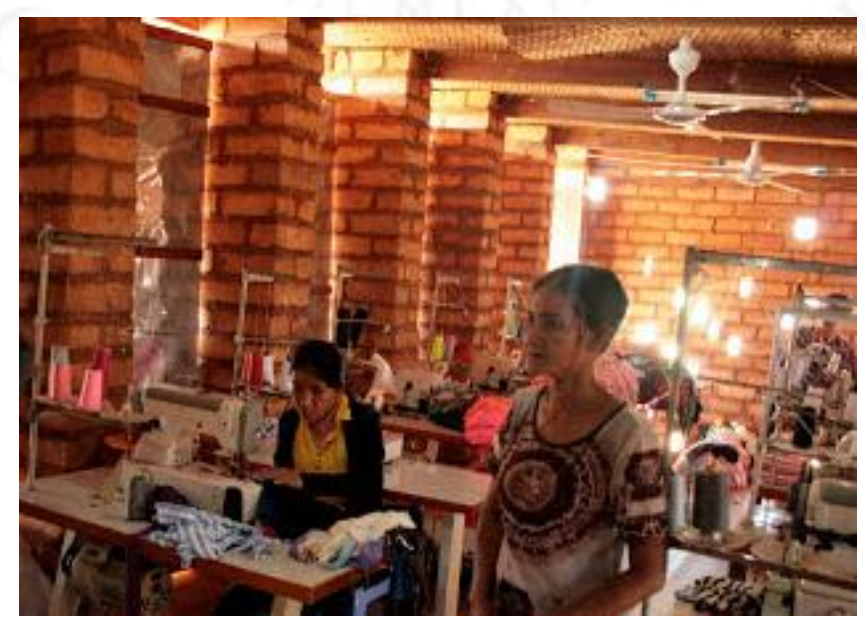

Fuente: (Ukumbi ONG, 2007) 


\subsubsection{Centro de Entrenamiento Indígena Käpäcäjui}

\subsubsection{Historia}

Cliente: Instituto Holcim, Instituto Mixto de Ayuda Social (IMAS) y la Asociación de Desarrollo Integral de la Reserva Indígena Cabecar del Bajo Chirripó

Ubicación: Grano de Oro, Costa Rica

Figura 5.30 Ubicación del Centro de Entrenamiento Indígena Kapacajui

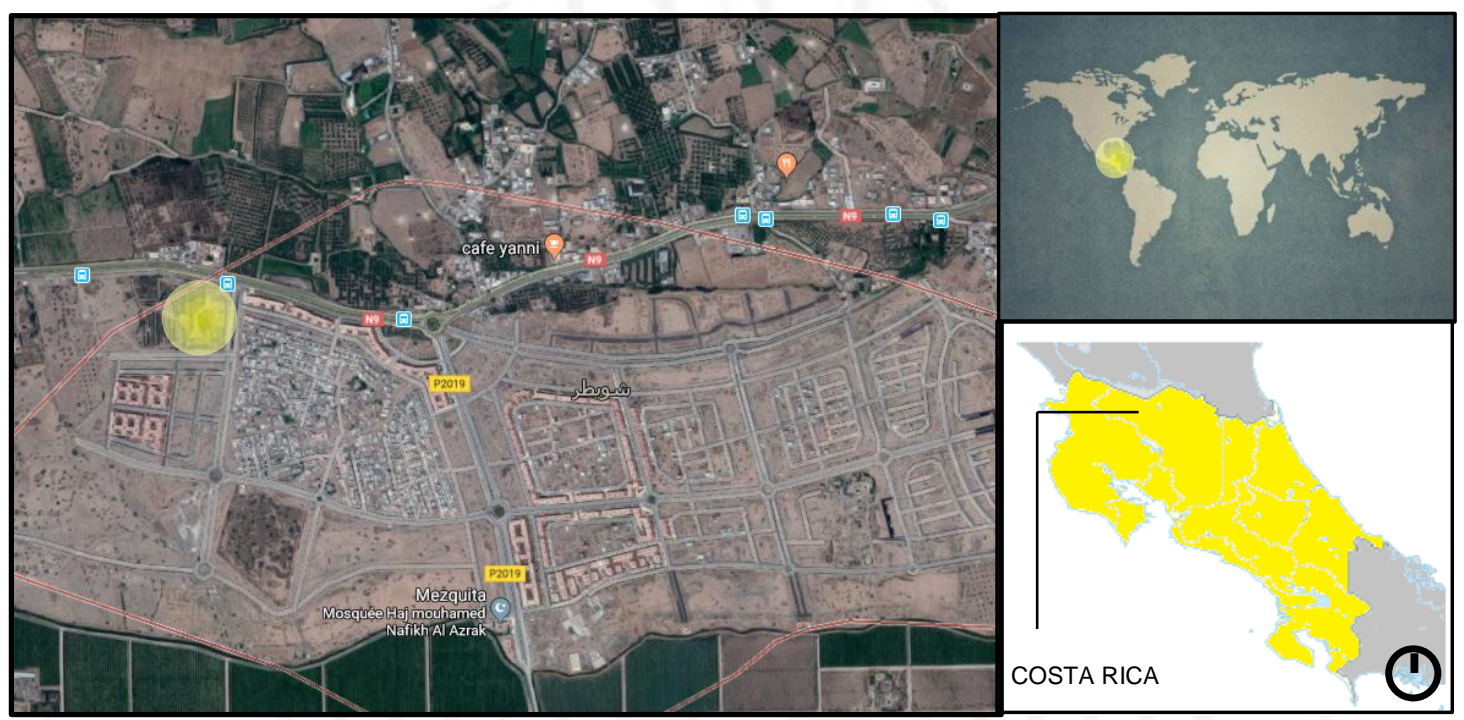

Elaboración propia

Año: 2014

Diseño: Entre Nos Atelier

Área del proyecto: $470.0 \mathrm{~m} 2$.

Costo estimado: $\$ 4000000$

La visión del proyecto surge desde una serie de talleres de diseño participativo y posterior validación de las propuestas. Dichos talleres de trabajo fueron claves para promover un sentimiento de apropiación en la comunidad a la hora de visualizar y tomar decisiones. Fue la oportunidad de entender y „, espacios coherentes con el entorno y centrados en las necesidades del usuario.

Como un proceso prospectivo, se indaga con la comunidad acerca de su percepción cualitativa de un espacio ,ideal ${ }^{\text {ee }} \mathrm{y}$ de la relación con determinantes funcionales. Esta información se dibuja, diagrama, interpreta y sintetiza con el 
apoyo de líderes comunales y traductores del dialecto local para establecer las pautas del proyecto y bases programáticas de partida. (Arch Daily, 2014)

\subsubsection{Ubicación y relación con el entorno}

Figura 5.31 Ubicación del Centro de Entrenamiento Indígena Kapacajui

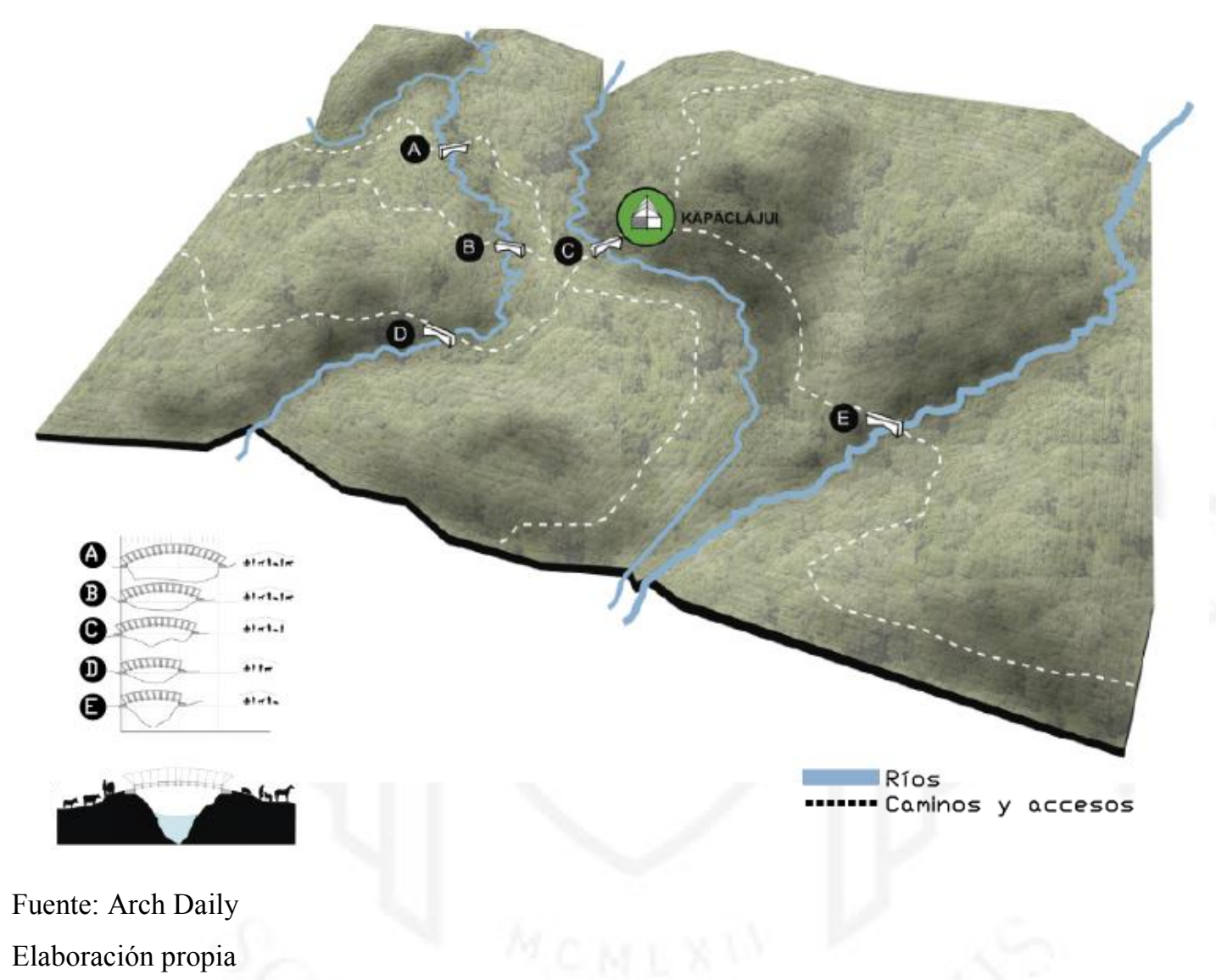

\subsubsection{Programa y relaciones programáticas}

El proyecto agrupado en paquetes programáticos sumaría 6 tipos referidos a:

Aprendizaje: de este paquete forman parte además del salón de cómputo la sala de entrenamiento que funciona como aula, taller y salón de usos múltiples.

Equipamiento educativo: el proyecto cuenta con una biblioteca de carácter comunal

Administración: comprende una sola oficina administrativa, ubicada en el primer nivel. 
Servicios: de este paquete forman parte la cafetería, un depósito y los baños de hombres y de mujeres, ubicados solo en el primer nivel.

Comunidad: dentro del proyecto existe un espacio destinado a actividades comunales.

Cuadro 5.5 Cuadro de áreas aproximado del Centro de Entrenamiento Indígena Kapacajui

\begin{tabular}{|c|c|c|c|}
\hline \multicolumn{4}{|c|}{ CUADRO DE ÁREAS APROXIMADO } \\
\hline PAQUETES & AMBIENTE & \begin{tabular}{|l|} 
ÁREA \\
APROXIMADA \\
$($ M2) \\
\end{tabular} & APORTE (\%) \\
\hline \multirow{2}{*}{ APRENDIZAJE } & SALÓN DE COMPUTACIÓN & 47.23 & $9 \%$ \\
\hline & SALA DE ENTRENAMIENTO & 58.29 & $11 \%$ \\
\hline $\begin{array}{c}\text { EQUIPAMIENTO } \\
\text { EDUCATIVO }\end{array}$ & BIBLIOTECA & 61.95 & $12 \%$ \\
\hline COMUNAL & SALA COMUNAL & 60.70 & $12 \%$ \\
\hline ADMINISTRACIÓN & OFICINA PRINCIPAL & 30.51 & $6 \%$ \\
\hline \multirow{4}{*}{ SERVICIOS } & SALA & 100.07 & $19 \%$ \\
\hline & COCINA & 17.08 & $3 \%$ \\
\hline & BAÑOS & 37.78 & $7 \%$ \\
\hline & CIRCULACIÓN & 61.90 & $12 \%$ \\
\hline \multirow[t]{2}{*}{ RECREACIÓN } & ÁREA LIBRE & 44.08 & $8 \%$ \\
\hline & TOTAL & 519.58 & $100 \%$ \\
\hline
\end{tabular}

Cuadro 5.6 Cuadro de áreas aproximado por paquete del Centro de Entrenamiento Indígena Kapacajui

\begin{tabular}{|c|c|c|}
\hline \multicolumn{2}{|c|}{ CUADRO DE ÁREAS APROXIMADO POR PAQUETE } \\
\hline \multicolumn{2}{|c|}{ APRENDIZAJE } & APORTE (\%) \\
\hline AMBIENTE & ÁREA APROXIMADA (M2) & $45 \%$ \\
\hline SALÓN DE COMPUTACIÓN & 47.23 & $55 \%$ \\
\hline SALA DE ENTRENAMIENTO & 58.29 & $100 \%$ \\
\hline TOTAL & 105.52 & \\
\hline
\end{tabular}

\begin{tabular}{|c|c|c|}
\hline \multicolumn{3}{|c|}{ CUADRO DE ÁREAS APROXIMADO POR PAQUETE } \\
\hline \multicolumn{3}{|c|}{ EQUIPAMIENTO EDUCATIVO } \\
\hline AMBIENTE & ÁREA APROXIMADA (M2) & APORTE (\%) \\
\hline BIBLIOTECA & 61.95 & $100 \%$ \\
\hline TOTAL & 61.95 & $100 \%$ \\
\hline
\end{tabular}




\begin{tabular}{|c|c|c|}
\hline \multicolumn{3}{|c|}{ CUADRO DE ÁREAS APROXIMADO POR PAQUETE } \\
\hline \multicolumn{2}{|c|}{ COMUNAL } & APORTE (\%) \\
\hline AMBIENTE & ÁREA APROXIMADA (M2) & $100 \%$ \\
\hline SALA COMUNAL & 60.70 & $100 \%$ \\
\hline TOTAL & 60.70 & \\
\hline
\end{tabular}

\begin{tabular}{|c|c|c|}
\hline \multicolumn{3}{|c|}{ CUADRO DE ÁREAS APROXIMADO POR PAQUETE } \\
\hline \multicolumn{3}{|c|}{ ADMINSITRACIÓN } \\
\hline AMBIENTE & ÁREA APROXIMADA (M2) & APORTE (\%) \\
\hline OFICINA PRINCIPAL & 30.51 & $100 \%$ \\
\hline TOTAL & 30.51 & $100 \%$ \\
\hline
\end{tabular}

\begin{tabular}{|c|c|c|}
\hline \multicolumn{3}{|c|}{ CUADRO DE ÁREAS APROXIMADO POR PAQUETE } \\
\hline \multicolumn{2}{|c|}{ SERVICIOS } & APORTE (\%) \\
\hline AMBIENTE & ÁREA APROXIMADA (M2) & $65 \%$ \\
\hline SALA & 100.07 & $11 \%$ \\
\hline COCINA & 17.08 & $24 \%$ \\
\hline BAÑOS & 37.78 & $100 \%$ \\
\hline TOTAL & 154.93 & \\
\hline
\end{tabular}

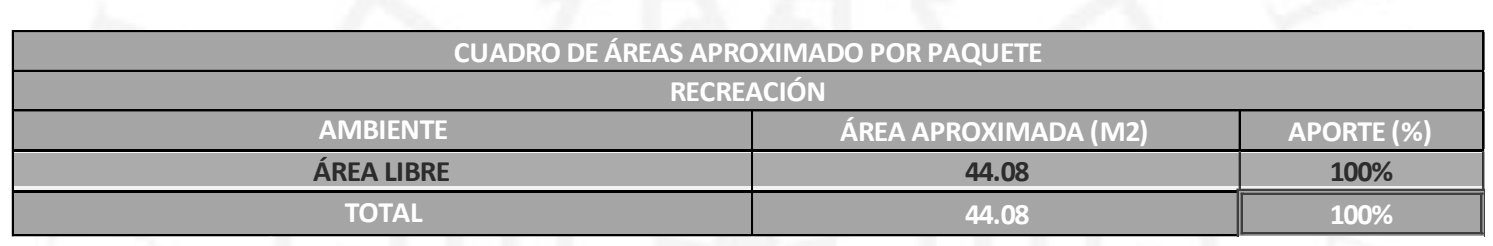

Elaboración propia

Figura 5.32 Plano primer nivel con paquete programático del Centro de Entrenamiento Indígena Kapacajui

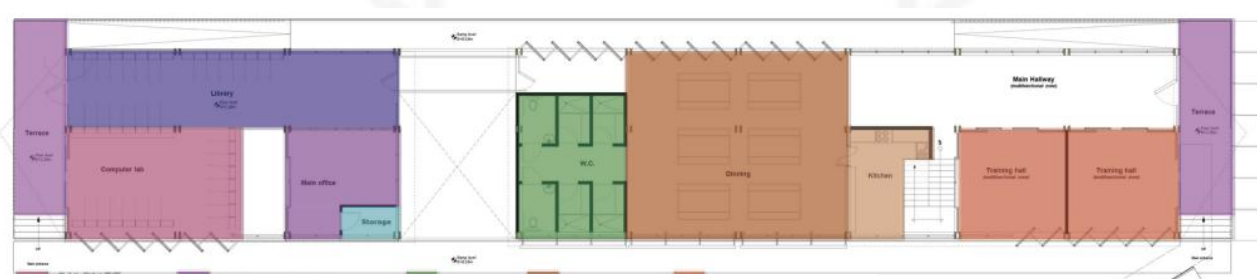

\section{PRIMER NIVEL}

Fuente: Arch Daily

Elaboración propia 


\begin{tabular}{|c|c|c|c|}
\hline APRENDIZAJE & EQUIPAMIENTO EDUCATIVO & ADMINISTRATIVO & SERVICIO \\
\hline AULA & BIBLIOTECA & OFICINA & BAÑOS \\
SALÓN DE CÓMPUTO & & MANTENIMIENTO \\
SALA DE ENTRENAMIENTO & & ARCHIVO & \\
\hline
\end{tabular}

Figura 5.33 Plano segundo nivel con paquete programático del Centro de Entrenamiento Indígena Kapacajui

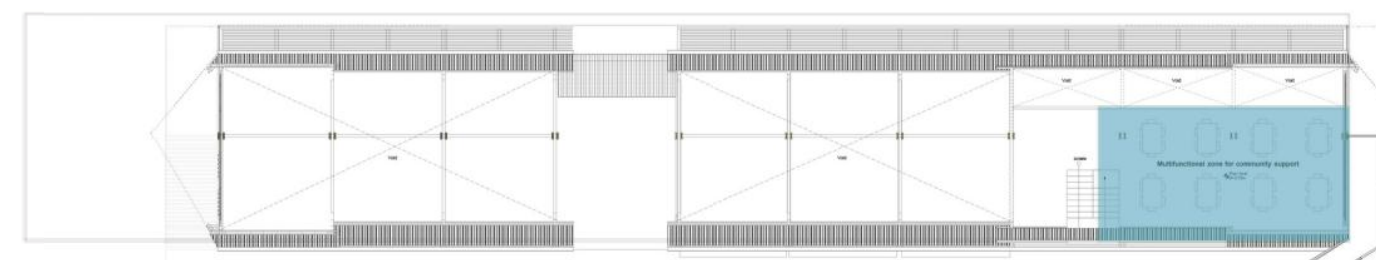

SEGUNDO NIVEL

Fuente: Arch Daily

Elaboración propia

\begin{tabular}{|c|c|c|c|}
\hline APRENDIZAJE & EQUIPAMIENTO EDUCATIVO & ADMINISTRATIVO & SERVICIO \\
\hline AULA & BIBLIOTECA & BAÑOS \\
SALÓN DE CÓMPUTO & & OFICINA & MANTENIMIENTO \\
SALA DE ENTRENAMIENTO & & ARCHIVO & \\
\hline
\end{tabular}




\subsubsection{Tipología espacial}

Figura 5.34 Tipología espacial del Centro de Entrenamiento Indígena Kapacajui

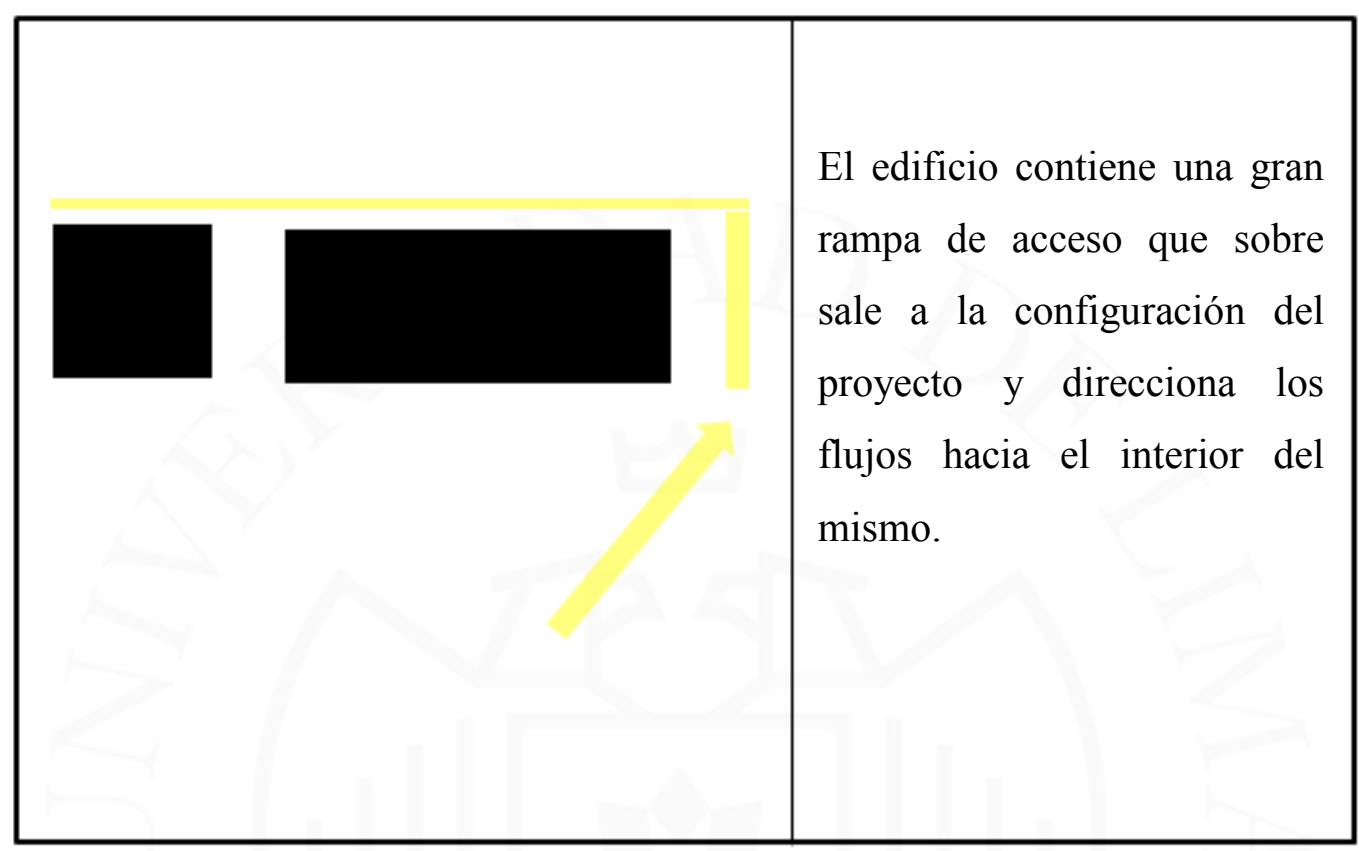

Elaboración propia

\subsubsection{Público - privado}

Figura 5.35 Análisis de accesibilidad a los ambientes del Centro de Entrenamiento Indígena Kapacajui
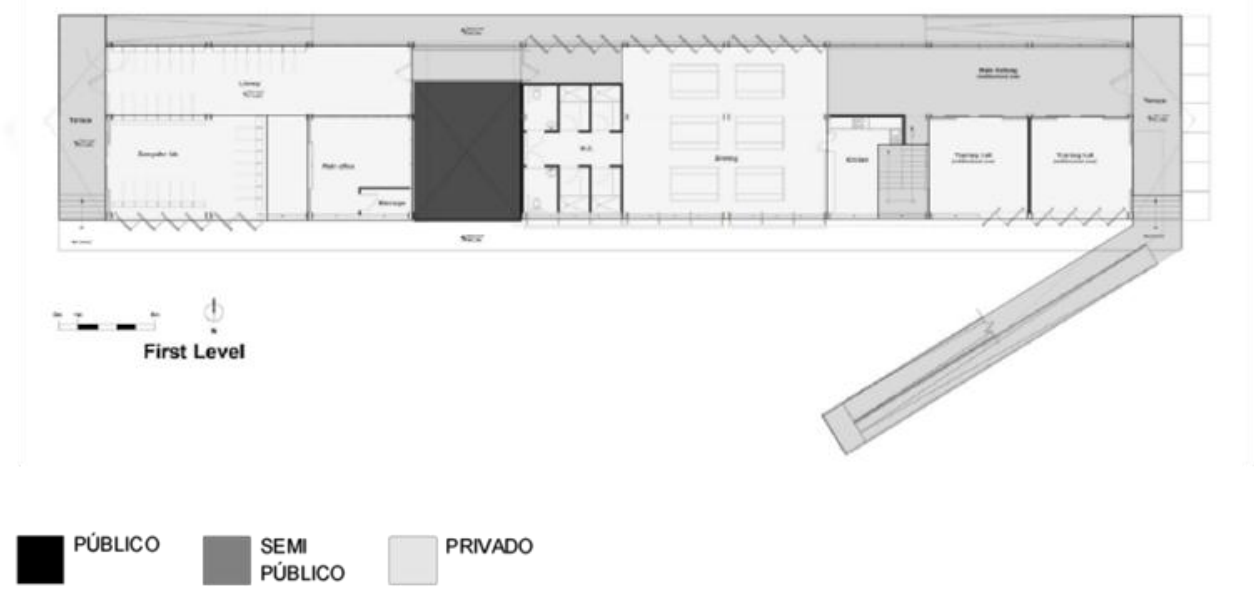

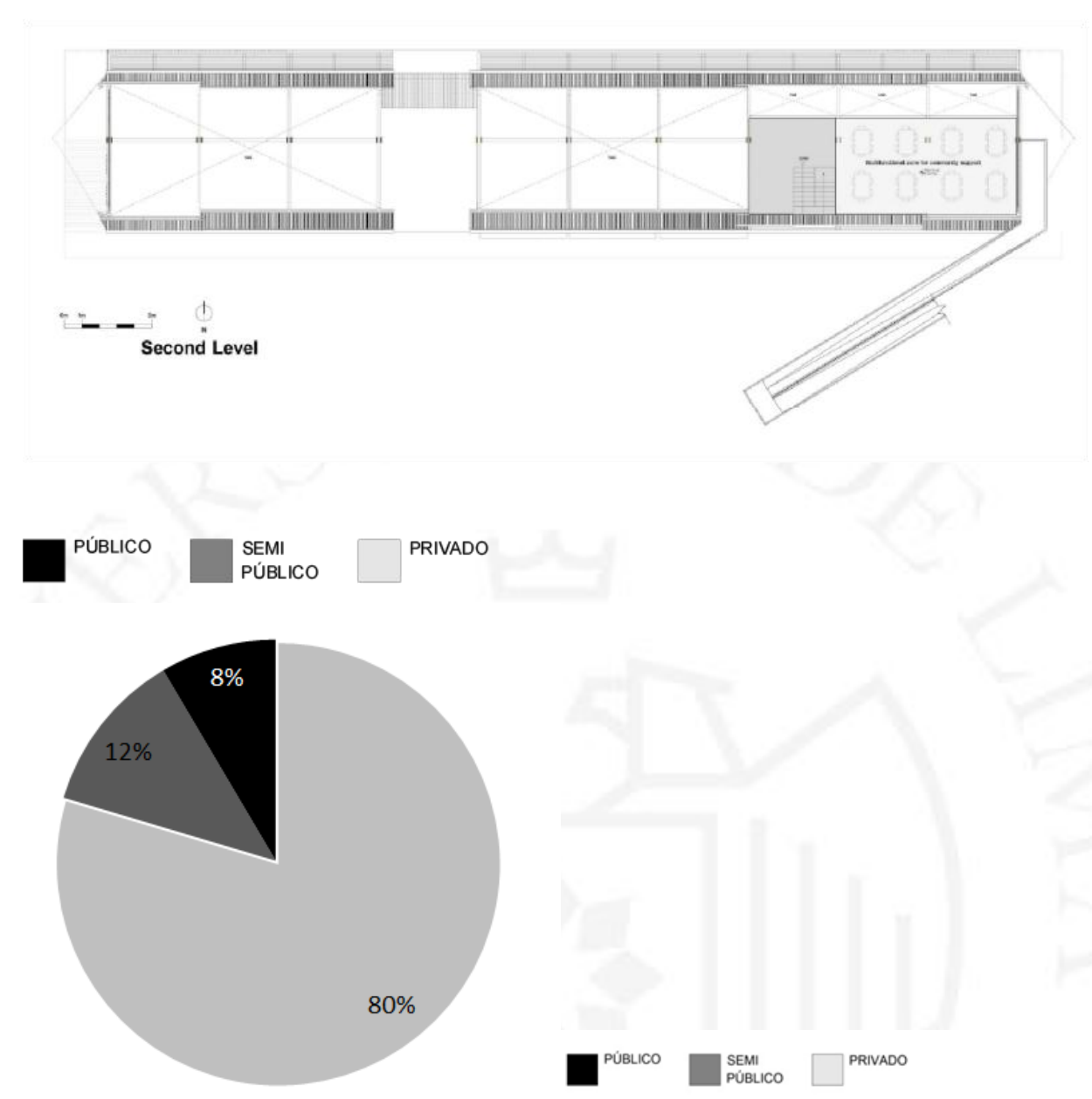

Fuente: Arch Daily

Elaboración propia

Figura 5.36 Análisis de flujos en el del Centro de Entrenamiento Indígena Kapacajui

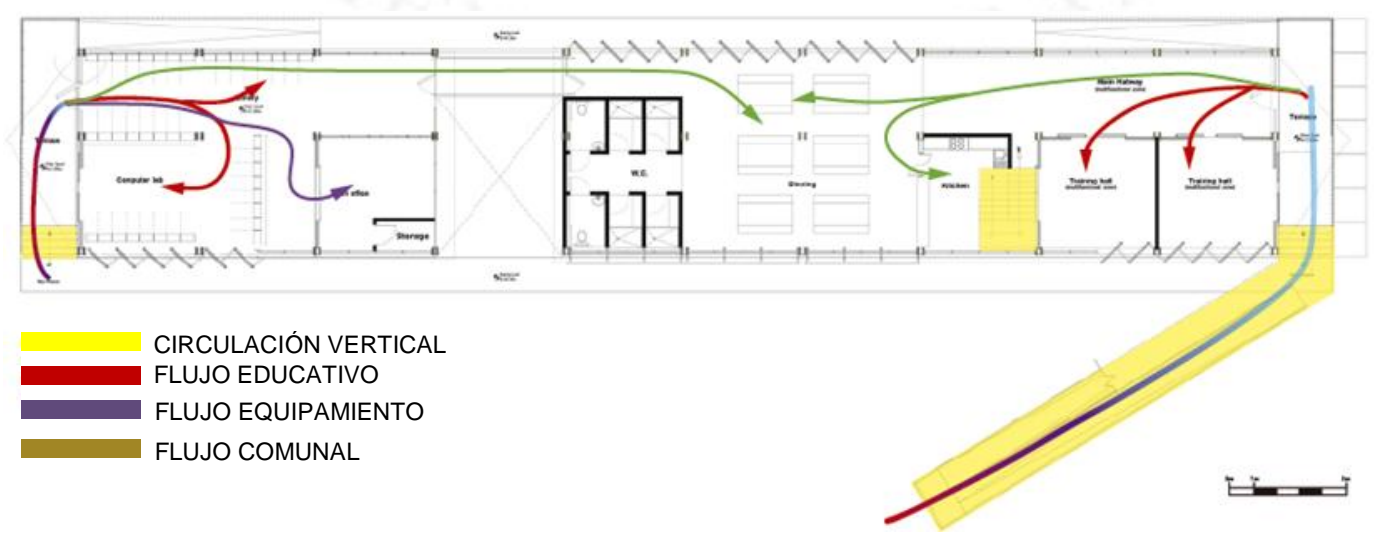




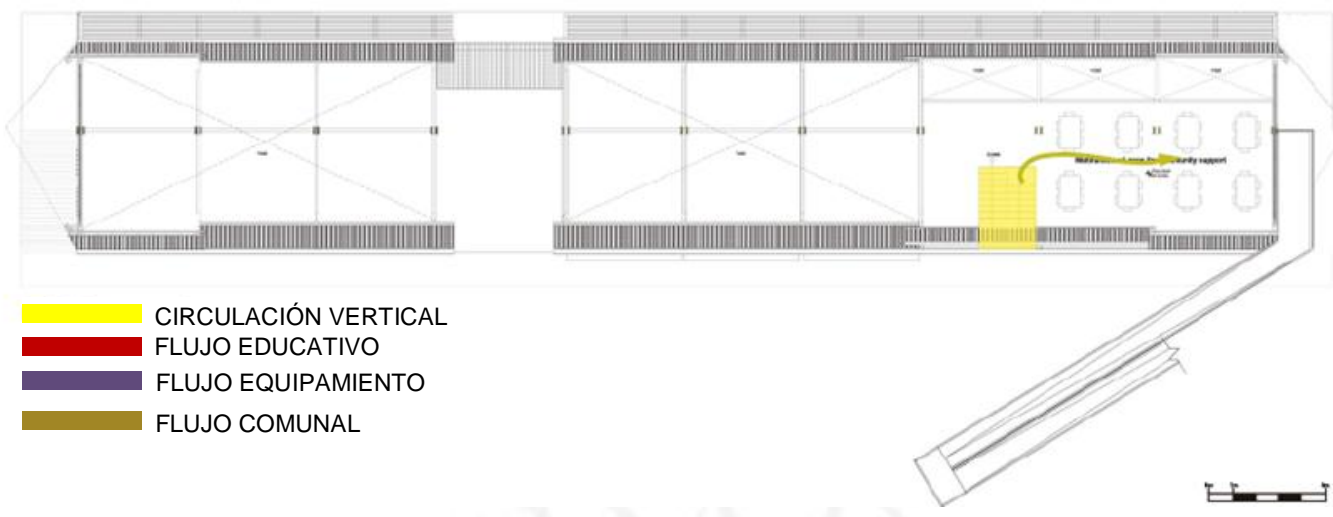

Fuente: Arch Daily

Elaboración propia

Figura 5.37 Análisis del área libre y área construida del Centro de Entrenamiento Indígena Kapacajui

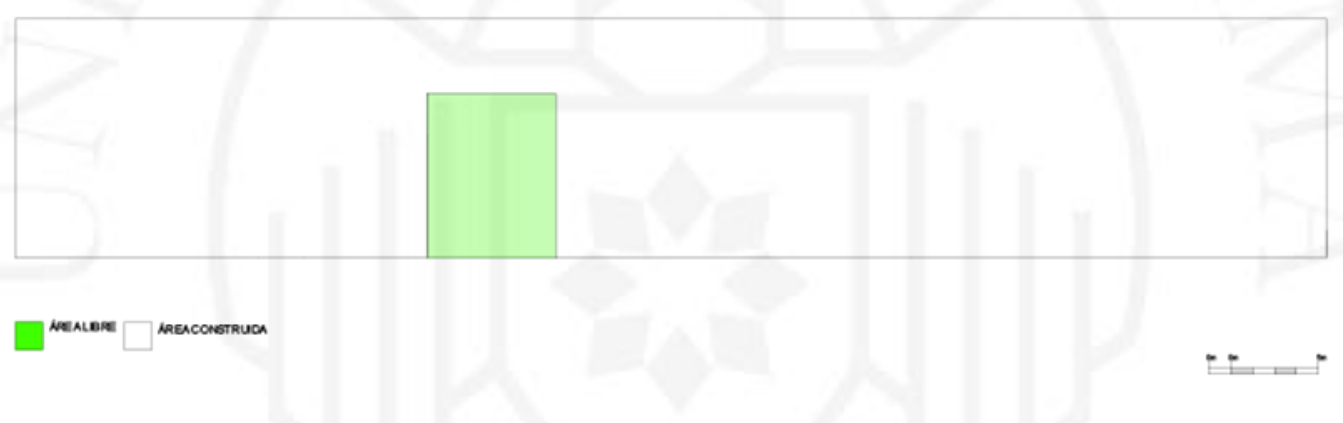

Fuente: Arch Daily

Elaboración propia

\subsubsection{Tecnología}

Destaca el traslape reticulado de los ,petatillos ${ }^{\text {ee }}$ entre diversos planos de transición vertical, generando una sensación visual de movimiento o efecto Moiré. La gradiente de intimidad y sensación de cobijo parcial, se puede " $\mathrm{c}$ entre aposentos o durante el recorrido interior-exterior mediante ras $^{\text {ee }}$ en la evolvente. Estas se materializan mediante paneles ensamblados como ,tejidos traslapados ${ }^{\text {ee }}$ de maderas multi-tonales, anticipando gradualmente lo que se puede encontrar hacia donde se transita. (Arch Daily, 2014) 
Figura 5.38 Detalle constructivo del Centro de Entrenamiento Indígena Kapacajui

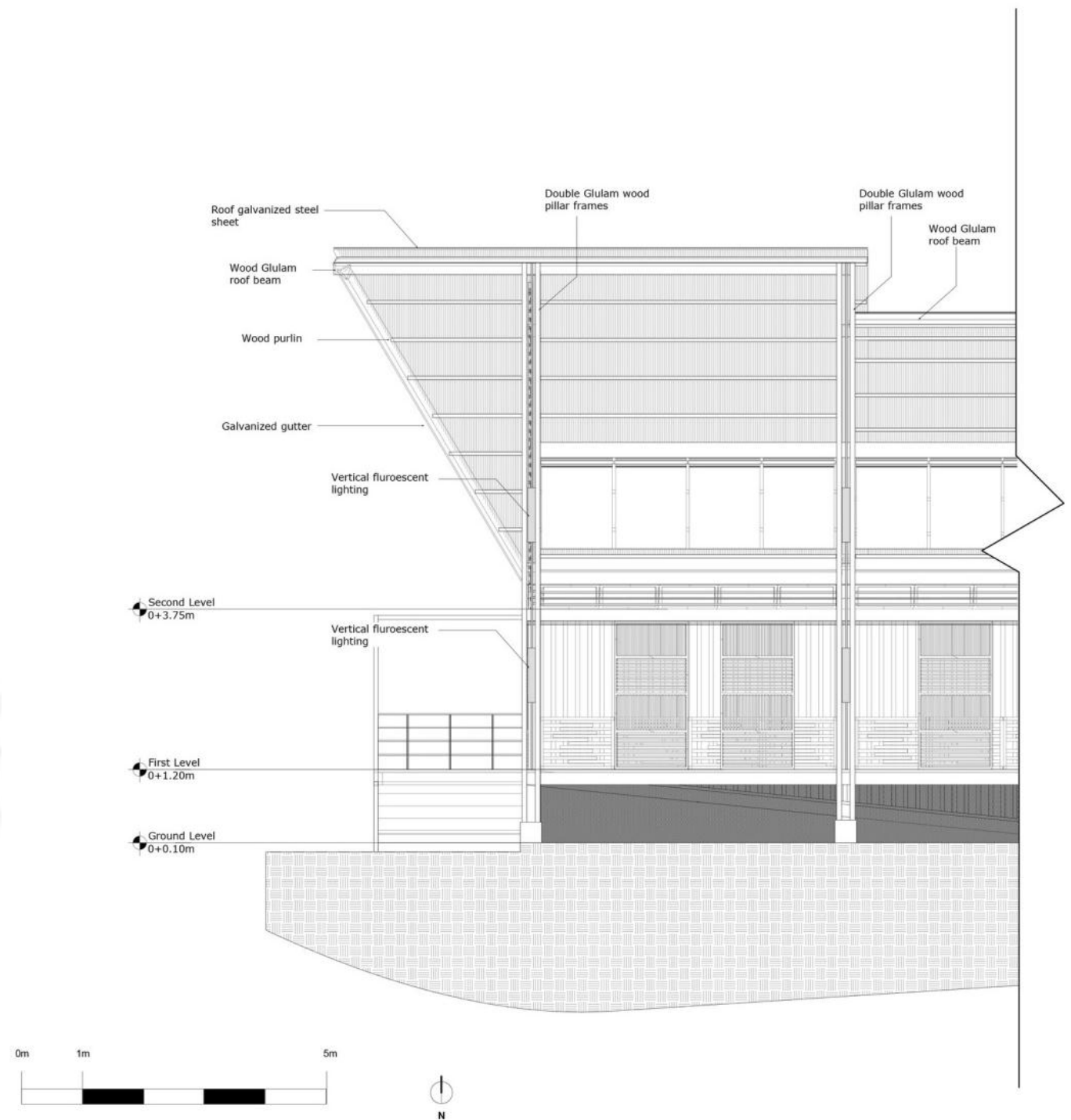

Fuente: Arch Daily 
Figura 5.39 Sistema constructivo del Centro de Entrenamiento Indígena Kapacajui

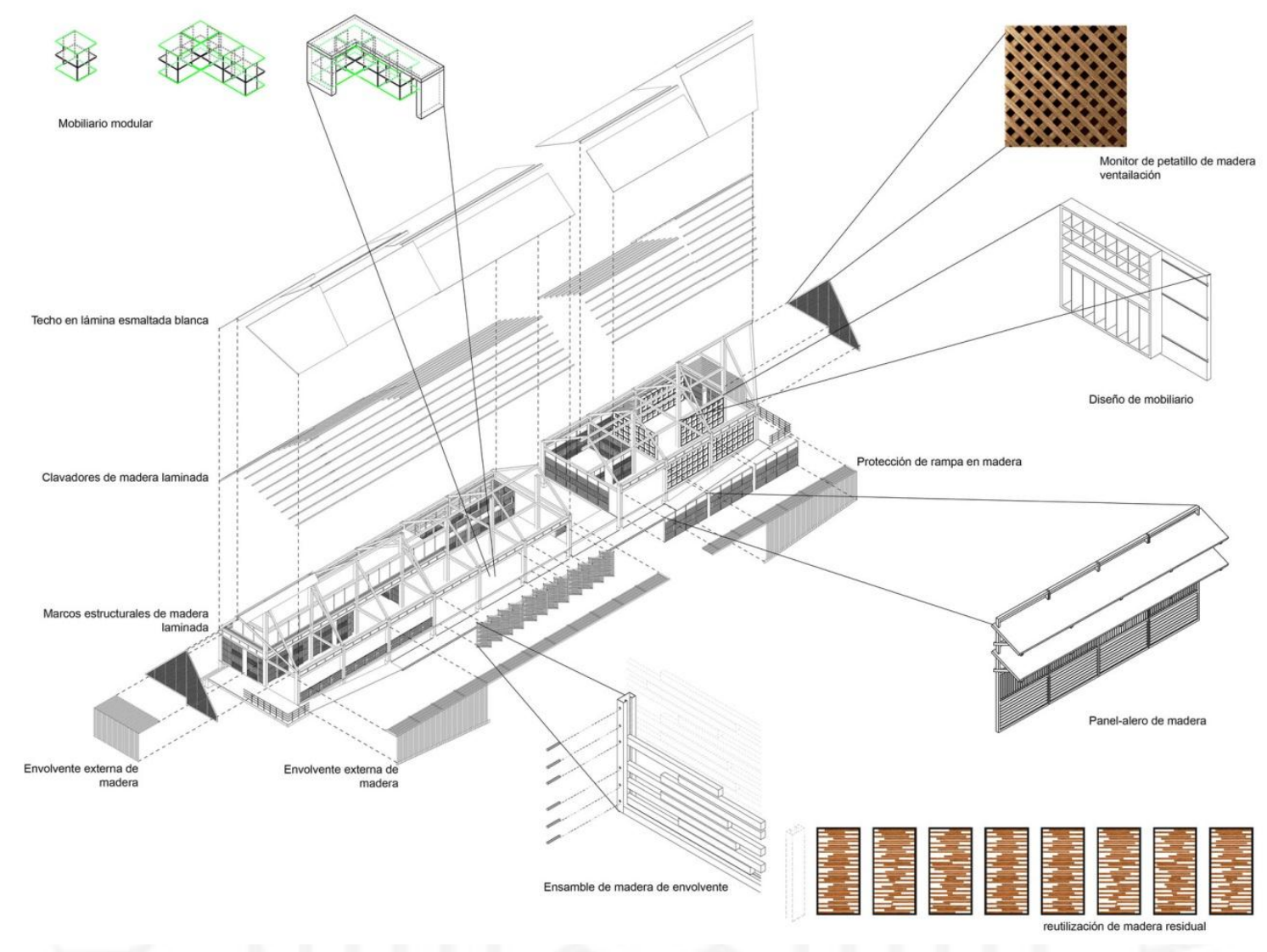

Fuente: Arch Daily

\subsubsection{Impacto social}

Comprende un centro de capacitación-albergue como facilitador de interacción entre locales, visitantes e impulsor para el desarrollo de proyectos comunales sustentables y en armonía con el entorno. A su vez el Centro forma parte de un sistema estratégico de integración rural para el fortalecimiento comunitario que incluye caminos, grutas y senderos. Adicionalmente se proyecta una red de puentes peatonales que vuelven accesibles tramos en momentos críticos del año y que pueden brindar cobijo de manera temporal. (Arch Daily, 2014) 


\subsubsection{CETPRO Politécnico Salesiano}

\subsubsection{Historia}

Cliente: Fundación Don Bosco

Ubicación: Lima, Perú

Figura 5.40 Ubicación del CETPRO Politécnico Salesiano

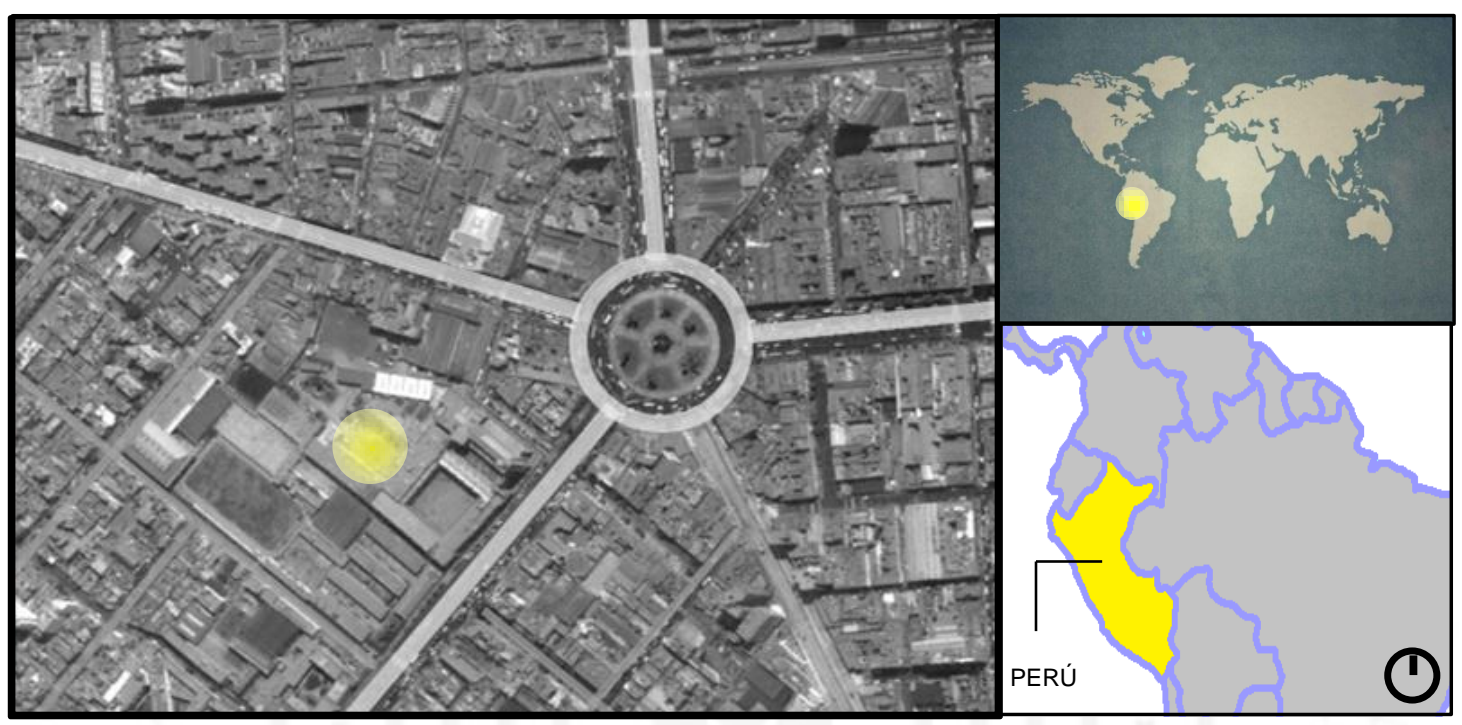

Elaboración propia

Año: 1900

Diseño: No se tiene registro

Área del proyecto: $1.628 \mathrm{~m} 2$

Costo estimado: $\$ 4000000$

El 28 de enero de 1900 fue inaugurado El Centro Técnico Productivo (CETPRO) Salesiano, cuya primera denominación fue Escuela de Artes y Oficios, luego se convirtió en Instituto Técnico Industrial, años después pasó a llamarse Cenecape y finalmente Centro Educativo Ocupacional (CEO) cuyo modelo educativo se modificó por su denominación actual; la instrucción educativa desde su inicio estuvo a cargo de la Congregación Salesiana, dirigida por la congregación Don Bosco quienes empezaron sus actividades evangelizadoras y educativas en el Perú desde el año 1890. (CETPRO Salesiano, 2017) 


\subsubsection{Ubicación y relación con el entorno}

El Centro Técnico Productivo se ubica en Lima en el distrito de Breña en la segunda cuadra de la Av. Brasil.

Figura 5.41 Ubicación del CETPRO Politécnico Salesiano

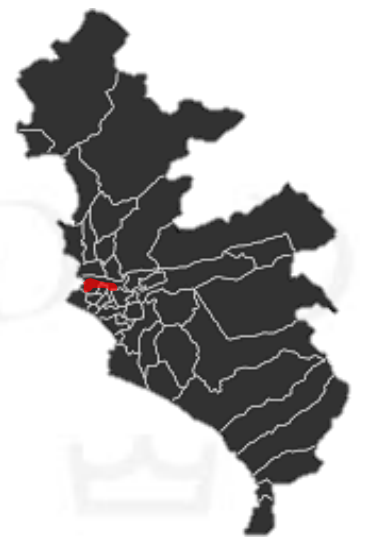

Elaboración Propia

Figura 5.42 Ubicación y relación con el entorno del CETPRO Politécnico Salesiano
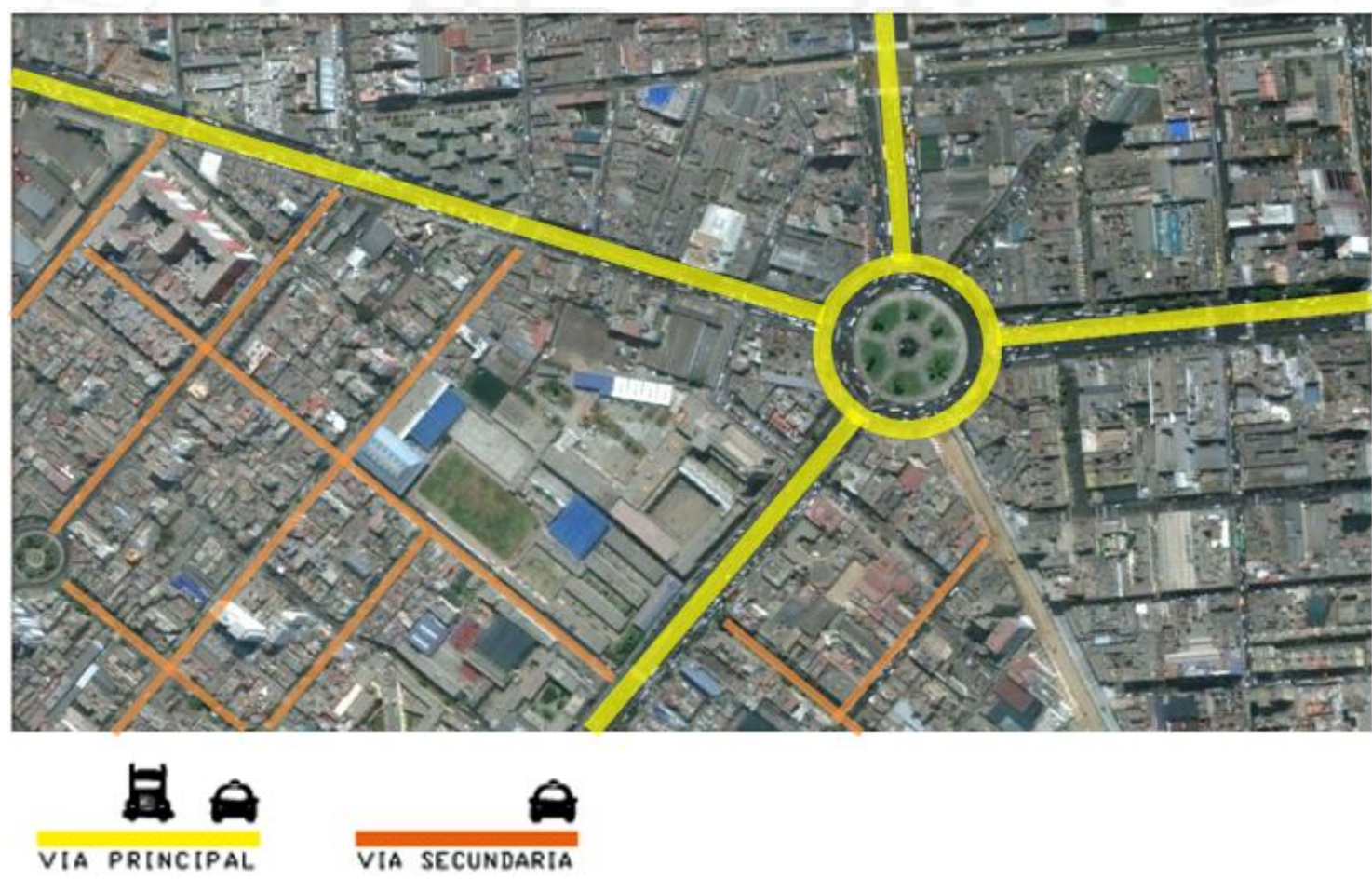

Elaboración Propia 


\subsubsection{Programa y relaciones programáticas}

El proyecto agrupado en paquetes programáticos sumaría 5 tipos referidos a:

Aprendizaje: de este paquete forman parte las aulas que suman un total de 17, los 24 talleres, la sala de profesores, los laboratorios y las salas de cómputo.

Equipamiento educativo: forman parte la sala de exposiciones, el auditorio la biblioteca, que cuenta también con un área de videoteca.

Administración: comprende las oficinas administrativas, se ubican en el primer nivel cerca al hall de ingreso, en el segundo nivel se encuentran las oficinas propias de la Congregación Salesiana.

Servicios: dentro de los servicios están los referidos a iglesia, comedor, áreas comunes, baños y camerinos.

Recreación: existe un amplio jardín central y áreas deportivas.

Cuadro 5.7 Cuadro de áreas aproximado del CETPRO Politécnico Salesiano

\begin{tabular}{|c|c|c|c|}
\hline \multicolumn{4}{|c|}{ CUADRO DE ÁREAS APROXIMADO } \\
\hline PAQUETES & AMBIENTE & ÁREA APROXIMADA (M2) & APORTE $(\%)$ \\
\hline \multirow{4}{*}{ APRENDIZAJE } & AULAS & 1219.43 & $5.2 \%$ \\
\hline & TALLERES & 3575.59 & $15.3 \%$ \\
\hline & LABORATORIOS & 490.06 & $2.1 \%$ \\
\hline & SALA DE PROFESORES & 50.80 & $0.2 \%$ \\
\hline \multirow{5}{*}{ EQUIPAMIENTO EDUCATIVO } & SALA DE EXPOSICIÓNES & 67.58 & $0.3 \%$ \\
\hline & SALAS DE COMPUTO & 300.32 & $1.3 \%$ \\
\hline & AUDITORIO & 280.48 & $1.2 \%$ \\
\hline & LBRERÍA & 167.35 & $0.7 \%$ \\
\hline & BIBLIOTECA & 620.70 & $2.7 \%$ \\
\hline \multirow{2}{*}{ ADMINISTRACIÓN } & OFICINAS & 1209.96 & $5.2 \%$ \\
\hline & SALA DE REUNIONES & 51.41 & $0.2 \%$ \\
\hline \multirow{5}{*}{ SERVICIOS } & CAPILLA & 88.19 & $0.4 \%$ \\
\hline & COMEDOR & 90.33 & $0.4 \%$ \\
\hline & VESTUARIOS & 50.82 & $0.2 \%$ \\
\hline & SERVICIOS & 250.12 & $1.1 \%$ \\
\hline & DEPÓSITOS & 1733.99 & $7.4 \%$ \\
\hline \multirow{4}{*}{ RECREACIÓN } & ÁREAS COMUNES & 561.87 & $2.4 \%$ \\
\hline & CIRCULACIÓN & 3943.29 & $16.9 \%$ \\
\hline & ÁREA LIBRE & 8547.49 & $36.7 \%$ \\
\hline & TOTAL & 23299.7879 & $100 \%$ \\
\hline
\end{tabular}

Elaboración Propia 
Cuadro 5.8 Cuadro de áreas aproximado por programa del CETPRO Politécnico Salesiano

\begin{tabular}{|c|c|c|}
\hline \multicolumn{3}{|c|}{ CUADRO DE ÁREAS APROXIMADO POR PAQUETE } \\
\hline \multicolumn{2}{|c|}{ APRENDIZAJE } \\
\hline AMBIENTE & ÁREA APROXIMADA (M2) & $22.9 \%$ \\
\hline AULAS & 1219.43 & $67.0 \%$ \\
\hline TALLERES & 3575.59 & $9.2 \%$ \\
\hline LABORATORIOS & 490.06 & $1.0 \%$ \\
\hline SALA DE PROFESORES & 50.80 & $100 \%$ \\
\hline
\end{tabular}

\begin{tabular}{|c|c|c|}
\hline \multicolumn{3}{|c|}{ CUADRO DE ÁREAS APROXIMADO POR PAQUETE } \\
\hline \multicolumn{3}{|c|}{ EQUIPAMIENTO EDUCATIVO } \\
\hline AMBIENTE & ÁREA APROXIMADA (M2) & APORTE (\%) \\
\hline SALA DE EXPOSICIÓNES & 67.58 & $2.7 \%$ \\
\hline SALAS DE COMPUTO & 300.32 & $19.5 \%$ \\
\hline AUDITORIO & 280.48 & $11.7 \%$ \\
\hline LIBRERÍA & 167.35 & $43.2 \%$ \\
\hline BIBLIOTECA & 620.70 & $100 \%$ \\
\hline TOTAL & 1436.43 & 2 \\
\hline
\end{tabular}

\begin{tabular}{|c|c|c|}
\hline \multicolumn{3}{|c|}{ CUADRO DE ÁREAS APROXIMADO POR PAQUETE } \\
\hline \multicolumn{2}{|c|}{ ADMINISTRACIÓN } \\
\hline AMBIENTE & ÁREA APROXIMADA (M2) & APORTE (\%) \\
\hline OFICINAS & 1209.96 & $95.9 \%$ \\
\hline SALA DE REUNIONES & 51.41 & $4.1 \%$ \\
\hline TOTAL & 1261.3662 & $100 \%$ \\
\hline
\end{tabular}




\begin{tabular}{|c|c|c|}
\hline \multicolumn{2}{|c|}{ CUADRO DE ÁREAS APROXIMADO POR PAQUETE } \\
\hline \multicolumn{2}{|c|}{ SERICIOS } \\
\hline AMBIENTE & ÁREA APROXIMADA (M2) & APORTE (\%) \\
\hline CAPILLA & 88.19 & $4.0 \%$ \\
\hline COMEDOR & 90.33 & $4.1 \%$ \\
\hline VESTUARIOS & 50.82 & $2.3 \%$ \\
\hline SERVICIOS & 250.12 & $11.3 \%$ \\
\hline DEPÓSITOS & 1733.99 & $78.3 \%$ \\
\hline TOTAL & 2213.46 & $100 \%$ \\
\hline
\end{tabular}

\begin{tabular}{|c|c|c|}
\hline \multicolumn{2}{|c|}{ CUADRO DE ÁREAS APROXIMADO POR PAQUETE } \\
\hline \multicolumn{2}{|c|}{ RECREACIÓN } \\
\hline AMBIENTE & ÁREA APROXIMADA (M2) & APORTE (\%) \\
\hline ÁREAS COMUNES & 561.87 & $4.3 \%$ \\
\hline CIRCULACIÓN & 3943.29 & $30.2 \%$ \\
\hline ÁREA LIBRE & 8547.49 & $65.5 \%$ \\
\hline TOTAL & 13052.65 & $100 \%$ \\
\hline
\end{tabular}

Elaboración Propia 
Figura 5.43 Plano primer nivel con paquete programático CETPRO Politécnico Salesiano

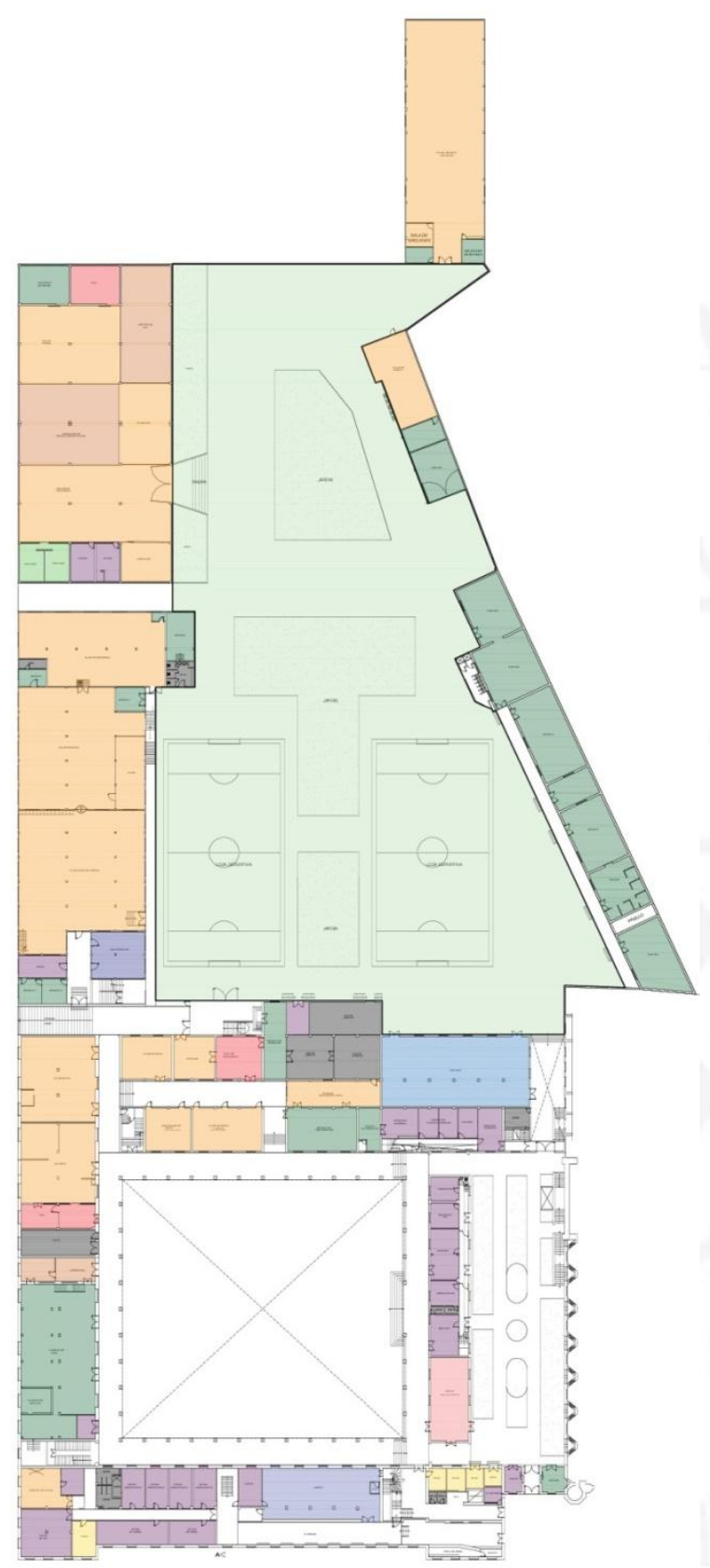

Fuente: Bibliocad

Elaboración Propia

\begin{tabular}{|c|c|c|c|}
\hline APRENDIZAJE & EQUIPAMIENTO EDUCATIVO & ADMINISTRATIVO & SERVICIO \\
\hline AULA & BIBLIOTECA & & CAFETERÍA \\
& AUDITORIO & OFICINA & COCINA \\
TALLER & SALA DE ENTRENAMIENTO & & VESTIDORES \\
& SALA DE ESTUDIO & ARCHIVO & BAÑOS \\
\cline { 2 - 4 } SALA DE ENTRENAMIENTO & SALA DE EXPOSICIÓN & & MANTENIMIENTO \\
\hline \hline
\end{tabular}


Figura 5.44 Plano segundo nivel con paquete programático CETPRO Politécnico Salesiano

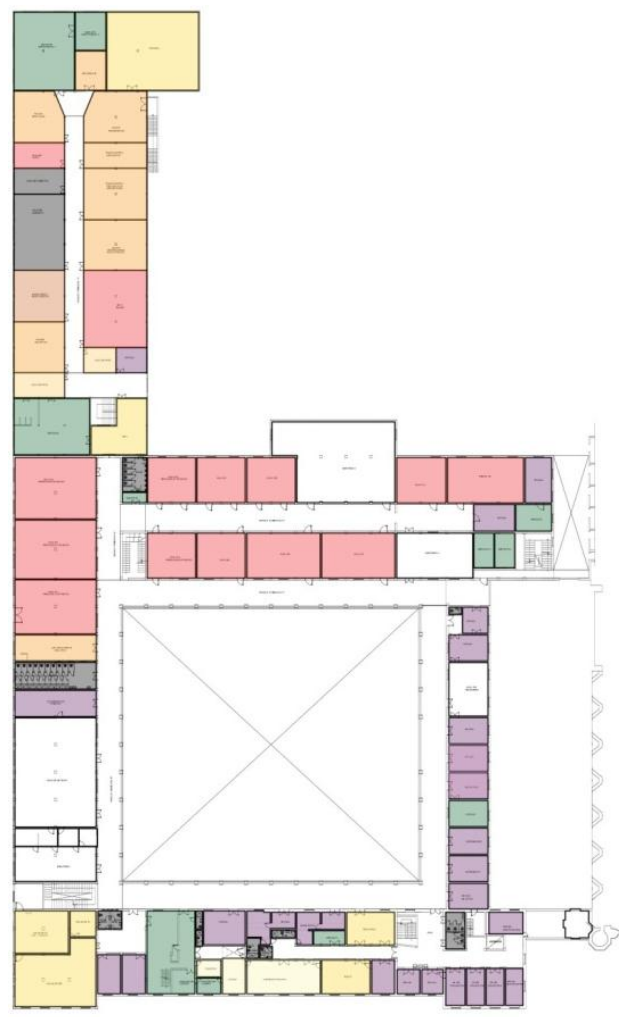

Fuente: Bibliocad

Elaboración Propia

\begin{tabular}{|c|c|c|c|}
\hline APRENDIZAJE & EQUIPAMIENTO EDUCATIVO & ADMINISTRATIVO & SERVICIO \\
\hline IAULA & BIBLIOTECA & & CAFETERÍA \\
& AUDITORIO & OFICINA & COCINA \\
TALLER & SALA DE ENTRENAMIENTO & VESTIDORES \\
\cline { 2 - 4 } & SALA DE ESTUDIO & ARCHIVO & BAÑOS \\
SALA DE ENTRENAMIENTO & SALA DE EXPOSICIÓN & & MANTENIMIENTO \\
\hline
\end{tabular}




\subsubsection{Tipología espacial}

La edificación de dos niveles se organiza delimitando dos grandes patios centrales donde se ubican una plaza un área deportiva correspondientemente.

\begin{tabular}{|l|l|}
\hline & $-\quad \begin{array}{l}\text { EL EDIFICIO SE PEGA A LOS } \\
\\
\end{array}$ \\
& BORDES, DEJANDO UNA PLAZA \\
& CENTRAL QUE CONECTA A MODO \\
& DE PUENTE LOS DOS EXTREMOS. \\
& $\begin{array}{l}\text { EL PROGRMA GIRA ENTORNO AL } \\
\text { PATIO CENTRAL }\end{array}$ \\
\hline
\end{tabular}




\subsubsection{Público - privado}

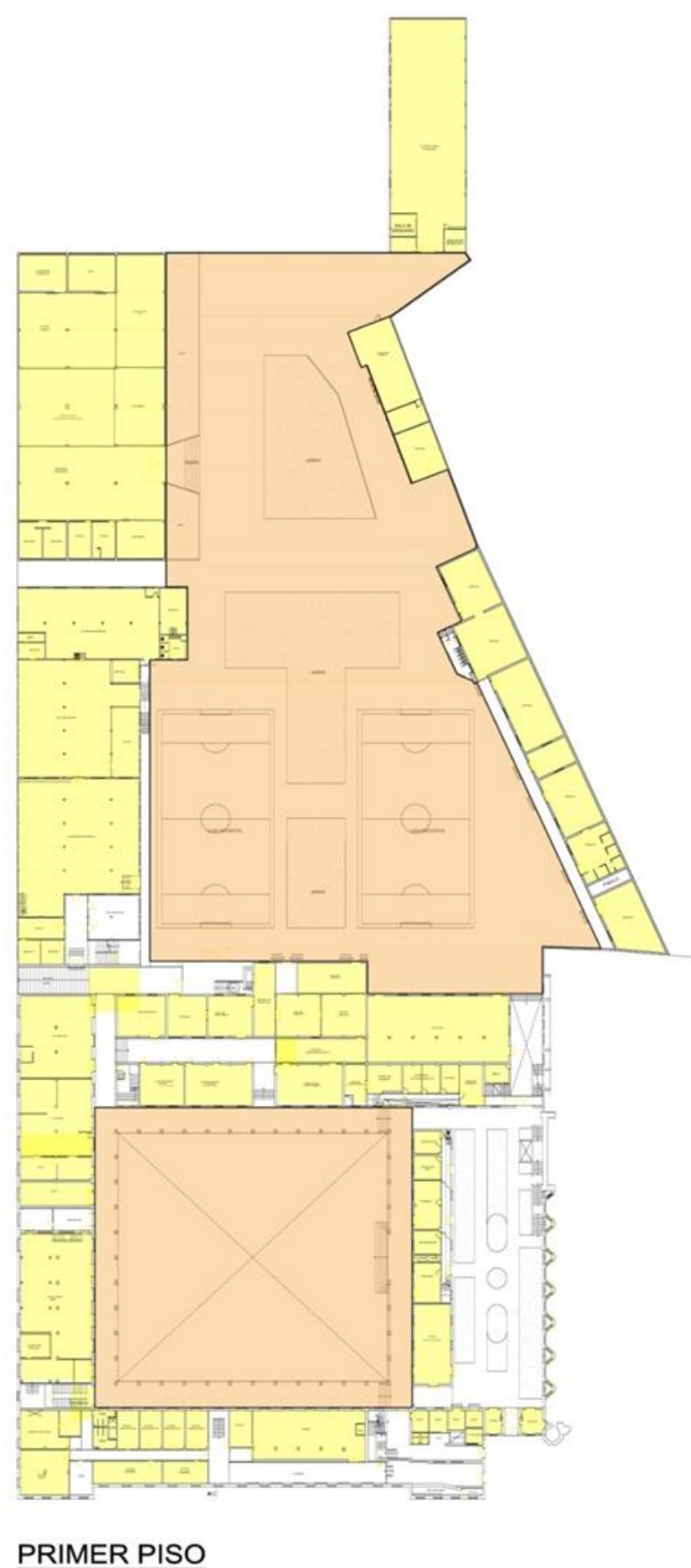

Fuente Propia 


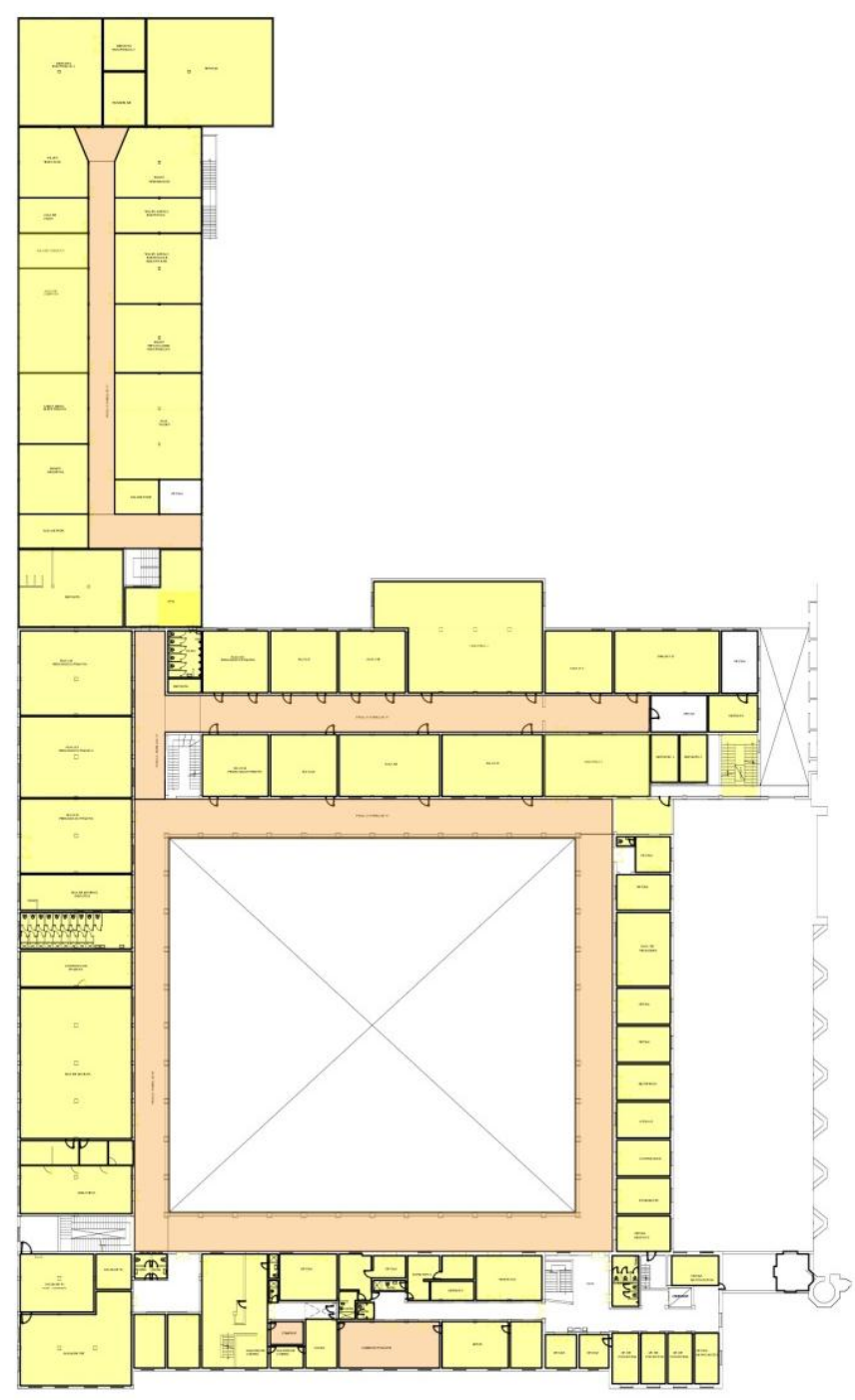

Fuente Propia 


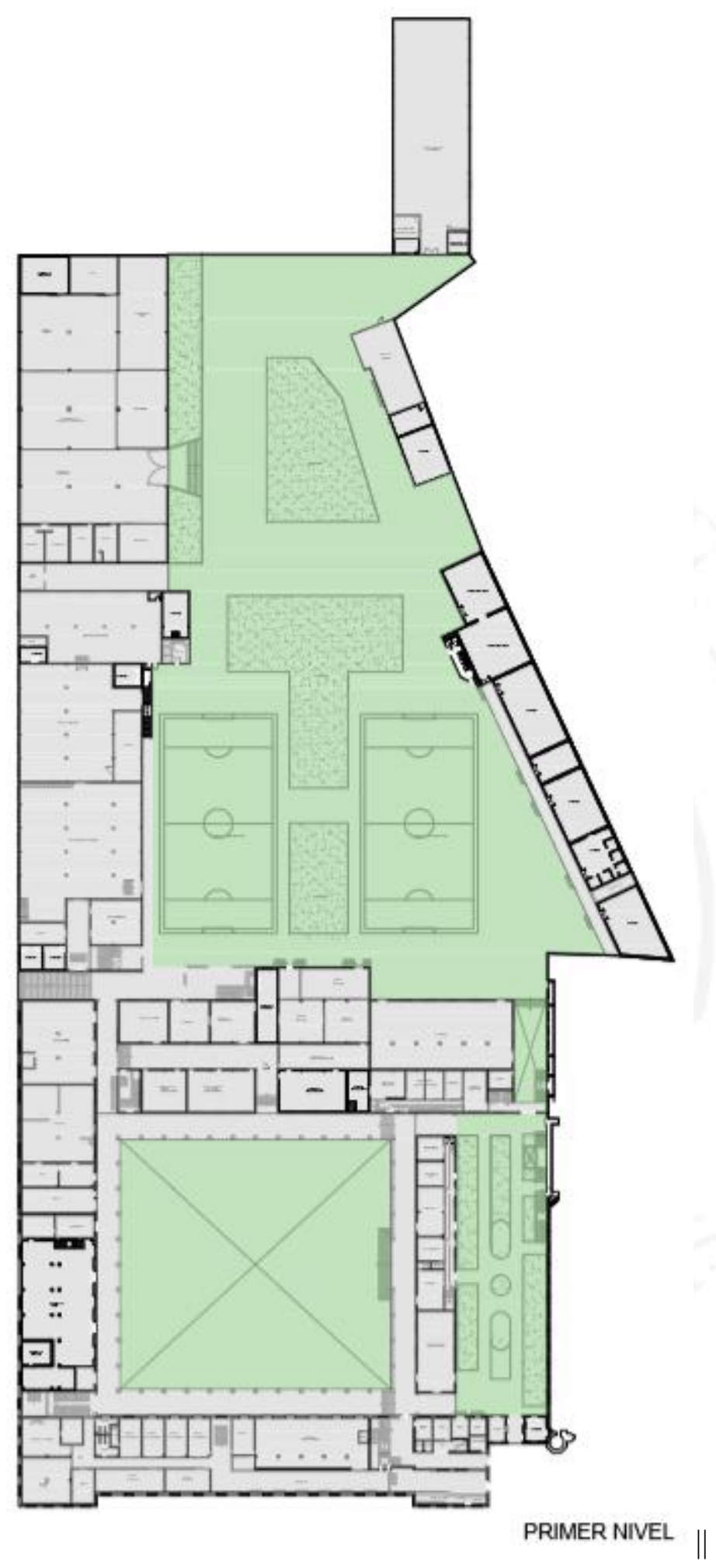

Fuente Propia 

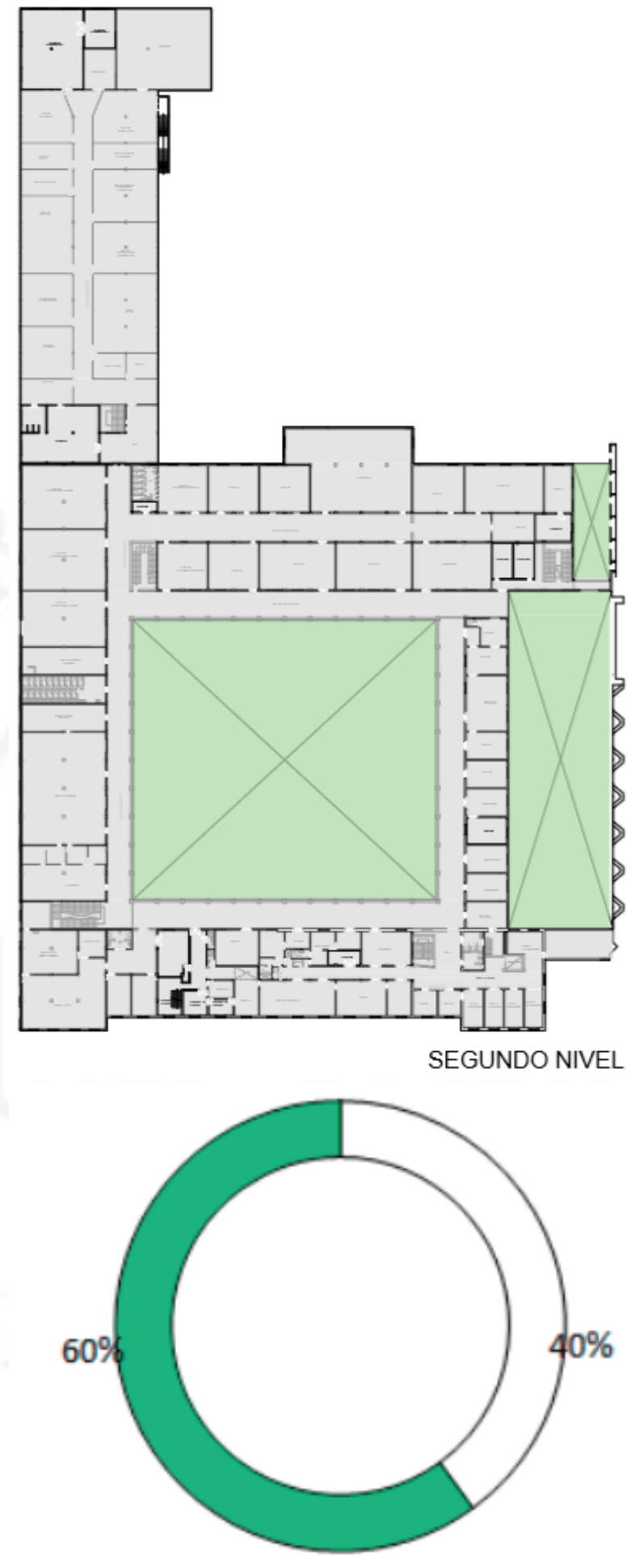

ÁREA LIBRE ÁREA CONSTRUIDA

Fuente Propia 


\subsubsection{Tecnología}

El proyecto ha utilizado un sistema constructivo de pórticos y muros de confinamiento.

\subsubsection{Impacto social}

Es una opción educativo-pastoral que trata de responder a las necesidades de los jóvenes más necesitados, y se inserta en un proyecto global de educación y de evangelización.

El centro de educación técnico - productiva , ofrece una educación orientada a la adquisición y desarrollo de competencias laborales y empresariales en una perspectiva de desarrollo sostenible, competitivo y humano, así como a la promoción de la cultura innovadora que responda a la demanda del sector productivo y a los avances de la tecnología, del desarrollo local, regional y nacional. (CETPRO Salesiano, 2017)

\subsection{Cuadro comparativo y gráficos de casos análogos}




\subsection{Conclusiones parciales}

Del estudio de casos análogos realizado sobre referentes internacionales respecto a su historia se concluye que en todos los casos las edificaciones datan del presente siglo y que su denominación actual como Centro de Formación, Escuela Vocacional o Centro de Entrenamiento no ha sufrido ningún proceso de cambio al contrario del referente nacional cuya construcción data de 1900 y ha pasado por cuatro modificaciones desde su concepción inicial como Escuela de Artes y Oficios hasta su actual denominación como Centro Técnico Productivo.

Respecto a su ubicación, es un patrón común en los referentes internacionales la localización de este equipamiento educativo cerca a áreas denominadas marginales, siendo el fin de cada institución promover el desarrollo local con recursos originarios del lugar, asegurando así la continuidad y éxito de los oficios aprendidos; en Perú en cambio, a pesar de lo visto en el marco teórico sobre la indicación específica de localizar a un CETPRO cerca a un entorno inmediato productivo, y dirigir la enseñanza de los oficios en base a las actividades productivas que el recurso pueda ofrecer, la realidad es totalmente distinta y encontramos que la ciudad se encuentra sobre poblada con este tipo de equipamiento educativo y que todos ofrecen similares carreras estableciéndose un claro conflicto entre oferta y demanda pero lo más preocupante aún es que ninguno se pensó localizar en un entorno rural que es la parte más vulnerable, la que posee un sólido recurso y la que más necesita un equipamiento que promueva su desarrollo local y los ayude a mejorar su calidad de vida.

El análisis del programa conllevó a la organización de los ambientes en paquetes programáticos, siendo el primero el de aprendizaje donde se agrupan la aulas, los talleres, los laboratorios y las salas de asesoría, aquí se observa que en todos los casos los talleres representan un área importante dentro de cada proyecto, los constituyen grandes espacios con mínima estructura y están directamente relacionados con las aulas, su relación con los laboratorios es un poco más distante según sea el oficio; el siguiente paquete es el de equipamiento educativo, del que forman parte las salas de cómputo, bibliotecas y auditorios; constituyen esta organización también el paquete administrativo, el de servicios y el de recreación, aunque en los referentes internacionales el paquete comunal es un común denominador, de éste forma parte un área destinada a la comunidad para reuniones de coordinación. 


\section{CAPÍTULO VI: MARCO CONTEXTUAL}

\subsection{Análisis del lugar}

\subsubsection{Lomas de Lúcumo}

Del análisis realizado sobre el Valle del Río Lurín en el Marco Referencial de la presente investigación, se concluyó que el distrito a insertar y desarrollar este equipamiento urbano denominado CETPRO, era el distrito de Pachacamac, pues se vio en los déficits económicos y sociales presentes una oportunidad para fomentar el desarrollo local como herramienta para mejorar la calidad de vida de la población, aprovechando los recursos ambientales, productivos y turísticos del distrito como el principal potencial.

Dentro de Pachacamac se sitúa el Centro Poblado Rural Quebrada Verde, donde actualmente se viene gestionando desde el año 2003 el programa de turismo comunal desarrollado por la "Asociación Circuito Ecoturístico Lomas de Lúcumo", donde se administra el circuito ecoturístico del mismo nombre el cual promueve el turismo, la cultura y sobre todo la protección del "Ecosistema Frágil Lomas de Lúcumo", fenómeno estacional presente en las regiones de la costa del Perú y Chile.

La ubicación geográfica del Perú, en latitudes tropicales y frente a un mar frío, ha propiciado la presencia de una franja xérica, dominada por un desierto de arenas magníficas y que se engalana con una vegetación singular que denominamos lomas. Para el poblador de la costa de Lima, no hay ambiente natural más resaltante y sorprendente que estas "lomas". Ellas se desarrollan con las garúas estacionales en algunas laderas que miran al mar, algunas anualmente y otras en respuesta a precipitaciones mayores como las del evento El Niño. (Lleellish, Odar, \& Trinidad, 2015)

Nieuwland y Mamani en su artículo "Las Lomas de Lima" realizan la siguiente descripción sobre este casi mágico ecosistema:

Las lomas son oasis de neblina de alta diversidad florística en medio de un entorno árido, formadas gracias a las precipitaciones de las nieblas invernales 
provenientes del océano Pacífico, las que son interceptadas por las estribaciones andinas ricas en minerales. Poseen un amplio banco de semillas que rebrotan estacionalmente. Se trata de ecosistemas únicos de la costa peruana en los que se entrelazan complejas relaciones biológicas y antrópicas. Esta complejidad hace de ellas un campo de estudio idóneo para la geografía, más allá de su estudio como paisaje y como territorio cambiante; es decir, como un objeto geográfico por excelencia. (Nieuwland \& Mamani, 2017)

Son los vientos alisos los que traen, desde la fría corriente peruana hasta esta suerte de montañas, las nubes condensadas que luego caerán en forma de rocío enverdeciendo por completo el área durante los meses de junio a noviembre, que es considerada la Temporada de Lomas, el resto del año esta región permanece con un aspecto árido.

Figura 6.1 Vista del C.P.R. Quebrada Verde en Temporada de Verano

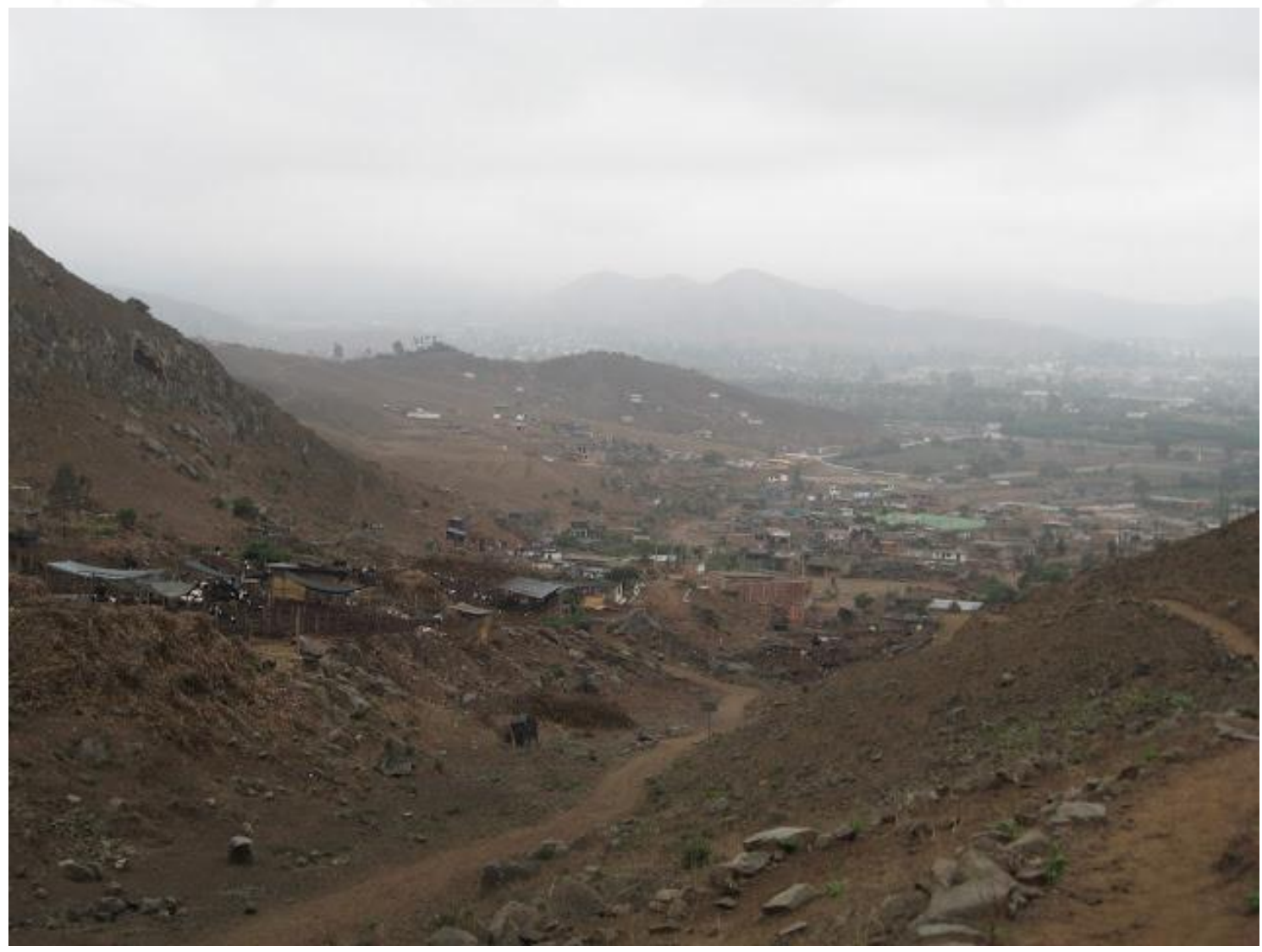

Fuente: (Solórzano, 2017) 
Figura 6.2 Vista del C.P.R. Quebrada Verde en Temporada de Lomas

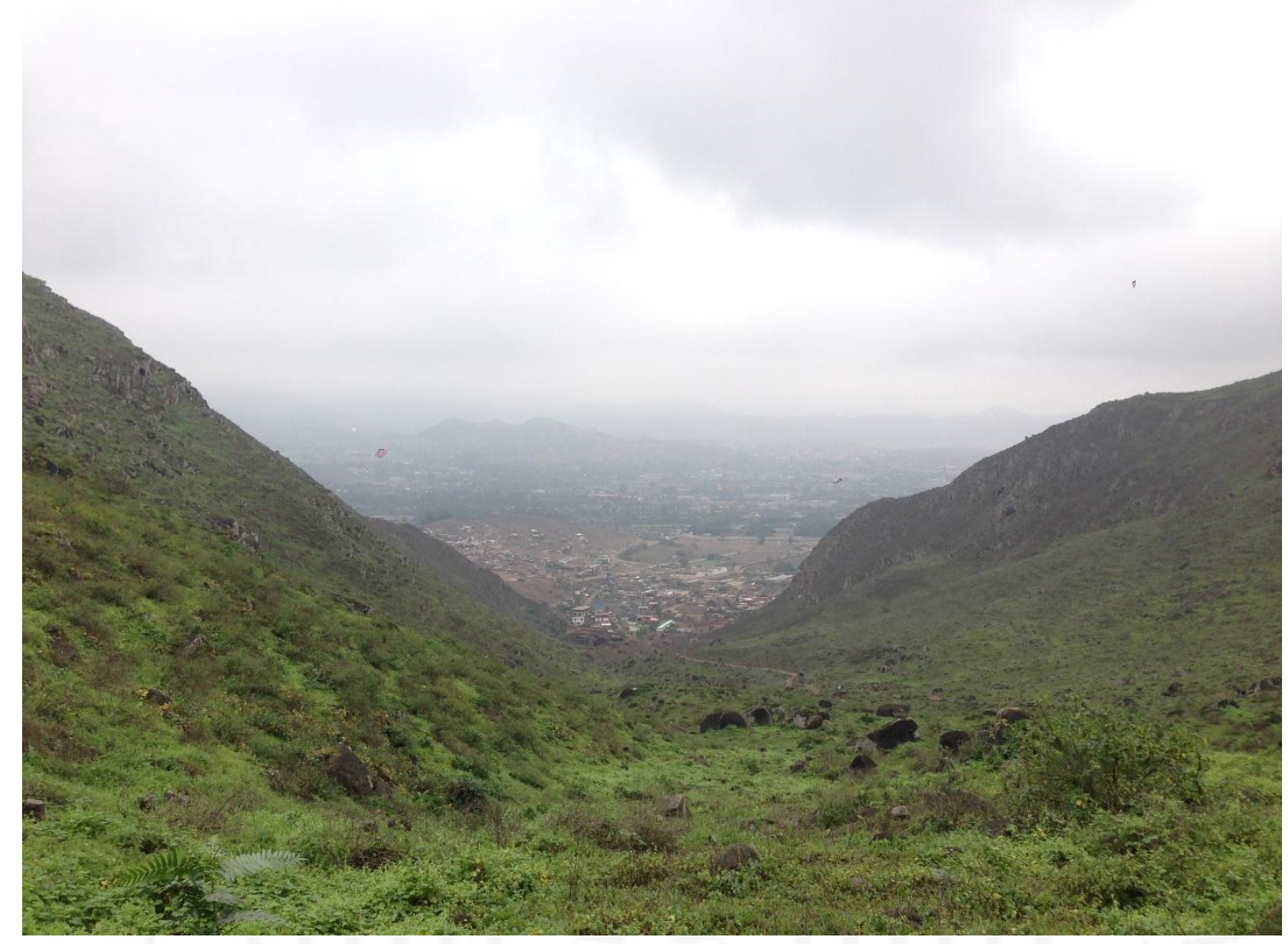

Fuente Propia

Figura 6.3 Gráfico de Ingreso Anual de visitantes al Circuito Ecoturístico Lomas de Lúcumo 2010-2016

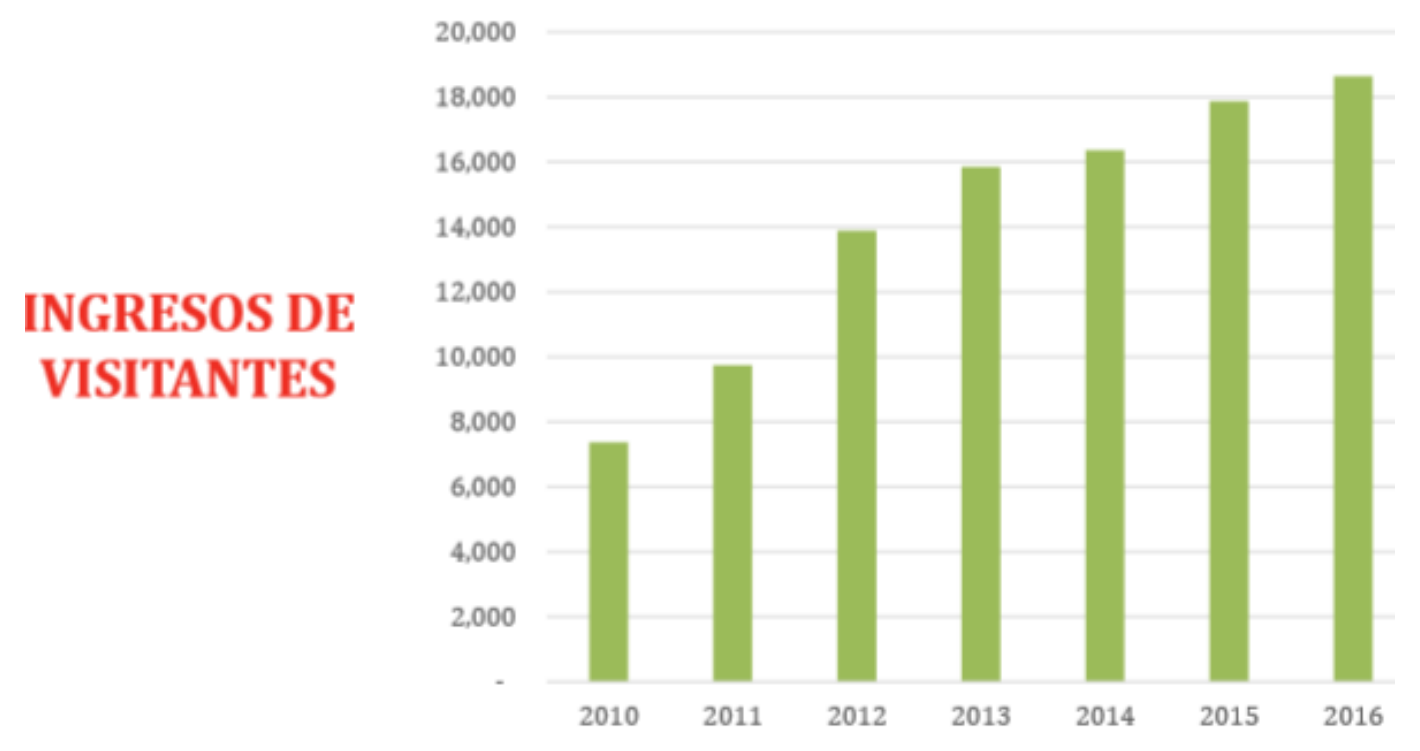

Fuente: (Mendoza Flores, 2017) 
El Circuito Ecoturístico Lomas de Lúcumo ha presentado un importante crecimiento turístico llegando hacia el año 2016 a sobrepasar los 18000 visitantes, la gestión viene siendo la adecuada pues se reinvierten los ingresos en la mejora del circuito y de la calidad de vida de la población en general, además de emplear a más de 75 familias del C.P.R. Quebrada Verde y comunidades aledañas durante la temporada de Lomas.

Los siguientes subtítulos analizarán la viabilidad del proyecto a partir de los siguientes factores:

\subsubsection{Características de las construcciones de la zona}

El Centro Poblado Rural Quebrada Verde, posee variadas tipologías de vivienda, existe aún un fuerte porcentaje de construcciones precarias, de esteras y madera donde sus habitantes se dedican a la crianza de animales menores o a trabajo agrícola en las áreas cercanas al poblado, el proyecto pretende generar desarrollo local que permita mejorar las condiciones de habitabilidad de poblaciones como esta, mejorando así su calidad de vida. Se presenta como tipología también las casas huerta, vivienda comercio en algunos puntos y finalmente viviendas de exclusivo uso residencial que en su mayoría son de material noble de hasta dos pisos caracterizadas por la auto construcción.

Figura 6.4 Análisis de la densidad urbana del C.P.R. Quebrada Verde

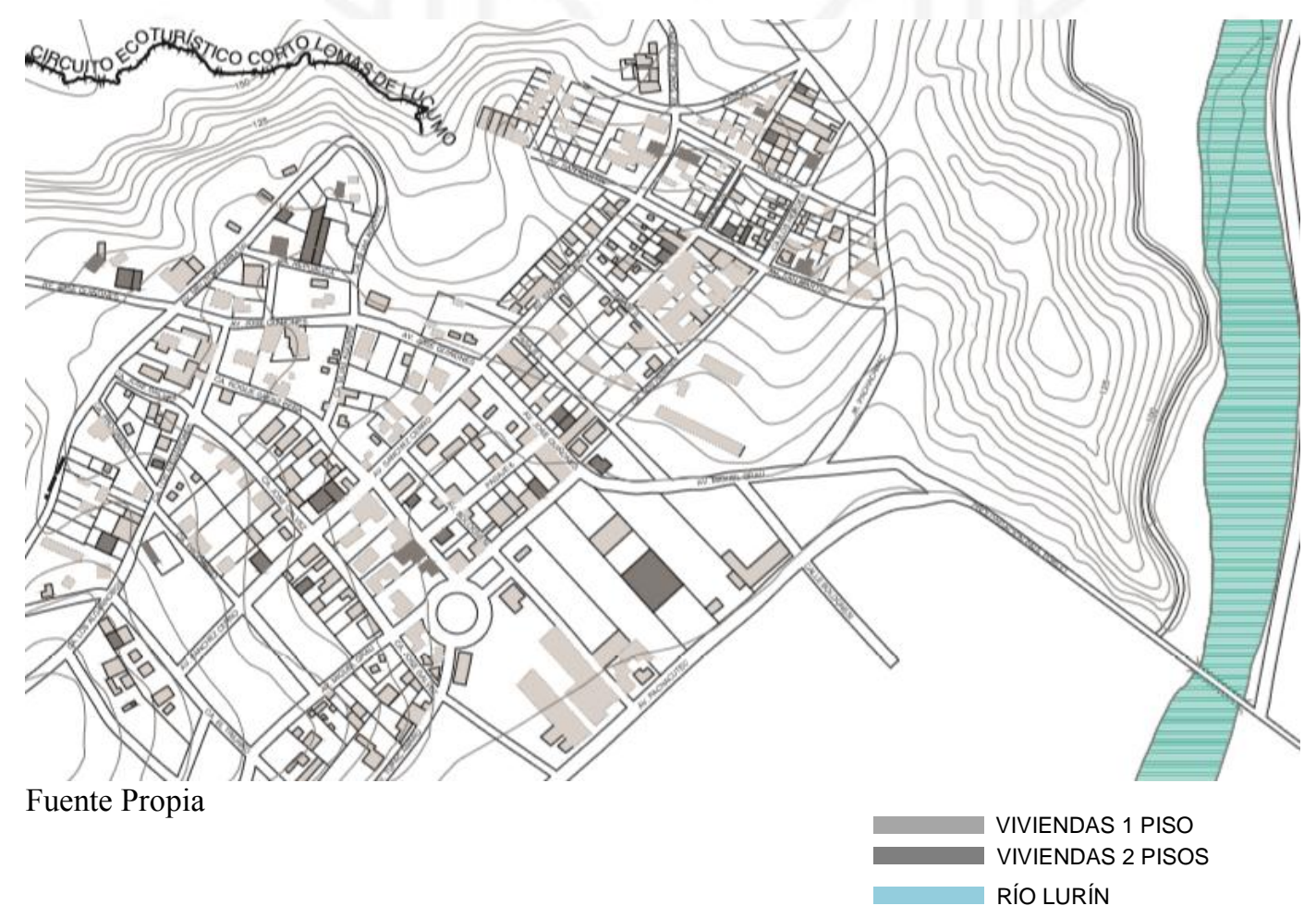


Figura 6.5 Gráficos sobre densidad urbana y área construida en el C.P.R. Quebrada Verde

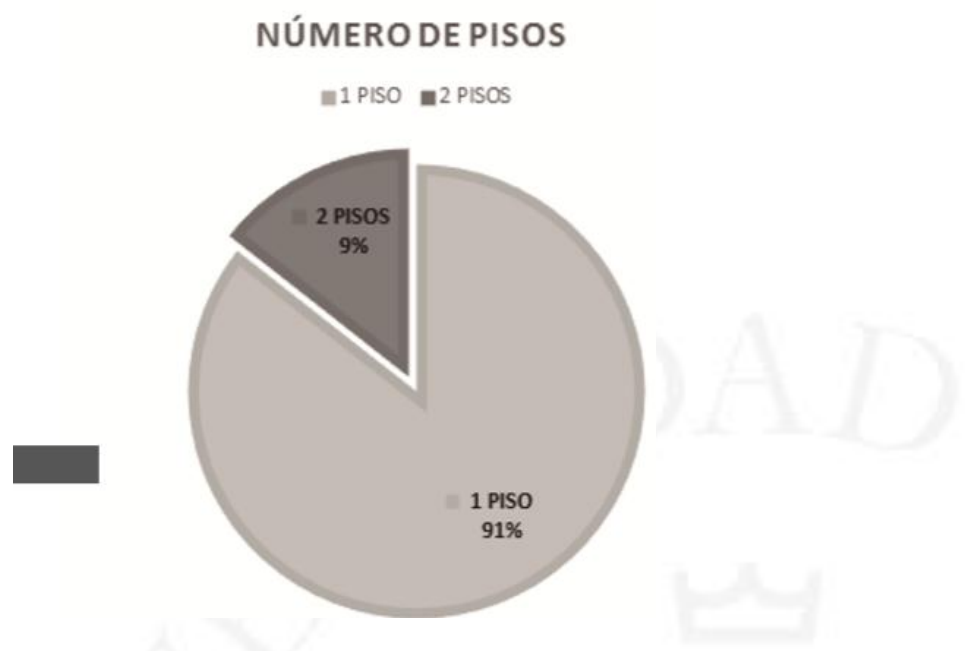

ÁREA CONSTRUIDA DEL CENTRO POBLADO

-

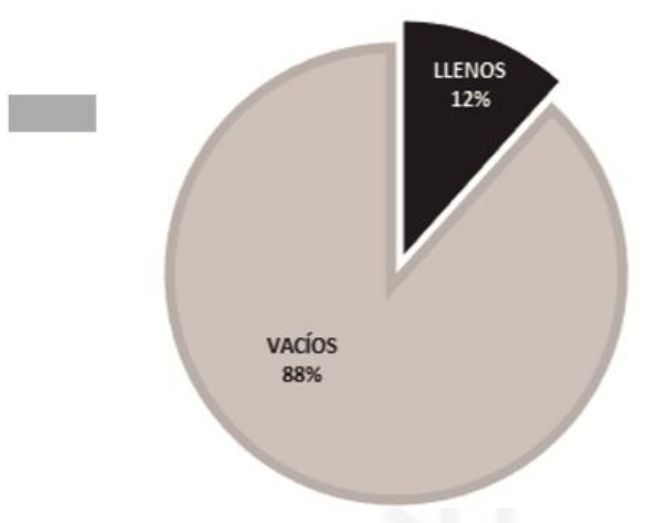

ÁREA CONSTRUIDA GENERAL

-
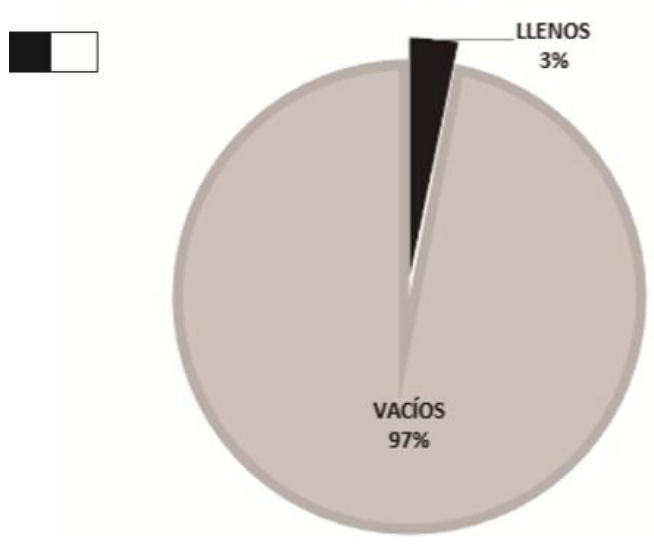

Fuente Propia 
E1 9\% de las viviendas de Quebrada Verde poseen construcciones de dos pisos y 91\% de un solo piso, en proporción existe un área construida de $12 \%$.

\subsubsection{Consideraciones ambientales}

Las siguientes imágenes muestran la inclinación del recorrido solar y el estudio de sombras durante los meses de verano e invierno.

Figura 6.6 Recorrido solar y estudio de sombras verano e invierno

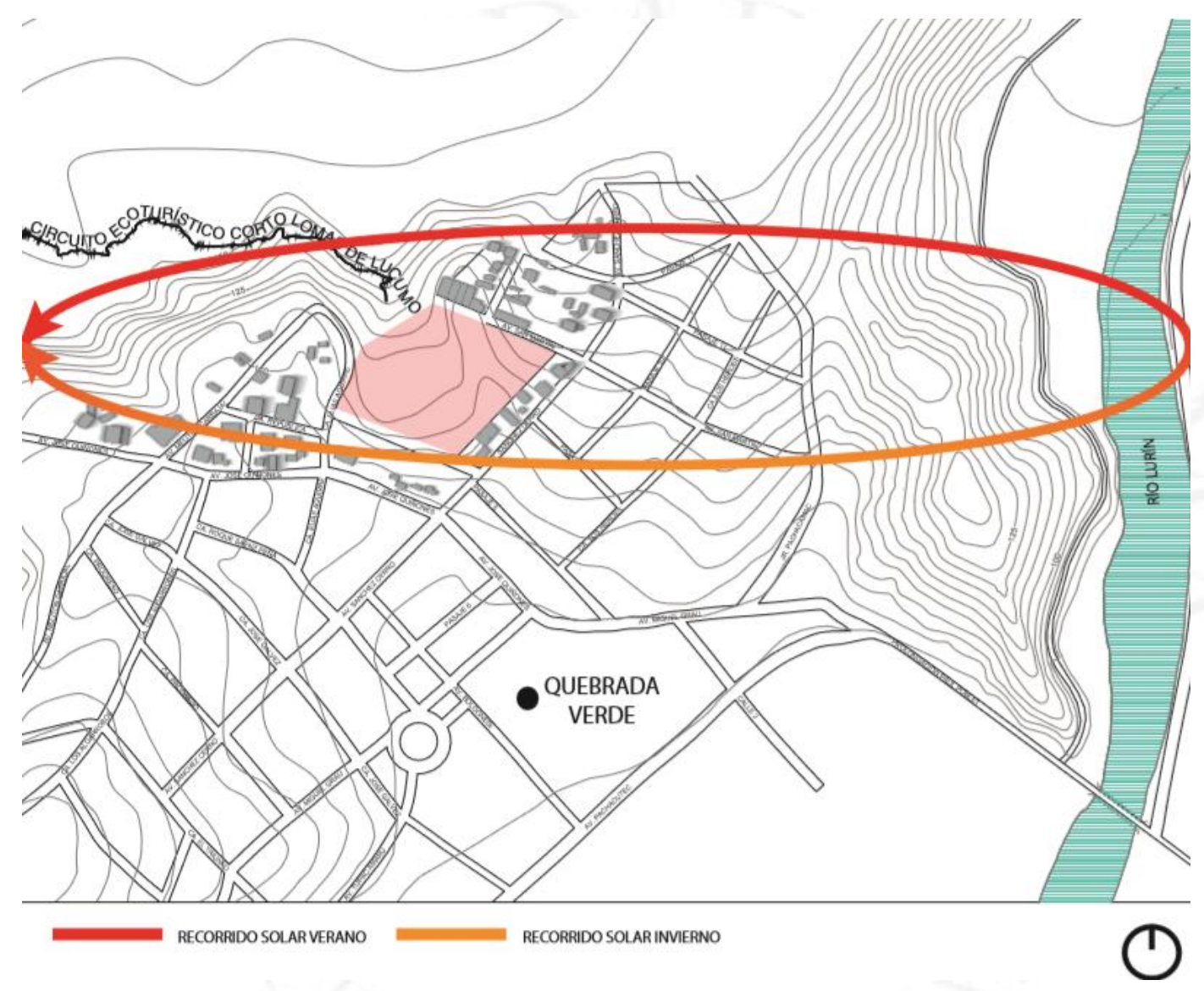

\section{ESTUDIO DE SOMBRAS}

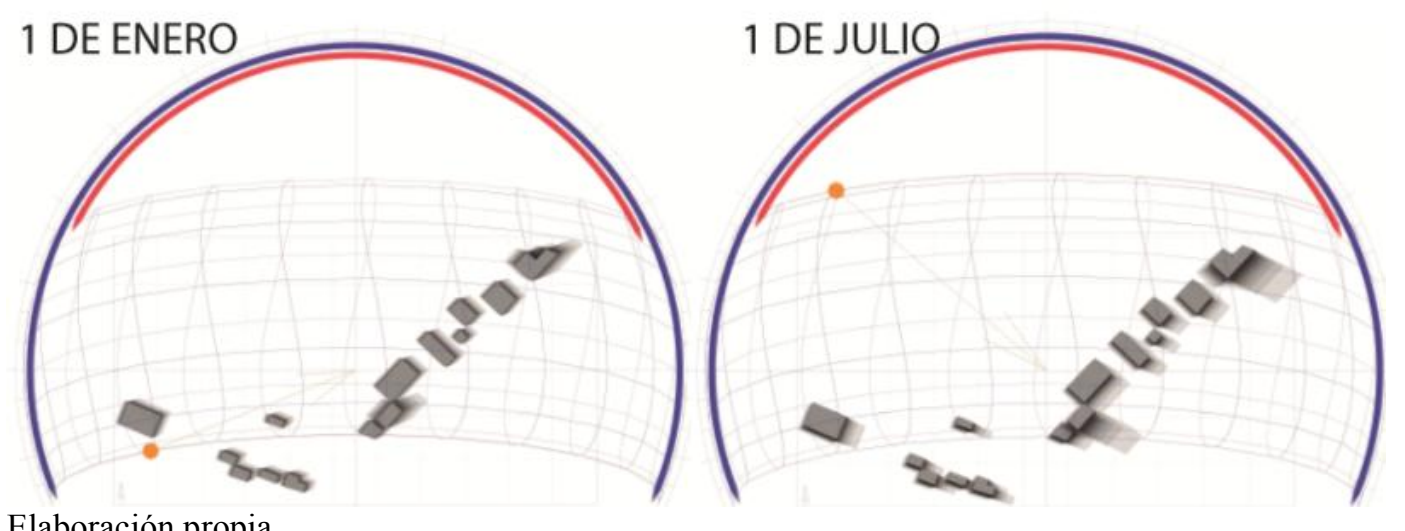

Elaboración propia 
La Estación Metereológica más cercana al área de estudio es la de Villa María de Triunfo, cuyo análisis sobre la velocidad y dirección del viento se muestra a continuación.

Figura 6.7 Análisis de dirección y velocidad del viento en el C.P.R. Quebrada Verde

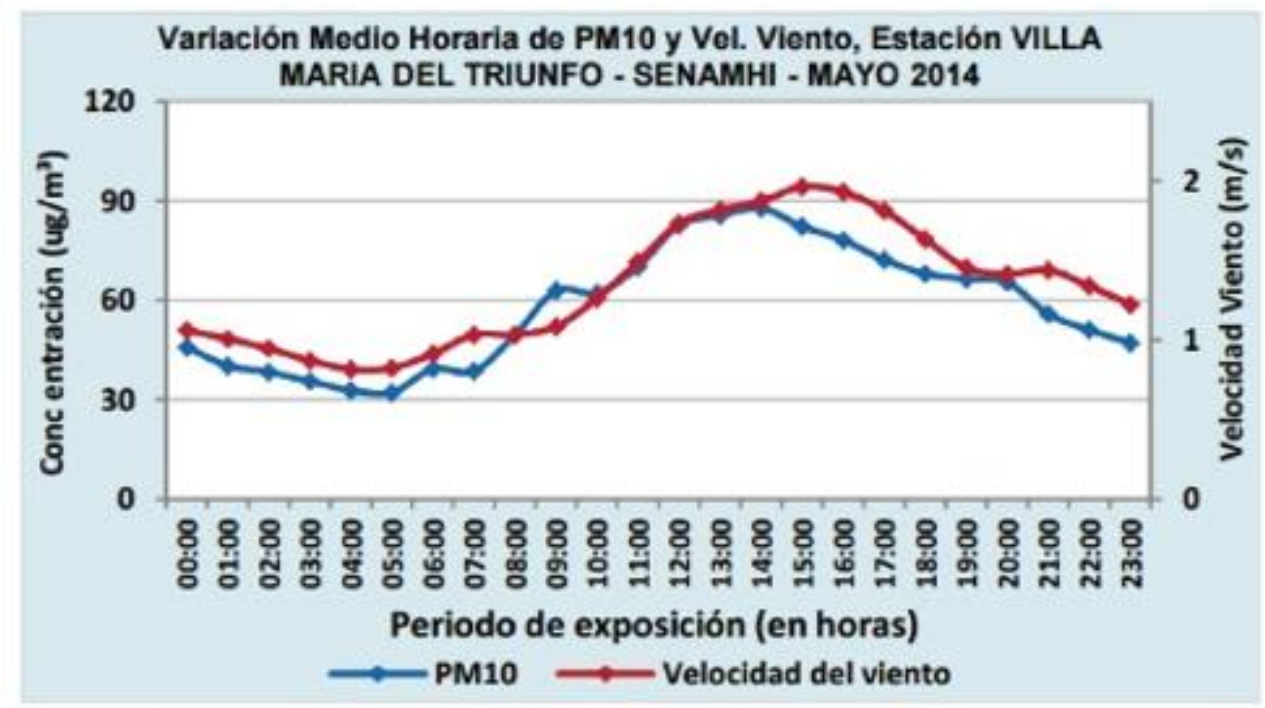

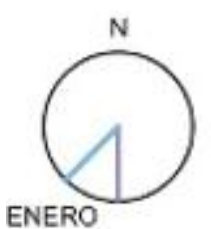

ENERO

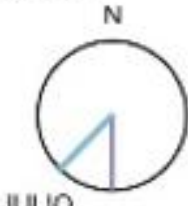

JULIO

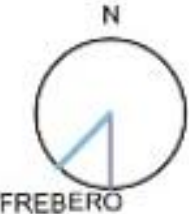

FREBERO

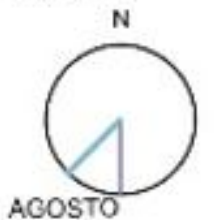

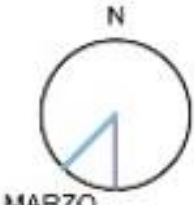

MARZO

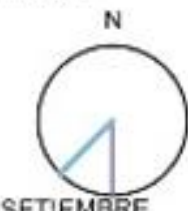

SETIEMBRE

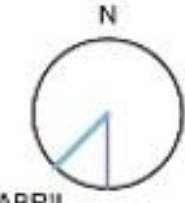

ABRIL

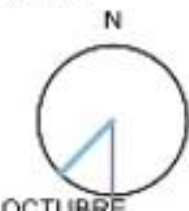

OCTUBRE

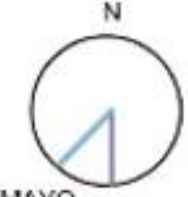

MAYO
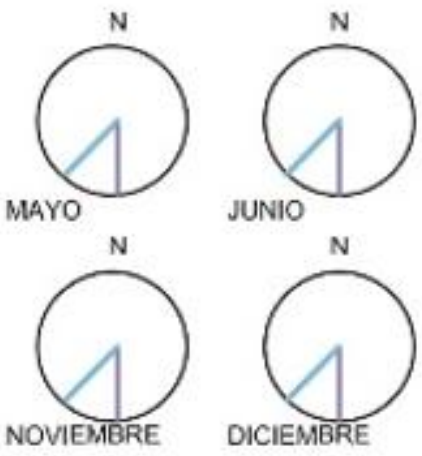

\section{VELOCIDAD EN $(\mathrm{m} / \mathrm{s})$}

$0: 00-8: 00$

$0.0-1.0$

9:00-23:00

$1.1-2.0$

Fuente: SENAMHI

Siendo el Ecosistema Lomas de Lúcumo parte del Sistema de Lomas Costeras del Perú, es importante localizar las lomas presentes en Lima Metropolitana, las cuales se muestran en la siguiente imagen en color verde claro, donde observamos que suelen situarse constantemente a ambos bordes de las cuencas que conforman los Valles de la ciudad, en este caso el Ecosistema de la presente investigación se localiza al límite de la Cuenca del Río Lurín. 
Este ecosistema frágil viene siendo amenazado por el crecimiento urbano de los centros poblados ubicados en sus límites y la extracción de materiales para la construcción por parte de Cementos Lima.

Figura 6.8 Mapeo de Lomas Costeras en Lima Metropolitana

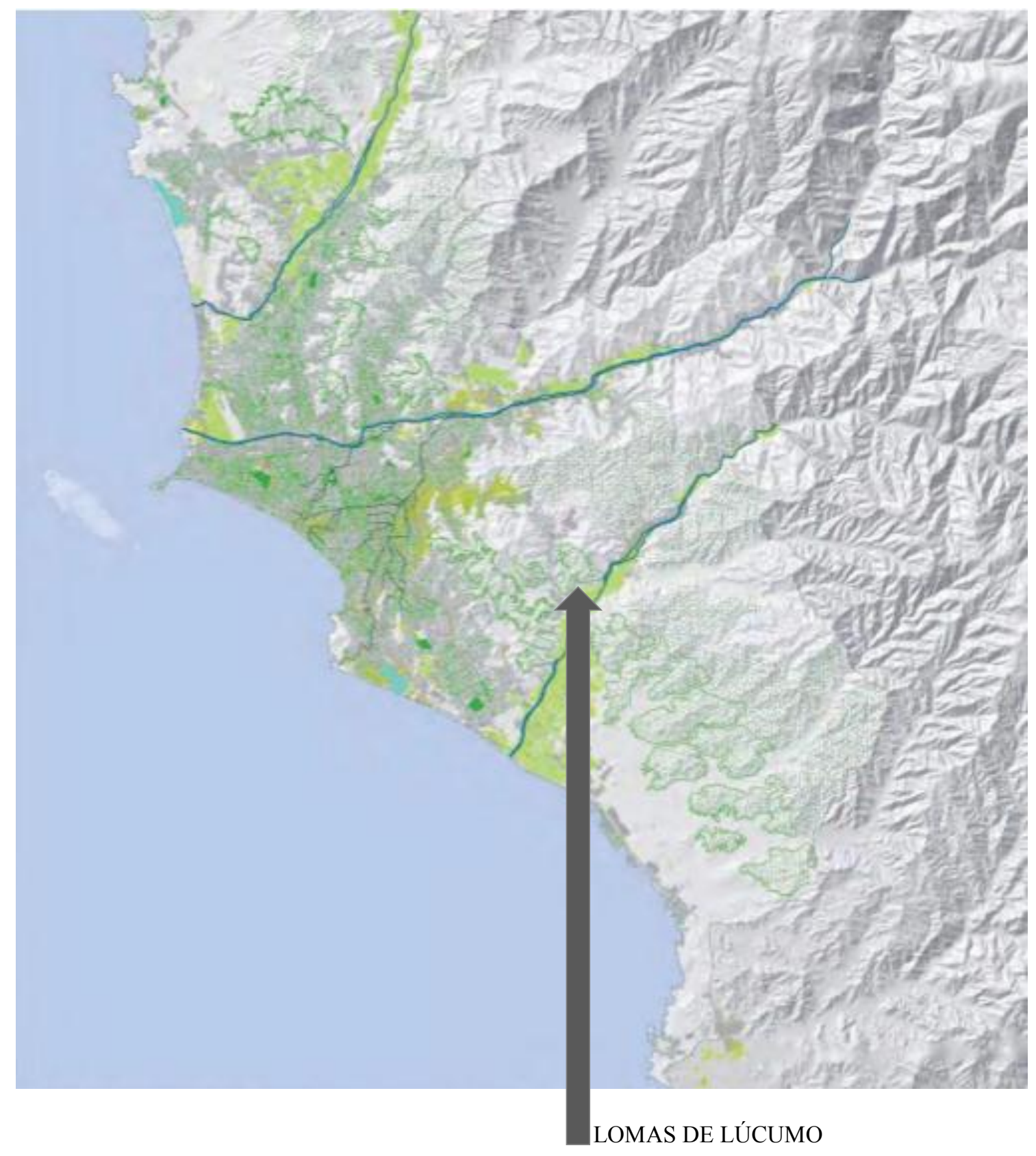

Fuente: (Eisenberg, Nemcova, Poblet, \& Stokman, 2013) 
Figura 6.9 Explicación gráfica del Fenómeno de Lomas

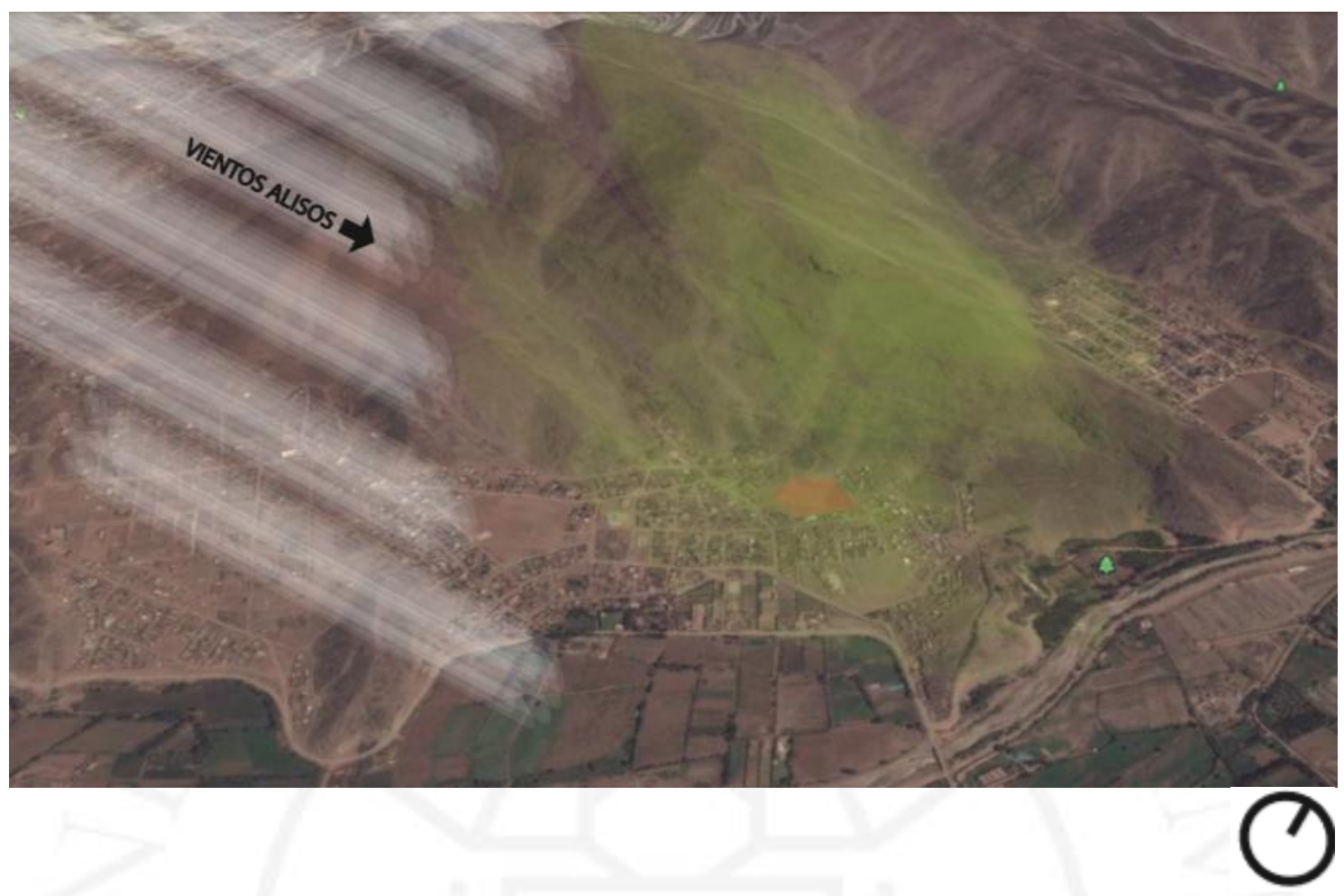

Fuente Propia

Hacia el año 2011 el grupo ecologista peruano "Comando Ecológico" inició las labores de reforestación en el ecosistema Lomas de Lúcumo, apoyado por algunas instituciones, voluntarios y pobladores de Quebrada Verde iniciaron con la plantación de especies nativas como tara, lúcumo y huarango, éstas últimas especies ya estaban presentes de forma silvestre en el ecosistema, por lo que se había comprobado su desarrollo y sostenibilidad, hacia el año 2015 ya se habían reforestado 60 árboles en la Loma y 120 en la entrada al circuito ecoturístico, cuya finalidad es detener el crecimiento urbano y proteger este ecosistema frágil, formando un colchón de amortiguamiento para el calor y mitigando de alguna forma la contaminación; su proyección hacia el año 2060 es haber formado núcleos de nichos ecológicos que actúen como regeneradores del ecosistema naturalmente, recuperando de esta forma el ecosistema que alguna vez fue parte de Las Lomas antes de la llegada de los españoles. Cabe indicar que el proyecto no ha pensado ejecutar un borde protector limítrofe a toda el área de Lomas, gestión que sería esencial para la preservación de las mismas. (Comando Ecológico, 2017) 
Figura 6.10 Plan de Reforestación Ecosistema Lomas de Lúccumo

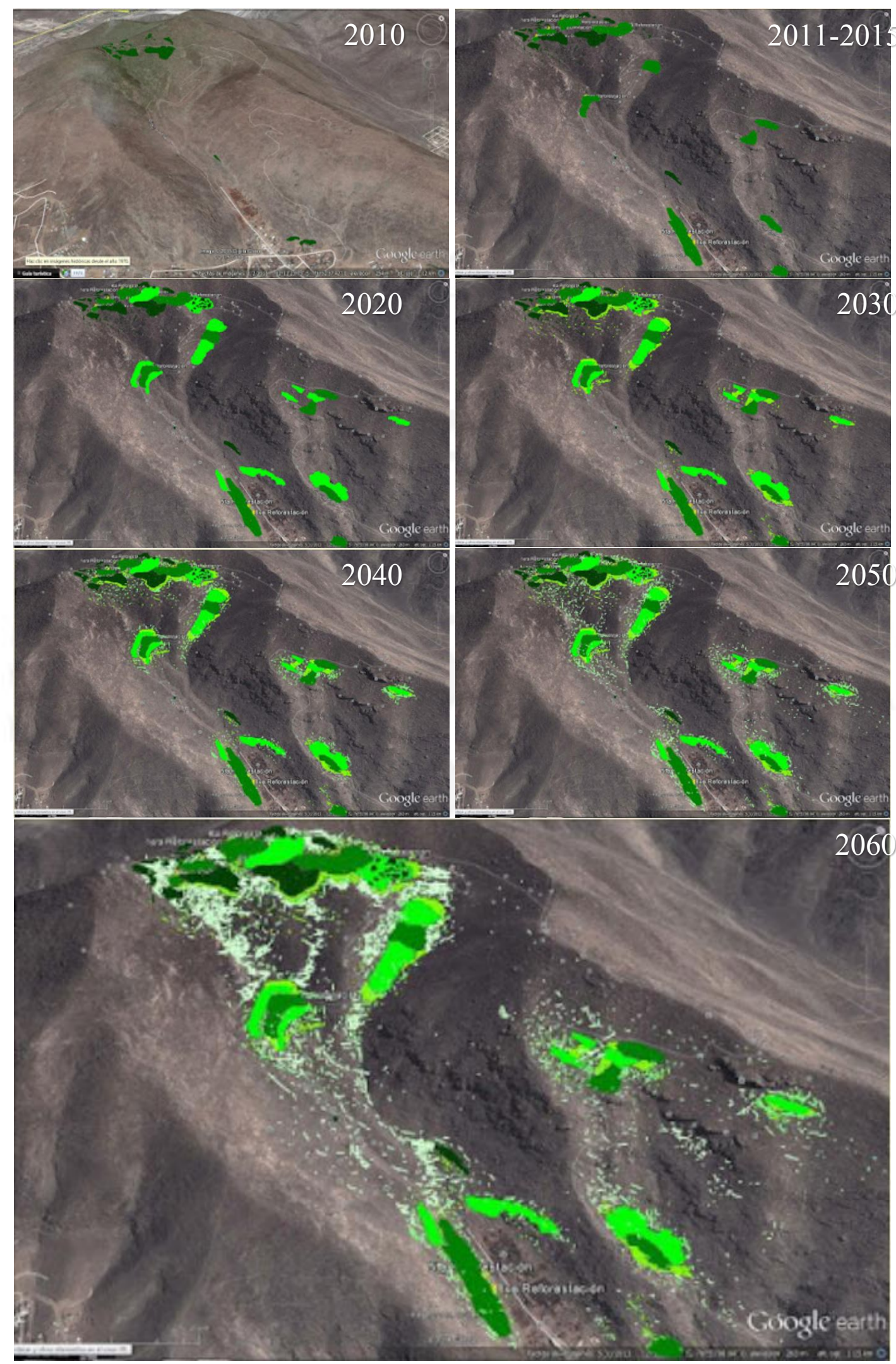

Fuente: (Comando Ecológico, 2017) 


\subsubsection{Riesgos}

El estudio geográfico denominado Valle del Río Lurín determinó que el tipo de suelo presente en el C.P.R. Quebrada Verde correspondía a un depósito eólico pleistocénico, el cual la autora describe:

Lo conforman las acumulaciones eólicas antiguas y en la actualidad se hallan estabilizadas formando cerros de arena, como el cerro Loma de Corvina. Por lo general se observa como grandes extensiones en forma de mantos de arena, cuya superficie tiene un modelado suave, con coloración gris claro. Los depósitos del Pleistoceno han adquirido cierta coherencia por el material cementante, principalmente el limo. Sobre ellos se han instalado viviendas de urbanización precaria y algunos sectores del área urbana de Lurín, Pachacamac, quebrada Verde, entre otros. (Huamán Durand, 2014)

Figura 6.11 Tipos de Suelo en el Valle Lurín

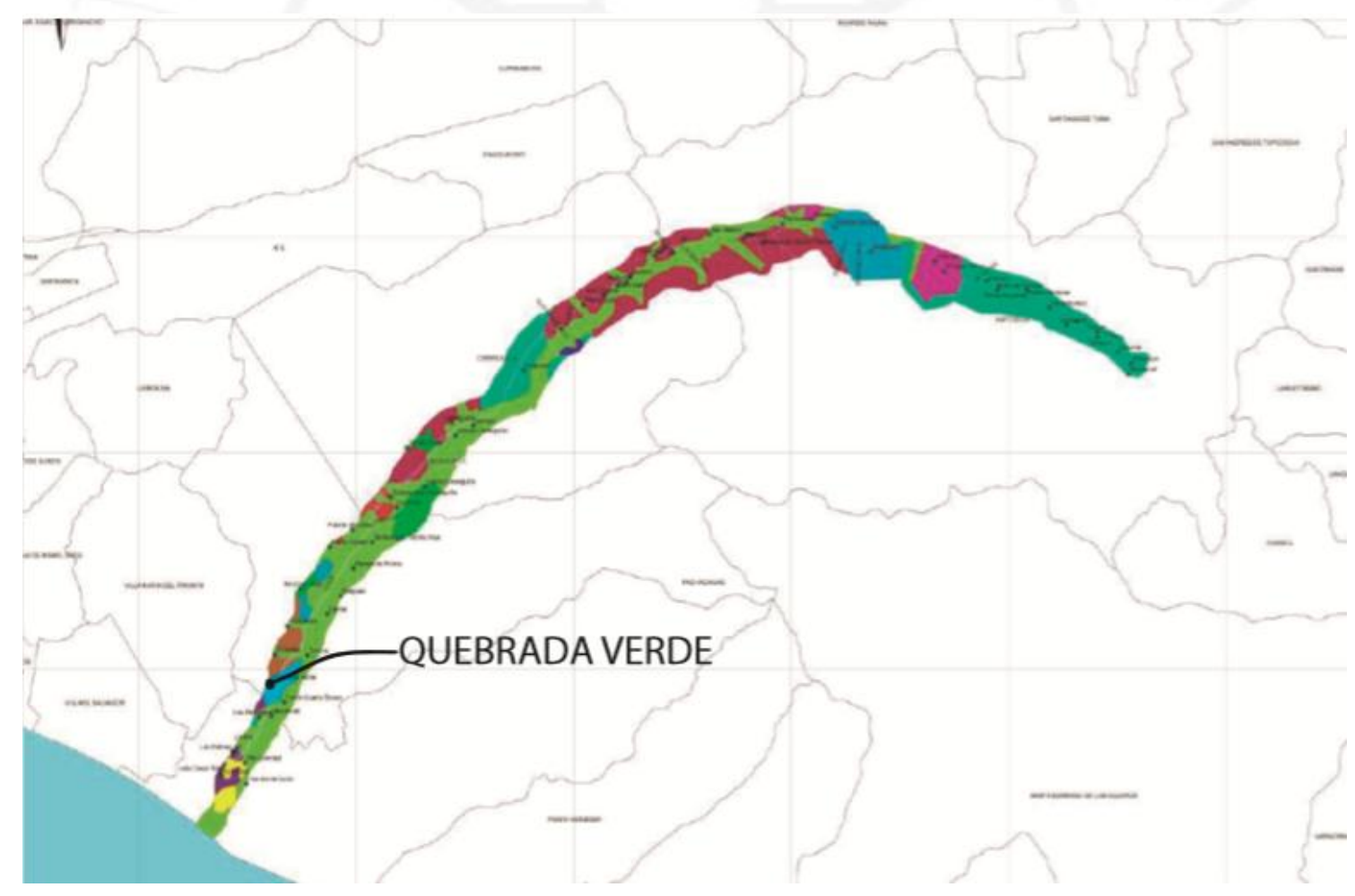




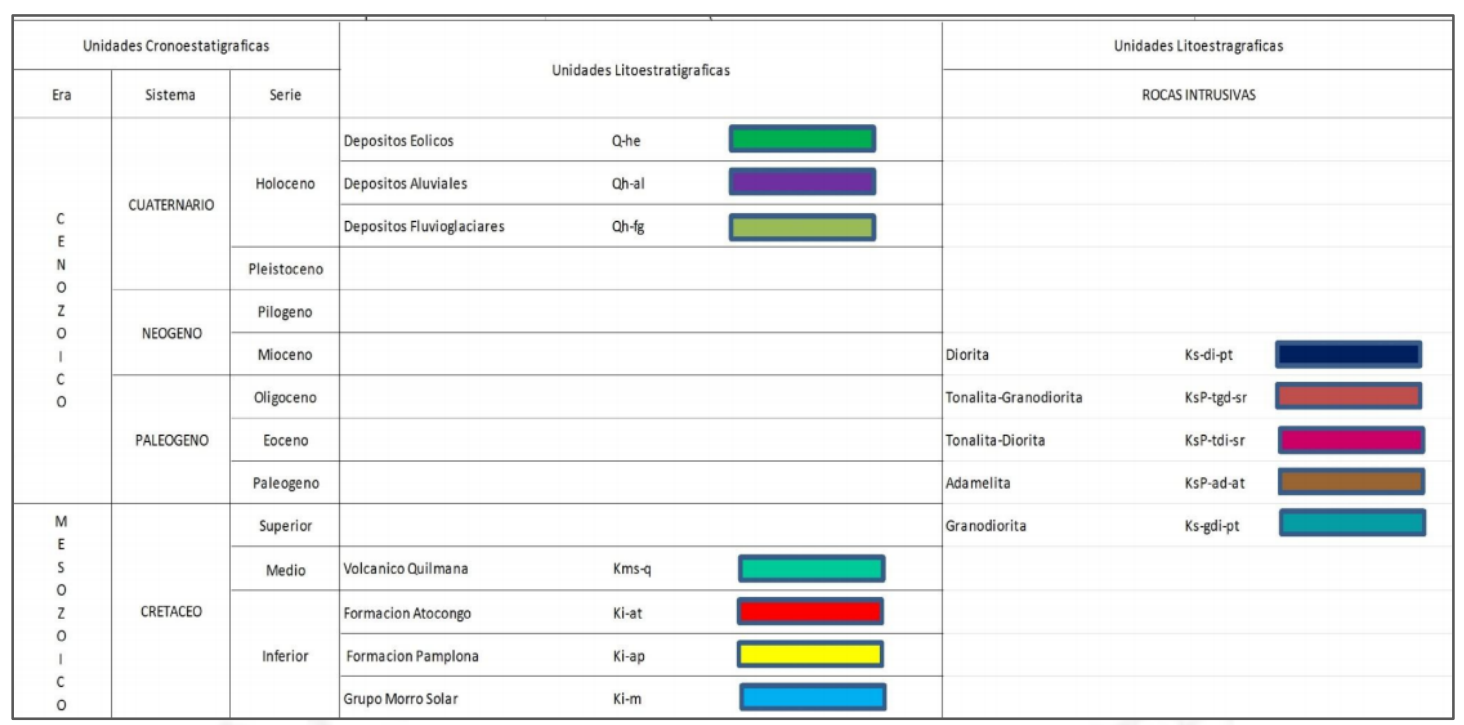

Fuente: (Huamán Durand, 2014)

El mismo estudio refiere que Quebrada Verde es vulnerable a deslizamientos tras un fuerte sismo, pero que el efecto puede contrarrestarse con un proyecto de forestación y mantenimiento de andenes incaicos o la construcción de nuevos andenes agrícolas en las áreas con mayor peligro.

Figura 6.12 Análisis de Vulnerabilidad Sísmica en el Valle Lurín

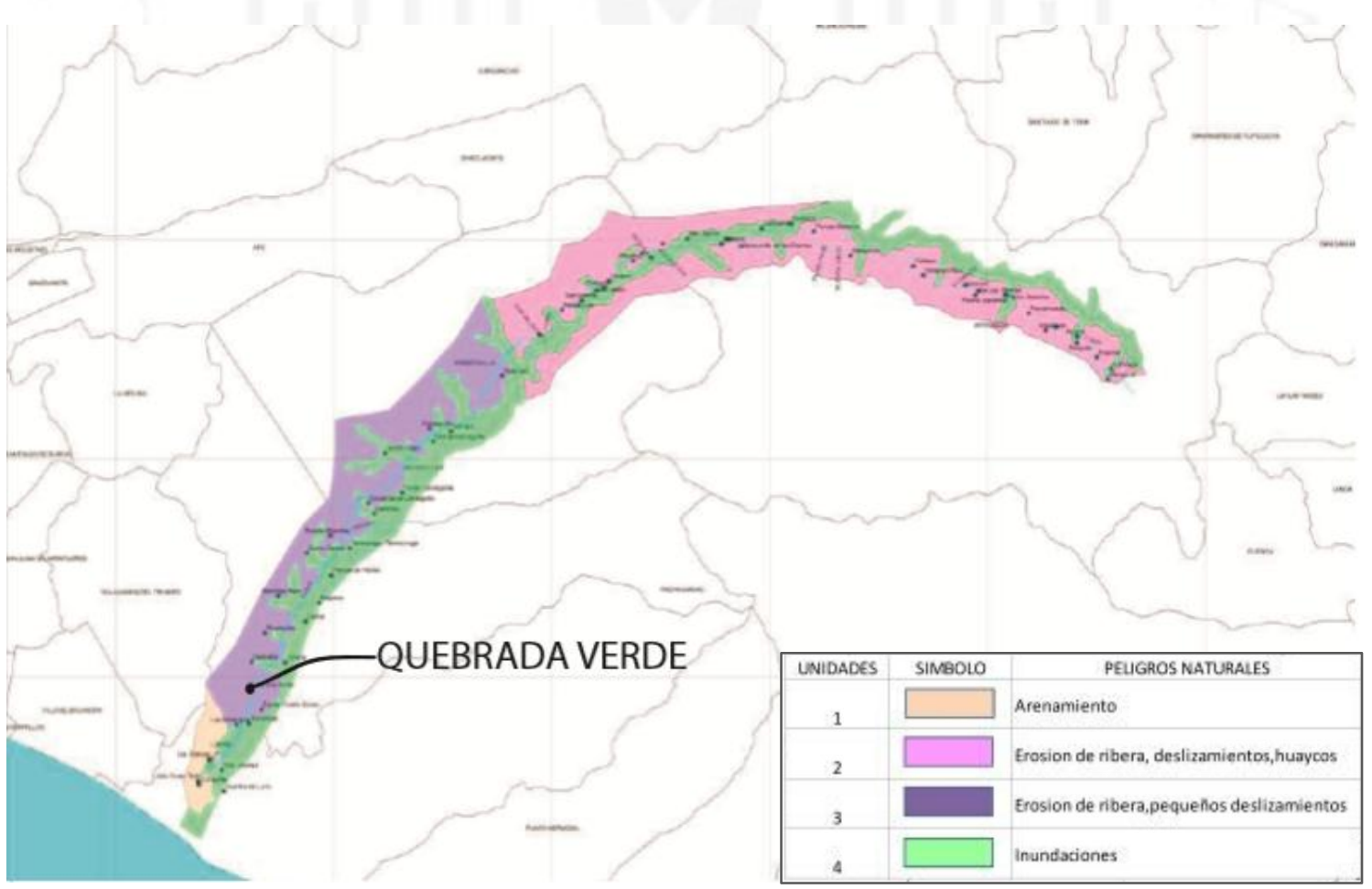

Fuente: (Huamán Durand, 2014) 
A continuación se muestra el estudio de suelos realizado por Fabiola Coral exactamente en el área de Lomas en el cual encontró caliza altamente fraccionada en la parte alta de la misma hacia los $350 \mathrm{msnm}$ y material granular en las áreas más cercanas al poblado bajo los $130 \mathrm{msnm}$.

Figura 6.13 Gráfica del corte donde se realizó el análisis de suelos

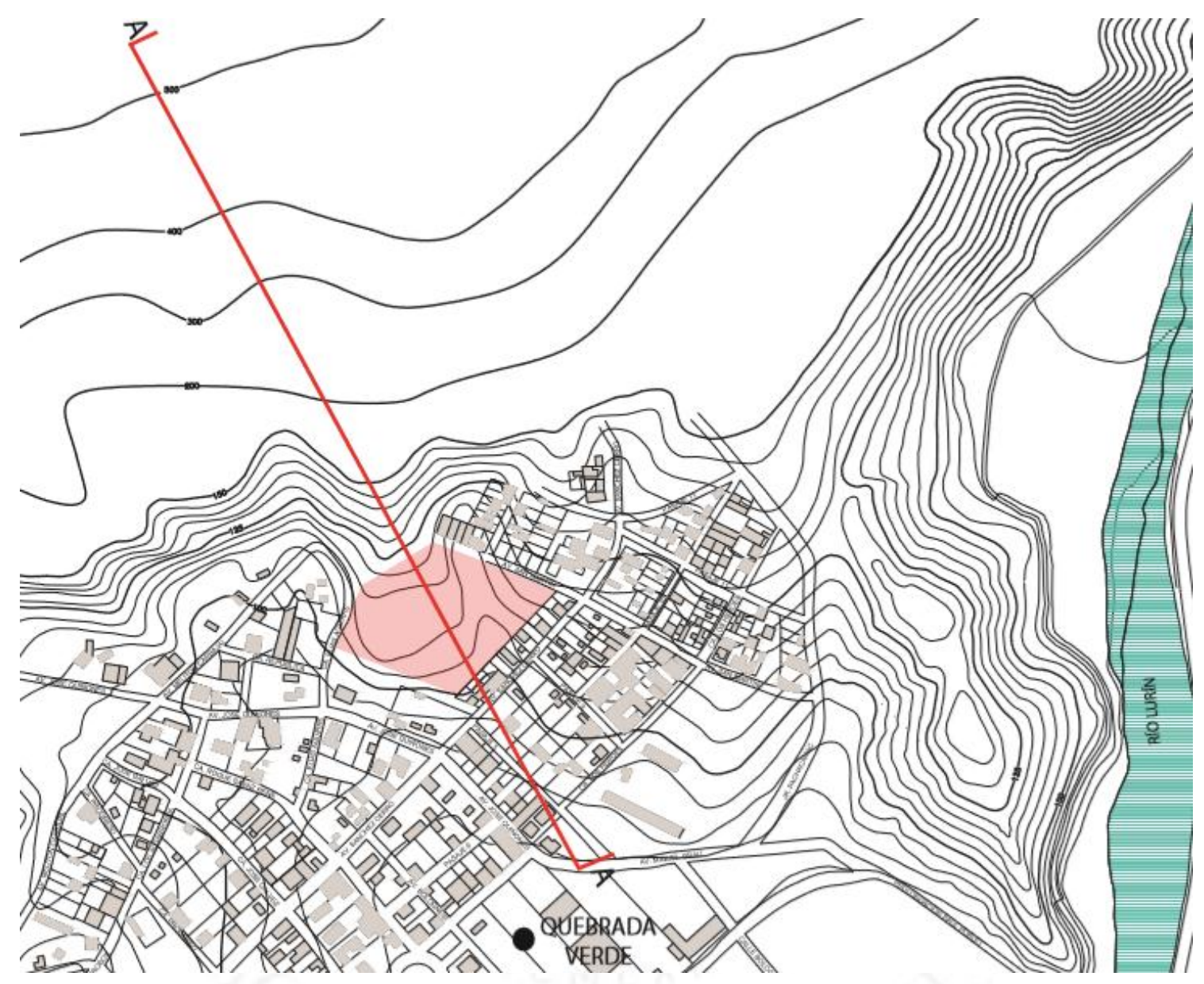

Elaboración propia 
Figura 6.14 Corte que muestra el Análisis de Suelo en Lomas de Lúcumo

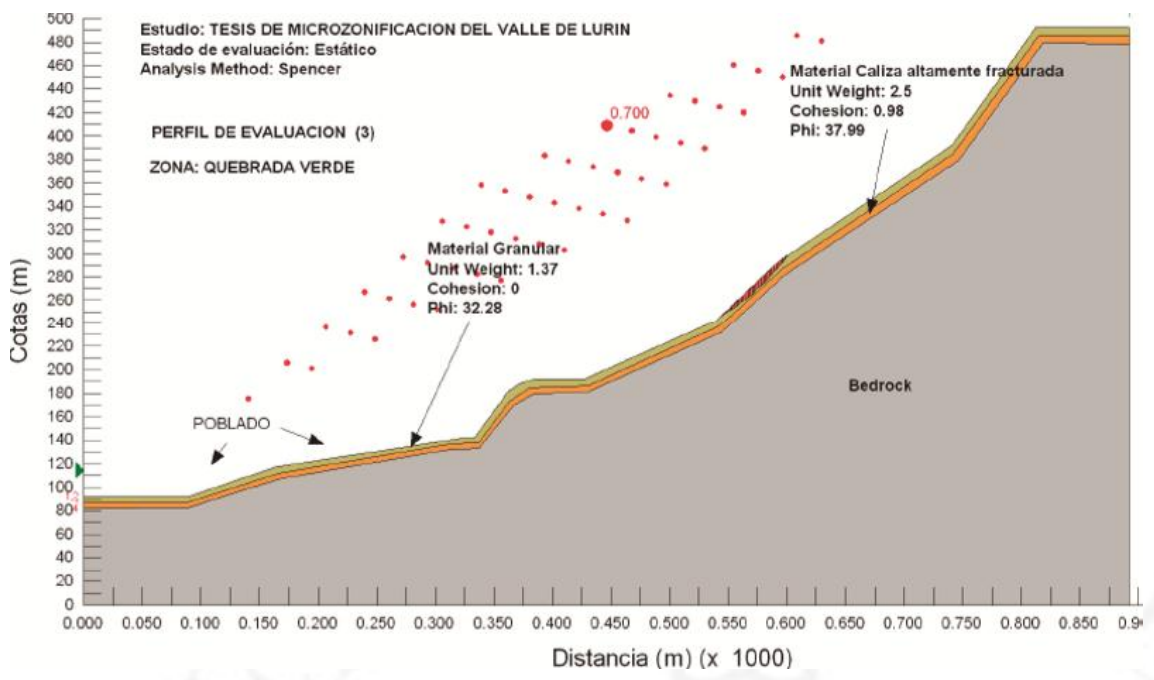

Fuente: (Coral Mestanza, 2007)

Figura 6.15 Mapa de riesgos

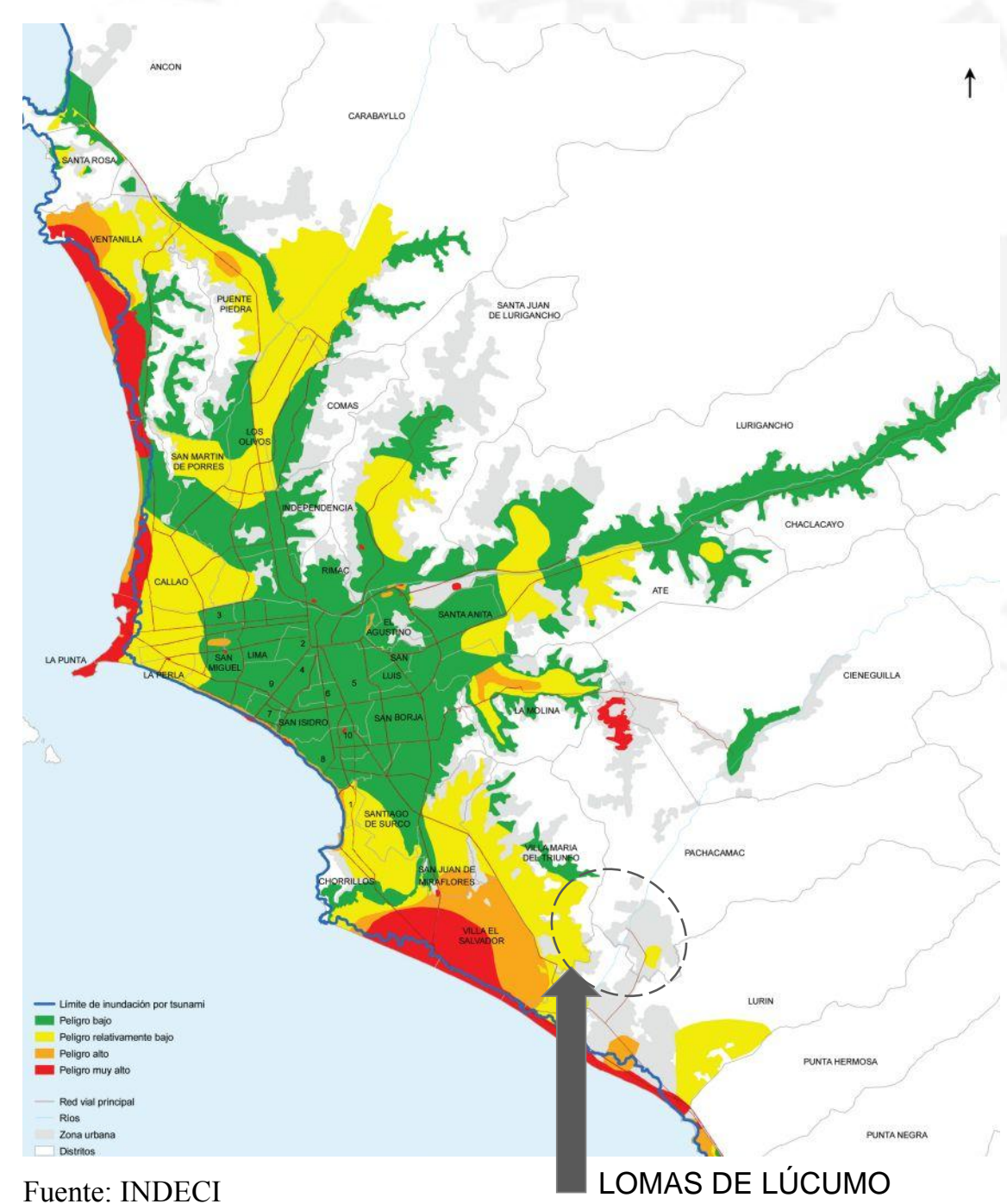




\subsubsection{Limitaciones normativas de acuerdo al proyecto}

El proyecto se ubica en Quebrada Verde, donde no existe una zonificación normativa sobre los lotes que conforman dicho poblado, estableciendo una zonificación general de Centro Poblado Rural, donde la normativa especifica únicamente que no se pueden realizar construcciones por encima de los dos niveles, que el área libre debe cubrir el $40 \%$ del área del terreno y que los demás parámetros que limitan las construcciones deberán estar regidos al Reglamento Nacional de Edificaciones.

El Reglamento Nacional de Edificaciones en la Norma A.040 en su Artículo 5 establece que los locales educacionales deberán tener en cuenta la presencia de vías de acceso cuya dimensión permita el ingreso de vehículos de emergencia, que al mismo pueda tener acceso la población, que el lugar donde se ubique le brinde la capacidad para abastecerse de dotaciones de servicios básico, que el terreno permita incorporar áreas de futura expansión, con pendientes menores al 5\% y cuyas condiciones morfológicas no generen riesgos frente a un eventual desastre natural. (Ministerio de Vivienda Construcción y Saneamiento, 2006)

Dentro del terreno destinado para el desarrollo arquitectónico del proyecto se encuentra una cancha de futbol de condiciones algo precarias, significando entonces un área de recreación pública, debido a la cual se pensaba poco posible la ejecución del equipamiento urbano planteado sobre ésta área, pero dado el caso de pertenecer al dominio comunal del Centro Poblado Rural Quebrada Verde, éste podría gestionar el mismo según mejor le convenga en pro de mejorar las condiciones de habitabilidad y/o desarrollo local de la comunidad, aun así se ha considerado incluir en el diseño del proyecto ésta cancha aunque no en las mismas proporciones pero sí mejorar su equipamiento.

\subsubsection{Vías de acceso y transporte}

Se puede llegar hasta Quebrada Verde desde la Av. Panamericana Sur entrando por la Av. Manuel Valle hasta el puente del mismo nombre si es que se viene desde los distritos de Lima Centro o Lima Norte, pero si se viene desde Lima Este se puede llegar 
por la Av. Víctor Malasquez que es la que continúa doblando a la izquierda desde Av. La Molina siguiendo la ruta que lleva a Manchay, seguir de frente hasta el cruce con la carretera a Cieneguilla y doblar hacia la izquierda con dirección a Pachacamac Pueblo hasta el puente Quebrada Verde tras pasar por los Centros Poblados Picapiedra y Guayabo.

Existe una única línea de transporte público que cubre la ruta Pachacamac Pueblo Cieneguilla Pueblo, ésta tiene un paradero formal dentro del C.P.R. Quebrada Verde; las unidades combi llegan al paradero cada 15 minutos aproximadamente.

Figura 6.16 Ruta desde Cercado de Lima hacia Lomas de Lúcumo

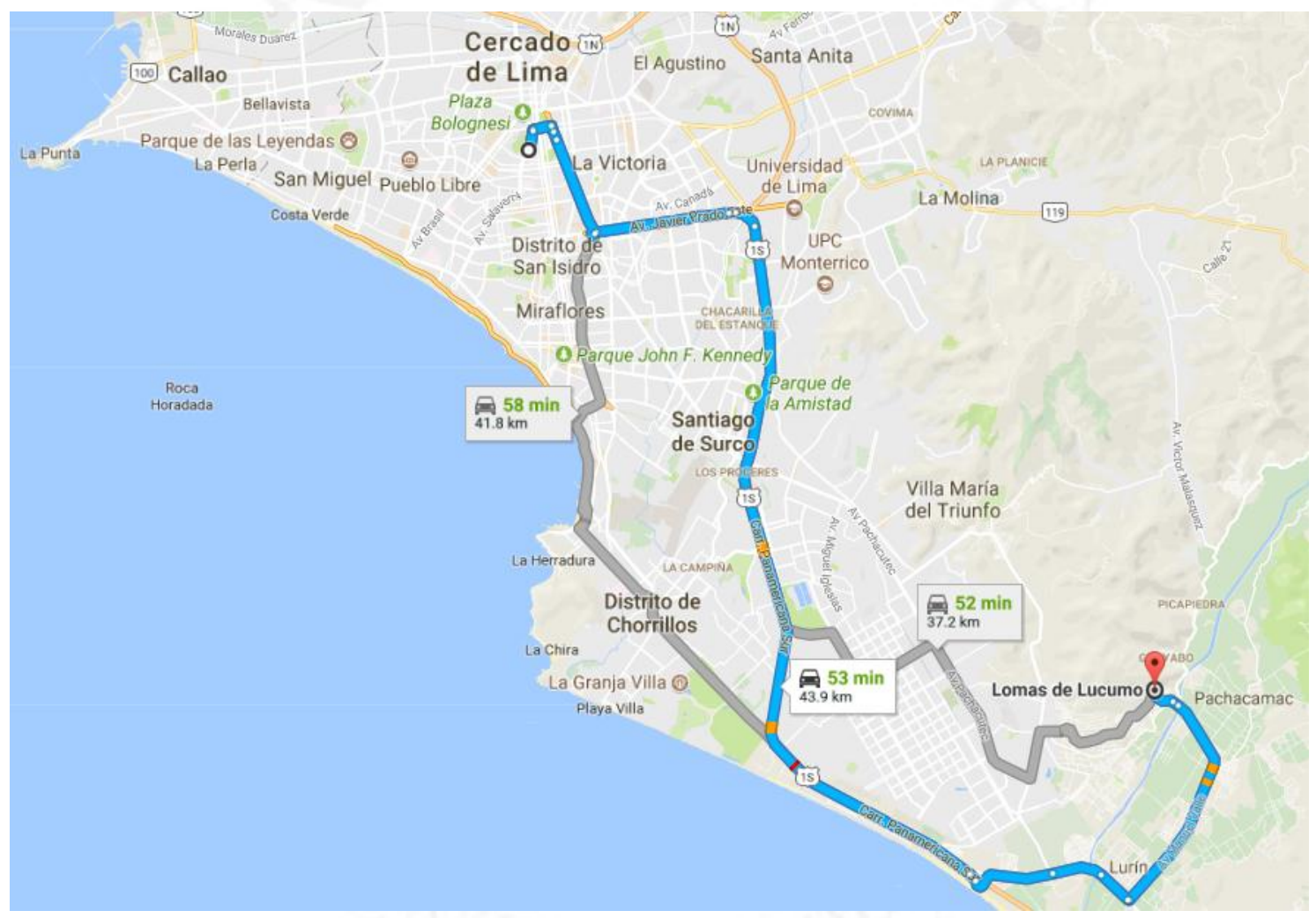

Fuente: Google maps 
Figura 6.17 Plano que muestra las vías y flujos vehiculares y peatonales en Quebrada Verde

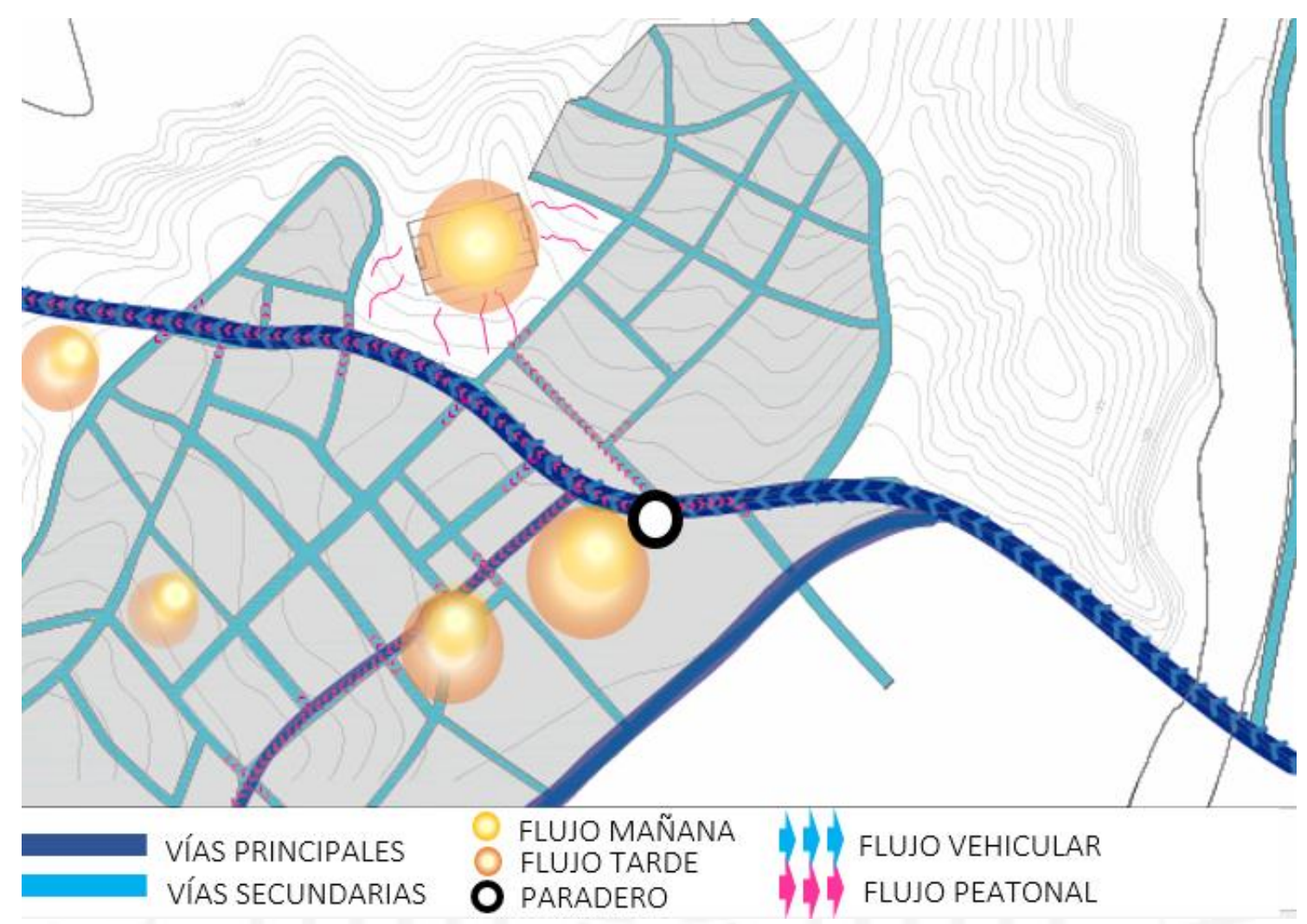

Elaboración propia

Para llegar al Circuito Ecoturístico Lomas de Lúcumo es necesario continuar por la Avenida que sigue en el puente Quebrada Verde llamada José Quiñonez, hasta llegar a la boletería del mismo.

\subsubsection{Infraestructura y servicios disponibles}

El C.P.R. Quebrada Verde cuenta con alumbrado eléctrico más no tiene acceso a la red pública de agua ni desagüe, sin embargo existe un proyecto a corto plazo para su instalación; la población con ayuda de la Asociación Vive Pachacamac y sus colaboradores hicieron posible la instalación de un tanque de agua en la parte alta del poblado que abastece al mismo pero la dotación es fraccionada e insuficiente, por otro lado la Universidad Católica y la empresa Rotaria vienen promoviendo en la zona el uso de baños ecológicos secos; éstas gestiones se vienen desarrollando a fin de contrarrestar 
la falta de acceso a servicios básicos mientras el Gobierno Local concluye las obras de redes de agua y desagüe cuyo proyecto ya ha sido aprobado.

Figura 6.18 Mapa que muestra el acceso a la Red de Agua en Poblaciones en laderas
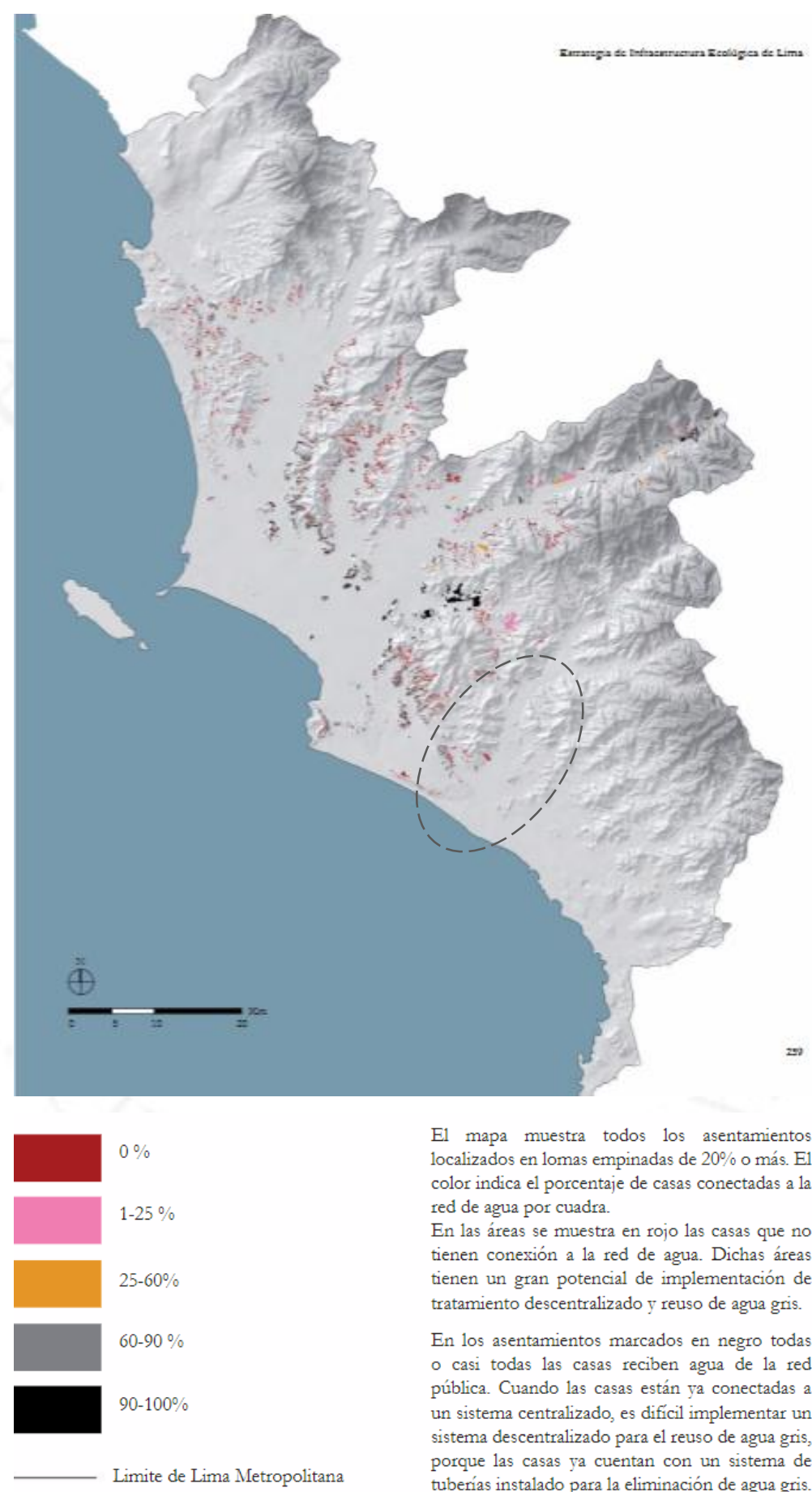

E1 mapa muestra todos los asentamientos localizados en lomas empinadas de $20 \%$ o más. E1 color indica el porcentaje de casas conectadas a la red de agua por cuadra.

En las áreas se muestra en rojo las casas que no tienen conexión a la red de agua. Dichas áreas tienen un gran potencial de implementación de tratamiento descentralizado y reuso de agua gris.

En los asentamientos marcados en negro todas - casi todas las casas reciben agua de la red pública. Cuando las casas están ya conectadas a un sistema centralizado, es difícil implementar un sistema descentralizado para el reuso de agua gris, porque las casas ya cuentan con un sistema de tuberías instalado para la eliminación de agua gris. Alterar esa infraestructura existente puede no ser económicamente viable.

Fuente: (Eisenberg, Nemcova, Poblet, \& Stokman, 2013) 


\subsubsection{Uso de suelo}

El siguiente plano muestra los usos de suelo presentes en el área de estudio:

Figura 6.19 Gráfico que muestra los porcentajes de suelo presentes en Quebrada Verde
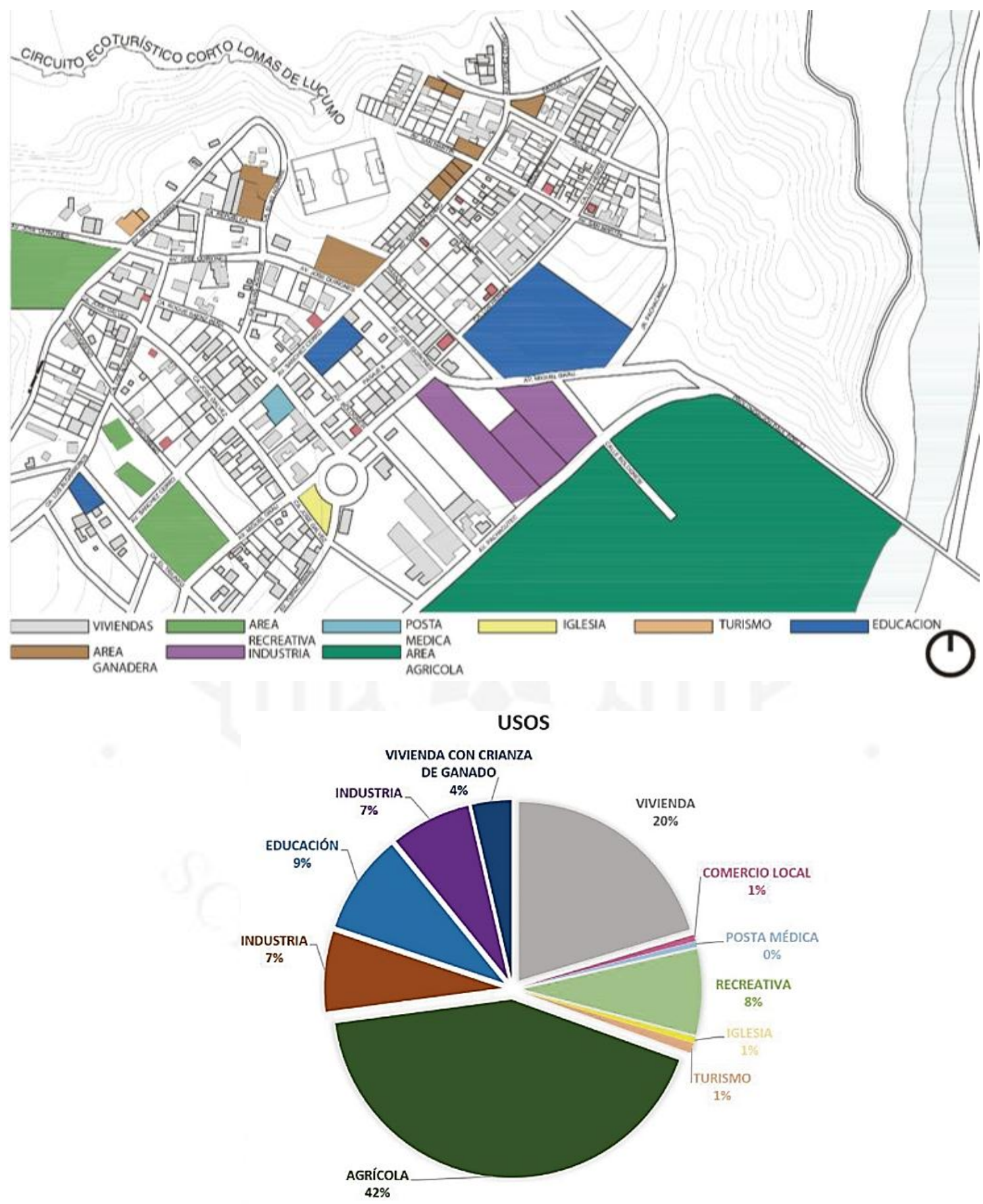

Elaboración propia 
Del análisis anterior de observa que el $20 \%$ de las construcciones tiene uso exclusivo de vivienda, un $4 \%$ posee viviendas con áreas acondicionadas para la crianza de ganado y solo un $1 \%$ son viviendas comercio; existe una pequeña posta médica, una iglesia y una pequeña área destinada a turismo donde se ubica la boletería, cafetería y servicios higiénicos del Circuito Ecoturístico Lomas de Lúcumo; para educación se ha destinado un 9\% del área total del Centro Poblado Rural distribuido en tres instituciones, dos privadas y una pública dedicadas a la enseñanza de educación hasta nivel secundario, $7 \%$ de los usos pertenecen al sector industrial; finalmente el área recreativa alcanza un $8 \%$ y el área agrícola es la de mayor proporción con $42 \%$.

Los resultados obtenidos exponen el déficit de equipamiento urbano en el Centro Poblado, se observa entonces que no existen en el radio de influencia instituciones dedicadas a la educación superior, que la población utiliza el turismo, la ganadería y sobre todo la agricultura como actividades productivas, sectores que pueden potenciar su desarrollo mediante el equipamiento urbano propuesto en la presente investigación.

\subsubsection{Morfología}

El terreno se ubica justo al final del Circuito Ecoturístico Lomas de Lúcumo, el cual se observa no está definido en relación al sendero de circulación de salida del mismo, siendo entonces los usuarios los que eligen por donde ir; sería importante entonces que el proyecto pueda definir el fin del circuito, que sea un remate donde se sienta la transición entre la naturaleza y la ciudad; localizando el proyecto en esta área se asegura además que el turista lo incluya en su recorrido, observe con detenimiento que procesos se realizan en su interior y pueda finalmente adquirir los productos elaborados por el Centro Técnico Productivo, contribuyendo así al desarrollo local de la población

El siguiente mapa es una vista macro del área a intervenir, nos muestra el límite del Ecosistema Lomas de Lúcumo (en color verde), los circuitos turísticos (en color naranja), el límite del C.P.R. Quebrada Verde (en color amarillo) y las vías de circulación vehicular aledañas al ecosistema (en color rojo). 
Figura 6.20 Mapa del área total del Ecosistema Lomas de Lúcumo

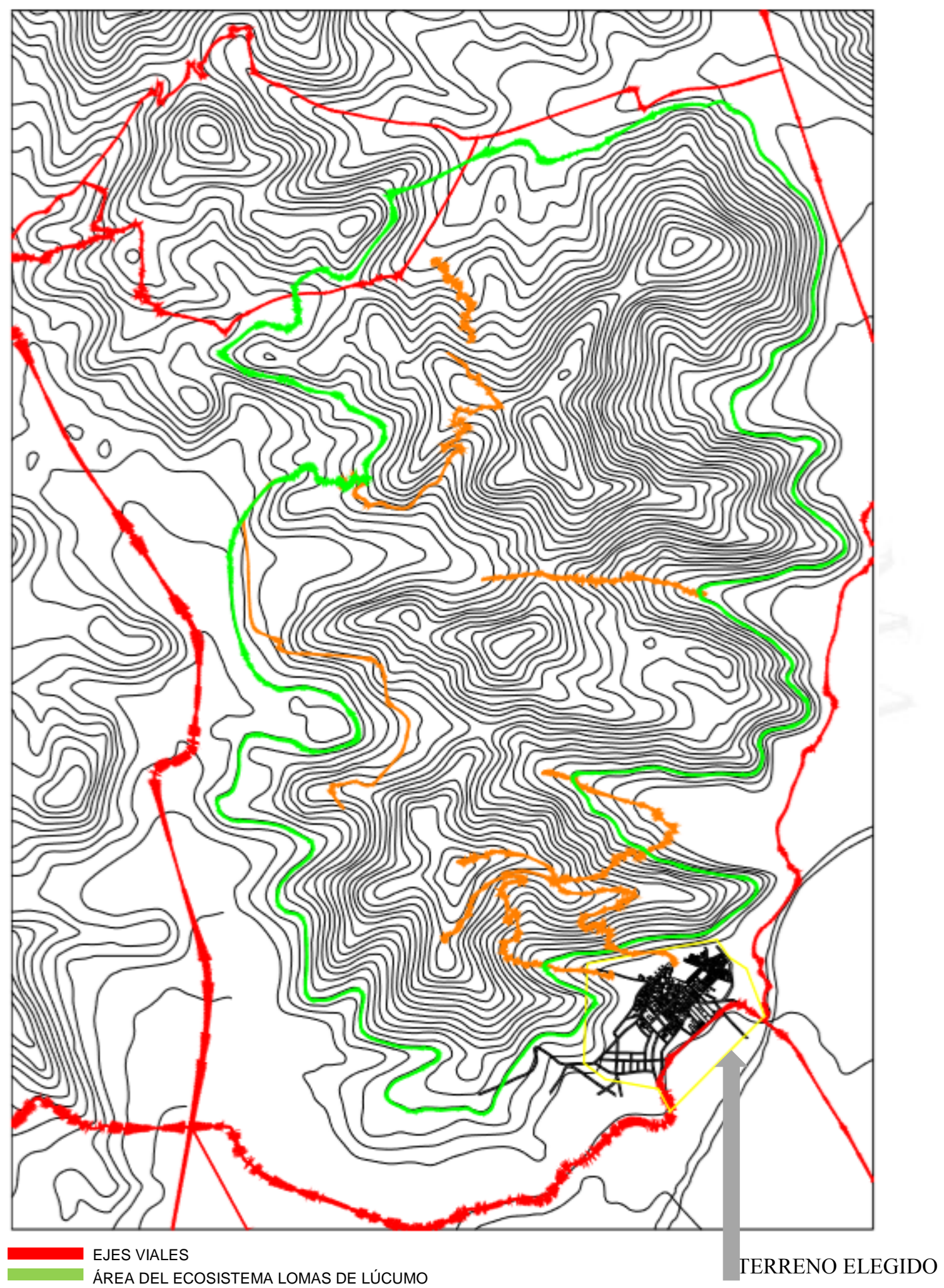

ÁREA DEL ECOSISTEMA LOMAS DE LÚCUMO

Elaboración propia 
Figura 6.21 Plano del área de estudio con cotas de nivel a escala macro

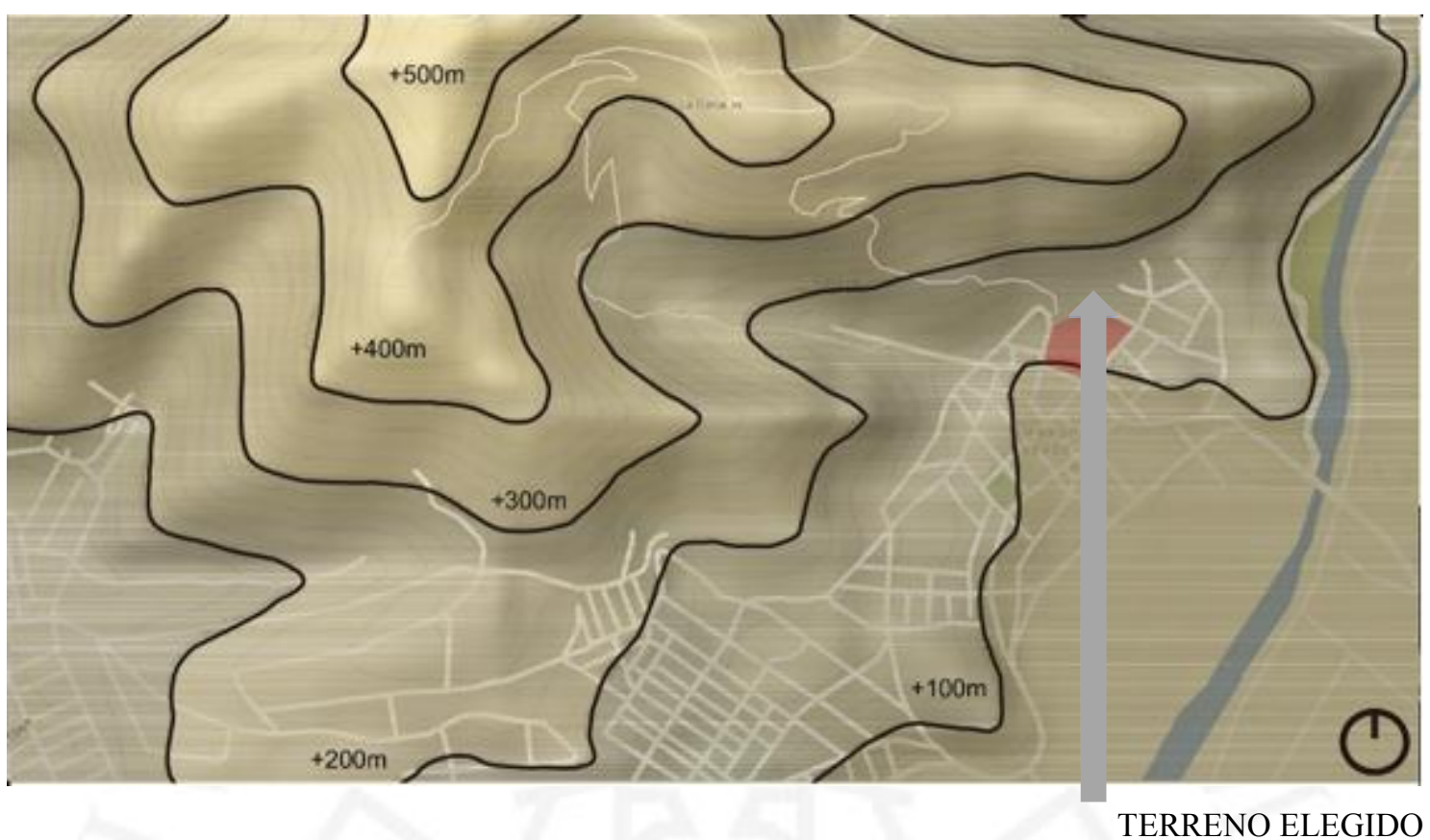

Elaboración propia

Figura 6.22 Plano detallado de las condiciones morfológicas del terreno

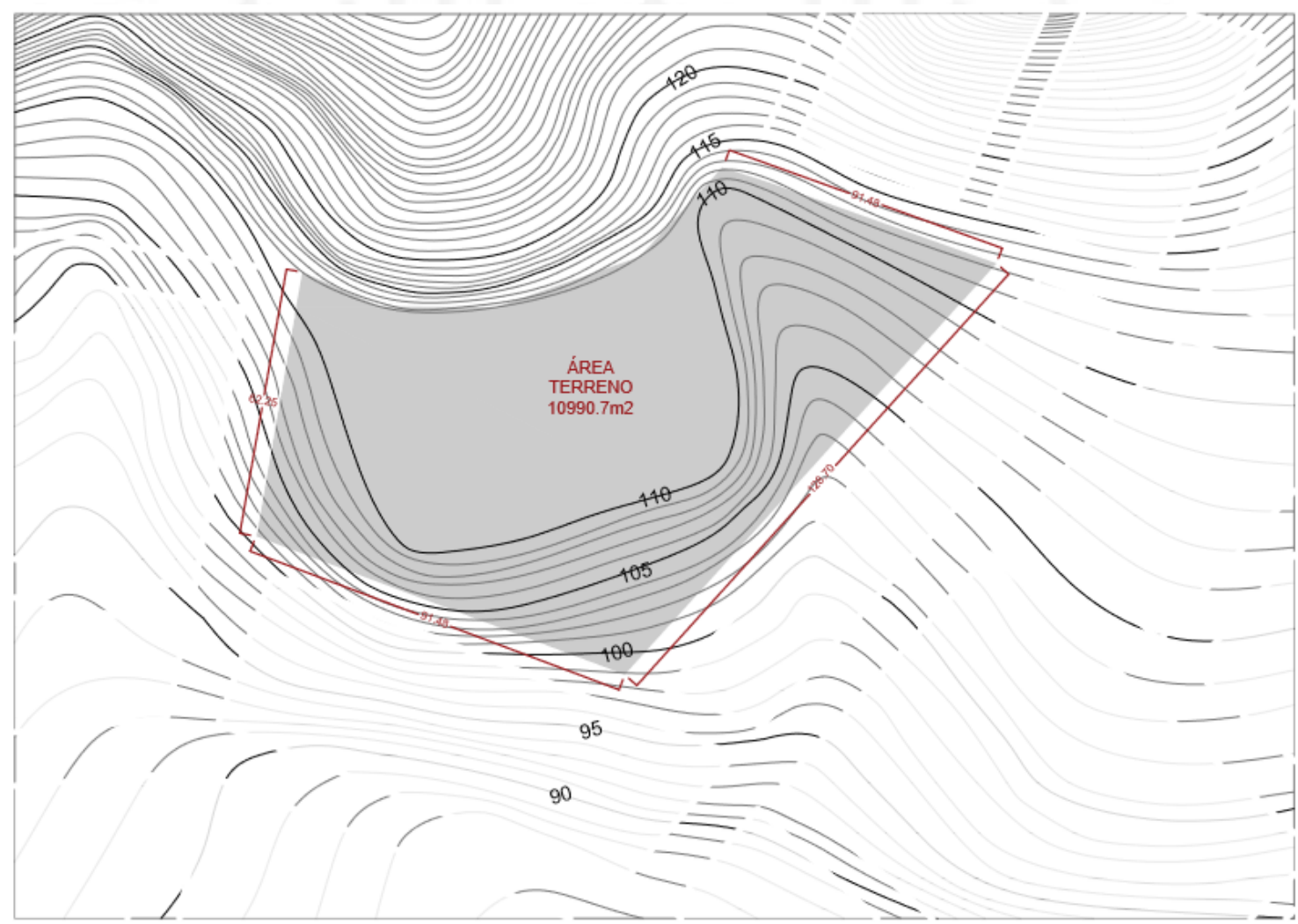

Elaboración propia 


\subsubsection{Percepción}

A continuación se muestran vistas fotográficas del terreno que será parte del equipamiento urbano a desarrollar, en las cuales se puede percibir la precariedad de las viviendas de la zona y de sus vías de acceso, no existe contaminación visual ni ruido en el área de estudio.

Figura 6.23 Vistas fotográficas del terreno

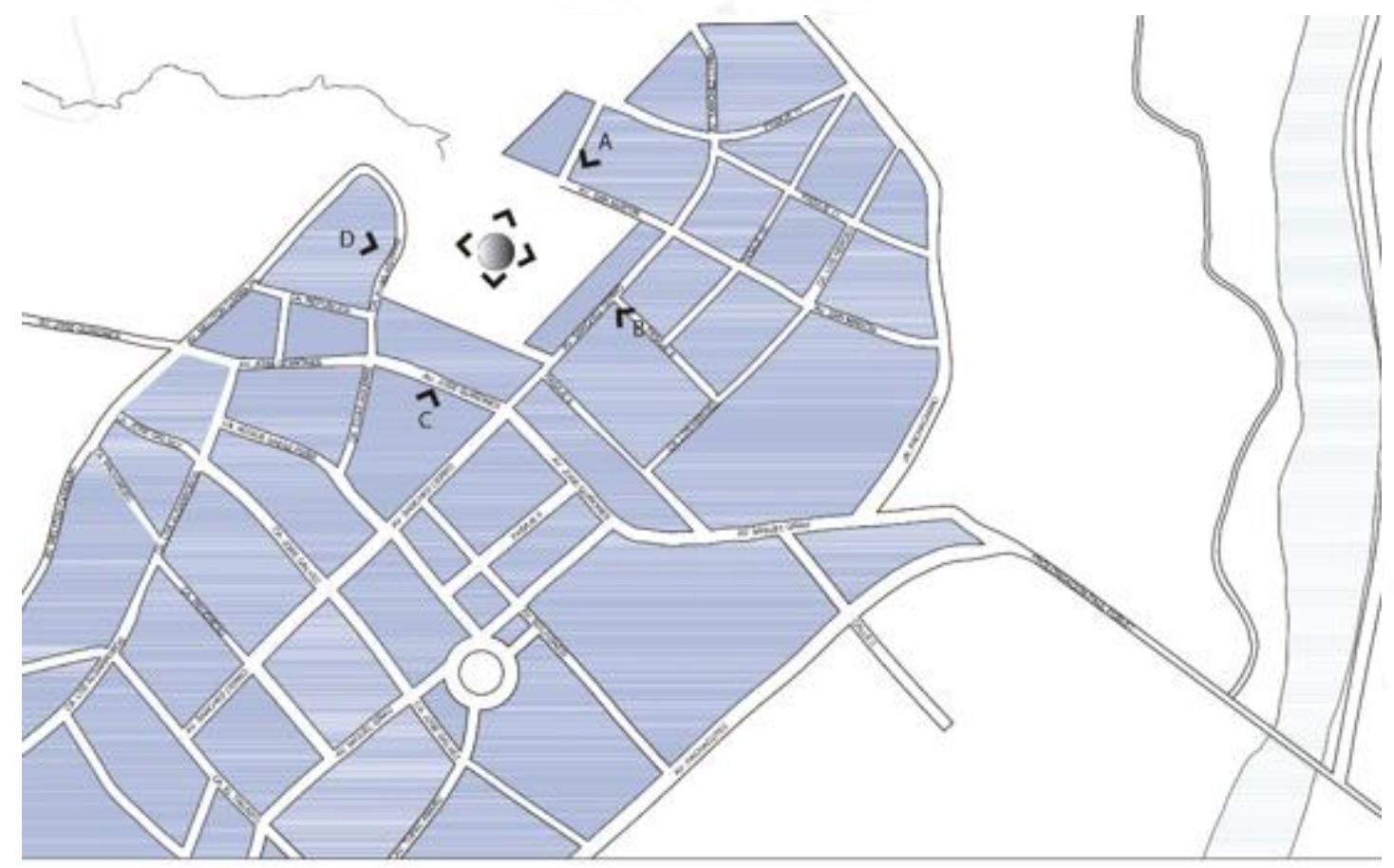

> VISTAS FOTOGRAFICAS

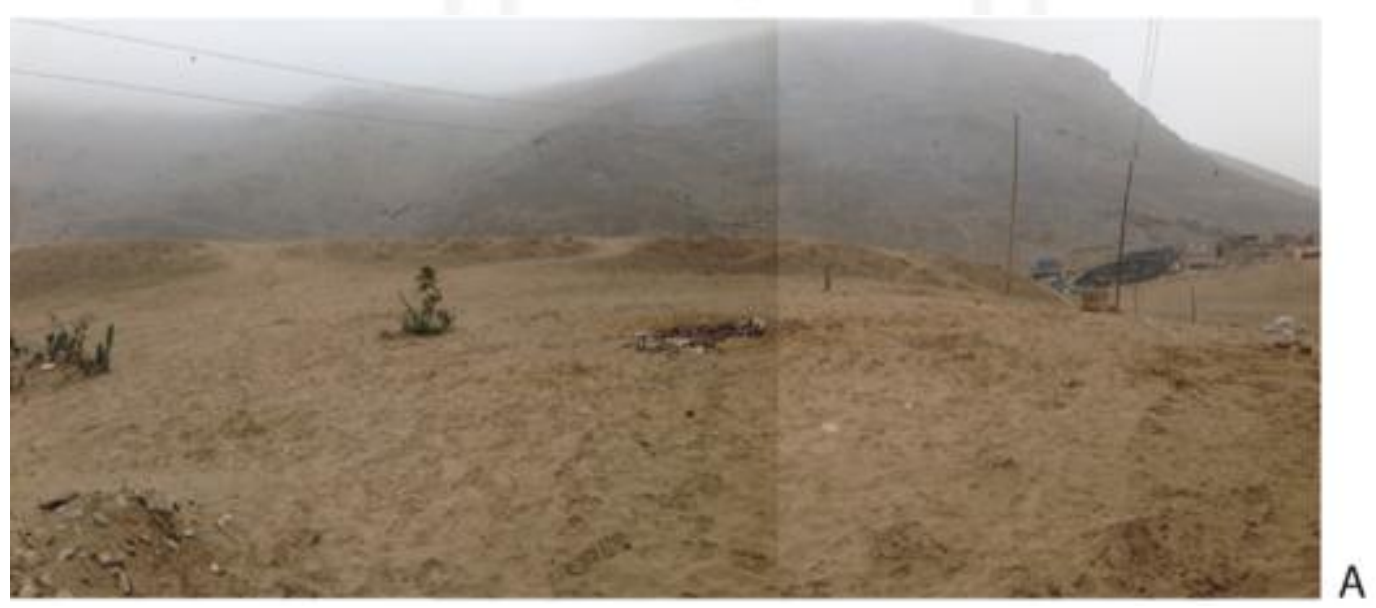



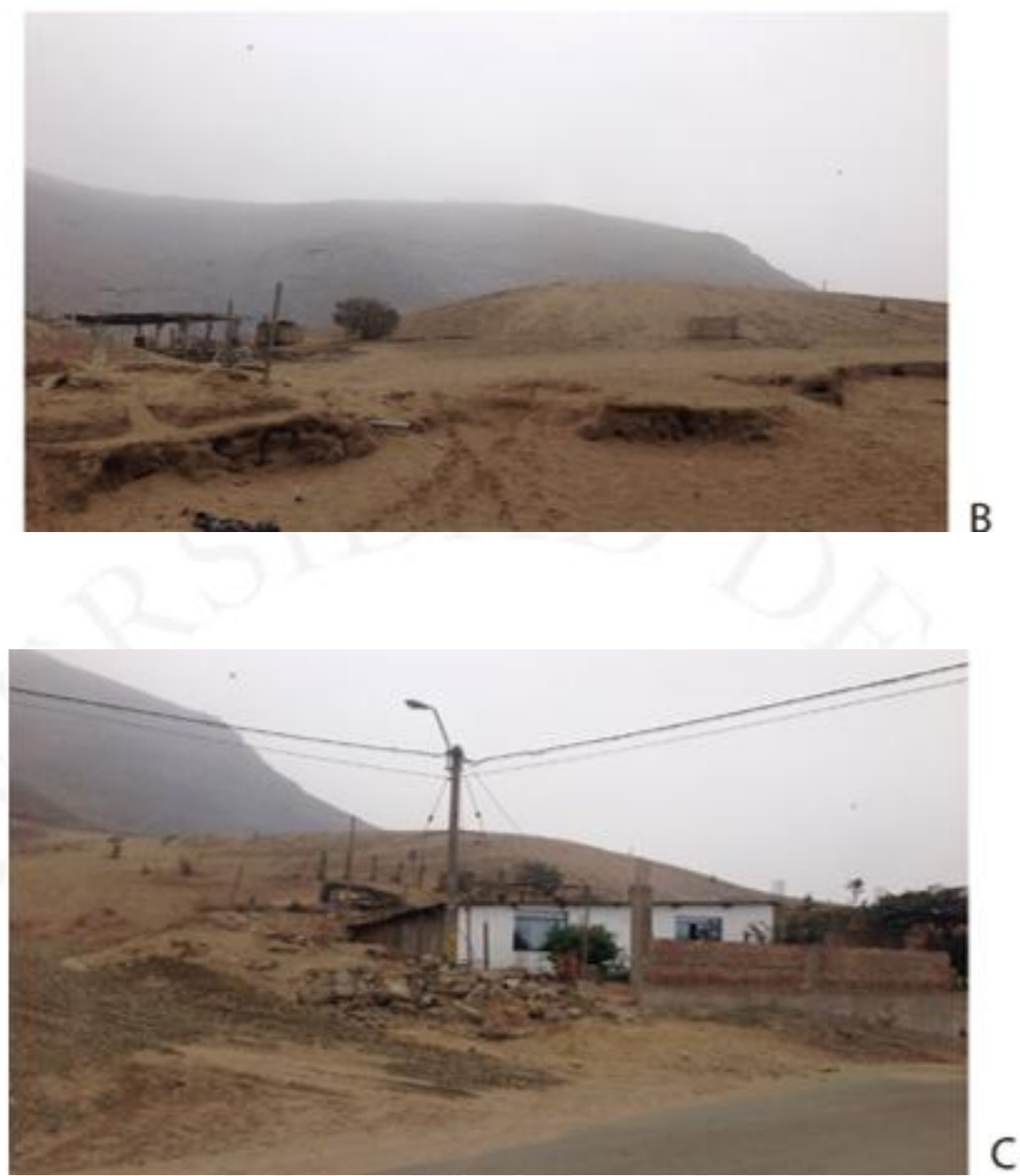

Fuente propia

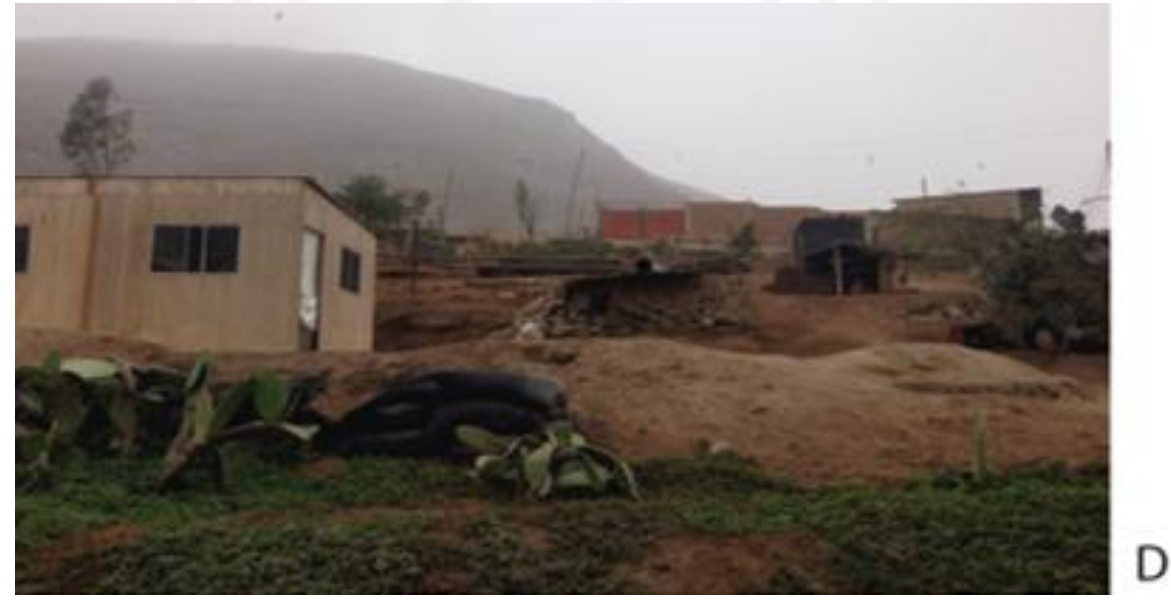


Figura 6.24 Vista fotográfica de Quebrada Verde desde el terreno

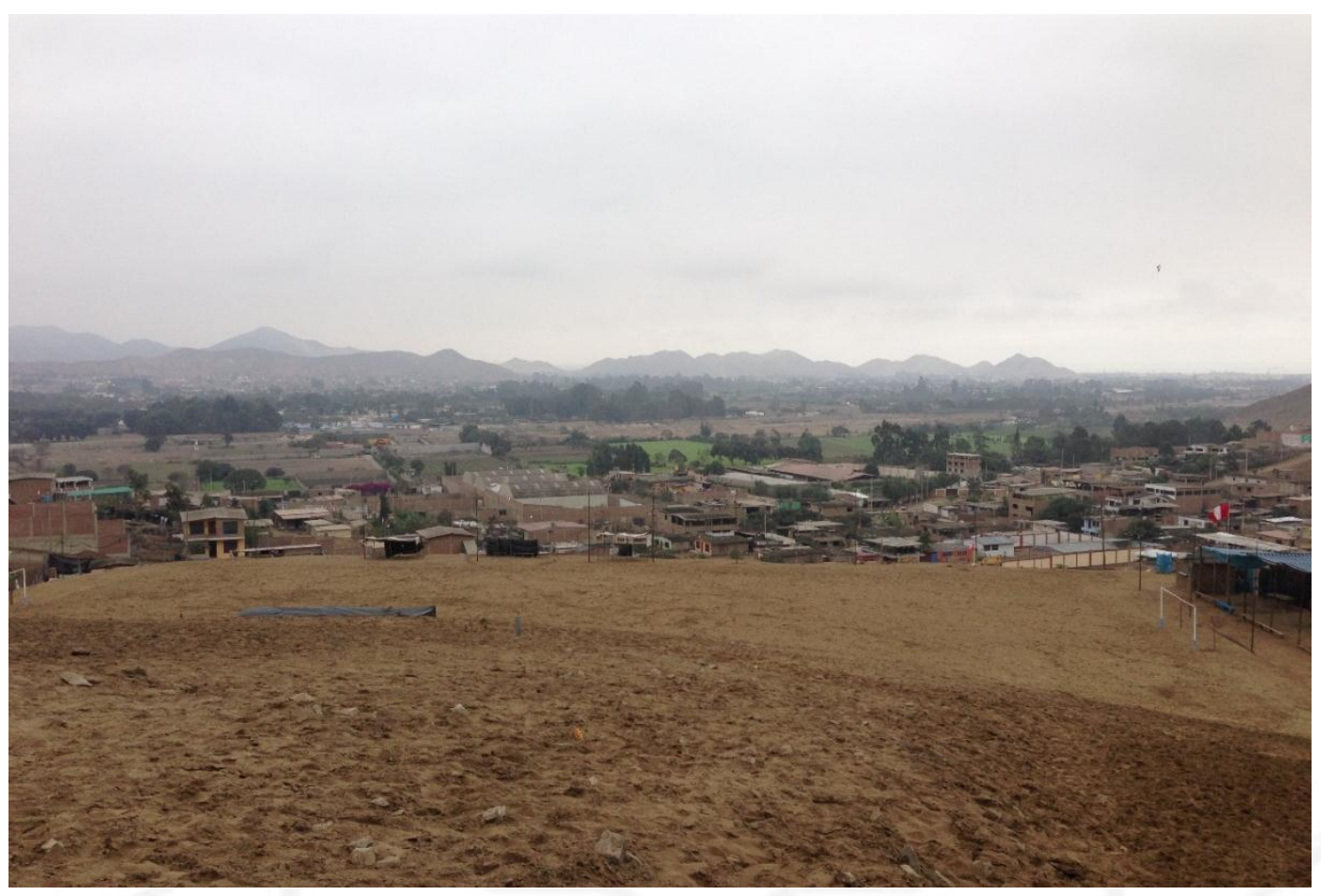

Fuente propia

Figura 6.25 Vista fotográfica del terreno desde las Lomas de Lúcumo

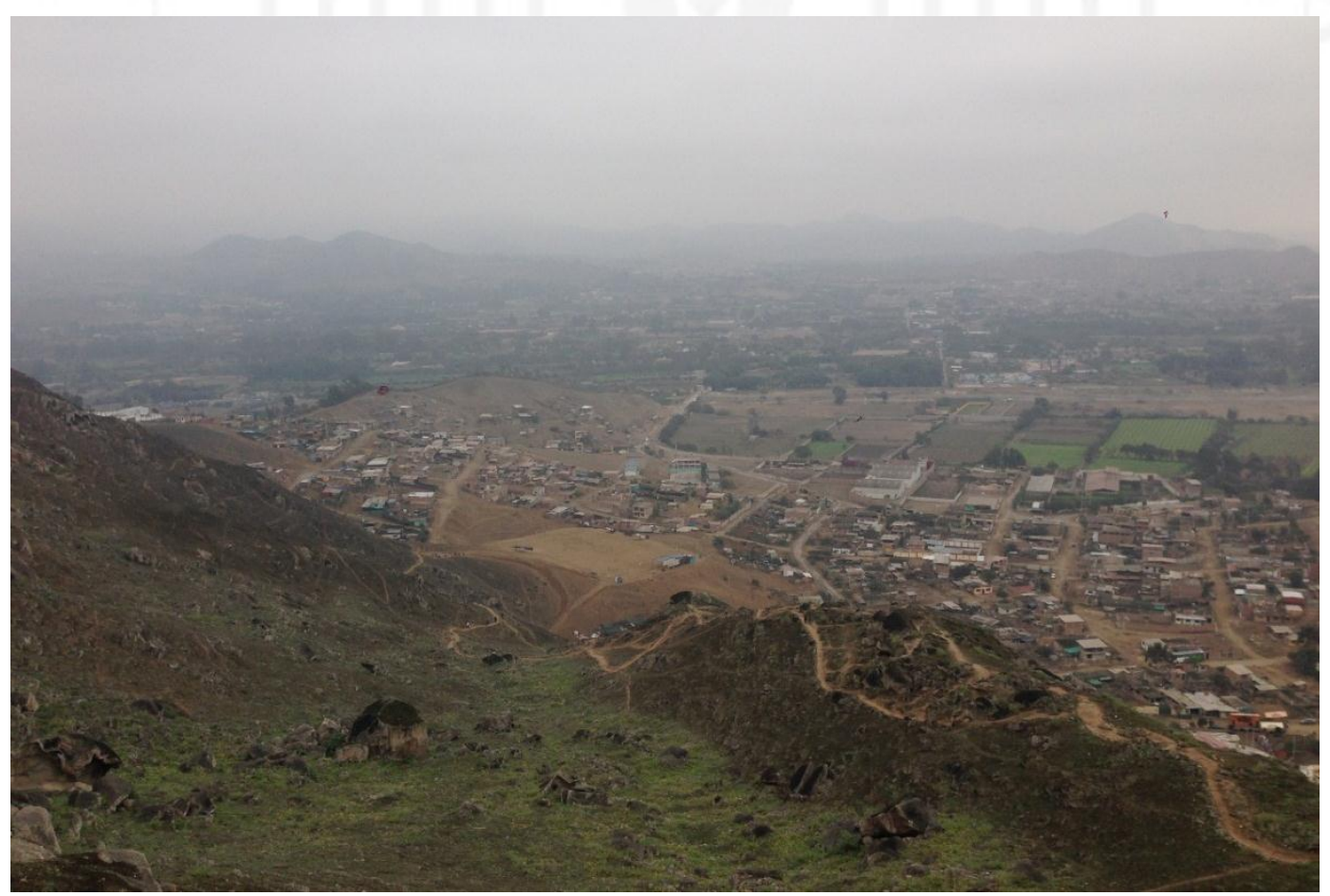

Fuente propia 
Figura 6.26 Vista fotográfica del terreno desde las Lomas de Lúcumo

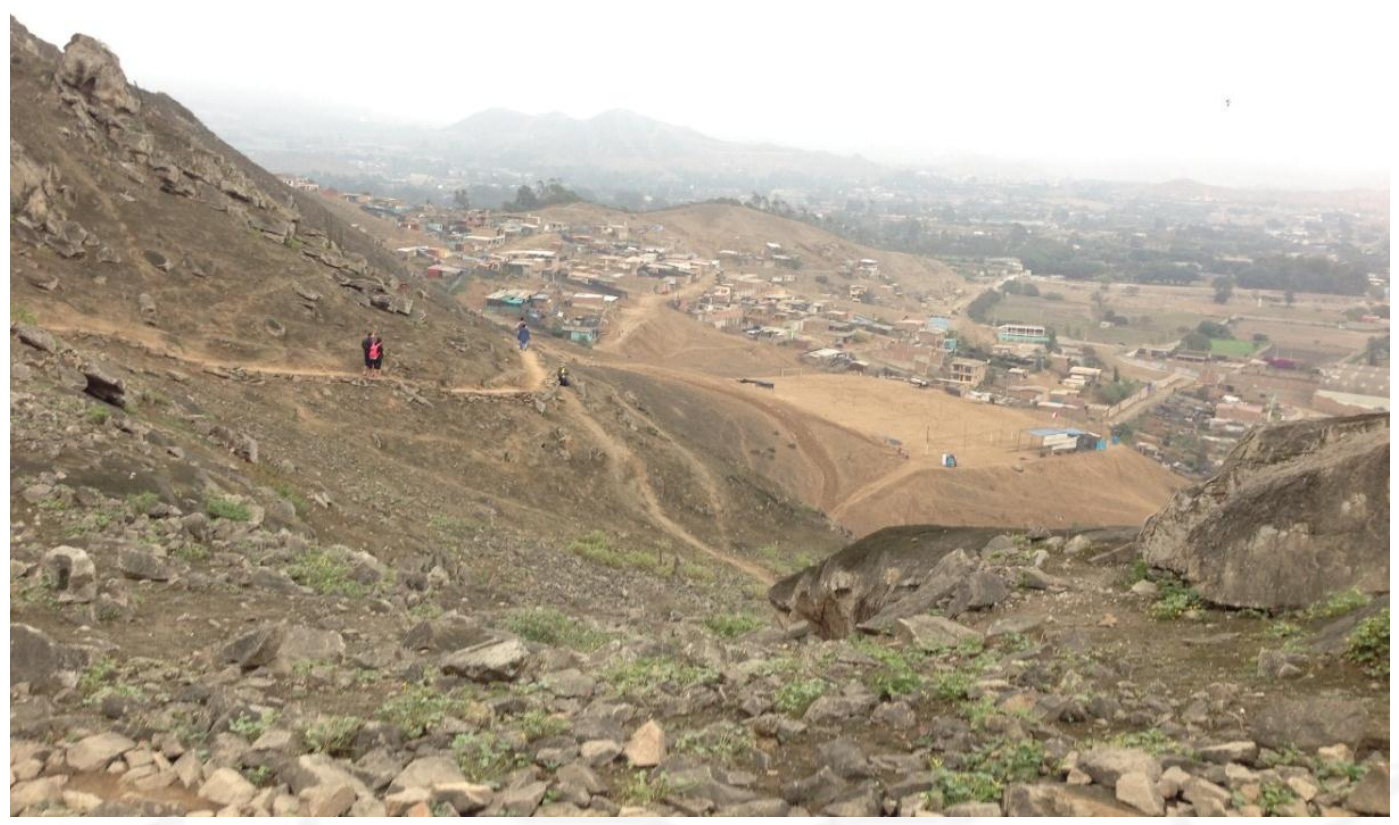

Fuente propia

Figura 6.27 Vista fotográfica del terreno desde las Lomas de Lúcumo

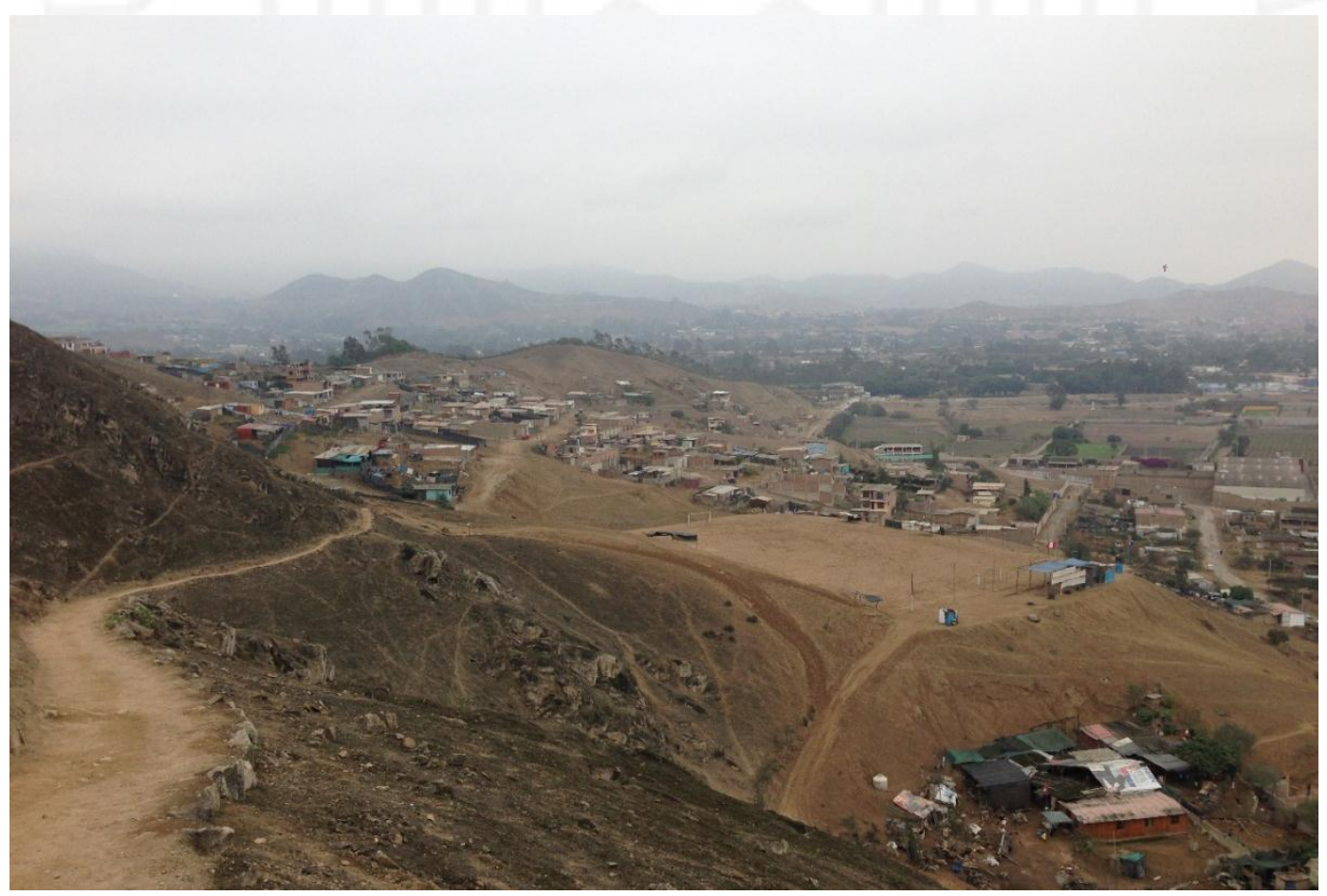

Fuente propia 


\subsection{Redes de equipamiento y radio de influencia}

Se establecieron distintas redes de equipamiento, entre ellas la comercial que incluía a los mercados más cercanos pertenecientes al distrito a los que se les podría abastecer de la producción del CETPRO; se definió también la red educativa que incluía a los colegios de educación secundaria del distrito que representan nuestro principal público objetivo; la red turística que incluye a las Lomas aledañas al área de estudio donde podría replicarse el proyecto y establecer un circuito turístico de mayor extensión; la red agraria que involucra áreas agrícola de gran extensión, siendo los agricultores también a parte del público objetivo de la institución y finalmente se determinó la red de equipamiento formada por los centros poblados cercanos a Quebrada Verde que limitan con el Ecosistema de Lomas para incentivarlos a compartir las políticas de preservación de este ecosistema e incluirlos en su gestión.

Figura 6.28 Redes de equipamiento en el distrito de Pachacamac

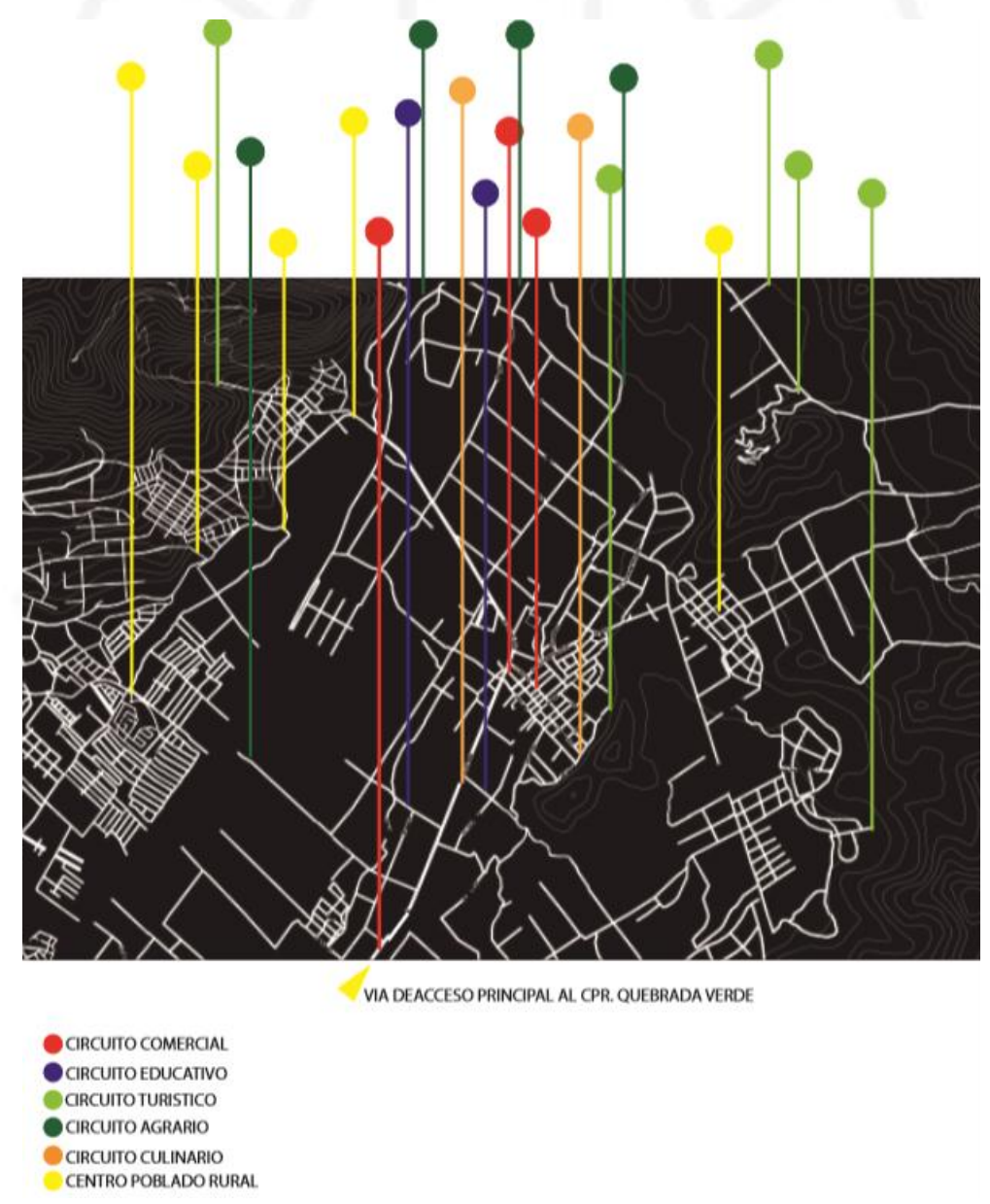

Elaboración propia 
Figura 6.29 Fotografías de las Redes de equipamiento en el distrito de Pachacamac
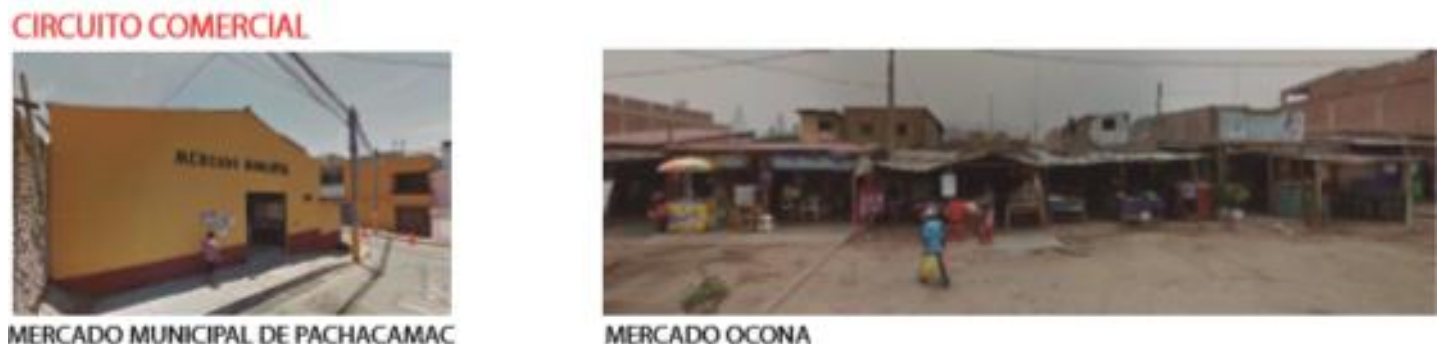

MERCADO OCONA

\section{CIRCUITOEDUCATIVO}
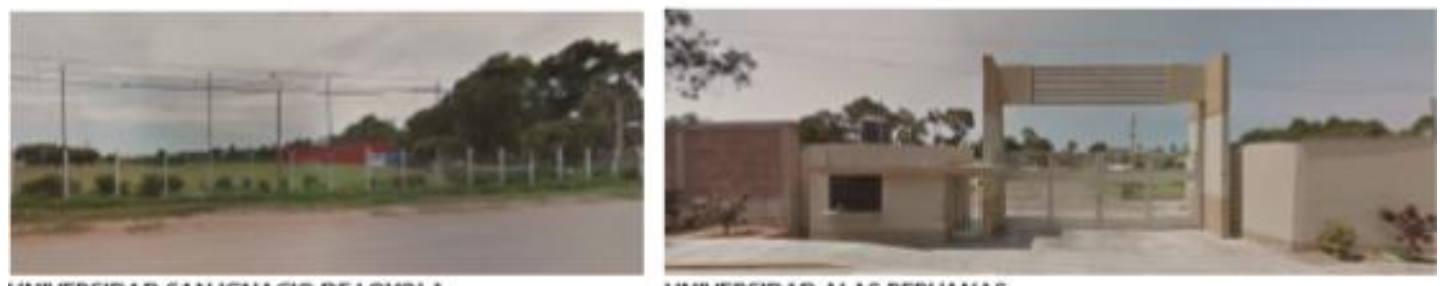

UNIVERSIDAD SAN IGNACIO DE LOYOLA

UNIVERSIDAD ALAS PERUANAS

\section{CIRCUITOTURISTICO}
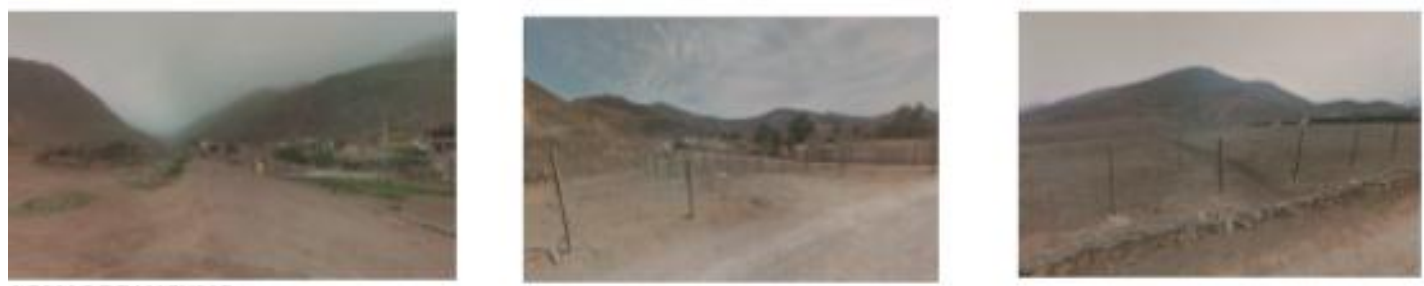

LOMAS DE LUCUMO

\section{CIRCUITO AGRARIO}

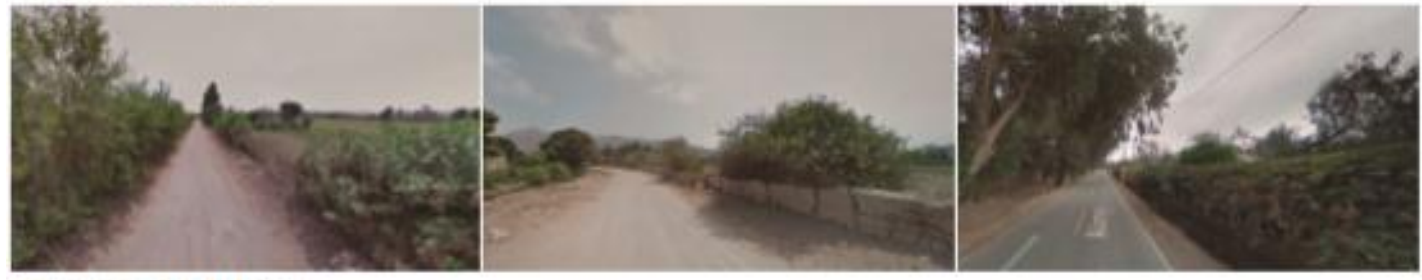

CIRCUITO CULINARIO

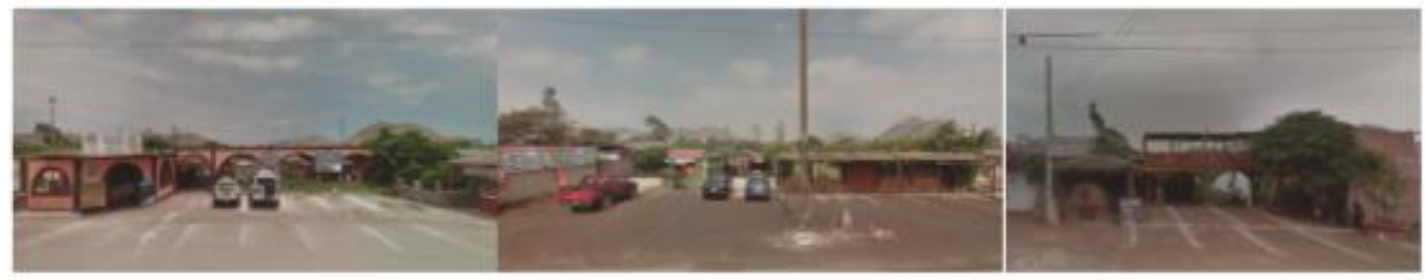

Elaboración propia

\subsection{Variables del lugar}




\subsection{Conclusiones parciales}

Dentro del distrito de Pachacamac se sitúa el Centro Poblado Rural Quebrada Verde, donde actualmente se viene gestionando desde el año 2003 el programa de turismo comunal desarrollado por la "Asociación Circuito Ecoturístico Lomas de Lúcumo", donde se administra el circuito ecoturístico del mismo nombre el cual promueve el turismo, la cultura y sobre todo la protección del "Ecosistema Frágil Lomas de Lúcumo", fenómeno estacional presente en las regiones de la costa del Perú y Chile; provocado por los vientos alisos que traen desde la fría corriente peruana hasta esta suerte de montañas, las nubes condensadas que luego caerán en forma de rocío enverdeciendo por completo el área durante los meses de junio a noviembre, que es considerada la Temporada de Lomas, el resto del año esta región permanece con un aspecto árido.

El Centro Poblado Rural Quebrada Verde, posee variadas tipologías de vivienda, existe aún un fuerte porcentaje de construcciones precarias, de esteras y madera donde sus habitantes se dedican a la crianza de animales menores o a trabajo agrícola en las áreas cercanas al poblado, el proyecto pretende generar desarrollo local que permita mejorar las condiciones de habitabilidad de poblaciones como esta, mejorando así su calidad de vida. Se presenta como tipología también las casas huerta, vivienda comercio en algunos puntos y finalmente viviendas de exclusivo uso residencial que en su mayoría son de material noble de hasta dos pisos caracterizadas por la auto construcción.

Las condiciones climáticas del área de estudio son las correspondientes a la cuenca baja del Valle del Río Lurín donde el valor mínimo registrado es de $19^{\circ} \mathrm{C}$ y el máximo de $21.1^{\circ} \mathrm{C}$ y cuyas precipitaciones registran mayores volúmenes en los meses de diciembre a marzo y menores volúmenes de mayo a setiembre llegando incluso a $0.0 \mathrm{~mm}$.

El estudio geográfico denominado Valle del Río Lurín determinó que el tipo de suelo presente en el C.P.R. Quebrada Verde correspondía a un depósito eólico pleistocénico, siendo vulnerable a deslizamientos tras un fuertes sismos, pero que este efecto puede contrarrestarse con un proyecto de forestación y mantenimiento de andenes incaicos o la construcción de nuevos andenes agrícolas en las áreas con mayor peligro. 
Con respecto a la normativa y parámetros del lugar, es importante resaltar que el terreno elegido para el desarrollo del proyecto no cuenta con zonificación ni parámetros urbanos, pues en el plano del distrito se considera a todo Quebrada Verde con la denominación de Centro Poblado Rural, especificando únicamente que no se pueden realizar construcciones por encima de los dos niveles, que el área libre debe cubrir el $40 \%$ del área del terreno y que los demás parámetros que limitan las construcciones deberán estar regidos al Reglamento Nacional de Edificaciones.

Sobre la legalidad y propiedad del terreno, se debe señalar que ésta es de dominio comunal, sin embargo ha venido por muchos años siendo destinada a área deportiva, es por esta razón que el proyecto contempló conservar la esencia de este espacio, y además dotarlo de equipamiento; su carácter seguirá siendo público y de gestión comunal.

Los resultados obtenidos tras el análisis de usos de suelo en Quebrada Verde exponen el déficit de equipamiento urbano en el Centro Poblado, se observa entonces que no existen en el radio de influencia instituciones dedicadas a la educación superior, que la población utiliza el turismo, la ganadería y sobre todo la agricultura como actividades productivas, sectores que pueden potenciar su desarrollo mediante el equipamiento urbano propuesto en la presente investigación.

El terreno se ubica justo al final del Circuito Ecoturístico Lomas de Lúcumo, el cual se observa no está definido en relación al sendero de circulación de salida del mismo, siendo entonces los usuarios los que eligen por donde ir; sería importante entonces que el proyecto pueda definir el fin del circuito, que sea un remate donde se sienta la transición entre la naturaleza y la ciudad; localizando el proyecto en esta área se asegura además que el turista lo incluya en su recorrido, observe con detenimiento que procesos se realizan en su interior y pueda finalmente adquirir los productos elaborados por el Centro Técnico Productivo, contribuyendo así al desarrollo local de la población.

El área del terreno es de $10990.7 \mathrm{~m} 2$, casi un aproximado de 1.1 hectáreas la pendiente del terreno va desde la cota 100 hasta la 110, cuenta además con un área llana que contempla el $40 \%$ de su área, su forma constituye un pentágono irregular con acceso a vías desde todos los lados de su perímetro. 
Se establecieron distintas redes de equipamiento, entre ellas la comercial que incluía a los mercados más cercanos pertenecientes al distrito a los que se les podría abastecer de la producción del CETPRO; se definió también la red educativa que incluía a los colegios de educación secundaria del distrito que representan nuestro principal público objetivo; la red turística que incluye a las Lomas aledañas al área de estudio donde podría replicarse el proyecto y establecer un circuito turístico de mayor extensión; la red agraria que involucra áreas agrícola de gran extensión, siendo los agricultores también parte importante del público objetivo de la institución y finalmente se determinó la red de equipamiento formada por los centros poblados cercanos a Quebrada Verde que limitan con el Ecosistema de Lomas para incentivarlos a compartir las políticas de preservación de este medio e incluirlos en su gestión. 


\section{CAPÍTULO VII: CONCLUSIONES FINALES}

De la presente Investigación respecto al estudio histórico sobre Centros Técnicos Productivos, a su situación actual en el País y sobre todo en la Provincia de Lima se concluye que éstos desde su instauración como Escuela de Artes y Oficios hacia los años 1780 en Europa producto de la institución formal de los Gremios Profesionales, y tras su traslado como modalidad educativa a nuestro País hacia 1860 por parte de congregaciones católicas sufre continuos cambios hasta obtener su denominación actual, mas nunca pierde su esencia educativa dirigida a la instrucción en oficios de los sectores más vulnerables de la sociedad; es así que tras el estudio cuantitativo de los mismos se concluye que el Valle de Pachacamac es el que posee menos distritos con este equipamiento educativo aun cuando el análisis realizado lo coloca como el último valle verde de Lima, como el de mayor producción agrícola y como el lugar de numerables escenarios culturales cuyos restos arqueológicos datan desde 10000 años atrás representados por el arte rupestre realizada por los primeros pobladores de Lomas, el valle también presenta vestigios del Periodo Formativo, de la Cultura Lima, el Imperio Huari, el Señorío Ichma y hasta el Imperio Inca; siendo propiamente el distrito de Pachacamac el mayor poseedor de éstas manifestaciones culturales que representan además de su área agrícola ya mencionada y sus recursos ecológicos, importantes actividades productivas que serían potenciadas con la instalación de un Centro Técnico Productivo en este distrito.

Respecto al estudio teórico realizado sobre definiciones, conceptualizaciones y teorías instauradas que permitan desarrollar objetivamente el proyecto ubicado al linde del Ecosistema Frágil Lomas de Lúcumo y teniendo como premisa constituir un cinturón protector del mismo que compone un paisaje de borde, se ha concluido finalmente que éste no define un límite ni una barrera, si no más un espacio de transición en este caso entre lo natural y lo construido, lo que se define como borde urbano-natural. De las teorías de Kevin Lynch referidas a potenciar un espacio de borde, se tomó a la transición, de lo natural a lo construido; el arbolado, mediante la generación de borde productivo de plantaciones de lúcumo, cuya dimensión de su copa marcará un claro borde entre el ecosistema Lomas de Lúcumo y Quebrada Verde; al 
hacerlo visible a grandes distancias, el borde productivo antes mencionado delimitará la totalidad de las Lomas de Lúcumo, convirtiéndose en un referente de protección a gran escala. Del autor Gary Leggett, y su teoría de entender el borde, tanto en lo que lo une como en lo que lo separa, se basa el desarrollo de la cabida y el programa arquitectónico del proyecto. Finalmente se concluye que este borde constituye territorialmente el punto de intercambio entre ambos medios y es aquí también ocurren diversos intercambios socio-ecológicos siendo determinante promover las condiciones para que se desarrollen espontáneamente éstas interacciones llevando a construir una nueva identidad alimentada por ambos escenarios, lo que ayudará en la formación de una percepción colectiva del paisaje pues éste finalmente es una apreciación subjetiva de una realidad sustentada sobre características intrínsecas a cada individuo respecto a su formación, cultura y educación.

Sobre el estudio de las normas y Reglamentos establecidod por el Ministerio de Educación y el Ministerio de Vivienda se concluye que la ubicación de éste equipamiento educativo denominado Centro Técnico Productivo debe tener en cuenta que el área pueda acceder a la dotación de servicios básicos requeridos, que la población pueda llegar sin problemas al mismo, que considere en su diseño áreas de futura expansión, que la iluminación y ventilación hayan sido diseñadas sobre un análisis de condiciones ambientales previo, que las vías de acceso posean las dimensiones suficientes para el ingreso de las entidades responsables de solucionar alguna emergencia y que el terreno no constituya un área vulnerable frente a un potencial desastre natural. Por las condiciones que posee el distrito inicialmente mencionadas, se considera de gran importancia gestionar o mantener una alianza según sea el caso con las siguientes instituciones, como Ministerio de Educación, Ministerio de Cultura, Ministerio del Ambiente, Ministerio de Agricultura, Municipalidad de Pachacamac, con la Asociación Circuito Ecoturístico Lomas de Lúcumo y con el Grupo GEA, el principal promotor del turismo comunal en el distrito.

En cuanto al estudio de casos análogos al presente proyecto de investigación se concluye que su ubicación, que es un patrón constante en éste tipo de equipamiento educativo situarse cerca a áreas denominadas marginales y los oficios en los que éste instruye a la población están directamente ligados a los recursos propios del lugar, respecto al análisis del programa se identifica que el área de talleres que precisamente 
constituye la instrucción práctica del oficio, son las de mayor número y dimensión, que también cuentan con áreas de complemento educativo como bibliotecas, auditorio y salas de exposición y el material de sus edificaciones es el recurso constructivo inmediato, siendo en varios casos la misma población partícipe de la construcción del proyecto. Del estudio de referentes relacionados a las estrategias proyectuales se concluye que al estar situados dentro de un contexto natural y sobre una pendiente pronunciada, la finalidad arquitectónica siempre es lograr una relación sutil entre arquitectura y paisaje en base a la topografía, donde ninguno compita ni se interponga, al contrario la lectura debería ser la de un todo, basándonos en estrategias de permeabilidad, transición y continuidad.

Del estudio del lugar donde se desarrolla el presente trabajo de tesis ubicado en el distrito de Pachacamac, dentro del Centro Poblado Rural Quebrada Verde exactamente al final del Circuito Ecoturístico Lomas de Lúcumo se concluye que el lugar cumple con todos los requerimientos antes estudiados para la instauración y desarrollo de un Centro Técnico Productivo, ya que su entorno está dotado de potenciales recursos productivos, como el turismo, la agricultura, la historia y la cultura, los cuales alcanzarían mayor desarrollo si se formara en oficios afines que garanticen la gestión y un mejor manejo de los mismos a fin de promover el desarrollo local del Centro Poblado el cual presenta índices de calidad de vida muy por debajo del promedio establecido. 


\section{CAPÍTULO VIII: PROYECTO}

\subsection{Estrategias proyectuales}

\subsubsection{Nivel Macro}

El diseño del proyecto arquitectónico responde al análisis de las variables del lugar realizado en la presente investigación, es así que con respecto a las condiciones medio ambientales se consideró la siguiente ubicación de los volúmenes teniendo en cuenta la dirección e intensidad del viento registrada y el recorrido solar, estableciendo el primero la ubicación de un volumen programático que tendrá la función de corta vientos y el segundo la ubicación más favorable del programa educativo a fin de que la iluminación que reciba sea difusa y no directa.

Figura 8.1 Asoleamiento y vientos

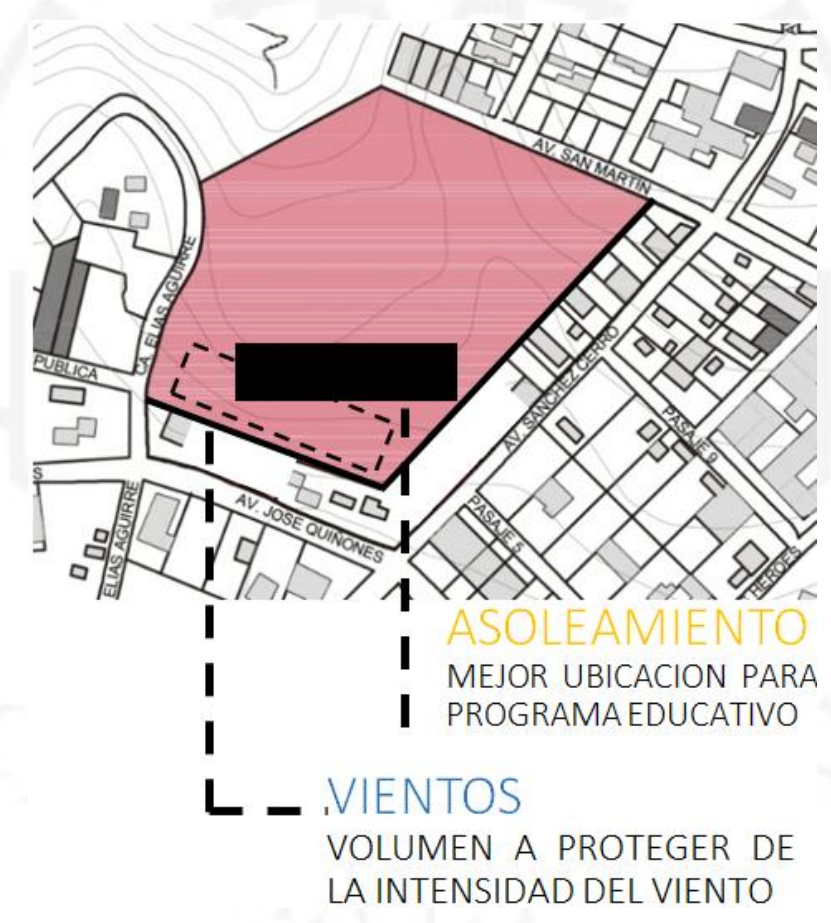

Elaboración propia

El análisis de la vulnerabilidad del suelo presente en el área de estudio determinó que existía un posible riesgo de deslizamiento frente a un eventual sismo, siendo la reforestación y la construcción de andenes productivos la estrategia planteada a fin de contrarestar este peligro. 
Figura 8.2 Vulnerabilidad del suelo

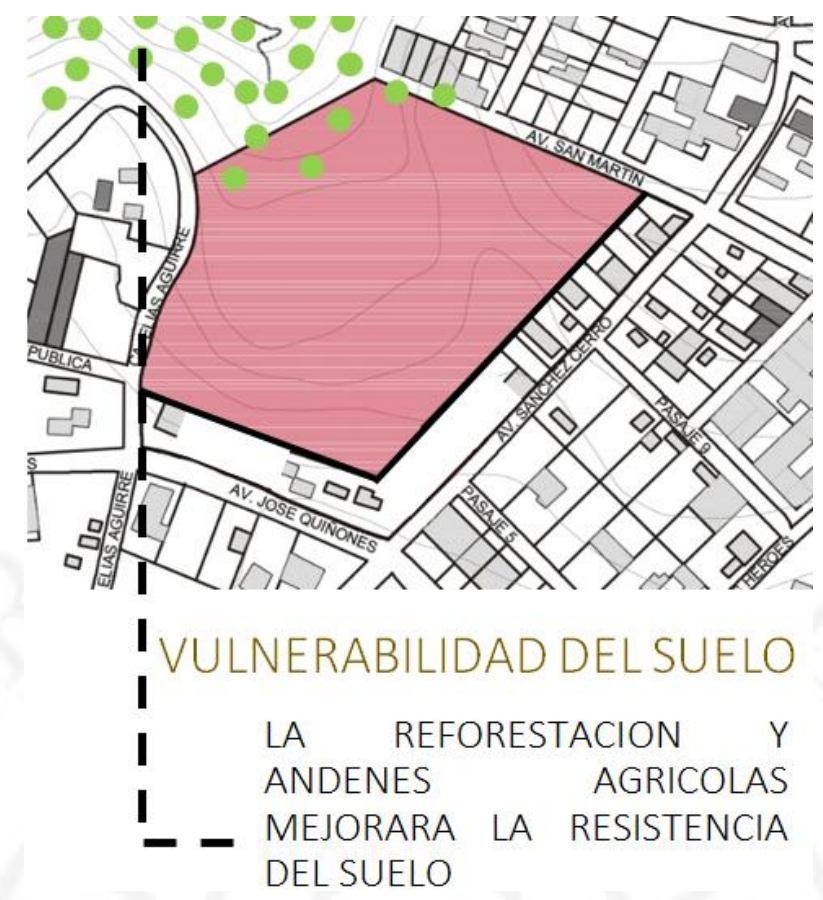

Elaboración propia

Al ubicarse el proyecto sobre una topografía cambiante y pronunciada al igual que los referentes estudiados, el diseño replica la estrategia paisajista de seguir la topografía, y adecuarse a ella de tal forma que se pueda percibir que el volumen nace de la misma.

Figura 8.3 Topografía del terreno

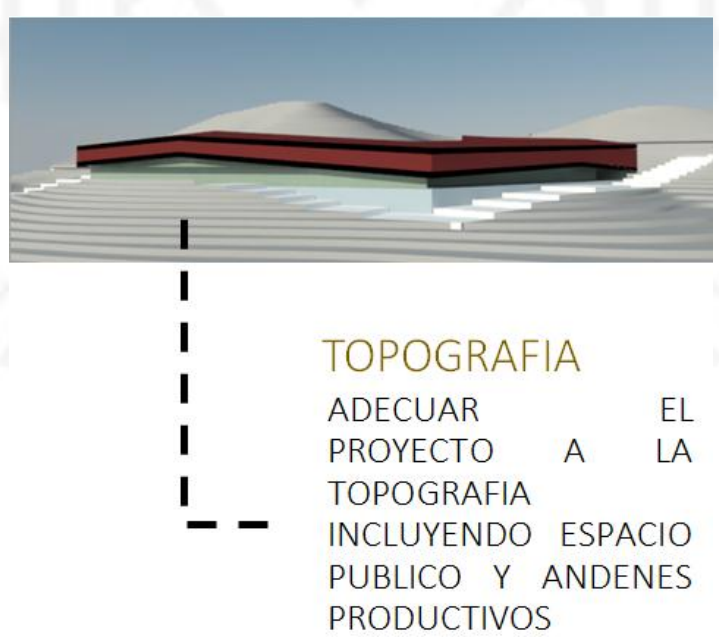

Elaboración propia

El estudio a nivel macro del Ecosistema Lomas de Lúcumo identificó que éstas son vulnerables frente a una posible expansión urbana en las laderas de la misma, 
promovida por agentes externos a las poblaciones aledañas, a esta preocupante amenaza se le suma la cercana extracción de recursos para la construcción por parte de Cementos Lima, ambas condiciones representan un peligro latente para la continuidad de este ecosistema estacional; ante esta problemática se planteó como estrategia proyectual demarcar los límites de las Lomas de Lúcumo en su totalidad para establecer los puntos claros de expansión urbana. Ésta área representará un espacio de transición entre la ciudad y este ecosistema, se lo ha denominado borde y si bien pretende ser un cinturón de protección, no deberá percibirse como un límite ni una barrera, al contrario será un espacio de interacción entre el hombre y la naturaleza no solo territorialmente sino también en todos los ámbitos que impliquen las relaciones establecidas entre ambos elementos.

Figura 8.4 Propuesta a nivel macro

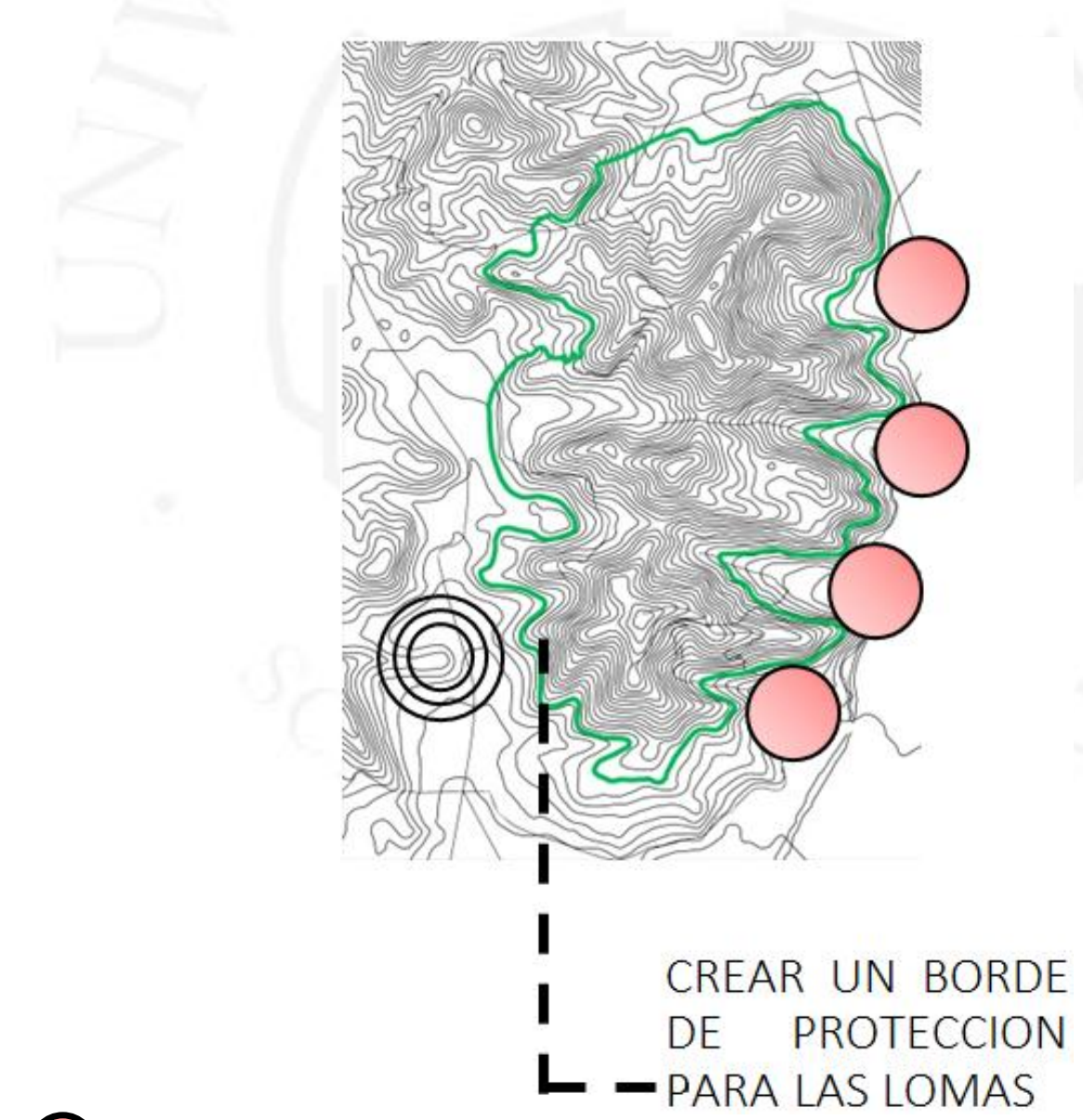

CENTRO POBLADO RURAL

ZONA DE EXTRACCIÓN DE RECURSOS

Elaboración propia 
Para que este gran borde verde pueda hacerse realidad es necesario un sistema de irrigación que permita abastecer la producción de Lúcuma y el funcionamiento de andenes de cultivo con fines educativos dispuestos al borde de la Loma. Por esta razón se determinó un punto de extracción de agua del Río Lurín, la principal fuente natural de este recurso que abastece la zona. Dicha extracción se realizaría en el Puente Manchay ubicado a 200 m.s.n.m donde también hay un ecosistema de Lomas, la población de este Centro Poblado Rural utilizaría el recurso para replicar el proyecto dado que en esta zona existen similares condiciones ambientales y socioeconómicas; el agua se canalizaría hasta llegar al área de protección por todo el borde de la misma, llegando incluso a ser parte del volumen arquitectónico más alto a $126 \mathrm{~m} . \mathrm{s} . n . m$ con el fin de no interrumpir su continuidad y que se siga percibiendo este gran cinturón verde .

Cuadro 8.1 Características de la cuenca del río Lurín

\section{CARACTERÍSTICAS DE LA CUENCA DEL RÍO LURIN}

\begin{tabular}{|c|c|c|c|c|c|c|}
\hline Nombre & código & $\begin{array}{c}\text { Progre- } \\
\text { siva }\end{array}$ & $\begin{array}{c}\text { Altitud } \\
\text { msnm. }\end{array}$ & $\begin{array}{r}\text { Area } \\
\mathrm{km} 2\end{array}$ & $\begin{array}{l}\text { Modulo } \\
\mathrm{m} 3 / \mathrm{seg}\end{array}$ & Lugar \\
\hline Lurin & $P-30$ & $\begin{array}{r}0 \\
17 \\
17 \\
46 \\
61 \\
67 \\
70 \\
79 \\
82 \\
105\end{array}$ & $\begin{array}{r}0 \\
200 \\
200 \\
1005 \\
1545 \\
1775 \\
2010 \\
2830 \\
2990 \\
4790\end{array}$ & $\begin{array}{r}1624 \\
1428 \\
1263 \\
928 \\
684 \\
430 \\
347 \\
266 \\
119 \\
0\end{array}$ & $\begin{array}{l}6.6 \\
6.6 \\
6.6 \\
6.5 \\
5.9 \\
4.6 \\
4.1 \\
3.7 \\
1.6 \\
0.0\end{array}$ & $\begin{array}{l}\text { d. Océano Pacifico } \\
\text { h.e.a Pte. Manchay } \\
\text { c.Q.Tinajas } \\
\text { h.e.a Antapucro } \\
\text { c.Q. Chamacha } \\
\text { c.R. Canchahuara } \\
\text { c.Q. Llacamayqui } \\
\text { h.e.a. San Damian } \\
\text { c.Q. Taquia } \\
\text { Naciente }\end{array}$ \\
\hline Qda. Tinajas & P-3001 & $\begin{array}{l}17 \\
45\end{array}$ & $\begin{array}{r}200 \\
2850\end{array}$ & $\begin{array}{c}165 \\
0\end{array}$ & $\begin{array}{l}0.0 \\
0.0\end{array}$ & $\begin{array}{l}\text { d. R. Lurfin } \\
\text { Naciente }\end{array}$ \\
\hline Qda. Chamacha & $\mathrm{P}-3002$ & $\begin{array}{l}61 \\
82\end{array}$ & $\begin{array}{l}1545 \\
4425\end{array}$ & $\begin{array}{l}88 \\
0\end{array}$ & $\begin{array}{l}0.3 \\
0.0\end{array}$ & $\begin{array}{l}\text { d.R.Lurin } \\
\text { Naciente }\end{array}$ \\
\hline Canchahuara & P-3003 & $\begin{array}{r}67 \\
102\end{array}$ & $\begin{array}{l}2775 \\
4540\end{array}$ & $\begin{array}{c}162 \\
0\end{array}$ & $\begin{array}{l}1.1 \\
0.0\end{array}$ & $\begin{array}{l}\text { d. R. Lurin } \\
\text { Naciente }\end{array}$ \\
\hline $\begin{array}{l}\text { Qda . Lla comay - } \\
\text { quí }\end{array}$ & $\mathrm{p}-3005$ & $\begin{array}{l}70 \\
82\end{array}$ & $\begin{array}{l}2010 \\
3945\end{array}$ & $\begin{array}{l}67 \\
0\end{array}$ & $\begin{array}{l}0.0 \\
0.0\end{array}$ & $\begin{array}{l}\text { d. } \mathrm{R} \text {. Lurin } \\
\text { Naciente }\end{array}$ \\
\hline Qda.Taquía & $P-3007$ & $\begin{array}{r}82 \\
103\end{array}$ & $\begin{array}{l}2990 \\
4590\end{array}$ & $\begin{array}{c}125 \\
0\end{array}$ & $\begin{array}{l}1.8 \\
0.0\end{array}$ & $\begin{array}{l}\text { d.R. Lurín } \\
\text { Naciente }\end{array}$ \\
\hline
\end{tabular}

Fuente: $\underline{\text { http://repositorio.ana.gob.pe }}$ 
Figura 8.5 Ubicación del Puente Manchay

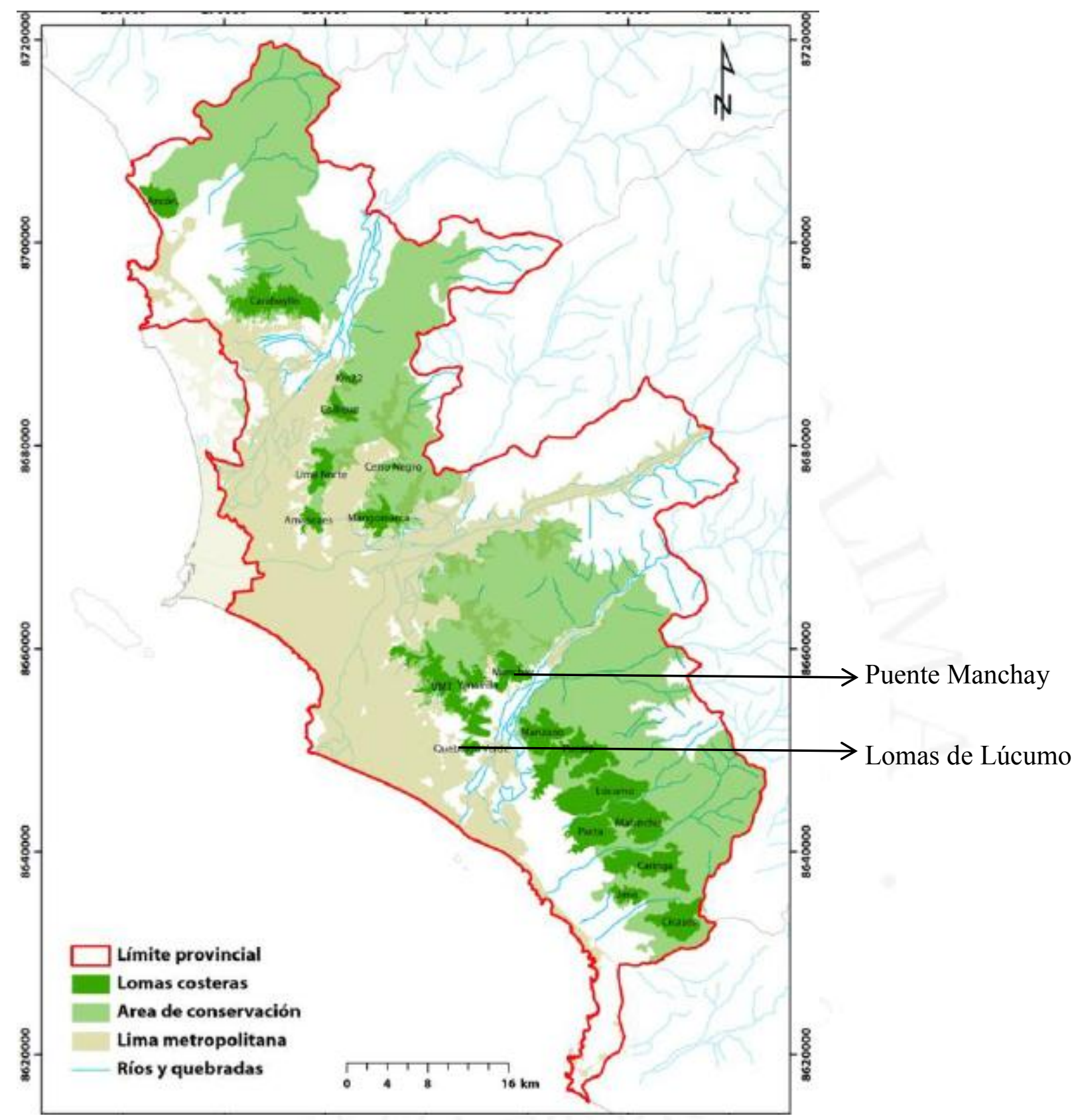

Fuente: http://repositorio.ana.gob.pe

Como propuesta arquitectónica a nivel macro se establece que el Centro Técino Productivo Lomas de Lúcumo sea parte de éste gran cinturón verde de protección pero no representando un límite, si no un borde. 
Figura 8.6 Estrategia proyectual macro

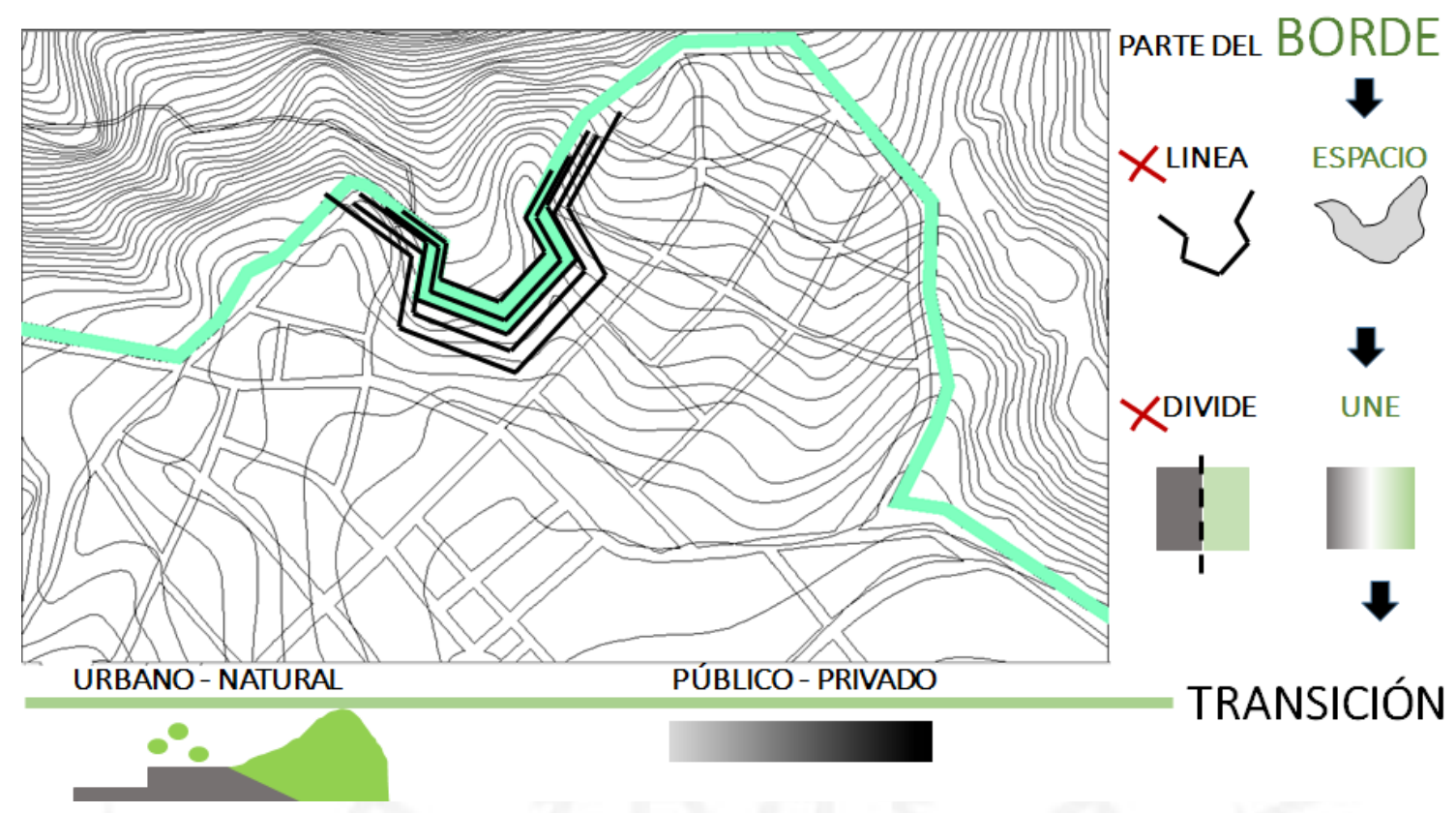

Elaboración propia

Los ingresos peatonales y vehiculares al proyecto han sido determinados por el estudio de transitabilidad vial, los flujos y dinámicas establecidas dentro de la comunidad, determinando la siguiente ubicación de los mismos.

Figura 8.7 Análisis de factibles puntos de ingreso al proyecto

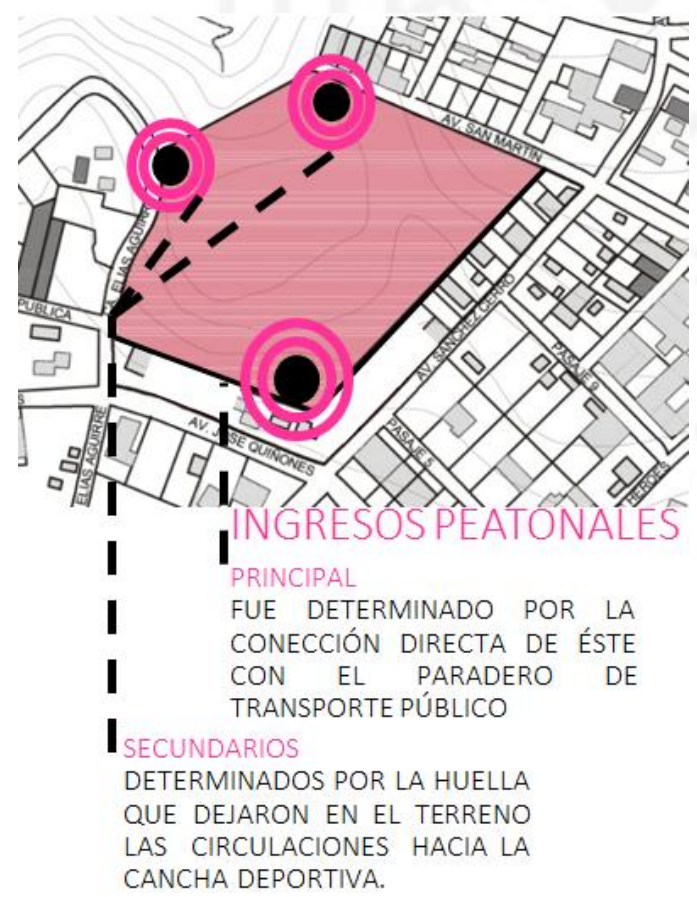

Elaboración propia 
Actualmente el terreno cuenta con una cancha de futbol de arena y equipamiento muy precario, se determinó como estrategia mantenerla aunque no en sus dimensiones actuales y dotarla de infraestructura deportiva complementaria.

Figura 8.8 Propuesta para equipamiento deportivo

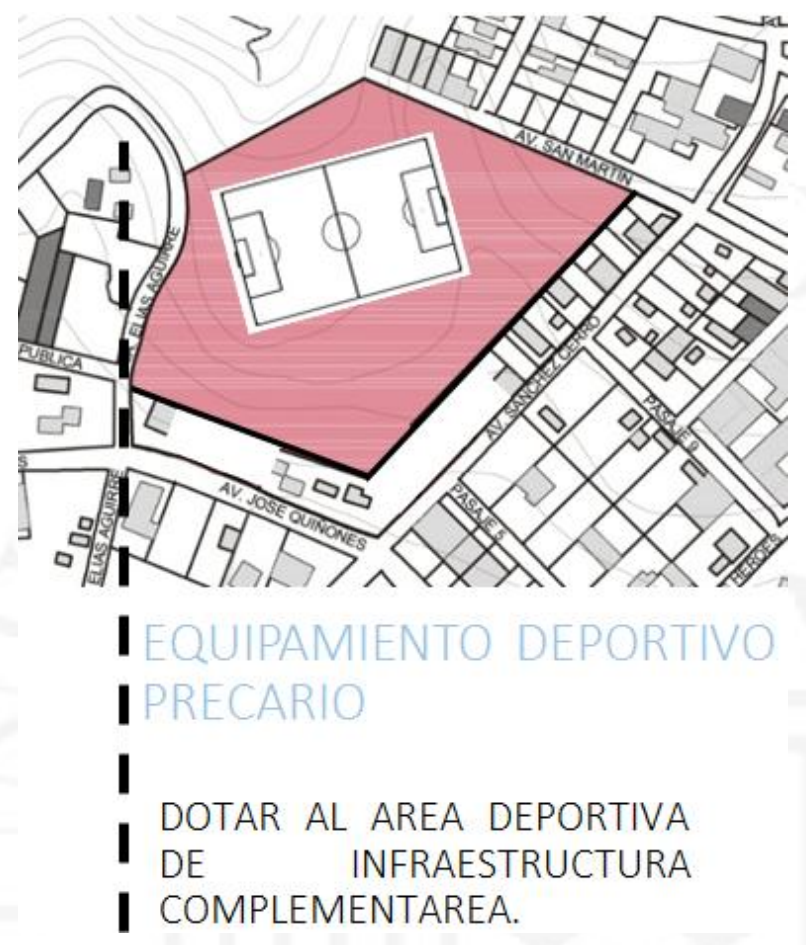

Elaboración propia 


\subsubsection{Nivel Proyecto}

Como propuesta a nivel macro el proyecto pretende constituir un borde de protección hacia las Lomas, este elemento arquitectónico debería percibirse parte del ecosistema, de la naturaleza del lugar. Eso me llevó a analizar que ocurría exactamente en su entorno y observarlo desde distintas escalas.

Figura 8.9 Análisis de Ecosistema Lomas de Lúcumo a gran escala

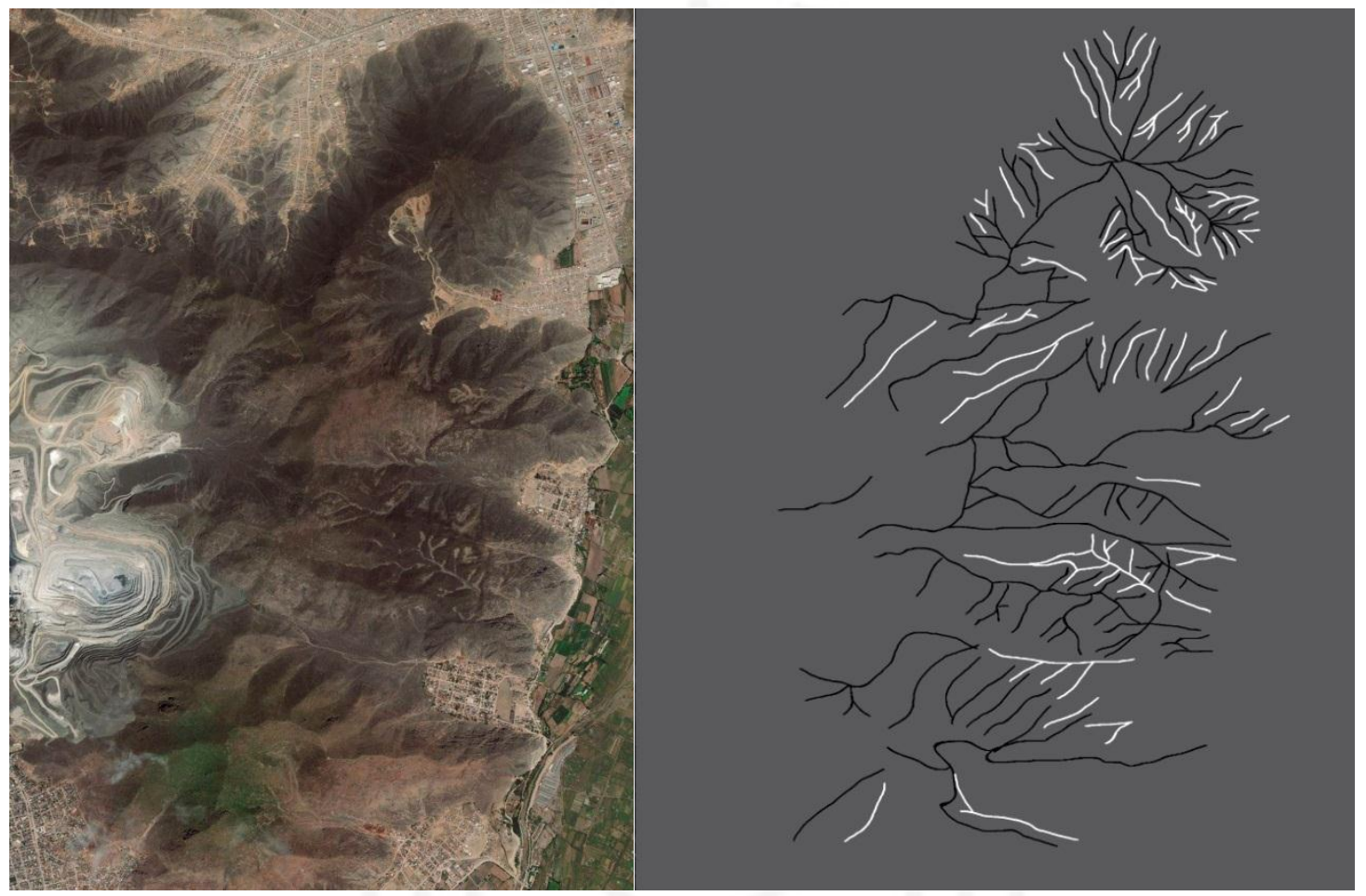

Elaboración propia

Desde una vista aérea la geomorfología de las Lomas de Lúcumo siguen un sistema de quebradas, depreciaciones y elevaciones que van formando un patrón de interconexiones. 
Figura 8.10 Análisis de una quebrada en el Ecosistema Lomas de Lúcumo

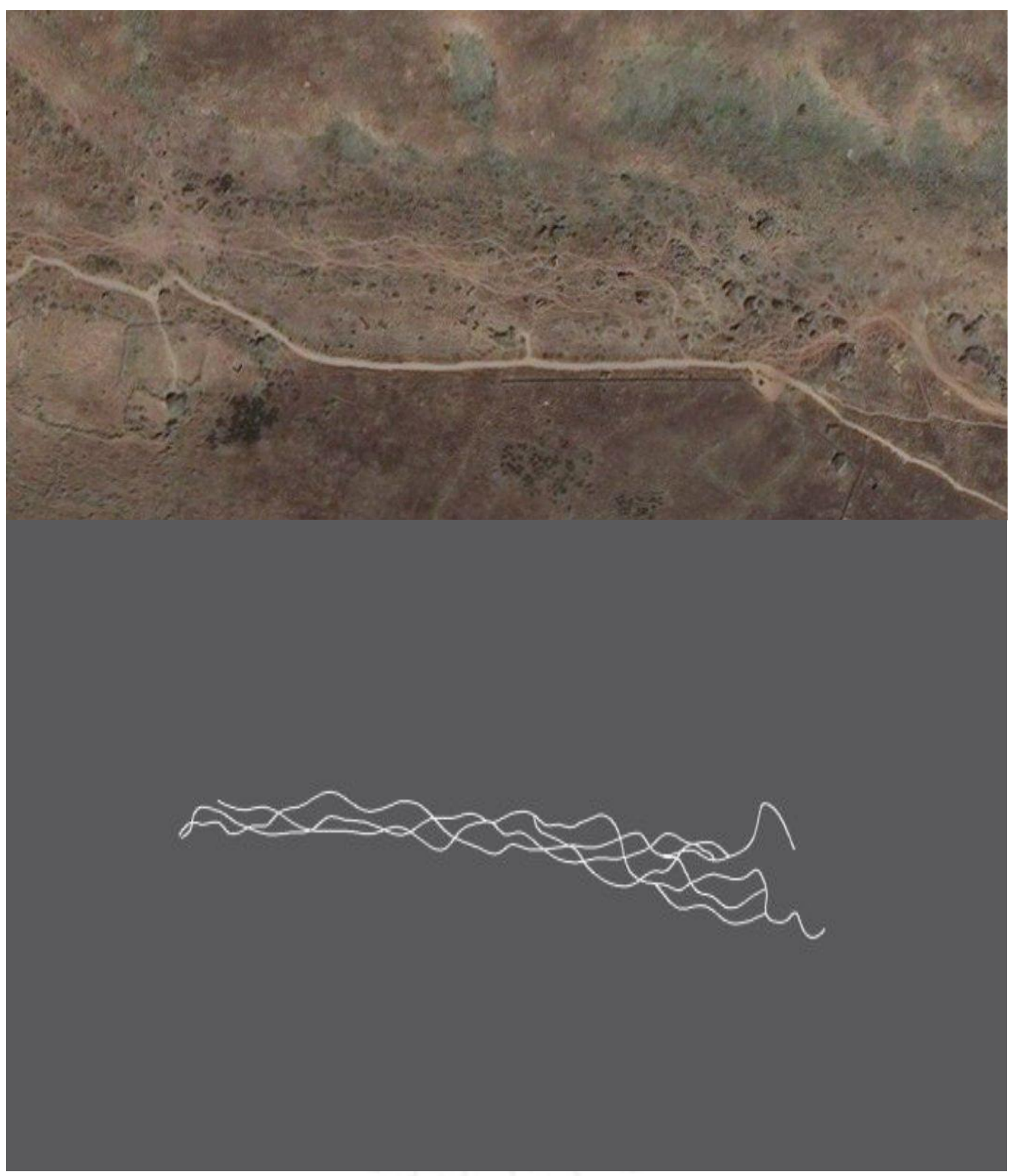

Elaboración propia

La toma más detallada de una quebrada nos deja percibir este mismo patrón de conexiones lineales que representan la huella que deja el agua en su transitar. 
Figura 8.11 Análisis de una toma en elevación del Ecosistema Lomas de Lúcumo

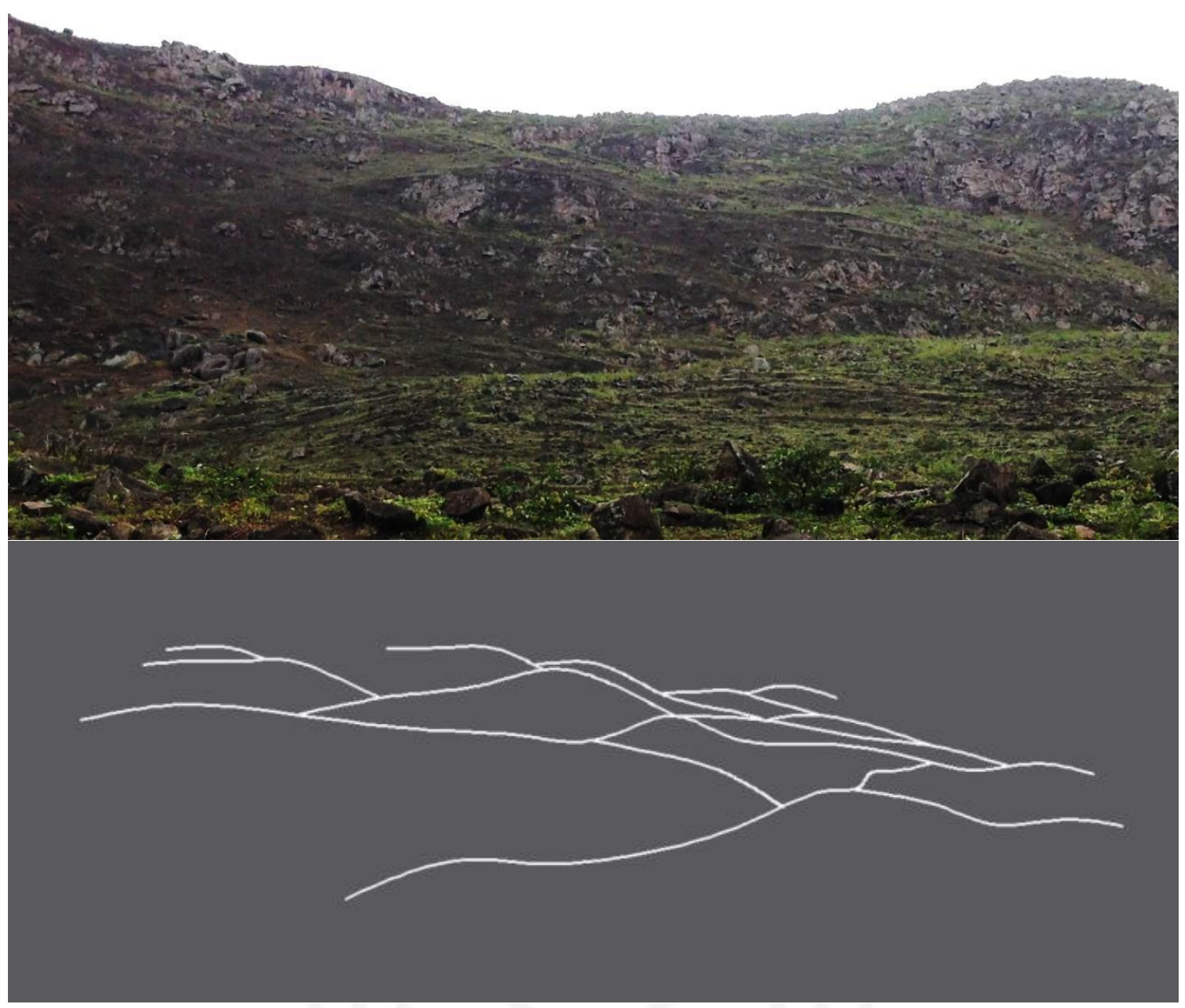

Elaboración propia

Finalmente una toma en elevación del entorno de Lomas permite observar nuevamente este patrón presente en el ecosistema, esta vez es una red verde, formada por la vegetación que va conectándose siguiendo la humedad. 
Figura 8.12 Conceptualización de las reacciones ecosistémicas generadas por el hidrotropismo y tigmotropismo en el entorno natural del Ecosistema Lomas de Lúcumo.
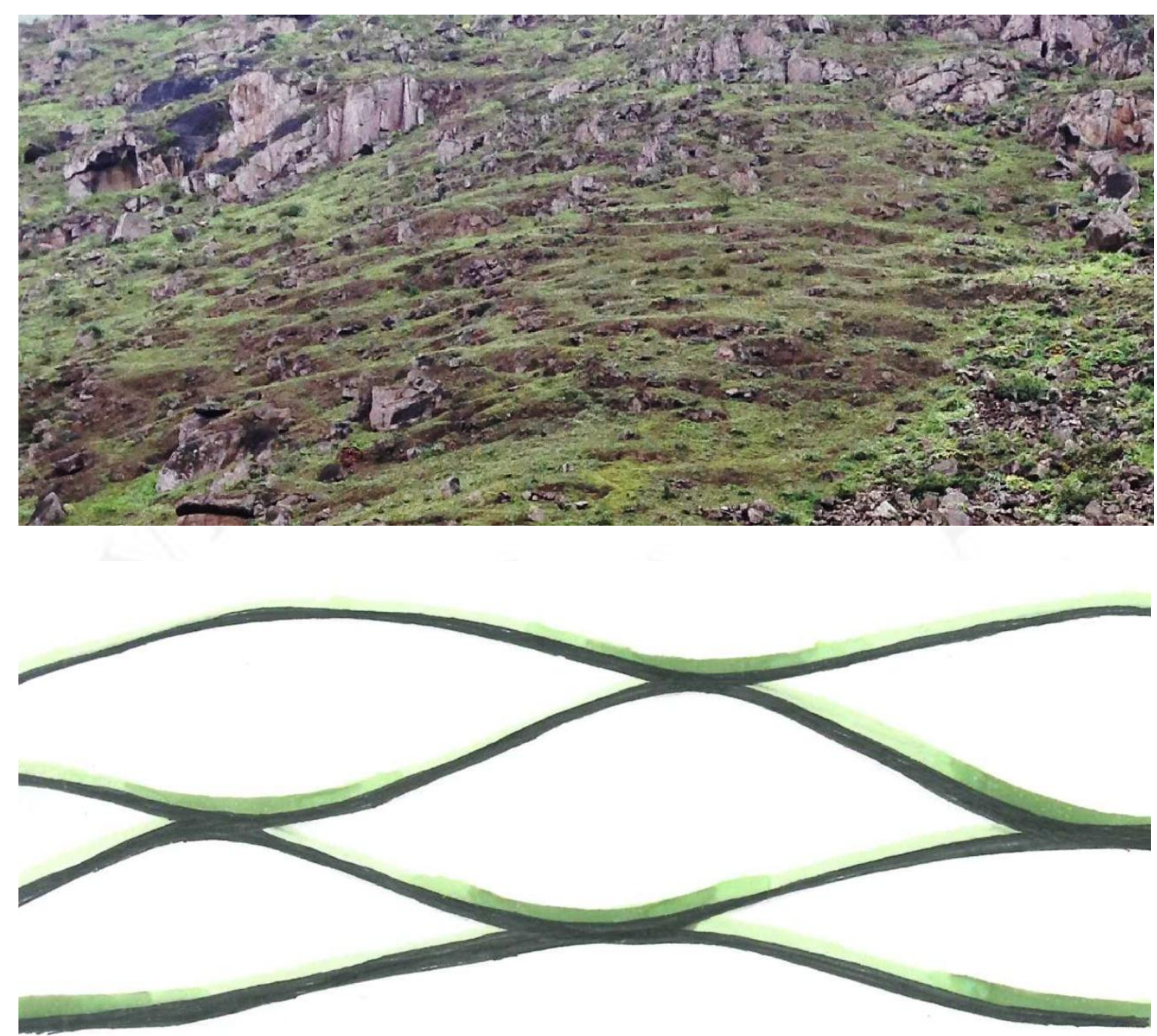

Elaboración propia

Tras el análisis de entorno natural, presente en el Ecosistema Lomas de Lúcumo, se determinó la siguiente estrategia proyectual que determinaría la forma del proyecto respondiendo a las reacciones ecosistémicas del entorno donde las líneas de la naturaleza establecen puntos de conexión para formar redes o sistemas: 
Del paisaje se extienden líneas que al enlazarce forman un elemento de protección pero la forma en la que se conectan no busca la impenetrabilidad de un límite si no más bien éstas se despliegan en ciertos momentos lograndose de esta forma configurar un borde.

Figura 8.13 Representación conceptual de la estrategia proyectual plateada para el proyecto

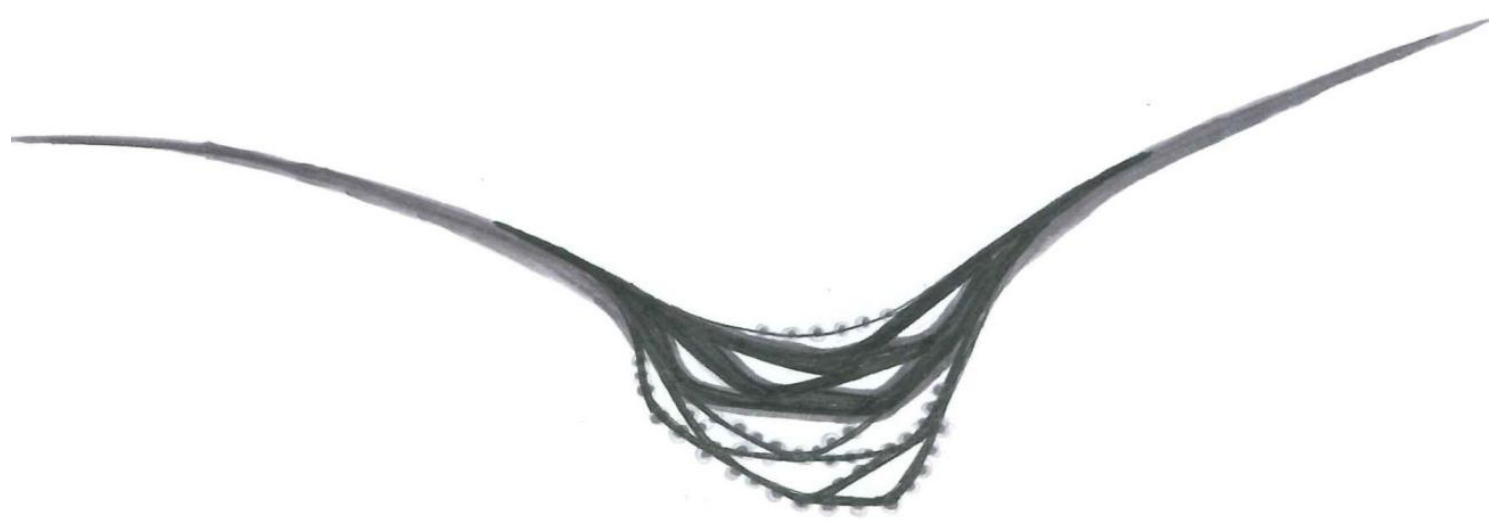

Elaboración propia

Se pensó en que estas líneas originadas la naturaleza funcionen como elementos elevados que permiten almacenar vida bajo ellos, a modo de representar la vegetación que crece en las hundiduras de la roca en el ecosistema de Lomas. 
Figura 8.14 Representación conceptual de la estrategia proyectual plateada para el proyecto

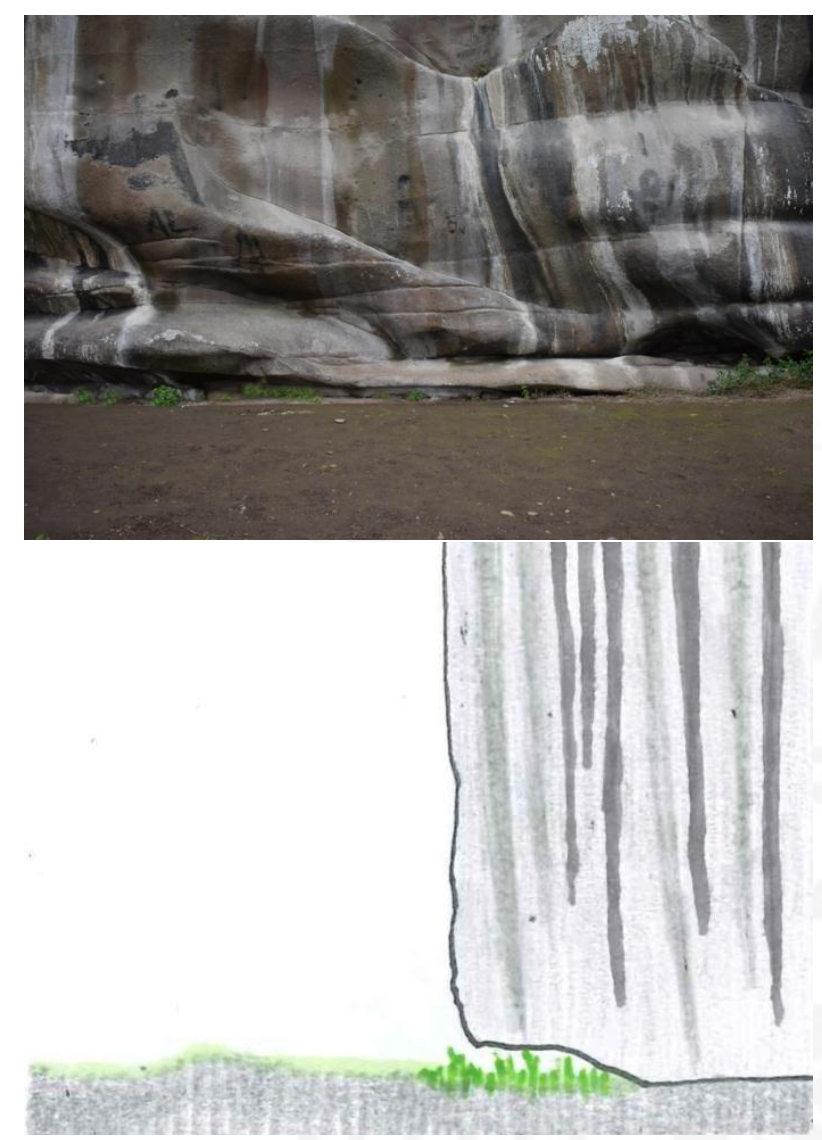

Elaboración propia

Por ésta razón el programa se ubica bajo ésta especie de cajas protectoras que almacenas las dinámicas funcionales del proyecto.

Figura 8.15 Representación esquemática de estrategia proyectual

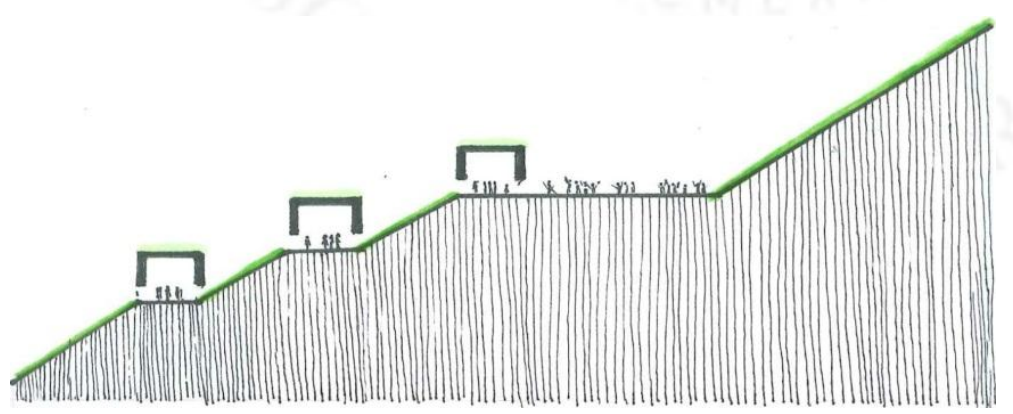

Elaboración propia 
Tal cual la dinámica natural del entorno, la circulación en el proyecto fluje hacia los puntos de conexión concentrándose aquí siempre la llegada de las mismas.

Figura 8.16 Representación esquemática de estrategia proyectual

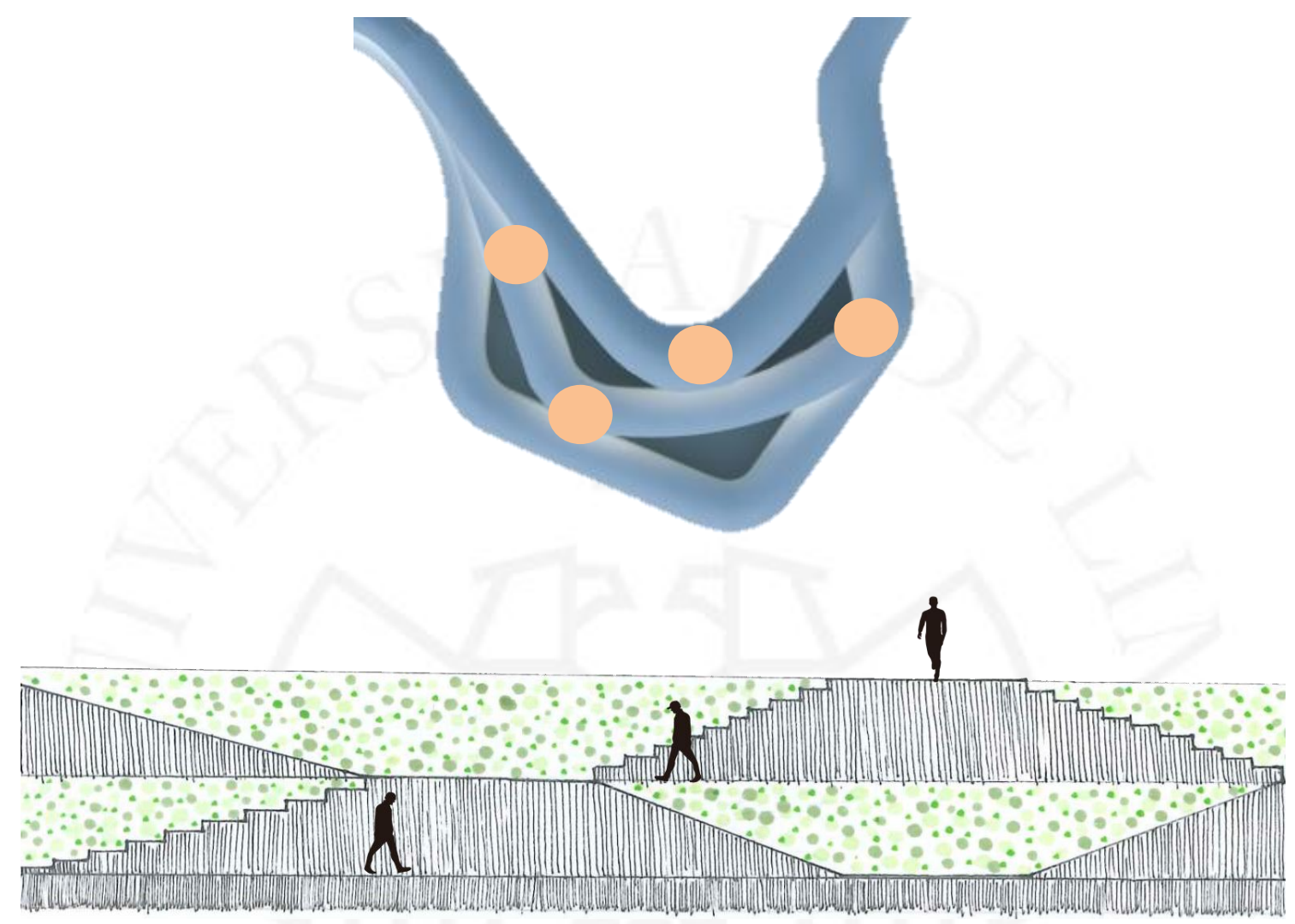

Elaboración propia

Figura 8.17 Fotografía de una quebrada de las Lomas de Lúcumo

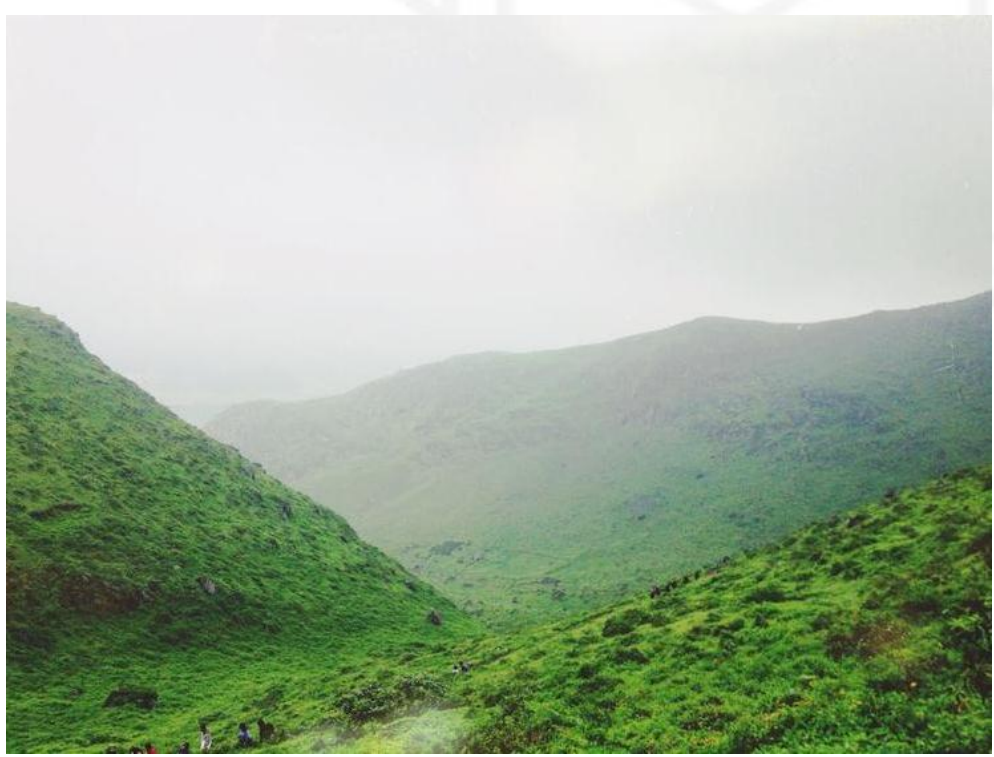

Fuente propia 
Para el espacio público previo al volumen había que solucionar una llegada al primer acseso del proyecto desde el nivel +2.00 hasta el nivel +13.00 , diseñándose para éste fin un conjunto de rampas que extraen del análisis del entorno la forma de transitar en las quebradas, donde se camina entre dos pendientes.

Figura 8.18 Representación esquemática de estrategia proyectual

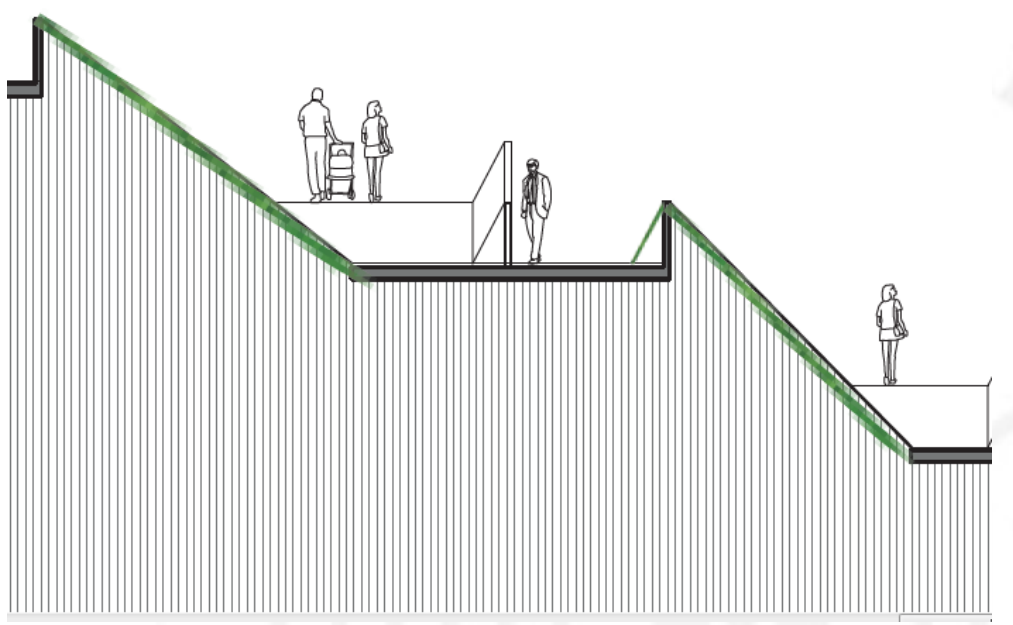

Elaboración propia

Figura 8.19 Fotografía de las rocas en el Ecosistema Lomas de Lúcumo

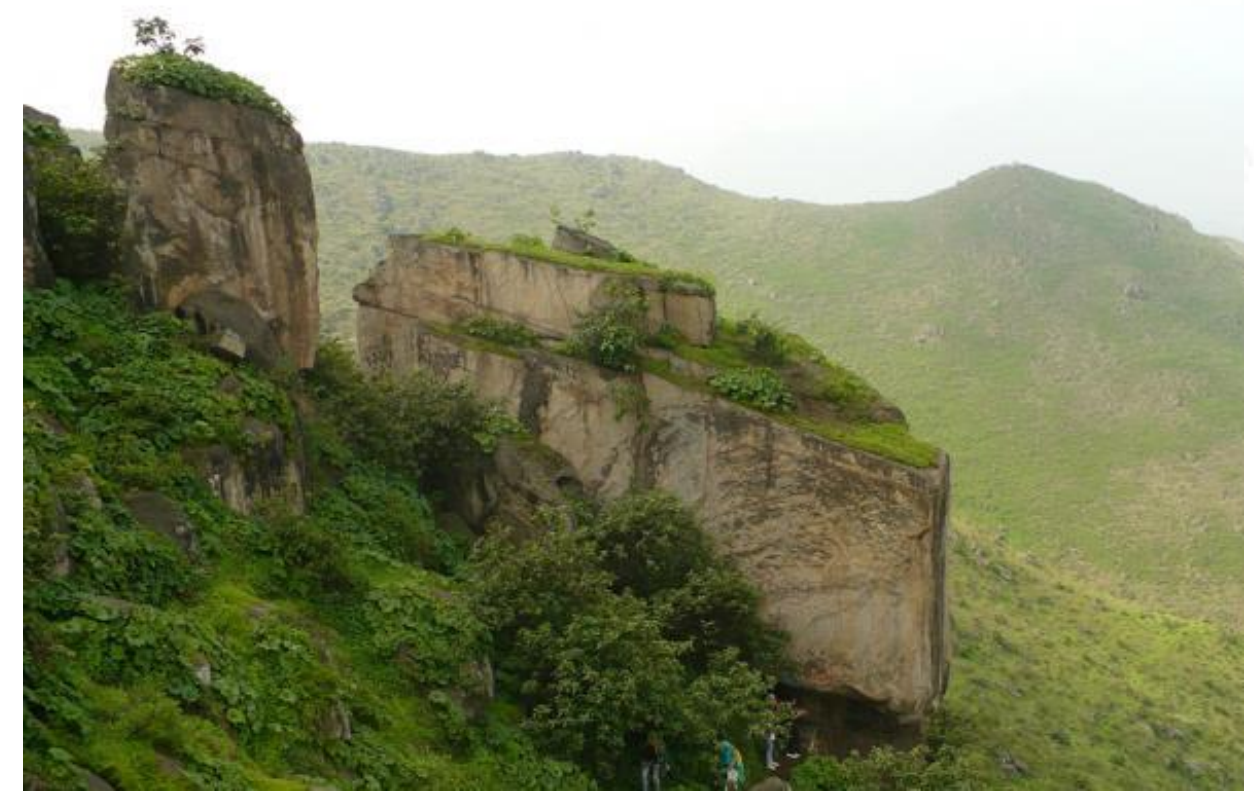

Fuente propia 
La fachada del proyecto en cada volumen es vertical, al igual que la roca en el ecosistema de lomas, esta condición no permite que se forme humedad en la misma, pero sí en el techo para lo cual se pensó revestirlo de bloques de concreto poroso, esta característica del material nos permitirá trabajar la estacionalidad en el proyecto, pues cuando sea temporada de Lomas, aquí se almacenará humedad y podrá generar vida.

Figura 8.20 Análisis de las laderas en el entorno del Ecosistema Lomas de Lúcumo
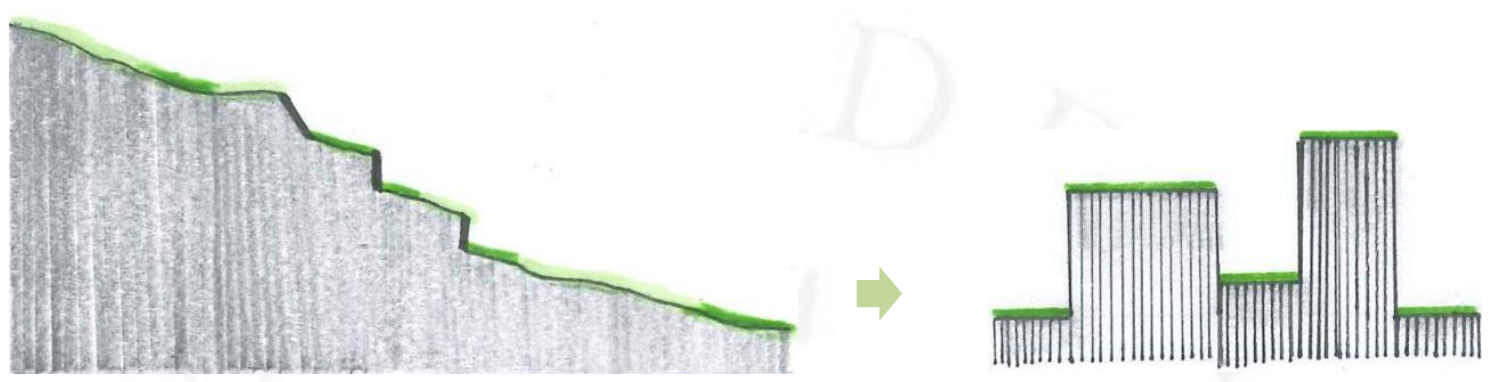

Elaboración propia

Figura 8.21 Análisis del fenómeno estacional de Lomas
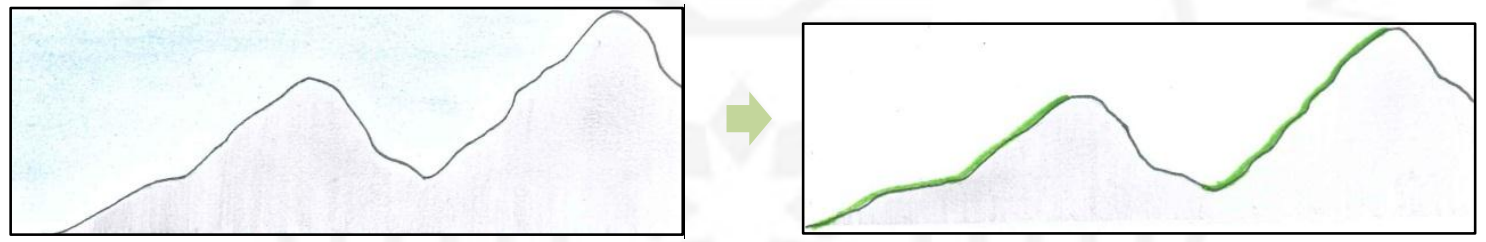

Elaboración propia

El análisis de la estacionalidad del fenómeno de Lomas también influye en la disposición de los volúmenes enlazados, pues éstos se disponen en gradiente de tal forma que los vientos alisios causantes del verdor de las lomas puedan traspasar todo el proyecto y lo llenen de verde.

Figura 8.22 Representación esquemática de la estrategia proyectual propuesta
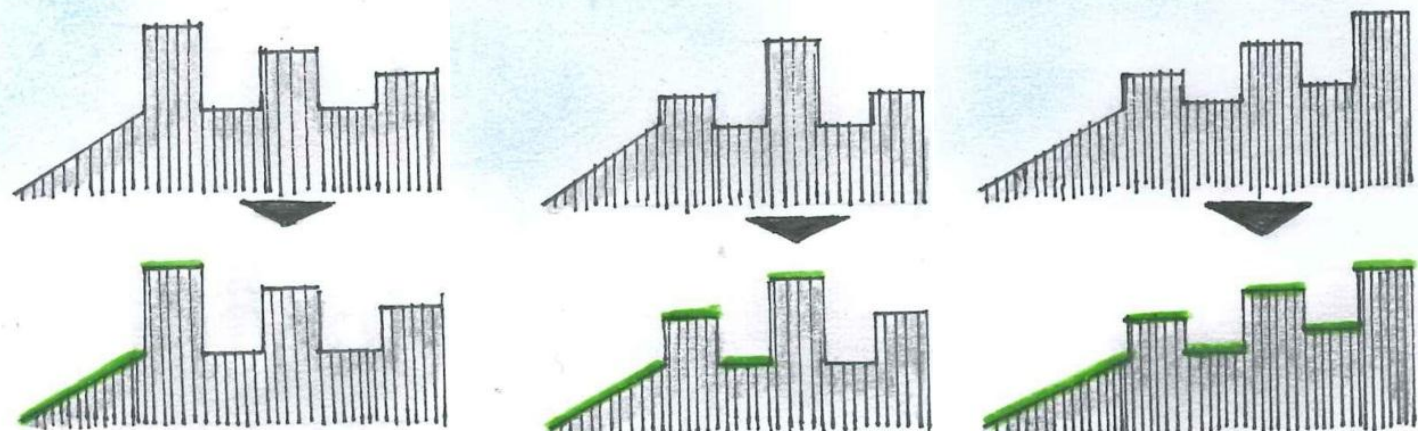

Elaboración propia 
Para que la fachada se perciba como un elemento macizo tal cual y que a la vez nos permita ventilar e luminar los ambientes, se pensó en paneles de hormigón de alto rendimiento Polymere, cuyos patrones de perforación buscan expresar la huella trazada por la humedad en las rocas presentes en el ecosistema.
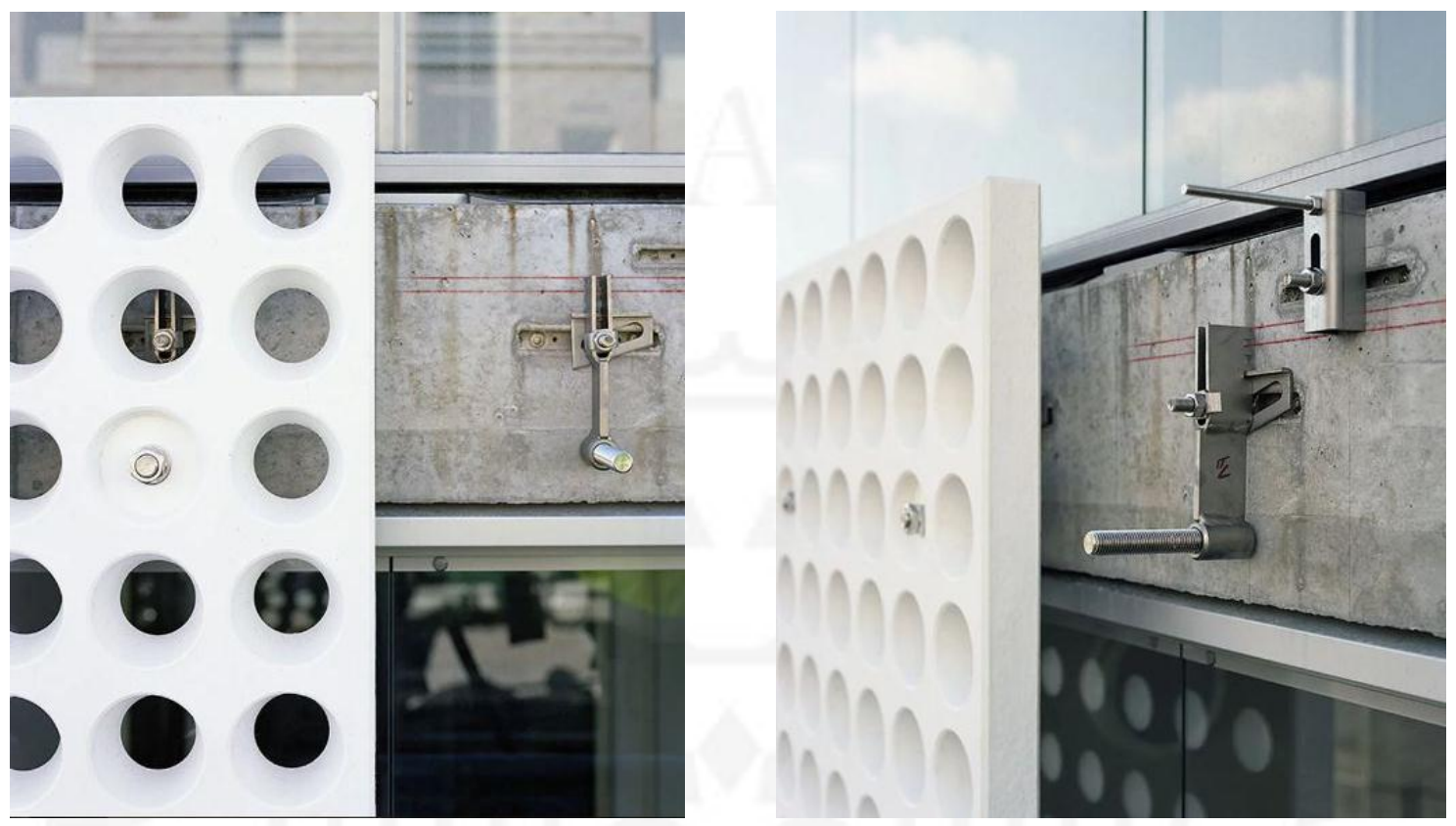

\subsection{Programa arquitectónico}

8.3 Cuadro de áreas y costo de obra 


\subsection{Cálculo de usuarios}

Cuadro 8.2 PEA dedicada a la agricultura en Valle Bajo del Río Lurín

\begin{tabular}{|c|c|c|c|c|c|}
\hline \multirow{4}{*}{$\begin{array}{c}\text { PACHACAMAC } \\
2012\end{array}$} & & TOTAL & $\begin{array}{l}\text { De } 15 \text { a } 44 \\
\text { años }\end{array}$ & $\begin{array}{c}\% \text { con } \\
\text { respecto a la } \\
\text { Población } \\
\text { Total }\end{array}$ & $\begin{array}{l}\text { AL } 2015 \\
\text { (ÚLTIMOS } \\
\text { DATOS) }\end{array}$ \\
\hline & POBLACIÓN: & 102 691h & & & $129653 \mathrm{~h}$ \\
\hline & PEA: & $82661 \mathrm{~h}$ & 65637 & & \\
\hline & $\begin{array}{l}\text { PEA } \\
\text { AGRÍCOLA: }\end{array}$ & $5665 \mathrm{~h}$ & 3570 & $3.47 \%$ & $4498 \mathrm{~h}$ \\
\hline \multirow{3}{*}{$\begin{array}{l}\text { LURÍN } \\
2012\end{array}$} & POBLACIÓN: & $76874 h$ & & & $85132 h$ \\
\hline & PEA: & 65 513h & 49547 & & \\
\hline & $\begin{array}{l}\text { PEA } \\
\text { AGRÍCOLA: }\end{array}$ & $6386 \mathrm{~h}$ & 4161 & $5.41 \%$ & $4605 \mathrm{~h}$ \\
\hline \multirow{3}{*}{$\begin{array}{c}\text { CIENEGUILLA } \\
2012\end{array}$} & POBLACIÓN: & $38328 \mathrm{~h}$ & & & $47080 \mathrm{~h}$ \\
\hline & PEA: & $32336 \mathrm{~h}$ & $24360 \mathrm{~h}$ & & \\
\hline & $\begin{array}{l}\text { PEA } \\
\text { AGRÍCOLA: }\end{array}$ & $2498 \mathrm{~h}$ & $1562 \mathrm{~h}$ & $4.07 \%$ & $1916 \mathrm{~h}$ \\
\hline TOTAL 2015 & & & & & $11019 \mathrm{~h}$ \\
\hline
\end{tabular}

La sustentación sobre el cálculo de usuarios se realizó en base a los alumnos que se encuentran culminando el último año de secundaria, pertenecientes a los distritos que conforman el Valle Bajo del Río Lurín, abarcando específicamente Cieneguilla, Lurín y Pachacamac.

Al 2015 habría 11019 habitantes de los distritos del Valle Bajo del Río Lurín dedicados a la agricultura. 
Cuadro 8.3 Matrícula en el Sistema Educativo Técnico Productivo en el distrito de Pachacamac

PACHACAMAC 2012

\begin{tabular}{|c|c|c|c|c|c|c|c|c|c|c|c|}
\hline \multirow{3}{*}{$\begin{array}{l}\text { Etapa, modalidad y nivel } \\
\text { educativo }\end{array}$} & : MATF & $\begin{array}{l}\text { CULA EN } \\
\text { SEGUUN }\end{array}$ & $\begin{array}{l}\text { EL SISTE } \\
\text { ETAPA, N }\end{array}$ & $\begin{array}{l}\text { 1A EDUCA } \\
\text { ODALIDA }\end{array}$ & $\begin{array}{l}\text { IVO POR } \\
\text { Y NIVEL }\end{array}$ & $\begin{array}{l}\text { TIPO DE G } \\
\text { EDUCATIV }\end{array}$ & $\begin{array}{l}\text { ESTIÓN Y } \\
D, 2012\end{array}$ & REA GEC & GRÁFIC & & \\
\hline & \multirow{2}{*}{ Total } & \multicolumn{2}{|c|}{ Gestión } & \multicolumn{2}{|c|}{ Área } & \multicolumn{2}{|c|}{ Sexo } & \multicolumn{2}{|c|}{ Pública } & \multicolumn{2}{|c|}{ Privada } \\
\hline & & Pública & Privada & Urbana & Rural & Masculino & Femenino & Urbana & Rural & Urbana & Rural \\
\hline Total & $\underline{24336}$ & $\underline{12717}$ & $\underline{11619}$ & $\underline{12848}$ & $\underline{11488}$ & $\underline{12390}$ & $\underline{11946}$ & $\underline{8243}$ & $\underline{4474}$ & $\underline{4605}$ & $\underline{7014}$ \\
\hline Básica Regular & $\underline{22402}$ & $\underline{12477}$ & $\underline{9925}$ & $\underline{11453}$ & $\underline{10949}$ & $\underline{11444}$ & $\underline{10958}$ & $\underline{8003}$ & $\underline{4474}$ & $\underline{3450}$ & $\underline{6475}$ \\
\hline Inicial & 5595 & 2672 & 2923 & 2751 & 2844 & 2907 & 2688 & 1617 & 1055 & 1134 & 1789 \\
\hline Primaria & 10412 & 6059 & 4353 & 5341 & 5071 & 5266 & 5146 & 3864 & 2195 & 1477 & 2876 \\
\hline Secundaria & 6395 & 3746 & 2649 & 3361 & 3034 & 3271 & 3124 & 2522 & 1224 & 839 & 1810 \\
\hline Básica Alternativa 1/ & $\underline{1308}$ & $\underline{240}$ & $\underline{1068}$ & $\underline{1208}$ & $\underline{100}$ & $\underline{691}$ & $\underline{617}$ & $\underline{240}$ & $=$ & $\underline{968}$ & 100 \\
\hline \multicolumn{12}{|l|}{ Básica Especial } \\
\hline Técnico-Productiva & $\underline{417}$ & $=$ & $\underline{417}$ & $\underline{162}$ & $\underline{255}$ & $\underline{155}$ & $\underline{262}$ & $=$ & $=$ & $\underline{162}$ & $\underline{255}$ \\
\hline Superior No Universitaria & $\underline{209}$ & $=$ & $\underline{209}$ & $\underline{25}$ & $\underline{184}$ & $\underline{100}$ & $\underline{109}$ & $=$ & $=$ & $\underline{25}$ & $\underline{184}$ \\
\hline Pedagógica & 25 & - & 25 & 25 & - & 2 & 23 & - & - & 25 & - \\
\hline Tecnológica & 184 & - & 184 & - & 184 & 98 & 86 & - & - & - & 184 \\
\hline Artística & - & - & - & - & - & - & - & - & - & - & . \\
\hline
\end{tabular}

Fuente: MINEDU

En Pachacamac al 2012 existían 8850 habitantes de 15 a 44 años dedicados a la Manufactura significando el público objetivo de los CETPROS en Pachacamac. Representando una demanda anual del $4.71 \%$.

Cuadro 8.4 Matrícula en el Sistema Educativo Técnico Productivo en el distrito de Lurín

LURIN 2012

\begin{tabular}{|c|c|c|c|c|c|c|c|c|c|c|c|}
\hline \multirow{3}{*}{$\begin{array}{l}\text { Etapa, modalidad y nivel } \\
\text { educativo }\end{array}$} & LA EN & $\begin{array}{l}\text { L SISTEM } \\
\text { ETAPA }\end{array}$ & $\begin{array}{l}\text { A EDUCA } \\
\text { MODAL }\end{array}$ & $\begin{array}{l}\text { TIVO POR } \\
\text { DAD Y NII }\end{array}$ & $\begin{array}{l}\text { TIPO D } \\
\text { VEL ED }\end{array}$ & $\begin{array}{l}\text { E GESTIÓN } \\
\text { UCATIVO, } 2\end{array}$ & $\begin{array}{l}Y \text { A ÁREA G } \\
012\end{array}$ & DGRÁF & $A, S$ & ÚN & \\
\hline & \multirow{2}{*}{ Total } & \multicolumn{2}{|c|}{ Gestión } & \multicolumn{2}{|c|}{ Área } & \multicolumn{2}{|c|}{ Sexo } & \multicolumn{2}{|c|}{ Pública } & \multicolumn{2}{|c|}{ Privada } \\
\hline & & Pública & Privada & Urbana & Rural & Masculino & Femenino & Urbana & Rural & Urbana & Rural \\
\hline Total & $\underline{20836}$ & $\underline{13170}$ & $\underline{7666}$ & $\underline{19880}$ & $\underline{956}$ & 10326 & $\underline{10510}$ & 12352 & $\underline{818}$ & 7528 & $\underline{138}$ \\
\hline Básica Regular & $\underline{18580}$ & 12107 & $\underline{6473}$ & 17624 & $\underline{956}$ & $\underline{9373}$ & $\underline{9207}$ & $\underline{11289}$ & $\underline{818}$ & $\underline{6335}$ & $\underline{138}$ \\
\hline Inicial & 3819 & 2336 & 1483 & 3500 & 319 & 1926 & 1893 & 2078 & 258 & 1422 & 61 \\
\hline Primaria & 8694 & 5692 & 3002 & 8151 & 543 & 4446 & 4248 & 5226 & 466 & 2925 & 77 \\
\hline Secundaria & 6067 & 4079 & 1988 & 5973 & 94 & 3001 & 3066 & 3985 & 94 & 1988 & - \\
\hline Básica Alternativa 1/ & $\underline{794}$ & $\underline{230}$ & $\underline{564}$ & $\underline{794}$ & $=$ & $\underline{459}$ & $\underline{335}$ & $\underline{230}$ & $=$ & $\underline{564}$ & $=$ \\
\hline Básica Especial & $\underline{92}$ & $\underline{92}$ & $=$ & $\underline{92}$ & $=$ & $\underline{61}$ & $\underline{31}$ & $\underline{92}$ & $=$ & $=$ & $=$ \\
\hline Técnico-Productiva & $\underline{987}$ & $\underline{428}$ & $\underline{559}$ & $\underline{987}$ & $=$ & $\underline{278}$ & $\underline{709}$ & $\underline{428}$ & $=$ & $\underline{559}$ & $=$ \\
\hline Superior No Universitaria & $\underline{383}$ & $\underline{313}$ & $\underline{70}$ & $\underline{383}$ & $=$ & $\underline{155}$ & $\underline{228}$ & $\underline{313}$ & $=$ & $\underline{70}$ & $=$ \\
\hline Pedagógica & - & - & - & - & - & - & - & - & - & - & - \\
\hline Tecnológica & 383 & 313 & 70 & 383 & - & 155 & 228 & 313 & - & 70 & - \\
\hline Artística & - & - & - & - & - & - & - & - & - & - & - \\
\hline
\end{tabular}

Fuente: MINEDU 
En Lurín al 2012 existían 8850 habitantes de 15 a 44 años dedicados a la Manufactura significando el público objetivo de los CETPROS en Pachacamac. Representando una demanda anual del 11.15\%.

Cuadro 8.5 Matrícula en el Sistema Educativo Técnico Productivo en el distrito de Cieneguilla

CIENEGUILLA 2012

\begin{tabular}{|c|c|c|c|c|c|c|c|c|c|c|c|}
\hline \multirow{3}{*}{$\begin{array}{c}\text { Etapa, modalidad y nivel } \\
\text { educativo }\end{array}$} & MATRICI & $\begin{array}{l}\text { UA EN E } \\
\text { SEGÚN }\end{array}$ & $\begin{array}{l}\text { L SISTEM } \\
\text { ETAPA, M }\end{array}$ & $\begin{array}{l}\text { IA EDUC } \\
\text { ODALID }\end{array}$ & $\begin{array}{l}\text { TIVO PO } \\
\text { D Y NIVE }\end{array}$ & $\begin{array}{l}\text { R TIPO DE } \\
\text { L EDUCATI }\end{array}$ & $\begin{array}{l}\text { GESTIÓN } \\
\text { VO, } 2012\end{array}$ & ÁREA C & OGRÁF & $\mathrm{CA}$ & \\
\hline & \multirow{2}{*}{ Total } & \multicolumn{2}{|c|}{ Gestión } & \multicolumn{2}{|c|}{ Área } & \multicolumn{2}{|c|}{ Sexo } & \multicolumn{2}{|c|}{ Pública } & \multicolumn{2}{|c|}{ Privada } \\
\hline & & Pública & Privada & Urbana & Rural & Masculino & Femenino & Urbana & Rural & Urbana & Rural \\
\hline Total & $\underline{4933}$ & $\underline{3455}$ & $\underline{1478}$ & $\underline{3571}$ & 1362 & $\underline{2524}$ & $\underline{2409}$ & $\underline{2228}$ & 1227 & 1343 & $\underline{135}$ \\
\hline Básica Regular & $\underline{4839}$ & $\underline{3414}$ & $\underline{1425}$ & $\underline{3477}$ & 1362 & $\underline{2482}$ & $\underline{2357}$ & $\underline{2187}$ & 1227 & $\underline{1290}$ & $\underline{135}$ \\
\hline Inicial & 926 & 605 & 321 & 673 & 253 & 499 & 427 & 373 & 232 & 300 & 21 \\
\hline Primaria & 2058 & 1338 & 720 & 1561 & 497 & 1063 & 995 & 907 & 431 & 654 & 66 \\
\hline Secundaria & 1855 & 1471 & 384 & 1243 & 612 & 920 & 935 & 907 & 564 & 336 & 48 \\
\hline Básica Alternativa 1/ & $\underline{53}$ & $=$ & $\underline{53}$ & $\underline{53}$ & $=$ & $\underline{33}$ & $\underline{20}$ & $=$ & $=$ & $\underline{53}$ & $=$ \\
\hline Básica Especial & $=$ & $=$ & $=$ & $=$ & $=$ & $=$ & $=$ & $=$ & $=$ & $=$ & $=$ \\
\hline Técnico-Productiva & $=$ & $=$ & $=$ & $=$ & $=$ & $=$ & $=$ & $=$ & $=$ & $=$ & $=$ \\
\hline Superior No Universitaria & $\underline{41}$ & $\underline{41}$ & $=$ & $\underline{41}$ & $=$ & $\underline{9}$ & $\underline{32}$ & $\underline{41}$ & $=$ & $=$ & $=$ \\
\hline Pedagógica & - & - & - & - & - & - & - & - & - & - & - \\
\hline Tecnológica & 41 & 41 & - & 41 & - & 9 & 32 & 41 & - & - & - \\
\hline Artística & - & - & - & - & - & - & - & - & - & - & - \\
\hline
\end{tabular}

1/ Incluye Educsción de Adultos.

Fuente: MINISTERIO DE EDUCACIÓN - Censo Escolar.

En Lurín al 2012, ni a la actualidad existen equipamientos que brinden Educación Técnica Productiva, por lo que no se podrá obtener datos del distrito.

Tras el análisis se decide entonces que el CETRO Lomas de Lúcumo atienda una demanda anual de 5\% con respecto a la población total interesada en el ámbito agrícola en el Valle Bajo del Río Lurín, siendo entonces un total de 550 alumnos, al año. 


\section{REFERENCIAS}

Ballén Velásquez, L. M. (2014). “Desbordando" la categoría de borde. Bitácora 24 Universidad Nacional de Colombia, Bogotá, 87-95.

Barsky, A. (2005). El Periurbano Productivo, un espacio en constante transformación. Revista Electrónica de Geografía y Ciencias Sociales.

Instituto Metropolitano de Planificación. (2013). Plan de Ordenamiento Territorial Cuencas Lurín-Chilca. Lima.

"Heringer", A. (24 de Setiembre de 2008). Anna Heringer Architecture. Recuperado el 10 de Mayo de 2016, de http://www.anna-heringer.com/index.php?id=66

"Rodrigues", M. d. (7 de Junio de 2013). Historia de la Educación Técnica, UNAM. Recuperado el 14 de Mayo de 2016, de http://biblioweb.tic.unam.mx/diccionario/htm/articulos/sec_14.htm

“Instituto Superior Tecnológico Público José Pardo". (27 de Enero de 2013). Instituto Superior Tecnológico Público José Pardo. Recuperado el 15 de Mayo de 2016, de http://www.jpardo.edu.pe/intro/

Águila Flores, J. (2014). Espacio intersticial. Universidad Internacional de Andalucía, $1-294$.

Álvares Olivares, J. (2014). La Escuela de Artes y Ofcios de Medellín y la profesionalización de los artesanos. Historia y Sociedad, Medellín, Colombia, 99-119.

Aponte, G. (2012). Paisaje de borde, el papel estructurante de las quebradas en las laderas de Medellín. Medellín: Maestría en Diseño del Paisaje - Universidad Pontificia Bolivariana .

Arch Daily. (Dicembre de 2014). Arch Daily. Recuperado el 23 de Mayo de 2016, de http://www.archdaily.pe/pe/758214/centro-de-capacitacion-indigena-kapaclajuientre-nos-atelier 
Arch20. (12 de 11 de 2017). Arch20. Obtenido de https://www.arch2o.com/jeanmoulin-high-school-duncan-lewis-scape-architecture/

Archdaily. (12 de 11 de 2017). Archdaily. Obtenido de https://www.archdaily.pe/pe/806219/escuela-secundaria-jean-moulin-duncanlewis-scape-architecture

Arias De Saavedra Alías, I. (2001). Las sociedades economicas amigos del pais en Andalucía. Chronica Nova, 7-33.

Aristizábal Uribe, A. (2013). Paisaje de borde Una propuesta para recuperar las quebradas de Medellín. Revista Universitas Científica , 54-57.

Arredondo González, E. (2015). Arquitectura de paisaje, razón de ser e importancia. Bitácora Arquitectura 36, 106-112.

Autoridad Nacional del Agua. (22 de Noviembre de 2018). Observatorio del Agua: Chillón, Rimac y Lurín. Obtenido de http://observatoriochirilu.ana.gob.pe/

Barletta, F., Pereira, M., Robert, V., \& Yoguel, G. (2013). Argentina: dinámica reciente del sector de software y servicios informáticos. Revista de la CEPAL(110), 137155.

Obtenido

de

http://www.cepal.org/publicaciones/xml/1/50511/RVE110Yoqueletal.pdf

Bastida, R. (1919). Enseñanza Profesional y Técnica, escuelas de artes y oficios. España: Sociedad de Estudios Vascos.

Basulto, D., \& Assael, D. (Marzo de 2008). Archdaily. Recuperado el 11 de Mayo de 2016, de http://www.archdaily.com/130914/sra-pou-vocational-schoolarchitects-rudanko-kankkunen

Blanes Nadal, G., \& Millán Verdú, C. (2002-2003). EL ORIGEN DE LA ESCUELA DE ARTES Y OFICIOS DE ALCOY, 1886/1888. ESPAÑA.

Blanes, G., \& Garrigós, L. (2001). Los inicios de la escuela de artes y oficios de Alcoy 1888-1901. Análisis sociológico del alumnado. ILUIL, 5-31.

Caballero Cortéz, Á. (1986). La sociedad económica de amigos del país de Málaga. Historia de la educación: Revista interuniversitaria , 339-358. 
Canales Arévalo, M., \& Sabelino Torres, H. (2008). EDUCACIÓN TÉCNICO PRODUCTIVA: Guía de orientación para la programación modular . Lima: Gráfica Técnica SRL.

Canales, M. (2007). Diseño Curricular Básico de la Educación Técnico Productiva. Lima: MINEDU.

Cancer, L. (1994). El paisaje como elemento de la ordenación territorial. Geographicalia, 17-30.

Castelli, L., \& Spallasso, V. (2007). Planificación y Conservación del Paisaje. Buenos Aires: Fundación Naturaleza para el Futuro.

Castillo Ventura, G. (2016). Plan Maestro de Intervención Urbano-Arquitectónica del Borde del acantilado del Río Chira en la Ciudad de Sullana - Tesis para optar el Título de Arquitecto. Lima: Universidad Nacional de Piura.

CETPRO Salesiano. (11 de 11 de 2017). CETPRO Salesiano. Obtenido de http://www.cetprosalesiano.com/?page_id=136

Chillón-Rímac-Lurín, A. T. (2004). Estudio Hidrológico de la Cuenca del Río Lurín. Lima.

Choy, M., \& Chang, G. (2014). Medidas macroprudenciales aplicadas en el Perú. Lima: Banco Central de Reserva del Perú. Obtenido de http://www.bcrp.gob.pe/docs/Publicaciones/Documentos-deTrabajo/2014/documento-de-trabajo-07-2014.pdf

Comando Ecológico. (06 de 11 de 2017). Comando Ecológico. Obtenido de Comando Ecológico

Coral Mestanza, F. (2007). Zonificación mediante planos temáticos de áreas con diferente peligro en la parte baja del Río Lurín. Lima: Universidad Ricardo Palma.

Custance, A. (1975). Convergencia, y el origen del hombre. El Pórtico Nº, 1-15.

D. K. Ching, F. (2015). Arquitectura, forma, espacio y orden. (Cuarta ed.). Nueva Jersey: John Wiley \& Sons, Hoboken. 
Di Pace, M., Crojethovich Martín, A., \& Barsky, A. (2007). Ecología de la ciudad. Buenos Aires: Prometeo Libros.

Dirección Regional de Educación. (1 de Mayo de 2016). Dirección Regional de Educación de Lima Metropolitana. Recuperado el 1 de Mayo de 2016, de http://www.drelm.gob.pe/politicas/aprendizajes/centro-de-educacion-tecnicoproductiva

Dittbor Cordua, P. (2007). Historia y perspectivas acerca de la educación técnica de nivel superior. Calidad en la Educación, 16.

Eisenberg, B., Nemcova, E., Poblet, R., \& Stokman, A. (2013). Estrategia de infraestructura Ecológica de Lima. Lima.

Fernandez, A., Guerra, M., \& Leiva, L. (2002). Sobre el Peru: Homenaje a Jose Agustin de la Puenta Candamo. Lima: Fondo Editorial PUCP.

García Aguaida, M. (2011). Los Umbrales como Instrumentos para la Identidad Urbana. Universidad de Los Andes.

García Nieto, J. P. (2013). Consturye tu Web comercial: de la idea al negocio. Madrid: RA-MA.

Grupo GEA. (30 de 10 de 2017). Grupo GEA. Obtenido de http://grupogea.org.pe/nosotros/historia-de-gea/

Hassell Studio. (s.f.). Hassell Studio. Obtenido de https://www.hassellstudio.com/en/cms-projects/detail/nanjing-tangshangeopark-museum-/

Helg, A. (1984). La educación en Colombia, 1918-1957: una historia social, económica y política. Colombia: Plaza \& Janés Editores Colombia S.A.

Huamán Durand, L. F. (2014). Trabajo de Investigación: Valle del Río Lurín. Lima: Univerdidad Nacional Mayor de San Marcos.

INEI. (2014). Compendio Estadístico Provincia de Lima. Lima: Instituto Nacional de Estadístuca e Informática. 
Instituto Metropolitano de Planificación . (23 de Noviembre de 2018). Instituto Metropolitano de Planificación . Obtenido de http://www.imp.gob.pe/

Leggett, G. (2006). Polis, visiones y versiones de Lima a inicios del siglo 21. Lima: La Moderna.

Letelier, S. (1996). Articulaciones. Cuaderno de Visualidad Arquitectónica, 1-22.

Lleellish, M., Odar, J., \& Trinidad, H. (2015). Guía de Flora de las Lomas de Lima. Lima: Servicio Nacional Forestal y de Fauna Silvestre.

Lomas de Lúcumo. (30 de 10 de 2017). Lomas de Lúcumo. Obtenido de http://www.lomasdelucumo.org/historia.php

Lynch, K. (2015). La Imagen de la ciudad. Barcelona: Gustavo Gili.

Maderuelo, J. (2010). El paisaje urbano. Estudios Geográficos Vol. LXXI, 575-600.

Másmela Díaz, P. (2010). El paisaje como elemento de la ordenación territorial. Un análisis de paisaje desde su enfoque visual en el borde centro oriental de Medellín, Colombia - Trabajo de Tesis para optar al título de Magíster en Estudios Urbano Regionales. Medellín.

Mendoza Flores, J. (2017). Circuito Ecoturístico Lomas de Lúcumo, destino Valle de Lurín. Lima: Encuentro Nacional turismo rural comunitario.

Mesa, F., \& Mesa, F. (2013). Permeabilidad. La Libertad de los Fragmentos, 1-6.

MINEDU. (2015). Norma Técnica de Infraestructura para Locales de Educaión Superior. Lima.

Ministerio de Agricultura. (30 de 10 de 2017). Ministerio de Agricultura. Obtenido de http://www.minagri.gob.pe/portal/nosotros/que-hacemos

Ministerio de Agricultura y Riego. (28 de Noviembre de 2018). MINAGRI. Obtenido de http://minagri.gob.pe/portal/download/pdf/sectoragrario/agricola/lineasdecultivo semergentes/LUCUMA.pdf

Ministerio de Cultura. (30 de 10 de 2017). Ministerio de Cultura. Obtenido de http://www.cultura.gob.pe/es/informacioninstitucional/quienessomos

Ministerio de Educación. (2005). Reglamento de educación Técnico Productiva. Lima. 
Ministerio de Educación. (7 de Julio de 2015). Dirección Regional de Educación de Lima Metropolitana. Recuperado el 12 de Mayo de 2016, de http://www.drelm.gob.pe/politicas/aprendizajes/centro-de-educacion-tecnicoproductiva

Ministerio de Educación. (30 de 10 de 2017). Ministerio de Educación. Obtenido de http://www.minedu.gob.pe/p/ministerio-funciones.php

Ministerio de Trabajo y Promocion del empleo. (1996). Diagnostico de la formacion profesional en el Peru.

Ministerio de Trabajo y Promocion del empleo. (1996). Diagnostico de la formacion profesional en el Peru.

Ministerio de Vivienda Construcción y Saneamiento. (2006). Reglamento Nacional de Edificaciones. Lima.

Ministerio del Ambiente. (30 de 10 de 2017). Ministerio del Ambiente. Obtenido de http://www.minam.gob.pe/?el-ministerio=mision-y-vision

Miró Quesada Sosa, A. (1907-1998). Artes y oficios del Perú. Lima: Lumen, 1940.

Molero, J. L. (2013). Estado situacional al 2011 de la capacitacion de gestion de actividades y proyectos productivos en centros de educacion tecnico productiva (CETREPO) salesianos, ubicado en los departamentos de Arequipa, Huancayo, Lima y Piura. Lima.

Mujica B., E., Rostworowski de Diez Canseco, \& Santillana, I. (1983). Poblaciones de Lomas: Análisis Histórico del Caso Pachacamac. Lima.

Municipalidad de Pachacamac. (30 de 10 de 2017). Municipalidad de Pachacamac. Obtenido de http://www.munipachacamac.gob.pe/municipalidad/misionvision.html

Nieuwland, B., \& Mamani, J. (2017). Las lomas de Lima: enfocando ecosistemas desérticos como espacios abiertos en Lima metropolitana. Espacio y Desarrollo $N^{\circ} 29,109-133$. 
Núñez Inoguchi, V., \& Pinto Balcazar, F. (2016). Bordes Urbanos en el Ecoentorno Urbano - Rural del Distrito de Jacobo Hunter - Tesis para obtener el Grado Académico de Arquitecto. Lima.

Odiledecq Estudio. (11 de 11 de 2017). Odiledecq Estudio. Obtenido de http://www.odiledecq.com/EN-5-project-64-

FANGSHAN_TANGSHAN_NATIONAL_GEOPARK_MUSEUM_China_Nan jing

Pedrera, A. M. (1998). Origen y Desarrollo de las Escuelas de artes y oficios en España. EDICIONES UNIVERSIDAD DE SALAMANCA, 319-330.

Ramírez Velázquez , B. (2010). Del suburbio y la periferia al borde: el modelo de crecimiento de la Zona Metropolitana del Valle de México.

Raymundo, R., Bussink, C., \& Prain, G. (Mayo de 2007). La Dinámica de La Agricultura en Lima. Urban Harvest Working Paper Series.

Raymundo, R., Coen, B., \& Prain, G. (2007). La dinámica de la agricultura en Lima 1972-2002. Lima.

Riesco Chueca, P., Gómez Zotano, J., \& Álvarez Sala, D. (2008). Región, Comarca, Lugar: Escalas de referencia en la Metodología del Paisaje. Cuadernos Geográficos 43, 227-255.

Robles Ortiz, E. (2004). LAS PRIMERAS ESCUELAS NORMALES EN EL PERÚ. Revista Historia de la Educación Latinoamericana, 57-86.

Saavedra, J., \& Chacaltana, J. (2001). Exclusión y Oportunidad: jóvenes urbanos y su inserción en el mercado de trabajo y en el mercado de capacitación. Lima: GRADE.

Salazar Hernández, C. A., \& Zuleta Ruiz , B. (2014). La noción de borde en la narrativa urbana - Estudio de caso: Medellín, Colombia. BITACORA 24 - Universidad Nacional de Colombia, Bogotá, 96-104.

Sánchez Ayala, L. (2015). De territorios, límites, bordes y fronteras: una conceptualización para abordar conflictos sociales. DEBATE, 175-179. 
Santos-Fernandes Pinto de Freitas, R. (2011). Arquitectura Híbrida: contexto, escala, orden - Tesis Doctoral. Barcelona.

Senamhi. (2007). Monitoreo de la calidad de agua de los ríos Rímac, Chillón y Lurín. Lima.

Sennett , R. (2006). The Open City . Urban Age, 1-5.

Shady Solis, R., \& Quispe Loayza, E. (1999). El Proceso Cultural de Las Sociedades Prehispánicas de Lima. Boletín del Museo de Arqueología y Antropología.

Sifuentes, E., Albujar, E., Contreras, S., \& Leon, C. (2017). Anuario Estadistico de la Producción Agrícola y Ganadera 2016. Lima: Ministerio de Agricultura y Riego.

SINIA - Ministerio del ambiente. (2009). Viene de las alturas: disponibilidad y usos del agua. Lima.

Solórzano, P. (03 de 11 de 2017). La Brújula del Azar. Obtenido de http://labrujuladelazar.blogspot.pe

Sousa, J., \& Pereira, F. (1988). Historia de la Escuela de Artes y Oficios de Santiago de Compostela 1888-1988. España: Diputación Provincial.

Sulmont, D., Valcárcel, M., \& Twanama, W. (1991). El Camino a la Educación Técnica: Los otros profesionales. Lima: Fondo Editorial de la Pontificia Universidad Católica del Perú.

Torres Tovar, C. A. (2014). Bordes y fronteras: Políticas y prácticas de control del crecimiento urbano. Bitácora 24 - Universidad Nacional de Colombia, Bogotá, 7-10.

Ukumbi ONG. (julio de 2007). Ukumbi. Recuperado el 9 de Mayo de 2016, de http://ukumbi.org/projects/srapou.html

Villamizar Duarte, N. (2014). Bordes urbanos:teorías, políticas y prácticas para la construcción de territorios de dialogo. Bitácora 24 - Universidad Nacional de Colombia, Bogotá, 61-63. 
Villanueva Vargas, J. (2016). La Gobernanza de los Recursos Hídricos en la Cuenca del Río Lurín en el marco de la creación del Consejo de Recursos Hídricos de Cuenca Chillón, Rímac, Lurín. Lima.

Wittmann, R. (2006). ¿Hubo una revolución en la lectura a finales del siglo XVIII? En G. Cavallo, \& R. Chartier, Historia de la lectura en el mundo occidental (págs. 435-472). México D.F.: Santillana.

Zubelzu Mínguez, S., \& Allende Álvarez, F. (2015). El concepto de paisaje y sus elementos constituyentes: requisitos para la adecuada gestión del recurso y adaptación de los instrumentos legales en España. Revista Colombiana de Geografía, 29-42. 